\title{
WEST VALLEY DEMONSTRATION PROJECT ANNUAL SITE ENVIRONMENTAL REPORT CALENDAR YEAR 2004
}

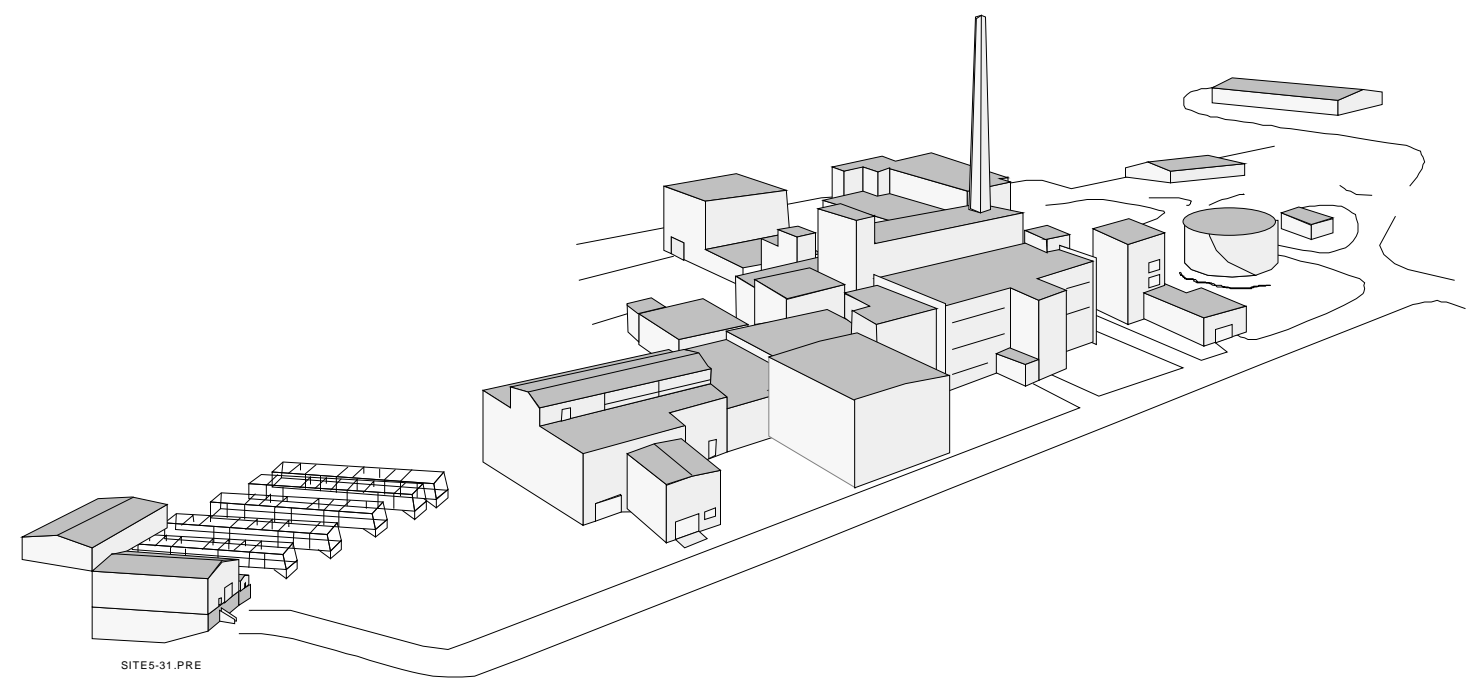

\section{WEST VALLEY NUCLEAR SERVICES COMPANY AND URS GROUP, INC.}
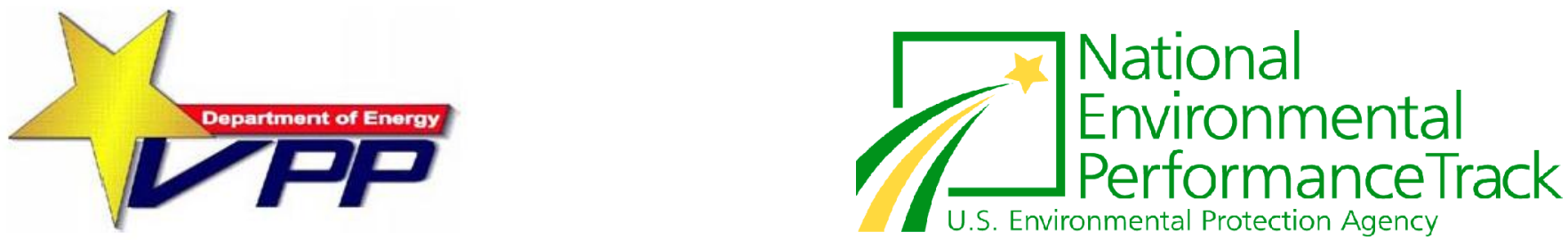

Prepared by: West Valley Nuclear Services Co. and URS Group, Inc.

Prepared for: U.S. Department of Energy Ohio Field Office OH/WVDP 



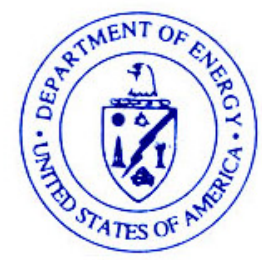

\section{Department of Energy \\ Ohio Field Office \\ West Valley Demonstration Project \\ 10282 Rock Springs Road \\ West Valley, NY 14171-9799}

To the Reader:

This report, prepared by the U.S. Department of Energy (DOE) Ohio Field Office West Valley Demonstration Project (OH/WVDP), summarizes the environmental protection program at the West Valley Demonstration Project (WVDP) for calendar year 2004.

Monitoring and surveillance of the WVDP facilities are conducted to verify that public health and safety and the environment are protected. The quality assurance requirements applied to the environmental monitoring program by the DOE ensure the validity and accuracy of the monitoring data. Also included in this report are groundwater and ambient air data from the New York State Energy Research and Development Authority's New York State-licensed Disposal Area.

At the WVDP, radiological air emissions are controlled and permitted by the U.S. Environmental Protection Agency (EPA) under National Emission Standards for Hazardous Air Pollutants, Subpart H, regulations. Nonradiological liquid effluent discharges are controlled and permitted through the New York State Pollutant Discharge Elimination System.

Air, surface water, groundwater, drinking water, soil, sediment, and biological samples are collected and analyzed for radiological and nonradiological constituents. The resulting data are evaluated to assess effects of activities at the WVDP. Monitoring of treated water effluents and facility ventilation system emissions verified that the dose received by off-site residents continues to be minimal.

Calculated doses to the hypothetical maximally exposed off-site individual from airborne radiological releases in 2004 were less than one-tenth of one (1) percent of the EPA limit. Combined airborne and waterborne radiological releases in 2004 to the same individual were less than one-tenth of one (1) percent of the DOE limit.

The Project's continuing commitment to safety was reaffirmed in 2004 when it was recertified as a DOEVoluntary Protection Program (VPP) STAR site and approved for renewed membership in the EPA's National Environmental Performance Track. The WVDP is one of the few DOE sites to be awarded both the VPP STAR and National Environmental Performance Track membership. In 2004, West Valley Nuclear Services Company (WVNSCO) was awarded the DOE's Legacy of Stars Award, which was given in recognition of the continuance of three consecutive years as a Star of Excellence contractor.

If you have any questions or comments about the information in this report, please contact the WVNSCO Community Relations Department at (716) 942-2152 or complete and return the enclosed survey.

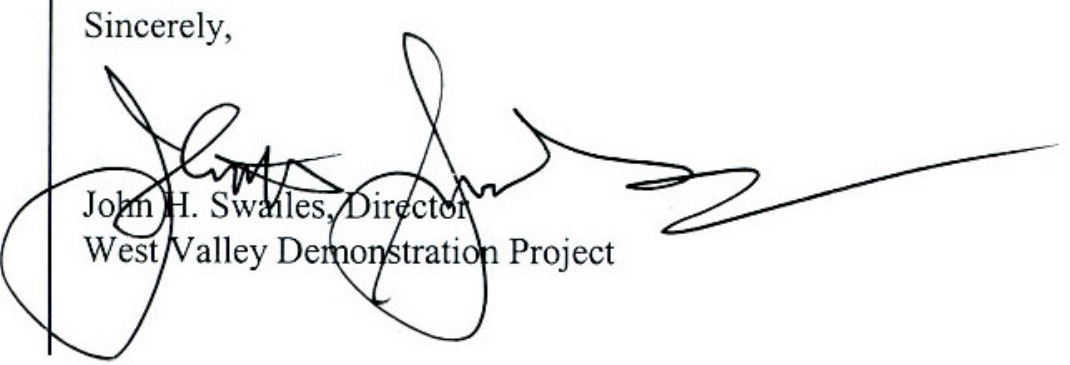





\section{SUMMARY OF CHANGES TO THE 2004 WVDP ANNUAL SITE ENVIRONMENTAL REPORT}

FROM THE 2003 ANNUAL SITE ENVIRONMENTAL REPORT

This report, prepared by the U.S. Department of Energy (DOE) West Valley Demonstration Project (WVDP) office, summarizes the environmental protection program at the WVDP for calendar year (CY) 2004. Monitoring and surveillance of the facilities used by the DOE for the WVDP are conducted in order to protect public health and safety and the environment. The quality assurance requirements applied to the environmental monitoring program by the DOE ensure the validity and accuracy of the monitoring data. Also included in this report are groundwater and ambient air data from the New York State Energy Research and Development Authority's New York State-licensed Disposal Area.

Changes in content for the 2004 Annual Site Environmental Report (ASER) are summarized below.

\section{REVISIONS AND ADDITIONS}

- $\quad$ The Environmental Compliance Summary was updated for CY 2004 to describe implementation of the WVDP environmental management system (EMS), compliance with DOE Orders, status of regulatory compliance, and permits effective during the year.

- Data and text were updated throughout to reflect results from the CY 2004 environmental monitoring program. Tables, graphs, maps, supplemental information sections, and references were updated.

- In an effort to further improve the readability of the ASER, sections were condensed by removing and referencing historical information and supplemental commentary and visual aids.

- $\quad$ To clarify the scope of the various super solid waste management units (SSWMUs) included in the groundwater program, one (1) new table that defines constituent solid waste management units for each SSWMU was added to Chapter 4.

- Data tables from three (3) air monitoring locations that were discontinued in 2003 (ANSEISK, ANLLW2V, and AFNASHV) were deleted from Appendix D. A data table for a new monitoring location at the Remote-Handled Waste Facility (ANRHWFK) was added.

- In Appendix E, Table E-1, that summarizes the groundwater monitoring network, was condensed and reformatted. Data formerly in two groundwater data tables that summarized indicator results from north plateau seeps and well points, respectively, were merged into other tables and the two tables were deleted from Appendix E.

- $\quad$ A data table summarizing analytical results for rail bed soil sampling was added to Appendix G.

- $\quad$ Two tables summarizing temperature and barometric pressure data were deleted from Appendix I.

- A new data table summarizing results of the Mixed Analyte Performance Evaluation Program, a crosscheck program in which the WVDP began participating in 2004, was added to Appendix J. 


\section{SPECIAL ISSUES IN CY 2004}

- $\quad$ Construction of the Remote-Handled Waste Facility was completed. Processing of radioactive waste in the facility began in June 2004.

- $\quad$ In the main plant, the head end cells and extraction cell \#2 were decontaminated.

- $\quad$ Major vessels were removed from the vitrification cell and packaged in secure containers. Decontamination of the vitrification cell continued throughout the year.

- $\quad$ Portable air samplers were used to monitor outdoor ventilation enclosures and portable ventilation units that were used in an expanded role to ventilate decontamination activities in the main plant.

- $\quad$ Processing, packaging, and shipping of low-level radioactive waste continued throughout the year.

- $\quad$ Sodium-bearing wastewater consisting of flushed liquid retrieved from the waste tank farm was solidified with cement into 17 containers that await off-site shipment.

- In preparation for future waste shipments by rail, the on-site railroad spur was repaired. Before repairs were completed, the rail bed soils were characterized for chemical constituents to identify appropriate soil management practices.

- In preparation for eventual site closure, several temporary office trailers and other structures that were no longer needed were dismantled and moved off site.

- $\quad$ The WVDP Waste Management Final Environmental Impact Statement was issued in January 2004. 


\title{
West Valley Demonstration Project Annual Site Environmental Report
}

for

\section{Calendar Year 2004}

\author{
Prepared for the U.S. Department of Energy \\ Ohio Field Office \\ West Valley Demonstration Project Office \\ under contract DE-AC24-81NE44139
}

\begin{abstract}
August 2005
West Valley Nuclear Services Company and URS Group, Inc.

10282 Rock Springs Road
\end{abstract}

West Valley, New York 14171-9799 
This page intentionally left blank

$i i$ 


\section{Preface}

Environmental monitoring at the West Valley Demonstration Project (WVDP) is conducted by the West Valley Nuclear Services Company (WVNSCO), under contract to the U.S. Department of Energy. The data collected provide an historical record of radionuclide and radiation levels and chemical data from natural and man-made sources in the survey area. The data also document the chemical and radiological quality of the groundwater on and around the WVDP and of the air and water released by the WVDP. Meteorological data are also presented.

It is the policy of the WVDP to conduct all activities, including design, construction, testing, start-up, commissioning, operation, maintenance, and decontamination and decommissioning, in a manner that is appropriate to the nature, scale, and environmental effects of these activities. The WVDP is committed to full compliance with applicable federal and New York State laws and regulations for the

protection of the environment, to continual improvement, to the prevention and/or minimization of pollution, and to public outreach, including stakeholder involvement.

This report represents a single, comprehensive source of off-site and on-site environmental monitoring data collected during 2004 by environmental monitoring personnel. The environmental monitoring program and results are discussed in the body of this report. Additional monitoring information is presented in the appendices. Appendix A contains maps of on-site and off-site sampling locations. Appendices $B$ through $L$ can be found in electronic format on the compact disk (as indicated by the $\mathbf{G D}$ icon) located inside the back cover. Appendix B is a summary of the site environmental monitoring schedule. Appendices $C$ through J contain summaries of data obtained during 2004 and are intended for those readers interested in more detail than is provided in the main body of the report. Appendix $K$ lists laws and regulations pertaining to the WVDP. Appendix L provides groundwater monitoring data from the New York State-licensed Disposal Area.

Requests for additional copies of the 2004 Annual Site Environmental Report and questions regarding the report should be referred to the WVDP Community Relations Department, 10282 Rock Springs Road, West Valley, New York 14171 (telephone: 716-942-2152). Additional Project information, including WVDP site environmental reports, is available on the internet at http://www.wv.doe.gov.

iii 
This page intentionally left blank

iv 


\section{Table of Contents}

PREFACE

iii

EXECUTIVE SUMMARY

EXE-1

Purpose of This Report

EXE-1

Major Site Programs

EXE-1

Operation of the Remote-Handled Waste Facility

EXE-1

Decontamination of Facilities

EXE-1

Waste Management

EXE-2

Preparation for Eventual Site Closure

EXE-2

Environmental Monitoring

EXE-2

Key Initiatives EXE-2

Environmental Performance Indicators

EXE-2

Pollution Prevention/Waste Minimization Goals

EXE-2

Environmental Management System

EXE-3

Recognition and Awards

EXE-3

Compliance

EXE-3

Environmental Monitoring

EXE-3

Groundwater Monitoring

EXE-4

Quality Assurance

EXE-4

Conclusion

EXE-5

INTRODUCTION

INT-1

Site Location

INT-1

General Environmental Setting

INT-1

Site Mission

INT-3

Primary Operations and Activities

INT-3

Relevant Demographics INT-4 


\section{Table of Contents}

ENVIRONMENTAL COMPLIANCE SUMMARY ECS-1

Compliance Program ECS-1

Compliance Status ECS-2

Environmental Protection Program (DOE Order 450.1) ECS-2

Radiation Protection of the Public and the Environment (DOE Order 5400.5) ECS-2

Radioactive Waste Management (DOE Order 435.1) ECS-2

Resource Conservation and Recovery Act ECS-2

Clean Air Act ECS-6

Emergency Planning and Community Right-to-Know Act ECS-7

Clean Water Act ECS-8

Safe Drinking Water Act ECS-12

Toxic Substances Control Act ECS-13

National Environmental Policy Act ECS-13

Decommissioning and/or Long-Term Stewardship at the WVDP and WNYNSC ECS-14 Migratory Bird Treaty Act ECS-14

Endangered Species Act ECS-14

Current Achievements and Program Highlights ECS-14

Vitrification Cell Dismantlement ECS-14

Process Cells in the Main Plant Decontaminated ECS-14

Remote-Handled Waste Facility Started Up ECS-15

Sodium-Bearing Wastewater Solidified ECS-15

Waste Shipping Continued ECS-15

Integrated Safety Management System ECS-15

STAR Status ECS-15

EPA National Environmental Performance Track ECS-15

Environmental Management System ECS-15 Environmental Issues and Actions ECS-15

Closed Landfill Maintenance ECS-15

Railroad Spur Rehabilitation ECS-16

Decommissioning and/or Long-Term Stewardship at the WVDP and WNYNSC ECS-16 Project Assessment Activities in 2004 ECS-16 


\section{Table of Contents}

CHAPTER 1. ENVIRONMENTAL PROGRAM INFORMATION

Introduction $1-1$

Radiation and Radioactivity

Measurement of Radioactivity

Measurement of Dose

Environmental Monitoring Program Overview

Data Reporting

Changes in the 2004 Environmental Monitoring Program

Decontamination and Dismantlement

Sodium-Bearing Waste Management

Rail Spur Repairs

Infrastructure Footprint Reduction

Remote-Handled Waste Facility Construction

Environmental Management of Aqueous Radioactive Waste

North Plateau Groundwater Recovery System

Environmental Management of Airborne Radioactive Emissions ___ 1-8

Environmental Management of Radiological Exposure

Unplanned Radiological Releases

NRC-Licensed Disposal Area Interceptor Trench and Pretreatment System

Waste Minimization Program

Pollution Prevention Awareness Program

Waste Management

Low-Level Radioactive Waste Shipping Program

National Environmental Policy Act Activities

Self-Assessments

Occupational Safety and Environmental Training

Voluntary Protection Program STAR Status

Environmental Management System Implementation

Integrated Safety Management System Implementation

Radiation Doses to the Maximally Exposed Off-Site Individual

State Pollutant Discharge Elimination System Permit Limit Exceptions

Waste Minimization and Pollution Prevention 


\section{Table of Contents}

CHAPTER 2. ENVIRONMENTAL RADIOLOGICAL PROGRAM INFORMATION

RADIATION IN THE ENVIRONMENT

Sources of Radiation

Exposure Pathways

Land Use Survey

Dose to the Public

Release of Materials Containing Residual Radioactivity

ROUTINE MONITORING PROGRAM ___ 2-6

Radiological Sampling Program Overview ___ 2-6

Overview of Water Effluent and Ambient Surface Water Monitoring ___ 2-6

Low-Level Waste Treatment Facility Effluent____ 2-7

Northeast Swamp and North Swamp Drainage____ 2-7

Other North Plateau Surface Waters and Water Effluent ___ 2-8

South Plateau Surface Water and Nuclear Regulatory Commission-Licensed Disposal Area

Interceptor Trench ___ 2-8

Ponded (Standing) Waters ___ 2 _ _ _ _ _ _ _ _ _ _ _

Off-Site Surface Water ___ 2-9

Overview of Drinking Water Monitoring ___ 2-10

On-Site Tap Water ___ 2-10

Off-Site Drinking Water Wells ___ 2-11

Overview of Sediment Monitoring ___ 2-11

On-Site Sediments ___ 2-11

Off-Site Sediments ___ 2-12

Overview of Air Emission and Ambient Air Monitoring ___ $2-12$

Ventilation and Emission Systems ___ 2-12

Perimeter and Remote Ambient Air Monitoring ____ 2-14

Atmospheric Deposition and Soil Monitoring ___ 2-15

Fallout Pots _ 2-15

Off-Site Surface Soil ___ 2-15

Overview of Food Chain Monitoring ___ 2-15

Fish _ 2 2-15

Venison___ 2-15

Beef $2-16$

Milk__ 2-16

Vegetables and Fruit ____ 2-16 


\section{Table of Contents}

Chapter 2 (concluded)

Direct Environmental Radiation Monitoring ____ 2-16

On-Site Radiation Monitoring _______ __-16

Perimeter and Off-Site Radiation Monitoring ___ 2-16

Confirmation of Results ___ 2-17

Meteorological Monitoring ___ 2-17

Special Monitoring _____ 2-18

RADIOLOGICAL EFFLUENTS AND DOSE___ 2-19

Dose Assessment Methodology ____ 2-19

Measurement of Radionuclide Concentrations in Liquid and Air Releases ___ 2-19

Measurement of Radionuclide Concentrations in Food ___ 2-19

Predicted Dose From Airborne Emissions ____ 2-21

Maximum Dose to an Off-Site Individual___ 2-21

Collective Population Dose ___ 2-21

Iodine Emissions From the Main Stack ___ 2-21

Predicted Dose From Waterborne Releases_____ 2-23

Maximum Dose to an Off-Site Individual___ 2-25

Collective Dose to the Population___ 2-25

Calculated Dose From Local Foodstuff Tests ___ 2-25

Predicted Dose From All Pathways ___ 2-26

Risk Assessment ___ 2-27

Dose to Biota: Aquatic and Terrestrial Wildlife___ 2-27

Summary __ 2-29

CHAPTER 3. ENVIRONMENTAL NONRADIOLOGICAL PROGRAM INFORMATION ___ 3-1

Overview of New York State Water Classifications, Water Quality Standards, and Water Effluent Limits

Surface Water, Subsurface Drainage Water, and Water Effluent Monitoring ___ $3-2$

SPDES Permit-Required Monitoring ___ 3-2

Mercury Analytical Method Study ___ 3-2

South Plateau Surface and Subsurface Water ___ 3-3

Other On-Site and Off-Site Surface Water Monitoring ___

Drinking Water Monitoring ___ 3-4

Soil and Sediment Monitoring ___ 3-5

Air Emission Monitoring ___ 3-6

$i x$ 


\section{Table of Contents}

CHAPTER 4. SITE HYDROLOGY AND GROUNDWATER MONITORING 4-1

Groundwater Monitoring Program Overview 4-1

Surface Water Hydrology ______ 4-1

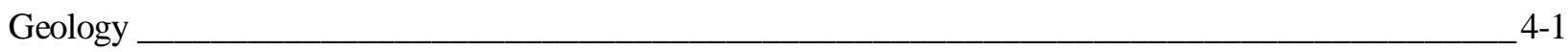

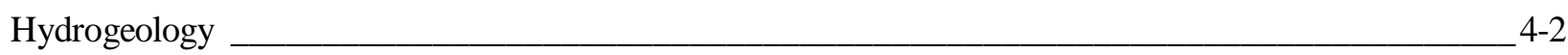

Kent Recessional Sequence ___ 4-2

Lavery Till ___ 4-2

Sand and Gravel and Till-Sand Units ____

Routine Groundwater Monitoring Program____ 4-4

Monitoring Well Network _______ 4-4

Groundwater Monitoring Program Highlights 1982 Through $2004 \_$4-7

Analytical Trigger Level Evaluation ____

Results of Routine Groundwater Monitoring____ 4-8

Long-Term Trends of Gross Beta and Tritium at Selected Groundwater Monitoring Locations __ 4-8

North Plateau Seeps___ 4-9

North Plateau Well Points ___ 4-9

Results of Radioisotopic Sampling ___ 4-9

Results of Monitoring at the NDA ___ 4-11

Off-Site Groundwater Monitoring ___ 4-11

Results for Volatile and Semivolatile Organic Compounds____ 4-11

Special Groundwater Monitoring ____ 4-12

Gross Beta Plume on the North Plateau ___ 4-12

North Plateau Groundwater Recovery System ___ 4-12

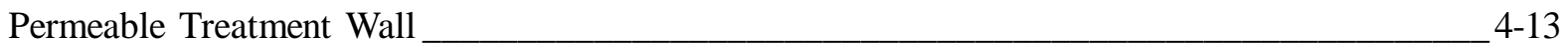

Northeast Swamp Drainage Monitoring ______ 4-13

North Plateau Groundwater Quality Early Warning Monitoring______-13

Investigation of Chromium and Nickel in the Sand and Gravel Unit and Evaluation of

Corrosion in Groundwater Monitoring Wells __ 4-13

Ten-Year Sampling Pump Inspections ___ 4-14 


\section{Table of Contents}

CHAPTER 5. QUALITY ASSURANCE

Quality Assurance Program ____ 5-1

Responsibility ___ 5-1

Planning ___ 5-1

Training _____ 5-1

Control of Design, Procedures, Items, and Documents ___ 5-2

Corrective Action ___ 5-2

Documentation ___ _ _ 5-2

Audits and Assessments___ 5-2

Quality Control ___ 5-2

Field QC ___ 5-2

Laboratory QC ___ 5-3

Independent Comparisons and Crosschecks ___ 5-3

Data Management ___ _ _ 5-4

Data Verification and Validation ___ 5-4

Data Assessment and Reporting ___ 5-5

Audits, Appraisals, and Self-Assessments ___ 5-5

Lessons Learned _ _ 5-5

Conclusion____ 5-5

REFERENCES AND BIBLIOGRAPHY ___ R\&B-1

GLOSSARY ___ GLO-1

ACRONYMS AND ABBREVIATIONS ___ A\&A-1

UNITS OF MEASURE ___ UOM-1

UNIT PREFIXES ___ UOM-1

SCIENTIFIC NOTATION ___ UOM-2

CONVERSION CHART __ UOM-2

DISTRIBUTION ___ DST-1

APPENDIX A. ENVIRONMENTAL MONITORING PROGRAM MAPS ___ A-i

$x i$ 


\section{Table of Contents}

\section{List of Figures}

INT-1. Location of the Western New York Nuclear Service Center INT-2

ECS-1. WVDP SPDES Effluent Limit Exceptions ECS-11

1-1. Annual Effective Dose Equivalent to the Maximally Exposed Off-Site Individual $1-14$

1-2. Yearly SPDES Effluent Limit Exceptions

1-3. Percentage of Waste-Reduction-Exceeding Goals $1-16$

1-4. Number of Immediately Reportable Spills or Releases $1-16$

2-1. Comparison of Doses From Natural and Man-Made Sources to the Dose From 2004 WVDP Effluents

2-2. Ten-Year Trends of Gross Alpha, Gross Beta, and Tritium Concentrations at Sampling Location WFFELBR

2-3. Ten-Year Trends of Cesium-137 in Stream Sediments at One Location Upstream and One Location Downstream of the WVDP

2-4. Ten-Year Trends of Gross Alpha and Gross Beta Concentrations at Rock Springs Road (AFRSPRD)

2-5. Ten-Year Trends of Environmental Radiation Levels at Perimeter TLDs $2-17$

2-6. Effective Dose Equivalent From Liquid and Airborne Effluents to a Maximally Exposed Individual Residing Near the WVDP

2-7. Collective Effective Dose Equivalent From Liquid and Airborne Effluents to the Population Residing Within 50 Miles $(80 \mathrm{~km})$ of the WVDP 


\section{Table of Contents}

List of Figures (concluded)

4-1. Geologic Cross Section Through the North Plateau __ 4-3

4-2. Geologic Cross Section Through the South Plateau __ 4-3

4-3. North Plateau Gross Beta Plume Area: Fourth-Quarter 2004 Results ___ 4-10

4-4. Average Yearly Gross Beta Concentrations at Locations Closer to the Source of the North Plateau Plume 4-15

4-5. Average Yearly Gross Beta Concentrations at Locations Closer to the Leading Edges of the North Plateau Plume____ 4-15

4-6. Average Yearly Gross Beta Concentrations at Locations Near Former Lagoon 1___ 4-16

4-7. Average Yearly Tritium Concentrations at Selected Locations in the Sand and Gravel Unit 4-16

4-8. Concentrations of 1,2-DCE-t, 1,1,1-TCA, and 1,1-DCA at Well 8612 in the Sand and Gravel Unit 4-17

4-9. Concentrations of Tributyl Phosphate at Selected Locations in the Sand and Gravel Unit 4-17

4-10. Annualized Average Strontium-90 Concentrations at WNSWAMP 4-18

A-1. West Valley Demonstration Project Base Map A-1

A-2. On-Site Surface Water and Soil/Sediment Sampling Locations A-2

A-3. Off-Site Surface Water and Soil/Sediment Sampling Locations A-3

A-4. On-Site Air Monitoring and Sampling Locations A-4

A-5. Off-Site Air and Fallout Sampling Locations A-5

A-6. Active WVDP Groundwater Monitoring Locations A-6

A-7. North Plateau On-Site Groundwater Monitoring Network A-7

A-8. South Plateau On-Site Groundwater Monitoring Network A-8 A-9. Near-Site Drinking Water and Biological Sampling Locations A-9 A-10. Location of On-Site Thermoluminescent Dosimeters (TLDs) A-10 A-11. Location of Off-Site Thermoluminescent Dosimeters (TLDs) Within 5 Kilometers of the WVDP _ A-11 A-12. Environmental Sampling Locations Between 5 and 10 Kilometers From the WVDP A-12

A-13. Environmental Sampling Locations More Than 10 Kilometers From the WVDP A-13 A-14. Estimated 2002 Population by Sector Within 80 Kilometers of the WVDP A-14 


\section{Table of Contents}

\section{List of Tables}

Compliance Tables:

ECS-1. Elements of the Environmental Management System Implementation at the WVDP ECS-17

ECS-2. West Valley Demonstration Project Environmental Permits ECS-21

ECS-3. West Valley Demonstration Project 2004 Air Quality Noncompliance Episodes ECS-23

ECS-4. Status of EPCRA Reporting in 2004 ECS-23

ECS-5. Reportable Chemicals Above Threshold Planning Quantities Stored at the WVDP in 2004 ECS-23

ECS-6. West Valley Demonstration Project 2004 NPDES/SPDES Permit Noncompliance Episodes ECS-24

ECS-7. West Valley Demonstration Project Migratory Bird Nest Depredation Episodes in 2004 ECS-24

2-1. Potential Local Off-Site Exposure Pathways Under Existing WVDP Conditions $2-4$

2-2. Release of Property Containing Residual Radioactive Material $2-5$

2-3. Summary of Annual Effective Dose Equivalents to an Individual and Population From WVDP Releases in 2004 $2-22$

2-4. 2004 Evaluation of Dose to Aquatic and Terrestrial Biota $2-30$

2-5. WVDP Radiological Dose and Release Summary $2-31$

4-1. Summary of Groundwater Monitoring Program by Geographic Area; Monitoring Year 2004 $4-5$

4-2. Summary of Groundwater Monitoring Program by Monitoring Purpose; Monitoring Year 2004 4-5

4-3. WVDP RCRA SSWMUs and Constituent SWMUs 4-6

xiv 


\section{Table of Contents}

\section{List of Figures \\ (Available only on CD, as indicated by the $\mathrm{GD}$ icon.)}

H-1. 2004 Average Yearly Gamma Exposure Rates Around the WVDP ___ H-6

H-2. 2004 Average Yearly Gamma Exposure Rates on the WVDP__ H-6

I-1. Regional Monitoring Station Wind Frequency Rose: 10-Meter I-3

I-2. Primary Monitoring Station Wind Frequency Rose: 10-Meter I-4

I-3. Primary Monitoring Station Wind Frequency Rose: 60-Meter I-5

I-4. Calendar Year 2004 Weekly Precipitation I-6

I-5. Calendar Year 2004 Cumulative Precipitation I-6 


\section{Table of Contents}

\section{List of Tables \\ (Available only on CD, as indicated by the $\mathrm{GD}$ icon.)}

APPENDIX B. 2004 ENVIRONMENTAL MONITORING PROGRAM B-i

APPENDIX C-1. SUMMARY OF WATER LIMITS, GUIDELINES, AND STANDARDS C-1

C-1 A. West Valley Demonstration Project State Pollutant Discharge Elimination System Sampling Program C-3

C-1B. New York Water Quality Standards and Guidelines C-5

C-1C. New York State Department of Health/U.S. Environmental Protection Agency MCLs, MCLGs, and Raw Water Standards C-7

C-1D. U.S. Department of Energy Derived Concentration Guides C-8

APPENDIX C-2. PROCESS EFFLUENT DATA C-9

C-2A. Total Radioactivity of Liquid Effluents Released From Lagoon 3 (WNSP001) in 2004 C-11

C-2B. Comparison of 2004 Lagoon 3 (WNSP001) Liquid Effluent Radioactivity Concentrations With U.S. Department of Energy Guidelines C-12 C-2C. 2004 SPDES Results for Outfall 001 (WNSP001): Water Quality $\mathrm{C}-13$ C-2D. 2004 SPDES Results for Outfall 001 (WNSP001): Metals C-15

C-2E. 2004 SPDES Results for Outfall 001 (WNSP001): Organics $\mathrm{C}-17$

C-2F. 2004 SPDES Results for Outfall 007 (WNSP007): Water Quality and Iron C-18

C-2G. 2004 SPDES Results for Outfall 008 (WNSP008): Water Quality C-19

C-2H. 2004 SPDES Results for Sums of Outfalls 001, 007, 008, and 116: Water Quality C-20

C-2I. 2004 Quarterly/Semiannual/Annual SPDES Results for Outfall 001 (WNSP001): Water

Quality, Metals, and Organics C-21

C-2J. 2004 Annual SPDES Results for Outfall 007 (WNSP007): Water Quality $\mathrm{C}-21$

C-2K. 2004 Annual SPDES Results for Outfall 008 (WNSP008): Water Quality $\mathrm{C}-22$ C-2L. 2004 Annual SPDES Results for Outfall 01B (WNSP01B): Water Quality $\mathrm{C}-22$ C-2M. 2004 Radioactivity at Sewage Treatment Outfall (WNSP007) $\mathrm{C}-22$

APPENDIX C-3. SITE SURFACE DRAINAGE, SUBSURFACE DRAINAGE, AND CONTAINED WATER C-23

C-3A. 2004 Radioactivity and pH in Surface Water at Facility Yard Drainage (WNSP005) C-25

C-3B. 2004 Radioactivity in Surface Water at French Drain (WNSP008) $\mathrm{C}-25$

C-3C. 2004 Water Quality of Surface Water at the North Swamp (WNSW74A) C-26

$x v i$ 


\section{Table of Contents}

List of Tables (continued)

C-3D. 2004 Water Quality of Surface Water at the Northeast Swamp (WNSWAMP)

C-29

C-3E. 2004 Indicator Results at Storage and Disposal Area Drainage (WNNDADR)

C-3F. 2004 Indicator Results in Subsurface Water at the NDA Interceptor Trench

(WNNDATR)

C-3G. 2004 Indicator Results at SDA Drainage (WNSDADR)

C-3H. 2004 Indicator Results in Surface Water at Cooling Tower Basin (WNCOOLW)

C-33

APPENDIX C-4. AMBIENT SURFACE WATER DATA C-35

C-4A. 2004 Radioactivity and pH in Surface Water Downstream of the WVDP in Cattaraugus Creek at Felton Bridge (WFFELBR)

C-4B. 2004 Water Quality of Surface Water Downstream of the WVDP in Buttermilk Creek at Thomas Corners Bridge (WFBCTCB) C-37

C-4C. 2004 Water Quality of Surface Water Downstream of the WVDP at Frank's Creek (WNSP006) C-40

C-4D. 2004 Total Dissolved Solids From Outfall WNSP116 C-43

C-4E. 2004 Indicator Results in Surface Water at Erdman Brook (WNERB53) C-43

C-4F. 2004 Indicator Results in Surface Water at Frank's Creek East of the SDA (WNFRC67) C-44

C-4G. 2004 Indicator Results in Surface Water at Drum Cell Drainage (WNDCELD) C-44

C-4H. 2004 Water Quality of Surface Water at the Standing Water (WNSTAW-Series) Locations C-45

APPENDIX C-5. POTABLE WATER (DRINKING WATER) DATA C-47

C-5A. 2004 Indicator Results in Potable Well Water Around the WVDP C-49

C-5B. 2004 Indicator Results in Main Plant Potable Water (WNDNKMP); 2004 Indicator Results in Environmental Laboratory Potable Water (WNDNKEL); and 2004 Indicator Results in Maintenance Shop Potable Water (WNDNKMS) C-50

C-5C. 2004 Water Quality Results in Utility Room Potable Water (WNDNKUR) C-51

C-5D. 2004 Water Quality Results in Utility Room Raw (Untreated) Water (WNURRAW) C-52

C-5E. 2004 Biological and Chlorine Results From Various Site Tap Water Locations C-52

C-5F. 2004 Tap Water Nitrate Results From WVDP Restroom Sink C-52 


\section{Table of Contents}

List of Tables (continued)

APPENDIX D. SUMMARY OF AIR MONITORING DATA

D-1

D-1. 2004 Effluent Airborne Radioactivity at Main Stack (ANSTACK) ___ D-3

D-2. 2004 Effluent Airborne Radioactivity at Vitrification System HVAC (ANVITSK) ___ _ D-4

D-3. 2004 Effluent Airborne Radioactivity at 01-14 Building (ANCSSTK) ___ D-5

D-4. 2004 Effluent Airborne Radioactivity at Contact Size-Reduction Facility (ANCSRFK) ___ _ D-5

D-5. 2004 Effluent Airborne Radioactivity at Supernatant Treatment System (ANSTSTK) ___ D-6

D-6. 2004 Effluent Airborne Radioactivity at Container Sorting and Packaging Facility (ANCSPFK) D-7

D-7. 2004 Effluent Airborne Radioactivity at Outdoor Ventilation Enclosures/Portable Ventilation Units D-8

D-8. 2004 Effluent Airborne Radioactivity at Remote-Handled Waste Facility Stack (ANRHWFK)

D-9. 2004 Ambient Airborne Radioactivity at Lag Storage (ANLAGAM) D-10

D-10. 2004 Ambient Airborne Radioactivity at the NDA (ANNDAAM) D-11

D-11. 2004 Ambient Airborne Radioactivity at SDA Trench 9 (ANSDAT9) D-11

D-12. 2004 Ambient Airborne Radioactivity at Rock Springs Road (AFRSPRD) D-12

D-13. 2004 Ambient Airborne Radioactivity at Dutch Hill Road (AFBOEHN) D-13

D-14. 2004 Ambient Airborne Radioactivity at Fox Valley Road (AFFXVRD) D-13

D-15. 2004 Ambient Airborne Radioactivity at the Bulk Storage Warehouse (AFBLKST) D-14

D-16. 2004 Ambient Airborne Radioactivity at Route 240 (AFRT240) D-14

D-17. 2004 Ambient Airborne Radioactivity at Thomas Corners Road (AFTCORD) D-15

D-18. 2004 Ambient Airborne Radioactivity at West Valley (AFWEVAL) D-15

D-19. 2004 Ambient Airborne Radioactivity at Springville (AFSPRVL) D-16

D-20. 2004 Radioactivity in Fallout: Dutch Hill (AFDHFOP) D-17

D-21. 2004 Radioactivity in Fallout: Rain Gauge (ANRGFOP) D-17

D-22. 2004 Radioactivity in Fallout: Route 240 (AF24FOP) D-17

D-23. 2004 Radioactivity in Fallout: Thomas Corners (AFTCFOP) D-18

D-24. 2004 Radioactivity in Fallout: Fox Valley Road (AFFXFOP) D-18 


\section{Table of Contents}

List of Tables (continued)

APPENDIX E. SUMMARY OF GROUNDWATER MONITORING DATA E-1

Groundwater Sampling Methodology E-2

2004 Groundwater Sampling and Analysis Agenda E-3

E-1. Groundwater Monitoring Network: Super Solid Waste Management Units E-4

E-2. 2004 Indicator Results From the Sand and Gravel Unit E-7

E-3. 2004 Indicator Results From the Lavery Till-Sand Unit E-11

E-4. 2004 Indicator Results From the Weathered Lavery Till Unit E-12

E-5. 2004 Indicator Results From the Unweathered Lavery Till Unit E-13

E-6. 2004 Indicator Results From the Kent Recessional Sequence E-14

E-7. 2004 Volatile Organic Compound Results at Selected Groundwater Monitoring Locations E-15

E-8. 2004 Tributyl Phosphate Results at Selected Groundwater Monitoring Locations E-15

E-9. 2004 Results for Metals in Groundwater E-16

E-10. 2004 Metals Indicator Results for Early Warning Monitoring Wells E-18

E-11. 2004 Radioactivity in Groundwater From Selected Monitoring Locations E-19

E-12. Practical Quantitation Limits E-23

APPENDIX F. SUMMARY OF BIOLOGICAL DATA F-1

F-1. 2004 Radioactivity Concentrations in Milk F-3

F-2. 2004 Radioactivity Concentrations in Meat F-4

F-3. 2004 Radioactivity Concentrations in Food Crops F-5

F-4. 2004 Radioactivity Concentrations in Fish Flesh From Cattaraugus Creek F-6

APPENDIX G-1. SUMMARY OF SOIL AND AQUATIC SEDIMENT GUIDELINES AND STANDARDS G-1

G-1A. Eastern U.S.A. Background Concentrations for Elements in Soils G-3

G-1B. Screening Concentrations for Elements in Contaminated Sediments G-4

G-1C. Elemental Screening Thresholds for In-Water and Riparian Management of Sediment and Dredge Material G-4 


\section{Table of Contents}

List of Tables (continued)

APPENDIX G-2. SOIL AND SEDIMENT DATA G-5

G-2A. 2004 Contaminants in On-Site Soils Downstream of the WVDP at Frank's Creek (SNSP006) G-7

G-2B. 2004 Contaminants in On-Site Soils From North Swamp (SNSW74A) G-8

G-2C. 2004 Contaminants in On-Site Soils From Northeast Swamp (SNSWAMP) G-9

G-2D. 2004 Radioactivity in Surface Soils Collected at Air Stations Around the WVDP G-10

G-2E. 2004 Radioactivity in Stream Sediments Around the WVDP G-12

G-2F. 2004 Contaminants in Rail Bed Soil Material G-13

APPENDIX H. SUMMARY OF DIRECT RADIATION MONITORING DATA H-1

H-1. Summary of 2004 Quarterly Averages of Off-Site TLD Measurements $\mathrm{H}-3$

H-2. Summary of 2004 Quarterly Averages of On-Site TLD Measurements $\mathrm{H}-4$

H-3. Third-Quarter 2004 TLD Results and Instantaneous Exposure Rate Readings With a HighPressure Ion Chamber at Each Monitoring Location H-5

APPENDIX I. SUMMARY OF METEOROLOGICAL DATA I-1

I-1. 2004 Site Precipitation Collection Data I-7

APPENDIX J. SUMMARY OF QUALITY ASSURANCE CROSSCHECK ANALYSES $\mathrm{J}-1$

J-1. Crosscheck Sample Comparisons From the DOE Environmental Measurements Laboratory Quality Assessment Program 60; QAP 0403; June 2004

J-2. Crosscheck Sample Comparisons From the DOE Mixed Analyte Performance Evaluation Program; May 2004 $\mathrm{J}-5$

J-3. Crosscheck Sample Comparisons From the DOE Mixed Analyte Performance Evaluation Program; November 2004

J-4. Crosscheck Sample Comparisons of Results Analyzed for Water Quality Parameters as Part of the EPA's 2004 Discharge Monitoring Report - Quality Assurance Study 24 for the National Pollutant Discharge Elimination System $\mathrm{J}-10$

$x x$ 


\section{Table of Contents}

List of Tables (concluded)

APPENDIX K. ENVIRONMENTAL LAWS, REGULATIONS, STANDARDS, AND

ORDERS $\mathrm{K}-1$

K-1. U.S. Department of Energy Radiation Protection Standards and Derived Concentration Guides $\mathrm{K}-3$

K-2. Environmental Laws, Regulations, Standards, and Orders $\mathrm{K}-4$

K-3. West Valley Demonstration Project Act $\mathrm{K}-7$

APPENDIX L. SUMMARY OF NEW YORK STATE ENERGY RESEARCH AND DEVELOPMENT AUTHORITY GROUNDWATER MONITORING DATA FOR THE NEW YORK STATE-LICENSED DISPOSAL AREA L-1

L-1. 2004 Contamination Indicator Results From SDA Monitoring Wells L-3

L-2. 2004 Radiological Indicator Results From SDA Monitoring Wells L-5

L-3. 2004 Radioisotopic Results From SDA Monitoring Wells L-7

$x x i$ 
This page intentionally left blank

xxii 


\section{EXECUTIVE SUMMARY}

\section{Purpose of This Report}

The Annual Site Environmental Report for the West Valley Demonstration Project (WVDP or Project) is published to provide information about environmental conditions at the WVDP to members of the public living near the site and to other interested stakeholders. The WVDP is located in western New York State, about 30 miles $(50 \mathrm{~km})$ south of Buffalo, within the New York Stateowned Western New York Nuclear Service Center. In accordance with U.S. Department of Energy (DOE) Order 231.1A, "Environment, Safety, and Health Reporting," this report summarizes calendar year (CY) 2004 environmental monitoring data so as to describe the performance of the WVDP's environmental management system (EMS), confirm compliance with standards and regulations, and highlight important programs. Activities at the WVDP are being conducted in conjunction with the New York State Energy Research and Development Authority.

\section{Major Site Programs}

The WVDP is located on the site of a former commercial nuclear fuel reprocessing plant, which was shut down in 1976. In 1980, Public Law 96-368 (the WVDP Act) was passed. This Act authorized the DOE to demonstrate a method for so- lidifying 600,000 gallons (2.3 million liters) of liquid high-level radioactive waste (HLW) that remained at the West Valley site. Vitrification of the HLW, begun in 1996, was completed in September 2002. Activities for decontaminating the vitrification and support facilities and for disposing of wastes were then initiated and continued through CY 2004. Major activities that occurred in 2004 were as follows.

Operation of the Remote-Handled Waste Facility (RHWF). Construction of the RHWF, a facility used to prepare higher-activity wastes for shipment and disposal, was completed in early 2004. Extensive start-up/readiness reviews were performed to assess readiness to begin radioactive operations. In June 2004 the facility began processing radioactive waste.

Decontamination of Facilities. Decontamination of three major cells in the main plant (the process mechanical cell, the general purpose cell, and extraction cell 2), including removal of equipment, vessels, and process piping, was completed in

$A$ reader opinion survey has been inserted in this report. If it is missing, please contact the Community Relations Department at (716) 9422152. Additional Project information is available on the internet at http://www.wv.doe.gov. 
2004. Major vessels were removed from the vitrification cell and packaged in secure containers. Decontamination activities in the vitrification cell continue.

Waste Management. Management of HLW, transuranic waste, mixed waste (i.e., waste that is both hazardous and radioactive), low-level radioactive waste (LLW), hazardous waste, and nonhazardous regulated waste continued to be a priority at the WVDP in 2004. Processing of LLW continued, and sodium-bearing waste originally from the waste tank farm and stored in the main process plant was solidified with cement into 17 containers that are currently stored on site.

In preparation for future waste shipments by rail, the on-site railroad spur was repaired in the summer of 2004.

No mixed or hazardous waste was shipped in 2004, however, 104,427 cubic feet (about 3,000 cubic meters) of LLW were sent off site. Approximately 20 tons (18 metric tons) of nonradioactive, nonhazardous material were sent off site to solid waste management facilities in 2004. Of this amount, about one ton was recycled. The WVDP also shipped 1,070 tons (971 metric tons) of digested sludge and treated wastewater from the site sanitary and industrial wastewater treatment facility to the Buffalo Sewer Authority for disposal.

In 2004, as part of the site's EMS, the WVDP continued a long-term waste minimization and pollution prevention program to promote affirmative procurement and minimize the generation of LLW, mixed waste, hazardous waste, industrial waste, and sanitary waste.

Preparation for Eventual Site Closure. In 2004, preparation of the Decommissioning and/or LongTerm Stewardship Environmental Impact Statement continued. To reduce the site "footprint," several temporary office trailers and other structures that were no longer needed were dismantled and moved off site.

Environmental Monitoring. As part of the EMS, the WVDP continued to monitor the environment on and near the site to detect and evaluate changes in the environment resulting from Project (or preProject) activities and to assess the effect of any such changes on the environment or human population.

\section{Key Initiatives}

Environmental Performance Indicators. In 2004, the WVDP re-applied to the U.S. Environmental Protection Agency for continued membership in the National Environmental Performance Track program. The WVDP renewal request was accepted in December 2004. Three new commitments were established for the three-year period of CY 2004-2006: (1) elimination of halon 1301 from fire-suppression systems on site, (2) a 10\% reduction in total energy usage, and (3) a 10\% reduction in total radiological curies discharged in wastewater. The first commitment was completed in 2004. The other commitments are on track to be met during the three-year period.

\section{Pollution Prevention/Waste Minimization}

Goals. In 2004, the WVDP continued its program of reducing and eliminating the amount of waste generated from site activities. Emphasis on good business practices, source reduction, and recycling continued to reduce the generation of LLW, mixed waste, hazardous waste, sanitary wastes, and industrial wastes (such as paper, glass, plastic, wood, and scrap metal). Waste minimization goals for 2004 in three of the above five waste categories (LLW, mixed, and hazardous) were met or exceeded. Although generation of both industrial waste and sanitary waste was reduced in 2004, target reductions from the 1993 baselines were 
not met. (The industrial reduction target was $60 \%$; actual reduction was $11 \%$. The sanitary waste reduction target was $75 \%$; actual reduction was $58 \%$.)

\section{Environmental Management System}

The WVDP EMS satisfies the requirements of DOE Order 450.1, Environmental Protection Program. The WVDP EMS is an integral part of the WVDP Integrated Safety Management System. In 2004, the WVDP continued to demonstrate its commitment to an all-inclusive approach to safety, coordinating the EMS with other safety management and work planning processes through the integrated environmental, health, and safety management program.

Recognition and Awards. The DOE's Legacy of Stars Award was presented to the WVDP by the Voluntary Protection Program (VPP) Participants Association in 2004. The WVDP is the first (and only) site to receive the Legacy of Stars designation, which is given to sites in recognition of the continuance of three consecutive years as a Star of Excellence contractor. The Star of Excellence, the highest VPP award for safety, is awarded to sites that have full commitment to maintaining quality, safety, and health programs.

In 2004, the West Valley Nuclear Services Company was recognized by its parent company, Washington Group International, with a Safe Project of the Year Award. Both awards were given in a year that saw the WVDP achieve its best safety record in more than 20 years, reaching more than 2.5 million consecutive work hours without a lost time work injury or illness.

Compliance. Management at the WVDP continued to provide strong support for environmental compliance in 2004. DOE Orders and applicable state and federal statutes and regulations are integrated into the Project's compliance program.

\section{In CY 2004:}

- no notices of violation or inspection findings from any environmental regulatory agencies were received by the WVDP.

- inspections by the New York State Department of Environmental Conservation and the local department of health verified Project compliance with the applicable environmental and health regulations.

- the WVDP continued to successfully monitor waste management areas at the site to comply with the Resource Conservation and Recovery Act $\S 3008$ (h) Administrative Order on Consent.

- the Project met the requirements of the Emergency Planning and Community Right-to-Know Act by collecting information about hazardous materials used at the Project and making this information available to the local community.

- an updated New York State Pollutant Discharge Elimination System (SPDES) permit was received. The updated permit, which took effect on January 1,2005 , added 20 storm water monitoring points to the five effluent points already included in the permit. In May 2004, one exceedence of a permit limit occurred when total suspended solids exceeded the daily maximum limit.

Environmental Monitoring. As part of the EMS, the WVDP monitors on-site facilities and the surrounding environment. Radionuclides present at the WVDP are primarily residues from the reprocessing of commercial nuclear fuel during the 1960s and early 1970s. A very small fraction of these radionuclides is released off site during the year through ventilation systems and liquid dis- 
charges. Potential pathways of exposure include inhalation of gases and particulates, ingestion of locally-grown food products, consumption of fish, beef, and venison, and exposure to external penetrating radiation emitted from contaminated materials. These exposure pathways are routinely monitored at the WVDP.

Radiological Releases. The primary source of airborne radionuclide emissions at the WVDP is the main stack of the process building.

The largest single source of waterborne radioactivity in effluents from the WVDP is lagoon 3, from which treated water is released in batches. Eight batches totaling approximately 15.0 million gallons (56.6 million liters) were released from the Project in 2004. Seepage of groundwater contaminated with strontium-90 from pre-Project operations across the north plateau in an elongated plume was another waterborne source of radioactivity in 2004.

Estimated Dose. In 2004, the estimated dose to a maximally exposed off-site individual (MEOSI) from airborne emissions at the WVDP was $0.0015 \mathrm{mrem}(0.000015 \mathrm{mSv})$, about $0.02 \%$ of the 10 mrem EPA standard. Estimated dose from waterborne sources in 2004 was about $0.047 \mathrm{mrem}$ $(0.00047 \mathrm{mSv})$, with $0.016 \mathrm{mrem}$ attributable to liquid effluent releases and 0.031 mrem attributable to the north plateau drainage.

Total estimated dose to the MEOSI from both airborne and waterborne sources in 2004 was $0.049 \mathrm{mrem}(0.00049 \mathrm{mSv})$, about $0.05 \%$ of the annual 100 mrem DOE standard. In comparison, the typical dose to a member of the public from natural background sources is 295 mrem per year. Estimated dose to the population within a 50-mile (80-kilometer) radius of the WVDP from DOE activities in 2004 was 0.20 person-rem ( 0.002 person-Sv). This same population would have received approximately 453,000 person-rem from natural background radiation in 2004.

Dose to Biota. An evaluation of dose to biota for CY 2004, as part of the WVDP environmental monitoring program, resulted in the conclusion that populations of aquatic and terrestrial biota (both plants and animals) are not being exposed to doses in excess of the existing DOE dose standard for aquatic animals and the recommended standards for terrestrial biota.

Nonradiological Releases. Nonradiological releases from Project waste water were measured under the site's SPDES permit. In 2004, one measurement for total suspended solids exceeded the maximum daily limit.

Groundwater Monitoring. Monitoring of groundwater at the WVDP continued in 2004, including evaluation of new wells installed around the RHWF. Also, monitoring of strontium-90 activity in and around the groundwater plume on the north plateau continued.

Quality Assurance. In 2004, the WVDP continued to implement a quality assurance program for activities supporting the environmental monitoring program. As part of this ongoing effort, on-site and subcontract laboratories that analyze environmental samples for the WVDP participated in independent performance evaluation studies for both radiological and nonradiological constituents. In these studies, test environmental samples with concentrations known by the testing agency, but unknown by the laboratory, are analyzed. Of 101 radiological performance evaluation samples analyzed by and for the WVDP, a total of $96 \%$ fell within acceptance limits. Of 80 nonradiological performance evaluation samples analyzed, about $98 \%$ were acceptable. 
Several inspections, audits, and assessments of components of the environmental monitoring program were conducted in 2004. Although actions were recommended to improve the program, nothing was found that would compromise the quality of the data in this report or the environmental monitoring program in general.

\section{Conclusion}

In addition to demonstrating compliance with environmental regulations and directives, evaluation of data collected in 2004 continued to indicate that WVDP activities pose no threat to public health or safety or to the environment.

EXE - 5 
This page intentionally left blank

EXE - 6 


\section{INTRODUCTION}

\section{Site Location}

The West Valley Demonstration Project (WVDP or Project) is located in western New York State, about 30 miles (50 kilometers [km]) south of Buffalo, New York (Fig. INT-1). The WVDP facilities occupy a security-fenced area of about 167 acres (68 hectares [ha]) within the 3,338-acre (1,351 ha) Western New York Nuclear Service Center (WNYNSC) located primarily in the town of Ashford in northern Cattaraugus County. The security-fenced area is referred to as the Project premises.

\section{General Environmental Setting}

Climate. Although extremes of $98.6^{\circ} \mathrm{F}\left(37^{\circ} \mathrm{C}\right)$ and $-43.6^{\circ} \mathrm{F}\left(-42^{\circ} \mathrm{C}\right)$ have been recorded in western New York, the climate is moderate, with an average annual temperature (1971-2000) of $48^{\circ} \mathrm{F}$ $\left(8.9^{\circ} \mathrm{C}\right)$. Precipitation is markedly influenced by Lake Erie to the west and, to a lesser extent, by Lake Ontario to the north. Regional winds are generally from the west and south at about $9 \mathrm{mph}$ $(4 \mathrm{~m} / \mathrm{sec})$.

Ecology. The WNYNSC lies within the northern deciduous forest biome, and the diversity of its vegetation is typical of the region. Equally divided between forest and open land, the site provides a habitat especially attractive to white-tailed deer and various indigenous migratory birds, reptiles, and small mammals. No species on the federal endangered species list are known to be present on the WNYNSC.

Geology and Hydrology. The Project lies on New York State's Allegheny Plateau at an average elevation of about 1,300 feet (400 m). The underlying geologic sediments include a sequence of glacial sediments above shale bedrock. The Project is drained by several small streams and is divided by a stream valley into two general areas: the north plateau and the south plateau.

Frank's Creek, which enters the WVDP site from the south and flows northward, receives drainage from the south plateau. As Frank's Creek progresses northward, it is joined by tributaries Erdman Brook (between the south and north plateaus) and Quarry Creek (north of the Project's fenceline). Frank's Creek continues northward across the WNYNSC and flows into Buttermilk Creek, which leaves the WNYNSC and enters Cattaraugus Creek. (See Figs. A-2 and A-3.) Cattaraugus Creek ultimately drains into Lake Erie, to the northwest. 


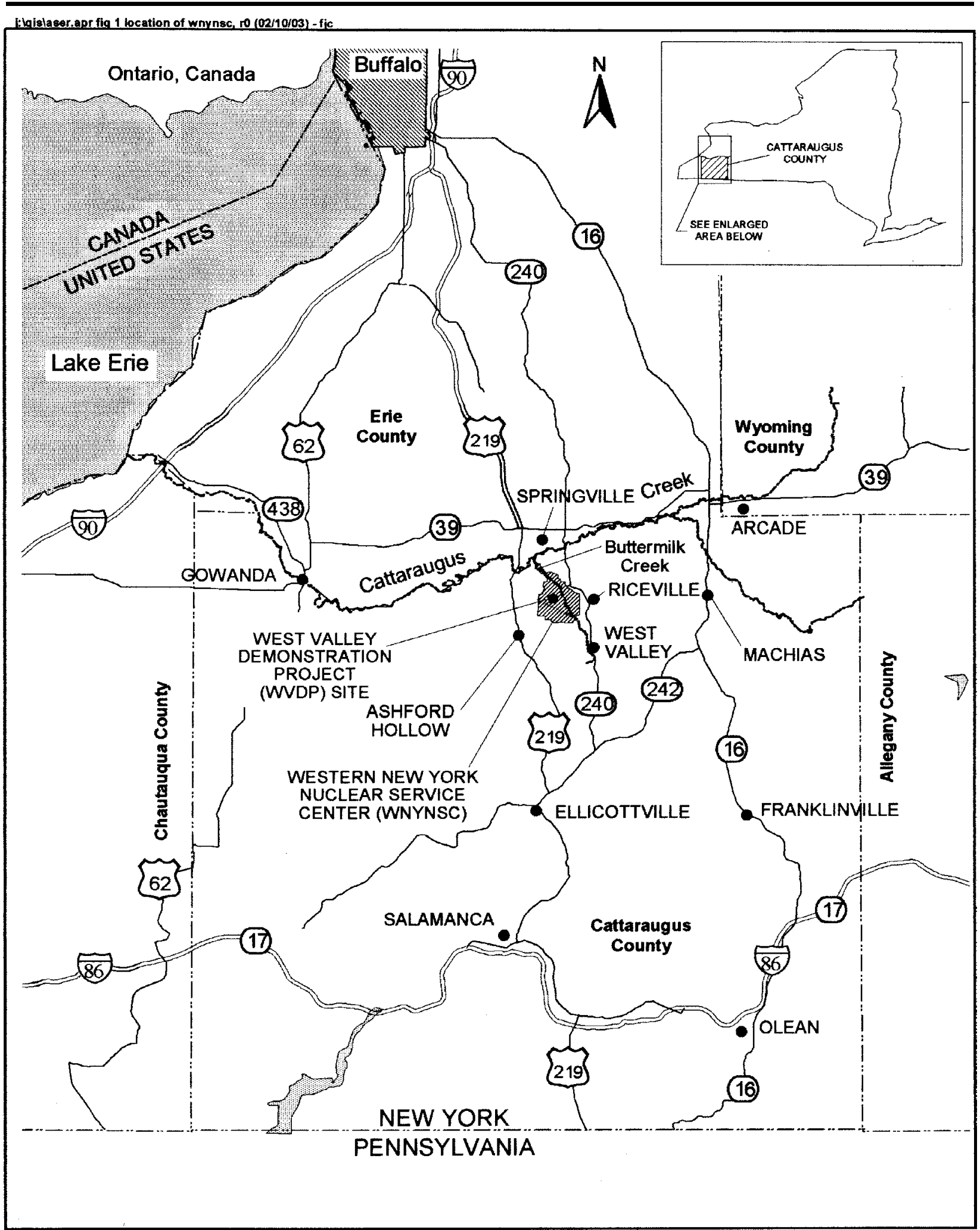

Figure INT-1. Location of the Western New York Nuclear Service Center

INT - 2 


\section{Site Mission}

From 1966 until 1972, the facility which later became the WVDP was the site of a commercial nuclear fuel reprocessing plant run by Nuclear Fuel Services, Inc. (NFS). Uranium and plutonium were recovered from spent nuclear fuel for reuse. In 1972 the reprocessing facility closed for expansion, but in 1976 NFS notified the New York State Energy Research and Development Authority that it was no longer economically feasible to continue in the fuel-reprocessing business and the plant was shut down. In 1980, Public Law 96-368 (the West Valley Demonstration Project Act) was passed. This Act authorized the U.S. Department of Energy (DOE) to demonstrate a method for solidifying 600,000 gallons (2.3 million liters) of liquid high-level radioactive waste (HLW) that remained at the West Valley site. (For a detailed history of the site, see the Introduction of the 2003 Annual Site Environmental Report. See Appendix K-3 ${ }^{\text {[D }}$ for the complete text of the WVDP Act.)

The purposes of the WVDP Act were to carry out the following activities: solidify the HLW that was left at the site from the original nuclear fuel reprocessing activities; develop suitable containers for holding and transporting the solidified waste; transport, in accordance with application provisions of law, the waste solidified at the Center to an appropriate Federal repository for permanent disposal; dispose of any low-level and transuranic radioactive waste resulting from the solidification of HLW; and decontaminate and decommission Project facilities used for solidification of radioactive waste.

Vitrification of the HLW, begun in 1996, was completed in September 2002. Activities for decontaminating the vitrification and support facilities and for disposing of wastes were then initiated and continue through the present.

\section{Primary Operations and Activities}

The following projects were initiated, continued, or completed in 2004:

Remote-Handled Waste Facility (RHWF). Construction of the RHWF, a facility used to prepare higher-activity wastes for shipment and disposal, was completed in early 2004. In June 2004 the facility began processing radioactive waste.

Decontamination of Facilities. Decontamination of three major cells in the main plant (the process mechanical cell, the general purpose cell, and extraction cell 2), including removal of equipment, vessels, and process piping, was completed in 2004. Major vessels were removed from the vitrification cell in 2004 and decontamination activities continued.

Waste Management. Part of the DOE's cleanup mission at the West Valley site is the disposal of low-level radioactive waste (LLW) that is generated through WVDP operations. In 2004, waste continued to be shipped off site to disposal facilities. (See a discussion of the LLW shipping program in Chapter 1.)

Environmental Monitoring. The primary goal of the WVDP's environmental monitoring program is to detect and evaluate changes in the environment resulting from Project (or pre-Project) activities and to assess the effect of any such changes on the human population.

Among the factors considered in designing the environmental monitoring program were the types of wastes and other by-products resulting from the processing of HLW; possible pathways for movement of contaminants into the environment; geologic, hydrologic, and meteorologic site conditions; quality assurance standards for monitoring 
and sampling procedures and analyses; and the limits and standards set by federal and state governments and agencies. (For more information on the design of the environmental monitoring program, see Environmental Monitoring Program and Exposure Pathway Monitoring in the Introduction of the 2003 Annual Site Environmental Report.) Results of the 2004 monitoring program are discussed in Chapters 2, 3, and 4 of this report.

\section{Relevant Demographics}

Although several roads and a railway approach or pass through the WNYNSC, the public does not have access to the Project grounds. Deer hunting may be allowed (a year-to-year decision), but fishing and human habitation on the WNYNSC are prohibited.

Land near the WNYNSC is used primarily for agriculture and arboriculture. Downstream of the WNYNSC, Cattaraugus Creek is used locally for swimming, canoeing, and fishing. Although some water is taken from the creek to irrigate nearby golf course greens and tree farms, no public drinking water is drawn from the creek before it flows into Lake Erie. Water from Lake Erie is used as a public drinking water supply.

The communities of West Valley, Riceville, Ashford Hollow, and the village of Springville are located within approximately 5 miles $(8 \mathrm{~km})$ of the Project. The nearby population, approximately 9,200 residents within 6.2 miles $(10 \mathrm{~km})$ of the Project, relies largely on an agricultural economy. No major industries are located within this area. The WVDP is one of the largest employers in Cattaraugus County.

INT - 4 


\section{ENVIRONMENTAL COMPLIANCE SUMMARY \\ Calendar Year 2004}

\section{Compliance Program}

The West Valley Demonstration Project (WVDP or Project) is currently focusing on several goals that will lead to completion of the WVDP Act. (See Appendix $\mathrm{K}^{\mathrm{GD}}$.) Construction of the remotehandled waste facility, used to process and package radioactive Project waste into shipping containers, was completed in early 2004 and processing of waste began in June 2004. Dismantlement of processing equipment in the vitrification facility began in 2004 and major vessels, including the melter, were removed. Decontamination of several former reprocessing cells within the main process building was completed and management of radioactively contaminated groundwater continued.

In January 2003, the U.S. Department of Energy (DOE), the federal agency that manages the WVDP, issued a directive (DOE Order 450.1) requiring implementation of an environmental management system (EMS) for conducting work at DOE sites, including the WVDP. In response to this directive, the existing WVDP EMS is continuously reviewed and enhanced. Elements of the WVDP EMS are summarized in Table ECS-1.

Activities at the WVDP are regulated by various federal and state laws that protect the public, workers, and the environment.
Major federal environmental laws and regulations applicable to the WVDP are: the Resource Conservation and Recovery Act; the Clean Air Act; the Emergency Planning and Community Rightto-Know Act (enacted as Title III of the Superfund Amendments and Reauthorization Act); the Clean Water Act; the Safe Drinking Water Act; the Toxic Substances Control Act; the Migratory Bird Treaty Act; and the National Environmental Policy Act. These laws are administered primarily by the U.S. Environmental Protection Agency (EPA), the U.S. Fish and Wildlife Service, the U.S. Army Corps of Engineers (ACOE), the New York State Department of Environmental Conservation (NYSDEC), and the New York State Department of Health (NYSDOH) through programs and regulatory requirements for permitting, reporting, inspecting, self-monitoring, and audits.

Because release of radiological and nonradiological materials from an active facility cannot be completely prevented, the EPA, NYSDEC, and DOE have established standards for such emissions and discharges that are intended to protect human health, safety, and the environment. The WVDP applies to the EPA for permits to release limited amounts of radiological constituents to the air and applies to NYSDEC for a permit to release limited amounts of nonradiological constituents to the air and water through controlled and monitored 
effluent releases in concentrations determined to be safe for humans and the environment. In general, the permits describe release points, specify management and reporting requirements, list discharge limits on those pollutants likely to be present, and define the sampling and analysis regimen. A summary of permits may be found in Table ECS-2.

\section{Compliance Status}

The following summary describes WVDP compliance with DOE Orders 450.1, 5400.5, and 435.1 and federal and state laws and regulations applicable to the Project.

\section{Environmental Protection Program (DOE} Order 450.1). DOE Order 450.1, issued in January 2003, requires DOE sites to implement an EMS by December 31, 2005. An EMS is a continuing cycle of systematic planning, implementing, evaluating, and improving processes and actions undertaken to achieve environmental goals. Since 1999, the WVDP has implemented an EMS via policies and procedures that provide for accomplishing work through proactive management, environmental stewardship, and integration of appropriate technologies across all Project functions. The West Valley Nuclear Services Co. (WVNSCO) EMS satisfies the requirements of both the "Code of Environmental Management Principles" for federal agencies and the International Organization for Standardization 14001, "Environmental Management Systems: Specifications for Guidance and Use."

\section{Radiation Protection of the Public and the En- vironment (DOE Order 5400.5). DOE Order} 5400.5, issued in February 1990, established standards and requirements for protection of the public and the environment against undue risk from radiation resulting from activities of the DOE and DOE contractors. The objectives of the Order were to ensure that (1) operations are conducted so that radiation exposures to members of the public are maintained within the limits established in the Order, (2) potential exposures to members of the public are as far below the limits as is reasonably achievable, (3) routine and non-routine releases are monitored and dose to the public is assessed, and (4) the environment is protected from radioactive contamination to the extent practical.

This report summarizes radiological releases from the WVDP in 2004, presents estimates of dose to the public and the environment in 2004, and compares these values with release and dose standards established by DOE Order 5400.5. (See Appendix $\mathrm{K}^{\mathbf{6 D}}$.) In 2004, both releases and estimates of dose to the public were well within applicable limits.

Radioactive Waste Management (DOE Order 435.1). DOE Order 435.1 was issued in July 1999, and updated in August 2001, to ensure that all DOE radioactive waste - including high-level waste (HLW), transuranic waste, low-level waste (LLW), and the radioactive component of mixed waste - is managed to (1) protect the public from exposure to radioactive materials, (2) protect the environment, (3) protect workers, and (4) comply with applicable federal, state, and local laws and regulations, as well as applicable Executive Orders and other DOE directives. The "WVDP Radioactive Waste Acceptance Program," a formal document describing how radioactive waste is managed at the WVDP, was updated in August 2004.

Resource Conservation and Recovery Act (RCRA). RCRA was enacted to ensure that hazardous wastes are managed in a manner that protects human health, safety, and the environment. RCRA and its implementing regulations govern the life cycle of hazardous waste from "cradle-tograve" and mandate that generators take responsibility for ensuring the proper treatment, storage, and ultimate disposal of their wastes. The EPA is the federal agency responsible for issuing guide-

ECS - 2 
lines and regulations for the proper management of solid and hazardous waste (including mixed [radioactive and hazardous] waste).

In New York, the EPA has delegated the authority to issue permits and enforce these regulations to NYSDEC. In addition, the U.S. Department of Transportation is responsible for issuing guidelines and regulations for labeling, packaging, and spillreporting for hazardous and mixed wastes while in transit.

A hazardous waste permit is required for facilities that treat or store large quantities of hazardous waste for more than 90 days or dispose of hazardous waste at the facility. New York State facilities in existence on the date that hazardous waste regulations impacting their operations took effect were required to apply for interim status from NYSDEC by submitting a RCRA Part A Permit Application. Facility operations during interim status are limited to those described in the Part A Permit Application and must comply with the Interim Status Standards regulations.

In 1984, the DOE notified the EPA of hazardous waste activities at the WVDP and identified the WVDP as a generator of hazardous waste. In June 1990, the effective date of the New York State regulations governing treatment, storage, and disposal of mixed (i.e., RCRA hazardous and Atomic Energy Commission radioactive) waste, the WVDP filed a RCRA Part A Permit Application with NYSDEC for storage and treatment of hazardous and mixed wastes, and has been operating under interim status ever since.

The WVDP updates its RCRA Part APermit Application as changes to the site's interim status waste-management operations occur. An updated RCRA Part A Permit Application was submitted to NYSDEC on March 6, 2001. On November 13, 2001, NYSDEC responded that the RCRA Part
A Permit modifications met the requirements for changes to interim status treatment and storage operations at the WVDP.

In a July 16, 2003 letter to the DOE, NYSDEC made an official request for the submittal of a Part 373 Permit Application for the WVDP. The complete Part 373 Permit Application was transmitted to NYSDEC on December 23, 2004. Facilities with interim status are treated as having been issued a permit until a final determination by NYSDEC on the Part 373 Permit Application is made.

Hazardous Waste Management Program. Hazardous wastes at the WVDP are managed in accordance with 6 NYCRR Parts 370-374 and 376. Hazardous and mixed waste activities must be reported to NYSDEC each year through the submittal of the facility's annual Hazardous Waste Report. This report summarizes the hazardous waste activities for the previous year, specifies the quantities of waste generated, treated, and/or disposed, and identifies the treatment, storage, and disposal facilities used. The annual Hazardous Waste Report, which reported that the WVDP made no hazardous waste shipments in CY 2004, was submitted to NYSDEC in February 2005.

In addition, a hazardous waste reduction plan must be updated annually and filed every two years. This plan, first submitted to NYSDEC in 1990, documents efforts to minimize the generation of hazardous waste. The hazardous waste reduction plan was updated in 2004, as required. The most recent Annual Status Report for the Hazardous Waste Reduction Program was submitted to NYSDEC in June 2003.

Annual inspections to assess compliance with hazardous waste regulations were conducted by NYSDEC on March 31, 2004 and the EPA on September 23, 2004. No deficiencies were noted.

ECS - 3 
Mixed Waste Management Program. Mixed waste contains both a radioactive component, regulated under the Atomic Energy Act, and a hazardous component, regulated under RCRA. Both the EPA and NYSDEC oversee mixed waste management at the WVDP.

The Federal Facility Compliance Act of 1992, an amendment to RCRA, requires DOE facilities to prepare plans (specifically, the Site Treatment Plan) for treating their mixed waste inventories and to update these plans annually to account for development of treatment technologies, capacities, and changes in mixed waste inventories. Each plan is approved by the respective state agency or the EPA after consultation with other affected states and after consideration of public comments.

The WVDP's Site Treatment Plan is comprised of two volumes: the Background Volume provides information on each mixed waste stream and information on the preferred treatment method for the waste, and the Plan Volume contains proposed schedules for treating the mixed waste to meet the land disposal restriction requirements of RCRA.

The DOE and NYSDEC entered into a Consent Order on August 27, 1996 that requires the completion of the milestones identified in the Plan Volume. The WVDP began implementing its Site Treatment Plan immediately and updates it annually to bring waste stream, inventory, and treatment information current through September 30, the end of the DOE fiscal year. The final update of fiscal year 2004 activities was sent by the DOE to NYSDEC by the due date of February 15, 2005.

In 2004, the WVDP made no mixed waste shipments.

RCRA $\$ 3008(h)$ Administrative Order on Consent. The DOE and the New York State Energy Research and Development Authority
(NYSERDA) entered into a RCRA $\$ 3008(h)$ Administrative Order on Consent with NYSDEC and the EPA in March 1992. The Consent Order required NYSERDA and the DOE's West Valley Demonstration Project Office to conduct RCRAfacility investigations (RFIs) at on-site solid waste management units (SWMUs) to determine if there had been a release or if there is a potential for release of RCRA-regulated hazardous constituents from SWMUs. The final RFI reports were submitted in 1997, completing the investigative activities associated with the Consent Order. No corrective actions were required as a result of the RFIs. Groundwater monitoring, as specified in the RFI reports, continued during 2004. The WVDP also continued to monitor SWMUs and to comply with the requirements of the RCRA $\$ 3008(\mathrm{~h}) \mathrm{Ad}$ ministrative Order on Consent. Ground water monitoring results are detailed in Chapter 4.

One SWMU was investigated in 2004: a breach in the laundry wastewater line. Notification had been submitted to the EPA and to NYSDEC, as required in 2003 .

Pursuant to a request from NYSDEC in a January 2004 correspondence, a report entitled "West Valley Demonstration Project Solid Waste Management Unit Assessment and Current Conditions Report" was submitted to NYSDEC in November 2004. This report summarized the historic activities of individual SWMUs through the RFI activities and provided current environmental monitoring data and information on site activities performed since the completion of the RFI reports.

Nonhazardous, Regulated Waste Management Program. The WVDP shipped approximately 20 tons (18.1 metric tons) of nonradioactive, nonhazardous material off site to solid waste management facilities in 2004. Of this amount, 0.97 tons (0.88 metric tons) of lead-acid batteries and spent lamps (i.e., universal wastes), were reclaimed or 
recycled at off-site, authorized reclamation and recycling facilities. The WVDP also shipped approximately 1,070 tons (971 metric tons) of digested sludge and treated wastewater from the site sanitary and industrial wastewater treatment facility to the Buffalo Sewer Authority for disposal.

Waste Minimization and Pollution Prevention. The WVDP continued a long-term program to minimize the generation of LLW, mixed waste, hazardous waste, industrial waste, and sanitary waste, and to promote affirmative procurement as directed by Executive Order 13101 ("Greening the Government Through Waste Prevention, Recycling, and Federal Acquisition") and Executive Order 13148 ("Greening the Government Through Leadership in Environmental Management"), which promote the Affirmative Procurement Program and RCRA $\$ 6002$, "Federal Procurement." These Executive Orders are also supported by DOE Order 450.1. The Affirmative Procurement Program specifies responsibilities and direction for federal agencies in acquiring recycled and environmentally preferable products and services designated by the EPA in 40 CFR Part 247, "Comprehensive Procurement Guideline for Products Containing Recovered Material." WVNSCO annually reports challenges and successes associated with the purchase and use of these materials and services to the DOE.

For purposes of waste-reduction tracking, waste streams are separated into either waste from sources directly associated with the vitrification process or from nonvitrification sources. See Chapter 1 for further discussion of waste minimization activities from all sources in 2004.

\section{Underground Storage Tanks Program. RCRA} regulations also cover the use and management of underground storage tanks and establish minimum design requirements to protect groundwater resources from releases. The regulations, specified in 40 CFR Part 280, require underground stor- age tanks to be equipped with overfill protection, spill prevention, corrosion protection, and leak detection systems. New tanks must comply with regulations at the time of installation.

New York State also regulates underground storage tanks through two programs - petroleum bulk storage (6 NYCRR Parts 612-614) and chemical bulk storage (6 NYCRR Parts 595-599). State registration and minimum design requirements are similar to those of the federal program except that petroleum tank fill ports must be color coded, using American Petroleum Institute standards, to indicate the product being stored.

A 550-gallon, double-walled, steel underground storage tank, upgraded in 1998 to bring it into compliance with the most recent EPA requirements (40 CFR Part 280.21), is used to store diesel fuel for the supernatant treatment system/permanent ventilation system standby power unit. This tank is equipped with aboveground piping, an upgraded interstitial leak-detection system, and a high-level warning device, and therefore meets the state requirements of 6 NYCRR Parts 612-614. This is the only underground petroleum storage tank currently in use at the WVDP.

A former underground petroleum storage tank, closed in place before the New York State underground storage tank program closure requirements were implemented in 1985, was removed in 1997. In accordance with a stipulation agreement with NYSDEC, a soil bioventing system was installed in August 1999 to remediate localized petroleum contaminated soils in the vicinity of the tank. The system stimulated natural in-situ biodegradation of petroleum hydrocarbons in the soil by providing an abundant oxygen supply to existing soil microorganisms within the contaminated soil zone. Soil and groundwater samples were collected in 2002 to evaluate whether an adequate level of remediation had been achieved. Based on the sample results,

ECS - 5 
NYSDEC determined that no further remediation was required. Final disposition is pending the Decommissioning and/or Long-Term Stewardship Environmental Impact Statement.

There are no underground chemical bulk storage tanks at the WVDP.

New York State-Regulated Aboveground Storage Tanks. New York State regulates aboveground petroleum bulk storage under 6 NYCRR Parts 612-614, and aboveground hazardous bulk chemical storage under 6 NYCRR Parts 595-599. These regulations require secondary containment, external gauges to indicate the content levels, monthly visual inspections of petroleum tanks, and documented daily, annual, and five-year inspections of chemical tanks. Documentation relating to these periodic inspections is maintained by the WVDP and is available for regulatory agencies to review. Petroleum tank fill ports also must be color-coded, and chemical tanks must be labeled to indicate the product stored.

WVDP registration at the end of 2004 included nine aboveground petroleum tanks: three containing No. 2 fuel oil, one containing unleaded gasoline, and the others containing diesel fuel.

Also registered are eight aboveground chemical storage tanks used as needed to contain nitric acid or nitric acid mixtures. These tanks were emptied in the fall of 2002, and seven of the tanks were permanently closed near the end of 2004. The required submittals were made to NYSDEC to remove these seven tanks from the registration and a new registration certificate is anticipated to be received by the WVDP in early 2005 .

In summary, there is one remaining chemical bulk storage tank at the WVDP, with plans under development for closure in 2005.
All the tanks are equipped with gauges and secondary containment systems. The WVDP is in compliance with the most recent requirements to upgrade chemical bulk storage tanks that went into effect in December 1999. The most current inspections by NYSDEC determined that the chemical bulk storage tanks and the petroleum bulk storage tanks were in compliance with New York State regulations.

Medical Waste Tracking. Medical waste can potentially expose humans to infectious diseases and pathogens from contact with bodily fluids. Medical evaluations, inoculations, and laboratory work at the on-site Health Services office regularly generate potentially infectious medical wastes that must be tracked in accordance with NYSDEC requirements (6 NYCRR Part 364.9).

The WVDP has retained the services of a permitted waste hauler and disposal firm to manage these medical wastes. Medical wastes are sterilized with an autoclave by the disposal firm to remove the associated hazard and are then disposed. Fifty-four pounds $(25 \mathrm{~kg}$ ) of medical waste consisting of dressings, protective clothing (such as rubber gloves), and needles, syringes, and other sharps were generated and disposed in 2004.

CleanAirAct (CAA). The CAA, including Titles I through VI, establishes a framework for the EPA to regulate air emissions from both stationary and mobile sources. These amendments mandate that each state establish a program to permit operation of sources of air pollution. In 1996, NYSDEC amended 6 NYCRR Parts 200, 201, 231, and 621 to implement the requirements of the new EPA CAATitle $\mathrm{V}$ permitting processes.

In New York State, NYSDEC issues permits for stationary sources that emit regulated pollutants, including hazardous air pollutants. Sources requiring permits are those that emit regulated pollutants 
from a particular source (e.g., a stack, duct, vent, or other similar opening), if the pollutants are in quantities above a predetermined threshold.

Radiological Emissions. Air emissions of radionuclides at the WVDP are regulated by the EPA under the National Emission Standards for Hazardous Air Pollutants (NESHAP) regulations, 40 CFR Part 61, Subpart H, "National Emission Standards for Emission of Radionuclides other than Radon from Department of Energy Facilities." The WVDP currently has permits for six radionuclide sources.

In 2004, in compliance with updated stack inspection requirements of 40 CFR 61, Appendix B, Method 114, sampling systems in use for major emission points were inspected and the results were documented. Visual inspections, leak checks, and cleaning were carried out, as appropriate.

Other less-significant sources of radionuclide emissions, such as those from the on-site laundry, do not require permits. Non-point radiological sources of air emissions, such as open-air lagoons, also do not require permits. The WVDP reports the radionuclide emissions from its non-permitted and permitted sources to the EPA annually, in accordance with NESHAP regulations. The annual NESHAP Report is submitted to the EPA by June 30th of the following calendar year. Calculations to demonstrate compliance with NESHAP radioactive dose limits showed CY 2004 doses to be approximately $0.02 \%$ of the 10 millirem standard.

Nonradiological Emissions. Nonradiological point sources of air emissions are regulated by NYSDEC. Major source facilities are required by 6 NYCRR Part 201 to file a Title V Permit Application unless emissions are capped below operating limits. The WVDP submitted - and received NYSDEC's approval of - a plan for capping oxides of nitrogen $\left(\mathrm{NO}_{\mathrm{x}}\right)$ and sulfur dioxide $\left(\mathrm{SO}_{2}\right)$ at 99 tons each.
Shutdown of the melter in September 2002 significantly reduced levels of $\mathrm{NO}_{\mathrm{x}}$ and $\mathrm{SO}_{2}$ at the WVDP, leaving site boilers and generators as the remaining contributors. An application made to NYSDEC to change the New York State Facility Air Permit to an Air Facility Registration Certificate was approved on October 28, 2004.

Air permits that were in effect at the WVDP in 2004 are included in Table ECS-2, West Valley Demonstration Project Environmental Permits. There were no air permit or regulatory exceedances in 2004. (See also Table ECS-3.)

\section{Emergency Planning and Community Right-} to-Know Act (EPCRA). EPCRA was designed to create a working partnership between industry, business, state and local governments, public health and emergency response representatives, and interested citizens. EPCRA is intended to address concerns about the effects of chemicals used, stored, and released in local communities.

Executive Order 13148, Greening the Government Through Leadership in Environmental Management, requires all federal agencies to comply with the following EPCRA provisions: planning notification (Sections 302-303), extremely hazardous substance (EHS) release notification (Section 304), material safety data sheet (MSDS)/chemical inventory (Sections 311-312), and toxic release inventory (TRI) reporting (Section 313). The WVDP continued to comply with these provisions in 2004, as shown in Table ECS-4.

- WVDP representatives participated in semiannual meetings of the Cattaraugus County Local Emergency Planning Committee (EPCRA Sections 302-303). WVDP representatives also attended meetings held by the Cattaraugus and Erie County Emergency Management Services concerning WVDP and other local emergency planning activities. Area hospitals and the West Valley

ECS - 7 
Volunteer Hose Company continued to participate in on-site briefings, emergency response exercises, and information exchanges concerning hazardoussubstance management at the WVDP. The WVDP continues to interface with off-site organizations with which Memoranda of Understanding or Letters of Agreement exist. These organizations are annually provided an opportunity to participate in a site tour and update to better understand on-site hazards for emergency response.

- Compliance with all EPCRA reporting requirements was maintained and all required reports were submitted within the required timeframe. There were no releases of EHS at the WVDP that triggered the release notification requirements of EPCRA Section 304.

- Under EPCRA Section 311 requirements, the WVDP reviews information about reportable chemicals every quarter. If a hazardous chemical not previously reported is present on site in an amount exceeding the threshold planning quantity, an MSDS and an updated hazardous chemical list are submitted to the state and local emergency response groups. This supplemental reporting ensures that the public and emergency responders have current information about hazardous chemicals at the WVDP. No new chemicals were added to the hazardous chemicals list in 2004 and no additional EPCRASection 311 notifications were required.

- Under EPCRA Section 312 regulations, the WVDP submits annual reports to state and local emergency response organizations and fire departments specifying the quantity, location, and hazards associated with chemicals stored on site. In 2004, nine reportable chemicals were stored at the WVDP above threshold planning quantities. A list of reportable chemicals is provided in Table ECS-5.
- Under EPCRA Section 313, the WVDP provides information about releases to all environmental media of EPA-listed TRI chemicals used at or above specified regulatory thresholds at the WVDP. In 2004, no chemical exceeded the reporting threshold for the EPCRA Section 313 report.

Clean Water Act (CWA). Section 404 of the CWA regulates the development of areas in and adjacent to waters of the United States. Supreme Court interpretations of Section 404 have resulted in the inclusion of certain non-isolated wetlands in the regulatory definition of waters of the United States. Section 404 regulates the disposal of solids, in the form of dredged or fill material, into these areas by granting the Army Corps of Engineers the authority to designate disposal areas and issue permits for these activities. Executive Order 11990, "Protection of Wetlands," directs federal agencies to "avoid to the extent possible the long- and short-term adverse impacts associated with the destruction or modification of wetlands and to avoid direct or indirect support of new construction in wetlands wherever there is a practical alternative." Article 24 of the New York State Environmental Conservation Law also contains requirements for the protection of freshwater wetlands.

Also, Section 401 of the CWA requires applicants for a federal license or permit pursuant to Section 404 to obtain certification from the state that the proposed discharge complies with effluent- and water-quality-related limitations, guidelines, and national standards of performance, identified under Sections 301-303, 306-307, and 511(c) of the CWA. The EPA delegated administration of this program to New York State.

Section 1102 of the CWA regulates process, sanitary, and other effluent discharges to surface waters. Administration of Section 402 in New York is delegated to NYSDEC. 
Wetlands. Jurisdictional wetlands are defined in Section 404 of the CWA as those satisfying specific technical criteria related to vegetation, soils, and hydrologic conditions. The WVDP notifies the ACOE and NYSDEC of proposed actions that could affect wetland units not specifically exempted from regulation or notification.

As a result of field assessments completed in 1998, 1999, and 2000, 83 jurisdictional wetlands ranging in size from 0.01 to 8.6 acres, a total of approximately 53 acres (22 ha) of wetland, were identified within the WVDP and adjacent parcels. This wetland delineation was submitted to the ACOE for verification of the wetland boundaries.

In 2003, remapping of site parcels to delineate wetland boundaries was initiated and completed to renew the five-year wetland map. A wetland map report was prepared and submitted to the ACOE for review and approval in the fall of 2004.

State Pollutant Discharge Elimination System (SPDES) Permit Modification. In response to a permit application filed in July 2003, NYSDEC issued a draft modification to the SPDES permit in May 2004 for public comment. The final modified permit was issued in November 2004 to take effect January 1, 2005. In addition to five existing permitted monitoring points, the modified permit authorizes discharges at 20 storm water outfalls. These outfalls receive storm water runoff from inactive waste disposal areas, areas where materials or wastes are stored or handled, and areas where construction or structure dismantlement or other soil disturbance activities may be performed. The modified SPDES permit contains sampling and analysis requirements and limits for storm water discharges at these outfalls.

Other changes to the SPDES permit that took effect January 1, 2005 include reduced monitoring at outfall 001 (WNSP001), reduced reporting fre- quency for the mercury analytical method study, new requirements for reporting water treatment chemical usage, added monitoring for chemical substances used for weed control, and a new requirement to prepare and implement a Storm Water Pollution Prevention Plan.

NYSDEC SPDES Inspection. In May and September 2004, NYSDEC completed its annual facility inspections of the WVDP with observations of the SPDES outfalls, the site sanitary and industrial wastewater treatment facility (WWTF), low-level waste treatment facility (LLWTF), and discharge monitoring records. No deficiencies were identified.

Process Sewer Integrity Evaluation. In 2002, NYSDEC requested that the integrity of the site process sewer system be assessed. This assessment was requested after an unplanned release occurred in 2001, when boiler wastewater was released through a suspected leaking underground sanitary sewer. Later in 2002, the WVDP issued a report evaluating the condition of the process sewer system, with a plan for an inspection of accessible lines between the main process building and the LLWTF.

Video camera inspection of the process sewer lines was initiated in 2003. During this inspection, a hole was discovered in a tributary line where laundry wastewater was released. The breached line was removed from service and laundry wastewater flow was diverted to another line with known integrity. Reports of this discovery were filed with NYSDEC in November and December 2003. Video inspection of process sewer lines was completed in the fall of 2004 and no other sewer integrity issues were identified. The final report and video recordings were submitted to NYSDEC for review in the fall of 2004.

SPDES-Permitted Outfalls. Point-source liquid effluent discharges to surface waters of New York

ECS - 9 
State are permitted through the New York SPDES program. In 2004, the WVDP had five SPDESpermitted compliance points for discharges to Erdman Brook and Frank's Creek.

- Outfall 001 (WNSP001) discharges treated wastewater from the LLWTF and the north plateau groundwater recovery system. The treated wastewater is held in lagoon 3 , sampled and analyzed, then periodically released after notifying NYSDEC. In 2004, eight batches totaling 15.0 million gallons (56.6 million liters) were released. The annual average concentration of radioactivity at the point of release was approximately $21.2 \%$ of DOE-derived concentration guides (DCGs). None of the individual releases exceeded the DCGs.

- Outfall 01B (WNSP01B) is an internal process compliance point established by the final SPDES permit modification issued on July 15, 2002. This internal outfall receives effluent from the liquid waste treatment system (LWTS) evaporator process after passing through a mercury pretreatment system. The LWTS pretreats residual radioactive wastes from the main process building and the HLW storage tanks before final polishing treatment at the LLWTF. Effluent is sampled and tested at this location to determine compliance with Federal Great Lakes Initiative and SPDES permit requirements for total mercury. In 2004 the LWTS was not operated, therefore no discharges were released from outfall WNSP01B.

- Outfall 007 (WNSP007) discharges the effluent from the WWTF, which treats sewage and various nonradioactive wastewaters from physical plant systems (e.g., water plant production residuals and boiler blowdown). The average daily flow at WNSP007 in 2004 was approximately 24,000 gallons (91,000 liters).

- Outfall 008 (WNSP008) formerly discharged groundwater and surface water runoff directed from the northeast side of the site's LLWTF lagoon system through a French drain to Erdman Brook. This outfall was capped off in May 2001, and no discharges were released from the outfall in 2004 .

- Monitoring point 116, located in Frank's Creek, represents the confluence of discharge from outfalls 001,007 , and 008 ; base stream flow; wet weather flows (e.g., surface water runoff); groundwater seepage; and augmentation water (untreated water from the site reservoirs). Monitoring point 116 is not a physical outfall but a location where the combination of source-flow inputs is used to calculate values for determining compliance with SPDES permit limits for total dissolved solids (TDS) during discharge of lagoon 3. Before discharge of lagoon 3, sample data for TDS and flow measurements from upstream sources are used to calculate the amount of augmentation water and lagoon 3 flow needed to maintain compliance with SPDES-permitted TDS limits.

As shown in Figure ECS-1, the annual number of effluent exceptions specified in the site's SPDES Permit have been substantially reduced, especially when compared to the peak of 35 exceptions noted in 1986. As indicated in this figure, there was one permit effluent limit exception recorded during 2004.

A test result for total suspended solids (TSS) for a sample obtained at outfall 001 in May 2004 was reported above the allowable (daily maximum) effluent limit. The increased TSS was caused by a storm event that resulted in runoff that carried soil and sediment down the sides of the effluent-holding lagoon and into the effluent water during the discharge.

In June 2004, the minimum permit requirement for monitoring total recoverable hexavalent chromium at outfall 001 was not met. An analytical interference resulted in an inaccurate and invalid test re- 


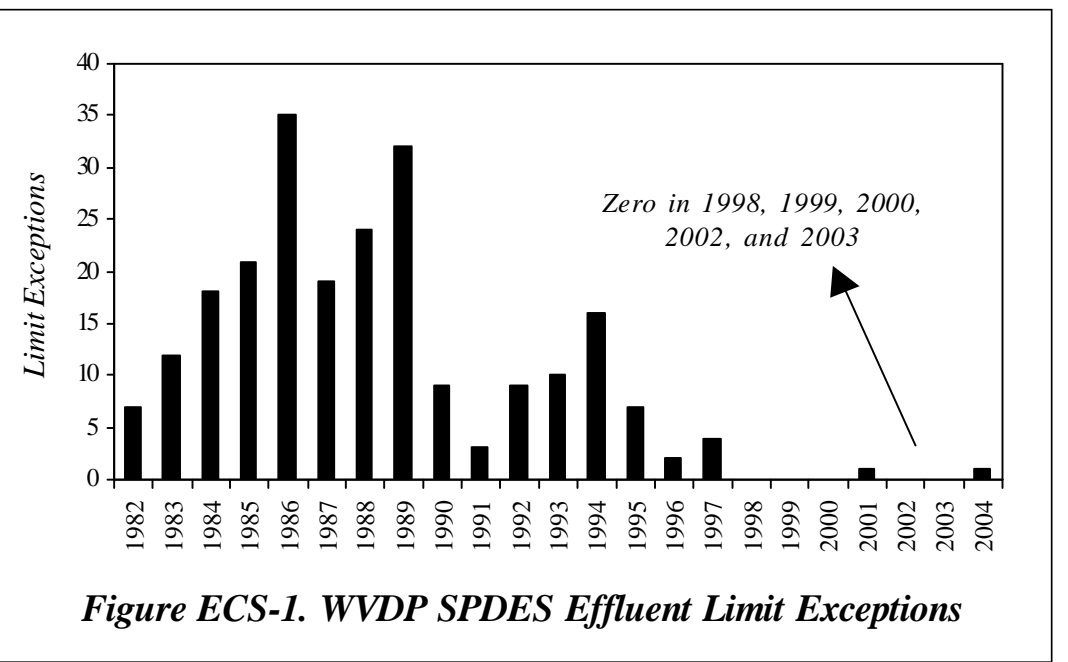

sult for one sample that was analyzed for this chemical substance. As a consequence, the number of valid sample analyses was one short of that required. (See Table ECS-6.)

North Plateau Groundwater Recovery System. In November 1995, the WVDP installed a groundwater recovery system to mitigate the movement of strontium-90 in groundwater and reduce groundwater seepage northeast of the process building. Three recovery wells, installed near the leading edge of the groundwater plume, collect contaminated groundwater from the underlying sand and gravel unit for treatment at the low-level waste treatment building using ion-exchange to remove strontium-90. After the groundwater is processed, it is discharged to lagoon 4 or 5 of the LLWTF. Approximately 39 million gallons (148 million liters) of groundwater have been processed through the system since its inception, including about 4.8 million gallons (18 million liters) in 2004.

In 1999, the Project installed a pilot-scale permeable treatment wall (PTW) to test this in-situ passive technology for treating contaminated groundwater. Analytical data collected from within and around the wall indicate that only a portion of the contaminated groundwater in this area is be- ing treated by the PTW. The hydrogeologic evaluation of the pilot test, completed in 2002, concluded that complex hydrogeologic conditions and disturbances from the installation are influencing groundwater flow into and around the pilot PTW.

Petroleum- and Chemical-Product Spill Reporting. The WVDP has a Spill Notification and Reporting Policy to ensure all spills are properly managed, documented, and remediated in accordance with applicable regulations. This policy identifies departmental responsibilities for spill management and proper spill-control procedures. The policy stresses the responsibility of each employee to notify the plant systems operations shift supervisor upon discovery of a spill. This first-line reporting requirement helps to ensure spills are properly evaluated and managed.

Under a 1996 agreement with NYSDEC, the WVDP is not required to report a spill of petroleum products onto an impervious surface if the spill is less than 5 gallons (19 liters) and is cleaned up within two hours of discovery. Any spill of 5 gallons or less onto the ground is entered into a petroleum spill log that is submitted monthly to NYSDEC on the fifteenth day following the subject month. A spill of more than 5 gallons on any surface must also be logged and reported within two hours to the NYSDEC hotline. A spill of any amount that enters state waters must be reported to the NYSDEC hotline within two hours of discovery and, if it has reached navigable state waters, also reported to the National Response Center. No reportable spills of over 5 gallons of petroleum products to an impervious surface, or to the ground or waters of the state, occurred at the WVDP in 2004.

ECS - 11 
The WVDP also reports spills or releases of hazardous substances in accordance with reporting requirements of RCRA, the Comprehensive Environmental Response, Compensation, and Liability Act (if a reportable quantity has been exceeded), and the CAA, EPCRA, CWA, and Toxic Substances Control Act (TSCA). No chemical spills or releases exceeded reportable quantities and, thus, no reporting during CY 2004 was required.

Any spill or release is cleaned up in a timely manner in accordance with the "WVDP Spill Notification and Reporting Policy," thereby minimizing any effects on the environment. Debris generated during cleanup is characterized and dispositioned appropriately.

Safe Drinking Water Act (SDWA). The SDWA requires that each federal agency operating or maintaining a public water system must comply with all federal, state, and local requirements regarding safe drinking water. Compliance with regulations promulgated under the SDWA in the state of New York is overseen by NYSDOH through county health departments.

The WVDP obtains its drinking water from surface water reservoirs on the Western New York Nuclear Service Center (WNYNSC) and is considered a non-transient, non-community public water supplier. The WVDP's drinking water treatment facility purifies the water by clarification, filtration, and chlorination before it is distributed on site.

Monitoring. As an operator of a drinking water supply system, the WVDP routinely collects and analyzes drinking water samples to monitor water quality. Results of these analyses are reported to the Cattaraugus County Health Department (CCHD), which also independently analyzes a monthly sample of WVDP tap water to determine bacterial and residual chlorine content, and an annual WVDP tap water sample for nitrate (as nitrogen).
Results for microbiological analysis of monthly tap water samples collected in 2004 indicated that total coliform and E. coli were not present in the potable water distribution system. Monthly tap water sample results for residual chlorine were positive on all occasions, indicating proper disinfection. The annual result for nitrate was also within the drinking water limit.

In the fall of 2004, the CCHD agreed to reduce monitoring for disinfection by-products (DBPs) to an annual collection as test results continued to indicate that the site is of low risk to exceed the maximum contaminant levels (MCLs) for these substances. Quarterly sample results for DBP precursors, including total trihalomethanes and five haloacetic acids, were below MCLs for these parameters. Monthly sample results for DBP precursors, including total organic carbon and alkalinity, were also below treatment system performance standards.

Cross-Connection Control. The SDWA requires that public water suppliers prevent cross-connections between the potable water supply and systems containing hazardous or infectious substances. Cross-connection control devices, such as double check valves and reduced-pressure zone valves, must be installed, inspected, and maintained at strategic locations at facilities where hazardous materials are used in a manner that could result in their introduction into the potable water distribution system under low pressure conditions. The WVDP has a total of 13 backflow prevention devices, all of which were tested and repaired as necessary by a NYSDOH-licensed tester (in 2003) to ensure that all devices are functioning properly.

NYSDOH and CCHD Inspection. In September 2004, the CCHD and NYSDOH completed an inspection of the drinking water production and supply facilities. No deficiencies were identified.

ECS - 12 
Toxic Substances Control Act. TSCA regulates the manufacture, processing, distribution, and use of chemicals, including asbestos-containing material (ACM) and polychlorinated biphenyls (PCBs).

Asbestos-Containing Material. In 2004, the WVDP continued to maintain compliance with all TSCA requirements pertaining to asbestos by managing ACM at the site in accordance with the Asbestos Management Plan (WVNSCO, revised December 6, 2002). The plan was prepared to ensure compliance with TSCA requirements and includes requirements for limiting worker exposure to ACM and for asbestos-abatement projects, maintenance activities, and periodic surveillance inspections (at least once every three years). The plan also identifies the inventory and status of onsite ACM.

Activities in 2004 included the repair or abatement of damaged/friable ACM, removal of less than 34 linear feet of ACM insulation from abandoned lines, and maintenance of signs and labels to warn workers of ACM. All activities associated with ACM are completed by personnel who are certified by the New York State Department of Labor (NYSDOL). WVNSCO maintains an asbestoshandling license issued by NYSDOL.

Polychlorinated Biphenyls. Because PCBs are regulated as a hazardous waste in New York State, the WVDP continued in 2004 to manage radioactively contaminated PCB waste as mixed waste and nonradioactive PCB waste as hazardous waste. Details concerning PCB-contaminated radioactive waste management, including a description of the waste, proposed treatment technologies, and schedules, can be found in Section 3.1.5 of the Site Treatment Plan, Fiscal Year 2004 Update (WVNSCO, February 10, 2005).

To comply with TSCA and PCB regulations, all operations associated with PCBs comply with the
PCB and PCB-Contaminated Material Management Plan. The WVDP also maintains an annual document $\log$ that details PCB use, appropriate on-site storage, and any changes in storage or disposal status. The WVDP complies with regulations for disposal of PCBs, which conditionally allow radioactive and nonradioactive $\mathrm{PCBs}$ to be stored for more than one year (40 CFR Parts 750 and 761).

\section{National Environmental Policy Act (NEPA).}

NEPA, as amended, establishes a national policy to ensure protection of the environment is included in federal planning and decision-making (Title I). Its goals are to prevent or eliminate potential damage to the environment that could arise from federal legislative actions or proposed federal projects.

Nationwide Management of Waste. In May 1997, DOE Headquarters issued the Final Waste Management Programmatic Environmental Impact Statement (EIS) to evaluate nationwide management and siting alternatives for treatment, storage, and disposal of five types of radioactive and hazardous waste. The alternatives address waste generated, stored, or buried over the next 20 years at 54 sites in the DOE complex.

The Final Waste Management Programmatic EIS was issued with the intent of developing and issuing separate records of decision for each type of waste analyzed. In 1998, the DOE issued records of decision for transuranic and non-wastewater hazardous waste. In 1999, the DOE issued the record of decision for HLW. This decision specifies that WVDP vitrified HLW will remain in onsite storage until it is accepted for disposal at a geologic repository.

On February 25, 2000, the DOE issued its record of decision for the management of LLW and mixed LLW, including West Valley's wastes. Hanford and the Nevada Test Site (NTS) were identified as

ECS - 13 
designated national DOE disposal sites for these waste types (Volume 65, Federal Register [FR], p. 10061 [65 FR 10061]). In 2001, West Valley successfully completed the program approval process for access to the NTS, and on July 17, 2001 received approval to ship. Twenty LLW shipments were sent to NTS in 2004.

Decommissioning and/or Long-Term Stewardship at the WVDP and WNYNSC. DOE published a Federal Register Notice of Intent (NOI) on March 26, 2001 (66 FR 16447) formally announcing its rescoping plan and preparation of the waste management EIS. DOE published an NOI on March 13, 2003 (68 FR 12044) announcing its intent to prepare, in cooperation with NYSERDA, a Decommissioning and/or Long-Term Stewardship EIS. The DOE and NYSERDA are joint lead agencies on this EIS, while the EPA, U.S. Nuclear Regulatory Commission, and NYSDEC are cooperating agencies. Work on preparation of the Decommissioning and/or Long-Term Stewardship EIS continued in 2004.

In May 2003, the DOE issued a draft of the Waste Management EIS (68 FR 26587) for public comment. The DOE considered public comments and issued the final EIS in January 2004.

Migratory Bird Treaty Act. The WVDP monitors wildlife activity near WVDP work areas and, where possible, implements controls to prevent and minimize nesting of migratory birds within radiologically contaminated areas of the site.

In July 2004, the U.S. Fish and Wildlife Service and NYSDEC renewed the bird depredation permit and license to allow for the removal of migratory bird nests. See Table ECS-7 for a summary of the bird depredation action taken at the WVDP during 2004.
Endangered Species Act. The WVDP periodically updates its information about the potential for federally listed or proposed endangered or threatened species in the vicinity of Project activities. This was last done via correspondence with the U.S. Fish and Wildlife Service in October 2003. Their reply on October 23, 2003 reconfirmed that, "except for occasional transient individuals," no plant or animal species protected under the Endangered Species Act were known to exist at the WVDP.

In December 2003, the WVDP submitted an inquiry to the NYSDEC's Natural Heritage Program seeking information in the state database of the potential for rare or endangered species or threatened ecological communities within the site premises. Corollary information was received from NYSDEC on January 26, 2004 confirming the absence of known New York State protected or endangered species at the WVDP.

\section{Current Achievements and Program Highlights}

Vitrification Cell Dismantlement. The WVDP's successful HLW vitrification program was the first program of that type in the nation to reach completion. The vitrification facility was closed in September 2002 after a total of 275 containers of vitrified HLW had been produced. Dismantlement of the vitrification cell continued through 2004. By the end of the year, all major vessels had been removed and packaged. Removal of remaining components is planned for 2005 .

Process Cells in the Main Plant Decontaminated. Decontamination of three former process cells in the main plant, the process mechanical cell, the general purpose cell, and extraction cell 2 , was completed in 2004. 
Remote-Handled Waste Facility Started Up. Construction of the remote-handled waste facility was completed in early 2004, readiness reviews were conducted, and processing of radioactive waste in the facility began in June 2004.

Sodium-Bearing Wastewater Solidified. Sodium-bearing wastewater, a mixed LLW, was solidified into storage containers in the fall of 2004.

Waste Shipping Continued. Off-site shipments of LLW continued in 2004. The rail spur to the site was repaired in the summer of 2004 to facilitate rail shipments of waste.

\section{Integrated Safety Management System} (ISMS). In August 2003, a self-assessment was conducted to confirm that the WVDP's integrated environmental, safety, and health management system continues to be effectively implemented at the WVDP. Results from the self-assessment were verified in the DOE's annual review, conducted in November 2004.

The WVDP continues to demonstrate its commitment to an all-inclusive approach to safety through its safety programs and through ongoing efforts to strengthen its integrated safety management program by encouraging worker involvement.

STAR Status. The WVDP has reaffirmed its commitment to DOE's Voluntary Protection Program (VPP). During the reporting period, the VPP was reviewed as part of the annual ISMS review. The DOE has also completed a programmatic review of the VPP and has recertified the WVDP as a DOE-VPP STAR site. At the annual VPP Participants National Conference, WVNSCO was awarded the DOE's Legacy of Stars Award, which is given to sites that maintain an outstanding safety record over a three-year period. WVNSCO is the first and only DOE contractor to receive this award.
In addition, the WVDP has been actively promoting VPP in the community by mentoring local businesses and providing assistance to support the Occupational Safety and Health Administration with VPP evaluations of other sites.

EPA National Environmental Performance Track. The WVDP was recognized as a top environmental leader in 2000 and was accepted into the EPA's National Environmental Performance Track. The WVDP was awarded Charter Member status as part of the first group of applicants. To qualify for the award, the WVNSCO had to demonstrate that it voluntarily has adopted and implemented an EMS, has attained previously specified environmental objectives, has made a commitment to achieve four future goals, has a public outreach program, and has a sustained record of environmental compliance.

In 2004 the WVDP re-applied to the EPA for continued membership in the Performance Track program. The WVDP renewal request was accepted in December 2004. Three new commitments have been established and are outlined in Table ECS-1.

Environmental Management System. The WVDP EMS is integrated with other safety management and work planning processes at the WVDP. In August 2004, a self-assessment of the WVDP environmental compliance program was completed by WVNSCO and it was concluded that required elements of the program are being implemented. An annual review by the DOE in November 2004 confirmed the results of the WVNSCO self-assessment.

\section{Environmental Issues and Actions}

Closed Landfill Maintenance. Closure of the on-site nonradioactive construction and demolition debris landfill (CDDL) was completed in August

ECS - 15 
1986. The landfill area was closed in accordance with NYSDEC requirements for this type of landfill, following a closure plan (Standish, 1985) approved by NYSDEC. To meet routine post-closure requirements, the CDDL cover was inspected twice in 2004 and found to be in generally good condition. The grass cover on the clay and soil cap is routinely maintained and cut, and drainage is maintained to ensure that no obvious ponding or soil erosion occurs.

Railroad Spur Rehabilitation. In 2004, a section of the bed for the railroad spur on the WNYNSC was rehabilitated to support future use of this rail line for waste shipments. Prior to removal, the rail bed soil material was sampled and tested for chemical constitutents that are typically found in soils associated with rail lines, to identify appropriate soil management practices. The test results indicated the soil did not have any appreciable contamination, with all results within soil cleanup objectives specified in NYSDEC guidance, Technical Administrative Guidance Memorandum \#4046, "Determination of Soil Clean-Up Objectives and Clean-Up Levels." The removed soil material was placed at the southeast corner of the WVDP premises, where it was subsequently stabilized with a vegetative cover to prevent sediment transport by storm water runoff.

\section{Decommissioning and/or Long-Term Stew- ardship at the WVDP and WNYNSC. Although} negotiations conducted between the DOE and NYSERDA to date have not resulted in agreement on long-term cleanup responsibilities, both parties remain committed to accomplishing important goals. These include completing EIS analyses to support decisions on site decommissioning and/or long-term stewardship. Other important Project goals include safely managing LLW, operating the remote-handled waste facility, and managing contaminated groundwater on the north plateau.

\section{Project Assessment Activities in 2004}

As the primary contractor for the DOE at the WVDP, WVNSCO maintains a comprehensive review program for proposed and ongoing operations. Assessments are conducted through formal surveillances and informal programs. Formal surveillances monitor compliance with regulations, directives, and DOE Orders. The informal program is used to identify issues or potential problems that can be corrected immediately.

The local DOE Project office and other agencies with responsibilities for the WVDP also independently review various aspects of the environmental and waste management programs, as discussed in preceding sections. In 2004, overall results reflected continuing, well-managed environmental programs at the WVDP.

ECS - 16 


\section{Compliance Tables}

DOE Headquarters uses environmental compliance summary information from sites across the DOE complex to compile national environmental summary reports. The tables on the following pages were prepared to assist in this compilation.

\section{Table ECS-1 \\ Elements of the Environmental Management System (EMS) Implementation at the WVDP}

Environmental Policy

Environmental Aspects and Impacts
The WVDP environmental policy is to conduct all activities, including design, construction, testing, startup, commissioning, operation, maintenance, and decontamination and decommissioning in a manner appropriate to the nature, scale, and environmental impacts of these activities. The WVDP is committed to full compliance with applicable federal and New York State laws and regulations for the protection of the environment, continual improvement, the prevention and/or minimization of pollution, and public outreach, including stakeholder involvement.

When operations have an environmental aspect, WVDP implements the EMS to minimize or eliminate any adverse potential impact. The EMS is a prerequisite for the EPA National Environmental Performance Track awarded by the EPA to the WVDP. Using the EMS, the WVDP evaluates its operations, identifies the aspects of operations that can impact the environment, and determines those impacts that are significant. The WVDP has determined that the following operational aspects have the potential to affect the environment:

- Waste generation and management

- Atmospheric emissions

- Liquid effluents

- Storage or use of chemicals and radioactive materials

- Natural resource usage - power and water consumption

- Noise

- Soil disturbance

- Disturbances to endangered species/protected habitats

- Contamination areas from historical operations

- Facility operations, maintenance, and decontamination activities

- Other facility-specific compliance aspects. 


\section{Table ECS-1 (continued) \\ Elements of the Environmental Management System Implementation at the WVDP}

\section{Legal and Other Requirements}

\section{Objectives and Targets}

Environmental Management Program

\section{Structure and \\ Responsibility}

The WVDP has implemented an environmental regulatory review and assessment process to deliver WVDP-level requirements and guidance to all staff. New or revised requirements (e.g., new regulations) are analyzed to determine their applicability to the WVDP and to identify whether actions are required to achieve compliance. This may involve developing or revising WVDP documents or operating procedures, implementing administrative controls, providing training, installing engineered controls, or increasing monitoring.

The performance-based management system is designed to develop, align, balance, and implement the WVDP's strategic objectives, including environmental objectives. Objectives and targets are developed by calendar year (CY). For the three-year period of CY 2004-2006, the following objectives were also commitments made under the EPA National Environmental Performance Track:

- Commitment 1 - Reduce the amount of Halon 1301 on site. The 2003 baseline was 580 pounds.

Results: CY 2004 - Exceeded commitment by shipping 603 lbs.

- Commitment 2 - Reduce total energy usage by 10\%. The 2003 baseline was about 166,000 million British thermal units (MMBTUs).

Results: CY 2004 - Exceeded commitment by reducing to about 144,000 MMBTUs, a reduction of $13 \%$.

- Commitment 3 - Reduce radiological curies in wastewater discharges by $10 \%$. The 2003 baseline was 0.0145 curies (Ci).

Results: CY 2004 - Exceeded commitment by reducing to $0.0125 \mathrm{Ci}$, a reduction of $14 \%$.

The WVDP has a pollution prevention program to conserve resources and minimize waste generation. The WVDP budgeting system is designed to ensure that priorities are balanced and that resources essential to the implementation and control of the EMS are provided.

All employees at the WVDP have specific roles and responsibilities in key areas, including environmental protection. Environmental and waste management technical support personnel assist the line organization with their environmental responsibilities. 


\section{Table ECS-1 (continued) \\ Elements of the Environmental Management System Implementation at the WVDP}

Training, Awareness and Competence

\section{Communication and \\ Community Involvement}

\section{EMS Documentation}

Document Control

\section{Operational Control}

Emergency Preparedness and Response
Training on EMS requirements has been provided to staff whose responsibilities include environmental protection. The training program includes general environmental awareness for all employees, regulatory compliance training for select staff, and specific courses for managers, internal assessors, EMS implementation teams, and operations personnel whose work can impact the environment.

The WVDP continues to improve processes for internal and external communications on environmental issues. Communications with the local community include monthly meetings with the local Citizen Task Force and meetings with the general public on a quarterly basis. Notable community involvement activities by the WVDP in 2004 included the Annual Food Drive and participation in the United Way Day of Caring.

The WVDP has comprehensive, up-to-date written environmental policies describing the EMS. Written procedures and manuals inform staff how to control processes and perform work at the WVDP in a manner that protects the environment.

The WVDP maintains a comprehensive electronic document control system to ensure the effective management of procedural documents. When facilities require additional procedures to control their work, document-control protocols are implemented to ensure that workers have access to the current version of procedures.

WVDP operations are evaluated for the adequacy of current controls to prevent impacts to the environment. As needed, additional administrative or engineered controls are identified and plans for upgrades and improvements are developed and implemented.

The WVDP has an emergency preparedness and response program and specialized staff to provide timely response to hazardous material releases or other environmental emergencies. This program includes procedures for preventing, as well as responding to, emergencies.

\section{ECS - 19}




\section{Table ECS-1 (concluded) \\ Elements of the Environmental Management System Implementation at the WVDP}

Monitoring and Measurement

Nonconformance and Corrective and Preventive Actions

Records

EMSAudit

\section{Management Review}

Liquid effluent and air-emission monitoring helps ensure the effectiveness of controls, adherence to regulatory requirements, and timely identification and implementation of corrective measures. The WVDP has a comprehensive, sitewide environmental monitoring program. Results are reported to regulatory agencies and summarized in this Annual Site Environmental Report. In addition, the WVDP assesses monitoring data for adverse trends to determine site performance, impacts from site conditions, and the need for proactive or corrective measures.

The WVDP continues to implement processes that identify and correct problems. This includes a lessons learned program to prevent recurrences, robust self-assessment and environmental assessment programs, and an electronic action tracking system.

EMS-related records, including audit and training records, are maintained to ensure integrity, facilitate retrieval, and protect from loss.

To periodically verify that the EMS is operating as intended, assessments are conducted by the DOE and its contractors. These assessments are designed to ensure that nonconformances are identified and addressed. In addition, compliance with regulatory requirements is verified through routine inspections, operational evaluations, and periodic assessments and self-assessments.

In addition to audits, a management review process has been established to involve top management in the overall assessment of environmental performance, the EMS, and progress toward achieving environmental goals. This review also identifies, as necessary, the need for changes to and continual improvement of the EMS.

ECS - 20 


\section{Table ECS-2}

\section{West Valley Demonstration Project Environmental Permits}

\begin{tabular}{|c|c|c|c|c|}
\hline $\begin{array}{c}\text { Permit Name and } \\
\text { Number }\end{array}$ & $\begin{array}{c}\text { Agency/Permit } \\
\text { Type }\end{array}$ & Description & 2004 Changes & Status \\
\hline $\begin{array}{l}\text { West Valley } \\
\text { Demonstration Project } \\
\text { RCRA Part A Permit } \\
\text { Application }\end{array}$ & $\begin{array}{l}\text { NYSDEC/Hazardous } \\
\text { Waste }\end{array}$ & $\begin{array}{l}\text { Provides interim status } \\
\text { under RCRA for treatment } \\
\text { and storage of hazardous } \\
\text { waste }\end{array}$ & $\begin{array}{l}\text { No changes to Part A. A Part } \\
\text { B Permit Application was } \\
\text { submitted on December 23, } \\
2004 \text {. }\end{array}$ & No expiration date. \\
\hline \begin{tabular}{|l|} 
Air Facility Registration \\
Certificate \\
$(9-0422-00005 / 00099)$
\end{tabular} & NYSDEC/Air Emissions & $\begin{array}{l}\text { Sitewide permit includes: } \\
-2 \text { boilers }\end{array}$ & $\begin{array}{l}\text { The State Facility Air Permit } \\
\text { was changed to an Air } \\
\text { Facility Registration } \\
\text { Certificate. }\end{array}$ & $\begin{array}{l}\text { Effective 10/28/04. No } \\
\text { expiration date. }\end{array}$ \\
\hline $\begin{array}{l}\text { Slurry-fed ceramic melter } \\
\text { (modification to WVDP- } \\
\text { 687-01) process building } \\
\text { ventilation } \\
\end{array}$ & EPA/NESHAP & $\begin{array}{l}\text { Slurry-fed ceramic melter } \\
\text { radionuclide emissions - } \\
\text { main plant stack modified } \\
\text { 2/18/97 }\end{array}$ & None & $\begin{array}{l}\text { Permit approved 2/18/97. } \\
\text { No expiration date. Request } \\
\text { to modify submitted to the } \\
\text { EPA } 8 / 99 \text {. }\end{array}$ \\
\hline $\begin{array}{l}\text { Vitrification Facility } \\
\text { Heating, Ventilation, and } \\
\text { Air-Conditioning } \\
\text { (HVAC) System }\end{array}$ & EPA/NESHAP & $\begin{array}{l}\text { Vitrification facility HVAC } \\
\text { system for radionuclide } \\
\text { emissions }\end{array}$ & None & $\begin{array}{l}\text { Permit approved 2/18/97. } \\
\text { No expiration date. }\end{array}$ \\
\hline $\begin{array}{l}01-14 \text { Building } \\
\text { Ventilation System } \\
\text { (WVDP-187-01) }\end{array}$ & EPA/NESHAP & $\begin{array}{l}\text { Liquid waste treatment } \\
\text { system ventilation of } \\
\text { radionuclide emissions in } \\
\text { the } 01-14 \text { building }\end{array}$ & $\begin{array}{l}\text { Charcoal filters were } \\
\text { temporarily installed to treat } \\
\text { emissions from sodium- } \\
\text { bearing waste for a three- } \\
\text { month period. Upon } \\
\text { completion, the system was } \\
\text { returned to normal. }\end{array}$ & $\begin{array}{l}\text { Issued 10/5/87. Modified } \\
\text { 5/25/89. No expiration } \\
\text { date. }\end{array}$ \\
\hline $\begin{array}{l}\text { Contact Size-Reduction } \\
\text { Facility (WVDP-287-01) }\end{array}$ & EPA/NESHAP & $\begin{array}{l}\text { Contact size-reduction and } \\
\text { decontamination facility } \\
\text { radionuclide emissions }\end{array}$ & None & $\begin{array}{l}\text { Issued 10/5/87. No } \\
\text { expiration date. }\end{array}$ \\
\hline $\begin{array}{l}\text { Supernatant Treatment } \\
\text { System/Permanent } \\
\text { Ventilation System } \\
\text { (WVDP-387-01) } \\
\end{array}$ & EPA/NESHAP & \begin{tabular}{|l|} 
Supernatant treatment \\
system ventilation for \\
radionuclide emissions
\end{tabular} & None & $\begin{array}{l}\text { Revised 1/1/97. No } \\
\text { expiration date. }\end{array}$ \\
\hline $\begin{array}{l}\text { Outdoor Ventilated } \\
\text { Enclosures } \\
\text { (WVDP-587-01) } \\
\end{array}$ & EPA/NESHAP & $\begin{array}{l}\text { Ten portable ventilation } \\
\text { units for removal of } \\
\text { radionuclides }\end{array}$ & None & $\begin{array}{l}\text { Issued 12/22/87. No } \\
\text { expiration date. }\end{array}$ \\
\hline $\begin{array}{l}\text { State Pollutant Discharge } \\
\text { Elimination System } \\
\text { (NY0000973) }\end{array}$ & NYSDEC/Water & $\begin{array}{l}\text { Covers discharges to surface } \\
\text { waters from various on-site } \\
\text { sources }\end{array}$ & None & $\begin{array}{l}\text { An amended permit } \\
\text { addressing storm water } \\
\text { discharges, monitoring } \\
\text { modifications, and other } \\
\text { items takes effect } 1 / 1 / 05 \text {. } \\
\text { Expires } 02 / 01 / 09 \text {. }\end{array}$ \\
\hline
\end{tabular}

ECS - 21 
Table ECS-2 (concluded) West Valley Demonstration Project Environmental Permits

\begin{tabular}{|c|c|c|c|c|}
\hline $\begin{array}{c}\text { Permit Name and } \\
\text { Number }\end{array}$ & $\begin{array}{c}\text { Agency/Permit } \\
\text { Type }\end{array}$ & Description & 2004 Changes & Status \\
\hline $\begin{array}{l}\text { Buffalo Pollutant } \\
\text { Discharge Elimination } \\
\text { System (04-05-TR096) }\end{array}$ & $\begin{array}{l}\text { Buffalo Sewer } \\
\text { Authority/sanitary sewage } \\
\text { and sewage sludge disposal }\end{array}$ & $\begin{array}{l}\text { Permit issued to hauler of } \\
\text { waste from the wastewater } \\
\text { treatment facility }\end{array}$ & Renewed 6/30/04. & $\begin{array}{l}\text { Hauler must renew permit } \\
\text { by } 6 / 30 / 05 \text {. }\end{array}$ \\
\hline $\begin{array}{l}\text { Fill Discharge Permit } \\
(94-973-29[4])\end{array}$ & $\begin{array}{l}\text { U.S. Army Corps of } \\
\text { Engineers/water }\end{array}$ & $\begin{array}{l}\text { Buttermilk Creek culvert } \\
\text { repairs and railroad spur } \\
\text { improvements }\end{array}$ & None & $\begin{array}{l}\text { Issued 4/27/00. Expires } \\
\text { 4/27/05. }\end{array}$ \\
\hline $\begin{array}{l}\text { Freshwater Wetlands } \\
\text { Permit and Water Quality } \\
\text { Certification } \\
(9-0422-00005 / 00093)\end{array}$ & NYSDEC/Water & $\begin{array}{l}\text { Buttermilk Creek culvert } \\
\text { repairs and railroad spur } \\
\text { improvements }\end{array}$ & None & $\begin{array}{l}\text { Issued 3/31/00. Expires } \\
\text { 4/1/05. }\end{array}$ \\
\hline $\begin{array}{l}\text { Chemical Bulk Storage } \\
(9-000158)\end{array}$ & $\begin{array}{l}\text { NYSDEC/chemical bulk } \\
\text { storage tank }\end{array}$ & $\begin{array}{l}\text { Registration of bulk storage } \\
\text { tanks used for listed } \\
\text { hazardous chemicals }\end{array}$ & $\begin{array}{l}\text { Cold chemical tanks 65D05 } \\
\text { and 65D06 were } \\
\text { permanently closed and } \\
\text { deleted from the registration } \\
\text { on 2/20/04. } \\
\text { Cold chemical tanks 65D02, } \\
65 \mathrm{D} 03,65 \mathrm{D} 04,65 \mathrm{D} 07, \\
65 \mathrm{D} 08,65 \mathrm{D} 09 \text {, and } 63-\mathrm{V}- \\
048 \text { were permanently } \\
\text { closed on } 11 / 10 / 03 \text {. A new } \\
\text { registration certificate } \\
\text { reflecting these closures is } \\
\text { anticipated in early } 2005 \text {. }\end{array}$ & Registration expires $7 / 5 / 05$ \\
\hline $\begin{array}{l}\text { Petroleum Bulk Storage } \\
(9-008885)\end{array}$ & $\begin{array}{l}\text { NYSDEC/petroleum bulk } \\
\text { storage tank registration }\end{array}$ & $\begin{array}{l}\text { Registration of bulk storage } \\
\text { tanks used for petroleum }\end{array}$ & None & $\begin{array}{l}\text { Registration expires 9/2/06. } \\
\text { Will be renewed before } \\
\text { expiration. }\end{array}$ \\
\hline $\begin{array}{l}\text { Bird Depredation License } \\
\text { (DWP04-041) }\end{array}$ & $\begin{array}{l}\text { New York State Division } \\
\text { of Fish and Wildlife }\end{array}$ & $\begin{array}{l}\text { State license for the removal } \\
\text { of all nests of migratory } \\
\text { birds }\end{array}$ & $\begin{array}{l}\text { License amended and } \\
\text { renewed on 7/27/04. }\end{array}$ & $\begin{array}{l}\text { NYS license expires } \\
6 / 30 / 05\end{array}$ \\
\hline $\begin{array}{l}\text { Bird Depredation Permit } \\
(\mathrm{MB} 747595-0)\end{array}$ & $\begin{array}{l}\text { U.S. Fish and Wildlife } \\
\text { Service }\end{array}$ & $\begin{array}{l}\text { Federal permit for the } \\
\text { limited taking of migratory } \\
\text { birds and active bird nests }\end{array}$ & $\begin{array}{l}\text { Permit renewed and } \\
\text { modified on } 7 / 16 / 04 \text {. }\end{array}$ & Permit expires 6/30/05. \\
\hline
\end{tabular}

ECS - 22 
Table ECS-3

West Valley Demonstration Project 2004 Air Quality

Noncompliance Episodes

\begin{tabular}{|ccccc|}
\hline Permit Type & Facility & Parameter & Date(s) Exceeded & Description/Solutions \\
EPA NESHAP & All & All & None & None \\
NYSDEC Air & All & All & None & None \\
& \multicolumn{2}{c}{ There were no episodes of noncompliance in 2004. } \\
\hline
\end{tabular}

Table ECS-4

Status of EPCRA Reporting in 2004

\begin{tabular}{|c|c|c|c|}
\hline & EPCRASection & Description of Reporting & Status* \\
\hline & EPCRA 302-303 & Planning Notification & Not Required \\
\hline & EPCRA 304 & $\begin{array}{l}\text { Extremely Hazardous Substance } \\
\text { Release Notification }\end{array}$ & Not Required \\
\hline & EPCRA 311 & Material Safety Data Sheet & Not Required \\
\hline & EPCRA 312 & Chemical Inventory & Yes \\
\hline & EPCRA 313 & Toxic Release Inventory Reporting & Not Required \\
\hline \multicolumn{4}{|c|}{$\begin{array}{l}\text { * "Yes" indicates that the site reported under the provision. } \\
\text { "No" indicates that the site should have reported but did not. } \\
\text { "Not Required" indicates that the site was not required to report under th }\end{array}$} \\
\hline
\end{tabular}

Table ECS-5

Reportable Chemicals Above Threshold Planning Quantities Stored at the WVDP in 2004

Hydrogen peroxide solution (35\%)

Liquid nitrogen

Oils - various grades

Portland cement

Diesel fuel \#2
Gasoline

Ion-exchange media

Sodium hydroxide

Sulfuric acid

ECS - 23

WVDP Annual Site Environmental Report

Calendar Year 2004 
Table ECS-6

\section{West Valley Demonstration Project 2004 NPDES/SPDES* Permit Noncompliance Episodes}

\begin{tabular}{|c|c|c|c|c|c|c|c|}
\hline $\begin{array}{l}\text { Permit } \\
\text { Type }\end{array}$ & Outfall(s) & Parameter & $\begin{array}{c}\text { No. of } \\
\text { Permit } \\
\text { Exceptions }\end{array}$ & $\begin{array}{l}\text { No. of } \\
\text { Samples } \\
\text { Taken }\end{array}$ & $\begin{array}{c}\text { No. of } \\
\text { Compliant } \\
\text { Samples } * *\end{array}$ & $\begin{array}{c}\text { Percent } \\
\text { Compliance } \\
\text { Samples }\end{array}$ & $\begin{array}{l}\text { Description/ } \\
\text { Solutions }\end{array}$ \\
\hline SPDES & All & All & 2 & 1,231 & 1,229 & $99.8 \%$ & $\begin{array}{l}\text { TSS from sediment in a } \\
\text { storm event; minimum } \\
\text { monitoring frequency for } \\
\text { total recoverable hexa- } \\
\text { valent chromium not met. }\end{array}$ \\
\hline SPDES & 001 & $T S S$ & 1 & 16 & 15 & $93.8 \%$ & See above. \\
\hline SPDES & 001 & $\begin{array}{l}\text { Hexavalent } \\
\text { Chromium, Total } \\
\text { Recoverable }\end{array}$ & 1 & 16 & 15 & $93.8 \%$ & See above. \\
\hline \multicolumn{8}{|c|}{$\begin{array}{l}\text { Radionuclides are not regulated under the site's SPDES permit. However, special requirements in the permit specify that the } \\
\text { concentration of radionuclides in the discharge is subject to requirements of DOE Order } 5400.5 \text {. }\end{array}$} \\
\hline
\end{tabular}

\section{Table ECS-7}

\section{West Valley Demonstration Project Migratory Bird Nest Depredation Episodes in 2004}

Permit/License Type

U.S. Fish and Wildlife - Bird Depredation Permit

U.S. Fish and Wildlife - Bird Depredation Permit

U.S. Fish and Wildlife - Bird Depredation Permit

U.S. Fish and Wildlife - Bird Depredation Permit

NYSDEC - Bird Depredation License
Parameter

Removal of Active Barn Swallow Nests

Removal of Active American Robin Nests

Removal of Active Eastern Phoebe Nests

Removal of Active Canada Goose Nests

Removal of Migratory Bird Nests
Permit/License Total Removed

Limit

in 2004

$\begin{array}{ll}15 & 0 \\ 15 & 0 \\ 5 & 0 \\ 5 & 0 \\ \text { timited } & 5\end{array}$

ECS - 24

WVDP Annual Site Environmental Report

Calendar Year 2004 


\section{ENVIRONMENTAL PROGRAM INFORMATION}

\section{Introduction}

The vitrified high-level radioactive waste (HLW) presently stored at the Western New York Nuclear Service Center (WNYNSC) on the West Valley Demonstration Project (WVDP or Project) premises is the by-product of the reprocessing of spent nuclear fuel during the late 1960s and early 1970s. At that time, the WNYNSC was leased by Nuclear Fuel Services, Inc. (NFS) for a commercial nuclear fuel reprocessing facility.

As the WNYNSC is no longer an active nuclear fuel reprocessing facility, the WVDP environmental monitoring program focuses on measuring radioactivity and chemicals associated with the residual by-products of the former NFS operations, the Project's former HLW treatment operations, and the Project's operations for management of HLW, transuranic waste, and low-level radioactive waste (LLW). The following information about the operations at the WVDP and about radiation and radioactivity will be useful in understanding the activities of the Project and the terms used in reporting the results of environmental test measurements.

Radiation and Radioactivity. Radioactivity is a characteristic of some elements that have unstable atomic nuclei, which spontaneously disintegrate or "decay" into atomic nuclei of another isotope or element. The nuclei decay until only a stable, nonradioactive isotope remains. Depending on the isotope, this process can take anywhere from less than a second to billions of years.

As atomic nuclei decay, radiation is released in three main forms: alpha particles, beta particles, and gamma rays. By emitting energy or particles, the nucleus becomes more stable.

Alpha Particles. An alpha particle is a fragment of a much larger nucleus. It consists of two protons and two neutrons ( similar to the nucleus of a helium atom) and is positively charged. Compared to beta particles, alpha particles are relatively large and heavy and do not travel very far when ejected by a decaying nucleus. Therefore, alpha radiation is easily stopped by a thin layer of material such as paper or skin. However, if radioactive material is ingested or inhaled, the alpha particles released inside the body can damage soft internal tissues because their energy can be absorbed by tissue cells in the immediate vicinity of the decay. An example of an alpha-emitting radionuclide is the uranium isotope with an atomic weight of 232 (uranium-232). Uranium-232 was in the HLW mixture at the WVDP as a result of a thorium-based nuclear fuel reprocessing campaign conducted by NFS. Uranium-232 has been detected in liquid waste streams. 


\section{Radioactivity}

Atoms that emit radiation are called radionuclides. Radionuclides are unstable isotopes of an element that have the same number of protons but different numbers of neutrons, resulting in different atomic masses. For example, the element hydrogen has two stable isotopes, hydrogen-1 $\left(\mathrm{H}^{1}\right)$ and hydrogen-2 $\left(\mathrm{H}^{2}\right)$ (deuterium), and one radioactive isotope, hydrogen-3 $\left(\mathrm{H}^{3}\right)$ (tritium). The numbers following the element's symbol identify the atomic mass, which is the number of protons plus neutrons in the nucleus. Thus, $H^{l}$ has one proton and no neutrons, $H^{2}$ has one proton and one neutron, and $H^{3}$ has one proton and two neutrons.

When radioactive atoms decay by emitting radiation, the daughter products that result may be either radioactive or stable. Generally, radionuclides with high atomic numbers, such as uranium-238 and plutonium-239, have many generations of radioactive progeny. For example, the radioactive decay of plutonium-239 creates uranium-235, thorium-231, protactinium-231, and so on, through 11 progeny until only the stable isotope lead-207 remains.

Radionuclides with lower atomic numbers often have no more than one daughter. For example, strontium-90 has one radioactive daughter, yttrium-90, which finally decays into stable zirconium; cobalt-60 decays directly to stable nickel with no intermediate nuclide.

The time required for half of the radioactivity of a radionuclide to decay is referred to as the radionuclide's half-life. Each radionuclide has a unique half-life; both strontium-90 and cesium-137 have half-lives of approximately 30 years while plutonium-239 has a half-life of 24,110 years. Knowledge of radionuclide half-lives is often used to estimate past and future inventories of radioactive material. For example, a 1.0-millicurie source of cesium-137 in 2000 would have measured 2.0 millicuries in 1970 and will be 0.5 millicuries in 2030.

Radiation emitted by radionuclides may consist of electromagnetic rays, such as $x$-rays and gamma rays, or charged particles, such as alpha and beta particles. A radionuclide may emit one or more of these radiations at characteristic energies that can be used to identify them.

\section{Background Radiation}

Background radiation is always present, and everyone is constantly exposed to low levels of such radiation from both naturally occurring and man-made sources. In the United States the average total annual exposure to low-level background radiation is estimated to be about 360 millirem (mrem) or 3.6 millisieverts ( $\mathrm{mSv}$ ). Most of this radiation, approximately $295 \mathrm{mrem}(2.95 \mathrm{mSv})$, comes from natural sources. The rest comes from medical procedures, consumer products, and other man-made sources (National Council on Radiation Protection and Measurements Report 93, 1987). (See Figure 2-1 in Chapter 2, Environmental Radiological Program Information.)

Background radiation includes cosmic rays; the decay of natural elements, such as potassium, uranium, thorium, and radon; and radiation from sources such as chemical fertilizers, smoke detectors, and televisions. Actual doses vary depending on such factors as geographic location, building ventilation, and personal health and habits.

\section{$1-2$}


Beta Particles. A beta particle is an electron emitted during the breakdown of a neutron in a radioactive nucleus. Compared to alpha particles, beta particles are smaller, have less of a charge, travel at a higher speed (close to the speed of light), and can be stopped by wood or less than an inch of aluminum. If released inside the body, beta particles do much less damage than an equal number of alpha particles because beta particles deposit energy in tissue cells over a larger volume than alpha particles. Strontium-90, a fission product found in the stabilized supernatant, is an example of a beta-emitting radionuclide.

Gamma Rays. Gamma rays are high-energy "packets" of electromagnetic radiation, called photons, that are emitted from the nucleus. Gamma rays are similar to $\mathrm{x}$-rays but generally are more energetic. If an alpha or beta particle released by a decaying nucleus does not carry off all the energy generated by the nuclear disintegration, the excess energy may be emitted as gamma rays. If the released energy is high, a very penetrating gamma ray is produced that can be effectively reduced only by shielding consisting of several inches of a dense material, such as lead, or of water or concrete several feet thick. Although large amounts of gamma radiation are dangerous, gamma rays are also used in lifesaving medical procedures. An example of a gamma-emitting radionuclide is barium- $137 \mathrm{~m}$, a short-lived daughter product of cesium-137. Both barium-137m and its precursor, cesium-137, are major constituents of the WVDP HLW.

Measurement of Radioactivity. The rate at which radiation is emitted from a disintegrating nucleus can be described by the number of decay events or nuclear transformations that occur in a radioactive material over a fixed period of time. This process of emitting energy, or radioactivity, is measured in curies $(\mathrm{Ci})$ or becquerels $(\mathrm{Bq})$.
The curie is based on the decay rate of the radionuclide radium-226. One gram of radium-226 decays at the rate of 37 billion nuclear disintegrations per second (3.7E+10 d/s), so one curie equals 37 billion nuclear disintegrations per second. One becquerel equals one decay, or disintegration, per second. (See the Scientific Notation section at the back of this report or the Data Reporting section in this chapter for information on exponentiation [i.e., the use of "E" to mean the power of 10].)

Very small amounts of radioactivity are sometimes measured in picocuries. A picocurie is one-trillionth (1E-12) of a curie, equal to $3.7 \mathrm{E}-02 \mathrm{~d} / \mathrm{s}$ (3.7E-02 $\mathrm{Bq})$, or 2.22 disintegrations per minute.

Measurement of Dose. The amount of energy absorbed by the receiving material is measured in rads (radiation absorbed dose). A rad is 100 ergs of radiation energy absorbed per gram of material. (An erg is the approximate amount of energy necessary to lift a mosquito one-sixteenth of an inch.) "Dose" is a means of expressing the amount of energy absorbed, taking into account the effects of different kinds of radiation.

Alpha, beta, and gamma radiation affect the body to different degrees. Each type of radiation is given a quality factor that indicates the extent of human cell damage it can cause compared with equal amounts of other ionizing radiation energy. Alpha particles cause 20 times as much damage to internal tissues as $\mathrm{x}$-rays, so alpha radiation has a quality factor of 20, compared to gamma rays, $\mathrm{x}$-rays, or beta particles, all of which have a quality factor of one.

The unit of dose measurement to humans is the rem (roentgen equivalent man). The number of rem are equal to the number of rads multiplied by the quality factor for each type of radiation. Dose can also be expressed in sieverts. One sievert equals 100 rem. 


\section{Environmental Monitoring Program Overview}

Human beings are exposed to radioactivity from site activities primarily through air, water, and food. At the WVDP all three pathways are monitored, but air and surface water pathways are the two primary means by which radioactive material can move off site.

Site geology (types of soil and bedrock), hydrology (location and flow of surface water and groundwater), and meteorology (wind speed, patterns, and direction) are all considered when evaluating potential exposure through the major pathways.

The on-site and off-site monitoring program at the WVDP includes measuring the concentration of alpha and beta radioactivity, conventionally referred to as "gross alpha" and "gross beta," in air and water effluents. Measuring the total alpha and beta radioactivity from key locations produces a comprehensive picture of on-site and off-site levels of radioactivity from all sources. For a U.S. Department of Energy (DOE) site such as the WVDP, frequent updating and tracking of the overall radioactivity levels in effluents is an important tool in maintaining acceptable operations.

More-detailed measurements are also made for specific radionuclides. Strontium-90 and cesium137 are measured because they have been previously detected in WVDP waste materials. Radiation from other important radionuclides, such as tritium or iodine-129, is not sufficiently energetic to be detected by gross measurement techniques, so these must be analyzed separately using methods with greater sensitivity. Heavy elements, such as uranium, plutonium, and americium, require special analysis because they exist in such small concentrations in the WVDP environs.
The radionuclides monitored at the Project are those that might produce relatively higher doses or that are most abundant in air and water effluents. Because man-made sources of radiation at the Project have been decaying for more than 30 years, the monitoring program does not routinely include short-lived radionuclides, that is, isotopes with a half-life of less than two years, which would be present at less than 1/1,000 of the original radioactivity levels. (See Appendix $B^{{ }^{\mathrm{CD}}}$ for the schedule of samples and radionuclides measured and Appendix $\mathrm{K}^{\mathbf{6 D}}$ for a listing of the half-lives of radionuclides measured in WVDP samples and related DOE protection standards, such as the derived concentration guides [DCGs]. See also the discussion of DCGs in this chapter.)

Data Reporting. Because the decay of radioactive atoms is a random process, an inherent uncertainty is associated with all measurements of environmental radioactivity. This can be demonstrated by repeatedly measuring the number of atoms that decay in a radioactive sample over some fixed period of time. The result of such an experiment would be a range of values for which the average value would provide the best indication of how many radioactive atoms were present in the sample.

In actual practice, an environmental sample is usually measured for radioactivity only once. The inherent uncertainty of the measurement, then, stems from the fact that it cannot be known whether the result from one measurement is higher or lower than the "true" value.

The term confidence interval is used to describe the range of measurement values above and below the test result within which the "true" value is expected to lie. This interval is derived statistically. The width of the interval is based primarily on a predetermined confidence level, that is, the probability that the confidence interval actually en- 


\section{Derived Concentration Guides}

A derived concentration guide (DCG) is defined in DOE Order 5400.5 as the concentration of a radionuclide in air or water that, under conditions of continuous exposure by one exposure mode (i.e., ingestion of water, immersion in air, or inhalation) for one year, would result in an effective dose equivalent of $100 \mathrm{mrem}(1 \mathrm{mSv})$ to a "reference man." These concentrations DCGs - are used as reference screening levels to enable WVDP personnel reviewing effluent and environmental data to decide if further investigation is needed. (See Appendix $K^{\mathrm{GD}}$ for a list of DCGs.)

For liquid effluent screening purposes, the percentages of the DCGs for all radionuclides present are summed. If the total is less than 100\%, then the effluent complies with the DOE guideline. DCGs are also compared with radionuclide concentrations from these sources to verify that Best Available Technology standards for treatment of water are being met.

The DOE provides DCGs for airborne radionuclides in locations where members of the public could, over an extended period of time, breathe air containing contaminants. DCGs are only applicable to radionuclides in air breathed by members of the public. DCGs may be used as a comparative basis for screening concentrations from air emission points.

DOE Orders and federal regulations require that the hypothetical dose to the public from facility effluents be estimated using specific computer codes. (See Dose Assessment Methodology in Chapter 2, Environmental Radiological Program Information.) Doses estimated for WVDP activities are calculated using actual site data and are not related directly to summed DCG values. Dose estimates for liquid effluents are based on the product of radionuclide quantities released and the site-specific dose equivalent effects for that radionuclide. Although airborne DCGs are used for comparison purposes, the more stringent U.S. Environmental Protection Agency (EPA) National Emission Standards for Hazardous Air Pollutants regulate Project airborne effluents at the point of release. For a consistent guide to relative concentrations, both air and water sampling results are compared with DCGs throughout this report.

compasses the "true" value. The WVDP environmental monitoring program uses a $95 \%$ confidence level for all radioactivity measurements and calculates confidence intervals accordingly.

The confidence interval around a measured value is indicated by the plus-or-minus $( \pm)$ value following the result (e.g., 5.30 $\pm 3.6 \mathrm{E}-09$ microcuries per milliliter $[\mu \mathrm{Ci} / \mathrm{mL}])$, with the exponent of $10^{-9}$ expressed as "E-09." Expressed in decimal form, the result $5.30 \pm 3.6 \mathrm{E}-09$ would be $0.00000000530 \pm 0.0000000036 \mu \mathrm{Ci} / \mathrm{mL}$. A sample measurement expressed this way is correctly interpreted to mean "there is a $95 \%$ probability that the concentration of radioactivity in this sample is between 1.7E-09 $\mu \mathrm{Ci} / \mathrm{mL}$ and $8.9 \mathrm{E}-09 \mu \mathrm{Ci} / \mathrm{mL}$." (See also Scientific Notation at the end of this report.) If the confidence interval for the measured value includes zero (e.g., 5.30 $\pm 6.5 \mathrm{E}-09 \mu \mathrm{Ci} / \mathrm{mL}$ ), the value is considered to be below the detection limit. The values listed in tables of radioactivity measurements in the appendices include the confidence interval regardless of the detection limit value. 
In general, the detection limit is the minimum amount of constituent or material of interest detected by an instrument or method that can be distinguished from background and instrument noise. Thus, the detection limit is the lowest value at which a sample result shows a statistically positive difference from a sample in which no constituent is present.

Nonradiological data are conventionally presented without an associated uncertainty and are expressed by the detection limit prefaced by a "lessthan" symbol $(<)$ if that analyte was not measurable.

Units of measure, as used in this document, are listed in the Units of Measure section in the back of this report. In the text, traditional radiological units (e.g., rem, rad, curie, roentgen) are presented first, followed by Systeme Internationale (S.I.) units. Nonradiological measurements are presented in metric units. A conversion chart for comparing traditional and S.I. radiological units and English and metric nonradiological units is presented in the Units of Measure section.

Changes in the 2004 Environmental Monitoring Program. Two modifications to the environmental sampling and surveillance network were made in 2004.

- A new air sampling location (ANRHWFK) at the recently constructed remote-handled waste facility (RHWF) was brought on line in May 2004 and radiological operations began at this facility in June 2004.

- Portable air samplers were used to monitor outdoor ventilated enclosures/portable ventilation units, which were used in an expanded role in 2004 to ventilate decontamination activities in the main plant.
See Appendix $B^{\text {GD }}$ for a detailed summary of the program changes and the sample points and parameters measured in 2004.

\section{Completion of Vitrification}

HLW from NFS operations was originally stored in two of four underground tanks (tanks 8D-2 and 8D-4). Contents in the tanks were pretreated to remove sodium salts and sulfates and most of the radioactive cesium, and resulting wastes were fixed into about 20,000 drums of cemented LLW between 1988 and 1990. Vitrification of the HLW began in 1996 and continued through September 2002. (See the 2002 WVDP Annual Site Environmental Report [West Valley Nuclear Services Company [WVNSCO] and URS, 2003] for a complete description of the vitrification process.)

Over the course of vitrification, more than 12.2 million cesium/strontium curies were transferred to the vitrification facility and 275 canisters were filled. Two additional waste canisters were generated when the melter was evacuated. Canisters are in temporary storage in a shielded cell in the main plant, the former chemical processing cell, and are being maintained until a disposal facility becomes available.

\section{Activities at the WVDP}

The WVDP's environmental management system (EMS) is an important factor in the environmental monitoring program and the accomplishment of its mission. Significant components, initiatives, and accomplishments at the WVDP in 2004 are summarized below.

Decontamination and Dismantlement. Decontamination of the head end cells (including the general purpose cell and the process mechanical cell ) and in extraction cell 2 continued and was completed in 2004 with the removal of excess 
equipment. Decontamination of the vitrification cell continued and dismantlement began with removal of the jumpers and major equipment and vessels, including the melter. More than 150 waste containers of dismantled hardware were successfully removed. This work will continue in 2005.

Sodium-Bearing Waste Management. Sodiumbearing wastewater consisting of flushed liquid retrieved from the waste tank farm was solidified on site during 2004. A portable system was used to solidify approximately 11,500 gallons $(43,500 \mathrm{li}$ ters) of this LLW. The solidified material was placed into 17 ten-ton steel containers for off-site transport to the Nevada Test Site (NTS).

Rail Spur Repairs. Reconstruction of a 750-footlong section of the rail spur that services the WVDP was completed during 2004 to support waste shipments from the site. The work included lifting rails and ties, removing loose soil under the rail bed, installing drainage, and grading and compacting with new stone. Before removal, the rail bed soils were characterized for chemical constituents in order to identify appropriate soil management practices.

Infrastructure Footprint Reduction. Personnel were relocated to available on-site locations, which enabled the removal of several office and storage trailers from the WVDP site. Similar reductions of the site's infrastructure footprint will continue in 2005.

\section{Remote-Handled Waste Facility Construc-} tion. As part of project operations, various contaminated materials and components were removed from the former process building and stored awaiting disposal. As work progresses toward eventual decommissioning, additional materials and components will be removed from the waste tank farm and the former process building. Before these waste materials can be shipped for disposal, they must be characterized, sorted, processed as necessary, and packaged to meet regulatory requirements for transportation. Construction of the RHWF, where these activities take place, was completed in 2004. DOE authorized the startup of radioactive processing on June 3, 2004 and two waste processing campaigns were completed by the end of 2004 .

Environmental Management of Aqueous Radioactive Waste. Water containing radioactive material from site process operations is collected and treated in the low-level waste treatment facility (LLWTF), which includes the LLW treatment building and associated holding lagoons. (Water from the sanitary system, which does not contain added radioactive material, is managed in a separate system.)

The treated process water is held, sampled, and analyzed before its release through a New York State Pollutant Discharge Elimination System (SPDES)-permitted outfall. In 2004, about 15.0 million gallons (56.6 million liters) of water were treated in the LLWTF system and discharged through outfall 001, the lagoon 3 weir. The total 2004 discharge waters contained an estimated 12.6 millicuries of gross alpha plus gross beta radioactivity. Comparable releases during the previous 19 years averaged about 32 millicuries per year. The 2004 release was about $40 \%$ of this average. (See "Overview of Water Effluent and Ambient Surface Water Monitoring” in Chapter 2.)

Approximately 0.083 curies of tritium were released in WVDP-controlled liquid effluents in 2004 - about $7 \%$ of the 19 -year annual average of 1.12 curies.

North Plateau Groundwater Recovery System (NPGRS). The NPGRS operated throughout 2004, recovering groundwater from an area near the leading edge of the strontium-90 plume on the north plateau. For a more detailed discus- 
sion of the plume and the NPGRS, see Chapter 2, "Northeast Swamp and North Swamp Drainage," and Chapter 4, "Results of Routine Groundwater Monitoring" and "Special Groundwater Monitoring."

\section{Environmental Management of Airborne Ra-} dioactive Emissions. Ventilated air from the various WVDP facilities is sampled continuously during operation for particulate matter and for gaseous radioactivity. In addition to monitors that alarm if particulate matter radioactivity increases above preset levels, the sample media are analyzed in the laboratory for the specific radionuclides that are present in the radioactive materials being handled.

Air used to ventilate the facilities undergoing radioactive material cleanup is passed through filtration devices before being emitted to the atmosphere. These filtration devices are generally more effective for particulate matter than for gaseous radioactivity. For this reason, facility air emissions tend to contain a greater amount of gaseous radioactivity (e.g., tritium and iodine-129) than radioactivity associated with particulate matter (e.g., strontium-90 and cesium-137). However, gaseous radionuclide emissions still remain so far below the most restrictive regulatory limit for public safety that additional treatment technologies beyond those already provided are not necessary.

Gaseous radioactivity emissions from the main plant in 2004, the second full year since vitrification was completed, included approximately 5.57 millicuries of tritium (as hydrogen tritium oxide) and 0.028 millicuries of iodine-129. (See Chapter 2 for a discussion of iodine-129 emissions from the main plant stack.) As expected, these 2004 values are quite low in comparison to values from 1997, the first full year the vitrification system operated at a relatively high rate of production. In 1997, tritium and iodine-129 emissions were 140 millicuries and 7.43 millicuries, respectively.
Particulate matter radioactive emissions from the main plant in 2004 included approximately 0.13 millicuries of gross beta-emitting radioactivity and 0.004 millicuries of gross alpha-emitting radioactivity. In 1997, beta-emitting and alpha-emitting radioactivity emissions were 0.4 millicuries and 0.001 millicuries, respectively. Increased alpha-emitting radioactivity in main stack air effluent in 2004 was related to ongoing decontamination and decommissioning activities in the main process building.

Environmental Management of Radiological Exposure. Environmental radiation is measured with thermoluminescent dosimeters (TLDs) at onsite and off-site locations. (See Figs. A-10 and A11 for the locations of on-site and off-site TLD monitoring points.) Although exposure rates at many on-site locations were elevated with respect to background, results from perimeter TLDs that would be more representative of exposure to the public were statistically indistinguishable from background results. (See "Direct Environmental Radiation Monitoring" in Chapter 2.)

Unplanned Radiological Releases. There were no unplanned airborne radiological releases on site or off site to the environment from the Project in 2004. In addition, there were no unplanned releases to the off-site environment of waterborne radioactivity in 2004. (See "RCRA 3008(h) Administrative Order on Consent" and "Process Sewer Integrity Evaluation" in the Environmental Compliance Summary section.)

\section{Nuclear Regulatory Commission (NRC)-Li-} censed Disposal Area (NDA) Interceptor Trench and Pretreatment System. Radioactively-contaminated $n$-dodecane, in combination with tributyl phosphate (TBP), was discovered at the northern boundary of the NDA in 1983, shortly after the DOE assumed control of the WVDP. Extensive sampling and monitoring through 1989 revealed the possibility that the n-dodecane/TBP 
could migrate. To contain migration of this subsurface radioactive organic contaminant, an interceptor trench and liquid pretreatment system (LPS) were built.

As in previous years, no water containing TBP was encountered in the trench and no water was treated by the LPS in 2004. More than 404,000 gallons $(1,530,000$ liters $)$ of radiologically contaminated water were collected from the interceptor trench and transferred to the LLWTF for treatment during the year. Results of surface and groundwater monitoring in the vicinity of the trench are discussed in Chapter 2 under "South Plateau Surface Water and NDA Interceptor Trench" and in Chapter 4 under "Results of Monitoring at the NDA."

Waste Minimization Program. The WVDP formalized a waste minimization program in 1991 to reduce the generation of LLW, mixed waste, and hazardous waste. This program is a comprehensive and continual effort to prevent or minimize pollution, with the overall goals of reducing health and safety risks, protecting the environment, and complying with all federal and state regulations. (See also the "Waste Minimization" and "Pollution Prevention" sections in the Environmental Compliance Summary and later in this chapter.)

\section{Pollution Prevention Awareness Program.} The WVDP's Pollution Prevention (P2) Awareness Program is a significant part of the Project's waste minimization program. The goal of the program is to make all employees aware of the importance of pollution prevention both at work and at home.

A crucial component of the P2 Awareness Program at the WVDP is the Pollution Prevention Coordinators group. This group communicates, shares, and publicizes prevention, reduction, reuse, and recycling information to all departments at the WVDP. The P2 Coordinators identify and facilitate the implementation of effective source reduction, reuse, recycling, and procurement of recycled products. The WVDP employs an incentive-based program (the Bright Ideas Program) to encourage waste stream reduction/elimination, energy savings, and affirmative procurement. This program continues to foster cost savings and avoidances resulting from waste minimization and P2 activities.

Waste Management. The WVDP continued its accomplishments in reducing and eliminating waste generated by site activities. Reductions in the generation of LLW, mixed waste, hazardous waste, industrial wastes, and sanitary waste, such as paper, plastic, wood, and scrap metal were targeted.

Waste minimization and recycling activities during 2004 resulted in cost savings and reduced waste generation. To accomplish this, the following items were recycled:

- paper and paper products - 115 tons (104 metric tons)

- scrap metals - 30.2 tons (27.4 metric tons)

- other materials - 18.0 tons (16.3 metric tons).

Low-Level Radioactive Waste Shipping Program. The WVDP initiated the LLW shipping program in 1997 to reduce the inventory of legacy and newly-generated waste stored on site. Most waste was sent to commercial disposal facilities until July 2001, when the WVDP was approved to ship LLW to the NTS, a DOE facility. During calendar year (CY) 2004, a total of 20 shipments (about 104,000 cubic feet [about 3,000 cubic meters]) were safely shipped for off-site disposal. An accelerated LLW shipping schedule is planned for 2005 . 
National Environmental Policy Act (NEPA) Activities. Under NEPA, the DOE is required to consider the overall environmental effects of its proposed actions or federal projects. The President's Council on Environmental Quality established a screening system of analyses and documentation that requires each proposed action to be categorized according to the extent of its potential environmental effect. The levels of documentation include categorical exclusions (CXs), environmental assessments (EAs), and environmental impact statements (EISs).

CXs evaluate and document actions that will not have a significant effect on the environment. EAs evaluate the extent to which the proposed action will affect the environment. If a proposed action has the potential for significant effects, an EIS is prepared that describes proposed alternatives to an action and explains the effects.

Facility maintenance, decontamination activities, and minor projects that support HLW vitrification are documented and submitted for approval as CXs, although EAs occasionally are necessary for larger-scale activities.

In December 1988, the DOE published a joint Notice of Intent (NOI) with the New York State Energy Research and Development Authority (NYSERDA) to prepare an EIS for the completion of the WVDP and closure of the facilities at the WNYNSC.

The draft EIS, which describes the potential environmental effects associated with Project completion and various site closure alternatives, was completed in 1996 and released without a preferred alternative for a six-month public review and comment period. Having met throughout 1997 and 1998 to review alternatives presented in the draft EIS, the West Valley Citizen Task Force (see inset) issued the West Valley Citizen Task Force
Final Report (July 29, 1998). This report provided recommendations and advice on the development of a preferred alternative. The Task Force continues to meet and discuss issues related to Project completion and site closure decision-making.

In 2001, the DOE formally initiated its plan to split the scope of the 1996 draft EIS into two phases one for near-term waste management decisionmaking and one for final decommissioning and/or long-term stewardship decision-making. Each phase will be covered by a separate EIS.

DOE published a Federal Register (FR) NOI on March 26, 2001 (66 FR 16447) formally announcing its rescoping plan and preparation of the waste management EIS. The DOE also published an Advance NOI on November 6, 2001 (66 FR 56090) announcing its commitment to begin work, in cooperation with NYSERDA, on the Decommissioning and/or Long-Term Stewardship EIS.

\section{West Valley Citizen Task Force}

In addition to the public comment process required by the National Environmental Policy Act, the New York State Energy Research and Development Authority, with participation from the DOE, formed the West Valley Citizen Task Force in January 1997. The mission of the Task Force is to provide advice on the completion of the West Valley Demonstration Project and cleanup, closure, and/or long-term management of the facilities at the site. The Task Force process has helped illuminate the various interests and concerns of the community, increased the two-way flow of information between the site managers and the community, and provided an effective way for the Task Force members to establish mutually-agreed-upon recommendations for the site managers to consider in their decision-making process. 
On May 16, 2003, the DOE issued the draft Waste Management EIS (68 FR 26587) for public comment. The DOE considered public comments received and issued the final Waste Management EIS in January 2004.

Because the NRC is authorized by the WVDP Act to prescribe decommissioning criteria for the WVDP, from 1998 until early 2002 the NRC worked to develop those decommissioning criteria through a series of draft policy papers and public meetings. On February 1, 2002, the NRC issued its "Decommissioning Criteria for the West Valley Demonstration Project (M-32) at the West Valley Site; Final Policy Statement" in the Federal Register (67 FR 5003). The Final Policy Statement applies the NRC's License Termination Rule (10 Code of Federal Regulations Part 20, Subpart E) as the decommissioning criteria for the WVDP and as the decommissioning goal for the entire WNYNSC.

The DOE published an NOI on March 13, 2003 (68 FR 12044) announcing its intent to prepare, in cooperation with NYSERDA, the Decommissioning and/or Long-Term Stewardship EIS. The DOE and NYSERDA are joint lead agencies on this EIS. The EPA, the NRC, and the New York State Department of Environmental Conservation (NYSDEC) are cooperating agencies on the Decommissioning and/or Long-Term Stewardship EIS. Work on preparation of this EIS continued in 2004.

The DOE and NYSERDA continue efforts to reach agreement on a preferred alternative and agency responsibilities for decommissioning and/ or long-term stewardship at the WVDP and the WNYNSC.

Self-Assessments. Self-assessments continued to be conducted in 2004 to review the management and effectiveness of the WVDP environ- mental protection and monitoring programs. Results of these self-assessments are evaluated and corrective actions are tracked through to completion. Overall results of these self-assessments found that the WVDP continued to implement quality requirements and, in some cases, improve the quality of the environmental protection and monitoring program. (See the Environmental Compliance Summary and Chapter 5, Quality Assurance.)

\section{Occupational Safety and Environmental}

Training. The safety of personnel who are involved in industrial operations under DOE cognizance is protected by standards mandated by DOE Order 440.1A, "Worker Protection Management for DOE Federal and Contractor Employees," which directs compliance with specific Occupational Safety and Health Act (OSHA) requirements. This act governs diverse occupational hazards ranging from electrical safety and protection from fire to the handling of hazardous materials. The purpose of OSHA is to maintain a safe and healthy working environment for employees.

Hazardous waste operations and emergency response regulations require that employees at treatment, storage, and disposal facilities, particularly those who may be exposed to health and safety hazards during hazardous waste operations, receive training appropriate to their job function and responsibilities. The WVDP environmental, health, and safety training matrix identifies the specific training requirements for such employees.

The WVDP provides basic 24-hour hazardous waste operations and emergency response training. (Emergency response training includes spill response measures and controlling contamination of groundwater.) The WVDP trains decontamination workers and their supervisors according to the 40-hour program for hazardous waste operations and emergency response to meet the additional 
OSHA training requirements of a cleanup site. The additional training provides workers with information and techniques for decontamination operations.

Training programs also contain information on waste minimization, pollution prevention, and the WVDP environmental management program. In addition to this standard training, employees working in radiological areas receive training on subjects such as understanding radiation and radiation warning signs, dosimetry, and respiratory protection. Qualification standards for specific job functions at the site are required and maintained. Training programs have evolved into a comprehensive curriculum of knowledge and skills necessary to maintain the health and safety of employees and ensure the continued compliance of the WVDP.

Medical emergencies on site are handled by the WVDP Emergency Medical Response Team. This team consists of on-site professional medical staff and volunteer New York State-certified emergency medical technicians.

Any person working at the WVDP who has a personal photo badge receives general employee training that covers health and safety, emergency response, and environmental compliance issues. All visitors to the WVDP receive a site-specific briefing on safety and emergency procedures before being admitted to the site.

\section{Voluntary Protection Program STAR Status.} On May 5, 2000 the WVDP received Voluntary Protection Program (VPP) STAR status. This prestigious award was granted in recognition of the WVDP's excellent worker safety and health programs. (See also the Environmental Compliance Summary.)

The WVDP has reaffirmed its commitment to DOE's VPP and was reviewed as part of the an- nual integrated safety management system (ISMS) review. The DOE recertified the WVDP as a DOE-VPP STAR site. At the annual VPP Participants National Conference, WVNSCO was awarded the DOE's Legacy of Stars Award, which is given to sites with an outstanding safety record over a three-year period.

In addition, the WVDP has been actively promoting VPP in the community by mentoring local businesses and providing assistance to support OSHA with VPP evaluations of other sites.

Employees of the WVDP reached 2.5 million safe work hours and two years without a lost-time work accident on November 30, 2004. In recognition of this safety record, WVNSCO employees were awarded the President's Award for Safety for the second consecutive year.

Environmental Management System Implementation. The Project's EMS provides the basic policy and direction for work at the WVDP through procedures that support proactive management, environmental stewardship, and the integration of appropriate technologies throughout all aspects of work at the WVDP. EMS implementation is summarized in Table ECS-1.

The WVDP EMS satisfies requirements of the new DOE Order 450.1, "Environmental Protection Program." (See the discussion of new DOE Order 450.1 in the Environmental Compliance Summary.) The EMS is also in compliance with the "Code of Environmental Management Principles" (CEMP) for federal agencies and International Organization for Standardization 14001, Environmental Management Systems: "Specification for Guidance and Use," which is being implemented worldwide. The CEMP was developed by the EPA in response to Executive Order (EO) 12856, "Federal Compliance with Right-to-Know Laws and Pollution Prevention Requirements," to 
serve as the basis for responsible environmental management. (EO 12856 was revoked in April 2000 by EO 13148, "Greening the Government Through Leadership in Environmental Management.")

Following the principles and performance objectives of the CEMP helps to ensure that a federal facility's environmental performance is proactive, flexible, cost-effective, and sustainable. The WVDP has been renewed for membership in the EPA's National Environmental Performance Track program for implementation of this EMS. New objectives were developed for the three-year period of 2004-2006. (See National Environmental

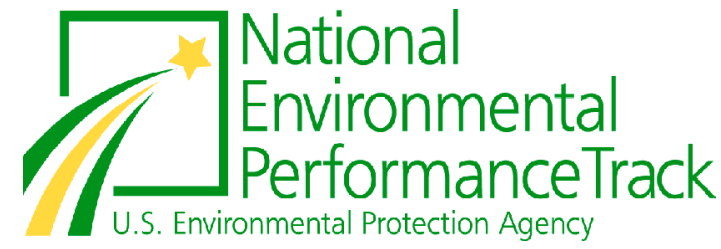

The National Environmental Performance Track is designed to recognize and encourage top environmental performers - those who go beyond compliance with regulatory requirements to attain levels of environmental performance and management that benefit people, communities, and the environment.

The logo identifies those facilities that qualify for Achievement Track membership. Achievement Track facilities can participate in a peer exchange network to share experience, benchmark each other's performance, share information on successful practices and strategies, and receive recognition for their work at state and local levels. The WVDP was approved for renewed membership in this program in 2004.
Performance Track inset in this chapter.) The most recent self-assessment by WVNSCO, performed in December 2004, verified that the EMS continues to be effectively implemented at the WVDP.

Integrated Safety Management System Implementation. A plan to integrate environmental, safety, and health (ES\&H) management programs at the WVDP was developed and initiated in 1998. During this development, the EMS was identified as an integral part of the ISMS. Environmental subject matter experts participate in a sitewide work review group to review work plans, identify ES\&H concerns, and specify practices that ensure work is performed safely.

Implementation of an ISMS at the WVDP, including the EMS, was verified by the DOE Ohio Field Office in November 1998. The most recent selfassessment by WVNSCO, performed in August 2004, verified that the ISMS continues to be effectively implemented at the WVDP. An annual ISMS review by the DOE occurred in November 2004. The DOE specifically evaluated the integration of EMS into the ISMS and confirmed results of the WVNSCO self-assessment.

\section{Performance Measures}

Performance measures can be used to evaluate effectiveness, efficiency, quality, timeliness, productivity, safety, or other areas that reflect achievements related to organization or process goals, and can be used as a tool to identify the need to institute changes.

The performance measures applicable to operations conducted at the WVDP, discussed here, reflect process performance related to wastewater treatment in the LLWTF, the identification of spills and releases, the reduction in waste generation, the potential radiological dose received by the maximally exposed off-site individual (MEOSI), 
and the transfer of HLW to the vitrification system.

\section{Radiation Doses to the Maximally Exposed} Off-Site Individual. One of the most important pieces of information derived from environmental monitoring program data is the potential radiological dose to an off-site individual from on-site activities. As an overall assessment of Project activities and the effectiveness of the as-low-asreasonably-achievable concept, the potential radiological dose to the MEOSI is an indicator of well-managed radiological operations. The effective dose equivalents for air effluent emissions, liquid effluent discharges, and other liquid releases (such as swamp drainage) from 1995 through 2004 are graphed in Figure 1-1. Note that the sum of these values is well below the DOE standard of 100 mrem per year. These consistently low results indicate that radiological activities at the site are well-controlled. (See also Table 2-3 in Chapter 2, Environmental Radiological Program Information.)

\section{State Pollutant Discharge Elimination System} Permit Limit Exceptions. Effective operation of the site wastewater treatment facilities is indicated by compliance with the applicable discharge permit limitations. Approximately 60 parameters are monitored regularly as part of the SPDES permit requirements. The analytical results are reported to NYSDEC via Discharge Monitoring Reports, required under the SPDES program.

Although the goal of the LLWTF and wastewater treatment facility operations is to maintain effluent water quality consistently within the permit requirements, occasionally SPDES permit limit exceptions do occur. All SPDES permit limit exceptions are evaluated to determine their cause and to identify corrective measures.

A Water Task Team, composed of WVDP personnel with expertise in wastewater engineering, treatment plant operations and process monitoring, and National Pollutant Discharge Elimination System/SPDES permitting and compliance, was

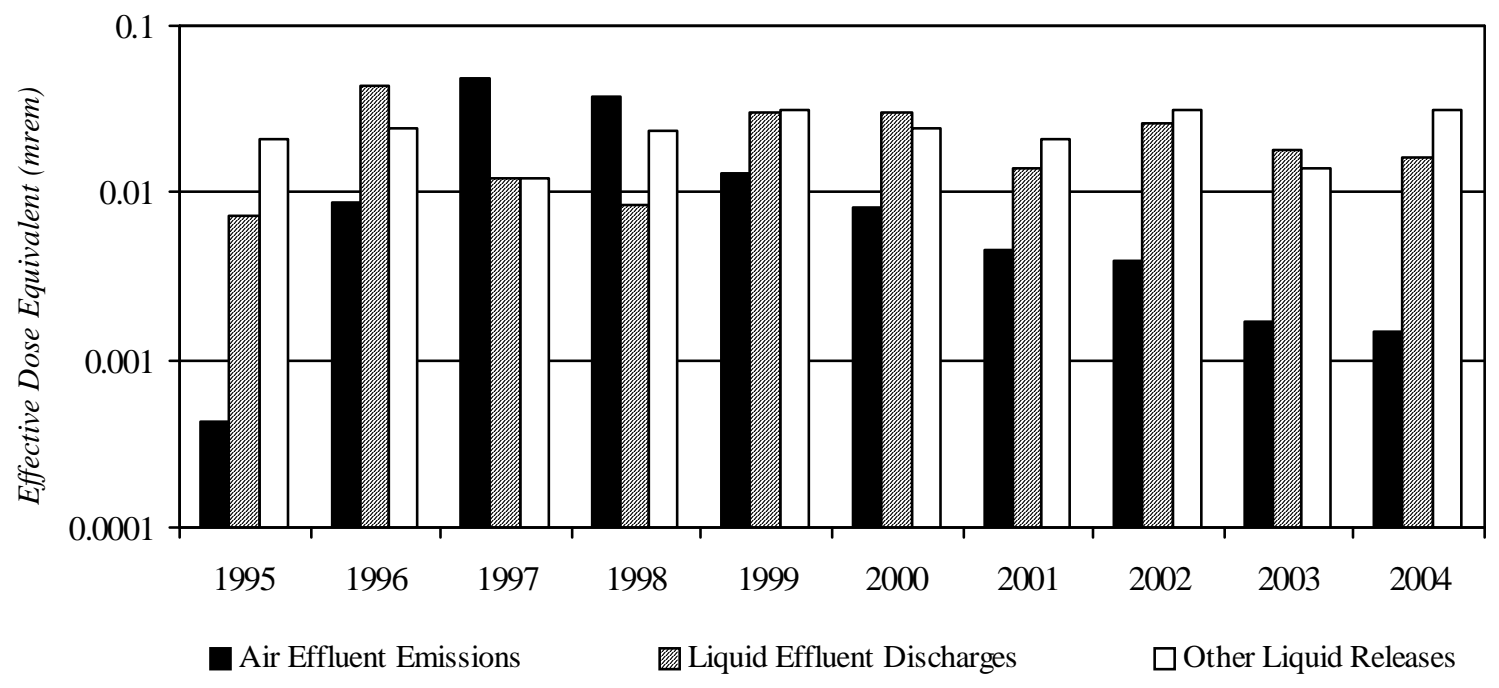

Figure 1-1. Annual Effective Dose Equivalent to the Maximally Exposed Off-Site Individual 


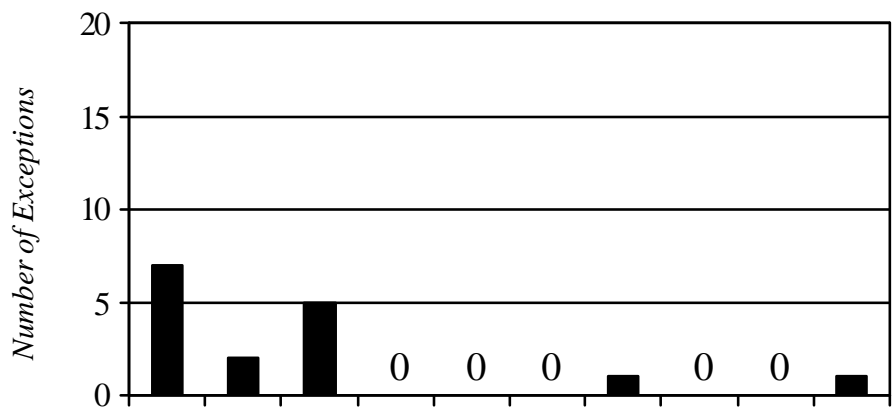

1995199619971998199920002001200220032004

Figure 1-2. Yearly SPDES Effluent Limit Exceptions

formed in 1995 to address the causes of these exceptions. The Water Task Team's efforts produced three consecutive years $(1998,1999$, and 2000) with no permit limit exceptions. In 2001, one permit limit exception for total recoverable lead occurred at outfall 008 - the french drain for the LLWTF lagoon system. One SPDES limit exception occurred in May 2004 when a test result for total suspended solids (TSS) for a sample obtained at outfall 001 was reported above the allowable (daily maximum) effluent limit. (See Fig. 1-2.) The increased TSS was caused by a storm event that resulted in runoff carrying soil and sediment down the sides of the effluent-holding lagoon and into the effluent water during the discharge.

In June 2004, the minimum permit requirement for monitoring total recoverable hexavalent chromium at outfall 001 was not met. An analytical interference resulted in an inaccurate and invalid test result for one sample that was analyzed for this chemical substance. As a consequence, the number of valid sample analyses was one short of that required.

Although exceptions are not always related to operating deficiencies, corrective actions may include improved operation or treatment techniques. In 1997, the WVDP notified NYSDEC of the presence of mercury in the influent wastewater to the
LLWTF and of its likely presence at outfall 001 at concentrations below the detectable level of 0.2 micrograms per liter $(\mu \mathrm{g} / \mathrm{L})$. In 2002, a modification to the SPDES permit required that samples being collected for measurement of mercury be analyzed in duplicate by EPA Method 245.1 (with a method detection level of $0.2 \mu \mathrm{g} / \mathrm{L}$ ) and by newer, moresensitive, EPA Method 1631E. Results of the comparison are reported to NYSDEC on a quarterly basis. Results from EPAMethod 1631E in 2004 were consistent with those from EPAMethod 245.1. (See Chapter 3, Mercury Analytical Method Study, for a discussion of this study.)

Waste Minimization and Pollution Prevention. In 2004, the WVDP continued its program of reducing and eliminating the amount of waste generated from site activities. Emphasis on good business practices, source reduction, and recycling continued to promote reduction of LLW, mixed waste, hazardous waste, industrial wastes, and sanitary wastes, such as paper, glass, plastic, wood, and scrap metal.

To demonstrate effectiveness of the waste minimization program, a graph of the percentage of waste reduction achieved above the annual goal for each category is presented in Figure 1-3 for CYs 1996 through 2004.

The WVDP set the following cumulative nonvitrification waste-reduction goals for fiscal year (FY) 2004: a 75\% reduction in the generation of LLW, an $80 \%$ reduction in the generation of mixed waste, a $70 \%$ reduction in the generation of hazardous waste, a $60 \%$ reduction in the generation of industrial waste, and a $75 \%$ reduction in the generation of sanitary waste. These goals were based on quantities of routine waste generated in 1993. (As of FY 2002, all WVDP pollution prevention 


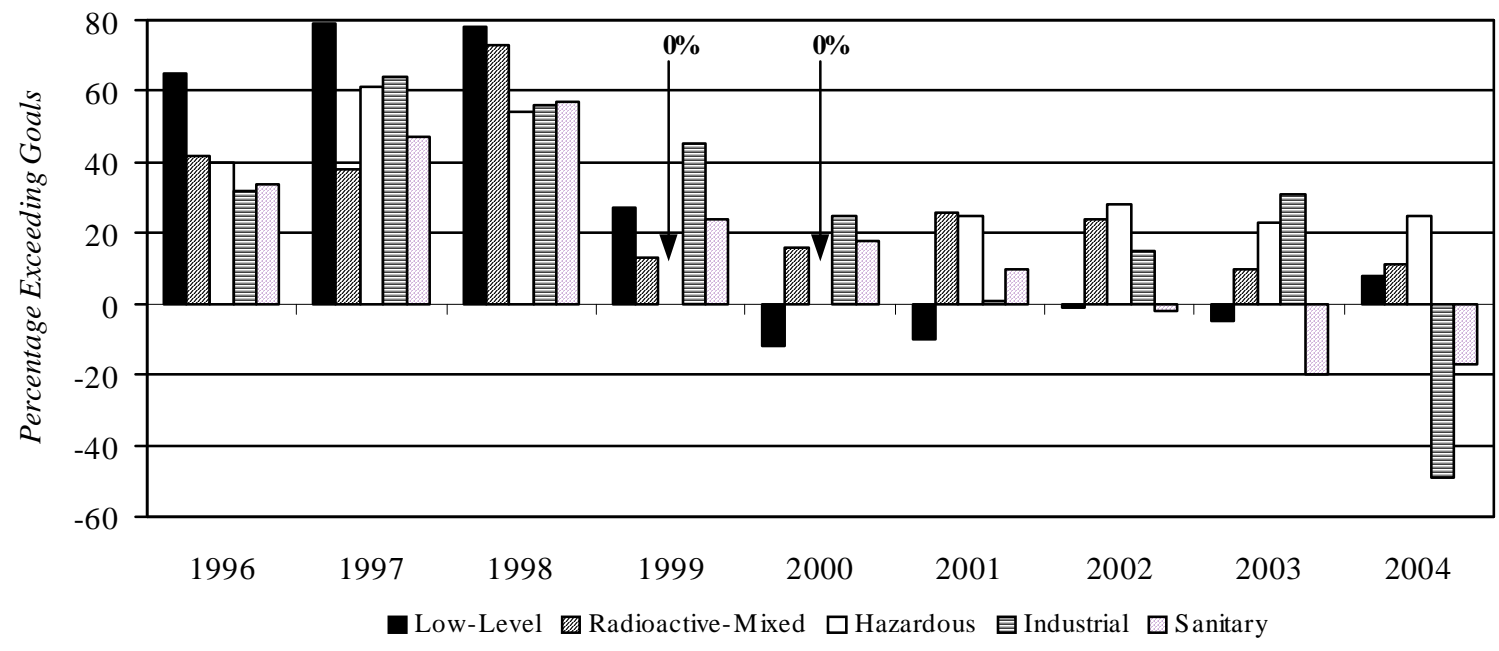

Figure 1-3. Percentage of Waste-Reduction-Exceeding Goals

goals are in alignment with the DOE's pollution prevention goals, which are based on a federal fiscal year.)

All but two of these goals were exceeded during FY 2004. LLW generation was reduced by $83 \%$. Mixed waste generation was reduced by $91 \%$, hazardous waste by $95 \%$, industrial waste by $11 \%$ (below the goal of 60\%), and sanitary waste generation was reduced by $58 \%$ (below the goal of $75 \%)$. Industrial and sanitary waste generation during FY 2004 exceeded expectations due to numerous activities to support site closure milestones and efforts to improve housekeeping and eliminate unnecessary paper.

Hazardous waste and industrial waste volumes have been tracked separately for vitrification-related and nonvitrification-related waste streams since vitrification began in 1996. To maintain historical comparability, the percentages in Figure 13 include only the nonvitrification portions of these two waste streams.
Spills and Releases. Chemical spills greater than the applicable reportable quantity must be reported immediately to NYSDEC, the National Response Center, and other agencies as required. There were no reportable chemical spills during 2004.

Petroleum spills greater than five gallons - or of any amount that travel to waters of the state must be reported immediately to the NYSDEC spill hotline and entered in the WVDP's monthly $\log$. There were no reportable petroleum spills in

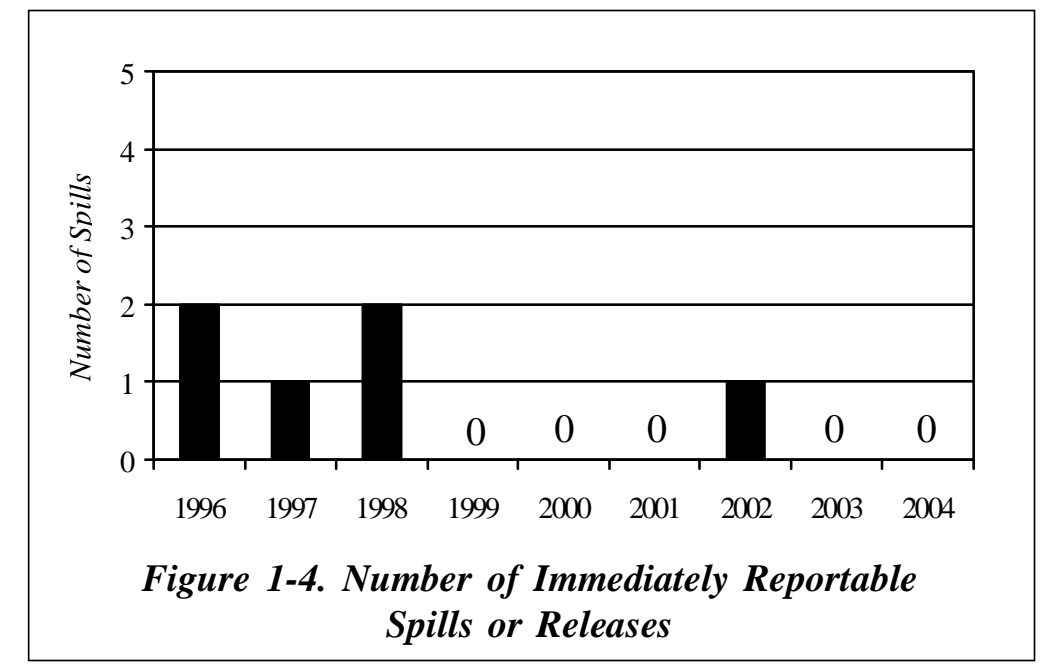


2004. Figure 1-4 is a bar graph of immediatelyreportable spills from 1996 to 2004.

Prevention is the best means of protection against oil, chemical, and hazardous substance spills or releases. WVDP employees are trained in applicable standard operating procedures for equipment that they use, and best management practices have been developed that identify potential spill sources and preventive measures that will reduce the likelihood of releases. Spill training, notification, and reporting policies have also been developed to emphasize the responsibility of each employee to report spills immediately upon discovery. This first-line reporting helps to ensure that spills will be properly documented and mitigated in accordance with applicable regulations. 
This page intentionally left blank

$$
1-18
$$




\section{ENVIRONMENTAL RADIOLOGICAL PROGRAM INFORMATION}

\section{Radiation in the Environment}

\section{Sources of Radiation}

Members of the public are routinely exposed to ionizing radiation from both natural and man-made sources. An individual living in the United States (U.S.) is estimated to receive an average annual effective dose equivalent of about 360 millirem (mrem) (3.6 millisieverts [mSv]) (National Council on Radiation Protection and Measurements Report93 [1987b]).

While most of the radiation dose received by the general public is from natural background sources, man-made sources of radiation also contribute to the average dose. Such sources include diagnostic and therapeutic $\mathrm{x}$-rays, nuclear medicine, fallout residues from atmospheric nuclear weapons tests, effluents from nuclear fuel-cycle facilities, and consumer products such as smoke detectors and cigarettes (Fig. 2-1).

Routine activities at the West Valley Demonstration Project (WVDP or Project) have the potential to release radioactive or hazardous substances that could affect the environment.

\section{Exposure Pathways}

The radionuclides present at the WVDP site are residues from the reprocessing of commercial nuclear fuel during the 1960s and early 1970s by a previous site operator. A very small fraction of these radionuclides is released off site during the year through ventilation systems and liquid discharges. These releases make a negligible contribution to the radiation dose to the surrounding population through several exposure pathways.

An exposure pathway consists of a route for a source of contamination or radiation to be transported by environmental media to a receptor where exposure may occur. For example, a member of the public could be exposed to low concentrations of radioactive particles carried by prevailing winds.

The potential pathways of exposure from Project emissions are inhalation of gases and particulates, ingestion of locally grown food products, consumption of fish, beef, and venison, and exposure to external penetrating radiation emitted from contaminated materials. Table 2-1 summarizes the potential exposure pathways for the local off-site population and describes the rationale for includ- 


\section{Ionizing Radiation}

Radiation can be damaging if, in colliding with other matter, the alpha or beta particles or gamma rays knock electrons loose from the absorber atoms. This process is called ionization, and the radiation that produces it is referred to as ionizing radiation. Ionization changes an electrically neutral atom, in which the positively charged protons and the negatively charged electrons balance each other, into a charged atom called an ion. An ion can be either positively or negatively charged. Various kinds of ionizing radiation produce different degrees of damage.

\section{Potential Effects of Radiation}

Biological effects of radiation can be either somatic or genetic. Somatic effects of radiation exposure are limited to the exposed individual. For example, sufficiently high exposure to radiation can cause clouding of the lens of the eye or a decrease in white blood cells.

Radiation can also cause chromosomes to break or rearrange themselves or to join incorrectly with other chromosomes. These changes may produce genetic effects and may show up in future generations. Radiation-produced genetic defects and mutations in the offspring of an exposed parent, while not positively identified in humans, have been observed in some animal studies.

The effect of radiation depends on the amount absorbed within a given exposure time. The only observable effect of an instantaneous whole-body dose of $50 \mathrm{rem}(0.5 \mathrm{~Sv})$ might be a temporary reduction in white blood cell count. An instantaneous dose of 100-200 rem (1-2 Sv) might cause additional temporary effects, such as vomiting, but usually would have no long-lasting side effects. Assessing biological damage from low-level radiation is difficult because other factors can cause the same symptoms as radiation exposure. Moreover, the body is able to repair damage caused by low-level radiation. There have been no documented effects from exposures of less than 10 rem.

The effect most often associated with exposure to relatively high levels of radiation appears to be an increased risk of cancer. However, scientists have not been able to demonstrate with certainty that exposure to low-level radiation causes an increase in injurious biological effects, nor have they been able to determine if there is a level of radiation exposure below which there are no adverse biological effects.

\section{Health Effects of Low-Level Radiation}

Radionuclides entering the body through air, water, or food are distributed in different organs of the body. For example, isotopes of iodine concentrate in the thyroid. Strontium, plutonium, and americium isotopes concentrate in the skeleton. When inhaled, particulate uranium and plutonium isotopes may remain in the lungs for a long period of time. Some radionuclides such as tritium, carbon-14, or cesium-137 are distributed uniformly throughout the body. Thus, depending on the radionuclide, some organs may receive quite different doses. Moreover, at the same dose levels, certain organs (such as the breast) are more prone to developing a fatal cancer than other organs (such as the thyroid).

Because of the uncertainty and difficulty in measuring the incidence of increased cancer resulting from exposure to ionizing radiation, to be conservative, a linear model is used to predict health risks from low levels of radiation. This model assumes that there is a risk associated with all dose levels even though the body may effectively repair damage incurred from low levels of alpha, beta, and gamma radiations.

$2-2$ 
ing or excluding each pathway when calculating dose from the WVDP. For instance, drinking water is not considered a pathway for exposure from the WVDP because surveys revealed that local residents do not use Cattaraugus Creek as a source of drinking water.

\section{Land Use Survey}

Periodic surveys of local residents provide information about local family sizes, sources of food, and gardening practices. In early 2003, census information from calendar year (CY) 2000 was used to update population files used for dose assessment. Information from the most recent land use survey, conducted in early 2002, was used to confirm the locations of the nearest residences. These parameters are required for computer models that are used for the annual dose assessments. (See the discussion of Dose Assessment Methodology later in this chapter for more information on calculation of dose to the public.)

\section{Dose to the Public}

Each year the potential radiological dose to the public that is attributable to operations and effluents from the WVDP is assessed to verify that no individual could credibly have received a dose exceeding the limits established by the regulatory agencies.

Estimated doses are compared directly with current radiation standards established by the U.S. Department of Energy (DOE) and the U.S. Environmental Protection Agency (EPA) for protection of the public. These values are also compared with the annual dose an average U.S. resident receives from natural background radiation and to doses reported in previous years for the Project. Figure 2-1 shows the relative contribution to the annual dose in mrem from natural and man-made sources in comparison with the estimated CY 2004 maximum individual dose from the WVDP. (Units of dose measurement are explained in detail later in this chapter.)

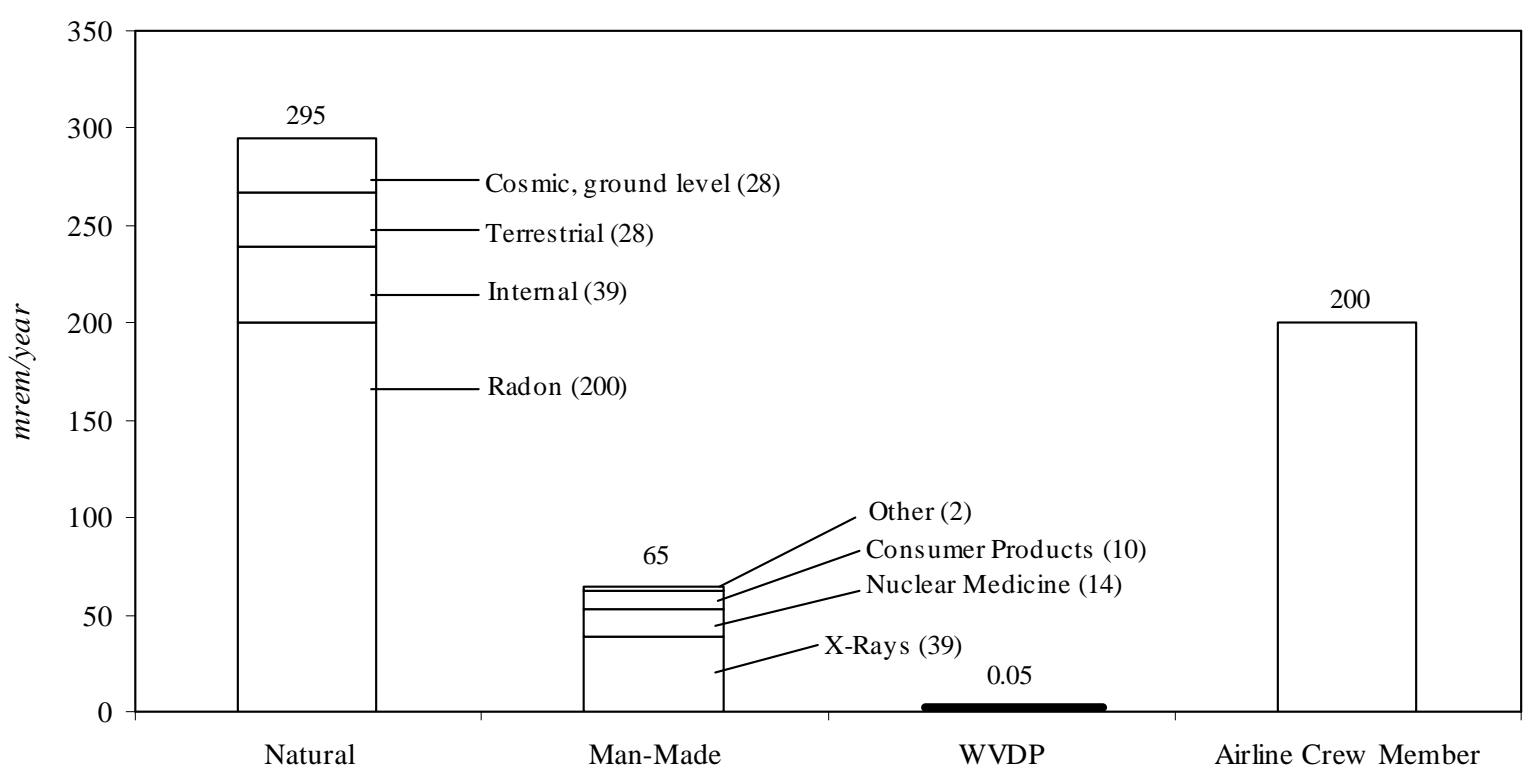

Figure 2-1. Comparison of Doses From Natural and Man-Made Sources to the Dose From 2004 WVDP Effluents

$2-3$ 
As can be seen in Figure 2-1, natural sources of radiation contribute $295 \mathrm{mrem}(2.95 \mathrm{mSv})$ and man-made sources contribute $65 \mathrm{mrem}(0.65 \mathrm{mSv})$ of the total annual U.S. average dose of $360 \mathrm{mrem}$ (3.60 mSv). In 2004, the WVDP contributed a very small amount $(0.049 \mathrm{mrem}[0.00049 \mathrm{mSv}])$ of the total annual man-made radiation dose to the maximally exposed off-site individual (MEOSI) residing near the WVDP. This is much less than the average dose received from using consumer products and is insignificant compared to the federal standard of 100 mrem allowed from any DOE site operations in a calendar year and the 295 mrem received annually from natural sources. The dose from WVDP operations also is small compared to the estimated average additional dose an airline crew member typically receives from cosmic radiation (200-900 mrem/year).

The results of these conservative dose calculations demonstrate that the potential maximum dose to an off-site resident is well below permissible standards and is consistent with the as-low-asreasonably-achievable philosophy of radiation protection.

The following sections describe the monitoring program used to measure radiation in the environment near the WVDP and the methods used and results of dose assessments using these measurements.

\section{Table 2-1 \\ Potential Local Off-Site Exposure Pathways Under Existing WVDP Conditions}

\section{Exposure Pathway and Transporting Medium}

Inhalation: gases and particulates in air (included)

Ingestion: cultivated crops (included)

Ingestion: surface and groundwater (excluded)

Ingestion: fish, beef, venison, and milk (included)

External exposure: radiation from particulates and gases directly from air or surface water or indirectly from surface deposition (included)

\section{Reason for Inclusion/Exclusion}

Off-site transport of contaminants from WVDP stacks or resuspended particulates from soils or water

Local agricultural products irrigated with potentially contaminated surface or groundwater; foliar deposition and uptake of deposited airborne contaminants

No documented use of local surface water or downgradient groundwater wells as drinking water by local residents

Fish exposed to contaminants in water or sediments may be consumed; beef, venison, and milk consumption following deposition of transported airborne and surface water contaminants

Transport of air particulates and gases to offsite receptors; transport of contaminants in surface water and direct exposure during stream use and swimming

\section{$2-4$}




\section{Release of Materials Containing Residual}

Radioactivity. The release of property containing residual radioactivity from DOE facilities is carefully controlled by DOE guidelines and procedures. In two special memoranda issued in January and July of 2000, the Secretary of Energy placed a moratorium on release of contaminated materials and on unrestricted release, for metal recycling from radiological areas within DOE facilities. The moratorium will remain in effect until directives clarifying the release criteria have been developed and implemented. Any transfer that places property (real property, structures, equipment, or scrap metal) containing radioactivity into public use is classified as a type of environmental release.
In keeping with DOE initiatives to expand environmental information provided to the public, certain details of transfers of property containing residual radioactivity are to be included in Annual Site Environmental Reports. The information provided should include, among other things, the type of material and amount of residual radioactivity, the basis for releasing the property for public use (including release limits and when the property was released), the end use and cost savings associated with release of the property, and potential doses to individuals and potential collective dose to the public associated with each release. As indicated in Table 2-2, the WVDP did not release any property classified per DOE Order 5400.5 as material containing residual radioactivity in 2004.

Table 2-2

Release of Property Containing Residual Radioactive Material

\begin{tabular}{|ccccccccc|}
\hline $\begin{array}{c}\text { Approved } \\
\text { Limit }\end{array}$ & Rationale & $\begin{array}{c}\text { Date } \\
\text { of } \\
\text { Approval }\end{array}$ & $\begin{array}{c}\text { Type } \\
\text { of } \\
\text { Material }\end{array}$ & $\begin{array}{c}\text { Basis } \\
\text { for } \\
\text { Release }\end{array}$ & $\begin{array}{c}\text { End } \\
\text { Use }\end{array}$ & $\begin{array}{c}\text { Volume } \\
\text { of } \\
\text { Material }\end{array}$ & $\begin{array}{c}\text { Total } \\
\text { Activity }\end{array}$ & $\begin{array}{c}\text { Maximum } \\
\text { Individual } \\
\text { Dose }\end{array}$ \\
$N A$ & $N A$ & $N A$ & None & $N A$ & $N A$ & 0 & 0 & 0 \\
Dose
\end{tabular}




\section{Routine Monitoring Program}

\section{Radiological Sampling Program Overview}

Samples from environmental media listed in Table 2-1 are collected each year and measured for radioactivity. Environmental sampling locations are shown on maps in Appendix A and the complete environmental monitoring schedule is summarized in Appendix $\mathrm{B}^{\mathbf{6 0}}$. This schedule provides information on monitoring and reporting requirements and the types and extent of sampling and monitoring at each location. An explanation of the codes that identify the sample medium and the specific sampling or monitoring location is also found in Appendix $B^{\text {GD }}$. For example, a sample location code such as AFGRVAL indicates an air sample (A), collected off-site (F), at the Great Valley (GRVAL) sampling station. These codes are used throughout this report for ease of reference and to be consistent with the data reported in the appendices.

The food pathway is monitored by collecting samples of beef, milk, and produce at near-site and remote locations, samples of fish upstream and downstream of the site, and samples of venison from deer from near-site and background locations. Stream sediments are sampled upstream and downstream of the WVDP, and both on-site groundwater and off-site drinking water are routinely sampled. Direct radiation is monitored on site, at the perimeter of the site, in communities near the site, and at background locations.

The primary focus of the monitoring program, however, is on surface water and air pathways, as these are the principal means of transport of radionuclides from the WVDP.
Liquid and air effluents are monitored on site by collecting samples at locations where radioactivity or other regulated substances are released or might be released. Release points include water effluent outfalls and plant ventilation stacks.

Surface water samples are collected within the Project area from ponds, swamps, seeps, and drainage channels that flow through the Western New York Nuclear Service Center (WNYNSC) and then off site into Cattaraugus Creek.

Both surface water and air samples are collected at perimeter locations where the highest off-site concentrations of transported radionuclides might be expected. Samples are also collected at remote locations to provide background concentration data for comparison with data from on-site and nearsite samples.

\section{Overview of Water Effluent and Ambient Surface Water Monitoring}

The Project is drained by several small streams. Frank's Creek flows along and receives drainage from the south plateau. As Frank's Creek flows northward, it is joined by a tributary, Erdman Brook, which receives effluent from the low-level waste treatment facility (LLWTF). On the north plateau, beyond the Project fence line, the north and northeast swamp areas and Quarry Creek drain into Frank's Creek. Frank's Creek continues across the WNYNSC and flows into Buttermilk Creek, which leaves the WNYNSC and enters Cattaraugus Creek (Figs. A-2 and A-3).

Liquid effluents from three locations (the LLWTF and the two natural drainages from the northeast 
and north swamps) are primary contributors to site dose estimates. (See Predicted Dose From Waterborne Releases later in this chapter for an estimate of the dose attributable to these waterborne effluents.)

\section{Low-Level Waste Treatment Facility Efflu-} ent. The discharge from the LLWTF through the lagoon 3 weir (WNSP001 on Fig. A-2) into Erdman Brook is the largest single source of radioactivity released to surface waters from the Project. There were eight batch releases totaling about 15.0 million gallons (56.6 million liters) in 2004.

The total amounts of radioactivity from specific radionuclides in the lagoon 3 effluent are listed in Appendix C-2 ${ }^{\mathbf{C D}}$. The annual average concentration of each radionuclide is divided by its corresponding DOE derived concentration guide (DCG) to determine what percentage of the DCG was released. (DCGs are discussed in Chapter 1. DOE DCGs for radionuclides of interest at the WVDP are listed in Appendix $\mathrm{K}^{\mathbf{6 .}}$.) As a DOE policy, the sum of the percentages calculated for all radionuclides released should not exceed $100 \%$. The combined annual average of radionuclide concentrations from lagoon 3 effluent in 2004 was approximately $21.2 \%$ of the DCGs.

The LLWTF was designed to efficiently remove strontium-90 and cesium-137, the more prevalent of the long-lived fission products in WVDP wastewaters. Other radionuclides, such as uranium isotopes, are also removed to a lesser extent. Uranium isotopes are found in WVDP liquid waste because they were present in the nuclear fuel that was once reprocessed at the site. Uranium-232, a major contributor to the combined DCG in lagoon 3 effluent, averaged about $8 \%$ of its DCG in 2004. Variations in liquid effluent radionuclide ratios continue to reflect the dynamic nature of the waste streams being processed through the LLWTF.
Outfall WNSP001 and other selected discharge points are also monitored for nonradiological parameters under the New York State Pollutant Discharge Elimination System program. See Chapter 3, Environmental Nonradiological Program Information.

\section{Northeast Swamp and North Swamp Drain-}

age. These two drainages conduct surface water and emergent groundwater off site. The northeast swamp sampling location (WNSWAMP) is used to monitor surface water drainage from the northeastern portion of the site's north plateau. The north swamp sampling point (WNSW74A) is used to monitor drainage to Quarry Creek from the northern portion of the plateau (Fig. A-2).

Data summaries from these two locations are found in Appendix C- $3^{\text {Go }}$. Elevated gross beta concentrations at WNSWAMP, first noted in 1993, continued to be observed in 2004 . Gross beta activity at this location is largely attributable to strontium-90. Concentrations of all radioisotopic parameters detected at the two locations, other than strontium-90 at WNSWAMP, were less than $1 \%$ of the respective DCGs for these parameters.

Strontium-90 concentrations at WNSWAMP in 2004 averaged 1.31E-06 microcuries per milliliter $(\mu \mathrm{Ci} / \mathrm{mL})$ (48.5 Becquerels per liter $[\mathrm{Bq} / \mathrm{L}])$, higher than the average result in 2003. (See Chapter 4 for a graph of annualized average strontium90 concentrations at WNSWAMP in 2004.) Even though waters with elevated strontium-90 concentrations drain from WNSWAMP into Frank's Creek, concentrations in waters collected from Cattaraugus Creek downstream at the first point of access by the general public (WFFELBR) were only slightly higher than those at background location WFBIGBR, upstream of the location where site drainage enters Cattaraugus Creek. 
Other North Plateau Surface Waters and Water Effluent. Discharges from WNSP001 and WNSP007 leave the site through point WNSP006. Radiological results of analyses from WNSP006 and WNSP007 are summarized in Appendices $\mathrm{C}-4^{\mathrm{GD}}$ and $\mathrm{C}-2^{\mathrm{ED}}$, respectively.

WNSP006. WNSP006 is located more than 2.5 miles $(4.0 \mathrm{~km})$ upstream from Thomas Corners Road, the last monitoring point before Buttermilk Creek leaves the WNYNSC and before the public has access to the creek waters. Many of the constituents detected in effluent from WNSP001 were not detectable a short distance downstream at location WNSP006. Radionuclides that were detected were found at concentrations at small percentages of the respective DCGs. The highest strontium-90 concentration at WNSP006 in 2004 was $3.52 \mathrm{E}-08 \mu \mathrm{Ci} / \mathrm{mL}(1.30 \mathrm{~Bq} / \mathrm{L})$, which is less than $4 \%$ of its $\mathrm{DCG}(1 \mathrm{E}-06 \mu \mathrm{Ci} / \mathrm{mL})$.

Average concentrations for the radiological parameters detected at WNSP007 in 2004 were also at small percentages of their respective DCGs.

WNSPOO5 and WNCOOLW. Sampling point WNSP005 monitors overland drainage and groundwater seepage on the east side of the main plant and WNCOOLW monitors coolant water from a contained basin within the facility. Summaries of radiological data for WNSP005 and WNCOOLW are found in Appendix C- $3{ }^{\text {ted }}$.

Although most radiological concentrations for both locations were below detection levels in 2004, gross beta and strontium- 90 were detected at WNSP005. The gross beta and strontium-90 levels at WNSP005 may be influenced by inactive Lagoon 1. (See Chapter 4, "Long-Term Trends of Gross Beta and Tritium at Selected Groundwater Monitoring Locations.") Although elevated with respect to background, gross beta and strontium- 90 concentrations at WNSP005 were well below the strontium-90 DCG.
South Plateau Surface Water and Nuclear Regulatory Commission (NRC)-Licensed Disposal Area (NDA) Interceptor Trench. Two inactive underground radioactive waste disposal areas, the NDA and the New York State-Licensed Disposal Area (SDA), lie on the south plateau of the site. (The SDA is managed by the New York State Energy Research and Development Authority [NYSERDA].) The drum cell, an aboveground structure used to store approximately 20,000 drums of processed low-level radioactive waste, is located nearby. Surface waters, which flow from the south to the north, are routinely monitored at several points around these areas (Fig. A-2). In addition to routine samples collected by the WVDP, samples are collected and analyzed by the New York State Department of Health (NYSDOH) at the two stream sampling points that receive drainage from the south plateau, WNFRC67 and WNERB53.

NRC-Licensed Disposal Area. Sampling point WNNDATR is a sump at the lowest point in the collection trench system that intercepts groundwater from the northeastern and northwestern sides of the NDA. Water collected underground at this location is pumped to the LLWTF for treatment prior to discharge at outfall WNSP001. (See Chapter 1 and Chapter 4 for an explanation of the NDA Interceptor Trench and Pretreatment System.) If contamination were to migrate through the NDA, it would most likely be first detected in samples from WNNDATR.

Surface water drainage downstream of the NDA is monitored at WNNDADR. Further downstream, water from sampling point WNERB53 in Erdman Brook, which represents surface waters from the NDA before they join with drainage from the main plant and lagoon areas, is also monitored. Some drainage from western and northwestern portions of the SDA also passes through sampling points WNNDADR and WNERB53. (See Appendix $\mathrm{C}-4^{\mathrm{GD}}$.) 
Annual concentrations from WNNDATR are listed in Appendix C- $3{ }^{\text {बD }}$ and quarterly results are listed under "NDATR" in Appendix $\mathrm{E}^{\mathbf{6 0}}$.

No gross alpha or cesium-137 activity was detected at WNNDATR, WNNDADR, and WNERB53 in 2004. No iodine-129 was detected at WNNDATR and WNNDADR in 2004. (Samples from WNERB53 are not analyzed for iodine-129.) Strontium-90 and associated gross beta results at all three locations were elevated with respect to background (WFBCBKG), but all were far below the strontium-90 DCG. Residual soil contamination from past waste burial activities is thought to be the source of the strontium90 activity. The NDA is thought to be the predominant source of gross beta activity observed at WNNDATR.

Although tritium concentrations at WNNDATR and WNNDADR were also elevated with respect to background values (those from WNERB53 were not), the maximum concentrations from both WNNDATR and WNNDADR were less than $1 \%$ of the DCG for tritium in water $(2 \mathrm{E}-03 \mu \mathrm{Ci} /$ $\mathrm{mL}$ ). Allowing for seasonal variations, tritium concentrations seem to be generally decreasing at both WNNDATR and WNNDADR. Since the half-life of tritium is slightly longer than 12 years, decreasing tritium concentrations may be partially attributable to radioactive decay.

New York State-Licensed Disposal Area. Point WNSDADR is used to monitor drainage from trench covers on the southwestern area of the SDA. Immediately south of the SDA, and upstream of WNSDADR, sampling point WNDCELD is used to monitor surface drainage from the area around the drum cell (Fig. A-2). To the northeast, sampling point WNFRC67, in Frank's Creek, is used to monitor drainage downstream of the drum cell and the eastern and southern borders of the SDA. Summaries of results from
WNSDADR, WNDCELD, and WNFRC67 may be found in Appendices C $-3{ }^{\text {GD }}$ and $\mathrm{C}-4{ }^{\text {Go }}$.

Gross beta and tritium concentrations at WNSDADR, although higher than background concentrations, were a small percentage of the DCGs. All other radiological results from surface waters at the SDA were statistically indistinguishable from background.

Ponded (Standing) Waters. Four ponds near the site were tested in 2004. For comparison, a background pond 8.8 miles (14.1 kilometers $[\mathrm{km}]$ ) north of the Project was also tested. (See Figs. A-2, A3 , and A-13 for the locations of the five ponds and Appendix C- $4^{\mathrm{GD}}$ for a summary of sampling results.) All radiological results were statistically the same as concentrations in the background pond.

Off-Site Surface Water. Samples of surface water are collected at four off-site locations, two on Buttermilk Creek and two on Cattaraugus Creek. Offsite sampling locations are shown on Fig. A-3.

Fox Valley Road and Thomas Corners Bridge Sampling Locations. Buttermilk Creek is the major surface drainage from the WNYNSC. One monitoring station is located upstream of the WVDP at Fox Valley Road (WFBCBKG) and one is located downstream at Thomas Corners Bridge (WFBCTCB). The Thomas Corners Bridge sampling location is upstream of Buttermilk Creek's confluence with Cattaraugus Creek. This sampling location represents an important intercept point in the pathway to humans because dairy cattle have access to the water here. A listing of radionuclide concentrations at background location WFBCBKG compared with those downstream at WFBCTCB may be found in Appendix C $-4{ }^{\text {GD }}$.

Gross alpha, tritium, technetium-99, and cesium137 concentrations at Thomas Corners Bridge were statistically indistinguishable from background con- 
centrations in 2004. Gross beta and strontium-90 concentrations at Thomas Corners Bridge, although detected at less than $2 \%$ of the strontium90 DCG, were elevated in comparison to background. These elevated concentrations may be attributed to small amounts of radioactivity moving from the site via Frank's Creek.

Cattaraugus Creek at Felton Bridge and Bigelow Bridge Sampling Locations. Radiological data from samples taken at Felton Bridge (WFFELBR), downstream of the point where Buttermilk Creek enters Cattaraugus Creek, and from Bigelow Bridge (WFBIGBR), upstream of this point, are summarized in Appendix C $-4{ }^{\text {更 }}$.

No statistically significant differences were noted between upstream and downstream concentrations of gross alpha, tritium, strontium-90, and cesium137. Gross beta concentrations at Felton Bridge (WFFELBR), however, were slightly higher than background concentrations, although detected at less than $1 \%$ of the DOE DCG for strontium-90.
Figure 2-2 shows gross alpha, gross beta, and tritium results over the past ten years at Felton Bridge. For the most part, tritium concentrations represent detection limits and not detected radioactivity. Taking into account seasonal fluctuations, gross beta activity appears to have remained relatively constant at this location over the last decade.

\section{Overview of Drinking Water Monitoring}

Drinking water (potable water) is sampled both off site (near the WVDP) and on site. Off-site drinking water samples are taken from wells that represent the nearest unrestricted use of groundwater near the Project; none of these wells draw from groundwater units underlying the site. Drinking water and utility water for the Project are drawn from two on-site surface water reservoirs.

On-Site Tap Water. On-site drinking water sources were monitored for radionuclides at four

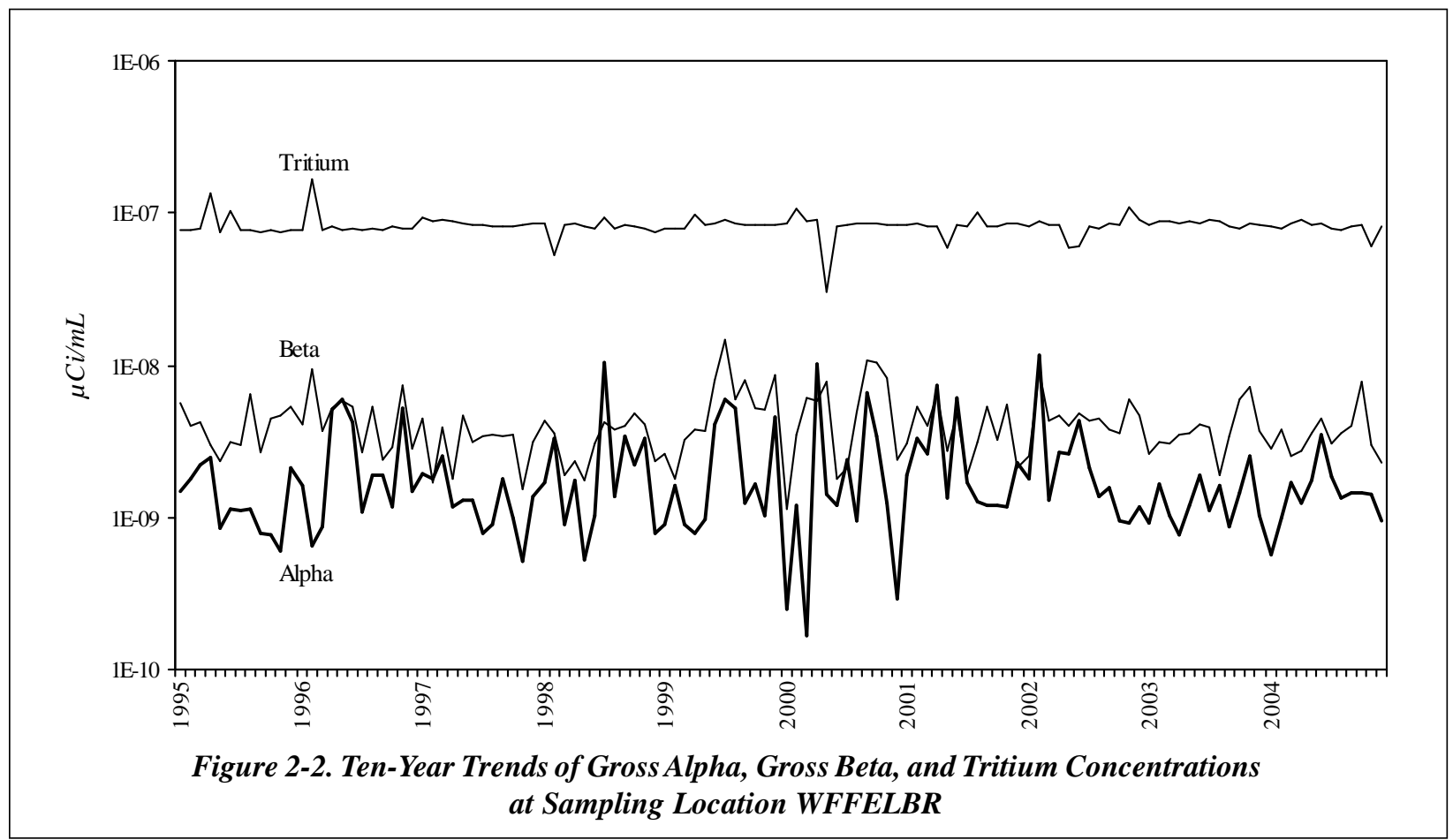


locations: the entry point at the utility room (WNDNKUR), the Environmental Laboratory (WNDNKEL), the maintenance shop (WNDNKMS), and the main plant (WNDNKMP). No differences were noted between control values at the utility room and those from other site locations. Data tables may be found in Appendix C- $5^{\text {CDD }}$.

Off-Site Drinking Water Wells. Nine off-site private, residential groundwater wells between 0.9 miles $(1.5 \mathrm{~km})$ and 4.3 miles $(7 \mathrm{~km})$ from the facility (WFWEL01 through WFWEL05 and WFWEL07 through WFWEL10) were sampled for radiological parameters in 2004. A tenth private well (WFWEL06), 18 miles (29 km) south of the site, provides a background sample. Sampling locations are shown in Figures A-9, A-12, and A-13 and results are presented in Appendix C- $5^{\text {G0 }}$. Radiological results in 2004 were close to or statistically indistinguishable from background.

\section{Overview of Sediment Monitoring}

Particulate matter in streams can adsorb radiological constituents in liquid effluents, settle on the bottom of the stream as sediment, and subsequently be eroded or resuspended, especially during periods of high stream flow. These resuspended sediments may provide a pathway for radiological constituents to reach humans either directly via exposure or indirectly through the food pathway.

On-Site Sediments. Sediments are collected at three on-site surface water sampling points where liquid effluents leaving the site are most likely to be radiologically contaminated: Frank's Creek where it leaves the security fence (SNSP006), the north swamp drainage swale (SNSW74A), and the northeast swamp drainage swale (SNSWAMP) (Fig. A-2). (Note that swamp sediment samples may be partially composed of soils.) Results from radiological analyses of these samples are listed in Appendix G- $2^{\mathrm{GD}}$. As in previous years, gross beta,

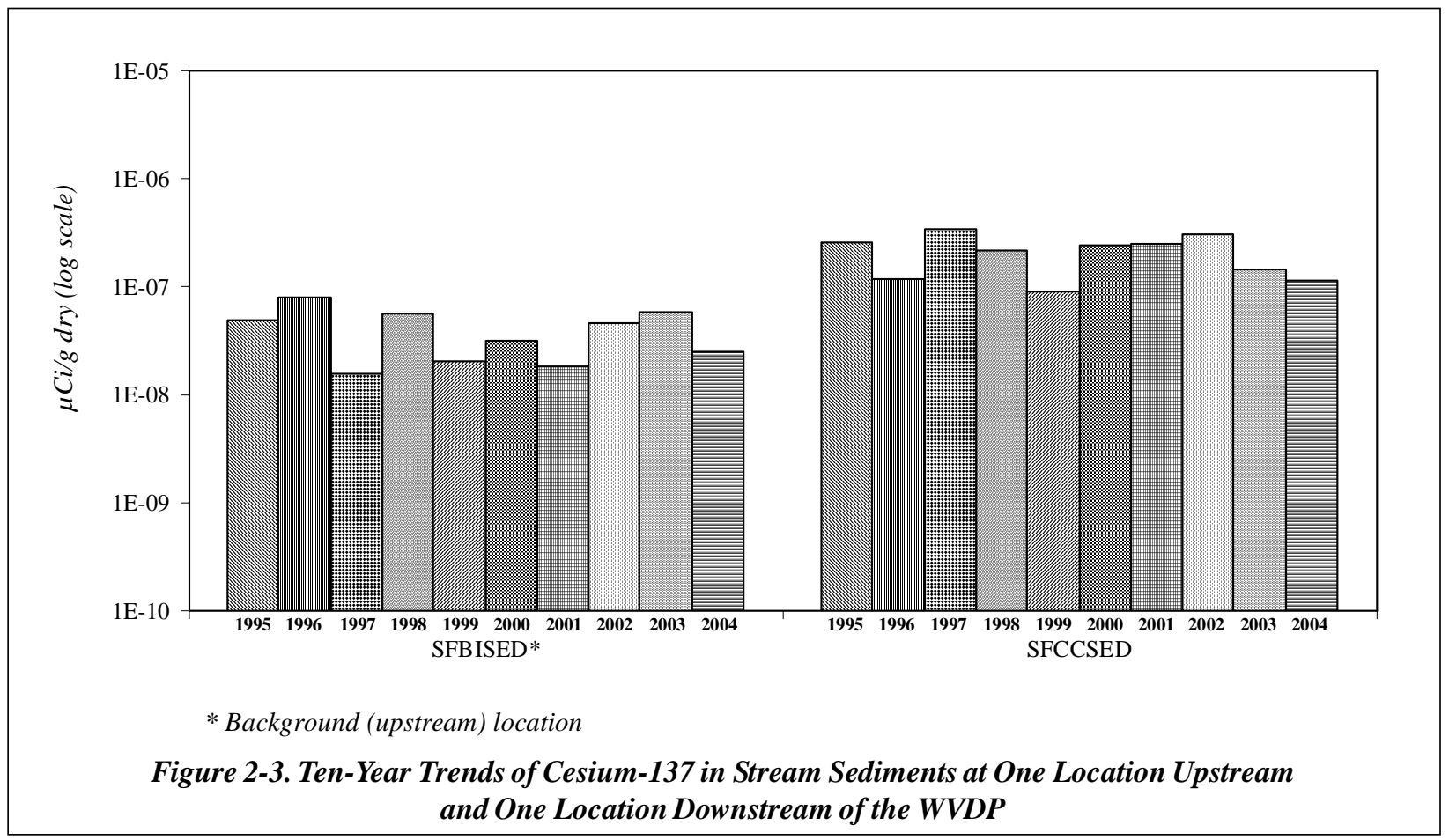


strontium-90, cesium-137, and certain alpha isotopic results higher than background were noted.

Off-Site Sediments. Sediments are collected off site at three locations downstream of the WVDP: Buttermilk Creek at Thomas Corners Road (SFTCSED), Cattaraugus Creek at Felton Bridge (SFCCSED), and Cattaraugus Creek at the Springville dam (SFSDSED). The first two points are at water sampling locations. The third is behind the Springville dam where significant sediments accumulate, including sediments that may have adsorbed radionuclides from the site. Sediments are also collected at two locations upstream of waters receiving effluents from the WVDP, Buttermilk Creek at Fox Valley Road (SFBCSED) and Cattaraugus Creek at Bigelow Bridge (SFBISED). The two upstream locations provide background data for comparison with downstream points (Fig. A-3).

Most radiological results from downstream sediment sampling sites were statistically the same as those from background locations, except for cesium-137 concentrations that were statistically higher than background. A comparison of annual averaged cesium- 137 concentrations from 1995 through 2004 for two off-site sampling locations is illustrated in Figure 2-3. As the figure indicates, cesium-137 concentrations are relatively stable at the background location (SFBISED) and are generally higher at the location downstream of the WVDP (SFCCSED). Although cesium-137 activity historically is elevated in downstream Cattaraugus Creek sediments relative to upstream sediments, the levels are far lower than those of naturally occurring gamma emitters, such as potassium-40.

\section{Overview of Air Emission and Ambient Air Monitoring}

Permits obtained from the EPA allow air containing small amounts of radioactivity to be released from plant ventilation stacks during normal operations. The air released must meet criteria specified in the National Emission Standards for Hazardous Air Pollutants (NESHAP) regulations to ensure that the environment and the public's health and safety are protected. Dose-based comparisons of WVDP emissions against NESHAP criteria are presented later in this chapter. (See Predicted Dose From Airborne Emissions, later in this chapter.)

Unlike NESHAP dose criteria, the DOE DCGs are expressed in units of $\mu \mathrm{Ci} / \mathrm{mL}$ and therefore can be directly compared with concentrations of radionuclides in WVDP air emissions. DOE standards and DCGs for radionuclides of interest at the WVDP are found in Appendix $\mathrm{K}^{\mathrm{GD}}$. When isotopic data are not available, gross alpha and beta measurements are assumed to come from americium-241 and strontium-90, respectively, because the DCGs for these radionuclides are the most limiting for major particulate emissions at the WVDP.

Ventilation and Emission Systems. The exhaust from each EPA-permitted ventilation system on site is continuously filtered and the permanent systems are monitored as air is released to the atmosphere. Because radionuclide concentrations in air emissions are quite low, a large volume of air must be sampled at each point to measure the quantity of specific radionuclides released from the facility. Emissions are sampled for both particulate (e.g., strontium-90 and americium-241) and gaseous forms of radioactivity (e.g., tritium and iodine-129). The total release of each radionuclide (in curies) varies from year to year in response to changing site activities. For instance, releases of 
iodine-129 decreased after vitrification was completed, while releases of tritium, strontium-90, cesium-137, and alpha isotopes generally increased when decontamination and dismantlement activities began. (Note that calculated dose has remained a small fraction of the standard. See "Predicted Dose From Airborne Emissions" later in this chapter.)

The Main Plant Ventilation Stack. The main plant ventilation stack (ANSTACK) is the primary source of airborne releases at the WVDP. This stack, which vents to the atmosphere at a height of approximately 200 feet (more than 60 meters), releases ventilation exhaust from several facilities, including the liquid waste treatment system, the analytical laboratories, and off-gas from the former vitrification system.

Total curies released from the main stack in 2004 are listed in Appendix $\mathrm{D}^{\mathbf{6 0}}$, together with annual averages, maxima, and a comparison of average isotopic concentrations with the applicable DCGs. As in previous years, the 2004 average radioactivity levels at the stack discharge point were already below concentration guidelines for airborne radioactivity in an unrestricted environment. Airborne concentrations from the stack to the site boundary are further reduced via dispersion by a factor of more than 200,000. Results from air samples taken just outside the site boundary confirm that WVDP operations had no discernible effect on off-site air quality. (See "Perimeter and Remote Ambient Air Monitoring," later in this chapter.)

Other On-Site Air Sampling Systems. Sampling systems similar to those of the main stack monitor airborne effluents from the former vitrification heating, ventilation, and air-conditioning system (ANVITSK), the 01-14 building ventilation stack (ANCSSTK), the contact size-reduction facility ventilation stack (ANCSRFK), the supernatant treatment system ventilation stack (ANSTSTK), the container sorting and packaging facility ventilation stack (ANCSPFK), and the remote-handled waste facility (ANRHWFK), which began "hot" operations in June 2004 (Fig. A-4).

Appendix $\mathrm{D}^{\mathrm{GD}}$ presents total radioactivity released for specific radionuclides (as available) at each of these sampling locations. Samples from locations ANVITSK, ANCSSTK, ANSTSTK, ANCSPFK, and ANRHWFK occasionally showed detectable concentrations of gross radioactivity, as well as specific beta- and alpha-emitting radionuclides, but none approached any DOE effluent limitations. (ANCSRFK did not operate in 2004, therefore no samples were taken.)

Permitted portable outdoor ventilation enclosures (OVEs) are used occasionally to provide the ventilation necessary for the safety of personnel working with radioactive materials in areas outside permanently ventilated facilities or in areas where permanent ventilation needs to be augmented. In 2004, decontamination of extraction cell 2 in the main plant was monitored by OVEs. Air samples from OVEs are collected continuously while those emission points are discharging, and data from these portable ventilation units are included in annual airborne emission evaluations. Average discharges from OVEs were well below DOE guidelines.

Three air samplers monitor ambient air near three on-site waste storage units - the lag storage area (ANLAGAM), the NDA (ANNDAAM), and the SDA (ANSDAT9) (Fig. A-4). These samplers were put in place to monitor potential diffuse releases of radioactivity. Monitoring data from these locations are presented in Appendix $\mathrm{D}^{\mathrm{GD}}$.

With the exception of tritium results at ANSDAT9, radiological data sets for the three locations were statistically indistinguishable from results for the background air monitoring location at Great Val- 
ley (AFGRVAL). Although tritium results at ANSDAT9 were elevated with respect to background, even the highest result $(5.51 \mathrm{E}-12 \mu \mathrm{Ci} / \mathrm{mL}$ [2.04E-01 Bq/m $\left.{ }^{3}\right]$ ) was less than $0.01 \%$ of the DOEDCG for tritium in air $(1 \mathrm{E}-07 \mu \mathrm{Ci} / \mathrm{mL})$.

Perimeter and Remote Ambient Air Monitoring. In 2004, samples for radionuclides in air were collected at six locations around the perimeter of the site and at three remote locations. Maps of the sampling locations are found on Figures A-5, A-12, and A-13.

The perimeter locations on Fox Valley Road (AFFXVRD), Rock Springs Road (AFRSPRD), Route 240 (AFRT240), Thomas Corners Road (AFTCORD), DutchHill Road (AFBOEHN), and at the site's bulk storage warehouse (AFBLKST) were chosen because they provide historical continuity (as former Nuclear Fuel Services, Inc. sampling locations) or because they represent the most likely locations for detecting off-site airborne concentrations of radioactivity.
The remote locations provide data from nearby communities (West Valley [AFWEVAL] and Springville [AFSPRVL]) and from a more distant background area (Great Valley [AFGRVAL], 18 miles [29 km] south of the site), which is considered representative of regional background air. Data from these locations are presented in Appendix $\mathrm{D}^{\mathrm{Gr}}$.

Ten-year gross alpha and gross beta concentrations at the Rock Springs Road location are shown in Figure 2-4. Within a range of seasonal and weekly fluctuations, the concentrations have been relatively constant over the past ten years.

Radioisotopic results from samples taken at the two near-site communities and from the site perimeter were statistically indistinguishable from results from the background samples, suggesting that there is no adverse site influence on the air quality at these near-site locations.

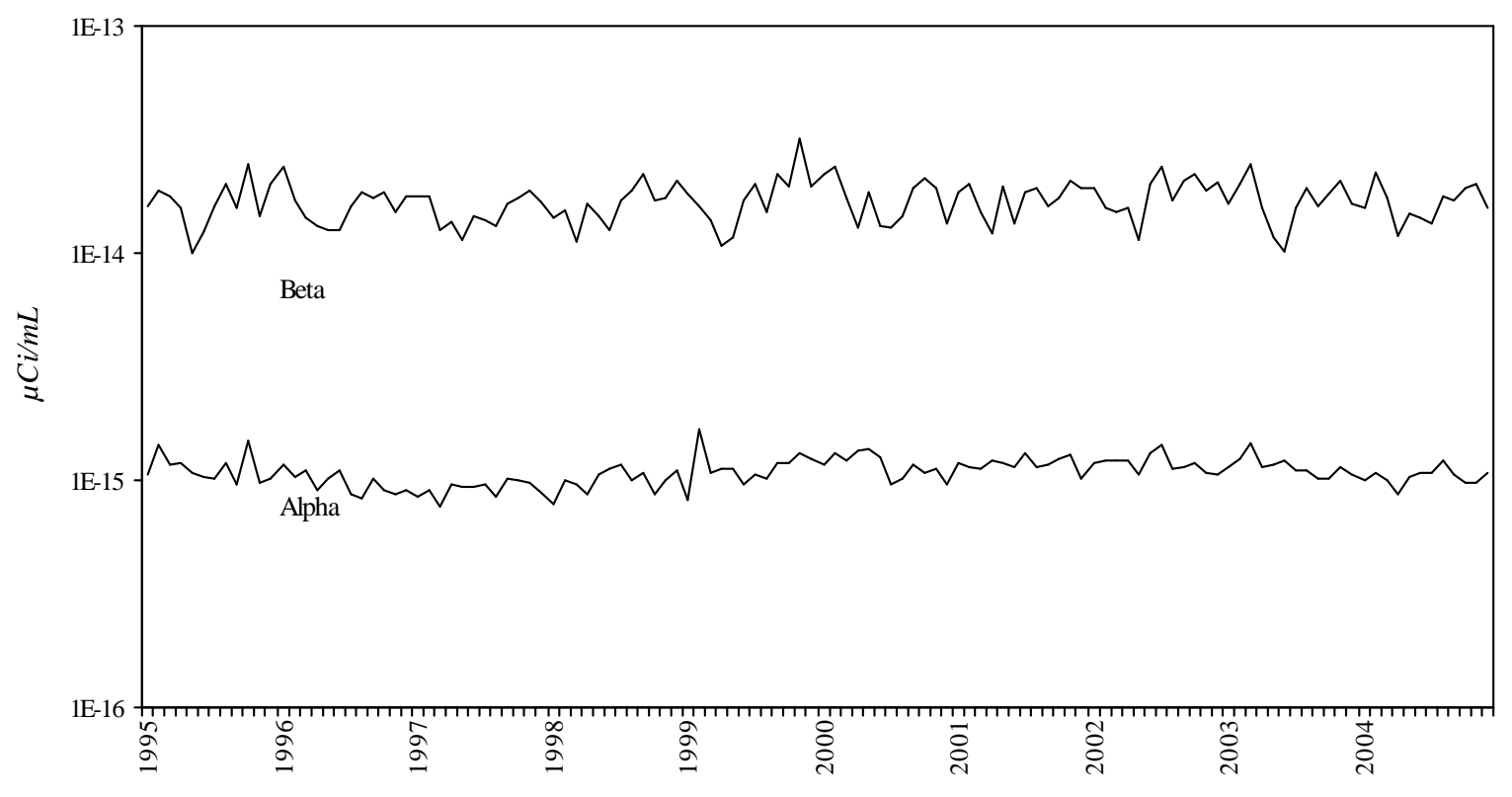

Figure 2-4. Ten-Year Trends of Gross Alpha and Gross Beta Concentrations at Rock Springs Road (AFRSPRD) 


\section{Atmospheric Deposition and Soil Monitoring}

Fallout Pots. Fallout samples are analyzed to monitor short-term deposition of radionuclides at four of the perimeter air sampler locations and at one on-site location near the rain gauge outside of the Environmental Laboratory (Figs. A-4 and A5 ). The data from precipitation analyses are presented in Appendix $D^{\text {Go }}$. The low levels of radioactivity released in main stack emissions did not measurably affect on-site or perimeter fallout pot samples in 2004.

Off-Site Surface Soil. Surface soil near the offsite air samplers is collected to assess long-term deposition of radionuclides. Maps of the off-site surface soil sampling locations are on Figures A-3, A-12, and A-13.

The measured concentrations of most site-related radionuclides in soils from the perimeter and community locations (Appendix G-2 ${ }^{\text {G马 }}$ ) were statistically indistinguishable from regional background concentrations. Elevated gross beta concentrations were noted at Thomas Corners, consistent with historical data from this soil sampling location.

\section{Overview of Food Chain Monitoring}

Each year food samples are collected from locations near the site (Fig. A-9) and from remote locations (Figs. A-12 and A-13). Fish and deer are collected during periods when they would normally be taken by sportsmen for consumption. Corn, apples, and beans are collected annually at the time of harvest. (See Measurement of Radionuclide Concentrations in Food, later in this chapter, for a discussion of estimating doses from foodstuffs.) Results are listed in Appendix $F^{\text {Co. }}$.
Fish. Fish are obtained under a collector's permit by electrofishing, a method that temporarily stuns the fish, allowing them to be netted for collection. Electrofishing allows more efficient species-selective control than sport fishing, with unwanted fish being returned to the creek essentially unharmed.

Fish were collected from three locations in Cattaraugus Creek in 2004: ten fish were collected at each of two locations downstream of WNYNSC drainage - one above the Springville dam (BFFCATC) and one below the Springville dam (BFFCATD). Ten more fish were collected upstream of the site (BFFCTRL). The fish taken below the dam (BFFCATD) included species that migrate about 40 miles (more than $60 \mathrm{~km}$ ) upstream from Lake Erie.

Strontium-90 results from fish downstream of the site (BFFCATC) were elevated in comparison with the background results (BFFCTRL). No other results were statistically higher than background. All results were within the range of historical values.

Venison. Radionuclide data for venison samples were taken from vehicle-deer accidents around the WNYNSC and from deer collected far from the site in the towns of Farmersville, Allegany, and Machias, New York.

Although the cesium-137 results for one near-site deer was elevated with respect to background, the result was consistent with historical results. The remainder of the data from 2004 show no statistical differences between concentrations of radionuclides in near-site and control samples.

From 1994 through 2004 (except 2001), during the big-game hunting season, hunters were allowed access to designated areas within the WNYNSC, excluding the WVDP premises, in a controlled hunting program established by NYSERDA. (The hunt 
was canceled in 2001 because of heightened security concerns.) Data from previous hunts have shown that concentrations of radioactivity in deer flesh have been very low, indicating that Project activities have little or no effect on the local herd.

Beef. No significant differences were found between results from near-site and background samples.

Milk. Near-site sample results were indistinguishable from background control sample results.

Vegetables and Fruit. WVDP-related nuclides in results from sweet corn, beans, and apples collected at harvest time were statistically the same as measurements from background samples.

\section{Direct Environmental Radiation Monitoring}

Monitoring points are located on site at the waste management units, at the site security fence, around the WNYNSC perimeter and the access road, and at a background location remote from the WVDP (Figs. A-10 through A-13). The identification numbers associated with each location were assigned in chronological order of original installation.

Quarterly and annual averages of thermoluminescent dosimeter (TLD) measurements at off-site and on-site locations are noted in Appendix $\mathrm{H}^{\text {(0) }}$. The results of measurements in 2004 show typical seasonal variations and are similar to results from previous years.

On-Site Radiation Monitoring. As in past years, the on-site monitoring point with the highest dose readings was location \#24. Sealed containers of radioactive components and debris from the plant decontamination work are stored nearby.
The average exposure rate at location \#24 was about 475 milliroentgens $(\mathrm{mR})$ per quarter $(216$ microroentgen per hour $[\mu \mathrm{R} / \mathrm{hr}])$ during 2004, slightly lower than the exposure rate in 2003 (231 $\mu \mathrm{R} / \mathrm{hr}$ ). Exposure rates at this location have been generally decreasing over time because the radioactivity in the materials stored nearby is decaying.

The on-site monitoring point with the second highest dose readings (location \#40) was near the waste tank farm. The average exposure rate at location \#40 in 2004 was about $112 \mathrm{mR} /$ quarter ( $51 \mu \mathrm{R} / \mathrm{hr}$ ), the same as in 2003. As expected, results from TLDs located near on-site facilities are generally higher than background results, however, these TLD locations are well within the WNYNSC boundary and are not accessible by the public.

In 2004, increases in exposure rates near the drum cell and at another location near the main plant (DNTLD38) were thought to be attributable to the movement past and storage of sodium-bearing radioactive waste containers near these monitoring points. Even though increases were noted at these two locations, no comparable exposure increases were noted at TLDs on the site perimeter.

Perimeter and Off-Site Radiation Monitoring. The perimeter TLDs (TLDs \#1-16 and \#20) are distributed in the 16 compass sectors around the facility near the WNYNSC boundary. Results from the perimeter and community TLDs were statistically the same as results from the background TLD. The perimeter TLD quarterly averages shown on Figure 2-5 indicate seasonal fluctuations but no long-term trends. The quarterly average of the 17 WNYNSC perimeter TLDs was $16.1 \mathrm{mR}$ per quarter $(7.4 \mu \mathrm{R} / \mathrm{hr})$ in 2004 , slightly lower than in 2003. 
Confirmation of Results. Performance of the environmental TLDs is confirmed periodically using a portable high-pressure ion chamber (HPIC) detection system. The TLD results include the entire third quarter of 2004; the HPIC results were collected over a period of less than 30 minutes.

Since these measurements are made with different systems and over differing periods of time, they are not directly comparable. The average relative percent difference between the two sets of measurements was about $28 \%$, indicating general agreement between these two different measurement methods. (Guidance in American National Standards Institute N545-1975, the standard for environmental dosimetry, uses measurement agreement within $30 \%$ total uncertainty as a performance specification for TLD measurements.)

\section{Meteorological Monitoring}

Meteorological monitoring at the WVDP provides representative and verifiable data that characterize the local and regional climatology. These data are used primarily to assess potential effects of routine and nonroutine releases of airborne radioactive materials and to develop dispersion models used to calculate the effective dose equivalent to off-site residents. Since dispersive capabilities of the atmosphere are dependent upon wind speed, wind direction, and atmospheric stability (which includes a function of the difference in temperature between two elevations), these parameters are closely monitored and are available to the emergency response organization at the WVDP. The on-site 197-ft $(60-\mathrm{m})$ meteorological tower (Fig. A-1) continuously monitors wind speed, wind direction, and temperature at both the 197-ft (60$\mathrm{m})$ and 33-ft (10-m) elevations. In addition, an independent, remote 33-ft (10-m) meteorological station, located approximately 5 miles $(8 \mathrm{~km})$ south of the site on a hillcrest on Dutch Hill Road (Fig.

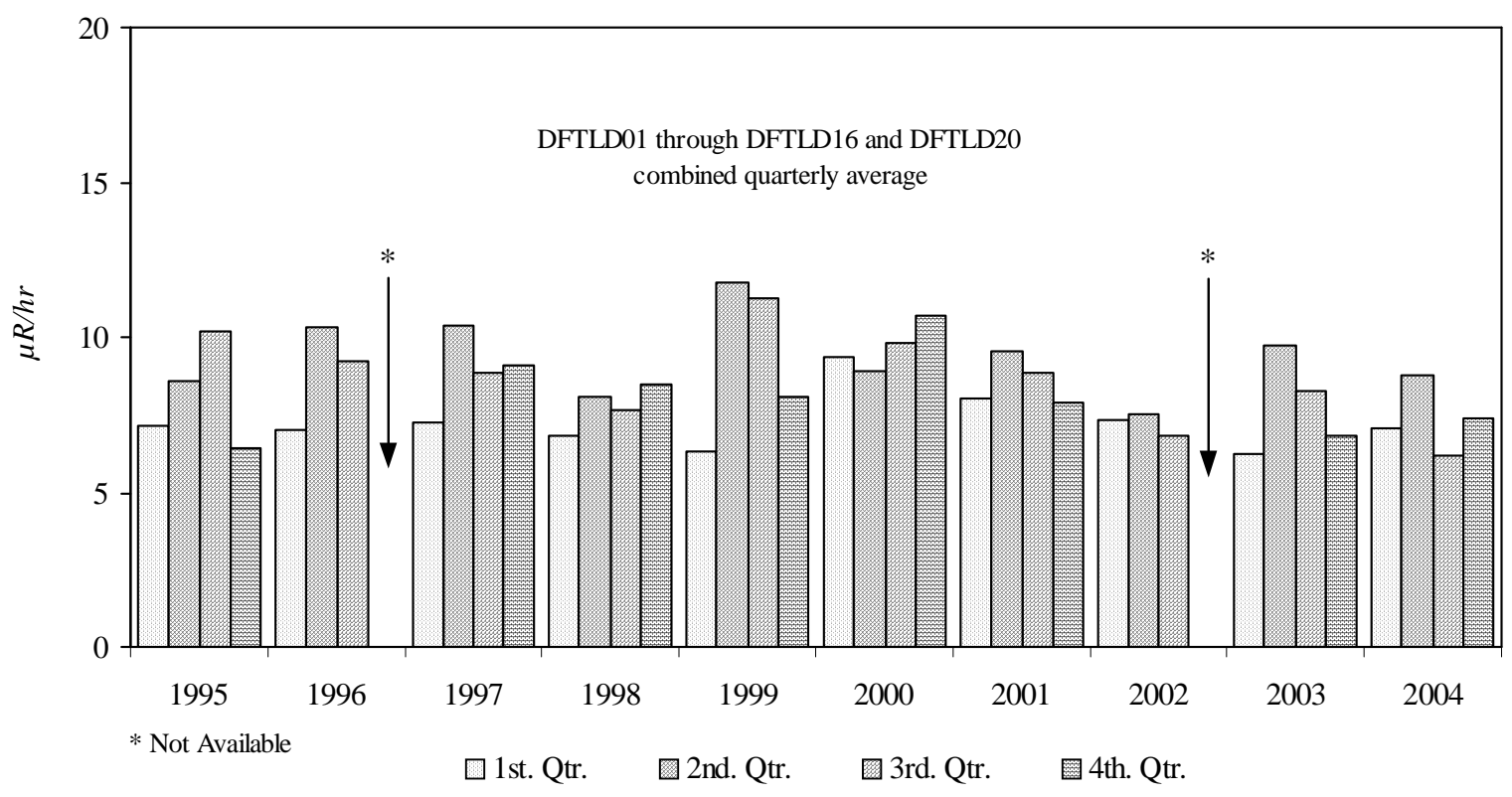

Figure 2-5. Ten-Year Trends of Environmental Radiation Levels at Perimeter TLDs 
A-12), continuously monitors wind speed and wind direction. Dewpoint, precipitation, and barometric pressure are also monitored on site.

The two meteorological locations supply data to the primary digital and analog data acquisition systems located within the Environmental Laboratory. On-site systems are provided with either uninterruptible or standby power backup in case of site power failures. In 2004, the on-site system data recovery rate (the time valid data were logged versus the total elapsed time) was approximately 93.1\%. Regional data at the 33-ft (10-m) elevation and mean wind speed and wind direction at the 33-ft and 197-ft (10-m and 60-m) elevations at the on-site tower during 2004 are shown in Appendix $I^{\text {GD }}$.

Weekly and cumulative total precipitation data are presented in Appendix I ${ }^{\text {GD }}$. Precipitation in 2004 was approximately 43.2 inches $(110 \mathrm{~cm})$, about $5 \%$ more than the long-term annual average (41.0 inches [104 cm]).

Documentation, such as meteorological system calibration records, site log books, and analog strip charts, is stored in protected archives. Meteorological towers and instruments are examined three times per week for proper function and are calibrated semiannually and/or whenever instrument maintenance might affect calibration.

\section{Special Monitoring}

Special monitoring comprises sampling and analyses not covered by the routine environmental monitoring program but that address items of environmental interest. Special monitoring programs are used to verify and/or track these items. Some special environmental monitoring was carried out in 2004 associated with a breach of the laundry waste water line (see "RCRA 3008[h] Administrative Order on Consent" and "Process
Sewer Integrity Evaluation" in the Environmental Compliance Summary) and with rehabilitation of the railroad spur (see "Soil and Sediment Monitoring" in Chapter 3). 


\section{Radiological Effluents and Dose}

\section{Dose Assessment Methodology}

The potential radiation dose to the general public from activities at the WVDP is evaluated by using a two-part methodology applied in a manner consistent with the requirements of DOE Order 5400.5. The first part uses the measurements of radionuclide concentrations in liquid and air released from the Project to determine annual total effect. The second part uses measurements of radioactivity in food from locations near the Project boundaries to evaluate the impact of the annual total release.

Radiological dose is evaluated for all major exposure pathways, including external irradiation, inhalation, and ingestion of local food products. The dose contributions from each radionuclide and pathway combination are then combined to obtain the total dose estimates reported in Table 2-3.

\section{Measurement of Radionuclide Concentra- tions in Liquid and Air Releases. Because it is difficult to distinguish the health effects of the small amount of radioactivity originating from the Project and naturally occurring radiation in the environ- ment, computer codes are used to model the envi- ronmental dispersion of radionuclides that originate from on-site monitored ventilation stacks and liq- uid discharge points.}

Actual data from release-monitoring samples are collected, together with annual weather measurements and the most recent demographic information. (See Appendices C, D, and $\mathrm{I}^{\mathrm{GD}}$.) The effective dose equivalent (EDE) to the maximally exposed off-site individual (MEOSI) and the collective EDE to the population within a 50 -mile $(80-\mathrm{km})$ radius are then calculated using conservative models that have been approved by the DOE and the EPA to demonstrate compliance with radiation standards. (See the inset on Radiation Dose and Units of Dose Measurement.)

Measurement of Radionuclide Concentrations in Food. The second part of the dose assessment is based on actual measurements of radioactivity in samples of foodstuffs grown in the vicinity of the WVDP and the comparison of these values with measurements of samples collected from locations well beyond the potential influence of site effluents.

If any of the near-site food samples contain radionuclide concentrations that are statistically higher than the concentrations in control samples, separate dose calculations are performed to verify that the calculated foodstuff dose is within the dose range estimated by computer modeling. (See Calculated Dose From Local Foodstuff Tests, later in this chapter.)

These estimates show that the concentrations of radioactivity, whether from sites near the WVDP or from distant locations, are small - usually near the analytical detection limits - thereby providing additional assurance that operations at the WVDP are not adversely affecting the public.

These calculated doses are used as an independent confirmation of (not added to) the computermodeled estimates (Table 2-3) because the models already include contributions from all environmental pathways. 


\section{Radiation Dose}

The energy released from a radionuclide is eventually deposited in matter encountered along the path of the radiation. The radiation energy absorbed by a unit mass of material is referred to as the absorbed dose. The absorbing material can be either inanimate matter or living tissue.

Alpha particles leave a dense track of ionization as they travel through tissue and thus deliver the most dose per unit path-length. However, alpha particles are not penetrating and must be taken into the body by inhalation or ingestion to cause harm. Beta and gamma radiation can penetrate the protective dead skin layer of the body from the outside, resulting in exposure of the internal organs to radiation.

Because beta and gamma radiations deposit much less energy in tissue per unit path-length relative to alpha radiation, they produce fewer biological effects for the same absorbed dose. To allow for the different biological effects of different kinds of radiation, the absorbed dose is multiplied by a quality factor to yield a unit called the dose equivalent. A radiation dose expressed as a dose equivalent, rather than as an absorbed dose, permits the risks from different types of radiation exposure to be compared with each other (e.g., exposure to alpha radiation compared with exposure to gamma radiation). For this reason, regulatory agencies limit the dose to individuals in terms of total dose equivalent.

\section{Units of Dose Measurement}

The unit for dose equivalent in common use in the U.S. is the rem, which stands for roentgen equivalent man. The international unit of dose equivalent is the sievert (Sv), which is equal to 100 rem. The millirem (mrem) and millisievert $(\mathrm{mSv})$, used more frequently to report the low dose equivalents encountered in environmental exposures, are equal to one-thousandth of a rem or sievert, respectively. Other radioactivity unit conversions are found on p. UOM-2 at the back of this report.

The effective dose equivalent (EDE), also expressed in units of rem or sievert, provides a means of combining unequal organ and tissue doses into a single "effective" whole body dose that represents a comparable risk probability. The probability that a given dose will result in the induction of a fatal cancer is referred to as the risk associated with that dose. The EDE is calculated by multiplying the organ dose equivalent by the organ-weighting factors developed by the International Commission on Radiological Protection (ICRP) in Publications 26 (1977) and 30 (1979). The weighting factor is a ratio of the risk from a specific organ or tissue dose to the total risk resulting from an equal whole body dose. All organ-weighted dose equivalents are then summed to obtain the EDE.

The dose from internally deposited radionuclides calculated for a fifty-year period following intake is called the fifty-year committed effective dose equivalent (CEDE). The CEDE sums the dose to an individual over fifty years to account for the biological retention of radionuclides in the body. The total EDE for one year of exposure to radioactivity is calculated by adding the CEDE to the dose equivalent from external, penetrating radiation received during the year. Unless otherwise specified, all doses discussed here are total EDE values, which include the CEDE for internal emitters.

A collective population dose is expressed in units of person-rem or person-sievert because the individual doses are summed over the entire potentially exposed population. The average individual dose can therefore be estimated by dividing the collective dose by the population.

$2-20$ 


\section{Predicted Dose From Airborne Emissions}

Airborne emissions of radionuclides are regulated by the EPA under the Clean Air Act and its implementing regulations. DOE facilities are subject to 40 Code of Federal Regulations (CFR) 61, Subpart H, NESHAP. Subpart H contains the national emission standards for emissions of radionuclides other than radon from DOE facilities. The applicable standard for radionuclides is a maximum of 10 mrem $(0.1 \mathrm{mSv})$ effective dose equivalent to any member of the public in any year.

Releases of airborne radioactive materials in 2004 from nominal ground-level stacks ( 1 to 24 meters high) and from the main 60-meter-high stack were modeled using the EPA-approved CAP88-PC computer code (Parks, June 1997). This air dispersion code estimates effective dose equivalents for the ingestion, inhalation, air immersion, and ground surface pathways.

Site-specific data for CY 2004 non-radon radionuclide releases in curies per year are listed in Appendix $D^{\text {GD }}$. Applicable information from these tables was used as input to the CAP88-PC code, as were wind data collected from the on-site meteorological tower during 2004 and current local population distribution information.

Resulting output from the CAP88-PC code was then used to determine the total EDE from air emissions to a maximally exposed individual and the collective dose to the population within a 50mile $(80-\mathrm{km})$ radius of the WVDP.

Maximum Dose to an Off-Site Individual. Based on the non-radon airborne radioactivity released from all sources at the site during 2004 (i.e., permitted stacks, stacks that do not require permits, and non-point sources), it was estimated that a person living in the vicinity of the WVDP could have received a total $\mathrm{EDE}$ of $0.0015 \mathrm{mrem}$ $(0.000015 \mathrm{mSv})$ from airborne releases. The computer model estimated that this MEOSI was located 1.2 miles $(1.9 \mathrm{~km})$ north-northwest of the site and was assumed to eat only locally-produced foods. More than $50 \%$ of the dose from main plant stack emissions was from iodine-129.

The maximum total EDE of 0.00078 mrem $(0.0000078 \mathrm{mSv})$ from the permitted stacks and vents is far below levels that could be directly measured at the exposed individual's residence. This dose is comparable to about one and one-half minutes of natural background radiation received by an average member of the U.S. population and is well below the $10 \mathrm{mrem}(0.1 \mathrm{mSv})$ NESHAP limit promulgated by the EPA and mandated by DOE Order 5400.5.

Collective Population Dose. The CAP88-PC program was used to estimate the collective EDE to the population. Based upon the latest U.S. census population data collected in CY 2000, 1.54 million people were estimated to reside within 50 miles $(80 \mathrm{~km})$ of the WVDP. This population received an estimated 0.012 person-rem $(0.00012$ person$\mathrm{Sv}$ ) total EDE from radioactive non-radon airborne effluents released from WVDP point and diffuse sources during 2004. (See the discussion of radon-220 later in this chapter.) The resulting average EDE per individual was 0.000008 mrem $(0.00000008 \mathrm{mSv})$.

Iodine Emissions From the Main Stack. In the ten-year period before the startup of vitrification, iodine-129, a long-lived radionuclide, was found in main stack emissions at levels of approximately 0.007 to $0.057 \mathrm{mCi} /$ year. In 1996, when vitrification operations began, $1.20 \mathrm{mCi}$ of iodine129 were released and in 1997, the first full year of vitrification, a maximum release of $7.4 \mathrm{mCi}$ was observed. The increase occurred because gaseous iodine was not as efficiently removed by the vitri- 


\section{Table 2-3}

\section{Summary of Annual Effective Dose Equivalents to an Individual and Population From WVDP Releases in 2004}

Exposure Pathways

\begin{tabular}{|c|c|c|}
\hline \multirow[t]{2}{*}{ Exposure Pathways } & \multicolumn{2}{|c|}{ Annual Effective Dose Equivalent } \\
\hline & $\begin{array}{l}\text { Maximally Exposed } \\
\text { Off-Site Individual } \\
\text { mrem }(\mathrm{mSv})\end{array}$ & $\begin{array}{l}\text { Collective Effective } \\
\text { Dose Equivalent }{ }^{2} \\
\text { person-rem (person-Sv) }\end{array}$ \\
\hline Airborne Releases ${ }^{3}$ & $1.5 \mathrm{E}-03(1.5 \mathrm{E}-05)$ & $1.2 \mathrm{E}-02(1.2 \mathrm{E}-04)$ \\
\hline$\%$ EPA standard (10 mrem) & $0.02 \%$ & NA \\
\hline \multicolumn{3}{|l|}{ Waterborne Releases ${ }^{4}$} \\
\hline Effluents only & $1.6 \mathrm{E}-02(1.6 \mathrm{E}-04)$ & $1.5 \mathrm{E}-02(1.5 \mathrm{E}-04)$ \\
\hline Effluents plus north plateau drainage & 4.7E-02 (4.7E-04) & $1.9 \mathrm{E}-01(1.9 \mathrm{E}-03)$ \\
\hline Total from all Pathways & $4.9 \mathrm{E}-02(4.9 \mathrm{E}-04)$ & $2.0 \mathrm{E}-01(2.0 \mathrm{E}-03)$ \\
\hline $\begin{array}{l}\% \text { DOE standard (100 mrem) - } \\
\text { air and water combined }\end{array}$ & $0.05 \%$ & NA \\
\hline $\begin{array}{l}\% \text { of natural background } \\
(295 \text { mrem; 453,000 person-rem) - } \\
\text { received from air and water combined }\end{array}$ & $0.02 \%$ & $0.00005 \%$ \\
\hline Estimated Airborne Radon- $220^{5}$ & $1.2 \mathrm{E}-02(1.2 \mathrm{E}-04)^{6}$ & 3.4E-01 (3.4E-03) \\
\hline
\end{tabular}

NA - Not applicable. Numerical regulatory standards are not set for the collective EDE to the population.

1 The maximum exposure to air discharges is estimated to occur at a residence 1.9 kilometers north-northwest of the main plant building.

2 A population of 1.54 million is estimated to reside within 80 kilometers of the site.

3 Releases are from atmospheric non-radon point and diffuse sources. Calculations use CAP88-PC to estimate individual and population doses. EPA and DOE limits for individual airborne dose are the same.

4 Estimates are calculated using the methodology described in the WVDP Manual for Radiological Assessment of Environmental Releases at the WVDP (WVNSCO, 2003).

5 Estimated airborne releases are based on indicator measurements and process knowledge. Dose estimates are calculated using CAP88-PC.

${ }^{6}$ The estimated dose from radon-220 is specifically excluded by rule from NESHAP totals. 


\section{Radon-220}

Radon-220 is a naturally occurring gaseous decay product of thorium-232 present in the airborne emissions from the WVDP main plant. Radon-220, also known as thoron, is associated with the thorium reduction extraction (THOREX)-related thorium-232 and uranium-232 in the high-level waste.

As reported in Chapter 2 of the 1996 WVDP Site Environmental Report (WVNSCO and Dames \& Moore, June 1997), thoron levels were observed to increase during startup of the 1996 high-level waste vitrification process. An estimate of the thoron released during each waste concentration cycle was developed and used to determine a theoretical annual release. During the vitrification phase, an average of about 12 curies per day were released. In 2004, with the vitrification process completed, the average was about three curies of thoron released per day.

Although large numbers of curies were released relative to other radionuclides, the calculated dose from thoron is quite small because of its short decay half-life and other characteristics. The NESHAP rule specifically excludes thoron from air emission dose calculations, so a dose estimate using CAP88-PC was calculated separately. The theoretical dose to the MEOSI located 1.2 miles $(1.9 \mathrm{~km})$ north-northwest of the site in 2004 would have been 0.012 mrem, and the collective dose to the population within an 80-kilometer radius would have been 0.34 person-rem. (See Table 2-3.) These theoretical doses are within the same range as doses from the man-made radionuclides found in WVDP effluents.

With vitrification completed, thoron releases have decreased to pre-vitrification levels. The figure presented here provides a relative indication of recent trends in the estimated annual thoron releases.

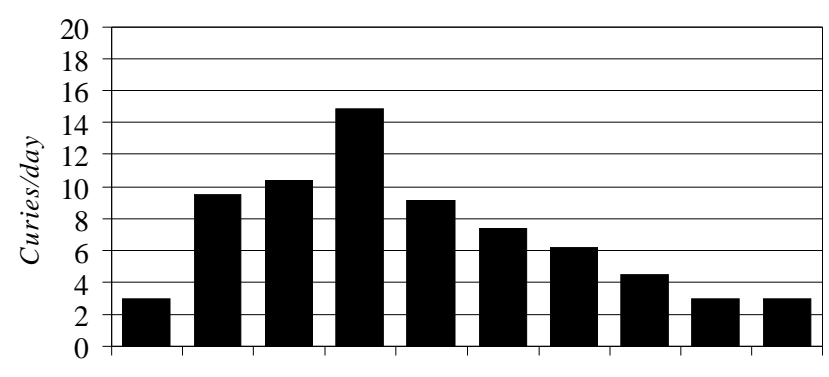

1995199619971998199920002001200220032004

Estimated Radon-220 Releases From the WVDP fication process off-gas treatment system as were most other radionuclides. As more high-level radioactive waste was vitrified, iodine-129 levels decreased and in 2003, the first full year since vitrification was completed, the total annual release had dropped to $0.065 \mathrm{mCi}$. In 2004, the total annual release decreased even further to 0.028 $\mathrm{mCi}$. Even so, in 2004, iodine-129 continued to account for the largest proportion of dose to an off-site individual from main stack airborne emissions.

\section{Predicted Dose From Waterborne Releases}

Currently there are no EPA standards establishing limits on the radiation dose to members of the public from liquid effluents except as applied in 40 CFR 141 and 40 CFR 143, Drinking Water Guidelines (EPA, 1984a; 1984b). Corollary limits for community water supplies are set by NYSDOH in the New York State Sanitary Code (Title 10 of the Official Compilation of Codes, Rules, and Regulations of the State of New York [NYCRR] 5- 
1.52). The private residential potable water wells sampled for radionuclides are upgradient of the WVDP and therefore do not represent a potential source of exposure to radiation from routine Project activities.

Since Cattaraugus Creek is not used as a drinking water supply, a comparison of the predicted concentrations and doses with the 4-mrem/year (0.04mSv/year) EPA and NYSDOH drinking water limits established in 40 CFR 141 and 40 CFR 143, and in 10 NYCRR §5-1.52, respectively, is not truly appropriate (although the values in creek samples are well below the EPAdrinking water limits). The estimated radiation dose was compared to the applicable guidelines provided in DOE Order 5400.5. The EDE to the MEOSI and the collective EDE to the population due to routine waterborne releases and natural drainage are calculated using dose conversion factors as tabulated in the "WVDP Manual for Radiological Assessment of Environmental Releases at the WVDP" (WVNSCO, 2003).

Since the Project's liquid effluents eventually reach Cattaraugus Creek, the most important individual exposure pathway is the consumption of fish from this creek by local sportsmen. It is conservatively assumed that a person may consume annually as much as 46 pounds $(21 \mathrm{~kg}$ ) of fish caught in the creek. Exposure to external radiation from shoreline or water contamination is also included in the model for estimating radiation dose. Population dose estimates assume that radionuclides are further diluted in Lake Erie before reaching municipaldrinking water supplies.

The computer codes GENII version 1.485 (Pacific Northwest Laboratory, 1988), which implements the models in NRC Regulatory Guide 1.109 (NRC, 1977), and LADTAPII (Simpson and McGill, 1980) were used to calculate site-specific unit dose factors for routine waterborne releases and dispersion of these effluents. Input data included local stream flow and dilution, drinking water usage, and stream usage factors. (See "WVDP Manual for Radiological Assessment of Environmental Releases at the WVDP" [WVNSCO, 2003] for a detailed description of the GENII code.)

Eight batches of liquid effluents were released from lagoon 3 (point WNSP001) during 2004. Measurements of the radioactivity discharged in these effluents, listed in Appendix C- $2^{\text {GD }}$, were combined with the unit dose factors to calculate the EDE to the MEOSI and the collective EDE to the population living within a 50-mile $(80-\mathrm{km})$ radius of the WVDP.

In addition to measurements from WNSP001, radioactivity measurements from sewage treatment facility effluents (WNSP007) were included in the EDE calculations. Results from the sewage treatment facility are also presented in Appendix C$2^{\text {con }}$. (The french drain at WNSP008, a third release point, has been sealed off since 2001 and was not included in this evaluation.)

Besides the two release points at WNSP001 and WNSP007, waters from two natural drainage channels originating on the Project premises contain measurable concentrations of radioactivity: the northeast swamp (WNSWAMP) and north swamp (WNSW74A). (See Northeast Swamp and North Swamp Drainage discussed earlier in this chapter.) The measured radioactivity from these points is reported in Appendix C- $3^{\mathbf{c 0}}$. These results are included in the EDE calculations for the MEOSI and the collective population.

There were no unplanned releases of waterborne activity to the off-site environment in 2004. (See "RCRA3008(h) Administrative Order on Consent" and "Process Sewer Integrity Evaluation" in the Environmental Compliance Summary.) 
Maximum Dose to an Off-Site Individual. Based on the radioactivity in liquid effluents discharged from the WVDP (lagoon 3 and the sewage treatment plant) during 2004, an off-site individual could have received a maximum EDE of $0.016 \mathrm{mrem}(0.00016 \mathrm{mSv})$. About $90 \%$ of this dose was from cesium-137. The maximum offsite individual EDE due to drainage from the north plateau (north swamp and northeast swamp) was $0.031 \mathrm{mrem}(0.00031 \mathrm{mSv})$.

The combined EDE to the maximally exposed individual from liquid effluents and drainage was 0.047 mrem $(0.00047 \mathrm{mSv})$. This annual dose is very small in comparison to the $295 \mathrm{mrem}(2.95 \mathrm{mSv})$ dose that is received by an average member of the U.S. population from natural background radiation.

Collective Dose to the Population. As a result of radioactivity released in liquid effluents from the WVDP (primarily from lagoon 3) during 2004, the population living within 50 miles $(80 \mathrm{~km})$ of the site received a collective EDE of 0.015 person-rem $(0.00015$ person-Sv). The collective dose to the population from the effluents plus the north plateau drainage was 0.19 person-rem $(0.0019$
person-Sv). The resulting average EDE from effluent releases and north plateau drainage (north swamp and northeast swamp) per individual is $0.00013 \mathrm{mrem}(0.0000013 \mathrm{mSv})$. This dose is an inconsequential addition to the dose that an average person receives in one year from natural background radiation.

\section{Calculated Dose From Local Foodstuff Tests}

As noted in the discussion of food chain monitoring earlier in this chapter, most radionuclide concentrations in near-site food samples were statistically indistinguishable from concentrations in background samples. Strontium-90 concentrations higher than background were noted in fish taken in Cattaraugus Creek downstream of the WVDP (BFFCATC) and cesium-137 higher than background was noted in one near-site deer. Even so, conservative estimates of dose due to consuming near-site fish, deer, beef, milk, beans, corn, and apples were all less than $0.2 \mathrm{mrem} /$ year. These independent estimates confirm the modeled dose estimates based on air and water effluent sampling results as summarized in Table 2-3.

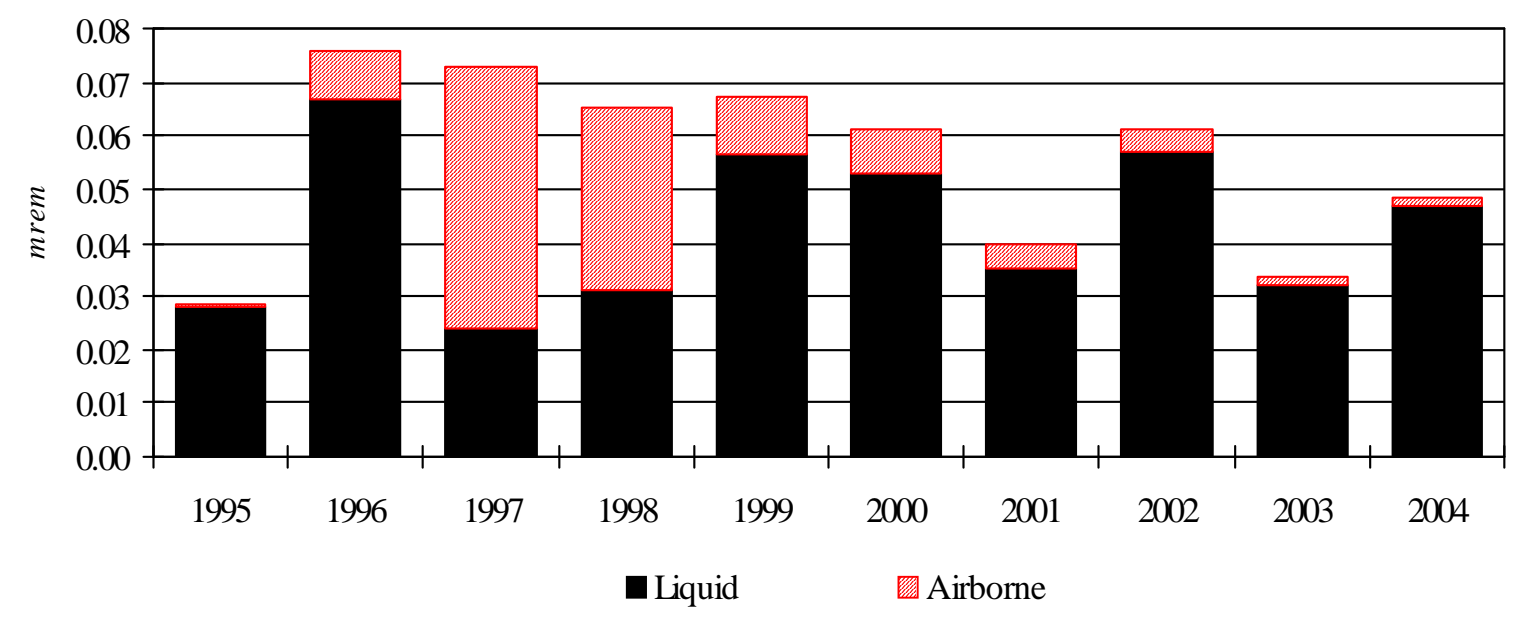

Figure 2-6. Effective Dose Equivalent From Liquid and Airborne Effluents to a Maximally Exposed Individual Residing Near the WVDP 


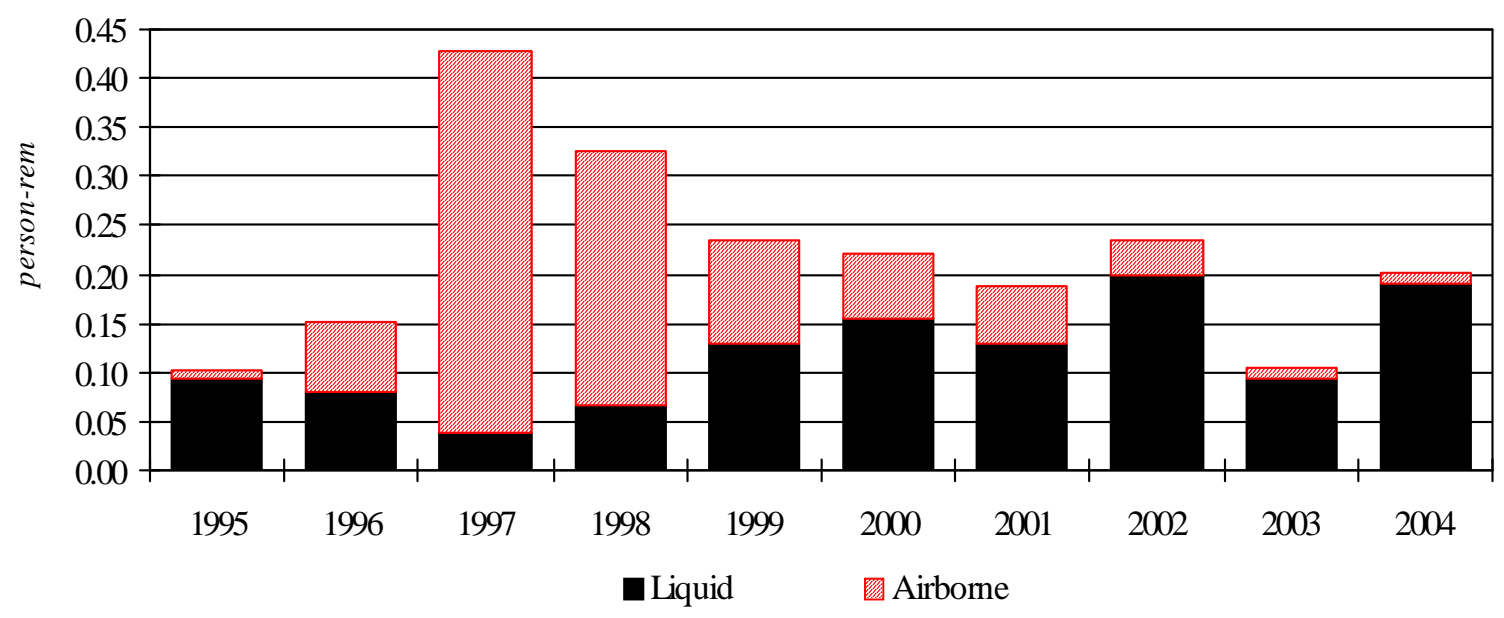

Figure 2-7. Collective Effective Dose Equivalent From Liquid and Airborne Effluents to the Population Residing Within 50 Miles $(80 \mathrm{~km})$ of the WVDP

\section{Predicted Dose From All Pathways}

The potential dose to the public from both airborne and liquid effluents released from the Project during 2004 is the sum of the individual dose contributions. The calculated maximum EDE from all pathways to a nearby resident was 0.049 mrem $(0.00049 \mathrm{mSv})$. This dose is $0.05 \%$ of the 100 mrem (1-mSv) annual limit in DOE Order 5400.5. The estimated dose from radon-220 to the same nearby resident was about $0.01 \mathrm{mrem}$.

The total collective EDE to the population within 50 miles $(80 \mathrm{~km})$ of the site was 0.20 person-rem $(0.0020$ person-Sv), with an average EDE of $0.0001 \mathrm{mrem}(0.000001 \mathrm{mSv})$ per individual. The estimated radon-220 dose to the population was approximately 0.3 person-rem.

Table 2-3 summarizes the dose contributions from all pathways and compares the individual doses with the applicable standards. The low doses calculated using computer modeling were corrobo- rated by the low or non-detectable doses calculated from local foodstuff test data.

Figure 2-6 shows the calculated annual dose to the hypothetical maximally exposed individual over the last ten years. The estimated dose for 2004 ( $0.05 \mathrm{mrem})$ is higher than the annual dose reported for 2003 (0.03 mrem). The decrease in dose fraction from air emissions in 2003 is attributed to the continuing decrease in iodine-129 emissions. Liquid doses, however, were slightly higher in 2004 than in 2003 ( 0.047 versus $0.032 \mathrm{mrem}$, respectively).

Figure 2-7 shows the collective dose to the population over the last ten years. (See Fig. A-14 for a map of the population sectors.) The overall radioactivity represented by these data confirms the continued inconsequential addition to the natural background radiation dose that individuals and population around the WVDP receive from Project activities. 


\section{Risk Assessment}

Estimates of cancer risk from ionizing radiation have been presented by the National Council on Radiation Protection and Measurements (NCRP) (1987b) and the National Research Council's Committee on Biological Effects of Ionizing Radiation (1990).

The NCRP estimates that the probability of fatal cancer occuring is between one and five per 10,000 people who each are exposed to one rem (i.e., a risk coefficient of between 0.0001 and 0.0005 ). DOE guidance has, in the past, recommended using a risk coefficient of 0.0005 (ICRP, 1991) to estimate risk to a MEOSI. Recent DOE guidance recommends using the even more conservative risk coefficient of 0.0006 provided by the Interagency Steering Committee on Radiation Standards (January 2003). The estimated risk to the hypothetical individual residing near the WVDP from airborne and waterborne releases in 2004 was 3 chances in 100 million (a risk coefficient of 0.00000003 ). This risk is well below the range of 0.000001 to 0.00001 per year considered by the ICRP in Report Number 26 (1977) to be a reasonable risk for any individual member of the public.

\section{Dose to Biota: Aquatic and Terrestrial Wildlife}

Radionuclides from both natural and man-made sources may be found in environmental media such as water, sediments, and soils. In the past, it has been assumed that if radiological controls are sufficient to protect humans, other living things are also likely to be sufficiently protected. This assumption is no longer considered adequate, since populations of plants and animals residing in or near these media or taking food or water from these media may be exposed to a greater extent than are humans. For this reason, the DOE prepared a technical standard which provides meth- ods and guidance to be used to evaluate doses of ionizing radiation to populations of aquatic animals, riparian animals (i.e., those that live along banks of streams or rivers), terrestrial plants, and terrestrial animals.

Methods in this technical standard, "A Graded Approach for Evaluating Radiation Doses to Aquatic and Terrestrial Biota" (DOE-STD-11532002, July 2002), were used in 2004 to evaluate radiation doses to aquatic and terrestrial biota within the confines of the WNYNSC, which includes the WVDP. Doses were assessed for compliance with the limit in DOE Order 5400.5 for native aquatic animal organisms (1 rad per day) and for compliance with the thresholds for terrestrial plants (also $1 \mathrm{rad}$ per day) and for terrestrial animals (0.1 rad per day), as proposed in DOESTD-1153-2002. Note that the absorbed dose unit (rad) is used for biota instead of the units used for indicating human risk (rem).

The RESRAD-BIOTA Code, a calculation tool provided by the DOE for implementing the technical standard, was used to compare existing radionuclide concentration data from environmental sampling with biota concentration guide (BCG) screening values and to estimate upper bounding doses to biota. Data collected from surface waters, sediments, and soils on and around the WNYNSC over a ten-year period (1991-2000) were used as a baseline. For a more near-term assessment, a second evaluation was completed using surface water data from 2004, sediment data from the last five years (2000-2004), and soil data from the last ten years (1995-2004). Differing time periods were used because radionuclide concentrations change more rapidly over time in surface waters than in sediments and soils, as reflected in their sampling frequencies (weekly or monthly for water, annually for sediments and soils). Longer time periods were also required for sediments and soils to obtain sufficient data points to produce 
reliable annual averages. (See Appendices A and $\mathrm{B}^{\mathbf{6 0}}$ for maps and descriptions of monitoring and surveillance locations. Radionuclides analyzed for each medium at each location are listed in Appen$\operatorname{dix} B^{\mathrm{GD}}$. See Appendices $C$ and $G^{\mathrm{GD}}$ for a summary of results from these locations in 2004.)

Concentration data for radionuclides in each medium were entered into the RESRAD-BIOTA Code. The value for each radionuclide was automatically divided by its corresponding BCG in order to calculate a partial fraction for each nuclide for each medium. Partial fractions for each medium were added to produce a sum of fractions.

It was found that the isotopes with the highest sums of fractions - the radionuclides that contributed the largest component of both aquatic and terrestrial dose to biota - were strontium-90 and cesium-137. Per guidance in DOE-STD-1153-2002, the populations of organisms most sensitive to strontium-90 and cesium-137 in this evaluation - that is, those populations residing on the WNYNSC that were most likely to be adversely affected via the aquatic and terrestrial pathways - were determined to be populations of the raccoon (aquatic dose) and the deer mouse (terrestrial dose). As such, this study does not pertain to pathways to humans, which were addressed earlier in this chapter.

Exposures from the aquatic pathway may be assumed to be less than the aquatic dose limit from DOE Order 5400.5 if the sum of fractions for the water medium plus that for the sediment medium is less than 1.0. Similarly, exposures from the terrestrial pathway may be assumed to be less than the proposed dose limits for both terrestrial plants and animals if the sum of fractions for the water medium plus that for the soil medium is less than 1.0 .

In accordance with the approach described in DOE-STD-1153-2002, a general screening was first conducted using the maximum radionuclide concentrations from surface waters, sediments, and soils. Maximum radionuclide concentrations exceeded applicable general screening BCG limits for both aquatic and terrestrial evaluations.

As recommended in DOE-STD-1153-2002, a sitespecific screening was then done using estimates of average radionuclide concentrations derived from measurements in surface waters, sediments, and soils. Results are summarized in Table 2-4.

At the site-specific screening level for the full tenyear period, the sums of fractions for the aquatic and terrestrial system evaluations were 0.45 and 0.57 , respectively. The comparable sums of fractions using the more near-term data were 0.17 and 0.31 , respectively. The sum of fractions for each assessment was less than 1.0, indicating that applicable BCGs were met for both the aquatic and terrestrial evaluations.

Upper bounding doses associated with the aquatic system evaluation were $0.0059 \mathrm{rad} /$ day to an aquatic animal and $0.017 \mathrm{rad} /$ day to a riparian animal, far below the $1 \mathrm{rad} /$ day standard from DOE Order 5400.5 for dose to a native aquatic animal. Upper bounding doses associated with the terrestrial system evaluation were 0.031 and $0.0027 \mathrm{rad} /$ day to terrestrial animals and plants, again well below the guidance thresholds ( 0.1 and $1.0 \mathrm{rad} /$ day, respectively).

It was therefore concluded that populations of aquatic and terrestrial biota (both plants and animals) on the WNYNSC are not being exposed to doses in excess of the existing DOE dose standard for native aquatic animals (U.S. DOE, February 1990) and the international standards for terrestrial organisms (InternationalAtomic Energy Agency [IAEA], 1992). 


\section{Summary}

Predictive computer modeling of airborne and waterborne releases resulted in estimated hypothetical doses to the maximally exposed individual that were orders of magnitude below all applicable EPA standards and DOE Orders, which place limitations on the release of radioactive materials and dose to individual members of the public. The collective population dose was also assessed and found to be orders of magnitude below the natural background radiation dose. Additionally, estimates of dose to biota indicated that biota at the WVDP are exposed at a fraction of the DOE and IAEA guidelines for dose to biota.

Based on the overall dose assessment, the WVDP was found to be in compliance with applicable effluent radiological guidelines and standards during calendar year 2004. Table 2-5 provides a summary of WVDP releases and calculated doses in the specified DOE format. 


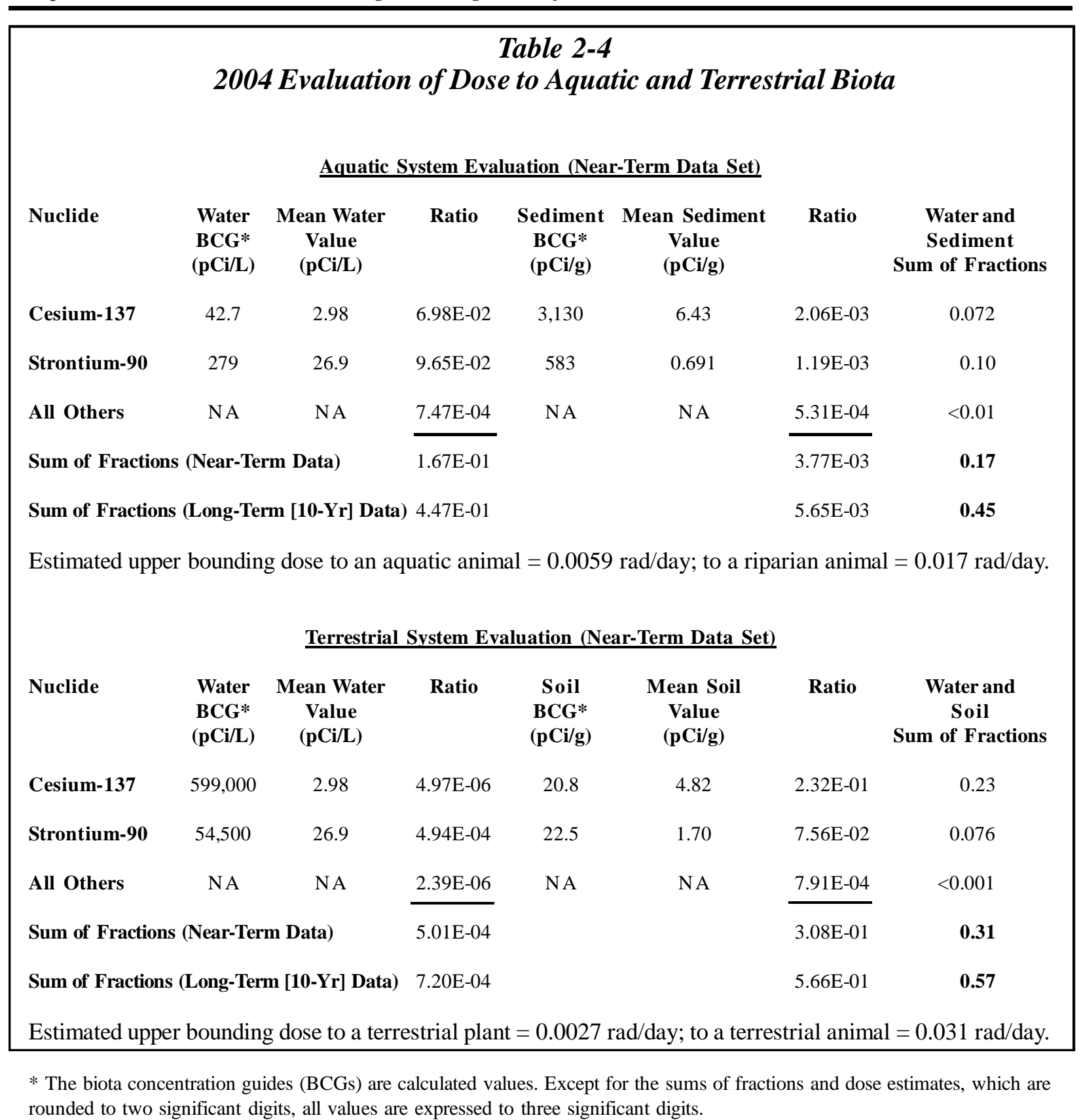

$$
2-30
$$


Table 2-5

WVDP Radiological Dose and Release Summary

WVDP Radiological Dose Reporting Table CY 2004

\begin{tabular}{|c|c|c|c|c|}
\hline $\begin{array}{c}\text { Dose to the } \\
\text { Maximally Exposed } \\
\text { Individual }\end{array}$ & $\begin{array}{c}\text { \% of DOE } \\
\text { 100-mrem Limit }\end{array}$ & $\begin{array}{c}\text { Estimated } \\
\text { Population Dose }\end{array}$ & $\begin{array}{c}\text { Population Within } \\
\text { 50 Miles } \\
\text { (2000 census })\end{array}$ & $\begin{array}{c}\text { Estimated Natural } \\
\text { Radiation Population } \\
\text { Dose }\end{array}$ \\
\hline $\begin{array}{cc}0.049 \\
\mathrm{mrem} \quad(\mathrm{mSv})\end{array}$ & 0.049 & $\begin{array}{c}0.20 \\
\text { person-rem } \\
(\text { person-Sv) }\end{array}$ & $1,536,000$ & $\begin{array}{c}0.0020 \\
\text { person-rem }\end{array}$ \\
\hline
\end{tabular}

\section{WVDP Radiological Atmospheric Emissions ${ }^{\text {a }}$ CY 2004 in Curies (Bq)}

\begin{tabular}{|c|c|c|c|c|c|c|c|c|c|c|}
\hline Tritium & Kr-85 & $\begin{array}{c}\text { Noble Gases } \\
\left(T_{1 / 2}<40 \mathrm{dy}\right)\end{array}$ & $\begin{array}{c}\text { Short-Lived } \\
\text { Fission and } \\
\text { Activation } \\
\text { Products } \\
\left(T_{1 / 2}<3 \mathrm{hr}\right)\end{array}$ & $\begin{array}{c}\text { Fission and } \\
\text { Activation } \\
\text { Products } \\
\left(\mathrm{T}_{1 / 2}>3 \mathrm{hr}\right)\end{array}$ & $\begin{array}{c}\text { Total } \\
\text { Radioiodine }\end{array}$ & $\begin{array}{c}\text { Total } \\
\text { Radiostrontium }\end{array}$ & $\begin{array}{c}\text { Total } \\
\text { Uranium }^{b}\end{array}$ & $\begin{array}{c}\text { Total } \\
\text { Plutonium }\end{array}$ & \begin{tabular}{|c|} 
Total \\
Other \\
Actinides
\end{tabular} & $\begin{array}{c}\text { Other } \\
(\text { Rn-220) }\end{array}$ \\
\hline $\begin{array}{c}5.60 \mathrm{E}-03 \\
(2.07 \mathrm{E}+08)\end{array}$ & NA & NA & NA & $\begin{array}{c}5.50 \mathrm{E}-05 \\
(2.04 \mathrm{E}+06)\end{array}$ & $\begin{array}{c}4.22 \mathrm{E}-05 \\
(1.56 \mathrm{E}+06)\end{array}$ & $\begin{array}{c}3.15 \mathrm{E}-05 \\
(1.17 \mathrm{E}+06)\end{array}$ & $\begin{array}{c}2.07 \mathrm{E}-07 \\
(7.66 \mathrm{E}+03)\end{array}$ & $\begin{array}{c}1.58 \mathrm{E}-06 \\
(5.86 \mathrm{E}+04)\end{array}$ & $\begin{array}{c}2.12 \mathrm{E}-06 \\
(7.84 \mathrm{E}+04)\end{array}$ & $\begin{array}{c}1.10 \mathrm{E}+03 \\
(4.05 \mathrm{E}+13)\end{array}$ \\
\hline
\end{tabular}

WVDP Liquid Effluent Releases ${ }^{\text {a }}$ of Radionuclide Material CY 2004 in Curies (Bq)

\begin{tabular}{|c|c|c|c|c|c|c|}
\hline Tritium & $\begin{array}{c}\text { Fission and } \\
\text { Activation } \\
\text { Products } \\
\left(\mathbf{T}_{1 / 2}>\mathbf{3} \mathbf{~ h r}\right)\end{array}$ & $\begin{array}{c}\text { Total } \\
\text { Radioiodine }\end{array}$ & $\begin{array}{c}\text { Total } \\
\text { Radiostrontium }\end{array}$ & $\begin{array}{c}\text { Total } \\
\text { Uranium }\end{array}$ & $\begin{array}{c}\text { Total } \\
\text { Plutonium }\end{array}$ & $\begin{array}{c}\text { Total } \\
\text { Other } \\
\text { Actinides }\end{array}$ \\
\hline $9.55 \mathrm{E}-02$ & $7.14 \mathrm{E}-03$ & $\begin{array}{c}1.78 \mathrm{E}-04 \\
(6.58 \mathrm{E}+06)\end{array}$ & $\begin{array}{c}2.00 \mathrm{E}-01 \\
(7.39 \mathrm{E}+09)\end{array}$ & $\begin{array}{c}1.07 \mathrm{E}-03 \\
(3.95 \mathrm{E}+07)\end{array}$ & $\begin{array}{c}1.63 \mathrm{E}-05 \\
(6.05 \mathrm{E}+05)\end{array}$ & $\begin{array}{c}2.95 \mathrm{E}-05 \\
(1.09 \mathrm{E}+06)\end{array}$ \\
\hline
\end{tabular}

NA - Not applicable

${ }^{a}$ The WVDP air and water releases are from point source and controlled liquid effluent releases, respectively.

${ }^{\mathrm{b}}$ Total uranium $($ grams $)=2.10 \mathrm{E}-01$

${ }^{\mathrm{c}}$ Total uranium $($ grams $)=7.86 \mathrm{E}+02$

$$
2-31
$$


This page intentionally left blank

$2-32$ 


\section{ENVIRONMENTAL NONRADIOLOGICAL PROGRAM INFORMATION}

Overview of New York State Water Classifications, Water Quality Standards, and Water Effluent Limits

The objective of the Clean Water Act of 1972 (CWA) (as stated in Section 101 of the Act) is to restore and maintain the integrity of the nation's waters and ensure that, wherever attainable, waters be made useful for fishing and swimming. To achieve this goal, New York State is delegated with authority under Sections 118,303 , and 510 of the CWA to (1) classify and designate the best uses for receiving waters, such as streams and rivers, within its jurisdiction; and (2) establish and assign water quality standards - goals for achieving the designated best uses for these classified waters. In addition to achieving CWA goals for fishing and swimming, New York has further classified its jurisdictional waters and established ambient water standards, guidelines, and maximum contaminant levels (MCLs) to achieve objectives under the Safe Drinking Water Act for drinking water. These standards serve as the basis for periodic evaluation of the integrity of the receiving waters and identification of needed controls, such as New York State Pollutant Discharge Elimination System (SPDES) permits and effluent limitations.
The definitions for best usage classifications of New York's jurisdictional waters and the water quality standard goals for these classifications are provided in Title 6 of the Official Compilation of Codes, Rules, and Regulations of the State of New York (NYCRR) Parts 701-704. Mapping of the Cattaraugus Creek drainage basin and assignment of best usage designations and classification to each receiving water segment within this drainage basin are described in 6 NYCRR Part 838. According to these regulations, Frank's Creek, Quarry Creek, and segments of Buttermilk Creek under the influence of West Valley Demonstration Project (WVDP) water effluents are identified as Class " $C$ " receiving waters with a minimum designated best usage for fishing with conditions suitable for fish survival. Cattaraugus Creek, in the immediate downstream vicinity of the Western New York Nuclear Service Center (WNYNSC), is identified as a Class " $\mathrm{B}$ " receiving water with best designated usages for swimming and fishing. All fresh (non-saline) groundwaters within New York are assigned a "GA" classification with a designated best usage as a potable water supply source.

Presented in Appendix C-1 ${ }^{\text {cod }}$ is a summary of the numerical water quality standards, guidelines, and MCLs assigned to these water classifications for those substances and parameters that are included 
in the WVDP environmental monitoring program for ambient water. Also included in Appendix $\mathrm{C}-1^{\text {(6) }}$ are SPDES permit discharge limits for site effluents.

\section{Surface Water, Subsurface Drainage Water, and Water Effluent Monitoring}

Appendix C-2 ${ }^{\mathrm{CD}}$ contains process effluent data with SPDES permit limits provided for comparison with these data. Appendices C-3 through C- $5^{\text {(6) }}$ present data for ambient surface water, subsurface drainage water, contained water, and potable water monitoring locations. Also provided for side-by-side comparison with these data are reference values, where available, including background ambient water monitoring data and/or pertinent ambient water quality standards (AWQS), guidelines, or MCLs.

SPDES Permit-Required Monitoring. Liquid discharges are regulated under the SPDES permit. The WVDP holds a SPDES permit that identifies the outfalls where liquid effluents are released to Erdman Brook (Fig. A-2) and specifies the sampling and analytical requirements for each outfall. In August 2003, the WVDP filed an application with the New York State Department of Environmental Conservation (NYSDEC) for renewal of the SPDES permit. In October 2003, NYSDEC issued a renewed permit, subsequently modified in February 2004, which will expire in 2009. The conditions and requirements of the SPDES permit are summarized in Appendix C-1 ${ }^{\text {co }}$. The permit identifies five outfalls:

- outfall WNSP001, discharge from the low-level waste treatment facility (LLWTF)

- outfall WNSP007, discharge from the sanitary and industrial wastewater treatment facility
- outfall WNSP008, groundwater effluent from the perimeter of the LLWTF storage lagoons (closed in May 2001 but still in the permit)

- outfall 116, a location in Frank's Creek that represents the confluence of outfalls WNSP001, WNSP007, and WNSP008, as well as storm water runoff, groundwater seepage, and augmentation water. (Samples from upstream sources are used to calculate total dissolved solids at this location and to demonstrate compliance with the SPDES permit limit for this parameter. Outfall 116 is referred to as a "pseudo-monitoring" point on the SPDES permit.)

- outfall WNSP01B, an internal monitoring point for the liquid waste treatment system evaporator effluent, being monitored for flow and total mercury.

Some of the more significant features of the SPDES permit are the requirements to report fiveday biochemical oxygen demand, total dissolved solids, iron, and ammonia data as flow-weighted concentrations and to apply a net discharge limit for iron. The net limit allows the Project to account for the iron that is naturally present in the site's incoming water. The flow-weighted limits apply to the flow-proportioned sum of the Project effluents.

One SPDES effluent limit exception for total suspended solids was observed in May 2004.

Mercury Analytical Method Study. The modified SPDES permit received by the WVDP in July 2002 required a comparison study of mercury determination by two analytical methods: U.S. Environmental Protection Agency (EPA) Method 245.1 (or 245.2) with a detection level of $0.2 \mu \mathrm{g} / \mathrm{L}$ (parts per billion) and EPAMethod 1631E, which allows determination of mercury at a minimum level of $0.5 \mathrm{ng} / \mathrm{L}$ (parts per trillion). The latter ("ultraclean") 
method supports the EPA's effort to make available an additional analytical method capable of measuring mercury accurately at ambient water quality criteria levels.

Since the SPDES permit enforcement compliance limit of $0.2 \mu \mathrm{g} / \mathrm{L}$ for total mercury is several orders of magnitude higher than the AWQS of 0.0007 $\mu \mathrm{g} / \mathrm{L}$ for dissolved mercury, the WVDP is required to conduct a mercury study using both methods (1631 and 245.1 or 245.2) whenever mercury samples are required under the terms of the SPDES permit. A report summarizing the analytical results from these two methods and its findings is required to be submitted quarterly to NYSDEC.

Sixteen sets of samples from outfall 001 were analyzed for mercury by the two test methods in 2004. Samples were analyzed at Severn Trent Laboratories using Method 245.1 and at General Engineering Laboratories using Method 1631E.

All sample results from Method 245.1 were less than $0.2 \mu \mathrm{g} / \mathrm{L}$, the practical quantitation limit for Method 245.1. Results generated with Method $1631 \mathrm{E}$ were consistent with results generated with Method 245.1. That is, all sample results generated with Method 1631E were reported at levels below $0.2 \mu \mathrm{g} / \mathrm{L}$. The average concentration for samples collected at outfall 001 using Method $1631 \mathrm{E}$ was $0.0134 \mu \mathrm{g} / \mathrm{L}$.

South Plateau Surface and Subsurface Water. An inactive underground radioactive waste disposal site, the U.S. Nuclear Regulatory Commission (NRC)-Licensed Disposal Area (NDA), lies on the south plateau of the site. Surface waters, which flow from the south to the north, are routinely monitored at several points around this area (Fig. A-2). Two of these points, WNNDATR and WNNDADR, are used to monitor (respectively) waters within the NDA water collection trench system and surface runoff and seepage immediately downstream of the NDA. Sampling point WNNDATR is an underground sump at the lowest point in the collection trench system that intercepts groundwater from the NDA. If radiological or nonradiological contamination were to migrate through the NDA, it would most likely be first detected in samples from WNNDATR.

Interceptor Trench and Pretreatment System. Radioactively-contaminated n-dodecane (similar to kerosene) in combination with tributyl phosphate (TBP) was discovered at the northern boundary of the NDA in 1983. To contain migration of this subsurface radioactive organic contaminant, an interceptor trench and a liquid pretreatment system (LPS) were built. (See "NRC-Licensed Disposal Area [NDA] Interceptor Trench and Pretreatment System" in Chapter 1.)

The trench was designed to intercept and collect subsurface water, which could be carrying ndodecane/TBP, to prevent the material from entering the surface water drainage ditch leading into Erdman Brook, and to prevent contamination of downgradient groundwater. The LPS was installed to separate the $n$-dodecane/TBP and to remove iodine-129 from the collected water before its transfer to the LLWTF. The separated ndodecane/TBP would be stored for subsequent treatment and disposal.

In 2004, as in previous years, no water containing TBP was encountered in the trench. Results of surface and groundwater monitoring in the vicinity of the trench are discussed in Chapter 2 ("South Plateau Surface Water and NDA Interceptor Trench") and in Chapter 4 ("Results of Monitoring at the NDA").

Total Organic Halides. Total organic halides (TOX) measurements are used as a screening 
mechanism to detect the presence of certain organic compounds and associated radionuclides. In 2004, concentrations of TOX at both WNNDATR and WNNDADR remained within the range of historical values.

Other On-Site and Off-Site Surface Water Monitoring. As part of the routine monitoring program, two sets of grab samples for nonradiological parameters at WNSP006 (Frank's Creek at the security fence), WNSWAMP (northeast swamp drainage), WNSW74A (north swamp drainage), WFBCTCB (Buttermilk Creek at Thomas Corners), and WFBCBKG (Buttermilk Creek at Fox Valley) were taken in 2004. These samples were screened for organic and inorganic constituents and selected anions, cations, and metals. Results of measurements for these locations are found in Appendices C- $3^{\text {GD }}$ and C $-4{ }^{\text {GD }}$.

At surface water monitoring locations WFBCTCB, WNSP006, and background reference location WFBCBKG, the maximum concentrations of total iron exceeded the water quality standard $(0.30 \mathrm{mg} / \mathrm{L})$. NYSDEC, in its $2002 \mathrm{CWA}$ 303(d) report to the EPA, indicated it found the scientific basis for the $0.30 \mathrm{mg} / \mathrm{L}$ standard to be insufficient. NYSDEC also indicated that its upcoming standards review is expected to include a proposed replacement of the $0.30 \mathrm{mg} / \mathrm{L}$ standard with a $1.0 \mathrm{mg} / \mathrm{L}$ guidance value, based on 1976 EPA criteria. Nonetheless, iron concentrations at these locations also exceeded this replacement value. Elevated iron concentrations are thought to be largely attributable to elevated background concentrations. However, they may further be elevated due to the influence of water runoff from industrial activities.

The maximum observed concentrations of dissolved aluminum at surface water locations WFBCTCB, WNSP006, and WFBCBKG exceeded the water quality standard for this param- eter. As seen with iron, elevated aluminum concentrations are thought to be largely attributable to elevated background concentrations. However, they also may further be elevated due to the influence of water runoff from industrial activities.

Monitoring results for the standing water locations (WNSTAW series) are presented in Appendix C$4^{\text {GD }}$. The total iron concentrations at WNSTAW4, WNSTAW5, and WNSTAW9 $(0.63,0.68$, and 0.48 $\mathrm{mg} / \mathrm{L}$, respectively) exceeded the $0.3 \mathrm{mg} / \mathrm{L}$ standard for Class " $D$ " surface waters. The elevated iron concentrations at these standing water locations are thought to be attributable to naturally elevated background concentrations of iron.

Monitoring results for $\mathrm{pH}$ at locations WNSP005, WFFELBR, WFBCTCB, WNFRC67, and WNDCELD are provided in Appendices C- $3^{\text {Go }}$ and $\mathrm{C}-4{ }^{\text {GD }}$. Although most $\mathrm{pH}$ values were within applicable standards, the minimum result at WFFELBR (6.23) in 2004 was below the lower $\mathrm{pH}$ limit of 6.5. Low $\mathrm{pH}$ of precipitation in the western New York region may suppress $\mathrm{pH}$ in ambient surface waters, especially during times of high rainfall when precipitation runoff may account for a large proportion of stream flow.

\section{Drinking Water Monitoring}

Site drinking water is monitored to verify compliance with EPA and New York State Department of Health (NYSDOH) regulations. (See "Safe Drinking Water Act" in the Environmental Compliance Summary.) Samples are collected annually and analyzed for nitrate, fluoride, cyanide, and metals concentrations. In addition, an annual sample was obtained for principal organic contaminants. The 2004 monitoring results indicated that the Project's drinking water met NYSDOH, EPA, and Cattaraugus County Health Department MCLs and drinking water quality standards. 
Conductivity and $\mathrm{pH}$ in off-site and on-site drinking water are presented in Appendix C $-5^{\text {GD }}$. With the exception of turbidity results measured in January 2004, including a peak value of 1.6 NTU on January 18, 2004, all results were within applicable limits during 2004. Elevated turbidity results in January 2004 occurred as a result of inclement weather that caused excessive ice formation and mechanical failure of the clarifier equipment. The clarifier is a step in the process for treating incoming source water to produce drinkable water.

Results for inorganic, organic, and indicator analyses of utility room potable water at the distribution system entry point, location WNDNKUR, are listed in Appendix C-5 ${ }^{\text {Co. }}$, as are monthly results for biological and residual chlorine analyses at site tap water locations. All results were within NYSDOH MCLs and EPA maximum contaminant level goals. The annual result for nitrate-nitrogen in a tap water sample from the WVDP restroom sink, as analyzed by the Cattaraugus County Department of Health, was also below the MCL.

\section{Soil and Sediment Monitoring}

Sediments are found at the bottom of surface waters, including streams located within the WVDP and WNYNSC premises. Sediments provide habitat for a wide variety of benthic organisms, as well as juvenile forms of pelagic organisms. These organisms in sediments are in constant contact with substances that may be adsorbed to sediment particles. Contaminated sediments are potential diffuse sources of contamination to the overlying water body.

In 1999, NYSDEC issued updated guidance for screening contaminated aquatic sediments. This guidance includes sediment quality criteria correlated to the severity of environmental impact. These criteria, which are derived from National
Oceanic and Atmospheric Administration (Long and Morgan, 1990) and 1992 Ministry of Ontario "Guidelines for the Protection and Management of Aquatic Sediment Quality in Ontario" (Persaud et al., 1992), are presented in Appendix G- $1^{\text {GD }}$.

Contaminants in soils are potential sources for contamination of groundwater, ambient air, flora, and fauna. Appendix G-1 ${ }^{\text {[o }}$ includes a summary of reference criteria, including background concentration ranges for eastern United States soils and sediment screening levels. Data for soil and sediment monitoring locations are provided in Appen$\operatorname{dix}$ G-2 ${ }^{\text {GD }}$. Also, provided for side-by-side comparison with these data, are available reference values, including background concentrations and/or sediment screening levels.

At SNSP006, all analytical results for sediments were below the Severe Effect Level and No Appreciable Contaminant Levels specified in the NYSDEC guidance. According to the NYSDEC "Technical Guidance for Screening Contaminated Sediments," these results suggest there is no pronounced disturbance of the sediment-dwelling biological community and that there is no significant harm to benthic aquatic life at this location.

The result for manganese in the sediment sample obtained at SNSP006 exceeded the Lowest Effect Level but was below the Severe Effect Level. Based on the NYSDEC sediment screening guidance, moderate impacts to benthic life could be expected at this location.

At SNSW74A and SNSWAMP, concentrations of zinc exceeded the eastern United States background soil concentration range identified in the NYSDEC Technical Administrative Guidance Memorandum (TAGM) \#4046 "Determination of Soil Clean-Up Objectives and Clean-Up Levels." Calcium and magnesium at SNSW74A also exceeded the eastern background soil concentration 
range. Concentrations of these naturally occurring metals above the natural background ranges may be indicative of localized, naturally elevated background concentrations of metals in soils or deposition of sediment from runoff from areas where industrial activities are occurring.

In 2004, a section of the bed for the railroad spur on the WNYNSC was rehabilitated to support future use of this rail line for waste shipments. Prior to removal, the railbed soil material was sampled, and tested for chemical constituents that are typically found in soils associated with rail lines, to identify appropriate soil management practices. The test results indicated the soil did not have any appreciable contamination, with all results within soil cleanup objectives specified in NYSDEC guidance, TAGM 4046. Refer to Appendix G- $2^{\text {Gov }}$ for the results for these constituents.

\section{Air Emission Monitoring}

Nonradiological air emissions are permitted under NYSDEC and EPA regulations. (The regulations that apply to the WVDP are listed in Appendix $\mathrm{K}^{\mathrm{ED}}$. The New York State Air Facility Registration Certificate held by the WVDP is described in a listing of West Valley Demonstration Project Environmental Permits in the Environmental Compliance Summary.)

The nonradiological air certificate covers emissions of regulated pollutants that include nitrogen oxides and sulfur dioxide.

The main contributing source of oxides of nitrogen and sulfur at the WVDP was the vitrification system melter, which was shut down in September 2002. Site boilers and standby diesel generators were left as the only contributors of nitrogen and sulfur oxides, at levels much lower than those emitted by the melter. 


\section{SITE HYDROLOGY AND GROUNDWATER MONITORING}

\section{Groundwater Monitoring Program Overview}

Groundwater at the West Valley Demonstration Project (WVDP or Project) is monitored to comply with all applicable state and federal regulations and to meet the requirements of U.S. Department of Energy (DOE) Order 450.1. The program enables the WVDP to obtain data to determine baseline conditions, to allow the early detection of groundwater contamination, to identify existing and potential groundwater contamination sources and maintain surveillance of these sources, and to provide data for decision-making.

The WVDP's “Groundwater Monitoring Plan” outlines groundwater characterization, current groundwater sampling requirements, and support of long-term monitoring requirements identified in the Resource Conservation and Recovery Act (RCRA) facilities investigation (RFI) and DOE programs. The "WVDP Groundwater Protection Management Program Plan" provides additional information regarding protection of groundwater from on-site activities.

\section{Surface Water Hydrology}

The Western New York Nuclear Service Center (WNYNSC) lies within the Cattaraugus Creek watershed, which empties into Lake Erie about 27 miles (43 km) southwest of Buffalo. Buttermilk Creek, a tributary of Cattaraugus Creek, drains most of the WNYNSC and all of the Project.

The WVDP lies within the watershed of Frank's Creek, which is a tributary of Buttermilk Creek and is located near the eastern and southern boundary of the WVDP; Quarry Creek, a tributary of Frank's Creek, is located near the northern boundary (Fig. A-1).

Another tributary of Frank's Creek, Erdman Brook, bisects the WVDP into a north and south plateau. The main plant, waste tanks, and lagoons are located on the north plateau. The drum cell, the U.S. Nuclear Regulatory Commission (NRC)Licensed Disposal Area (NDA), and the New York State-Licensed Disposal Area (SDA) are located on the south plateau.

\section{Geology}

The 167-acre (68-hectare [ha]) Project site is located within the WNYNSC, which comprises approximately 3,338 acres (1,351 ha) and is located near the northern border of Cattaraugus County. Beneath the WNYNSC is a sequence of recent and older glacial-age sediments filling a steep-sided valley incised in the bedrock, which is composed 
of shales and interbedded siltstones (Rickard, 1975).

Pleistocene sediments overlying the bedrock typically consist of a sequence of three glacial tills of Lavery, Kent, and possibly Olean age. The tills are separated by stratified fluvio-lacustrine deposits. In the northern part of the site, the Lavery till is capped by coarse-grained alluvial-fluvial deposits.

\section{Hydrogeology}

The sediments above the Kent till - the Kent recessional sequence, the Lavery till, the intra-Lavery till-sand, and the surficial sand and gravel - are generally regarded as containing all of the potential routes for the contaminant migration via groundwater from the Project. (Figs. 4-1 and 4-2 show the relative locations of these sediments on the north and south plateaus.) The Lavery till, the Kent recessional sequence, and the Kent till are common to both the north and south plateaus. The bottommost layer, the Kent till, is less permeable than the other geological units and does not provide a pathway for contaminant movement from the WVDP, therefore it is not discussed here.

The WVDP does not use groundwater for drinking or operational purposes, nor does it discharge effluent directly to groundwater. No public water supplies are drawn from groundwater downgradient of the site or from downstream Cattaraugus Creek. Upgradient of the site, groundwater is used for drinking water by local residents.

Kent Recessional Sequence. The Kent recessional sequence consists of a fine-grained lacustrine unit of interbedded clay and silty clay layers locally overlain by coarse-grained sands and gravels. These deposits underlie the Lavery till beneath most of the site, pinching out along the southwest- ern margin of the site where the walls of the bedrock valley intersect the sequence.

Groundwater flow in the Kent recessional sequence is predominantly to the northeast, toward Buttermilk Creek. Mean hydraulic conductivity is $2 \mathrm{E}-01 \mathrm{ft} /$ day $(8 \mathrm{E}-05 \mathrm{~cm} / \mathrm{sec})$ or $2.6 \mathrm{in} /$ day, based on recent testing. Recharge comes from the overlying Lavery till and inflow from the bedrock to the southwest. Discharge is to Buttermilk Creek.

Lavery Till. The Lavery till is predominantly an olive-gray, silty clay glacial till with scattered lenses of silt and sand. It underlies both the north and south plateaus and ranges up to 130 feet $(40 \mathrm{~m})$ in thickness beneath the active areas of the site, slightly increasing northeastward toward Buttermilk Creek and the center of the bedrock valley. Groundwater flow in the unweathered Lavery till is predominantly vertically downward at a relatively slow rate. Mean hydraulic conductivity is $1 \mathrm{E}-04 \mathrm{ft} /$ day $(3.5 \mathrm{E}-08 \mathrm{~cm} / \mathrm{sec})$ or $0.001 \mathrm{in} /$ day, based on recent testing.

On the south plateau, the upper zone of the Lavery till is exposed at the ground surface and is weathered and fractured to a depth of 3 to 16 feet $(0.9$ to $4.9 \mathrm{~m}$ ). This layer, referred to as the weathered Lavery till, is unique to the south plateau. The weathered Lavery till has been oxidized to a brown color and contains numerous desiccation cracks and root tubes.

Groundwater flow in the weathered till has both horizontal and vertical components. This enables groundwater to move laterally across the south plateau before moving downward into the unweathered Lavery till or discharging to nearby incised stream channels. Mean hydraulic conductivity is $5 \mathrm{E}-02 \mathrm{ft} /$ day $(2 \mathrm{E}-05 \mathrm{~cm} / \mathrm{sec})$ or $0.6 \mathrm{in} /$ day, based on recent testing. The highest conductivities are associated with dense fracture zones found within the upper 7 feet $(2 \mathrm{~m})$ of the unit. 
Hydrogeology

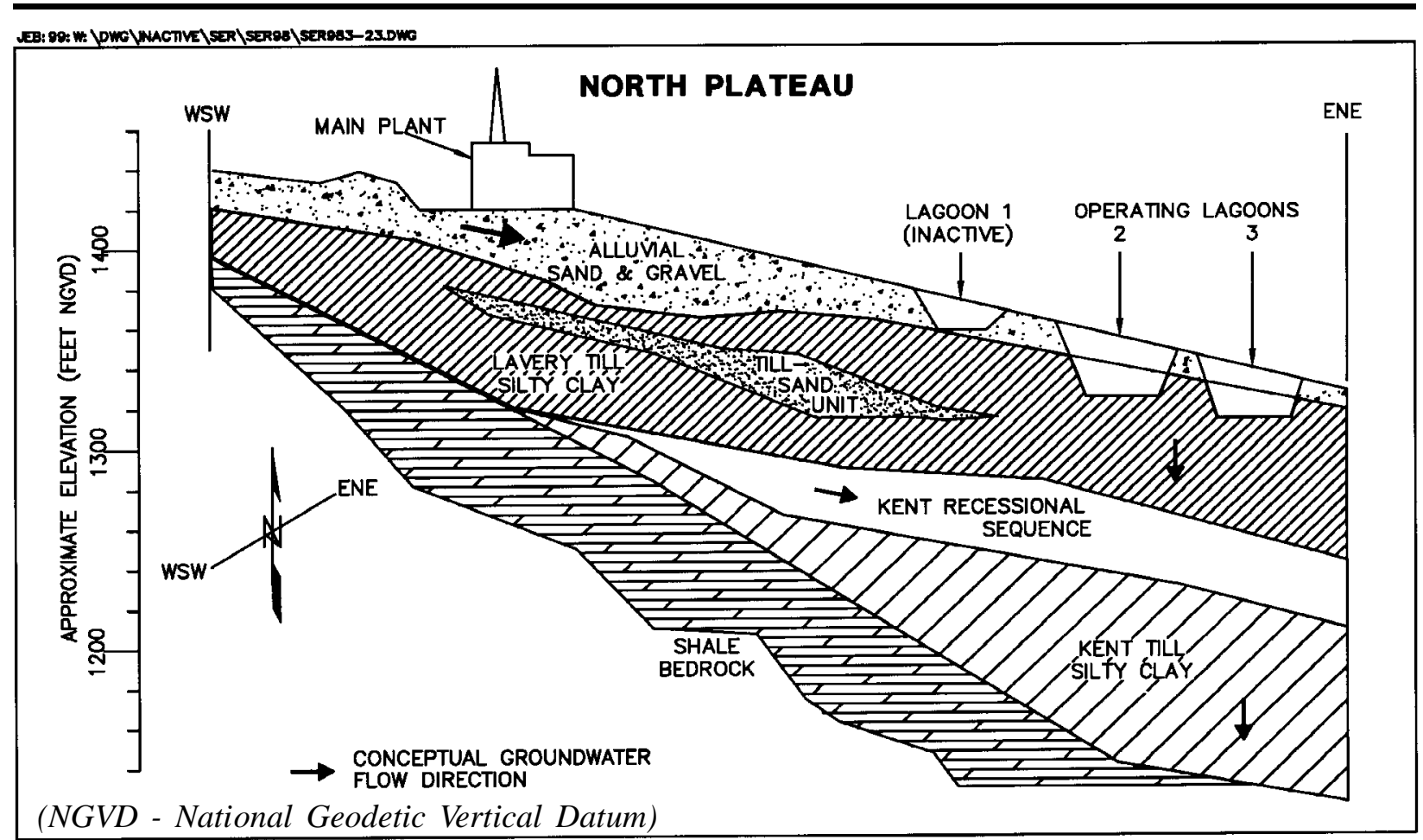

Figure 4-1. Geologic Cross Section Through the North Plateau (Vertical Exaggeration Approx. 2:1)

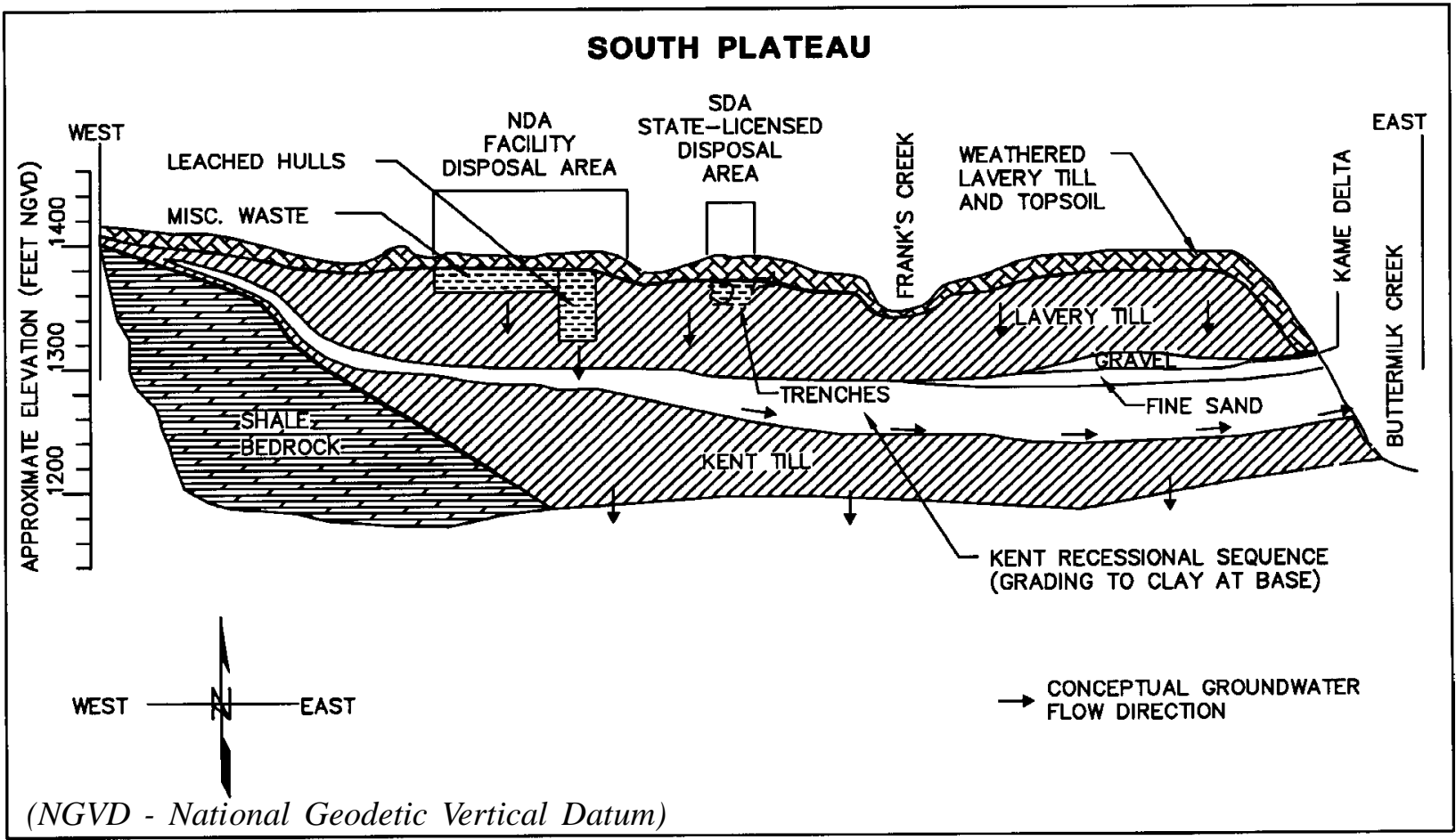

Figure 4-2. Geologic Cross Section Through the South Plateau (Vertical Exaggeration Approx. 2.5:1)

$$
4-3
$$


On the north plateau, the weathered till layer is much thinner or nonexistent and the unweathered Lavery till is overlain by the sand and gravel unit.

Sand and Gravel and Till-Sand Units. The sand and gravel unit and the Lavery till-sand are unique to the north plateau. The sand and gravel unit is a silty sand and gravel layer composed of younger Holocene alluvial deposits that overlie older Pleistocene-age glaciofluvial deposits. Together these two layers range up to 41 feet $(12.5 \mathrm{~m})$ in thickness near the center of the plateau and pinch out along the northern, eastern, and southern edges of the plateau, where they have been truncated by downward erosion of stream channels.

Groundwater in this unit generally flows northeastward across the plateau toward Frank's Creek. Groundwater near the northwestern and southeastern margins of the sand and gravel layer also flows radially outward toward Quarry Creek and Erdman Brook, respectively. There is minimal groundwater flow downward into the underlying Lavery till. Mean hydraulic conductivity is $16.4 \mathrm{ft} /$ day $(6 \mathrm{E}-03 \mathrm{~cm} / \mathrm{sec})$ or $200 \mathrm{in} /$ day, based on recent testing.

Within the unweathered Lavery till on the north plateau is another unit, the Lavery till-sand. This thin, sandy unit of limited areal extent and variable thickness is found primarily beneath the southeastern portion of the north plateau. Groundwater flows through this unit in an east-southeast direction. Surface discharge locations have not been observed. Mean hydraulic conductivity is $3.8 \mathrm{ft} /$ day $(1 \mathrm{E}-03 \mathrm{~cm} / \mathrm{sec})$ or $46 \mathrm{in} /$ day $(117 \mathrm{~cm} /$ day), based on recent testing.

Hydrologic conditions of the site are more fully described in "Environmental Information Document, Volume III: Hydrology, Part 4" (West Valley Nuclear Services Co. [WVNSCO], March 1996) and in the "RCRA Facility Investigation Re- port Vol. 1: Introduction and General Site Overview" (WVNSCO and Dames \& Moore, July 1997).

\section{Routine Groundwater Monitoring Program}

Groundwater is monitored in the five hydrogeologic units previously described: the sand and gravel, the weathered Lavery till, the unweathered Lavery till, the Lavery till-sand, and the Kent recessional sequence. In 2004, a total of 69 groundwater monitoring locations were sampled. These locations included 63 monitoring wells (including driven well points), five groundwater seepage points, and one sump/manhole. (See Tables 4-1 and 4-2 for a summary of groundwater monitoring activities in 2004.)

Monitoring Well Network. Most of the routine groundwater monitoring wells were originally assigned to monitor one (or more) of the super solid waste management units (SSWMUs) on the WVDP premises. Table 4-3 describes the SSWMUs and their constituent solid waste management units (SWMUs) on site. (See "RCRA $\$ 3008(\mathrm{~h})$ Administrative Order on Consent" in the Environmental Compliance Summary.)

Figures A-7 and A-8 in Appendix A show boundaries of ten of the WVDP SSWMUs. The eleventh SSWMU, the SDA, is a closed radioactive waste landfill. The SDA is contiguous with the Project premises and is owned and managed by the New York State Energy Research and Development Authority (NYSERDA). Groundwater monitoring results from the SDA are reported in Appendix $\mathrm{L}^{\mathrm{G}}{ }^{\mathrm{D}}$ but are not discussed here.

Appendix $\mathrm{E}^{\mathrm{GD}}$ lists the wells in the network, sorted by the geologic unit monitored, and the analytes measured in 2004. Note that monitoring of certain wells, marked by an asterisk, are specified in RFI reports prepared in accordance with the RCRA 


\section{Table 4-1}

\section{Summary of Groundwater Monitoring Program by Geographic Area; Monitoring Year 2004}

\begin{tabular}{|l|c|c|c|c|}
\hline \multicolumn{1}{|c|}{ NUMBER OF... } & $\begin{array}{c}\text { TOTAL } \\
\text { WVDP }\end{array}$ & $\begin{array}{c}\text { NORTH } \\
\text { PLATEAU }\end{array}$ & $\begin{array}{c}\text { SOUTH } \\
\text { PLATEAU }\end{array}$ & $\begin{array}{c}\text { OFF-SITE } \\
\text { RESIDENTIAL }\end{array}$ \\
\hline Monitoring Points Sampled - Analytica $*$ & 79 & 54 & 15 & 10 \\
\hline Monitoring Points - Water Elevations Only & 42 & 26 & 16 & 0 \\
\hline Monitoring Events & 5 & 4 & 4 & 1 \\
\hline Analyses & 1,353 & 1,146 & 160 & 47 \\
\hline Results & 10,987 & 9,679 & 1,197 & 111 \\
\hline Percent of Nondetectable Results & $85 \%$ & $85 \%$ & $85 \%$ & $65 \%$ \\
\hline Water Elevation Measurements & 412 & 288 & 124 & 0 \\
\hline
\end{tabular}

* Total number includes 69 on-site and 10 off-site points.

Table 4-2

Summary of Groundwater Monitoring Program by Monitoring Purpose; Monitoring Year 2004

\begin{tabular}{|c|c|c|}
\hline NUMBER OF... & $\begin{array}{c}\text { REGULATORY/ } \\
\text { WASTE MANAGEMENT }\end{array}$ & $\begin{array}{l}\text { ENVIRONMENTAL } \\
\text { SURVEILLANCE }\end{array}$ \\
\hline Monitoring Points Sampled - Analytical* & 34 & 45 \\
\hline Monitoring Points - Water Elevations Only & 0 & 42 \\
\hline Monitoring Events & 4 & 5 \\
\hline Analyses & 265 & 722 \\
\hline Results & 4,740 & 5,666 \\
\hline Percent of Nondetectable Results & $84 \%$ & $84 \%$ \\
\hline Water Elevation Measurements & 128 & 280 \\
\hline \multicolumn{3}{|l|}{ Ranges of Results For Positive Detections } \\
\hline \multicolumn{3}{|l|}{ Organic Compounds $(\mu \mathrm{g} / \mathrm{L})$} \\
\hline 1,1-Dichloroethane & $8.2-11$ & NA \\
\hline 1,2-Dichloroethylene (total) & $21-26$ & NA \\
\hline Tributyl phosphate & $2.0-410$ & NA \\
\hline \multicolumn{3}{|l|}{ Maximum Concentrations For } \\
\hline \multicolumn{3}{|l|}{ Radiological Parameters $(\mu \mathrm{Ci} / \mathrm{mL})$} \\
\hline Gross Beta & 2.92E-04 & 1.61E-04 \\
\hline Strontium-90 & $1.25 \mathrm{E}-04$ & $6.85 \mathrm{E}-05$ \\
\hline Tritium & $4.68 \mathrm{E}-06$ & 5.35E-05 \\
\hline
\end{tabular}

NA - Not applicable

* Total number includes 69 on-site and 10 off-site points.

$4-5$ 


\section{Table 4-3}

\section{WVDP RCRA SSWMUs and Constituent SWMUs}

\begin{tabular}{|c|c|}
\hline SSWMU & CONSTITUENT SWMUs \\
\hline SSWMU \#1 - Low-Level Waste Treatment Facilities (LLWTF) & $\begin{array}{l}\text { Former Lagoon } 1 \\
\text { LLWTF Lagoons } \\
\text { LLWTF Building } \\
\text { Interceptors } \\
\text { Neutralization Pit }\end{array}$ \\
\hline SSWMU \#2 - Miscellaneous Small Units & $\begin{array}{l}\text { Sludge Ponds } \\
\text { Solvent Dike } \\
\text { Equalization Mixing Basin } \\
\text { Paper Incinerator }\end{array}$ \\
\hline SSWMU \#3 - Liquid Waste Treatment System (LWTS) & $\begin{array}{l}\text { Liquid Waste Treatment System } \\
\text { Cement Solidification System } \\
\text { Main Process Building (specific areas) }\end{array}$ \\
\hline $\begin{array}{l}\text { SSWMU \#4 - High-Level Waste (HLW) Storage and } \\
\text { Processing Area }\end{array}$ & $\begin{array}{l}\text { Vitrification Facility } \\
\text { Vitrification Test Tanks } \\
\text { HLW Tanks } \\
\text { Supernatant Treatment System }\end{array}$ \\
\hline SSWMU \#5 - Maintenance Shop Leach Field & Maintenance Shop Leach Field \\
\hline SSWMU \#6 - Low-Level Waste Storage Area & $\begin{array}{l}\text { Lag Storage Additions 1, 2, 3, } 4 \\
\text { Hardstands (old and new) } \\
\text { Lag Storage }\end{array}$ \\
\hline $\begin{array}{l}\text { SSWMU \#7 - Chemical Process Cell (CPC) Waste Storage } \\
\text { Area }\end{array}$ & CPC Waste Storage Area \\
\hline SSWMU \#8 - Construction and Demolition Debris Landfill & Former Construction and Demolition Debris Landfill \\
\hline SSWMU \#9 - NRC-Licensed Disposal Area & $\begin{array}{l}\text { NRC-Licensed Disposal Area } \\
\text { Container Storage Area } \\
\text { Trench Interceptor Project }\end{array}$ \\
\hline $\begin{array}{l}\text { SSWMU \#10 - Integrated Radwaste Treatment System (IRTS) } \\
\text { Drum Cell }\end{array}$ & IRTS Drum Cell \\
\hline SSWMU \#11 - New York State-Licensed Disposal Area (SDA) & State-Licensed Disposal Area (NYSERDA) \\
\hline
\end{tabular}

$4-6$ 
$\S 3008$ (h) Administrative Order on Consent for the WVDP.

In addition to analytical samples, potentiometric (water level) measurements also are collected from wells listed in Table E- ${ }^{\text {cod }}$ in conjunction with the quarterly analytical sampling schedule (Appendix $\mathrm{E}^{\mathrm{GS}}$ ). Groundwater elevation data are used to produce groundwater contour maps, which delineate flow directions and gradients, and long-term trend graphs, which illustrate seasonal fluctuations and other changes to the groundwater system. In 2004, water levels were routinely measured at 42 locations in addition to those that were sampled. (See Figures A-6 and A-7 in Appendix A.)

Surface water elevation measurements are also collected at 11 locations on the north plateau where the water table in the sand and gravel unit intersects the ground surface in the form of standing water. These measurements are correlated with groundwater elevation measurements taken at nearby monitoring wells, and are used to help define groundwater flow direction and gradients in the sand and gravel unit in areas where monitoring well coverage is sparse or nonexistent.

\section{Groundwater Monitoring Program Highlights} 1982 Through 2004. Program content is dictated by regulatory requirements in conjunction with current operating practices and historical knowledge of previous site activities.

- Groundwater monitoring at the WVDP began in 1982 and continued to expand through 1992 with the addition of new wells, groundwater seep locations, a french drain outfall, and the NDA interceptor trench sump.

- An RFI expanded characterization program was conducted during 1993 and 1994 to fully assess potential releases of hazardous wastes or constituents from on-site SSWMUs. This investigation, which consisted of two rounds of sampling for a wide range of radiological and chemical parameters, provided valuable information regarding the presence or absence of groundwater contamination near each SSWMU. Results were used to guide later monitoring program modifications.

- In 1993, monitoring results indicated elevated gross beta activity in groundwater from the sand and gravel unit on the north plateau. Subsequent investigation of this area delineated a plume of contamination with a southwest to northeast orientation. (See Special Groundwater Monitoring and Figure 4-3 in this chapter for more detail.)

- Long-term monitoring needs were the focus of a 1995 groundwater monitoring program evaluation. After a comprehensive assessment, the number of sampling locations was reduced from 91 to 65 and analytical parameters were tailored to each sampling location for a more focused, efficient, and cost-effective program.

- In 1996, several groundwater seep monitoring locations on the northeast edge of the north plateau were added to the monitoring program.

- Four new groundwater monitoring wells were installed during August 2003 to provide upgradient and downgradient monitoring coverage for the remote-handled waste facility.

- From 1996 through 2004, in response to current sampling results and DOE and RCRA monitoring requirements, specific monitoring locations, analytes, and sampling frequencies were modified.

Analytical Trigger Level Evaluation. A computerized data-screening program uses "trigger levels" - preset conservative values for chemical and radiological concentrations and groundwater elevation measurements - to identify and promptly respond to anomalies in monitoring results. These 
levels, reviewed annually, are based on regulatory limits, detection limits, or statistically derived values.

\section{Results of Routine Groundwater Monitoring}

Tables in Appendix $\mathrm{E}^{\text {[D. }}$ group the results of groundwater monitoring within the five monitored hydrogeologic units. These tables contain results of sampling for radiological and nonradiological analytes. Table E-12 ${ }^{\text {GD }}$ lists the practical quantitation limits (PQLs) for individual Title 6 of the Official Compilation of Codes, Rules, and Regulations of the State of New York, Appendix 33 analytes. The PQL is the lowest level of an analyte that can be measured within specified limits of precision during routine laboratory operations (New York State Department of Environmental Conservation, 1991).

Data Tables. Groundwater monitoring data for 2004 are presented in Appendix $E^{\text {GD }}$. The wells in each table are arranged by hydraulic position relative to other wells within the same hydrogeologic unit. Wells identified as "UP" refer to either background wells or wells that are upgradient of other wells in the same hydrogeologic unit. Wells identified as "DOWN" are downgradient of other wells in that unit. In each table, wells are presented from upgradient to furthest downgradient. Hydraulic position provides the basis for presenting groundwater monitoring data in the tables and figures in this report.

Trend-Line Graphs. Trend-line graphs are included for monitoring locations that have historically shown radiological concentrations above background values, or concentrations of volatile organic compounds (VOCs) or semivolatile organic compounds (SVOCs) above PQLs.
Long-Term Trends of Gross Beta and Tritium at Selected Groundwater Monitoring Locations. Figures 4-4 through 4-7 show the trends of gross beta and tritium concentrations at selected monitoring locations in the sand and gravel unit. Use of a logarithmic scale allows locations having widely differing concentrations to be compared to average background concentrations plotted on each graph.

Gross Beta. In 2004, 12 wells (104, 105, 111, 116, $408,501,502,801,8603,8604,8605$, and 8609) showed gross beta concentrations that exceeded the DOE-derived concentration guide (DCG) for strontium-90 (1.0E-06 microcuries/milliliter [ $\mu \mathrm{Ci} /$ $\mathrm{mL}]$ ). Ten of the preceeding wells are within the groundwater plume of gross beta activity in the sand and gravel unit on the north plateau (Fig. 43 ). This area continues to be monitored closely. The source of the plume's activity can be traced to the soils beneath the southwest corner of the former process building. Lagoon 1, formerly part of the low-level waste treatment facility, has been identified as a source of the gross beta activity at the remaining wells, 8605 and 111.

- Figure 4-4 shows gross beta concentrations in wells 104, 408, 501, 502, and 8609 (that are somewhat centrally located on the north plateau and are closer to the plume's suspected source beneath the main plant). Figure 4-5 shows gross beta concentrations in wells $105,116,801,8603$, and 8604 (that are located further downgradient from the plume's suspected source and are closer to the leading edges). As in previous years, samples from well 408 continued to show the highest gross beta concentrations of all the wells within the north plateau gross beta plume. Except for short-term seasonal variations, gross beta results for well 408 progressively decreased from 2002 through 2004.

Wells 501 and 502 showed slight decreases relative to 2003 and 2002. Wells 105, 116, 8604, and 
8609 showed slight increases relative to 2003 values. Results in wells 104, 801, and 8603 were similar to 2003 results. Well 105 shows the largest overall increase over the last ten years.

- Figure 4-6 is a graph of gross beta concentrations at sand and gravel unit monitoring locations 111 and 8605, located near the eastern edge of the north plateau adjacent to former lagoon 1. Gross beta concentrations at wells 111 and 8605 were slightly higher in 2004 than in 2003.

Tritium. Figure 4-7 shows the tritium concentrations in wells $111,8603,8604,8605$, and 8609 . The figure indicates that tritium concentrations in these wells show slight decreases from 2003 to 2004.

North Plateau Seeps. Analytical results of sampling for radiological parameters from the sand and gravel unit seepage monitoring locations were compared with results from GSEEP, a seep monitored since 1991 that has not been affected by the gross beta plume. (Seep monitoring locations are noted on Figs. A-6 and A-7 in Appendix A.)

Gross Beta. Radiological monitoring results continue to indicate that the gross beta groundwater plume has not migrated to these seepage areas. With the exception of SP11, gross beta concentrations from all seep monitoring locations were less than or similar to GSEEP concentrations during 2004. Gross beta concentrations at SP11 show a slightly increasing trend since early 1999 and somewhat steeper increases during 2001 through 2004. Contamination observed at SP11 is believed to be attributable to re-infiltration of contaminated water that has surfaced from the strontium-90 groundwater plume. Although somewhat greater than values typically obtained at GSEEP, it is still well below the strontium-90 DCG (Table E-2 ${ }^{\text {GT }}$ ).

Gross Alpha. Gross alpha concentrations at all seep sampling locations were very low - gener- ally below the associated uncertainty or less than the detection limit.

Tritium. Tritium concentrations at the seeps remained similar to or less than concentrations at GSEEP. Tritium concentrations in the north plateau seeps, including GSEEP, are slightly higher levels than reported in background wells of the sand and gravel unit. Concentrations are similar to those seen in sand and gravel unit wells monitoring the lagoon areas of the north plateau, but are still far lower than the DCG for tritium.

North Plateau Well Points. Sampling at well points A, C, and H (Fig. A-6 in Appendix A) monitors tritium concentrations in the area east of the process building and fuel receiving and storage facility and west of former lagoon 1 . Samples from these locations have yielded concentrations of tritium that, while elevated with respect to historical monitoring of wells in the area, are well below the tritium DCG, $2.0 \mathrm{E}-03 \mu \mathrm{Ci} / \mathrm{mL}$ (Table E-2 ${ }^{\text {Gg }}$ ). Data from downgradient monitoring wells have not indicated similarly elevated levels of tritium.

Results of Radioisotopic Sampling. Groundwater samples for radioisotopic analyses are collected regularly from selected monitoring points in the sand and gravel unit and the weathered Lavery till (Table E-11 ${ }^{\text {GD }}$ ). Results in 2004 were generally similar to historical findings. Strontium90 remained the major contributor to elevated gross beta activity in the north plateau plume, as indicated by the similarity between strontium- 90 trends and gross beta trends in wells showing elevated gross beta results.

Carbon-14, technetium-99, and iodine-129, which have been detected at several monitoring locations at concentrations above background levels, contribute very small percentages to total gross beta concentrations. These detections have occurred at locations within the gross beta plume 


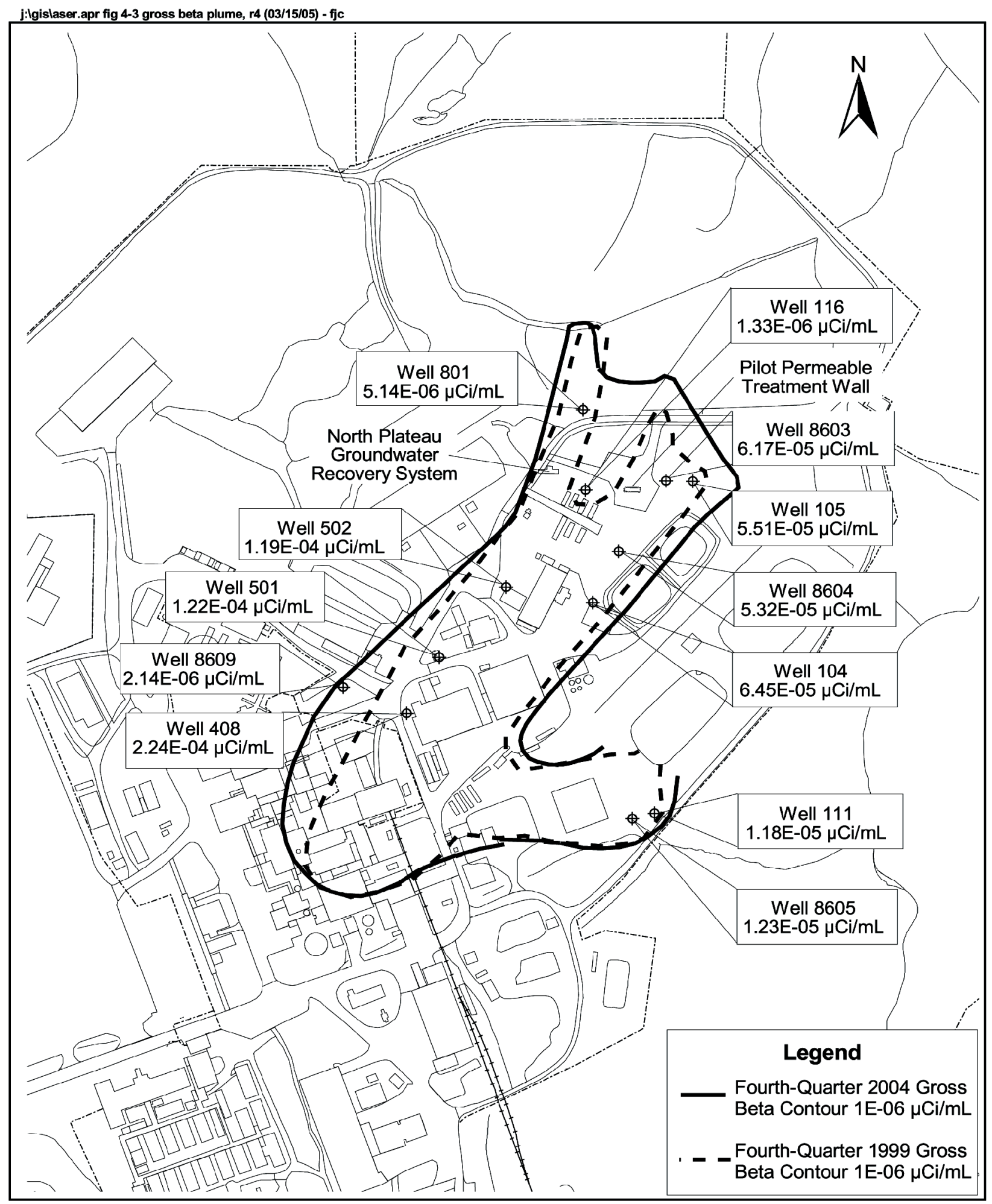

Figure 4-3. North Plateau Gross Beta Plume Area: Fourth-Quarter 2004 Results

$$
4-10
$$


and downgradient of former lagoon 1 and the NDA. None of the carbon-14, technetium-99, or iodine129 concentrations have been above DCGs, and quarterly gross beta analyses continue to provide appropriate trend surveillance.

Results of Monitoring at the NDA. A trench system was previously constructed along the northeast and northwest sides of the NDA to collect groundwater that may be contaminated with a mixture of n-dodecane and tributyl phosphate (TBP). (See also "Environmental Program Information, Nuclear Regulatory Commission [NRC]-Licensed Disposal Area [NDA] Interceptor Trench and Pretreatment System" in Chapter 1.) Monitoring results in 2004 indicated no TBP in groundwater near the NDA. Groundwater levels are monitored quarterly in and around the trench to ensure that an inward gradient is maintained, thereby minimizing outward migration of potentially contaminated groundwater.

Gross beta and tritium concentrations in samples from location WNNDATR, a sump at the lowest point of the interceptor trench, and from well 909 (Fig. A-6 in Appendix A), downgradient of WNNDATR, continued to be elevated with respect to background monitoring locations on the south plateau. Concentrations were still well below the DCGs.

WNNDATR. During 2004, gross beta concentrations at WNNDATR were similar to those seen during 2003. Tritium concentrations however, while still higher than at other NDA monitoring locations, were slightly lower than in 2003.

Well 909. Radiological indicator results have historically fluctuated at this location. In general, upward long-term trends in both gross beta and tritium were discernible until 1999, when both trends declined, followed by relatively consistent results during recent years. Gross beta concen- trations from well 909 are slightly higher than those at WNNDATR. Residual soil contamination near well 909 is the suspected source of elevated gross beta concentrations.

Off-Site Groundwater Monitoring. Groundwater is used as a potable water supply at off-site private residences near the WVDP. Nine off-site residential supply wells located within 4.3 miles $(7 \mathrm{~km})$ of the facility were sampled for radiological parameters in 2004. A tenth private well, located 18 miles $(29 \mathrm{~km})$ south of the site, provided a background location. These monitoring results are discussed in Chapter 2, Overview of Drinking Water Monitoring.

Results for Volatile and Semivolatile Organic Compounds. VOCs and SVOCs were sampled at specific locations (wells 8612, 8609, 803, 8605, 111, and seep sampling location SP12 [Fig. A-6 in Appendix A]) that have shown historical results above the PQLs. (See Tables E- $7^{\mathbf{C D}}$ and E- $8^{\text {[D. }}$ for sampling results, and Table E- $12^{\mathrm{GD}}$ for a list of PQLs.) Other monitoring locations are sampled for VOCs and/or SVOCs because they are downgradient of locations that have shown positive results or to comply with the RCRA $\S 3008(\mathrm{~h})$ Administrative Order on Consent.

1,1-Dichloroethane (1,1-DCA). Concentrations of 1,1-DCA at well 8612 decreased during 19951998 , with a lower rate of decrease during 19992004 (Fig. 4-8). The compound was not detected at wells 8609,803 , or groundwater seep SP12 during 2004.

Dichlorodifluoromethane (DCDFMeth). DCDFMeth was detected at well 8612 during 2004 at the PQL.

1,1,1-Trichloroethane (1,1,1-TCA). The compound 1,1,1-TCA was detected in well 8612 during 2004 at estimated levels below the PQL, but 
was not detected in well 803, 8609, or in seep SP12. (See Fig. 4-8 for a graph of 1,1,1-TCA concentrations at well 8612.)

Total 1,2-Dichloroethylene (1,2-DCE-t). Positive detections of 1,2-DCE-t were first noticed at well 8612 in 1995. Concentrations of 1,2-DCE-t increased from 1995 through 2002, but the trend has leveled from 2002 through 2004.

The VOCs 1,1-DCA, DCDFMeth, and 1,1,1-TCA are often found in combination with 1,2-DCE-t. In well 8612, each compound first exhibited an increasing trend that, over the past few years, was followed by a decreasing trend. It is expected that 1,2-DCE-t will exhibit similar behavior.

Tributyl Phosphate. Concentrations of TBP were detected in 2004 groundwater samples from well 8605 , near former lagoon 1 , at concentrations somewhat higher than those in 2003, but within the range of historical results. TBP also was previously detected in well 111, located near well 8605 , but at levels much lower than those at well 8605. TBP was detected at well 111 during 2004 at a concentration slightly above the PQL (Figure 4-9).

Ongoing detection of TBP in this localized area may be related to previously detected, positive concentrations of iodine-129 and uranium-232 in wells 111 and 8605, as noted in previous Annual Site Environmental Reports. The presence of these contaminants may reflect residual contamination from liquid waste management activities in the former lagoon 1 area during earlier nuclear fuel reprocessing.

\section{Special Groundwater Monitoring}

Gross Beta Plume on the North Plateau. Elevated gross beta activity has been detected in groundwater from the surficial sand and gravel unit in areas northeast of the building where Nuclear Fuel Services, Inc. reprocessed nuclear fuel (Fig. 4-3). In December 1993, elevated gross beta concentrations were detected in surface water at former sampling location WNDMPNE, located near the edge of the plateau. This detection initiated a subsurface groundwater and soil investigation in 1994 using a Geoprobe ${ }^{\circledR}$ mobile sampling system, which helped to identify the location and extent of the gross beta plume beneath and downgradient of the former process building.

The highest gross beta concentrations in groundwater and soil were found near the southeast corner of the process building. Strontium-90 and its daughter product, yttrium-90, were identified as the major isotopic components of this elevated gross beta activity (WVNSCO, 1995).

More attention was given in 1998 to the core area of the plume, determined to be beneath and immediately downgradient of the former process building. The 1998 study noted that, while the overall distribution of strontium-90 in groundwater within the plume was similar to 1994 , concentrations detected in 1998 samples were generally lower than in 1994 samples, due to radioactive decay and continuing migration and dispersion of the plume (WVNSCO, June 1999).

\section{North Plateau Groundwater Recovery Sys-} tem. In 1995, the north plateau groundwater recovery system (NPGRS) was installed to minimize the advance of the gross beta plume. The NPGRS is located near the leading edge of the western lobe of the plume where groundwater flows preferentially toward the edge of the plateau, seeps into a ditch, and flows as surface water toward monitoring location WNSWAMP. (See Northeast Swamp Drainage Monitoring in this chapter.) The NPGRS consists of three wells that extract contaminated groundwater, which is then treated by ion exchange to remove strontium-90. Treated wa- 
ter is transferred to the lagoon system and is ultimately discharged to Erdman Brook.

The NPGRS operated throughout 2004, processing about 4.8 million gallons (18 million liters). The system has recovered and processed approximately 39 million gallons (147 million liters) since November 1995.

Permeable Treatment Wall. A pilot-scale permeable treatment wall (PTW) was constructed in 1999 in the eastern lobe of the north plateau plume to test this passive, in-situ remediation technology. The PTW is a trench that is backfilled with clinoptilolite, a medium selected for its ability to adsorb strontium-90 ions from groundwater. The PTW extends vertically downward through the sand and gravel unit to the top of the underlying Lavery till and is approximately $30 \mathrm{ft}$ long by $10 \mathrm{ft}$ wide ( $9 \mathrm{~m}$ long by $3 \mathrm{~m}$ wide).

Additional test borings and monitoring well installations were completed in the vicinity of the PTW during the fall of 2001 to obtain improved definition of hydrogeologic conditions. Monitoring and evaluation of water levels and radiological concentrations upgradient, within, and downgradient of the PTW continued during 2004. The evaluation concluded that complex hydrogeologic conditions and disturbances from the installation are influencing groundwater flow into and around the pilot PTW.

Northeast Swamp Drainage Monitoring. Routine surface water sampling during 2004 continued to monitor radioactivity levels in surface water at location WNSWAMP (Appendix $\mathrm{C}^{\mathrm{GO}}$ ). Gross beta and strontium- 90 concentrations continued to fluctuate due to seasonal effects. Annualized average strontium-90 concentrations were relatively consistent during the first quarter of 2004, followed by steady increases for the remainder of the year, exceeding the DOE DCG by about August (Fig. 4-10). The main source of the elevated strontium-
90 is seepage of groundwater affected by the north plateau plume into a ditch upstream of WNSWAMP.

The annualized average concentration of strontium-90 in surface water at sampling location WNSWAMP (on the WVDP premises) remained elevated with respect to background. Even so, monitoring downstream at the first point of public access (WFFELBR) continued to show strontium90 concentrations that were only slightly higher than those at background location WFBIGBR. (See also Northeast Swamp and North Swamp Drainage in Chapter 2, Environmental Radiological Program Information.)

\section{North Plateau Groundwater Quality Early Warning Monitoring. Early-warning monitoring} of water recovered by the NPGRS is performed because this water is ultimately discharged offsite via the New York State Pollutant Discharge Elimination System (SPDES) outfall 001. Quarterly monitoring results from well 502, located directly upgradient of the NPGRS, can be used to identify analytical concentrations in groundwater that may affect compliance with the SPDES-permitted effluent limits. Results of sampling for metals at well 502 can be found in Appendix $E^{\text {cod }}$.

Investigation of Chromium and Nickel in the Sand and Gravel Unit and Evaluation of Corrosion in Groundwater Monitoring Wells. A 1997 and 1998 study of the effect of modifying sampling equipment and methodology on concentrations of chromium and nickel in groundwater samples from the sand and gravel unit noted that such modifications produced decreases in chromium and nickel concentrations. This supported the hypothesis (which is documented in the technical literature) that elevated concentrations were not representative of actual groundwater conditions, but were caused by release of metals from subsurface corrosion of stainless steel well mate- 
rials (WVNSCO and Dames \& Moore, June 1998).

To ensure continued monitoring well integrity and collection of high-quality samples representative of actual groundwater conditions, wells are periodically inspected for corrosion. Approximately threefourths of the stainless-steel wells monitoring the sand and gravel unit were internally inspected for corrosion during 2001. Wells containing corrosion were cleaned and then reinspected to verify that corrosion had been removed. Wells previously containing corrosion were inspected during late 2004. Cleaning and reinspection are planned for 2005.

Ten-Year Sampling Pump Inspections. Dedicated bladder pumps were installed in many WVDP monitoring wells in 1991. (See Groundwater Sampling Methodology [Appendix E ${ }^{\text {CD. }}$.) Pumps in all actively sampled wells were removed and inspected during 2001 to evaluate pump conditions after ten years of use. All pumps were found to be in good, serviceable condition during the 2001 inspection and during routine quarterly sampling activities through 2004. 


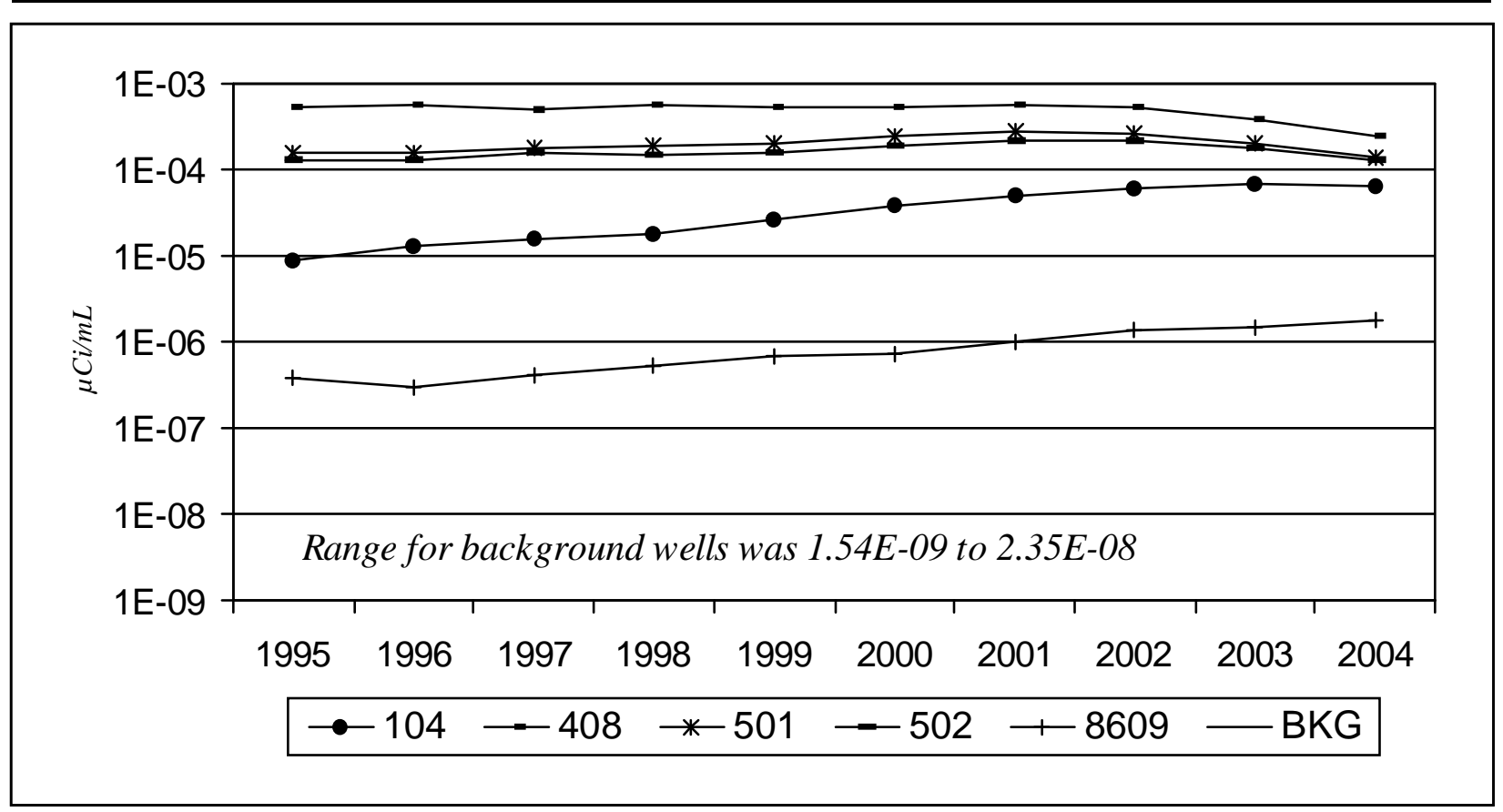

Figure 4-4. Average Yearly Gross Beta Concentrations at Locations Closer to the Source of the North Plateau Plume

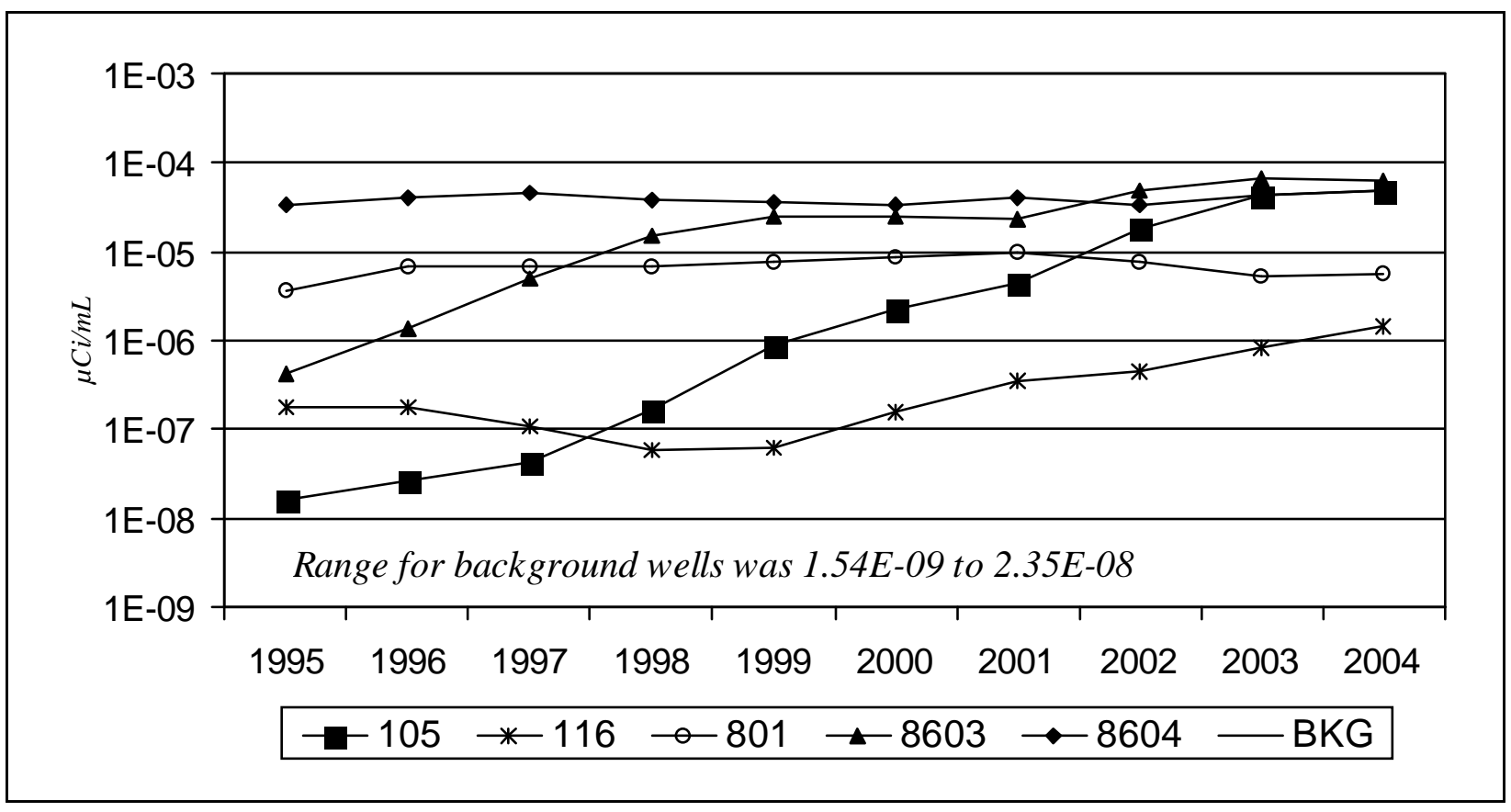

Figure 4-5. Average Yearly Gross Beta Concentrations at Locations Closer to the Leading Edges of the North Plateau Plume 
Chapter 4. Site Hydrology and Groundwater Monitoring

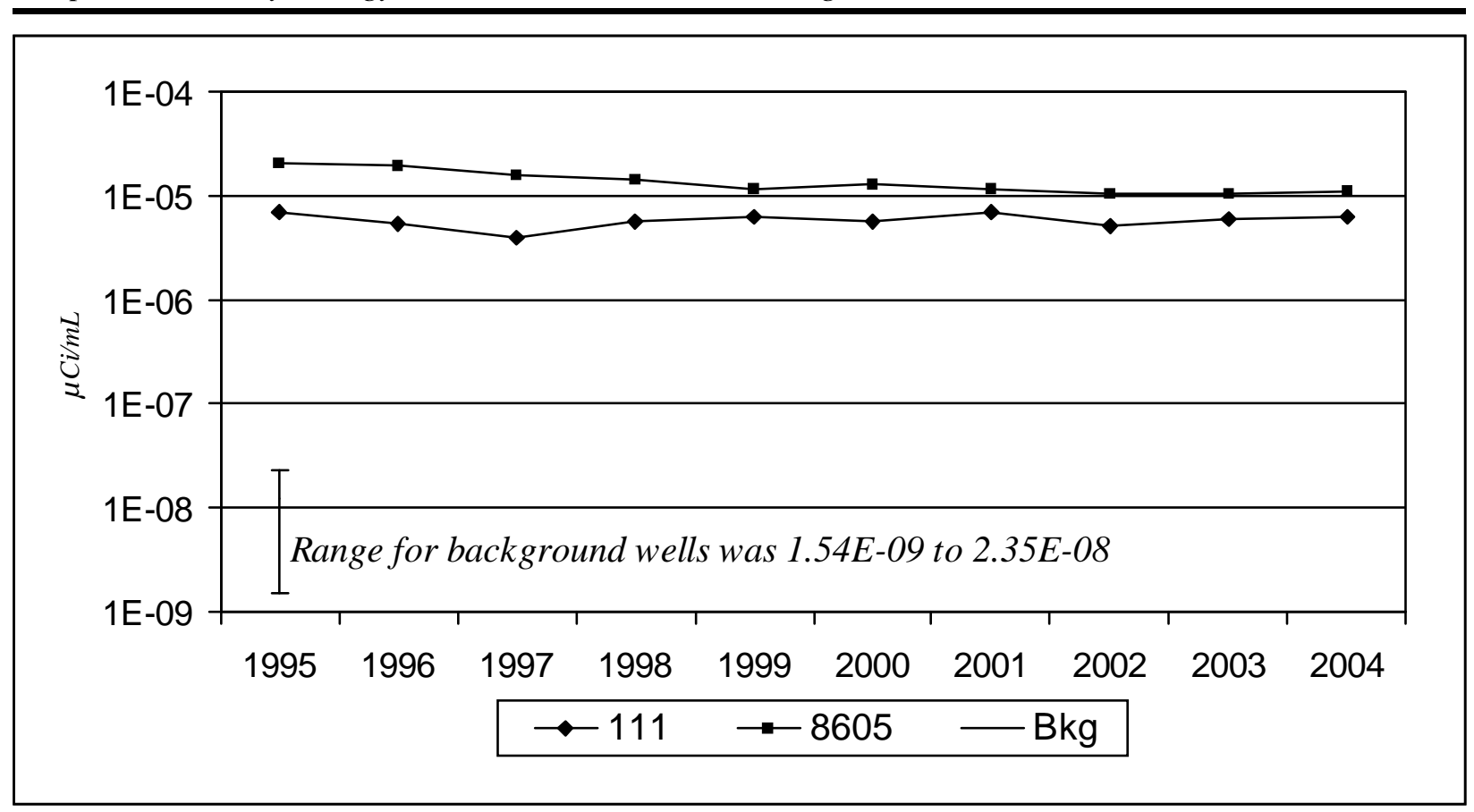

Figure 4-6. Average Yearly Gross Beta Concentrations at Locations Near Former Lagoon 1

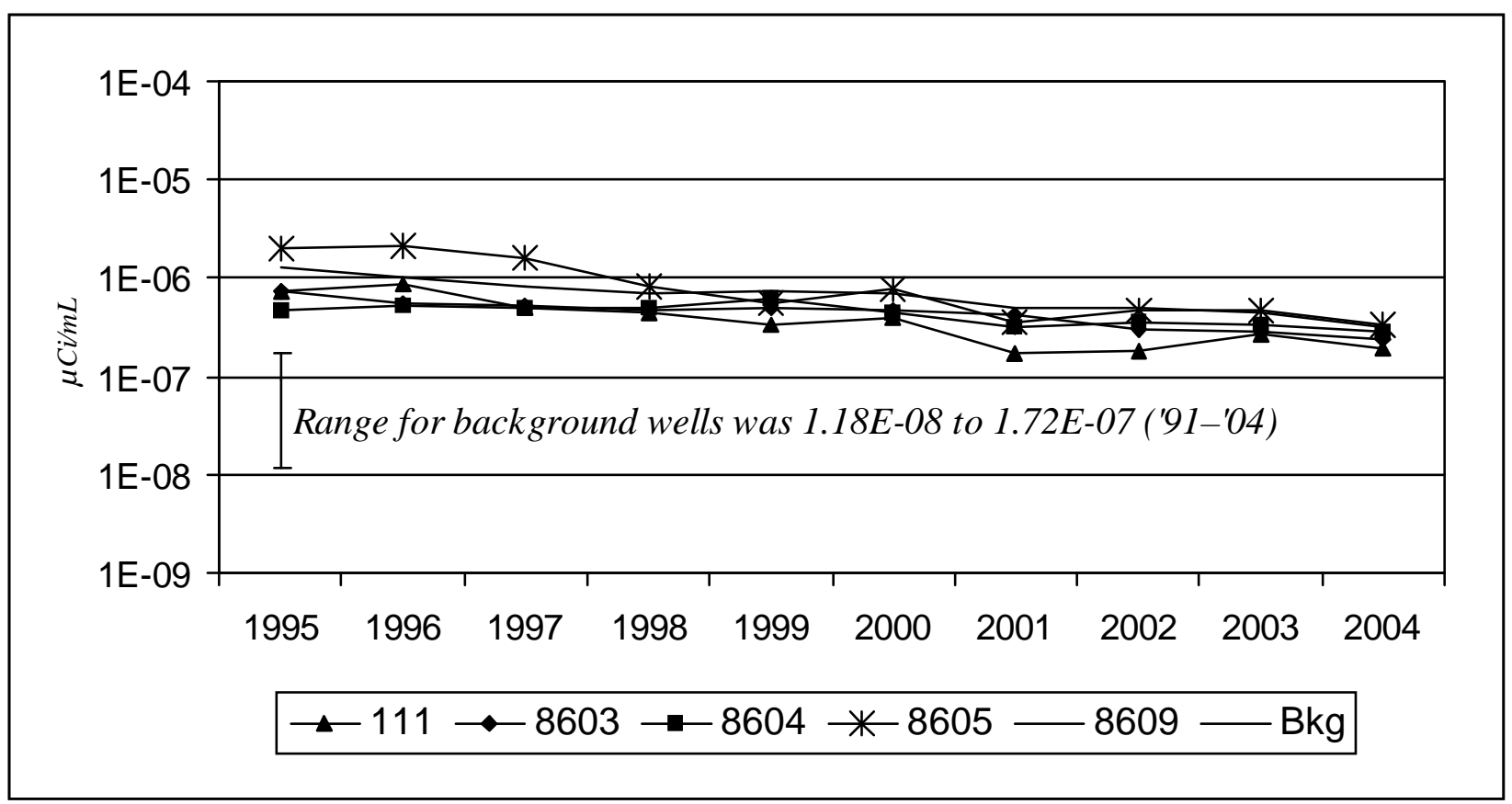

Figure 4-7. Average Yearly Tritium Concentrations at Selected Locations in the Sand and Gravel Unit 


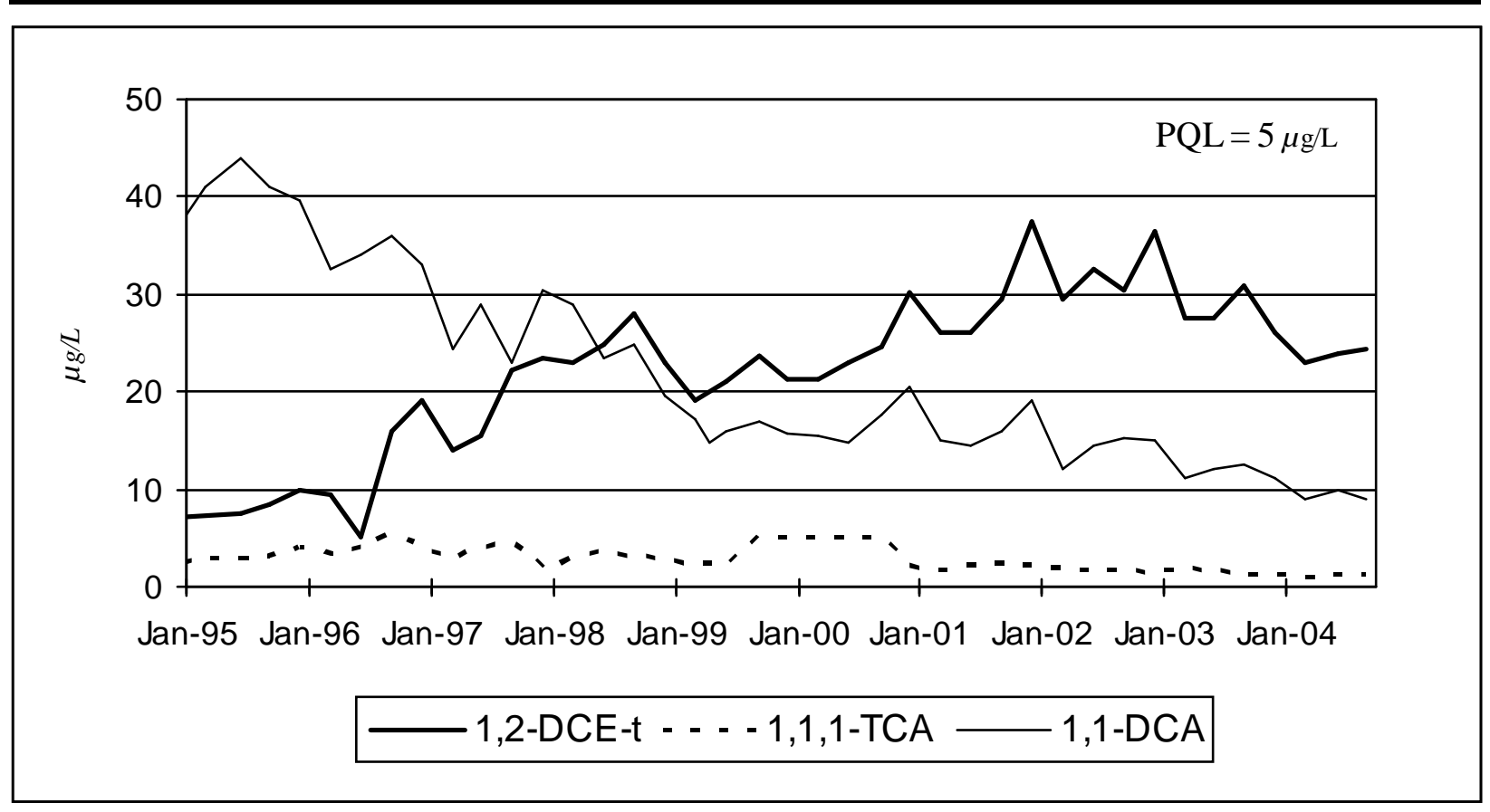

Figure 4-8. Concentrations of 1,2-DCE-t, 1,1,1-TCA, and 1,1-DCA at Well 8612 in the Sand and Gravel Unit

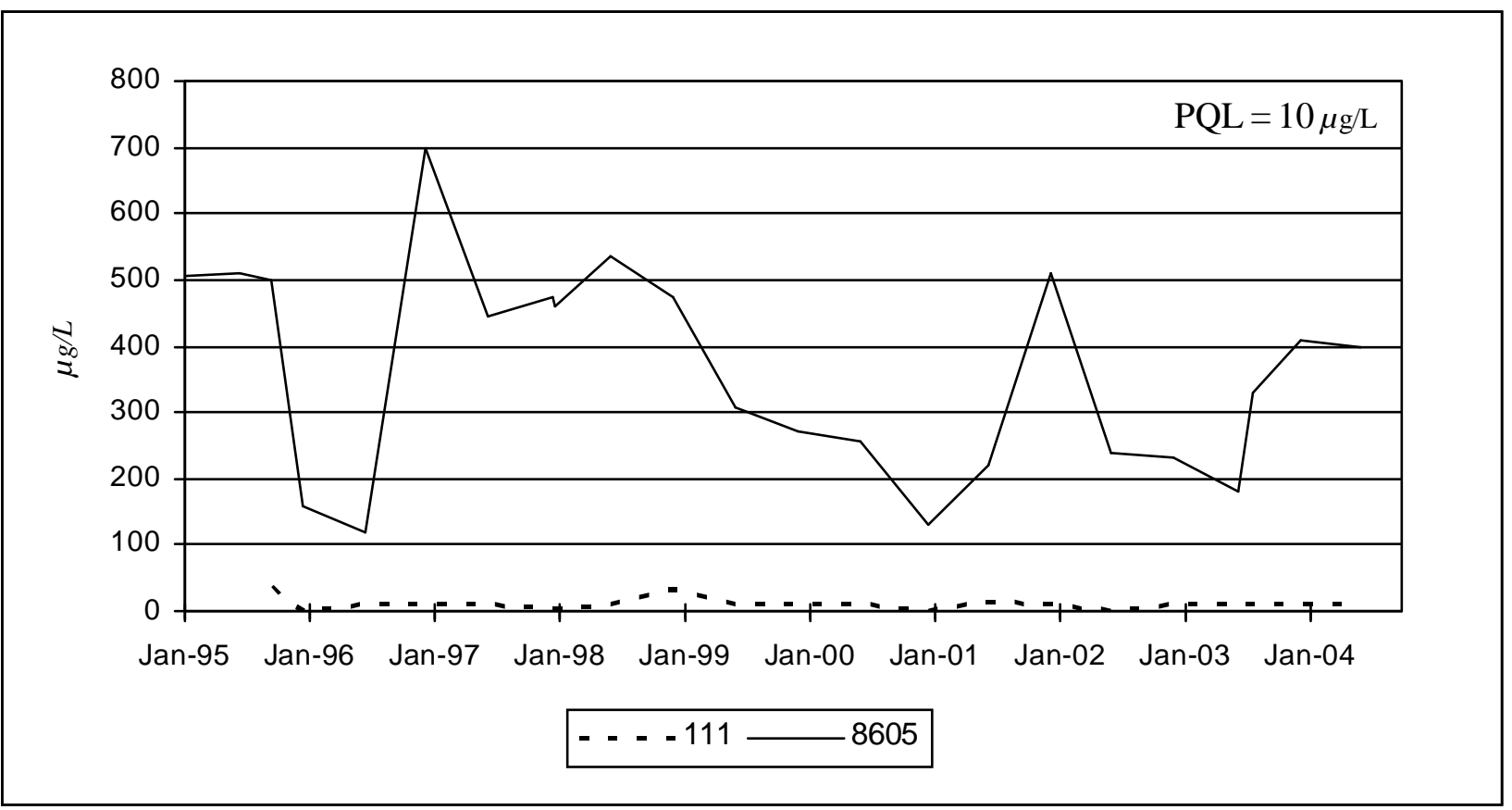

Figure 4-9. Concentrations of Tributyl Phosphate at Selected Locations in the Sand and Gravel Unit 


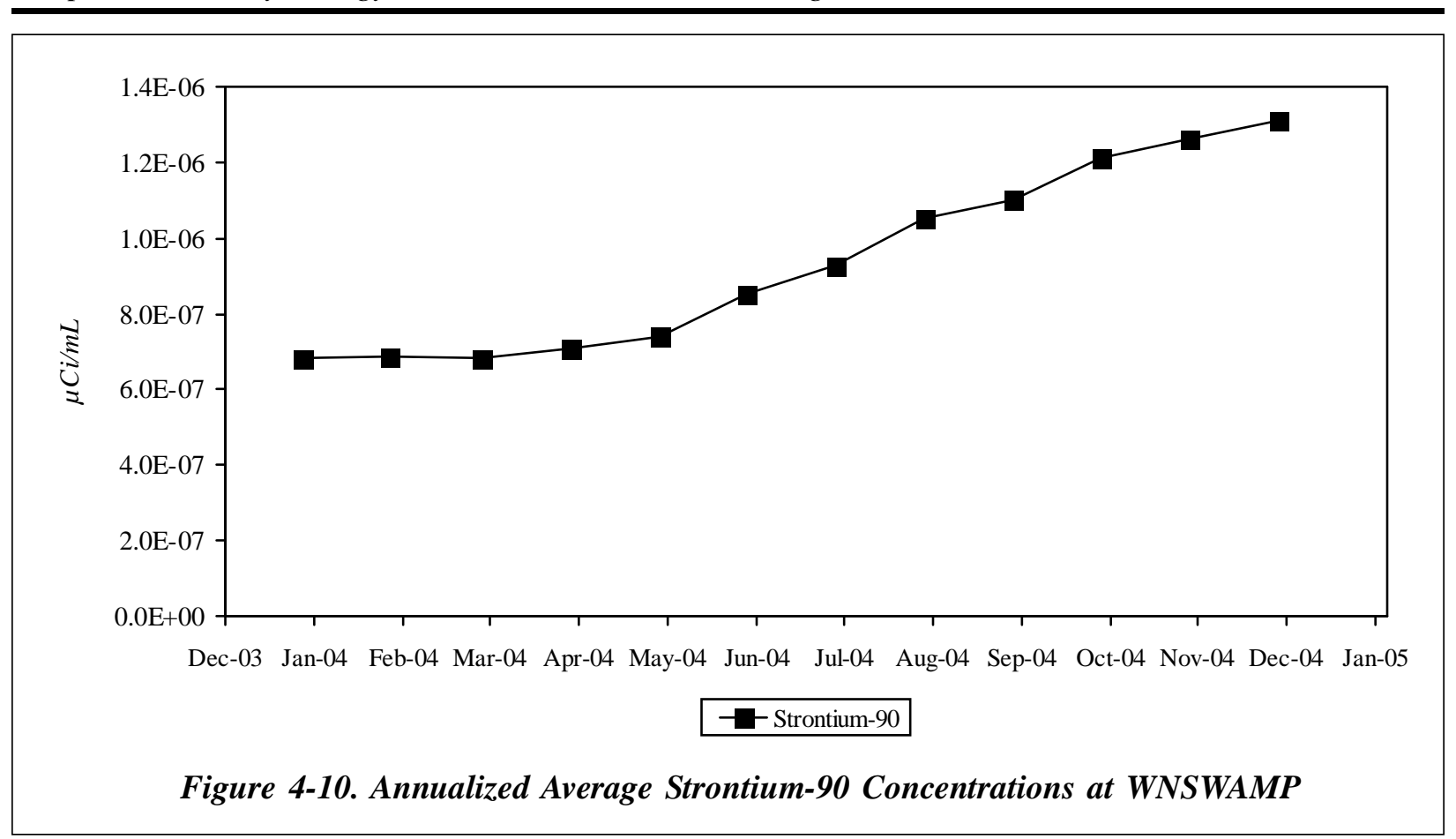

$$
4-18
$$




\section{QUALITY ASSURANCE}

\section{Quality Assurance Program}

The quality assurance (QA) program at the West Valley Demonstration Project (WVDP or Project) provides for and documents consistency, precision, and accuracy in collecting and analyzing environmental samples and in interpreting and reporting environmental monitoring data. West Valley Nuclear Services Co. (WVNSCO), by contract with the U.S. Department of Energy (DOE), implements the QA program at the WVDP. Subcontractor laboratories providing analytical services for the environmental monitoring program are contractually required to maintain a $\mathrm{QA}$ program consistent with WVNSCO requirements.

The quality requirements of Rule 10 Code of Federal Regulations Part 830, Subpart A, "Quality Assurance Requirements," Section 830.122, "Quality Assurance Criteria," and DOE Order 414.1A, "Quality Assurance" (DOE, 1999), provide the QA program policies and requirements applicable to activities at the WVDP. The WVDP QA program serves as an implementation process for meeting the DOE Order 450.1 requirement to provide "a consistent system for collecting, assessing, and documenting environmental data of known and documented quality." The integrated QA program also incorporates the requirements from the consensus standard "Quality Assurance Program
Requirements for Nuclear Facilities" (American Society of Mechanical Engineers NQA-1, 1989). Controlled documents specific to the WVDP are used to implement the integrated QA program. General areas addressed by the QA program include the following.

Responsibility. Responsibilities for overseeing, managing, and conducting an activity must be clearly defined. Personnel who verify that an activity has been completed correctly must be independent of those who performed it. Managers of programs, projects, and tasks at the WVDP are responsible for ensuring that QA requirements applicable to activities under their cognizance are implemented.

Planning. Work activities must be planned beforehand, the plan followed, and activities documented. Purchases of any equipment or items must be planned, specified precisely, and verified for correctness upon receipt.

Training. Anyone performing an activity in support of the WVDP environmental monitoring program must be trained in the appropriate procedures and qualified accordingly before carrying out the activity. 
Control of Design, Procedures, Items, and Documents. Any activity, equipment, or construction must be clearly described or defined and tested. Changes in the design must be tested and documented. Procedures must clearly state how activities will be conducted. New procedures must be developed each time an activity is added to the monitoring program. Procedures are reviewed periodically, updated when necessary, and are controlled so that only approved and current procedures are used.

Equipment or particular items affecting the quality of environmental data must be identified, inspected, calibrated, and tested before use. Calibration status must be clearly indicated. Items that do not conform to requirements must be identified as a nonconformity and segregated so as to prevent inadvertent use.

Corrective Action. Conditions adverse to quality must be promptly identified, a corrective action planned, responsibility assigned, and the problem remedied.

Documentation. Records of all activities must be kept to verify what was done and by whom. Records must be clearly traceable to an item or activity. Records such as field data sheets, chainof-custody forms, requests for analysis, sample shipping documents, sample logs, data packages, training records, and weather measurements, in addition to other records in both paper and electronic form, are maintained as documentation for the environmental monitoring program.

Audits and Assessments. Audits and assessments must be conducted to verify compliance with all aspects of the QA program and to determine its effectiveness. The WVDP environmental monitoring program is subjected to annual audits by external agencies and to internal management and self-assessments.

\section{Quality Control}

More than 13,000 environmental samples were collected and analyzed in 2004 as part of the WVDP environmental monitoring program. Quality control (QC), an integral part of QA, is used to ensure that samples are collected and analyzed in a consistent and repeatable manner. QC methods are applied both in the field and in the laboratory.

Field QC. Procedures are defined for collecting each type of sample, such as surface water, groundwater, soil, and air. Trained Environmental Laboratory field personnel collect the samples. Field sampling locations are clearly marked to ensure that routine samples are collected in the same location each time. Collection equipment that remains in the field is routinely inspected, calibrated, and maintained, and automated sampling stations are kept locked to prevent tampering. Samples are collected into certified pre-cleaned containers of an appropriate material and capacity. Containers are labeled with information about the sample, such as date and time of collection, sample collection personnel, and special field conditions. Collection information is documented and kept as part of the sample record.

Chain-of-custody documentation is maintained so as to trace sample possession from time of collection through analysis. Samples brought in from the field are transferred under signature to the sample custodian in the laboratory, where the samples are stored in a lockup before analysis or shipping. Samples sent off site for analysis are accompanied by an additional chain-of-custody form. Subcontract laboratories are required by contract to maintain internal chain-of-custody records and to store the samples under secure conditions.

Special field QC samples are collected and analyzed to assess the sampling process. Duplicate 
field samples are used to assess sample homogeneity and sampling precision. Field and trip blanks (laboratory-deionized water in sample containers) are used to detect contamination potentially introduced during sampling or shipping. Environmental background samples (samples of air, water, vegetation, meat, and milk taken from locations remote from the WVDP) are collected and analyzed to provide baseline information for comparison with on-site or near-site samples so that site influences can be evaluated.

Laboratory QC. In 2004, environmental monitoring samples were analyzed at several on-site and off-site laboratories. On-site analyses were conducted by the Environmental Laboratory ([ELAB], radiological indicator parameters, gamma spectroscopy, strontium-90 in water, and field $\mathrm{pH}$ and conductivity), the Wastewater Treatment Facility Laboratory (total residual chlorine, $\mathrm{pH}$, and settleable solids), and the Analytical and Process Chemistry Laboratory ([A\&PC], total dissolved solids).

Off-site analyses were performed by General Engineering Laboratories (GEL, in Charleston, South Carolina) for multimedia radiochemical parameters and low-level mercury; Severn Trent Laboratories (STL, in Buffalo, New York) for chemical analyses; Lionville Laboratory, Inc. (in Lionville, Pennsylvania) for chemical analysis of radiologically contaminated samples; Fruit Grower Laboratories (in Santa Paula, California) for analysis of biological contaminants in potable water; and Bechtel BWXT Idaho, LLC (at the Idaho National Engineering and Environmental Laboratory) for environmental thermoluminescent dosimeters. Subcontract laboratories are required to maintain all relevant certifications, participate in applicable crosscheck programs, and maintain a level of QC as defined in their contracts with WVNSCO.
Laboratory QC practices specific to each analytical method are described in approved references or procedures. QC practices include proper training of analysts, maintaining and calibrating measuring equipment and instrumentation, and routinely processing laboratory QC samples such as standards and spikes (to assess method accuracy), duplicates and replicates (to assess precision), and blanks (to assess the possibility of contamination). Standard reference materials (materials with known quantities or concentrations of constituents of interest) traceable to the National Institute of Standards and Technology are used to calibrate counting and test instruments and to monitor their performance.

\section{Independent Comparisons and Crosschecks.} To allow for independent confirmation of environmental monitoring data, samples of air filters, water, milk, fish, vegetation, and sediments are split or separately collected and sent to the New York State Department of Health (NYSDOH) for measurement and independent reporting to the public. Locations at which co-located samples are taken are listed in Appendix $\mathrm{B}^{\mathrm{CD}}$ of this report.

Crosscheck samples (performance evaluation samples) contain a quantity or concentration of a constituent of interest known to the agency conducting the crosscheck, but unknown to the participating laboratory. Crosscheck programs provide an additional means of testing accuracy of environmental measurements. Subcontract laboratories are required to perform satisfactorily on crosschecks, with satisfactory performance defined as having at least $80 \%$ of reported results falling within control limits. Crosscheck results that fall outside of control limits are addressed by formal corrective actions to determine any conditions that could adversely affect sample data and to ensure that actual sample results are reliable. 
The WVDP participates in formal crosscheck programs for both radiological and nonradiological analyses.

Radiological Crosschecks. Organizations performing radiological analyses as part of effluent or environmental monitoring are encouraged by the DOE to participate in formal crosscheck programs to test the quality of environmental measurements being reported to the DOE by its contractors. Crosscheck samples for radiological constituents are analyzed on site by the ELAB and off site by GEL.

In 2004, the WVDP participated in the DOE Environmental Measurements Laboratory Quality Assessment Program and the DOE Radiological Environmental Sciences Laboratory Mixed Analyte Performance Evaluation Program (MAPEP). Results are listed in Appendix $\mathrm{J}^{\text {G0 }}$. A total of 101 radiological crosscheck analyses were performed by or for the WVDP. Of these results, a total of 97 (96\%) were within acceptance limits.

Nonradiological Crosschecks. As a New York State Pollutant Discharge Elimination System (SPDES) Permittee, the WVDP is required to participate in the U.S. Environmental Protection Agency Discharge Monitoring Report - Quality Assurance performance evaluation studies for the National Pollutant Discharge Elimination System. Samples from this program are analyzed both on site and by subcontract laboratories. To achieve and maintain certification to analyze environmental samples from the state of New York, subcontract analytical laboratories are contractually required to demonstrate evidence of satisfactory performance on samples provided by the NYSDOH Environmental Laboratory Approval Program. In addition, subcontract laboratories performing nonradiological analyses of samples that contain radiological contamination participate in the
DOE MAPEP program. This mixed analyte program provides performance evaluation samples for both radiological and nonradiological constituents. In 2004, nonradiological crosschecks were analyzed by the WVDP Wastewater Treatment Facility Laboratory and by STL. Results are summarized in Appendix $\mathrm{J}^{\text {to }}$. A total of 80 nonradiological crosscheck analyses were performed by or for the WVDP. Of these results, a total of $78(97.5 \%)$ were within acceptance limits.

\section{Data Management}

The Environmental Laboratory Information Management System (LIMS) is a database system used at the WVDP for establishing sample identification number, maintaining the sample data log, tracking samples, managing field and analytical data, and recording status and results of data validation. The LIMS is used as a controlled-source database for generating reports and statistical evaluations of data sets to support environmental surveillance activities. Subcontract laboratories are requested to provide data in electronic format for direct entry into the LIMS by WVDP personnel.

All software packages used to generate data are verified and validated before use. All analytical data produced in the ELAB at the bench level are reviewed and signed off by a qualified person other than the one who performed the analysis. A similar in-house review is contractually required from subcontractor laboratories.

\section{Data Verification and Validation}

Data validation is the process by which analytical data from both on-site and off-site laboratories are reviewed to verify proper documentation of sample processing and data reporting, and to determine the quality and usability of the data. A graded ap- 
proach is applied that, based upon data quality objectives, dictates the rigor of review of the documentation associated with sample collection and/ or sample analysis. In the WVDP environmental program, each data point is validated per approved standard procedures before it is assigned approval status and made ready for data assessment.

\section{Data Assessment and Reporting}

Validated analytical data, field information, and historical project data are integrated and evaluated to determine whether the constituents of interest are actually present and, if so, at what concentrations. Data problems identified at this level are investigated and appropriately resolved.

Data from the environmental monitoring program are then evaluated to assess the effect, if any, of the site operations and activities on the environment and the public. Data from each sampling location are compared with historical results from the same location, with comparable background measurements, and (if applicable) with regulatory limits or guidance standards. Standard statistical methods are used to evaluate the data.

Before each technical report is issued, the final document is comprehensively reviewed by one or more persons who are knowledgeable in the technical aspects of the work.

\section{Audits, Appraisals, and Self- Assessments}

In 2004, the New York State Department of Environmental Conservation performed an inspection of WVDP's wastewater treatment facilities and the SPDES discharge monitoring program. The DOE conducted an on-site audit during which WVDP sampling practices were inspected. No findings were reported.
Two routine self-assessments of the environmental monitoring program were conducted in 2004. Topics examined were worker safety, compliance with Conduct of Operations requirements during field sampling activities, field safety, and reporting requirements associated with WVDPAnimal Control Operations. WVDP self-assessments in 2004 also examined the air sampling program, general health and safety, general software QA, and the chemical storage facility at the A\&PC Laboratory. Although actions were recommended to improve some program aspects, nothing was found that would compromise the quality of the data in this report or the environmental monitoring program in general.

\section{Lessons Learned}

Lessons learned data from audits, appraisals, and self-assessments are shared internally and externally through the WVDP lessons learned program. The WVDP maintains this system to promote the recurrence of desirable events and to minimize the recurrence of undesirable events.

\section{Conclusion}

The QA elements described in this chapter ensure that environmental monitoring data are consistent, precise, accurate, and complete. The multiple levels of scrutiny built into generating, verifying, validating, evaluating, and reporting data from the environmental monitoring program ensure that reliable data are reported. The effectiveness of the environmental monitoring program is evidenced by continuing favorable QA assessments. 
This page intentionally left blank

$$
5-6
$$




\section{REFERENCES AND BIBLIOGRAPHY}

(For a bibliographical listing that includes basis documents not specifically cited in the text, see the WVDP Annual Site Environmental Report for 2003.)

American National Standards Institute/American Society for Quality Control. 1994.

Specifications and Guidelines for Quality Systems for Environmental Data Collection and Environmental Technology Programs. ANSI/ASQC E4-1994.

American National Standards Institute, Inc. August 20, 1975. American National Standard: Performance Testing, and Procedural Specifications for Thermoluminescent Dosimetry (Environmental Applications). ANSI N545-1975.

American Society of Mechanical Engineers. 1989. Quality Assurance Program Requirements for Nuclear Facilities. ASME-NQA-1. New York: The American Society of Mechanical Engineers.

Brookhaven National Laboratory. January 2000. Nuclear Wallet Cards. National Nuclear Data Center. Upton, New York.

Citizen Task Force. July 29, 1998. West Valley Citizen Task Force Final Report.

Executive Order 11990. May 25, 1977. Protection of Wetlands. 42 FR 26961.

Executive Order 13101. September 16, 1998. Greening the Government Through Waste Prevention, Recycling, and Federal Acquisition. 63 FR 49643.

Executive Order 13148. April 26, 2000. Greening the Government Through Leadership in Environmental Management. 65 FR 24595. (This order revoked Executive Order 12856, Federal Compliance with Right-To-Know Laws and Pollution Prevention Requirements.)

International Atomic Energy Agency (IAEA). 1992. Effects of Ionizing Radiation on Plants and Animals at Levels Implied by Current Radiation Protection Standards. Technical Report Series No. 332, IAEA, Vienna, Austria.

$$
R \& B-1
$$


International Commission on Radiological Protection. 1977. Recommendations of the International Commission on Radiological Protection. ICRP Publication 26. Oxford: Pergamon Press.

1979. Recommendations of the International Commission on Radiological Protection - Limits for Intakes of Radionuclides by Workers. ICRP Publication 30. Oxford: Pergamon Press.

International Organization for Standardization. 1996. Environmental Management Systems. ISO 14001:1996.

Long, E.R., and L.G. Morgan. 1990. The Potential for Biological Effects of Sediment-Sorbed Contaminants Tested in the National States and Trends Program. National Oceanic Atmospheric Administration (NOAA) Technical Memorandum No. 5, OMA52, NOAA National Ocean Service, Seattle, Washington.

National Council on Radiation Protection and Measurements. 1987. Ionizing Radiation Exposure of the Population of the United States. NCRP-93. Bethesda, Maryland.

National Research Council. 1990. Health Effects of Exposure to Low Levels of Ionizing Radiation. Biological Effects of Ionizing Radiation (BEIR) V. Washington: National Academy Press.

New York State Department of Environmental Conservation. nd. Title 6, New York Codes, Rules, and Regulations (6 NYCRR). Environmental Conservation Rules and Regulations.

. January 24, 1994. Determination of Soil Cleanup Objectives and Cleanup Levels. Technical and Administrative Guidance Memorandum (TAGM) \#4046.

1995. Appendix 33 - Groundwater Monitoring List. Title 6 NYCRR Subpart 373-2.

. September 3, 1996. Federal Facility Compliance Act: Order on Consent.

. June 1998. Ambient Water Quality Standards and Guidance Values and Groundwater Effluent Limitations. Technical and Operational Guidance Series (TOGS) 1.1.1.

. January 25, 1999. Technical Guidance for Screening Contaminated Sediments.

. March 19, 1999. Stipulation of Agreement Pursuant to Section 17-0303 of the Environmental Conservation Law and Section 176 of the Navigation Law.

. February 1, 2004. State Pollutant Discharge Elimination System (SPDES)

Discharge Permit NY0000973.

$R \& B-2$ 
. January 2003. Draft Technical and Operational Guidance Series (TOGS) \#5.1.9.

In-Water and Riparian Management of Sediment and Dredge Material.

New York State Department of Health. nd. Environmental Laboratory Approval Program (ELAP) Certification Manual.

. nd. Title 10, New York Code, Rules, and Regulations (10 NYCRR). Sources of Water Supply. Part 5 (Drinking Water Supplies) and Part 170 (Sources of Water Supply).

Pacific Northwest Laboratory (PNL). November 1988. Napier, B.A., Strenge, D.L., Pelequin, R.A., and Ramsdell, J.V. GENII - The Hanford Environmental Radiation Dosimetry Software System. Version 1.485, PNL-6584.

Parks B.L. March 1992. User's Guide for CAP88-PC. Version 1.0. Las Vegas, NV: U.S. Environmental Protection Agency Office of Radiation Programs. 402-B-92-001.

. June 1997. CAP88-PC Version 2.0 User's Guide. Germantown, Maryland. U.S. Department of Energy.

Persaud, D., Jaagumagi, R., and A. Hayton. 1992. Guidelines for the Protection and Management of Aquatic Sediment Quality in Ontario. Ontario Ministry of the Environment, Queen's Printer for Ontario.

Rickard, L.V. 1975. Correlation of the Silurian and Devonian Rocks in New York State. New York State Museum and Science Service Map and Chart Series No. 24.

Simpson, D.B., and B.L. McGill. 1980. LADTAP II: A Computer Program for Calculating Radiation Exposure to Man from Routine Release of Nuclear Reactor Liquid Effluents. Technical Data Management Center. ORNL/NUREG/TDMC-1.

Standish, P.N. 1985. Closure of the Construction Landfill Site. Letter (WD:85:0434) to W.H. Hannum, Department of Energy, West Valley Project Office.

U.S. Congress. 1954. Atomic Energy Act of 1954. 42 United States Code (USC) §2011 et seq. 1955. Clean Air Act. 42 USC $\$ 7401$ et seq. . 1966. National Historic Preservation Act of 1966. 16 USC $\S 470$ et seq. 1969. National Environmental Policy Act of 1969. 42 USC $§ 4321$ et seq. . 1973. Endangered Species Act of 1973. 16 USC $\$ 1531$ et seq. 
. 1974. Safe Drinking Water Act. 42 USC $\$ 300 f$ et seq.

. October 23, 1976. Resource Conservation and Recovery Act of 1976. Public Law 94-580, 90 Stat. 2795, 42 USC $\$ 6901$ et seq.

. November 1976. Migratory Bird Treaty Act. 16 USC $§ 703$ et seq.

. 1977. Federal Water Pollution Control Act. 33 USC §1251 et seq. (Also known as the Clean Water Act)

. October 1, 1980. An Act to Authorize the Department of Energy to Carry Out a High-Level Liquid Nuclear Waste Management Demonstration Project at the Western New York Service Center in West Valley, New York. Public Law 96-368 [S. 2443]. Congressional Record, Vol. 126. (Also known as the WVDP Act)

December 11, 1980. Comprehensive Environmental Response, Compensation, and Liability Act of 1980. Public Law 96-510, 42 USC $\$ 9601$ et seq.

. 1986a. Toxic Substances Control Act. 15 USC §2601 et seq.

. 1986b. Emergency Planning and Community Right-to-Know Act of 1986. 42 USC $\S 11001$ et seq.

October 17, 1986. Superfund Amendments and Reauthorization Act (SARA) of 1986. Public Law 99-499, 100 Stat. 1613, Title 10.

U.S. Department of Commerce. U.S. Census Bureau. Census 2000.

U.S. Department of Energy. nd. Quality Assurance Criteria. 10 CFR 830.122.

July 1981. A Guide for Environmental Radiological Surveillance at U.S. Department of Energy Installations. DOE/EP-0023. Washington, D.C.

. July 1983. A Guide for Effluent Radiological Measurements at DOE Installations. DOE/EP-0096. Washington, D.C.

. February 8, 1990. Radiation Protection of the Public and the Environment. DOE Order 5400.5, including Change 2 (January 7, 1993). Washington, D.C.

. January 1991. Environmental Regulatory Guide for Radiological Effluent Monitoring and Environmental Surveillance. DOE/EH-0173T. Washington, D.C.

$R \& B-4$ 
. January 1996. Draft Environmental Impact Statement for Completion of the West Valley Demonstration Project and Closure or Long-Term Management of Facilities at the Western New York Nuclear Services Center. DOE/EIS-0226-D.

. May 1997. Final Waste Management Programmatic Environmental Impact Statement for Managing Treatment, Storage, and Disposal of Radioactive and Hazardous Waste. DOE/EIS-0200-F.

. March 27, 1998. Worker Protection Management for DOE Federal and Contractor Employees. DOE Order 440.1A. Washington, D.C.

. July 9, 1999. Radioactive Waste Management. DOE Order 435.1, including Change 1 (August 28, 2001). Washington, D.C.

September 29, 1999. Quality Assurance. DOE Order 414.1A, including Change 1 (July 12, 2001). Washington D.C. (DOE Order 414.1A was canceled by DOE Order 414.1B, April 29, 2004.)

February 25, 2000. Record of Decision for the DOE's Waste Management Program: Treatment and Disposal of Low-Level Waste and Mixed Low-Level Waste; Amendment of the Record of Decision for the Nevada Test Site. 65 FR 10061.

. October 26, 2000. National Environmental Policy Act Compliance Program. DOE Order 451.1B, including Change 1 (September 28, 2001). Washington, D.C.

. March 26, 2001. Revised Strategy for the Environmental Impact Statement for Completion of the West Valley Demonstration Project and Closure or Long-Term Management of Facilities at the Western New York Nuclear Service Center and Solicitation of Scoping Comments. 66 FR 16447.

. November 6, 2001. Advance Notice of Intent to Prepare an Environmental Impact Statement to Evaluate Decommissioning and/or Long-Term Stewardship at the West Valley Demonstration Project and Western New York Nuclear Service Center. 66 FR 56090.

July 2002. DOE Standard: A Graded Approach for Evaluating Radiation Doses to Aquatic and Terrestrial Biota. DOE-STD-1153-2002. Washington, D.C.

September 23, 2002. Radioactive Material Transportation Practices Manual. DOE M 460.2-1.

. January 2003. Estimating Radiation Risk from Total Effective Dose Equivalent (TEDE). International Steering Committee on Radiation Standards (ISCORS) Technical Report No. 1. DOE/EH-412/0015/0502, Rev. 1. 
. January 15, 2003. Environmental Protection Program. DOE Order 450.1, including Change 1 (January 24, 2005). Washington, D.C. (Canceled DOE Order 5400.1, General Environmental Protection Program, November 9, 1988, including Change 1 [June 29, 1990].)

March 13, 2003. Notice of Intent to Prepare an Environmental Impact Statement for Decommissioning and/or Long-Term Stewardship at the West Valley Demonstration Project and Western New York Nuclear Services Center. 68 FR 12044.

. May 16, 2003. Notice of Availability of the West Valley Demonstration Project Draft Waste Management Environmental Impact Statement. 68 FR 26587.

August 19, 2003. Environment, Safety, and Health Reporting. DOE Order 231.1A, including Change 1 (June 3, 2004). Washington, D.C.

December 2003. West Valley Demonstration Project Waste Management Environmental Impact Statement. DOE/EIS-0337F.

January 2004. Users Guide: RESRAD-BIOTA: A Tool for Implementing a Graded Approach to Biota Dose Evaluation. Version 1. DOE/EH-0676. (ISCORS Technical Report 2004-2).

. March 19, 2004. Environment, Safety, and Health Reporting Manual. DOE M 231.1-1A.

April 29, 2004. Quality Assurance. DOE Order 414.1B. Washington, D.C.

U.S. Department of Energy and New York State Energy Research and Development Authority. 1981. Cooperative Agreement between United States Department of Energy and New York State Energy Research and Development Authority on the Western New York Nuclear Service Center at West Valley, New York, effective October 1, 1980, as amended September 18.

U.S. Environmental Protection Agency. nd. 40 Code of Federal Regulations, Protection of the Environment, Chapter 1, Environmental Protection Agency.

March 1983. Mercury, Method 245.1 (Manual Cold Vapor Technique). Methods for Chemical Analysis of Water and Wastes. Environmental Monitoring and Support Laboratory. Cincinnati, Ohio.

1984a. Drinking Water Guidelines. 40 CFR 141, National Secondary Drinking Water Regulations, Subpart B, Maximum Contaminant Levels.

1984b. Drinking Water Guidelines. 40 CFR 143, National Secondary Drinking Water Regulations, Section 143.3, Secondary Maximum Contaminant Levels.

$R \& B-6$ 
December 15, 1989. National Emission Standards for Hazardous Air Pollutants:

Standards for Radionuclides. 40 CFR 61, including update of September 9, 2002. Washington,

D.C.: U.S. Government Printing Office.

1992. Region II Administrative Order on Consent. Docket No. II RCRA 3008(h) -

92-0202. In the Matter of: Western New York Nuclear Service Center.

. October 16, 1996. Code of Environmental Management Principles. 61 FR 54062.

. August 2002. Method 1631, Revision E: Mercury in Water by Oxidation, Purge and

Trap, and Cold Vapor Atomic Fluorescence Spectrometry. EPA-821-R-02-019.

U.S. Nuclear Regulatory Commission. October 1977. Regulatory Guide 1.109: Calculation of Annual Doses to Man from Routine Releases of Reactor Effluents for the Purpose of Evaluating Compliance with 10 CFR Part 50, Appendix I.

July 1997. Radiological Criteria for License Termination. 10 CFR Part 20,

Appendix E.

. February 1, 2002. Decommissioning Criteria for the West Valley Demonstration Project (M-32) at the West Valley Site; Final Policy Statement. 67 FR 5003.

URS Group, Inc. April 8, 2002. Land Use Survey. Rev. 0. AR \#2002-171.

West Valley Nuclear Services Co., Inc. May 1, 1995. Subsurface Probing Investigation on the North Plateau at the West Valley Demonstration Project. Rev. 0. WVDP-220.

. March 1996. Environmental Information Document, Volume III: Hydrology, Part 4. WVDP-EIS-009.

. June 11, 1999. 1998 Geoprobe ${ }^{\circledR}$ Investigation in the Core Area of the North Plateau Groundwater Plume. Rev. 0. WVDP-346.

. October 26, 1999. Asbestos Management Plan. Rev. 5. WVDP-072.

. March 21, 2001 and December 28, 2004. PCB and PCB-Contaminated Material Management Plan. Rev. 6 and Rev. 7. WVDP-080.

April 15, 2003. Manual for Radiological Assessment of Environmental Releases at the WVDP. Rev. 4. WVDP-065.

. July 10, 2003 and April 22, 2004. WVDP Environmental Management System.

Rev. 15 and Rev. 16. WV-980.

$R \& B-7$ 
. November 25, 2003 and October 27, 2004. WVDP Safety Management System (SMS) Description. Rev. 9 and Rev. 10. WVDP-310.

. December 2, 2003. Environmental Monitoring Program Plan. Rev. 12. WVDP-098.

. December 2, 2003 and November 3, 2004. WVDP Groundwater Protection Management Program Plan. Rev. 5 and Rev. 6. WVDP-091.

. December 3, 2003 and November 3, 2004. Groundwater Monitoring Plan. Rev. 7 and Rev. 8. WVDP-239.

December 23, 2003 and December 30, 2004. Waste Minimization/Pollution Prevention Awareness Plan. Rev. 7 and Rev. 8. WVDP-087.

. July 1, 2004. Annual Status Report for the Hazardous Waste Reduction Program.

February 28, 2005. New York State Department of Environmental Conservation Hazardous Waste Report for 2004.

February 10, 2005. Site Treatment Plan: Fiscal Year 2004 Update. Rev. 7. WVDP-299.

West Valley Nuclear Services Co., Inc. and Dames \& Moore. June 1997. West Valley Demonstration Project Site Environmental Report, Calendar Year 1996.

July 1997. Resource Conservation and Recovery Act Facility Investigation Report, Vol.1: Introduction and General Site Overview. WVDP-RFI-017.

. June 1998. Final Report: Evaluation of the Pilot Program to Investigate Chromium and Nickel Concentrations in Groundwater in the Sand and Gravel Unit.

West Valley Nuclear Services Co. and URS Group, Inc. January 2001. Results of Corrosion Evaluation in Selected Stainless Steel Monitoring Wells on the North Plateau and Recommendations for Long-Term Management.

August 2003. West Valley Demonstration Project Annual Site Environmental Report, Calendar Year 2002.

$R \& B-8$ 


\section{GLOSSARY}

\section{A}

accuracy. The degree of agreement between a measurement and its true value. The accuracy of a data set is assessed by evaluating results from standards or sample spikes containing known quantities of an analyte.

action plan. An action plan addresses assessment findings and root causes that have been identified in an audit or an assessment report. It is intended to define specific actions that the responsible group will undertake to remedy deficiencies. The plan includes a timetable and funding requirements for implementation of the planned activities.

alluvial fan. A cone-shaped deposit of alluvium made by a stream where it runs out onto a level plain.

alluvium. Sedimentary material deposited by flowing water, such as a river.

aquifer. A water-bearing unit of permeable rock or soil that will yield water in usable quantities to wells. Confined aquifers are bounded above and below by less permeable layers. Groundwater in a confined aquifer is under a pressure greater than the atmospheric pressure. Unconfined aquifers are bounded below by less permeable material, but are not bounded above. The pressure on the groundwater at the surface of an unconfined aquifer is equal to that of the atmosphere.

as low as reasonably achievable (ALARA). An approach to radiation protection that advocates controlling or managing exposures (both individual and collective) to the work force and the general public and releases of radioactive material to the environment as low as social, technical, economic, practical, and public policy considerations permit. As used in DOE Order 5400.5, ALARA is not a dose limit but, rather, a process that has as its objective the attainment of dose levels as far below the applicable limits of the Order as practicable.

$G L O-1$ 
B

background radiation. Natural and man-made radiation such as cosmic radiation and radiation from naturally radioactive elements and from commercial sources and medical procedures.

becquerel (Bq). A unit of radioactivity equal to one nuclear transformation per second.

British thermal unit (BTU, also MBTU, MMBTU). A standard unit of measurement used to denote both the amount of heat energy in fuels and the ability of appliances and air-conditioning systems to produce heating or cooling. A BTU is the amount of heat required to increase the temperature of a pint of water (which weighs exactly 16 ounces) by one degree Farenheit. One million BTUs may be expressed as one MBTU or one MMBTU (to represent a thousand thousand BTUs), which is occasionally used as a standard unit of measurement for natural gas and provides a convenient basis for comparing the energy content of various grades of natural gas and other fuels. One cubic foot of natural gas produces approximately 1,000 BTUs, so 1,000 cubic feet of gas is comparable to $1 \mathrm{MBTU}$.

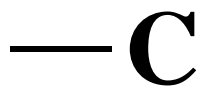

categorical exclusion (CX). A proposed action that normally does not require an environmental assessment or an environmental impact statement and that the Department of Energy has determined does not individually or cumulatively have a significant effect on the human environment. See 10 CFR 1021.410.

Class A, B, and C low-level waste. Waste classifications from the Nuclear Regulatory Commission's 10 CFR Part 61 rule. Maximum concentration limits are set for specific isotopes. Class A waste disposal is minimally restricted with respect to the form of the waste. Class B waste must meet more rigorous requirements to ensure physical stability after disposal. Higher concentration limits are set for the same isotopes in Class $\mathrm{C}$ waste, which also must meet physical stability requirements. Moreover, special measures must be taken at the disposal facility to protect against inadvertent intrusion.

compliance findings. Conditions that may not satisfy applicable environmental or safety and health regulations, DOE Orders and memoranda, enforcement actions, agreements with regulatory agencies, or permit conditions.

confidence coefficient or factor. The chance or probability, usually expressed as a percentage, that a confidence interval includes some defined parameter of a population. The confidence coefficients usually associated with confidence intervals are $90 \%, 95 \%$, and $99 \%$.

$G L O-2$ 
confidence interval. The range of values within which some parameter may be expected to lie with a stated degree of confidence. For example, a value of 10 with an uncertainty of 5 calculated at the $95 \%$ confidence level $(10 \pm 5)$ indicates there is a $95 \%$ probability that the true value of the population parameter lies between 5 and 15 .

consistency. The condition of showing steady conformity to practices. In the environmental monitoring program, approved procedures are in place so that data collection activities are carried out in a consistent manner to minimize variability.

cosmic radiation. High-energy subatomic particles from outer space that bombard the earth's atmosphere. Cosmic radiation is part of natural background radiation.

counting error. The variability caused by the inherent random nature of radioactive disintegration and by the detection process.

curie (Ci). A unit of radioactivity equal to 37 billion $\left(3.7 \times 10^{10}\right)$ nuclear transformations per second.

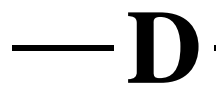

data set. A group of data (e.g., factual information such as measurements or statistics) used as a basis for reasoning, discussion, or calculation.

decay (radioactive). Disintegration of the nucleus of an unstable nuclide by spontaneous emission of charged particles and/or photons or by spontaneous fission.

derived concentration guide (DCG). The concentration of a radionuclide in air and water that, under conditions of continuous exposure for one year by one exposure mode (i.e., ingestion of water, submersion in air, or inhalation), would result in an effective dose equivalent of 100 mrem $(1 \mathrm{mSv})$. See Table $\mathrm{K}-1^{\mathrm{GD}}$ in Appendix $\mathrm{K}^{\mathrm{ED}}$.

detection limit or level (DL). This term may also be expressed as "method detection limit" (MDL). The smallest amount of a substance that can be distinguished in a sample by a given measurement procedure at a given confidence level. (See lower limit of detection.)

dispersion (groundwater). The process whereby solutes are spread or mixed as they are transported by groundwater as it moves through the subsurface.

dosimeter. A portable device for measuring the total accumulated exposure to ionizing radiation.

downgradient. The direction of water flow from a reference point to a selected point of interest at a lower elevation than the reference point. (See gradient.)

$G L O-3$ 
$\mathbf{E}$

effective dose. (See effective dose equivalent under radiation dose.)

effluent. Any treated or untreated air emission or liquid discharge to the environment, including storm water runoff.

effluent monitoring. Sampling or measuring specific liquid or gaseous effluent streams for the presence of pollutants.

enhanced work planning. A process used to evaluate and improve the program by which work is identified, planned, approved, controlled, and executed. The key elements are line management ownership, a graded approach to work management based on risk and complexity, worker involvement beginning at the earliest phases of work management, organizationally diverse teams, and organized, institution-wide communication.

environmental assessment (EA). An evaluation that provides sufficient evidence and analysis for determining whether an environmental impact statement or a finding of no significant impact is required. Detailed information found in 40 CFR 1508.9.

environmental impact statement (EIS). A detailed statement that includes the environmental impact of the proposed action, any adverse environmental effects that cannot be avoided should the proposal be implemented, and alternatives to the proposed action. Detailed information found in Section 102 (2) (C) of the National Environmental Policy Act.

environmental management system (EMS). The systematic application of business management practices to environmental issues, including defining the organizational structure, planning for activities, identifying responsibilities, and defining practices, procedures, processes, and resources.

environmental monitoring. The collection and analysis of samples or the direct measurement of environmental media. Environmental monitoring consists of two major activities: effluent monitoring and environmental surveillance.

environmental surveillance. The collection and analysis of samples or the direct measurement of air, water, soil, foodstuff, and biota in order to determine compliance with applicable standards and permit requirements.

erg. One-billionth (1E-09) of the energy released by a 100-watt bulb in one second. One dyne-cm.

$$
G L O-4
$$


evapotranspiration. The combined total precipitation returned to the air through direct evaporation and by transpiration of vegetation.

exposure. The subjection of a target (usually living tissue) to radiation.

$\mathbf{F}$

fallout. The settling to earth of radioactive materials mixed into the earth's atmosphere.

finding. A Department of Energy compliance term. A finding is a statement of fact concerning a condition in the Environmental, Safety, and Health program that was investigated during an appraisal. Findings include best management practice findings, compliance findings, and noteworthy practices. A finding may be a simple statement of proficiency or a description of deficiency (i.e., a variance from procedures or criteria). (See also self-assessment.)

fission. The act or process of splitting into parts. A nuclear reaction in which an atomic nucleus splits into fragments (i.e., fission products, usually fragments of comparable mass) with the evolution of approximately 100 million to several hundred million electron volts of energy.

$-\mathbf{G}$

gamma isotopic (also gamma scan). An analytical method by which the quantity of several gamma rayemitting radioactive isotopes may be determined simultaneously. Typical nuclear fuel cycle isotopes determined by this method include, but are not limited to, cobalt-60, zirconium-95, ruthenium-106, silver-110m, antimony-125, cesium-134, cesium-137, and europium-154. Naturally-occurring isotopes for which samples also often are analyzed are beryllium-7, potassium-40, radium-224, and radium-226.

gradient. Change in value of one variable with respect to another variable, such as a vertical change over a horizontal distance.

groundwater. Subsurface water in the pore spaces and fractures of soil and bedrock units.

$-\mathbf{H}$

half-life. The time in which half the atoms of a radionuclide disintegrate into another nuclear form. The halflife may vary from a fraction of a second to thousands of years.

$G L O-5$ 
hazardous waste. A waste or combination of wastes that because of quantity, concentration, or physical, chemical, or infectious characteristics may: a) cause or significantly contribute to an increase in mortality or an increase in serious irreversible or incapacitating reversible illness; or (b) pose a substantial present or potential hazard to human health or the environment when improperly treated, stored, transported, disposed of, or otherwise managed.

high-level waste (HLW). The highly radioactive waste material that results from the reprocessing of spent nuclear fuel, including liquid waste produced directly in reprocessing and any solid waste derived from the liquid, that contains a combination of transuranic waste and fission products in concentrations sufficient to require permanent isolation. (See also transuranic waste.)

hydraulic conductivity. The ratio of flow velocity to driving force for viscous flow under saturated conditions of a specified liquid in a porous medium; the ratio describing the rate at which water can move through a permeable medium.

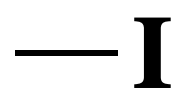

integrated safety management system (ISMS). The ISMS describes the programs, policies, and procedures used by WVNSCO and the DOE to ensure that WVNSCO establishes a safe workplace for the employees, the public, and the environment. The guiding principles of ISMS are line management responsibility for safety; clear roles and responsibilities; competence commensurate with responsibilities; balanced priorities; identification of safety standards and requirements; hazard controls; and operations authorization.

interim status. The status of any currently existing facility that becomes subject to the requirement to have a RCRA permit because of a new statutory or regulatory amendment to RCRA.

interstitial. The (annular) space between the inner and outer tank walls in a double-walled storage tank.

ion. An atom or group of atoms with an electric charge.

ion exchange. The reversible exchange of ions contained in solution with other ions that are part of the ionexchange material.

isotope. Different forms of the same chemical element that are distinguished by having the same number of protons but a different number of neutrons in the nucleus. An element can have many isotopes. For example, the three isotopes of hydrogen are protium, deuterium, and tritium, with one, two, and three neutrons in the nucleus, respectively.

$$
G L O-6
$$




\section{$\mathbf{K}$}

kame delta. A conical hill or short irregular ridge of gravel or sand deposited in contact with glacier ice.

$-\mathbf{L}$

lacustrine sediments. A sedimentary deposit consisting of material pertaining to, produced by, or formed in a lake or lakes.

land disposal restrictions (LDR). Regulations promulgated by the U.S. EPA (and by NYSDEC in New York State) governing the land disposal of hazardous wastes. The wastes must be treated using the best demonstrated available technology or must meet certain treatment standards before being disposed.

lower limit of detection (LLD). The lowest limit of a given parameter that an instrument is capable of detecting. A measurement of analytical sensitivity.

low-level waste (LLW). Radioactive waste not classified as high-level waste, transuranic waste, spent fuel, or uranium mill tailings. (See Class $A, B$, and C low-level waste.)

$\mathbf{M}$

maximally exposed individual (MEI). On-site (occupational) or off-site (non-occupational) person that receives the highest dose from a release scenario.

maximally exposed off-site individual (MEOSI). Member of the general public receiving the highest dose from the effluent release.

mean. The average value of a series of measurements.

metric ton. (See ton, metric.)

millirem (mrem). A unit of radiation dose equivalent that is equal to one one-thousandth of a rem. An individual member of the public can receive up to $500 \mathrm{mrem}$ per year according to DOE standards. This limit does not include radiation received for medical treatment or the roughly $360 \mathrm{mrem}$, on average, that people receive annually from background radiation.

$$
G L O-7
$$


minimum detectable concentration (MDC) or method detection limit (MDL). Depending on the sample medium, the smallest amount or concentration of a radioactive or nonradioactive analyte that can be reliably detected using a specific analytical method. Calculations of the minimum detectable concentrations are based on the lower limit of detection.

mixed waste (MW). A waste that is both radioactive and hazardous.

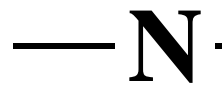

n-Dodecane/tributyl phosphate. An organic solution composed of 30\% tributyl phosphate (TBP) dissolved in n-dodecane used to first separate the uranium and plutonium from the fission products in the dissolved fuel and then to separate the uranium from the plutonium.

neutron. An electrically neutral subatomic particle in the baryon family with a mass 1,839 times that of an electron, stable when bound in an atomic nucleus, and having a mean lifetime of approximately 16.6 minutes as a free particle.

notice of violation (NOV). A letter of notice from a regional water engineer in response to an instance of significant noncompliance with a SPDES permit. Generally, an official notification from a regulatory agency of noncompliance with permit requirements.

nucleus. The positively-charged central region of an atom, made up of protons and neutrons and containing almost all of the mass of the atom.

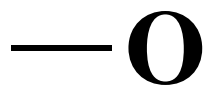

outfall. The discharge end of a drain or pipe that carries wastewater or other effluents into a ditch, pond, or river.

\section{$\mathbf{P}$}

parameter. Any of a set of physical properties whose values determine the characteristics or behavior of something (e.g., temperature, pressure, density of air). In relation to environmental monitoring, a monitoring parameter is a constituent of interest. Statistically, the term "parameter" is a calculated quantity, such as a mean or variance, that describes a statistical population.

particulates. Solid particles and liquid droplets small enough to become airborne.

$G L O-8$ 
person-rem. The sum of the individual radiation dose equivalents received by members of a certain group or population. It may be calculated by multiplying the average dose per person by the number of persons exposed. For example, a thousand people each exposed to one millirem would have a collective dose of one person-rem.

plume. The distribution of a pollutant in air or water after being released from a source.

precision. The degree of reproducibility of a measurement under a given set of conditions. Precision in a data set is assessed by evaluating results from duplicate field or analytical samples.

proglacial lake. A lake occupying a basin in front of a glacier, generally in direct contact with the ice.

proton. A stable, positively-charged subatomic particle in the baryon family with a mass 1,836 times that of an electron.

pseudo-monitoring point. A theoretical monitoring location rather than an actual physical location; a calculation based on analytical test results of samples obtained from other associated, tributary, monitored locations. (Point 116 at the WVDP is classified as a "pseudo" monitoring point because samples are not physically collected at that location. Rather, using analytical results from samples collected from "real" upstream outfall locations, compliance with the total dissolved solids limit in the WVDP's SPDES permit is calculated for this theoretical point.)

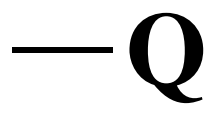

quality factor (QF). The extent of tissue damage caused by different types of radiation of the same energy. The greater the damage, the higher the quality factor. More specifically, the factor by which absorbed doses are multiplied to obtain a quantity that indicates the degree of biological damage produced by ionizing radiation. See radiation dose.) The factor is dependent upon radiation type (alpha, beta, gamma, or x-ray) and exposure (internal or external).

$-\mathbf{R}$

rad. Radiation absorbed dose. One hundred ergs of energy absorbed per gram.

radiation. The process of emitting energy in the form of rays or particles that are thrown off by disintegrating atoms. The rays or particles emitted may consist of alpha, beta, or gamma radiation.

$G L O-9$ 
alpha radiation. The least penetrating type of radiation. Alpha radiation can be stopped by a sheet of paper or the outer dead layer of skin.

beta radiation. Electrons emitted from a nucleus during fission and nuclear decay. Beta radiation can be stopped by an inch of wood or a thin sheet of aluminum.

gamma radiation. A form of electromagnetic, high-energy radiation emitted from a nucleus. Gamma rays are essentially the same as x-rays and require heavy shielding such as lead, concrete, or steel to be stopped.

internal radiation. Radiation originating from a source within the body as a result of the inhalation, ingestion, or implantation of natural or man-made radionuclides in body tissues.

\section{radiation dose:}

absorbed dose. The amount of energy absorbed per unit mass in any kind of matter from any kind of ionizing radiation. Absorbed dose is measured in rads or grays.

collective dose equivalent. The sum of the dose equivalents for all the individuals comprising a defined population. The per capita dose equivalent is the quotient of the collective dose equivalent divided by the population. The unit of collective dose equivalent is person-rem or personsievert.

collective effective dose equivalent. The sum of the effective dose equivalents for the individuals comprising a defined population. Units of measurement are person-rem or person-sievert. The per capita effective dose equivalent is obtained by dividing the collective dose equivalent by the population. Units of measurement are rem or sievert.

committed dose equivalent. A measure of internal radiation. The predicted total dose equivalent to a tissue or organ over a fifty-year period after a known intake of a radionuclide into the body. It does not include contributions from sources of external penetrating radiation. Committed dose equivalent is measured in rem or sievert.

committed effective dose equivalent. The sum of the committed dose equivalents to various tissues in the body, each multiplied by the appropriate weighting factor. Committed effective dose equivalent is measured in rem or sievert.

effective dose equivalent. The summation of the products of the dose equivalent received by specified tissues of the body and the appropriate weighting factors. It includes the dose from radiation sources internal and/or external to the body. The effective dose equivalent is expressed in units of rem or seivert.

$G L O-10$ 
radioactivity. A property possessed by some elements (such as uranium) whereby alpha, beta, or gamma rays are spontaneously emitted.

radioisotope. A radioactive isotope of a specified element. Carbon-14 is a radioisotope of carbon. Tritium is a radioisotope of hydrogen. (See isotope.)

radionuclide. A radioactive nuclide. Radionuclides are variations (isotopes) of elements. They have the same number of protons and electrons but different numbers of neutrons, resulting in different atomic masses. There are several hundred known nuclides, both manmade and naturally occurring.

reference man. A hypothetical aggregation of human physical and physiological characteristics arrived at by internal consensus. These characteristics may be used by researchers and public health workers to standardize results of experiments and to relate biological insult to a common base.

rem. An acronym for Roentgen Equivalent Man. A unit of radiation exposure that indicates the potential effect of radiation on human cells.

remote-handled waste. At the WVDP, waste that has an external surface dose rate that exceeds 100 millirem per hour or a high level of alpha and/or beta surface contamination and, therefore, must be handled in such a manner that a worker does not come into physical contact with it.

roentgen. A unit of exposure to ionizing radiation. It is that quantity of gamma or x-rays required to produce ions carrying one electrostatic unit of electrical charge in one cubic centimeter of dry air under standard conditions. The unit is named after Wilhelm Roentgen, German scientist who discovered x-rays in 1895.

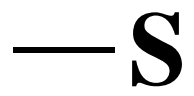

self-assessment. Appraisals of work at the WVDP by individuals, groups, or organizations responsible for overseeing and/or performing the work. Self-assessments are intended to provide an internal review of performance to determine that specific functional areas are in programmatic and site-specific compliance with applicable DOE directives, WVDP procedures, and regulations.

finding. A direct and significant violation of applicable Department of Energy, regulatory, or other procedural or programmatic requirements. A finding requires documented corrective action.

observation. A condition that, while not a direct and significant violation of applicable Department of Energy, regulatory, or other procedural or programmatic requirements, could result in a finding if not corrected. An observation requires documented corrective action.

good practice. A statement of proficiency or confirmed excellence worthy of documenting.

\section{$G L O-11$}


sievert. A unit of dose equivalent from the International System of Units (Systeme Internationale). Equal to one joule per kilogram.

solid waste management unit (SWMU). Any discernible unit at which solid wastes have been placed at any time, irrespective of whether the unit was intended for the management of solid or hazardous waste. Such units include any area at a facility at which solid wastes have been routinely and systematically released. (See also super solid waste management unit.)

spent fuel. Nuclear fuel that has been used in a nuclear reactor; this fuel contains uranium, activation products, fission products, and plutonium.

spill. A spill or release is defined as "any spilling, leaking, pumping, pouring, emitting, emptying, discharging, injecting, escaping, leaching, dumping, or otherwise disposing of substances from the ordinary containers employed in the normal course of storage, transfer, processing, or use."

stakeholder. A person or group that has an investment, share, or interest in something. At the WVDP stakeholders include Project management, scientists, other employees, politicians, regulatory agencies, local and national interest groups, and members of the general public.

standard deviation. An indication of the dispersion of a set of results around their average.

super solid waste management unit (SSWMU). Individual solid waste management units that have been grouped and ranked into larger units - super solid waste management units - because some individual units are contiguous or so close together as to make monitoring of separate units impractical. (See also solid waste management unit.)

surface water. Water that is exposed to the atmospheric conditions of temperature, pressure, and chemical composition at the surface of the earth.

surveillance. The act of monitoring or observing a process or activity to verify conformance with specified requirements.

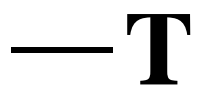

thermoluminescent dosimeter (TLD). A device that luminesces upon heating after being exposed to radiation. The amount of light emitted is proportional to the amount of radiation to which the luminescent material has been exposed.

ton, metric (also tonne). A unit of mass equal to 1,000 kilograms.

ton (short ton). A unit of weight equal to 2,000 pounds or 907.1847 kilograms.

$$
G L O-12
$$


transuranic (TRU) waste. Waste containing transuranic elements, that is, those elements with an atomic number greater than 92, including neptunium, plutonium, americium, and curium.

$-\mathbf{U}$

universal wastes. Wastes subject to special management provisions that are intended to ease the management burden and facilitate recycling of such materials. Four types of waste are currently covered under the universal waste regulations: hazardous waste batteries, hazardous waste pesticides that are either recalled or collected in waste pesticide collection programs, hazardous waste thermostats, and hazardous waste lamps.

upgradient. Referring to the flow of water or air, "upgradient" is analogous to upstream. Upgradient is a point that is "before" an area of study that is used as a baseline for comparison with downstream or downgradient data. (See gradient and downgradient.)

$-\mathbf{W}$

watershed. The area contained within a drainage divide above a specified point on a stream or river.

water table. The upper surface in a body of groundwater; the surface in an unconfined aquifer or confining bed at which the pore water pressure is equal to atmospheric pressure.

$-\lambda$

x-ray. Penetrating electromagnetic radiations having wave lengths shorter than those of visible light. They are usually produced by bombarding a metallic target with fast electrons in a high vacuum. In nuclear reactions it is customary to refer to photons originating in the nucleus as gamma rays and those originating in the extranuclear part of the atom as x-rays. These rays are sometimes called roentgen rays after their discoverer, W.C. Roentgen.

$G L O-13$ 
This page intentionally left blank

$$
G L O-14
$$




\title{
ACRONYMS AND ABBREVIATIONS
}

\author{
A\&PC \\ Analytical and Process Chemistry Laboratory \\ ACM \\ Asbestos-Containing Material \\ ACOE \\ (U.S.) Army Corps of Engineers \\ ALARA \\ As Low As Reasonably Achievable \\ ANSI \\ ASER \\ ASME \\ ASQ \\ AWQS \\ American National Standards Institute \\ Annual Site Environmental Report \\ American Society of Mechanical Engineers \\ American Society for Quality (formerly American Society for Quality Control \\ [ASQC]) \\ Ambient Water Quality Standard \\ BAT \\ Best Available Technology \\ BCG \\ Biota Concentration Guide \\ BEIR \\ Biological Effects of Ionizing Radiation \\ $\mathrm{BOD}_{5}$ \\ BSW \\ Biochemical Oxygen Demand (5-day) \\ BTU \\ Bulk Storage Warehouse \\ British Thermal Unit (also MBTU, MMBTU) \\ CAA \\ Clean Air Act \\ CCHD \\ CD \\ CDDL \\ Cattaraugus County Health Department \\ Compact Disk \\ CEDE \\ Construction and Demolition Debris Landfill \\ CEMP \\ Committed Effective Dose Equivalent \\ CERCLA \\ CFR \\ Code of Environmental Management Principles (for Federal Agencies) \\ CPC \\ Comprehensive Environmental Response, Compensation, and Liability Act \\ Code of Federal Regulations \\ CPC-WSA Chemical Process Cell Waste Storage Area
CSPF \\ CSPF \\ CSRF \\ Chemical Process Cell \\ Contact Size-Reduction Facility
}

$A \& A-1$ 


$\begin{array}{ll}\text { CSS } & \text { Cement Solidification System } \\ \text { CWA } & \text { Clean Water Act } \\ \text { CX } & \text { Categorical Exclusion } \\ \text { CY } & \text { Calendar Year }\end{array}$
D\&D Decontamination and Decommissioning
DBPs Disinfection By-Products
DCDFMeth Dichlorodifluoromethane
DCG Derived Concentration Guide
DL
Detection Limit or Detection Level
DMR Discharge Monitoring Report
DOE (U.S.) Department of Energy
DOE-EM Department of Energy, Office of Environmental Restoration and Waste Management
DOE-HQ Department of Energy, Headquarters Office
DOE-OH Department of Energy, Ohio Field Office
DOT (U.S.) Department of Transportation

EA Environmental Assessment

EDE Effective Dose Equivalent

EHS Extremely Hazardous Substance

EIS Environmental Impact Statement

ELAB (WVDP) Environmental Laboratory

EML (DOE) Environmental Measurements Laboratory

EMS Environmental Management System

EO Executive Order

EPA (U.S.) Environmental Protection Agency

EPCRA Emergency Planning and Community Right-to-Know Act

ERA Environmental Research Associates

ES\&H Environmental, Safety, and Health

ESR (WVDP) Effluent Summary Report

FR Federal Register

FRS Fuel Receiving and Storage

FY Fiscal Year

GEL General Engineering Laboratory

HAA5 Haloacetic Acid-Five (5)

HEPA High-Efficiency Particulate Air (filter)

HLW High-Level (radioactive) Waste

HPIC High-Pressure Ion Chamber

HTO Hydrogen Tritium Oxide

HVAC Heating, Ventilation, and Air Conditioning

$A \& A-2$ 
IAEA

ICRP

INEEL

IRTS

ISCORS

ISMS

ISO

LAS

LDR

LIMS

LLD

LLW

LLW2

LLWTF

LPS

LSA

LTR

LWTS

MAPEP

MCL

MCLG

MDC

MDL

MEI

MEOSI

MGD

ML

MMBTU

MSDS

MTAR

MW

NCRP

NDA

NEPA

NESHAP

NFS

NGVD

$\mathrm{NH}_{3}$

NIST

NOAA
International Atomic Energy Agency

International Commission on Radiological Protection

Idaho National Engineering and Environmental Laboratory

Integrated Radwaste Treatment System

Interagency Steering Committee on Radiation Standards

Integrated Safety Management System

International Organization for Standardization

Linear Alkylate Sulfonate

Land Disposal Restriction

Laboratory Information Management System

Lower Limit of Detection

Low-Level (radioactive) Waste

Low-Level (liquid) Waste Treatment Facility (new)

Low-Level (liquid) Waste Treatment Facility (old)

Liquid Pretreatment System

Lag Storage Area

License Termination Rule

Liquid Waste Treatment System

Mixed Analyte Performance Evaluation Program

Maximum Contaminant Level

Maximum Contaminant Level Goal

Minimum Detectable Concentration

Method Detection Limit (also Minimum Detection Level)

Maximally Exposed Individual

Maximally Exposed Off-Site Individual

Million Gallons per Day

Minimum Level

One million BTUs (a thousand thousand BTUs), also expressed as MBTU

Material Safety Data Sheet

Monthly Trend Analysis Report

(Radioactive and Hazardous) Mixed Waste

National Council on Radiation Protection and Measurements

Nuclear Regulatory Commission (NRC)-Licensed Disposal Area

National Environmental Policy Act

National Emission Standards for Hazardous Air Pollutants

Nuclear Fuel Services, Inc.

National Geodetic Vertical Datum

Ammonia

National Institute of Standards and Technology

National Oceanic and Atmospheric Administration

$A \& A-3$ 


\begin{tabular}{|c|c|}
\hline NOI & Notice of Intent \\
\hline NOV & Notice of Violation \\
\hline $\mathrm{NO}_{\mathbf{x}}$ & Nitrogen Oxides \\
\hline NPDES & National Pollutant Discharge Elimination System \\
\hline NPGRS & North Plateau Groundwater Recovery System \\
\hline NPOC & Nonpurgeable Organic Carbon \\
\hline NRC & (U.S.) Nuclear Regulatory Commission \\
\hline NTS & Nevada Test Site \\
\hline NTU & Nephelometric Turbidity Unit \\
\hline NYCRR & New York Official Compilation of Codes, Rules, and Regulations \\
\hline NYS & New York State \\
\hline NYSDEC & New York State Department of Environmental Conservation \\
\hline NYSDOH & New York State Department of Health \\
\hline NYSDOH ELAP & (NYSDOH) Environmental Laboratory Approval Program \\
\hline NYSDOL & New York State Department of Labor \\
\hline NYSERDA & New York State Energy Research and Development Authority \\
\hline NYSGS & New York State Geological Survey \\
\hline OH/WVDP & Department of Energy, West Valley Demonstration Project \\
\hline OSHA & Occupational Safety and Health Administration \\
\hline OVE & Outdoor Ventilated Enclosure \\
\hline $\mathbf{P 2}$ & Pollution Prevention \\
\hline PCB & Polychlorinated Biphenyl \\
\hline PQL & Practical Quantitation Limit \\
\hline PTW & Permeable Treatment Wall \\
\hline PUREX & Plutonium Uranium Reduction Extraction \\
\hline PVS & Permanent Ventilation System \\
\hline PVU & Portable Ventilation Unit \\
\hline QA & Quality Assurance \\
\hline QAP & Quality Assessment Program (also Quality Assurance Program) \\
\hline QC & Quality Control \\
\hline QF & Quality Factor \\
\hline RCRA & Resource Conservation and Recovery Act \\
\hline REM & Roentgen Equivalent Man \\
\hline RFI & RCRA Facility Investigation \\
\hline RHWF & Remote-Handled Waste Facility \\
\hline SAR & Safety Analysis Report \\
\hline SARA & Superfund Amendments and Reauthorization Act \\
\hline SD & Standard Deviation \\
\hline
\end{tabular}

A\&A - 4 


\begin{tabular}{|c|c|}
\hline SDA & (New York) State-Licensed Disposal Area \\
\hline SDWA & Safe Drinking Water Act \\
\hline SI & Systeme Internationale (International System of Units) \\
\hline $\mathrm{SO}_{2}$ & Sulfur Dioxide \\
\hline SPDES & (New York) State Pollutant Discharge Elimination System \\
\hline SRM & Standard Reference Material \\
\hline SSWMU & Super Solid Waste Management Unit \\
\hline STL & Severn Trent Laboratories \\
\hline STP & Site Treatment Plan \\
\hline STS & Supernatant Treatment System \\
\hline SVOC & Semivolatile Organic Compound \\
\hline SWMU & Solid Waste Management Unit \\
\hline TAGM & Technical and Administrative Guidance Memorandum \\
\hline TBP & Tributyl Phosphate \\
\hline TCE & Trichloroethylene \\
\hline TDS & TotalDissolved Solids \\
\hline THOREX & Thorium Reduction Extraction \\
\hline TLD & Thermoluminescent Dosimeter \\
\hline TOC & Total Organic Carbon \\
\hline TOGS & Technical and Operational Guidance Series \\
\hline TOX & Total Organic Halides \\
\hline TRI & Toxic Release Inventory \\
\hline TRU & Transuranic \\
\hline TSCA & Toxic Substances Control Act \\
\hline TSDF & Treatment, Storage, and Disposal Facility \\
\hline TSS & Total Suspended Solids \\
\hline TTHM & Total Trihalomethanes \\
\hline U.S. & United States \\
\hline URS & URS Group, Inc. \\
\hline USC & United States Code \\
\hline USGS & United States Geological Survey \\
\hline VF & Vitrification Facility \\
\hline VOC & Volatile Organic Compound \\
\hline VPP & (U.S. DOE) Voluntary Protection Program \\
\hline WNYNSC & Western New York Nuclear Service Center \\
\hline WVDP & West Valley Demonstration Project \\
\hline WVNS & West Valley Nuclear Services Company (now WVNSCO) \\
\hline WVNSCO & West Valley Nuclear Services Company \\
\hline WWTF & Wastewater Treatment Facility \\
\hline
\end{tabular}

$A \& A-5$ 
This page intentionally left blank

$A \& A-6$ 


\section{Units of Measure}

\begin{tabular}{|c|c|c|c|c|c|}
\hline Radioactivity & Symbol & Name & Volume & Symbol & Name \\
\hline & $\begin{array}{l}\mathrm{G} \\
\mathrm{mCi} \\
\mu \mathrm{Ci} \\
\mathrm{nCi} \\
\mathrm{pCi} \\
\mathrm{Bq} \\
\mathrm{d} / \mathrm{s}\end{array}$ & $\begin{array}{l}\text { curie } \\
\text { millicurie }(1 \mathrm{E}-03 \mathrm{Ci}) \\
\text { microcurie }(1 \mathrm{E}-06 \mathrm{Ci}) \\
\text { nanocurie(1E-09Ci) } \\
\text { picocurie }(1 \mathrm{E}-12 \mathrm{Ci}) \\
\text { becquerel }(27 \mathrm{pCi}) \\
\text { disintegrations per second }\end{array}$ & & $\begin{array}{l}\mathrm{cm}^{3} \\
\mathrm{~L} \\
\mathrm{~mL} \\
\mathrm{~m}^{3} \\
\mathrm{gal}^{3} \\
\mathrm{ft}^{3}\end{array}$ & $\begin{array}{l}\text { cubic centimeter } \\
\text { liter } \\
\text { milliliter } \\
\text { cubic meter } \\
\text { gallon } \\
\text { cubic feet }\end{array}$ \\
\hline \multirow[t]{2}{*}{$\underline{\text { Dose }}$} & $\underline{\text { Symbol }}$ & Name & $\underline{\text { Area }}$ & $\underline{\text { Symbol }}$ & Name \\
\hline & $\begin{array}{l}\mathrm{Sv} \\
\mathrm{mSv} \\
\mathrm{Gy} \\
\text { mrem }\end{array}$ & $\begin{array}{l}\text { sievert }(100 \mathrm{rem}) \\
\text { millisievert }(1 \mathrm{E}-03 \mathrm{~Sv}) \\
\text { gray }(100 \mathrm{rad}) \\
\text { millirem }(1 \mathrm{E}-03 \mathrm{rem})\end{array}$ & & ha & hectare $\left(10,000 \mathrm{~m}^{2}\right)$ \\
\hline \multirow[t]{2}{*}{$\underline{\text { Concentration }}$} & $\underline{\text { Symbol }}$ & $\underline{\text { Name }}$ & Length & $\underline{\text { Symbol }}$ & $\underline{\text { Name }}$ \\
\hline & $\begin{array}{l}\mu \mathrm{Ci} / \mathrm{mL} \\
\mathrm{mL} / \mathrm{L} \\
\mu \mathrm{Ci} / \mathrm{g} \\
\mathrm{mg} / \mathrm{L} \\
\mathrm{mg} / \mathrm{kg} \\
\mu \mathrm{g} / \mathrm{mL} \\
\mathrm{pCi} / \mathrm{L} \\
\mathrm{ng} / \mathrm{L} \\
\mu \mathrm{g} / \mathrm{L} \\
\mu \mathrm{g} / \mathrm{g} \\
\mathrm{Bq} / \mathrm{L} \\
\mathrm{ppm} \\
\mathrm{ppb} \\
\mathrm{ppt} \\
\mathrm{NTU} \\
\mathrm{SU}\end{array}$ & $\begin{array}{l}\text { microcuries per milliliter } \\
\text { milliliters per liter } \\
\text { microcuries per gram } \\
\text { milligrams per liter }(\mathrm{ppm}) \\
\text { milligrams per kilogram }(\mathrm{ppm}) \\
\text { micrograms per milliliter }(\mathrm{ppm}) \\
\text { picocuries per liter } \\
\text { nanograms per liter }(\mathrm{ppt}) \\
\text { micrograms per liter }(\mathrm{ppb}) \\
\text { micrograms per gram }(\mathrm{ppm}) \\
\text { becquerels per liter } \\
\text { parts per million } \\
\text { parts per billion } \\
\text { parts per trillion } \\
\text { nephlemetric turbidity units } \\
\text { standard units }\end{array}$ & $\underline{\text { Exposure }}$ & $\begin{array}{l}\underline{\text { Symbol }} \\
\mu \mathrm{R} \\
\mathrm{mR}\end{array}$ & $\begin{array}{l}\text { meter } \\
\text { kilometer }(1 \mathrm{E}+03 \mathrm{~m}) \\
\text { centimeter }(1 \mathrm{E}-02 \mathrm{~m}) \\
\text { millimeter }(1 \mathrm{E}-03 \mathrm{~m}) \\
\text { micrometer(1E-06 m) }\end{array}$ \\
\hline \multirow[t]{2}{*}{$\underline{\text { Mass }}$} & $\begin{array}{l}\text { Symbol } \\
\mathrm{g} \\
\mathrm{kg} \\
\mathrm{mg} \\
\mu \mathrm{g} \\
\mathrm{ng} \\
\mathrm{t}\end{array}$ & $\begin{array}{l}\text { Name } \\
\text { gram } \\
\text { kilogram }(1 \mathrm{E}+03 \mathrm{~g}) \\
\text { milligram }(1 \mathrm{E}-03 \mathrm{~g}) \\
\text { microgram }(1 \mathrm{E}-06 \mathrm{~g}) \\
\text { nanogram }(1 \mathrm{E}-09 \mathrm{~g}) \\
\text { metric ton }(1 \mathrm{E}+06 \mathrm{~g})\end{array}$ & $\frac{\text { Flow Rate }}{\text { or Speed }}$ & $\begin{array}{l}\text { Symbol } \\
\mathrm{mgd} \\
\text { cfm } \\
\text { Lpm } \\
\text { gpd } \\
\mathrm{m} / \mathrm{sec}\end{array}$ & $\begin{array}{l}\text { Name } \\
\text { million gallons per day } \\
\text { cubic feet per minute } \\
\text { liters per minute } \\
\text { gallons per day } \\
\text { meters per second }\end{array}$ \\
\hline & $\begin{array}{l}\text { centi } \\
\text { milli } \\
\text { micro } \\
\text { nano } \\
\text { pico }\end{array}$ & $\begin{array}{l}1 / 100=1 \times 10^{-2}=0.01 \\
1 / 1,000=1 \times 10^{-3}=0.0 \\
1 / 1,000,000=1 \times 10^{-6}= \\
1 / 1,000,000,000=1 \times 1 \\
1 / 1,000,000,000,000=\end{array}$ & $\begin{array}{l}2 \\
\text { E- } 03 \\
0001=E-06 \\
0.000000001 \\
0^{-12}=0.00000\end{array}$ & $\begin{array}{l}\mathrm{E}-09 \\
00001=\mathrm{E}-12\end{array}$ & \\
\hline & & $U O N$ & & & \\
\hline
\end{tabular}




\section{Scientific Notation}

Scientific notation may be used to express very large or very small numbers. A number smaller than 1 is expressed with a negative exponent (e.g., $1.3 \times 10^{-6}$ ). To convert this number to decimal form, the decimal point is moved left by the number of places equal to the exponent. Thus, $1.3 \times 10^{-6}$ becomes 0.0000013 .

A number larger than 10 is expressed with a positive exponent (e.g., $\left.1.3 \times 10^{6}\right)$. To convert this number to decimal form, the decimal point is moved right by the number of places equal to the exponent. Thus, $1.3 \times 10^{6}$ becomes $1,300,000$.

The power of 10 also is expressed as E. For example, $1.3 \times 10^{-6}$ also can be written as $1.3 \mathrm{E}-06$. The chart below shows equivalent exponential and decimal values.

$$
\begin{array}{lllll}
1.0 \times 10^{2}= & 1 \mathrm{E}+02= & 100 \\
1.0 \times 10^{1}= & 1 \mathrm{E}+01= & 10 \\
1.0 \times 10^{0}= & 1 \mathrm{E}+00= & 1 \\
1.0 \times 10^{-1}= & 1 \mathrm{E}-01= & 0.1 \\
1.0 \times 10^{-2}= & 1 \mathrm{E}-02= & 0.01 \\
1.0 \times 10^{-3}= & 1 \mathrm{E}-03= & & \\
1.0 \times 10^{-4}= & 1 \mathrm{E}-04= & 0.001 & \\
1.0 \times 10^{-5}= & 1 \mathrm{E}-05= & 0.00001 & \\
1.0 \times 10^{-6}= & 1 \mathrm{E}-06= & 0.000001 & \text { One millionth } \\
1.0 \times 10^{-7}= & 1 \mathrm{E}-07= & 0.0000001 & \\
1.0 \times 10^{-8}= & 1 \mathrm{E}-08= & 0.00000001 & \\
& & & &
\end{array}
$$

\section{Conversion Chart}

Both traditional radiological units (curie, roentgen, rad, rem) and the Systeme Internationale (S.I.) units (becquerel, gray, sievert) are used in this report. Nonradiological measurements are presented in both English and metric units. Frequently-used radioactivity and dose conversions are bolded.

$\begin{array}{lll}1 \text { centimeter }(\mathrm{cm}) & = & 0.3937 \text { inches }(\mathrm{in}) \\ 1 \text { meter }(\mathrm{m}) & = & 39.37 \text { inches }(\mathrm{in})=3.28 \text { feet }(\mathrm{ft}) \\ 1 \text { kilometer }(\mathrm{km}) & = & 0.62 \text { miles }(\mathrm{mi}) \\ 1 \text { milliliter }(\mathrm{mL}) & = & 0.0338 \text { ounces }(\mathrm{oz}) \\ & = & 0.061 \text { cubic inches }\left(\mathrm{in}^{3}\right) \\ & = & 1 \text { cubic centimeter }\left(\mathrm{cm}^{3}\right) \\ 1 \text { liter }(\mathrm{L}) & = & 1.057 \text { quarts }(\mathrm{qt}) \\ & = & 61.02 \text { cubic inches }\left(\mathrm{in}^{3}\right) \\ 1 \text { gram }(\mathrm{g}) & = & 0.0353 \text { ounces }(\mathrm{oz}) \\ & = & 0.0022 \text { pounds }(\mathrm{lbs}) \\ 1 \text { kilogram }(\mathrm{kg}) & = & 2.2 \text { pounds }(\mathrm{lbs}) \\ 1 \text { curie }(\mathrm{Ci}) & = & 3.7 \mathrm{E}+10 \text { disintegrations per second }(\mathrm{d} / \mathrm{s}) \\ \mathbf{1} \text { becquerel }(\mathbf{B q}) & = & \mathbf{1} \text { disintegration per second }(\mathbf{d} / \mathbf{s}) \\ & = & \mathbf{2 7} \text { picocuries }(\mathbf{p C i}) \\ 1 \text { roentgen }(\mathrm{R}) & = & 2.58 \mathrm{E}-04 \text { coulombs per kilogram of air }(\mathrm{C} / \mathrm{kg}) \\ \mathbf{1} \text { rad } & = & \mathbf{0 . 0 1} \text { gray }(\mathbf{G y}) \\ \mathbf{1} \text { rem } & = & \mathbf{0 . 0 1} \text { sievert }(\mathbf{S v}) \\ 1 \text { millirem }(\mathrm{mrem}) & = & 0.001 \text { rem } \\ 1 \text { sievert }(\mathbf{S v}) & = & \mathbf{1 0 0} \text { rem }\end{array}$




\section{Distribution}

$\underline{\text { Recipient }}$

$\underline{\text { Federal Organization }}$

DOE Office of Scientific and Technical Information

$\begin{array}{ll}\text { R. Hardwick } & \text { DOE - HQ } \\ \text { R. Natoli } & \text { DOE - HQ } \\ \text { G. Podonsky } & \text { DOE - HQ } \\ \begin{array}{l}\text { M. Rawlings } \\ \text { J. Craig }\end{array} & \text { DOE - HQ } \\ \text { R. Tormey } & \text { DOE - OH } \\ & \\ \text { C. Glenn } & \text { NRC - HQ } \\ \text { J. Greeves } & \text { NRC - HQ } \\ \text { R. Prince } & \text { NRC - Region 1 } \\ & \\ \text { R. Chaput } & \text { U.S. EPA - Region II } \\ \text { J. Eng } & \text { U.S. EPA - Region II } \\ \text { P. Giardina } & \text { U.S. EPA - Region II }\end{array}$

W. Kappel USGS

T. Reynolds

B. Higgins

L. Slaughter

R. Kuhl

J. Quinn

H. Clinton

C. Schumer
U.S. Congress, 26th Dist.

U.S. Congress, 27th Dist.

U.S. Congress, 28th Dist.

U.S. Congress, 29th Dist.

U.S. Congress, 30th Dist.

U.S. Senate, New York

U.S. Senate, New York

\section{$\underline{\text { Recipient }}$}

E. Wohlers

G. Felton

G. Fitzpatrick

J. Burrell
A. Billittier IV
B. Snyder, Jr.
R. Ground

\section{Local Organization}

\section{$\underline{\text { Recipient }}$}

J. Austin

E. Dassatti

R. Phaneuf

T. Rice

M. Wang

L. Winterberger

B. Youngberg

B. Bartz

S. Doleski

J. Sciascia

P. Concannon

M. Jackson

J. Strickland

L. Sturman

G. Baker

B. Ignatz

A. Salame Alfie

P. Piciulo

H. Brodie

R. Fakundiny

D. Burling

J. Giglio

C. Young

W. Stachowski

D. Volker

\section{$\underline{\text { Recipient }}$}

Cattaraugus County Health Dept.

Cattaraugus County Legislature

Cattaraugus County Legislature

Cattaraugus County Legislature
G. Eppolito
W. King
M. Steffan

$\underline{\text { State Organization }}$

Executive Chamber, State Capitol, Albany

NYSDEC - Albany

NYSDEC - Albany

NYSDEC - Albany

NYSDEC - Albany

NYSDEC - Albany

NYSDEC - Albany

NYSDEC - Buffalo

NYSDEC - Buffalo

NYSDEC - Buffalo

NYSDEC - Region 9

NYSDEC - Region 9

NYSDEC - Region 9

NYSDOH - Albany

NYSDOH - Buffalo

NYSDOH - Buffalo

NYSDOH - Troy

NYSERDA

NYSERDA - Albany

NYSGS

New York Assembly, 147th Dist.

New York Assembly, 149th Dist.

New York Senate, 57th Dist.

New York Senate, 58th Dist.

New York Senate, 59th Dist.

\section{Local Organization}

Mayor, Village of Springville Supervisor, Town of Ashford Supervisor, Town of Concord

DST - 1 


\section{Distribution}

\section{Publication}

Buffalo News, Buffalo, New York*

Salamanca Republican Press, Salamanca, New York *

Springville Journal, Springville, New York*

\section{Library}

Town of Concord Hulbert Library, Springville, New York

Seneca Nation of Indians Library, Cattaraugus Reservation, Irving, New York

Seneca Nation of Indians Library, Allegheny Reservation, Salamanca, New York

West Valley Demonstration Project, Public Reading Room, West Valley, New York

* Notice of public availability

DST - 2 


\section{Appendix A \\ Environmental Monitoring Program Maps}

$A-i$ 
This page intentionally left blank

$A-i i$ 


\section{Environmental Monitoring Program Sample Points}

The following maps contain points sampled as part of the West Valley Demonstration Project (WVDP) routine environmental monitoring program for 2004. This program met or exceeded the requirements of U.S. Department of Energy (DOE) Order 450.1, DOE Order 5400.5, and DOE/EH-0173T. Specific methods and recommended monitoring program elements are found in DOE/EP-0096, "A Guide for Effluent Radiological Measurements at DOE Installations," and DOE/EP-0023, "A Guide for Environmental Radiological Surveillance at U.S. Department of Energy Installations," which were the bases for selecting most of the sampling locations. Additional monitoring was mandated by air and water discharge permits (40 CFR 61 and SPDES).

The index on pages A-iv through A-vii is a list of the codes used to identify the various sampling locations, which are shown on Figures A-2 through A-13. The sample location code describes the physical location where the sample is collected. The code consists of seven or eight characters: The first character identifies the sample medium as Air, Water, Soil/Sediment, Biological, or Direct Measurement. The second character specifies oN-site or oFf-site. The remaining characters describe the specific location (e.g., AFGRVAL is Air oFf-site at GReat VALley). Distances are measured in a straight line from the on-site main stack to the sampling location. Sampling points located inside buildings (e.g., on-site drinking water) or points that do not have a fixed location (e.g., outdoor ventilated enclosures) are not shown on these maps. Areas labeled as "wetlands" do not depict the WVDP's formally delineated wetlands inventory. As an aid to the reader, these polygons indicate relatively low-lying areas that almost always contain wet surface soils or standing water during years with typical precipitation totals.

\section{List of Maps}

A-1. West Valley Demonstration Project Base Map A-1

A-2. On-Site Surface Water and Soil/Sediment Sampling Locations A-2

A-3. Off-Site Surface Water and Soil/Sediment Sampling Locations A-3

A-4. On-Site Air Monitoring and Sampling Locations A-4

A-5. Off-Site Air and Fallout Sampling Locations A-5

A-6. Active WVDP Groundwater Monitoring Locations A-6

A-7. North Plateau On-Site Groundwater Monitoring Network A-7

A-8. South Plateau On-Site Groundwater Monitoring Network A-8

A-9. Near-Site Drinking Water and Biological Sampling Locations A-9

A-10. Location of On-Site Thermoluminescent Dosimeters (TLDs) A-10

A-11. Location of Off-Site Thermoluminescent Dosimeters (TLDs) Within 5 Kilometers of the WVDP _ A-11

A-12. Environmental Sampling Locations Between 5 and 10 Kilometers From the WVDP ___ A-12

A-13. Environmental Sampling Locations More Than 10 Kilometers From the WVDP_____ A-13

A-14. Projected 2002 Population by Sector Within 80 Kilometers of the WVDP A-14 


\section{List of Sampling Locations}

On-Site Surface Water and Soil/Sediment Sampling Locations (Fig. A-2)

WNSP001

WNSP006

SNSP006

WNSP116

WNSP007

WNSWAMP

SNSWAMP

WNSW74A

SNSW74A

WNSDADR

WNSP008

WNSP005

WNCOOLW

WNFRC67

WNERB53

WNNDADR

WNDCELD

WNNDATR

WNSTAW6
Lagoon 3 Weir Point

Facility Main Drainage

Soil at WNSP006

Pseudo Monitoring Point in Frank's Creek

Sanitary Waste Discharge

Northeast Swamp Drainage Point

Soil at WNSWAMP

North Swamp Drainage Point

Soil at WNSW74A

SDA Runoff

French Drain LLWTF Area

South Facility Drainage

Cooling Tower

Frank's Creek East

Erdman Brook

Disposal Area Drainage

Drum Cell Drainage

NDA Trench Interceptor Project

Standing Water

\section{Off-Site Surface Water and Soil/Sediment Sampling Locations (Fig. A-3)}

$\begin{array}{ll}\text { WFBCBKG } & \text { Buttermilk Creek near Fox Valley, Background } \\ \text { WFBCTCB } & \text { Buttermilk Creek at Thomas Corners } \\ \text { WFBIGBR } & \text { Cattaraugus Creek at Bigelow Bridge, Background } \\ \text { SFBISED } & \text { Cattaraugus Creek at Bigelow Bridge, Background Sediment } \\ \text { WFFELBR } & \text { Cattaraugus Creek at Felton Bridge } \\ \text { SFTCORD } & \text { Soil at Thomas Corners Air Sampler } \\ \text { SFSDSED } & \text { Cattaraugus Creek at Springville Dam, Sediment } \\ \text { SFCCSED } & \text { Cattaraugus Creek at Felton Bridge, Sediment } \\ \text { SFTCSED } & \text { Buttermilk Creek at Thomas Corners, Sediment } \\ \text { SFBCSED } & \text { Buttermilk Creek at Fox Valley Road, Background Sediment } \\ \text { SFRSPRD } & \text { Soil at Rock Springs Road Air Sampler } \\ \text { SFRT240 } & \text { Soil at Route 240 Air Sampler } \\ \text { SFBLKST } & \text { Soil at Bulk Storage Warehouse Air Sampler } \\ \text { SFFXVRD } & \text { Soil at Fox Valley Road Air Sampler } \\ \text { SFBOEHN } & \text { Soil at Dutch Hill Road Air Sampler } \\ \text { WNSTAW4 } & \text { Standing Water } \\ \text { WNSTAW5 } & \text { Standing Water } \\ \text { WNSTAW9 } & \text { Standing Water }\end{array}$

$A-i v$ 


\section{List of Sampling Locations (continued)}

On-Site Air Monitoring and Sampling Locations (Fig. A-4)

$\begin{array}{ll}\text { ANSTACK } & \text { Main Plant } \\ \text { ANSTSTK } & \text { Supernatant Treatment System } \\ \text { ANCSSTK } & \text { 01-14 Building } \\ \text { ANCSRFK } & \text { Size-Reduction Facility } \\ \text { ANCSPFK } & \text { Container Sorting and Packaging Facility } \\ \text { ANVITSK } & \text { Vitrification Heating, Ventilation, and Air Conditioning } \\ \text { ANLAGAM } & \text { Lag Storage Area (ambient air) } \\ \text { ANNDAAM } & \text { NDAArea (ambient air) } \\ \text { ANSDAT9 } & \text { SDA Trench 9 (ambient air) } \\ \text { ANRGFOP } & \text { Rain Gauge Fallout } \\ \text { ANRHWFK } & \text { Remote-Handled Waste Facility }\end{array}$

Off-Site Air and Fallout Sampling Locations (Fig. A-5)

$\begin{array}{ll}\text { AFFXVRD } & \text { Fox Valley Sampler } \\ \text { AFFXFOP } & \text { Fox Valley Fallout } \\ \text { AFTCORD } & \text { Thomas Corners Sampler } \\ \text { AFTCFOP } & \text { Thomas Corners Fallout } \\ \text { AFRT240 } & \text { Route 240 Sampler } \\ \text { AF24FOP } & \text { Route 240 Fallout } \\ \text { AFBOEHN } & \text { Dutch Hill Road Sampler } \\ \text { AFDHFOP } & \text { Dutch Hill Fallout } \\ \text { AFRSPRD } & \text { Rock Springs Road Sampler } \\ \text { AFBLKST } & \text { Bulk Storage Warehouse Sampler }\end{array}$

$A-v$ 


\section{List of Sampling Locations (continued)}

Active WVDP Ground water Monitoring Locations (Fig. A-6)

North Plateau On-Site Groundwater Monitoring Network (Fig. A-7)

South Plateau On-Site Groundwater Monitoring Network (Fig. A-8)

$\begin{array}{ll}\text { SSWMU \#1 } & \text { Low-Level Waste Treatment Facility Wells } \\ \text { SSWMU \#2 } & \text { Miscellaneous Small Units Wells } \\ \text { SSWMU \#3 } & \text { Liquid Waste Treatment System Wells } \\ \text { SSWMU \#4 } & \text { HLW Storage and Processing Tank Wells } \\ \text { SSWMU \#5 } & \text { Maintenance Shop Leach Field Wells } \\ \text { SSWMU \#6 } & \text { Low-Level Waste Storage Area Wells } \\ \text { SSWMU \#7 } & \text { CPC Waste Storage Area Wells } \\ \text { SSWMU \#8 } & \text { CDDLWells } \\ \text { SSWMU \#9 } & \text { NDAUnits Wells and NDATR } \\ \text { SSWMU\#10 } & \text { IRTS Drum Cell Wells } \\ \text { RHWF } & \text { Remote-Handled Waste Facility Wells } \\ \text { SSWMU \#11 } & \text { SDA Unit Wells } \\ \text { North Plateau Seeps } & \text { Northeastern Edge of North Plateau } \\ \text { Well Points } & \text { Downgradient of Main Plant } \\ \text { WNWNB1S } & \text { Former North Plateau Background Well }\end{array}$

Near-Site Drinking Water and Biological Sampling Locations (Fig. A-9)

$\begin{array}{ll}\text { BFFCATC } & \text { Cattaraugus Creek Fish, Downstream } \\ \text { BFFCATD } & \text { Cattaraugus Creek Fish, Downstream of Springville Dam } \\ \text { BFMREED } & \text { North-Northwest Milk, Near-Site } \\ \text { BFMWIDR } & \text { Southeast Milk, Near-Site } \\ \text { BFMSCHT } & \text { South Milk, Near-Site } \\ \text { BFVNEAR } & \text { Produce, Near-Site } \\ \text { BFBNEAR } & \text { Beef, Near-Site } \\ \text { BFDNEAR } & \text { Venison, Near-Site } \\ \text { WFWEL Series } & \text { Private Wells }\end{array}$

Location of On-Site Thermoluminescent Dosimeters (TLDs) (Fig. A-10)

DNTLD Series $\quad$ On-Site Direct Radiation

Location of Off-Site Thermoluminescent Dosimeters (TLDs) Within 5 Kilometers of the WVDP (Fig. A-11)

DFTLD Series $\quad$ Off-Site Direct Radiation

$$
A-v i
$$




\section{List of Sampling Locations (concluded)}

Environmental Sampling Locations Between 5 and 10 Kilometers From the WVDP(Fig. A-12)

$\begin{array}{ll}\text { AFSPRVL } & \text { Springville Air Sampler } \\ \text { SFSPRVL } & \text { Soil at Springville Air Sampler } \\ \text { DFTLD21 } & \text { TLD at Springville Air Sampler } \\ \text { WFWEL10 } & \text { Drinking Water at Springville Air Sampler } \\ \text { BFVNEAR } & \text { Produce, Near-site } \\ \text { DFTLD22 } & \text { TLD at West Valley Air Sampler } \\ \text { SFWEVAL } & \text { Soil at West Valley Air Sampler } \\ \text { AFWEVAL } & \text { West ValleyAir Sampler }\end{array}$

Environmental Sampling Locations More Than 10 Kilometers From the WVDP(Fig. A-13)

BFMCTLS

BFVCTRL

WNSTAWB

Milk, South, Background

Produce, Background

Standing Water, Background

BFFCTRL

BFDCTRL

Cattaraugus Creek Fish, Background

Venison, Background

AFGRVAL

SFGRVAL

Great Valley Air Sampler, Background

DFTLD23

WFWEL06

Soil at Great Valley Air Sampler, Background

TLD at Great Valley Air Sampler

BFBCTRL

Drinking Water at Great Valley Air Sampler

Beef, Background

A - vii 
This page intentionally left blank

A - viii 


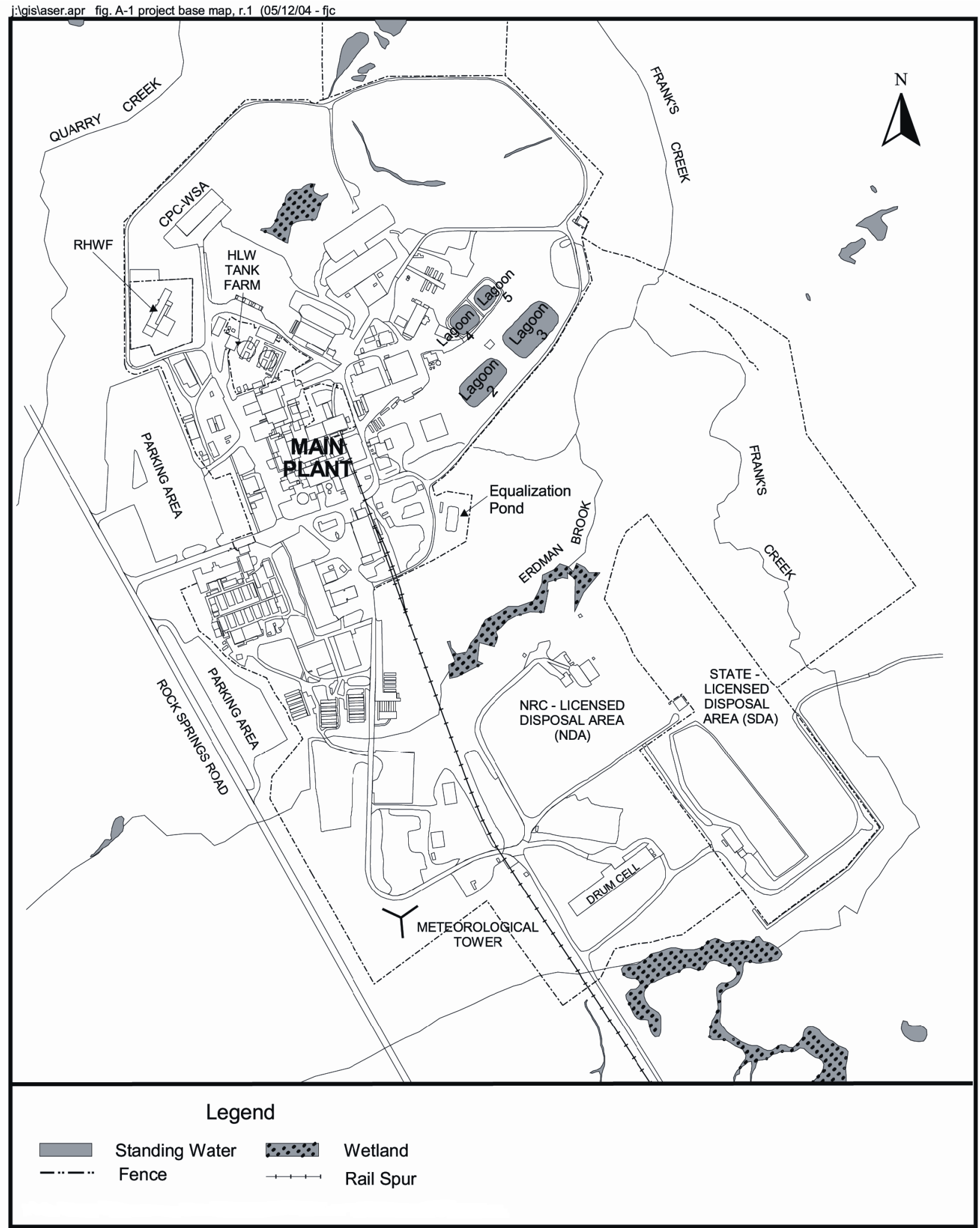

Figure A-1. West Valley Demonstration Project Base Map

$A-1$ 


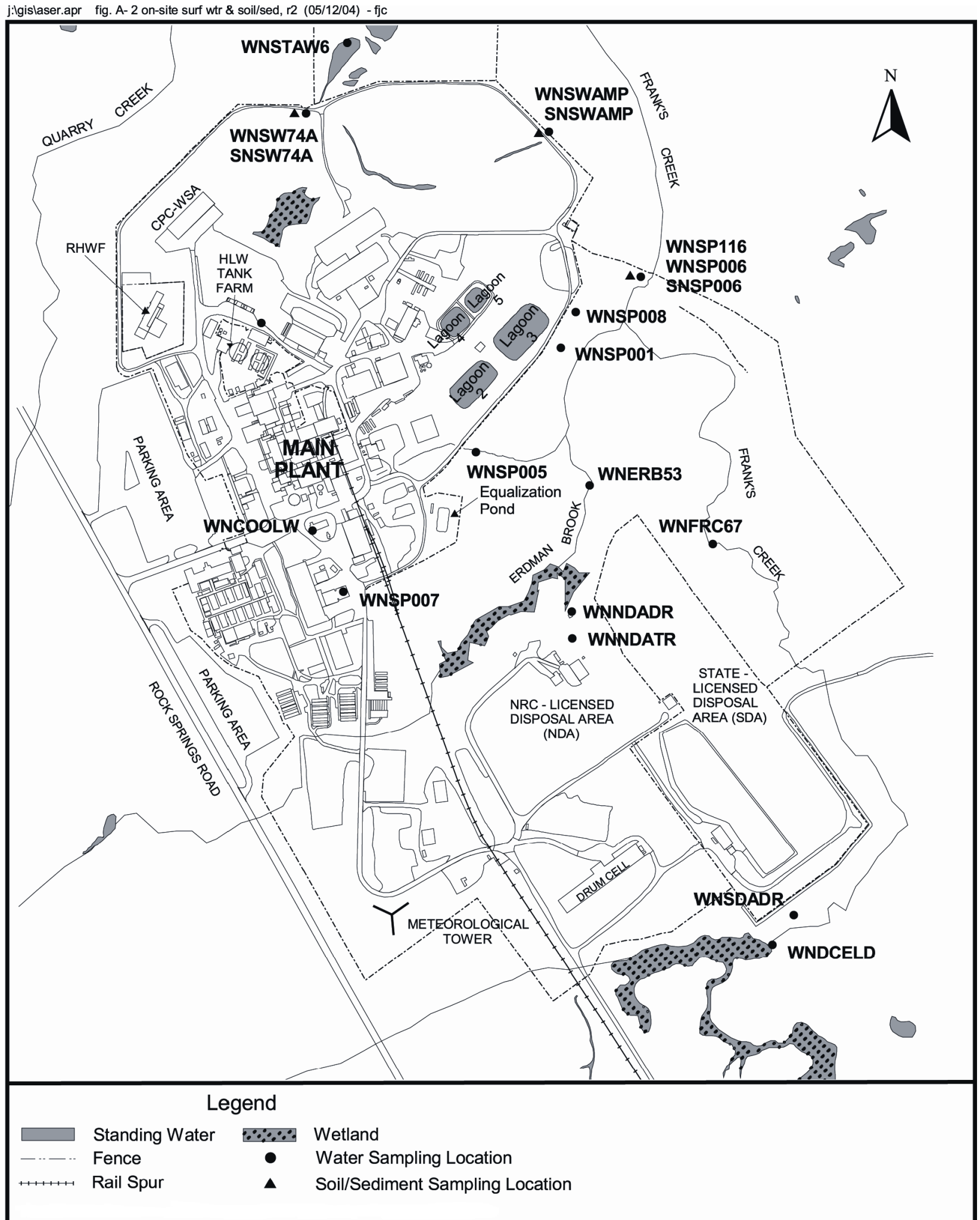

Figure A-2. On-Site Surface Water and Soil/Sediment Sampling Locations

A - 2 
j:lgislaser.apr fig. A-3 off-site surface water \& soil/sed, r2 (05/19/04) - fjc

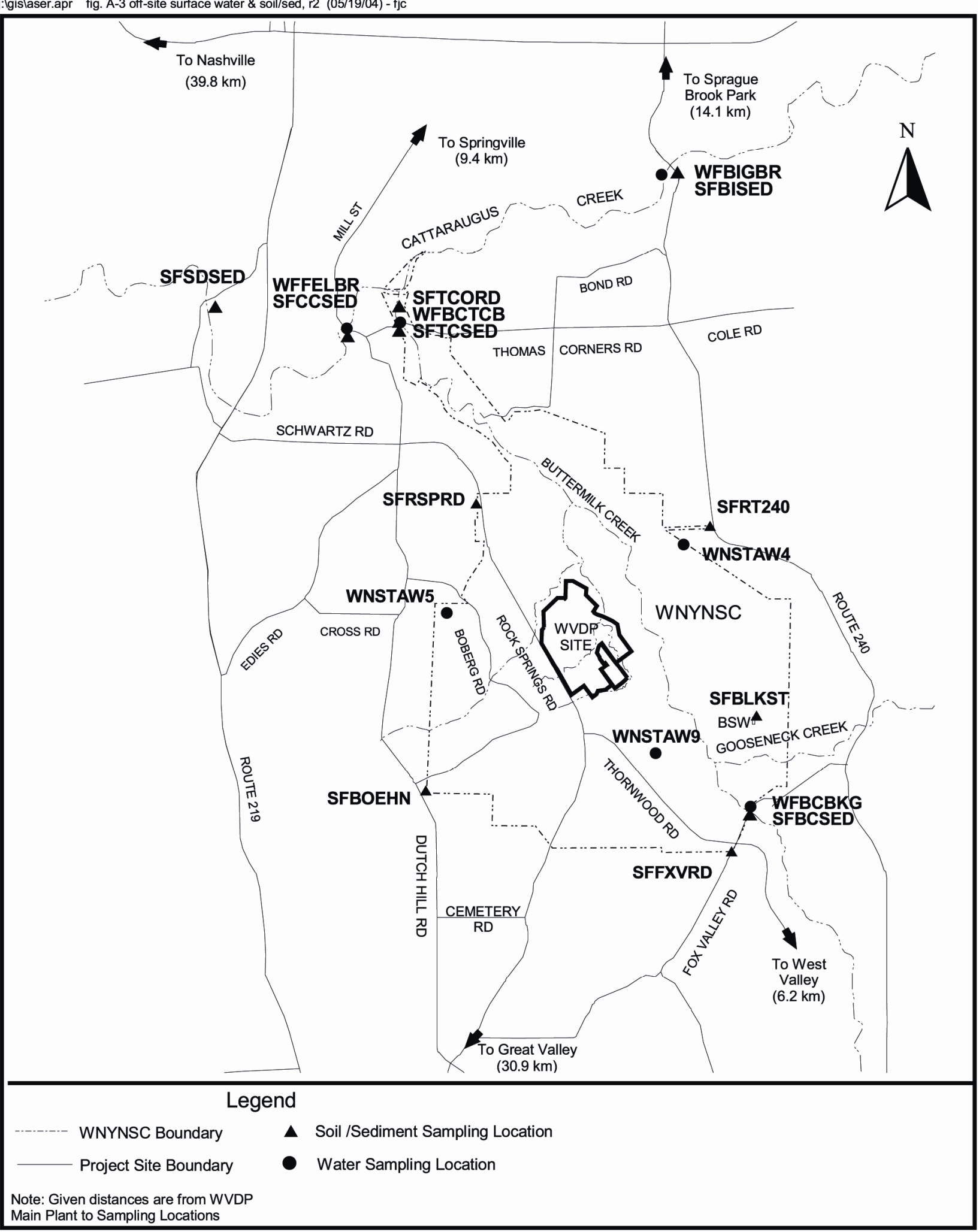

Figure A-3. Off-Site Surface Water and Soil/Sediment Sampling Locations

$$
\text { A - } 3
$$




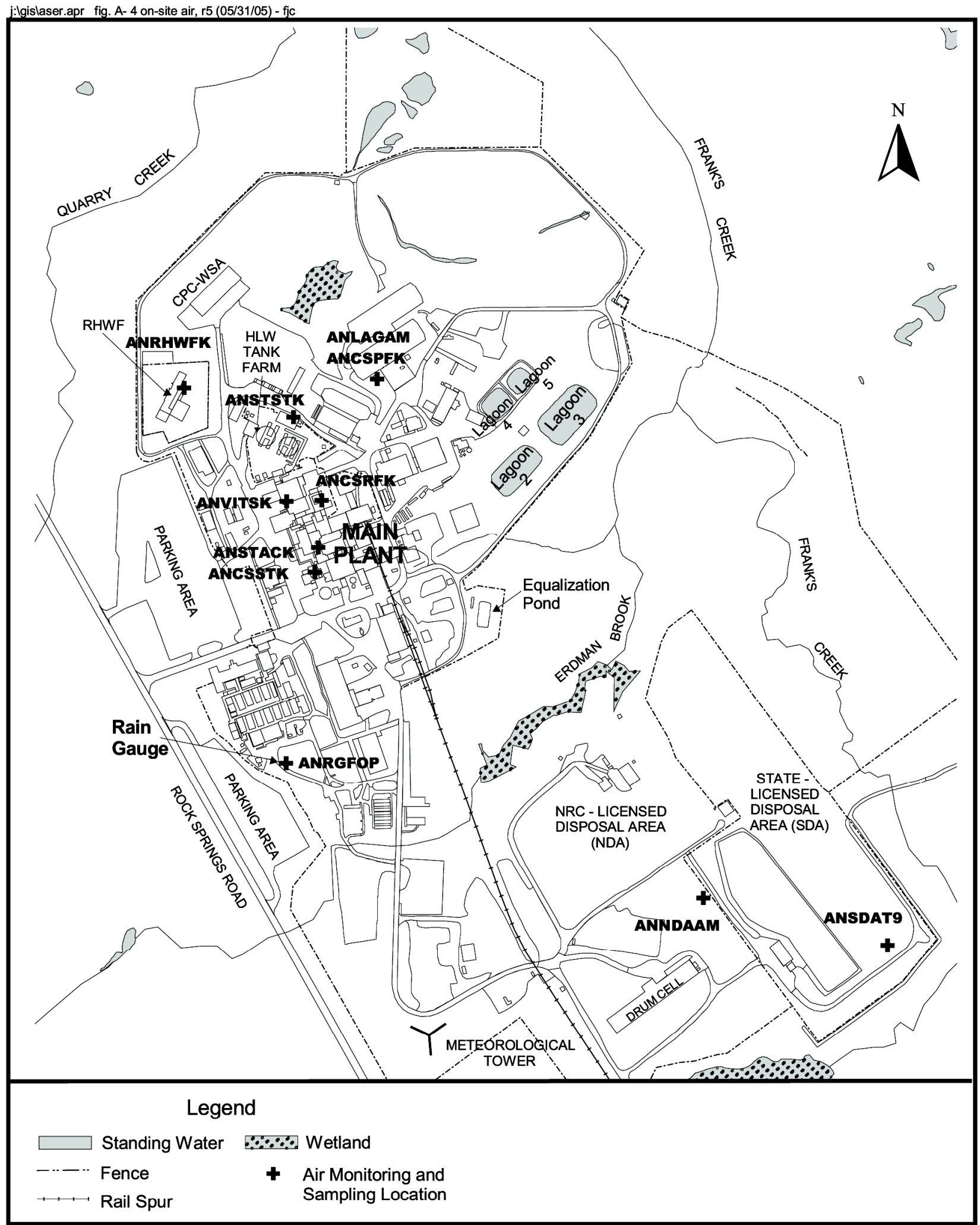

Figure A-4. On-Site Air Monitoring and Sampling Locations

A - 4 


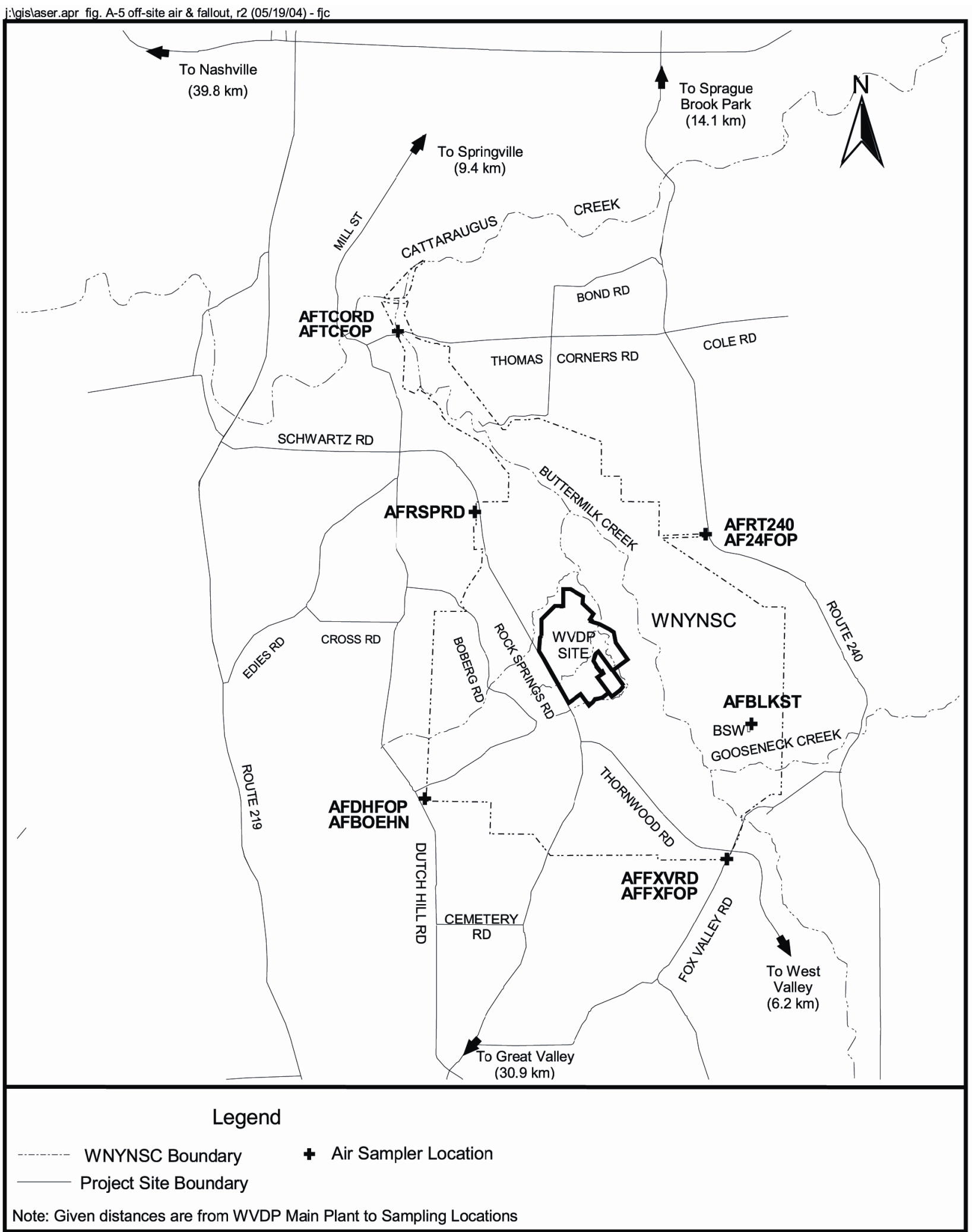

Figure A-5. Off-Site Air and Fallout Sampling Locations

A - 5 


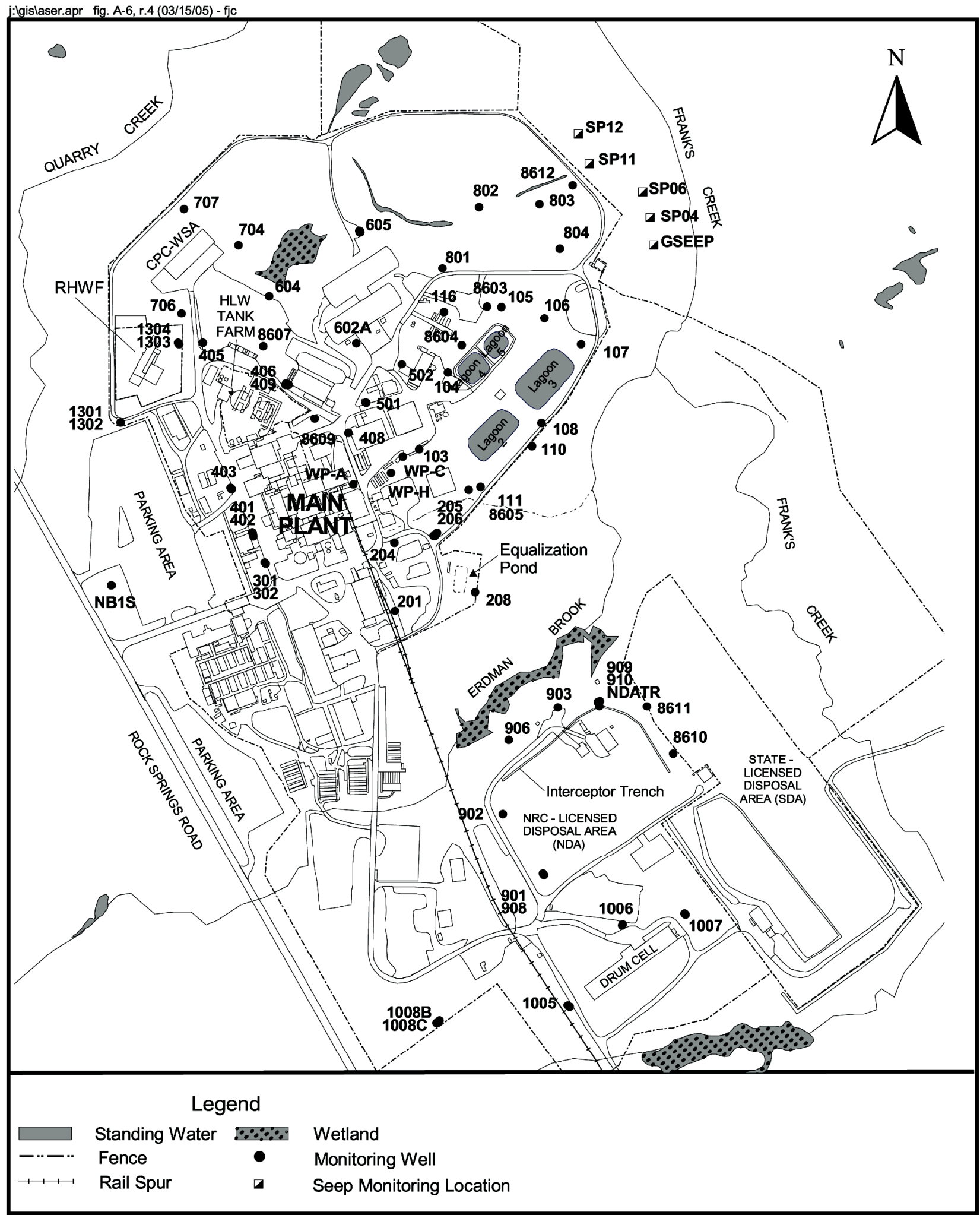

Figure A-6. Active WVDP Groundwater Monitoring Locations

$$
\text { A - } 6
$$




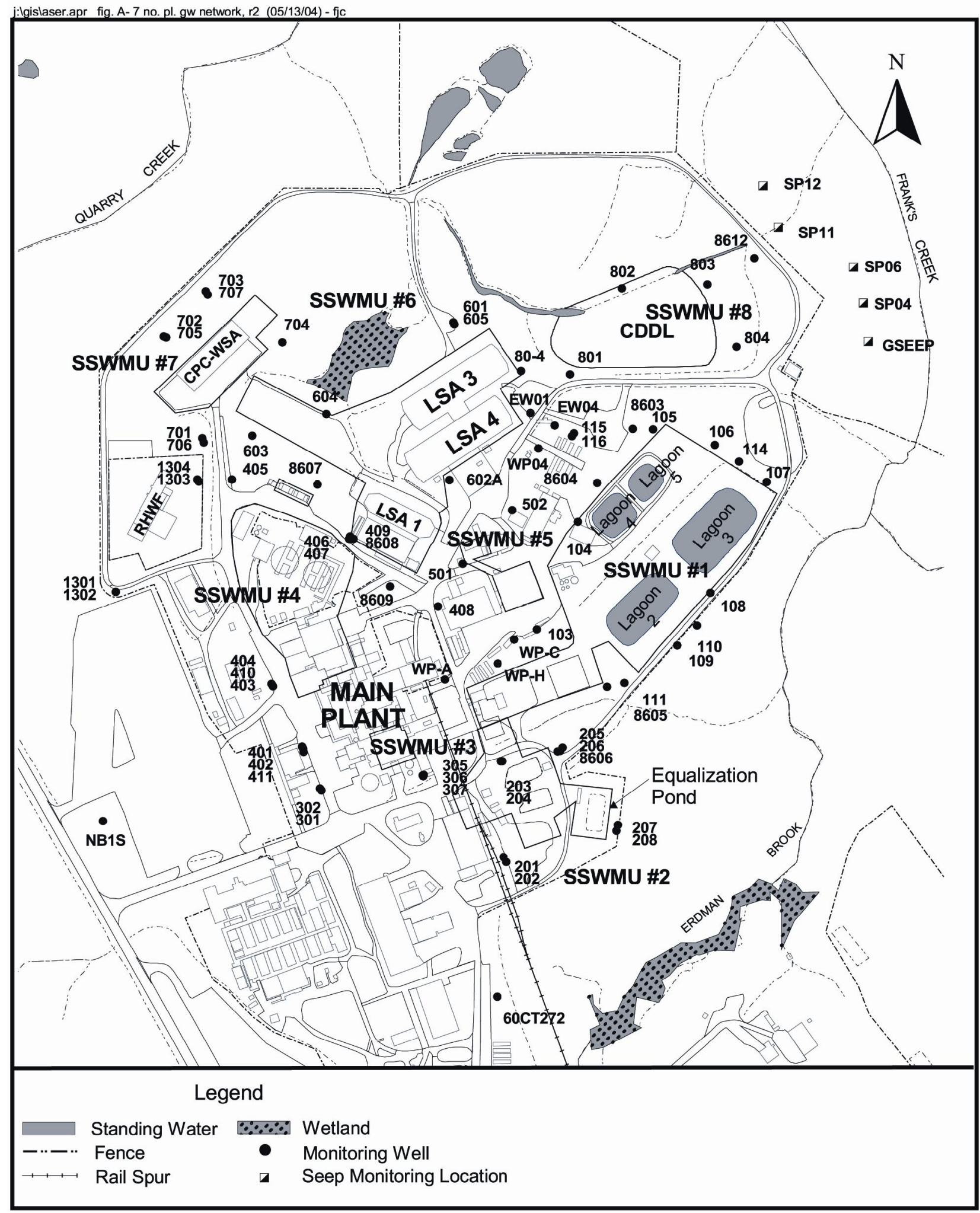

Figure A-7. North Plateau On-Site Groundwater Monitoring Network (Includes Wells Used for Water-Level Measurements)

$$
\text { A - } 7
$$






Figure A-8. South Plateau On-Site Groundwater Monitoring Network (Includes Wells Used for Water Level Measurements [WVDP] and SDA Wells [NYSERDA])

$$
\text { A - } 8
$$


j:lgislaser.apr fig. a-9 near-site biol \& wells, r5 (06/08/05) - fjc

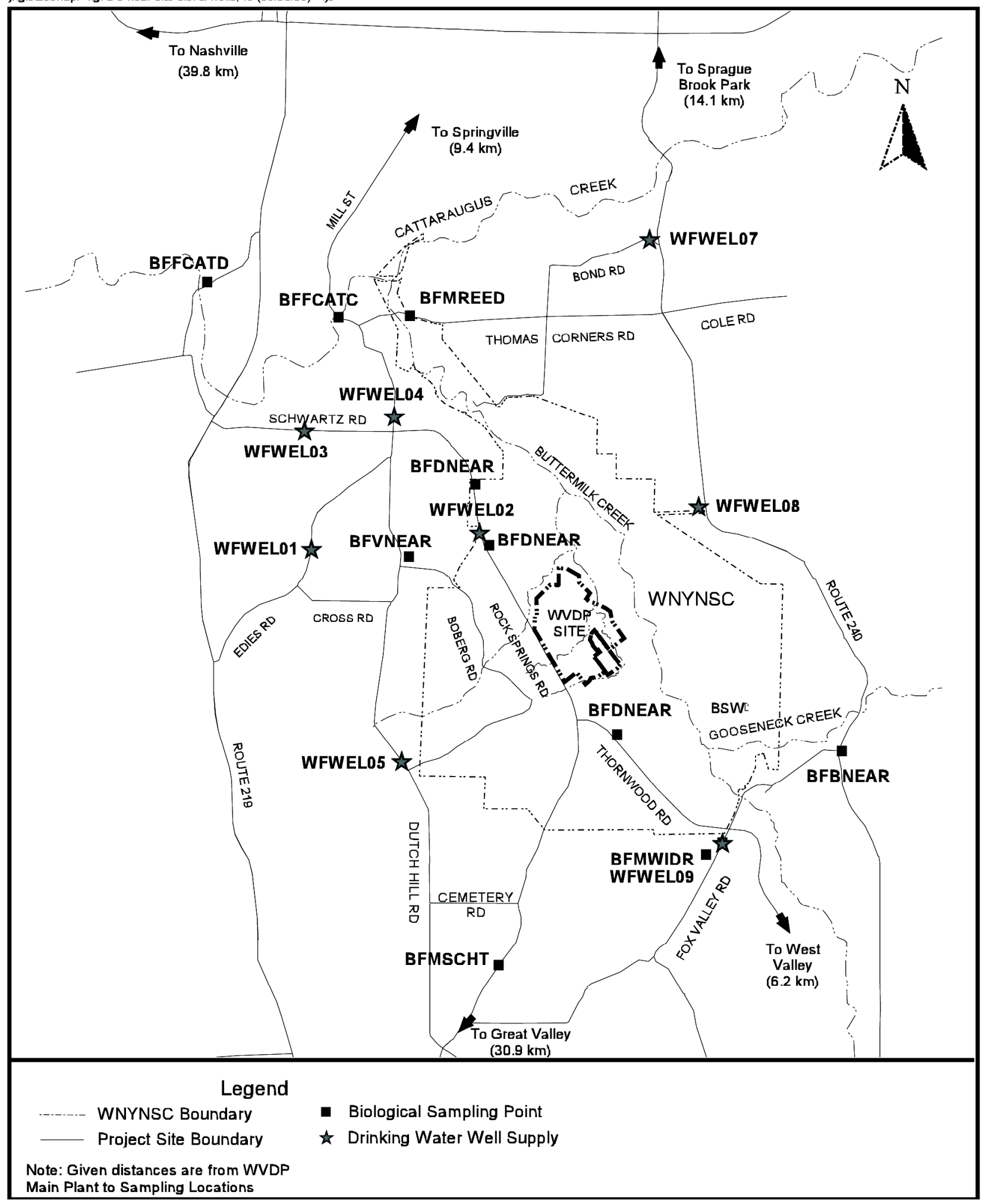

Figure A-9. Near-Site Drinking Water and Biological Sampling Locations

$$
\text { A - } 9
$$




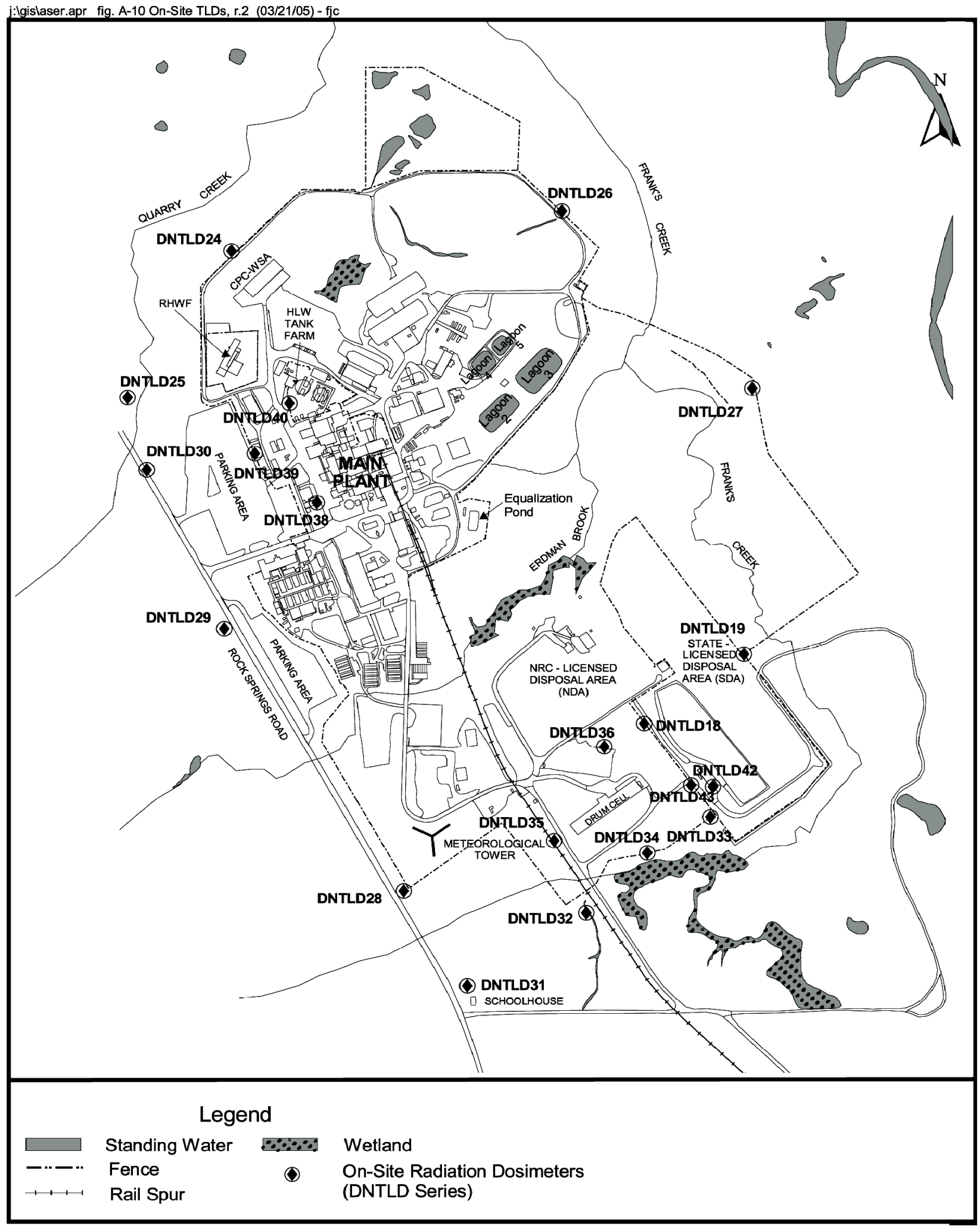

Figure A-10. Location of On-Site Thermoluminescent Dosimeters (TLDs)

$$
\text { A - } 10
$$




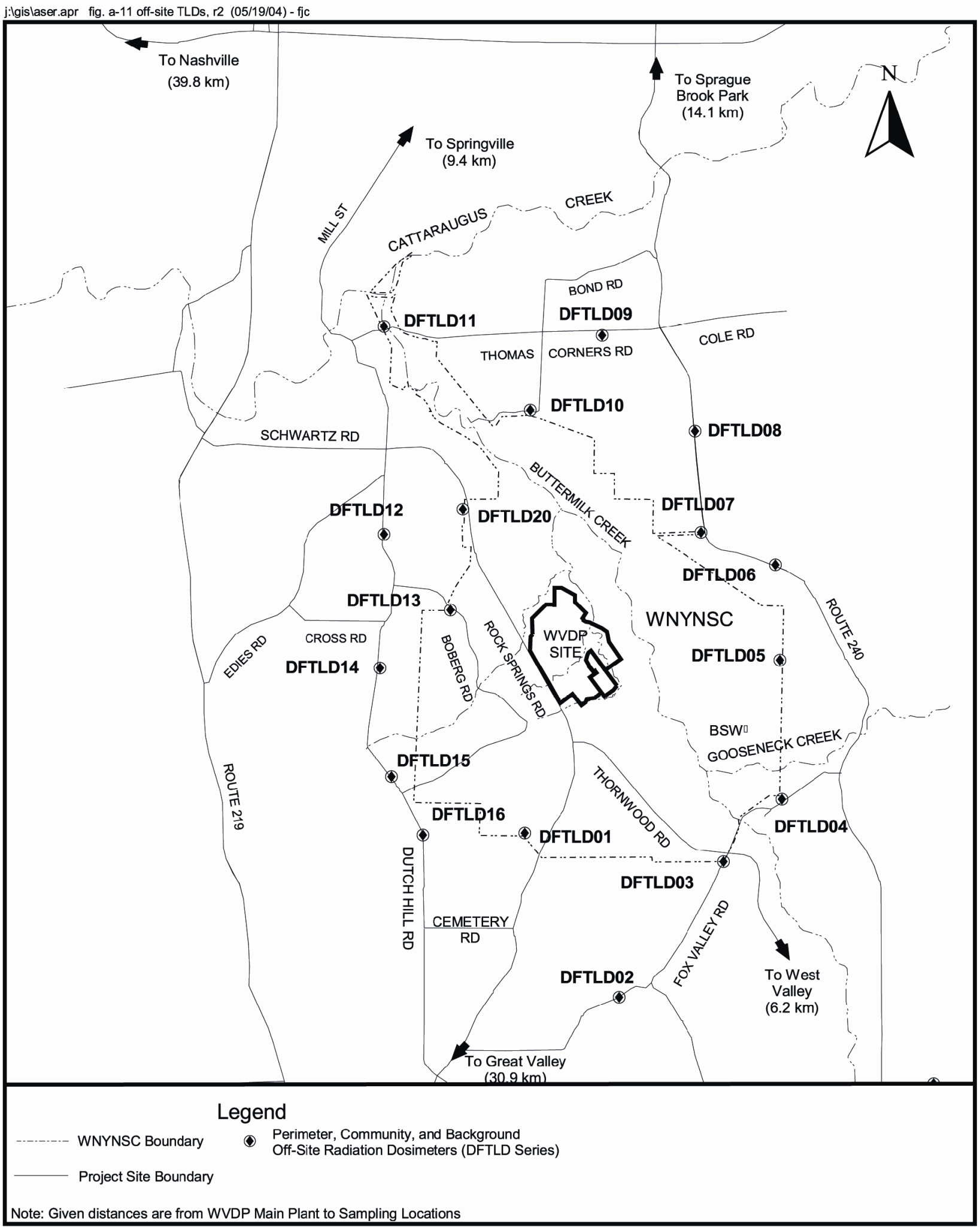

Figure A-11. Location of Off-Site Thermoluminescent Dosimeters (TLDs) Within 5 Kilometers of the WVDP

$$
\text { A - } 11
$$


Jigieleser.apr fig A12 regional points > 5km from site, is (05/04/05) - f)c

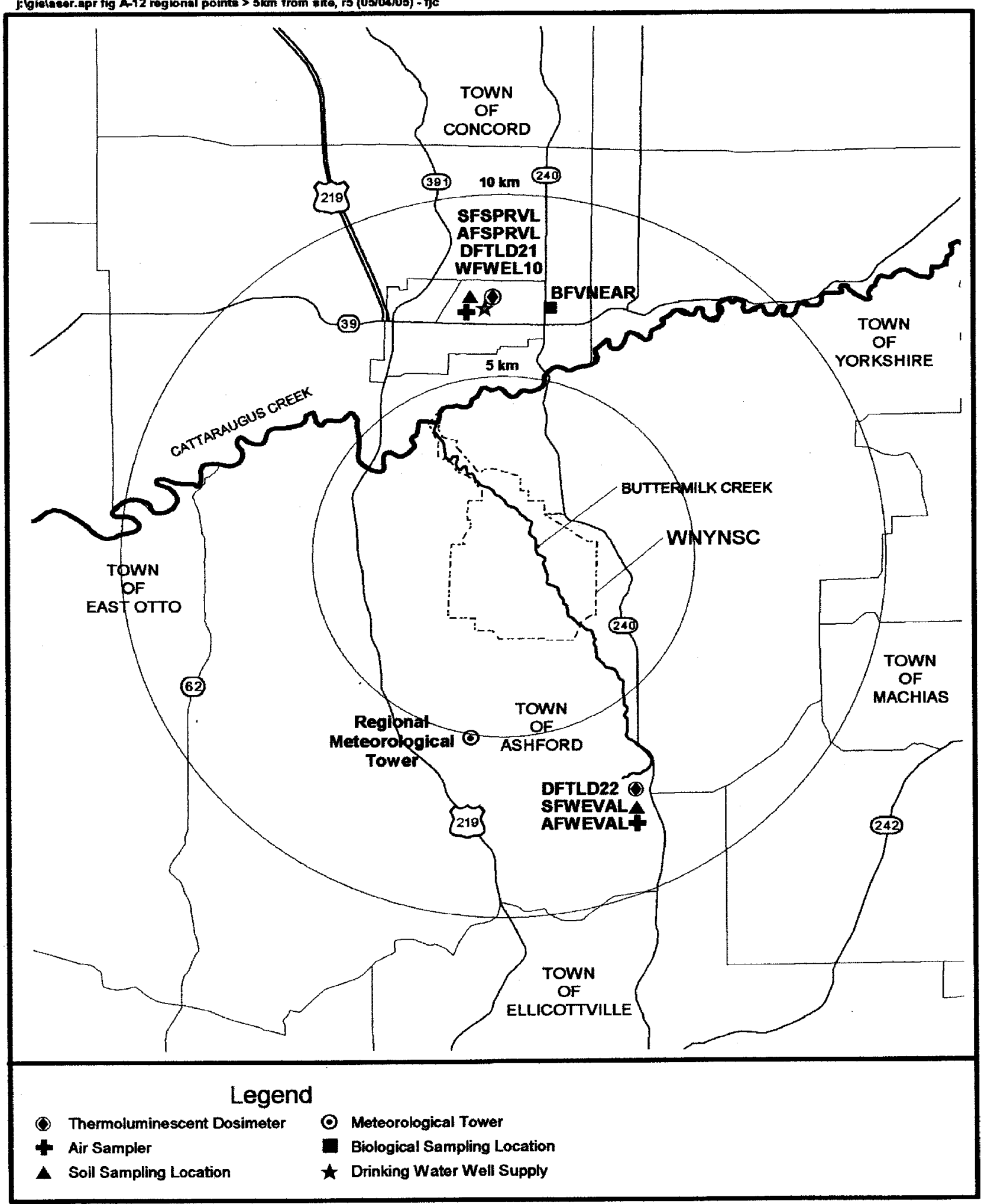

Figure A-12. Environmental Sampling Locations Between 5 and 10 Kilometers From the WVDP

$$
A-12
$$




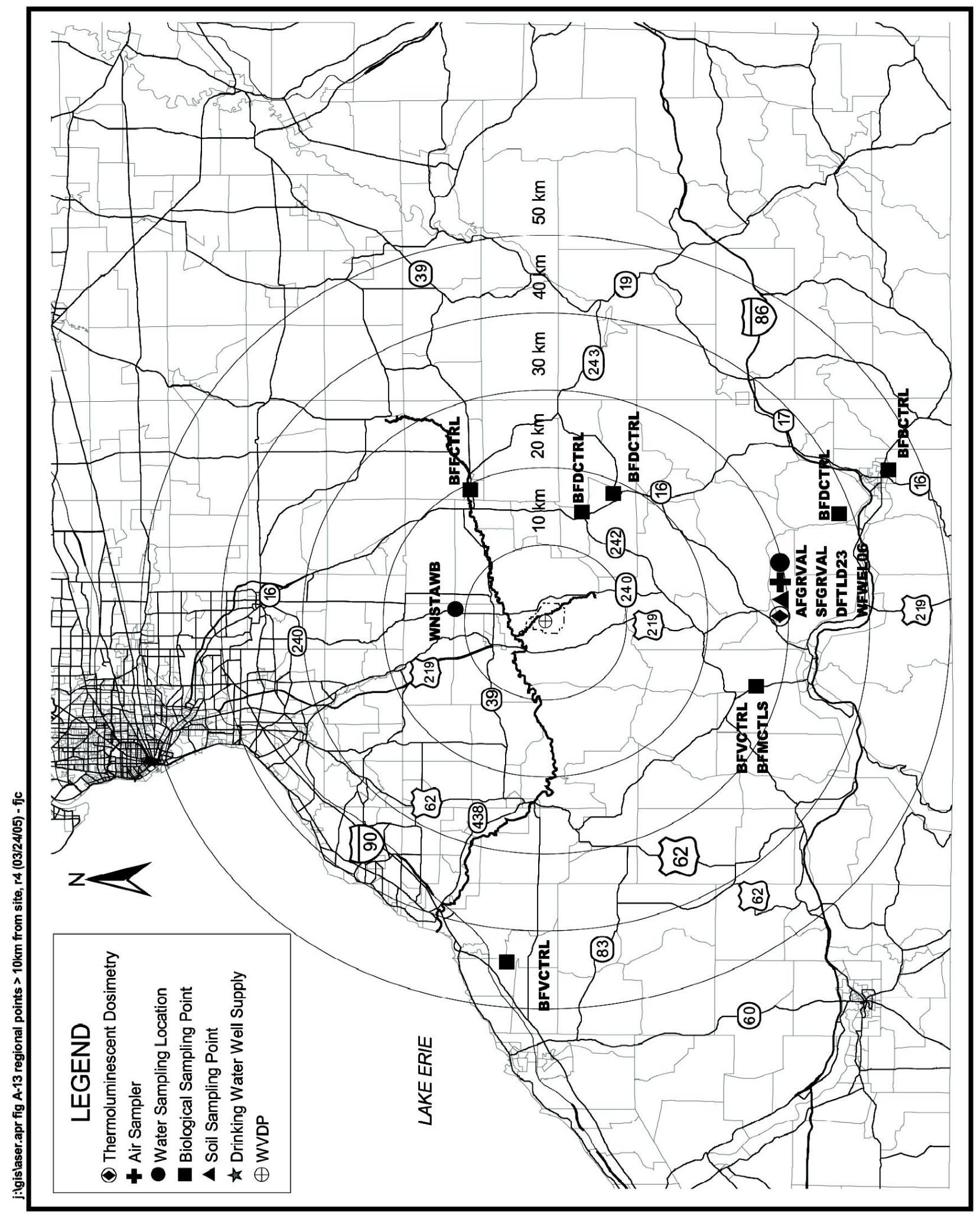

Figure A-13. Environmental Sampling Locations More Than 10 Kilometers From the WVDP

A - 13 


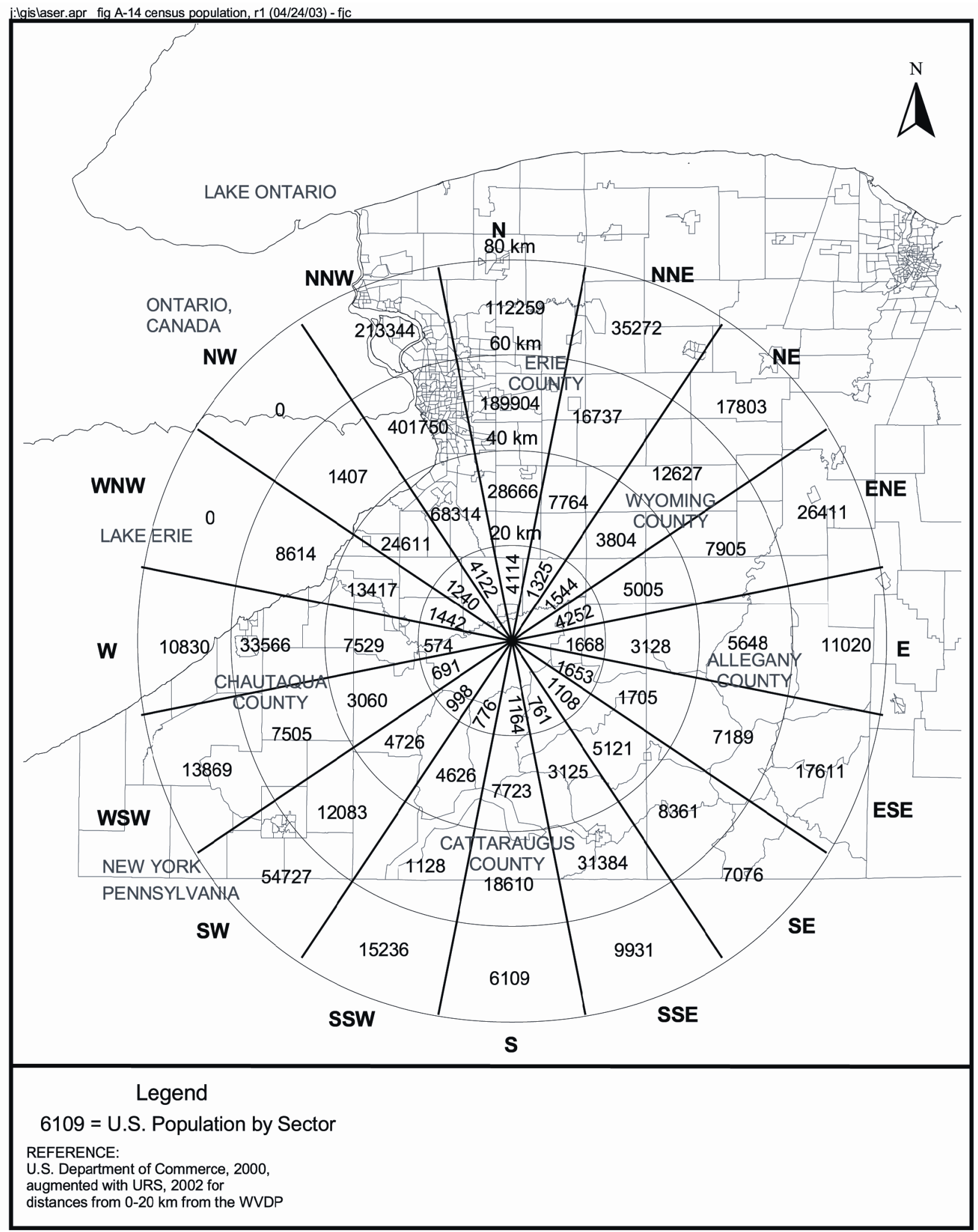

Figure A-14. Estimated 2002 Population by Sector Within 80 Kilometers of the WVDP

$$
\text { A - } 14
$$





\section{Appendix B 2004 Environmental Monitoring Program}

$B-i$ 
This page intentionally left blank

$B-i i$ 


\section{Environmental Monitoring Program}

The following schedule represents the West Valley Demonstration Project (WVDP) routine environmental monitoring program for 2004. This schedule met or exceeded the requirements of DOE Order 450.1, DOE Order 5400.5, and DOE/EH-0173T. Specific methods and recommended monitoring program elements are found in DOE/EP-0096, A Guide for Effluent Radiological Measurements at DOE Installations, and DOE/EP-0023, A Guide for Environmental Radiological Surveillance at U.S. Department of Energy Installations, which were the bases for selecting most of the schedule specifics. Additional monitoring was mandated by air and water discharge permits (40 CFR 61 and SPDES), which also required formal reports. Specifics are identified in the schedule under Monitoring/Reporting Requirements.

A computerized environmental data-screening system identifies analytical data that exceed preset limits. All locations are checked monthly for trends or notable results in accordance with criteria established in Documentation and Reporting of Environmental Monitoring Data (West Valley Nuclear Services Co., March 26, 2003). Reportable results are then described in monthly trend analysis reports (MTARs) for indicator parameters and chemical and isotopic parameters together with possible causes and corrective actions, if indicated. WVDP Effluent Summary Reports (ESRs) are transmitted with the MTARs.

\section{Schedule of Environmental Sampling}

The index on pages B-vi through B-viii is a list of the codes used to identify the various sampling locations, which are shown on Figures A-2 through A-13 in Appendix A. The schedule of environmental sampling at the WVDP is found in this appendix. Table headings in the schedule are as follows:

- Sample Location Code. Describes the physical location where the sample is collected. The code consists of seven or eight characters: The first character identifies the sample medium as Air, Water, Soil/Sediment, Biological, or Direct Measurement. The second character specifies oN-site or oFf-site. The remaining characters describe the specific location (e.g., AFGRVAL is Air oFf-site at GReat VALley). Distances noted at sampling locations are as measured in a straight line from the main stack on site.

- Monitoring/Reporting Requirements. Notes the bases for monitoring the location, any additional references to permits, and the reports that are generated from the sample data. Routine reports cited in this appendix are the Effluent Summary Report (ESR), the monthly trend analysis reports (MTARs), the State Pollutant Discharge Elimination System Discharge Monitoring Report (SPDES DMR), the Air Emissions Report (NESHAP), and the Annual Site Environmental Report (ASER).

- Sampling Type/Medium. Describes the collection method and the physical characteristics of the medium.

- Collection Frequency. Indicates how often the samples are collected or retrieved.

- Total Annual Sample Collections. Specifies the number of discrete physical samples collected annually for each group of analytes.

- Analyses Performed/Composite Frequency. Notes the type of analyses of the samples taken at each collection, the frequency of composite, and the analytes determined for the composite samples.

$B-i i i$

WVDP Annual Site Environmental Report

Calendar Year 2004 


\section{Summary of Monitoring Program Changes in 2004}

Location Code

ANRHWFK

OVEs/PVUs

\section{Description of Changes}

A new air sampling location (ANRHWFK) at the recently constructed remote-handled waste facility was brought on line in May 2004. Radiological operations began at this facility on June 14, 2004.

These air samples were used in an expanded role in 2004 to monitor decontamination activities in the main plant.

$B-i v$ 


\section{Index of Environmental Monitoring Program Sample Points}

\begin{tabular}{lll}
\multicolumn{2}{l}{ Air Effluent and On-Site Ambient Air (Fig. A-4) } & \\
ANSTACK & Main Plant & B-1 \\
ANSTSTK & Supernatant Treatment System & B-1 \\
ANCSSTK & 01-14 Building & B-1 \\
ANCSRFK & Size-Reduction Facility & B-1 \\
ANCSPFK & Container Sorting and Packaging Facility & B-1 \\
ANVITSK & Vitrification Heating, Ventilation, and Air Conditioning & B-1 \\
ANRHWFK & Remote-Handled Waste Facility & B-1 \\
OVES/PVUs* & Outdoor Ventilated Enclosures/Portable Ventilation Units & B-3 \\
ANLAGAM & Lag Storage Area (ambient air) & B-3 \\
ANNDAAM & NDAArea (ambient air) & B-3 \\
ANSDAT9 & SDA Trench 9 (ambient air) & B-3
\end{tabular}

\section{Liquid Effluent and On-Site Water (Fig. A-2)}

WNSP001

WNSP01B*

WNSP116

WNSP006

WNURRAW*

WNSP007

WNSWAMP

WNSW74A

WNSDADR

WNSP008

WNSP005

WNCOOLW

WNFRC67

WNERB53

WNNDADR

WNDCELD

WNNDATR

WNSTAW Series

WNDNK Series*
Lagoon 3 Weir Point

B-5

Internal Process Monitoring Point

B-7

Pseudo-Monitoring Point Outfall 116

B-7

Facility Main Drainage

Utility Room Raw Water

Sanitary Waste Discharge

Northeast Swamp Drainage Point

North Swamp Drainage Point

SDA Runoff

French Drain LLWTF Area

South Facility Drainage

Cooling Tower

Frank's Creek East

Erdman Brook

Disposal Area Drainage

Drum Cell Drainage

NDA Trench Interceptor Project

Standing Water

Site Potable Water
B-9

B-9

B-11

B-13

B-13

B-15

B-15

B-15

B-15

B-17

B-17

B-17

B-17

B-17

B-19

B-21

* Not detailed on map.

$$
B-v
$$




\section{Index of Environmental Monitoring Program Sample Points (continued)}

\begin{tabular}{lll}
\multicolumn{2}{l}{ On-Site Groundwater and Seeps (Figs. A-6 through A-8) } & \\
SSWMU \#1 & Low-Level Waste Treatment Facility Wells & B-23 \\
SSWMU \#2 & Miscellaneous Small Units Wells & B-23 \\
SSWMU \#3 & Liquid Waste Treatment System Wells & B-23 \\
SSWMU \#4 & HLW Storage and Processing Tank Wells & B-25 \\
SSWMU \#5 & Maintenance Shop Leach Field Wells & B-25 \\
SSWMU \#6 & Low-Level Waste Storage Area Wells & B-25 \\
SSWMU \#7 & CPC Waste Storage Area Wells & B-25 \\
SSWMU \#8 & CDDLWells & B-27 \\
SSWMU \#9 & NDA Units Wells and NDATR & B-27 \\
SSWMU\#10 & IRTS Drum Cell Wells & B-27 \\
RHWF & Remote-Handled Waste Facility Wells & B-27 \\
SSWMU \#11 & SDA Unit Wells & B-29 \\
North Plateau Seeps & Northeastern Edge of North Plateau & B-29 \\
Well Points & Downgradient of Main Plant & B-29 \\
WNWNB1S & Former North Plateau Background Well & B-29
\end{tabular}

\section{Off-Site Surface Water (Fig. A-3)}

WFBCBKG

WFBCTCB

WFBIGBR

WFFELBR
Buttermilk Creek near Fox Valley (background)

Buttermilk Creek at Thomas Corners

Cattaraugus Creek at Bigelow Bridge (background)

Cattaraugus Creek at Felton Bridge
B-31

B-31

B-33

B-33

Off-Site Drinking Water (Figs. A-9, A-12, and A-13)

WFWEL Series $\quad$ Private LocalWells

B-35

Off-Site Ambient Air (Figs. A-5, A-12, and A-13)

AFFXVRD

AFTCORD

AFRT240

AFSPRVL

AFWEVAL

AFBOEHN

AFRSPRD

AFGRVAL

AFBLKST
Fox Valley Sampler

B-37

Thomas Corners Sampler

B-37

Route 240 Sampler

B-37

Springville Sampler

West Valley Sampler

Dutch Hill Road Sampler

B-37

B-37

B-37

B-37

Rock Springs Road Sampler

B-37

Great Valley Sampler (background)

B-37

$B-v i$ 


\section{Index of Environmental Monitoring Program Sample Points (concluded)}

Fallout, Sediment, and Soil (Figs. A-2 through A-5, A-12, and A-13)

\begin{tabular}{llr} 
AFDHFOP & Dutch Hill Fallout & B-39 \\
AFFXFOP & Fox Valley Fallout & B-39 \\
AFTCFOP & Thomas Corners Fallout & B-39 \\
AF24FOP & Route 240 Fallout & B-39 \\
ANRGFOP & Rain Gauge Fallout & B-39 \\
SF Soil Series & Air Sampler Area Soil & B-39 \\
SFCCSED & Cattaraugus Creek at Felton Bridge, Sediment & B-39 \\
SFSDSED & Cattaraugus Creek at Springville Dam, Sediment & B-39 \\
SFBISED & Cattaraugus Creek at Bigelow Bridge, Background Sediment & B-39 \\
SFTCSED & Buttermilk Creek at Thomas Corners, Sediment & B-39 \\
SFBCSED & Buttermilk Creek at Fox Valley Road, Background Sediment & B-39 \\
SN Soil Series: & On-Site Soils/Sediments & B-39 \\
\multicolumn{1}{c}{ SNSW74A } & & B-39 \\
SNSWAMP & & B-39 \\
SNSP006 & & B-39
\end{tabular}

Off-Site Biological (Figs. A-9, A-12, and A-13)

$\begin{array}{llr}\text { BFFCATC } & \text { Cattaraugus Creek Fish, Downstream } & \text { B-41 } \\ \text { BFFCATD } & \text { Cattaraugus Creek Fish, Downstream of Springville Dam } & \text { B-41 } \\ \text { BFFCTRL } & \text { Cattaraugus Creek Fish, Background } & \text { B-41 } \\ \text { BFMREED } & \text { North-Northwest Milk, Near-Site } & \text { B-41 } \\ \text { BFMCTLS } & \text { Milk, South, Background } & \text { B-41 } \\ \text { BFMWIDR } & \text { Southeast Milk, Near-Site } & \text { B-41 } \\ \text { BFMSCHT } & \text { South Milk, Near-Site } & \text { B-41 } \\ \text { BFVNEAR* } & \text { Produce, Near-Site } & \text { B-43 } \\ \text { BFVCTRL* } & \text { Produce, Background } & \text { B-43 } \\ \text { BFBNEAR } & \text { Beef, Near-Site } & \text { B-43 } \\ \text { BFBCTRL } & \text { Beef, Background } & \text { B-43 } \\ \text { BFDNEAR } & \text { Venison, Near-Site } & \text { B-43 } \\ \text { BFDCTRL } & \text { Venison, Background } & \text { B-43 }\end{array}$

Direct Measurement Dosimetry (Figs. A-10 through A-13)

DFTLD Series $\quad$ Off-Site Direct Radiation $\quad$ B-45

$\begin{array}{lll}\text { DNTLD Series } & \text { On-Site Direct Radiation } & \text { B-47 }\end{array}$

* Near-site and background produce samples (corn, apples, and beans) are identified specifically as follows: corn = BFVNEAC and BFVCTRC; apples = BFVNEAAF and BFVCTRA; beans = BFVNEAB and BFVCTRB .

$$
B-v i i
$$




\section{Monitoring Program \\ On-Site Effluent Monitoring}

Air Effluents

\begin{tabular}{|c|c|c|c|c|c|c|c|c|}
\hline $\begin{array}{l}\text { Sample Location } \\
\text { Code }\end{array}$ & $\begin{array}{l}\text { Monitoring/Reporting } \\
\text { Requirements }\end{array}$ & $\begin{array}{c}\text { Sampling } \\
\text { Type/Medium }\end{array}$ & & $\begin{array}{l}\text { Collection } \\
\text { Frequency }\end{array}$ & & $\begin{array}{c}\text { Total Annual } \\
\text { Sample Collections }\end{array}$ & & $\begin{array}{l}\text { Analyses Performed/ } \\
\text { Composite Frequency }\end{array}$ \\
\hline $\begin{array}{l}\text { ANSTACK } \\
\text { Main Plant Ventilation } \\
\text { Exhaust Stack }\end{array}$ & & $\begin{array}{l}\text { Continuous } \\
\text { off-line air } \\
\text { particulate } \\
\text { monitors }\end{array}$ & $\rightarrow$ & $\begin{array}{l}\text { Continuous } \\
\text { measurement of } \\
\text { fixed filter; } \\
\text { replaced weekly }\end{array}$ & & NA & $\rightarrow$ & $\begin{array}{l}\text { Real-time alpha and } \\
\text { beta monitoring }\end{array}$ \\
\hline $\begin{array}{l}\text { Supernatant Treatment } \\
\text { System (STS) Ventila- } \\
\text { tion Exhaust }\end{array}$ & $\begin{array}{l}\text { Airborne radioac- } \\
\text { tive effluent points, } \\
\text { including the LWTS }\end{array}$ & $\begin{array}{l}\text { Continuous } \\
\text { off-line air } \\
\text { particulate }\end{array}$ & $\rightarrow$ & Weekly & $\rightarrow$ & $\begin{array}{l}52 \text { each } \\
\text { location }\end{array}$ & $\rightarrow$ & $\begin{array}{l}\text { Gross alpha/beta, } \\
\text { gamma isotopic* } \\
\text { upon collection, flow }\end{array}$ \\
\hline $\begin{array}{l}\text { ANCSSTK } \\
\text { 01-14 Building } \\
\text { Ventilation Exhaust }\end{array}$ & $\begin{array}{l}\text { Required by: } \\
\text { - } 40 \text { CFR } 61\end{array}$ & filters & & & & $\begin{array}{l}\text { Weekly filters } \\
\text { composited to } \\
4 \text { each }\end{array}$ & $\rightarrow$ & $\begin{array}{l}\text { Quarterly composites } \\
\text { for Sr-90, U-232, } \\
\text { U-233/234, }\end{array}$ \\
\hline $\begin{array}{l}\text { ANCSRFK } \\
\text { Contact Size-Reduction } \\
\text { Facility Exhaust }\end{array}$ & Reported in: & & & & & location & & $\begin{array}{l}\mathrm{U}-235 / 236, \mathrm{U}-238, \\
\text { total U, Pu-238, } \\
\mathrm{Pu}-239 / 240, \mathrm{Am}-241 \text {, }\end{array}$ \\
\hline $\begin{array}{l}\text { ANCSPFK } \\
\text { Container Sorting and } \\
\text { Packaging Facility } \\
\text { Exhaust } \\
\text { ANVITSK } \\
\text { Vitrification HVAC } \\
\text { Exhaust }\end{array}$ & $\begin{array}{l}\text { - } \text { MTARs } \\
\text { - ASER } \\
\text { - Air Emissions } \\
\text { Annual Report } \\
\text { (NESHAP) }\end{array}$ & $\begin{array}{l}\text { Continuous } \\
\text { off-line } \\
\text { desiccant } \\
\text { columns for } \\
\text { water vapor } \\
\text { collection }\end{array}$ & $\rightarrow$ & Weekly & $\rightarrow$ & $\begin{array}{l}52 \text { at each of } \\
\text { two locations }\end{array}$ & $\rightarrow$ & $\begin{array}{l}\text { H-3 (ANSTACK and } \\
\text { ANSTSTK only), flow }\end{array}$ \\
\hline $\begin{array}{l}\text { ANRHWFK } \\
\text { Remote-Handled Waste } \\
\text { Facility Exhaust }\end{array}$ & & $\begin{array}{l}\text { Continuous } \\
\text { off-line } \\
\text { charcoal } \\
\text { cartridges }\end{array}$ & $\rightarrow$ & Weekly & $\rightarrow$ & $\begin{array}{l}\text { Weekly } \\
\text { cartridges } \\
\text { composited to } \\
4 \text { each } \\
\text { location }\end{array}$ & $\rightarrow$ & $\begin{array}{l}\text { Quarterly composite } \\
\text { for I-129 }\end{array}$ \\
\hline
\end{tabular}

* Weekly gamma isotopic only if gross activity rises significantly.

NA - Not applicable.

$B-1$ 


\section{Sampling Rationale}

ANSTACK

ANSTSTK

ANCSRFK

ANCSPFK

ANVITSK

ANRHWFK
DOE/EH-0173T, 3.0; DOE/EP-0096, 3.3

Monitors and samples HEPA-filtered ventilation from most process areas, including cell ventilation, vessel offgas, fuel receiving and storage (FRS), head end ventilation, and an analytical aisle. Requires continuous effluent monitoring per 40 CFR Subpart H, Section 61.93(b) because potential emissions may exceed the $0.1 \mathrm{mrem}$ limit.

DOE/EH-0173T, 3.0; DOE/EP-0096, 3.3

Monitors and samples HEPA-filtered ventilation (permanent ventilation system [PVS]) from building areas involved in treatment of high-level waste supernatant. Requires continuous effluent monitoring per 40 CFR Subpart H, Section 61.93(b) because potential emissions may exceed the $0.1 \mathrm{mrem}$ limit.

DOE/EH-0173T, 3.0; DOE-EP-0096, 3.3

Monitors and samples HEPA-filtered ventilation from the 01-14 building, which houses equipment used to treat the ceramic melter off-gas. Requires effluent monitoring per 40 CFR Subpart H, Section 61.93(b) to confirm that emissions are less than the 0.1 mrem limit.

DOE/EH-0173T, 3.0; DOE-EP-0096, 3.3

Monitors and samples HEPA-filtered ventilation from a process area where radioactive tanks, pipes, and other equipment are cut up with a plasma torch to reduce volume.

DOE/EH-0173T, 3.0; DOE-EP-0096, 3.3

Monitors and samples ventilation from lag storage area 4, the container sorting and packaging facility.

DOE/EH-0173T, 3.0; DOE-EP-0096, 3.3

Vitrification facility heating, ventilation, and air conditioning (HVAC) effluent exhaust stack. Monitors and samples HEPA-filtered ventilation from building areas involved in treatment of high-level waste supernatant. Sampler brought on-line in late 1995 when nonradioactive operations began. Radioactive operation began with the first highlevel waste transfer in June 1996 and vitrification startup in July 1996. Vitrification was completed in 2002. Requires effluent monitoring per 40 CFR Subpart H, Section 61.93(b) because potential emissions may exceed the $0.1 \mathrm{mrem}$ limit.

DOE/EH-0173T, 3.0; DOE-EP-0096, 3.3

Monitors and samples HEPA-filtered ventilation from the remote-handled waste facility (RHWF), where contaminated waste equipment (i.e., pumps, tanks, piping) are size reduced before being packaged for disposal. Construction of the RHWF was completed early in 2004 and radiological operations began in June 2004.

Sampling locations are shown on Figure A-4.

$$
B-2
$$




\section{Monitoring Program \\ On-Site Effluent Monitoring}

Air Effluents

\begin{tabular}{|c|c|c|c|c|c|c|c|c|}
\hline $\begin{array}{l}\text { Sample Location } \\
\text { Code }\end{array}$ & $\begin{array}{l}\text { Monitoring/Reporting } \\
\text { Requirements }\end{array}$ & $\begin{array}{c}\text { Sampling } \\
\text { Type/Medium }\end{array}$ & & $\begin{array}{l}\text { Collection } \\
\text { Frequency }\end{array}$ & & $\begin{array}{c}\text { Total Annual } \\
\text { Sample Collections }\end{array}$ & & $\begin{array}{l}\text { Analyses Performed/ } \\
\text { Composite Frequency }\end{array}$ \\
\hline $\begin{array}{l}\text { OVEs/PVUs } \\
\text { Outdoor Ventilated } \\
\text { Enclsoures/Portable } \\
\text { Ventilation Units }\end{array}$ & $\begin{array}{l}\begin{array}{l}\text { Airborne radioactive } \\
\text { effluent points }\end{array} \\
\text { Required by: } \\
\text { - } 40 \text { CFR } 61 \\
\text { Reported in: } \\
\text { - ESR } \\
\text { - MTARs } \\
\text { - ASER } \\
\text { - Air Emissions } \\
\text { Annual Report } \\
\text { (NESHAP) }\end{array}$ & $\begin{array}{l}\text { Continuous } \\
\text { off-line air } \\
\text { particulate } \\
\text { filter }\end{array}$ & $\rightarrow$ & As required & $\rightarrow$ & $\begin{array}{l}\text { Collected } \\
\text { filters** } \\
\text { composited to } 4\end{array}$ & $\rightarrow$ & $\begin{array}{l}\text { Quarterly composites } \\
\text { for Sr-90, U-232, } \\
\mathrm{U}-233 / 234, \mathrm{U}-235 / 236 \text {, } \\
\mathrm{U}-238 \text {, total U, Pu-238, } \\
\mathrm{Pu}-239 / 240, \mathrm{Am}-241 \text {, } \\
\text { gamma isotopic, flow }\end{array}$ \\
\hline $\begin{array}{l}\text { ANLAGAM } \\
\text { Lag Storage Area } \\
\text { Ambient Air } \\
\text { ANNDAAM } \\
\text { NDA Ambient Air }\end{array}$ & $\begin{array}{l}\text { Ambient "diffuse } \\
\text { source" air } \\
\text { emissions } \\
\text { Reported in: } \\
\text { - MTARs } \\
\text { - ASER }\end{array}$ & $\begin{array}{l}\text { Continuous } \\
\text { air particulate } \\
\text { filter }\end{array}$ & & Weekly & $\rightarrow$ & $\begin{array}{l}52 \text { each } \\
\text { location } \\
\text { Weekly filter } \\
\text { composited to } 4 \\
\text { each location }\end{array}$ & $\rightarrow$ & $\begin{array}{l}\text { Gross alpha/beta, } \\
\text { flow } \\
\text { Quarterly composites } \\
\text { for Sr-90, U-232, } \\
\text { U-233/234, U-235/236, } \\
\text { U-238, total U, Pu-238, } \\
\text { Pu-239/240, Am-241, } \\
\text { gamma isotopic, flow }\end{array}$ \\
\hline $\begin{array}{l}\text { ANSDAT9**** } \\
\text { SDA Trench } 9 \\
\text { Ambient Air }\end{array}$ & $\begin{array}{l}\text { Ambient "diffuse } \\
\text { source" air } \\
\text { emissions } \\
\text { Reported in: } \\
\text { - ASER } \\
\text { - Reported to } \\
\text { NYSERDA }\end{array}$ & $\begin{array}{l}\text { Continuous } \\
\text { off-line } \\
\text { desiccant } \\
\text { columns for } \\
\text { water vapor } \\
\text { collection } \\
\text { Continuous } \\
\text { off-line } \\
\text { charcoal } \\
\text { cartridges }\end{array}$ & $\rightarrow$ & Monthly & $\rightarrow$ & $\begin{array}{l}52 \\
\text { Weekly filter } \\
\text { composited to } 4 \\
52\end{array}$ & $\begin{array}{l}\rightarrow \\
\rightarrow\end{array}$ & $\begin{array}{l}\text { Gross alpha/beta, } \\
\text { flow } \\
\text { Quarterly composite for } \\
\text { gamma isotopic, flow } \\
\text { H-3, flow }\end{array}$ \\
\hline
\end{tabular}

* Gamma isotopic only if gross activity rises significantly.

** If gross determination of individual filter is significantly higher than background, the individual sample would be submitted immediately for isotopic analysis.

*** Sampling frequency and analytical parameters as directed by NYSERDA.

$$
B-3
$$




\section{Sampling Rationale}

\section{OVEs/PVUs DOE/EH-0173T, 3.0; DOE/EP-0096, 3.3}

Outdoor ventilated enclosures; portable ventilation units used for handling radioactive materials or for decontamination in areas not having containment ventilation. Emissions are monitored to confirm that they are below the 0.1 mrem limit.

Sampling locations are not shown on figures.

ANLAGAM DOE/EH-0173T, 3.3.2

Monitors ambient air in the lag storage area, a possible diffuse source of air emissions.

ANNDAAM

DOE/EH-0173T, 3.3.2

Monitors ambient air in the NDA area, a possible diffuse source of air emissions.

ANSDAT9

DOE/EH-0173T, 3.3 .2

Monitors potential diffuse sources of air emissions at the SDA and south plateau area. WVDP support of NYSERDA.

- Sampling locations are shown on Figure A-4. 


\section{Monitoring Program \\ On-Site Effluent Monitoring}

\section{Liquid Effluents}

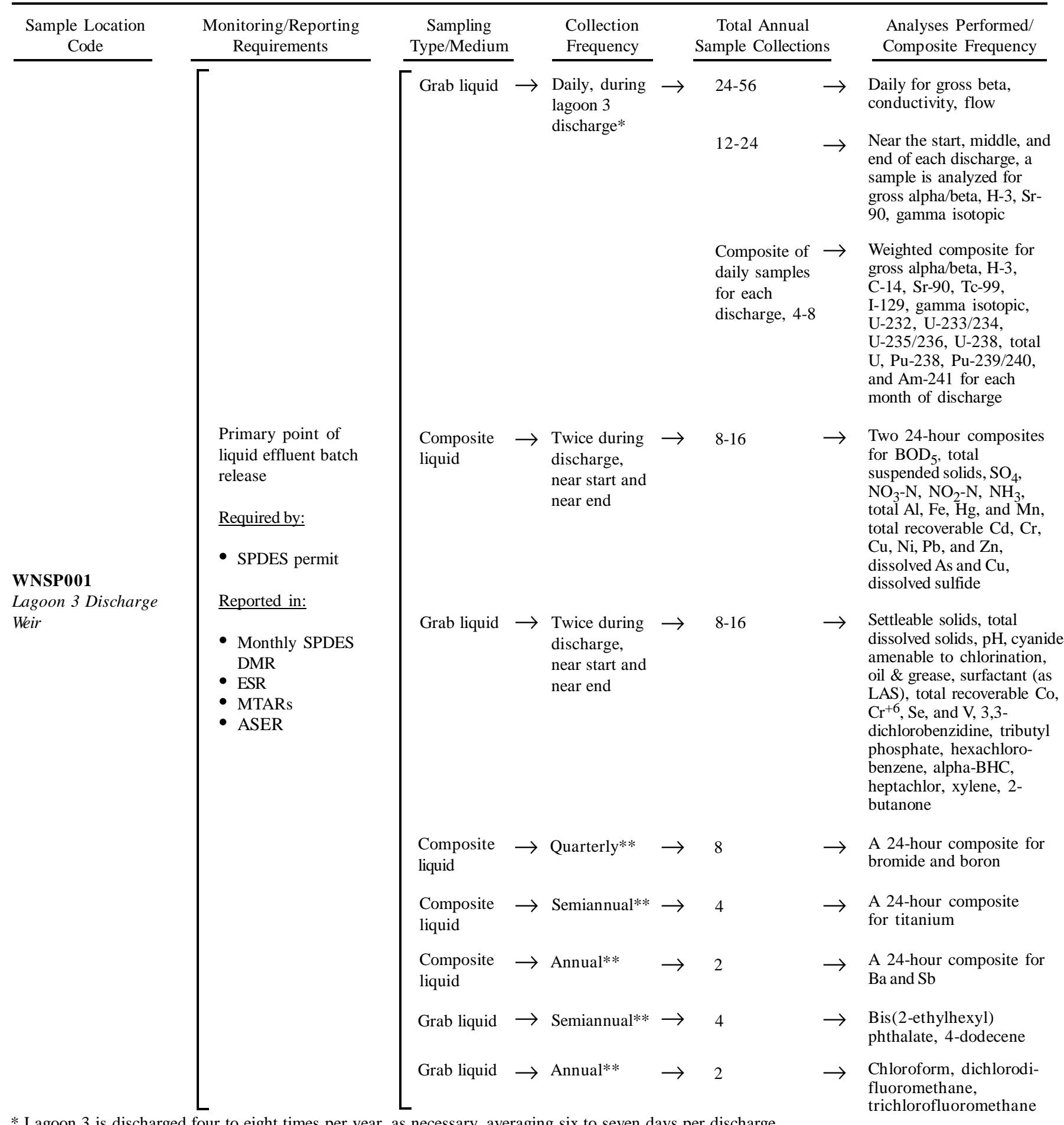

* Lagoon 3 is discharged four to eight times per year, as necessary, averaging six to seven days per discharge.

** Two samples are collected, one near the start and one near the end of the discharge.

$$
B-5
$$




\section{Sampling Rationale}

WNSP001 DOE Order 5400.5; DOE/EH-0173T, 2.3.3; New York State SPDES Permit no. NY0000973

By DOE Order all liquid effluent streams from DOE facilities shall be evaluated and their potential for release of radionuclides addressed. These requirements for radiological parameters are met by daily grab sampling during periods of lagoon 3 discharge.

Sampling for chemical constituents is performed near the beginning and end of each discharge period to meet the site SPDES Permit. Both grab samples and 24-hour composite samples are collected.

For permit requirements, total $\mathrm{Hg}$ is analyzed by U.S. EPA Method 245.1. For mercury studies, samples are analyzed by EPA Method 1631.

Sampling location is shown on Figure A-2.

$$
B-6
$$




\section{Monitoring Program \\ On-Site Effluent Monitoring}

\section{Liquid Effluents}

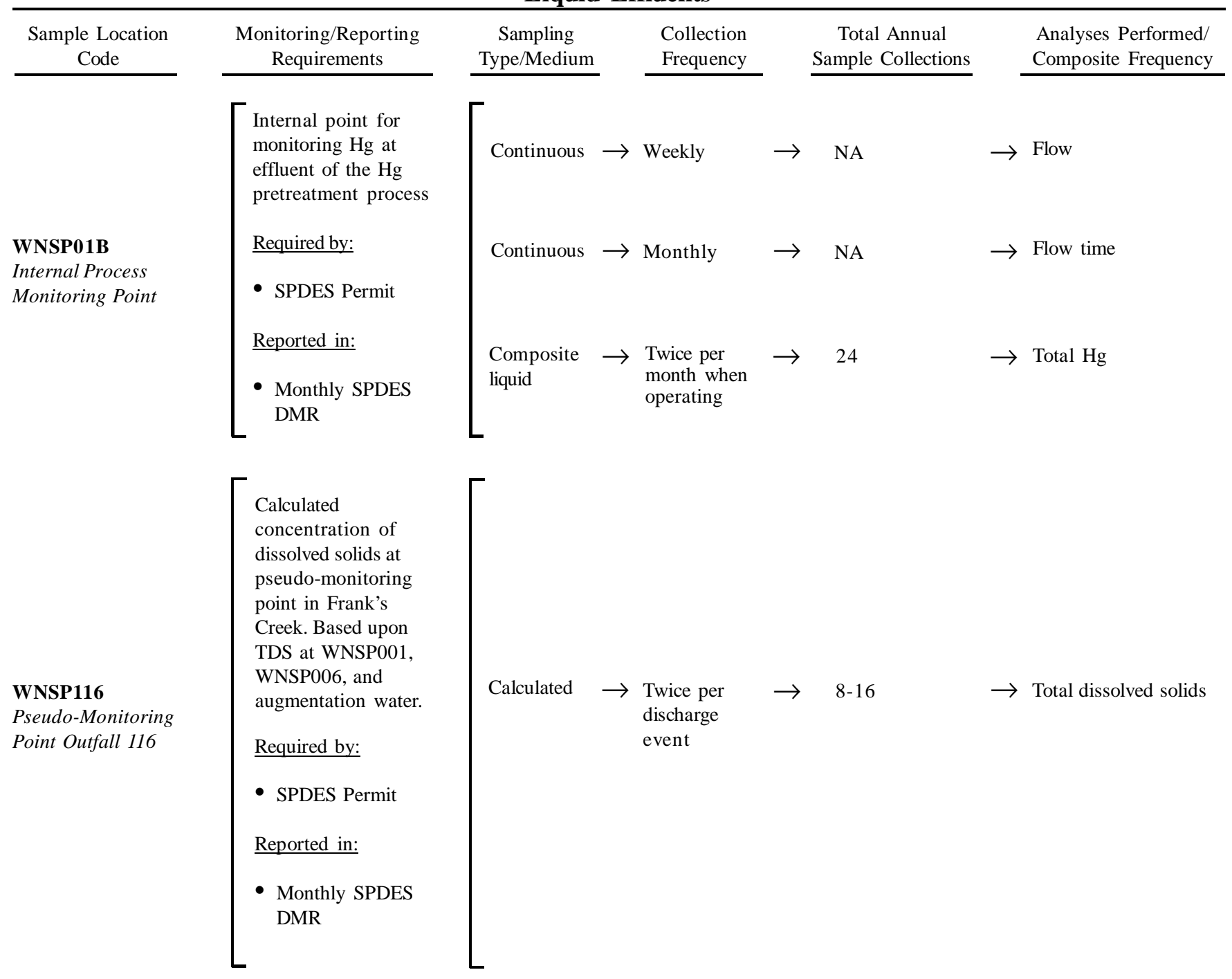

NA - Not applicable

$$
B-7
$$




\section{Sampling Rationale}

WNSP01B New York State SPDES Permit no. NY0000973

This internal point is used to monitor mercury in effluent from the proposed mercury pretreatment process. Effluent from this point is subsequently released to lagoon 3, which is monitored at point WNSP001.

For permit requirements, total $\mathrm{Hg}$ is analyzed by U.S. EPA Method 245.1. For mercury studies, samples are analyzed by EPA Method 1631.

WNSP116 New York State SPDES Permit no. NY0000973

This "pseudo-monitoring point," assumed to be in Frank's Creek, is calculated from actual total dissolved solids (TDS) measurements and flow measurements from points WNSP001 and WNSP006 and from augmentation water.

Sampling location WNSP116 is shown on Figure A-2. Sampling location WNSP01B is not shown on the figures.

$$
B-8
$$




\section{Monitoring Program \\ On-Site Effluent Monitoring}

\section{Liquid Effluents}

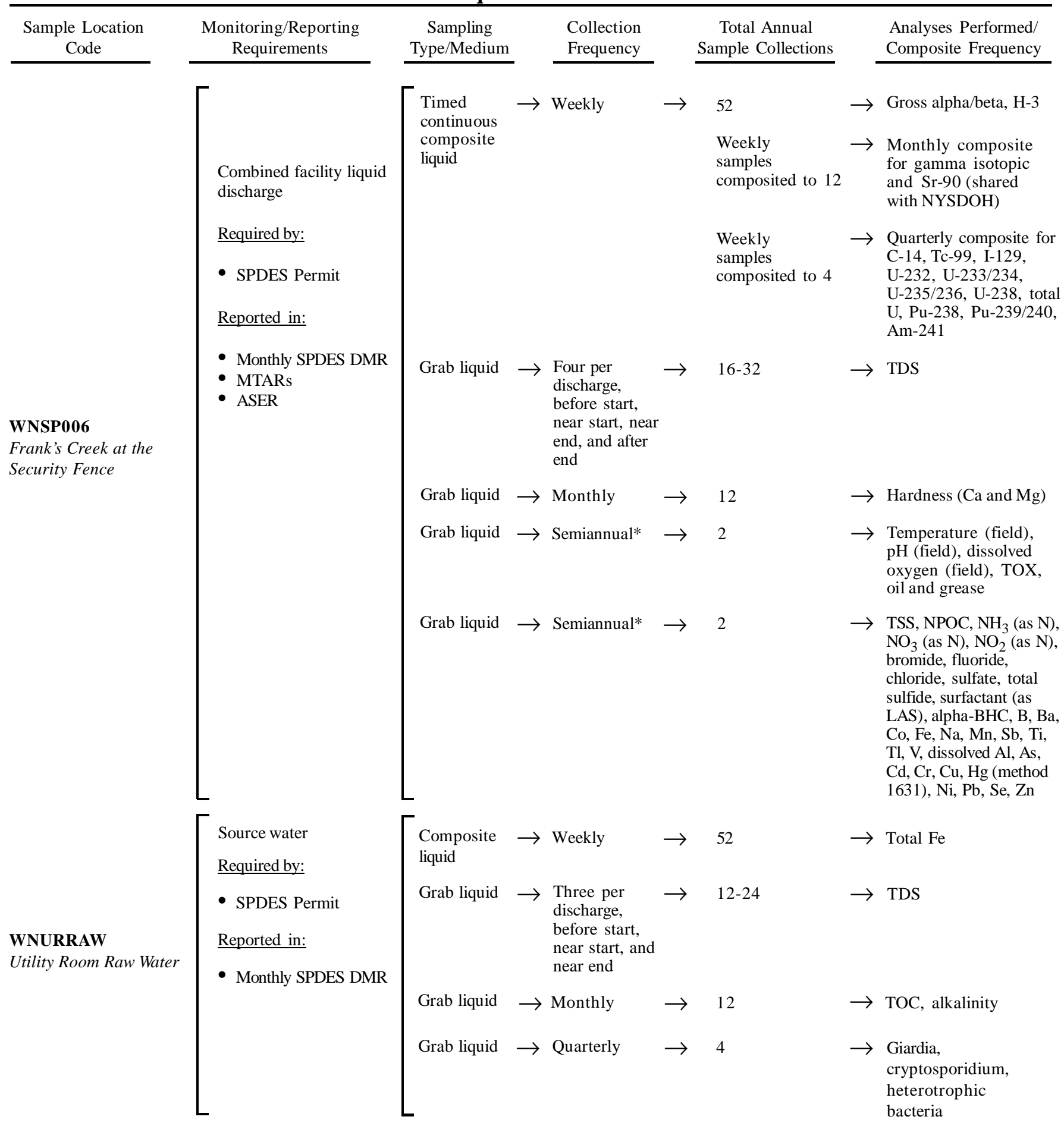

* Semiannual samples collected when points WNSP001 and WNSP007 are discharging.

$$
\text { B }-9
$$




\section{Sampling Rationale}

WNSP006 DOE/EH-0173T, 5.10.1.1; New York State SPDES Permit no. NY0000973; 6 NYCRR, Parts 702-704

By DOE Order all liquid effluent streams from DOE facilities shall be evaluated and their potential for release of radionuclides addressed.

TDS is measured before the discharge begins, shortly after it begins, near the end, and after the end of each lagoon 3 discharge period to meet requirements of the site SPDES Permit. Measurements of TDS and flow are used to calculate TDS at pseudo-monitoring point outfall 116 in Frank's Creek.

Semiannual samples are collected when WNSP001 and WNSP007 are discharging.

WNURRAW New York State SPDES Permit no. NY0000973; 10 NYCRR, Part 5, Subpart 5-1

TDS is measured near the beginning and end of each lagoon 3 discharge. Results are used for outfall 116 calculations. (See WNSP006 above.)

Sampling location WNSP006 is shown on Figure A-2. Sampling location WNURRAW is not shown on the figures. 


\section{Monitoring Program \\ On-Site Effluent Monitoring}

\section{Liquid Effluents}

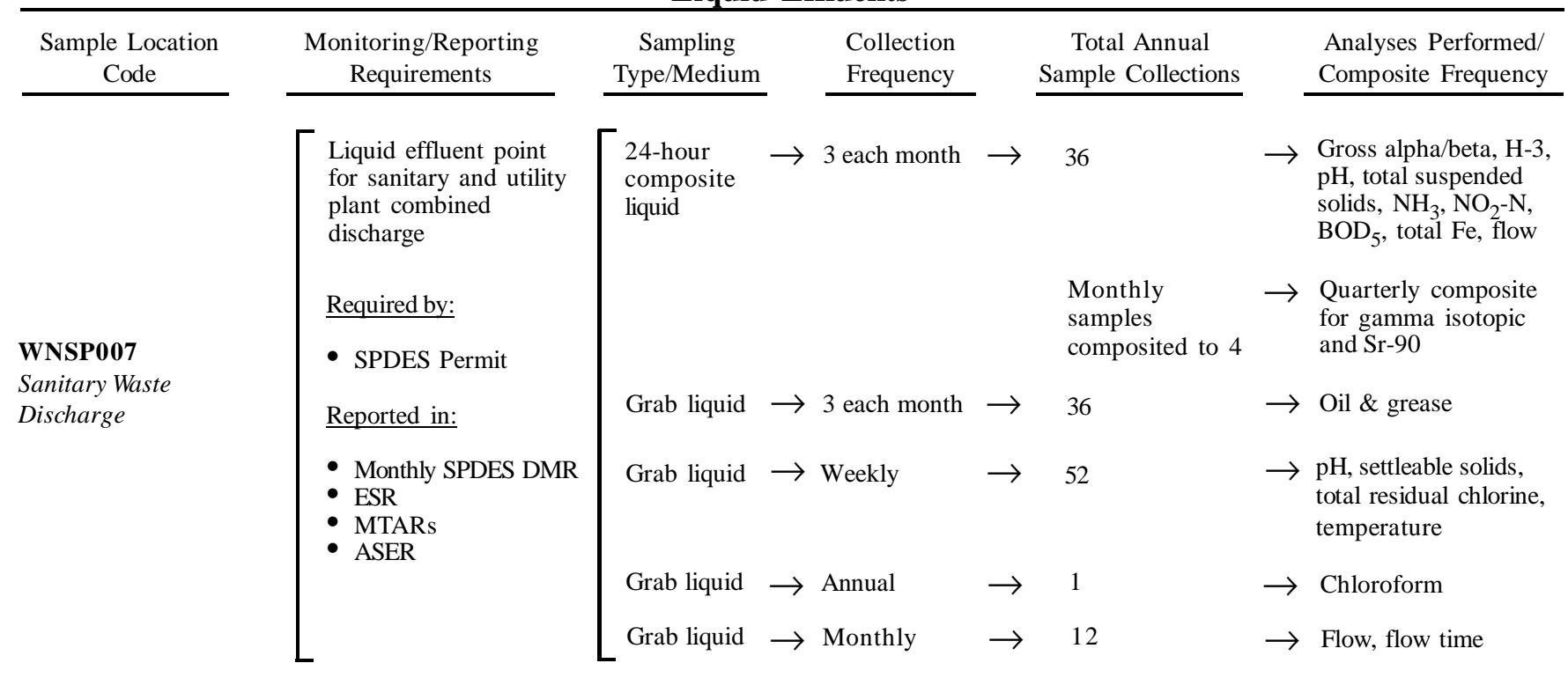

$B-11$ 


\section{Sampling Rationale}

WNSP007 DOE Order 5400.5; DOE/EH-0173T, 2.3.3; New York State SPDES Permit no. NY0000973

Monitoring of treated effluent from the sanitary and industrial wastewater treatment facility is performed in accordance with the New York State SPDES Permit no. NY0000973 and DOE Order 5400.5 criteria.

Sampling location WNSP007 is shown on Figure A-2.

$B-12$ 


\section{Monitoring Program \\ Environmental Surveillance}

On-Site Surface Water

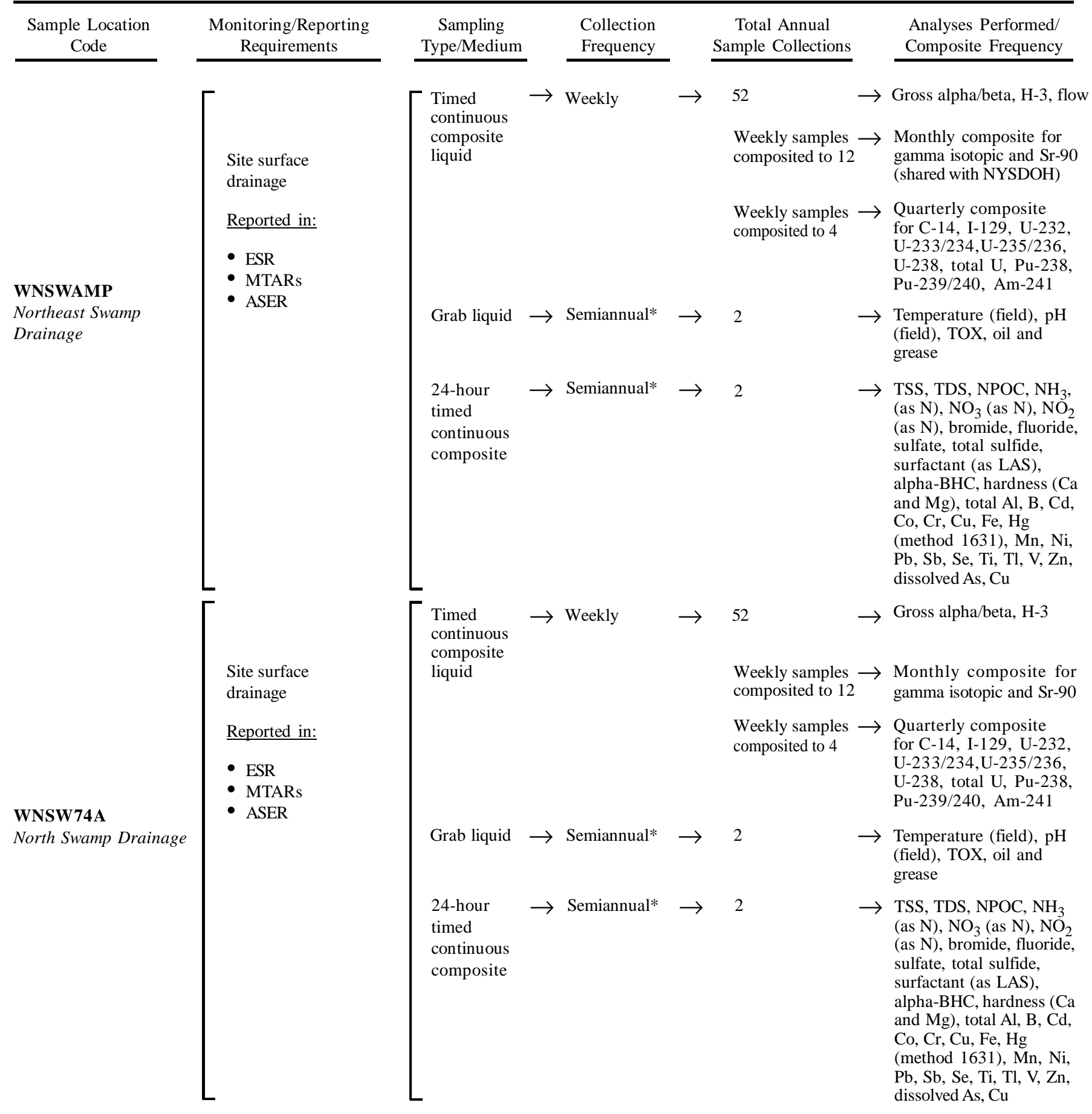

* Sampled during ambient (i.e., non-wet weather) conditions.

$B-13$ 


\section{Sampling Rationale}

\section{WNSWAMP DOE/EH-0173T, 5.10.1.1; 40 CFR, Part 122.26}

Northeast site surface water drainage; provides for sampling of uncontrolled surface waters from this discrete drainage path just before they leave the site's controlled boundary. Waters represent surface and subsurface drainages from the construction and demolition debris landfill (CDDL), old hardstand areas, and other possible north plateau sources of radiological or nonradiological contamination on the north plateau.

Monitoring for nonradiological parameters is performed during ambient conditions to verify authorized non-storm water flows. Storm water monitoring is performed per WVDP-233, "Monitoring Plan for Storm Water Discharges at the West Valley Demonstration Project."

WNSW74A

DOE/EH-0173T, 5.10.1.1; 40 CFR, Part 122.26

North site surface water drainage; provides for sampling of uncontrolled surface waters from this discrete drainage path just before they leave the site's controlled boundary. Waters represent surface and subsurface drainages from lag storage areas and other possible sources of radiological or nonradiological contamination on the north plateau.

Monitoring for nonradiological parameters is performed during ambient conditions to verify authorized non-storm water flows. Storm water monitoring is performed per WVDP-233.

Sampling locations are shown on Figure A-2.

\section{$B-14$}


2004 Monitoring Program

Environmental Surveillance

On-Site Surface Water

\begin{tabular}{|c|c|c|c|c|c|c|c|c|}
\hline $\begin{array}{l}\text { Sample Location } \\
\text { Code }\end{array}$ & $\begin{array}{l}\text { Monitoring/Reporting } \\
\text { Requirements }\end{array}$ & $\begin{array}{c}\text { Sampling } \\
\text { Type/Medium }\end{array}$ & & $\begin{array}{l}\text { Collection } \\
\text { Frequency }\end{array}$ & & $\begin{array}{c}\text { Total Annual } \\
\text { Sample Collections }\end{array}$ & & $\begin{array}{l}\text { Analyses Performed/ } \\
\text { Composite Frequency }\end{array}$ \\
\hline $\begin{array}{l}\text { WNSDADR } \\
\text { SDA Run-Off }\end{array}$ & $\begin{array}{l}\begin{array}{l}\text { Surface water run-off } \\
\text { from south portion } \\
\text { of SDA }\end{array} \\
\text { Required by: } \\
\text { - Interim Measures } \\
\text { Compliance } \\
\text { Reported in: } \\
\text { - ASER } \\
\text { - Reported to } \\
\text { NYSERDA }\end{array}$ & Grab liquid & $\rightarrow$ & Monthly & $\rightarrow$ & 12 maximum & $\rightarrow$ & $\begin{array}{l}\mathrm{pH} \text {, total suspended } \\
\text { solids, oil \& grease, flow, } \\
\text { gross alpha/beta, H-3, } \\
\text { gamma isotopic, } \\
\text { precipitation }\end{array}$ \\
\hline & $\begin{array}{l}\text { Drains subsurface } \\
\text { water from LLWTF } \\
\text { lagoon area } \\
\text { Required by: }\end{array}$ & Grab liquid & $\rightarrow$ & Monthly & $\rightarrow$ & 12 & $\rightarrow$ & Gross alpha/beta, H-3 \\
\hline $\begin{array}{l}\text { WNSP008* } \\
\text { French Drain }\end{array}$ & $\begin{array}{l}\text { - SPDES Permit } \\
\text { Reported in: } \\
\text { - Monthly SPDES } \\
\text { DMR } \\
\text { - ESR } \\
\text { - MTARs } \\
\text { - } \text { ASER }\end{array}$ & Grab liquid & $\rightarrow$ & 3 each month & $\rightarrow$ & 36 & $\begin{array}{l}\rightarrow \\
\\
\rightarrow\end{array}$ & $\begin{array}{l}\text { Conductivity, } \mathrm{pH} \text {, } \\
\mathrm{BOD}_{5} \text {, total } \mathrm{Fe} \text {, total } \\
\text { recoverable } \mathrm{Cd} \text { and } \mathrm{Pb} \text {, } \\
\text { flow } \\
\mathrm{As}, \mathrm{Cr} \text {, total } \mathrm{Ag} \text {, and } \\
\mathrm{Zn}\end{array}$ \\
\hline $\begin{array}{l}\text { WNSP005 } \\
\text { Facility Yard Drainage }\end{array}$ & $\begin{array}{l}\text { Combined drainage } \\
\text { from facility yard } \\
\text { area } \\
\text { Reported in: } \\
\text { - MTARs } \\
\text { - ASER }\end{array}$ & Grab liquid & $\rightarrow$ & Monthly & $\rightarrow$ & $\begin{array}{l}\text { Monthly samples } \\
\text { composited to } 4\end{array}$ & $\rightarrow$ & $\begin{array}{l}\text { Gross alpha/beta, H-3, } \\
\mathrm{pH} \\
\text { Quarterly composite } \\
\text { for gamma isotopic } \\
\text { and Sr-90 }\end{array}$ \\
\hline $\begin{array}{l}\text { WNCOOLW } \\
\text { Cooling Tower Basin }\end{array}$ & $\begin{array}{l}\text { Cools plant utility } \\
\text { steam system water } \\
\text { Reported in: } \\
\text { - MTARs } \\
\text { - ASER }\end{array}$ & Grab liquid & $\rightarrow$ & Quarterly & $\rightarrow$ & 4 & $\rightarrow$ & $\begin{array}{l}\text { Gross alpha/beta, H-3, } \\
\text { gamma isotopic, } \\
\text { Sr-90, pH }\end{array}$ \\
\hline
\end{tabular}

* Although WNSP008 is listed in the SPDES Permit, it was capped off in May 2001 and is no longer being sampled.

$B-15$

WVDP Annual Site Environmental Report

Calendar Year 2004 
Sampling Rationale

WNSDADR NYSERDA interim measures compliance.

WNSP008

DOE/EH-0173T, 5.10.1.3; New York State SPDES Permit no. NY0000973

French drain of subsurface water from lagoon (LLWTF) area. The SPDES Permit also provides for sampling of uncontrolled subsurface water from this discrete drainage path before these waters flow into Erdman Brook. Waters represent subsurface drainages from downward infiltration around the LLWTF and lagoon systems. This point would also monitor any subsurface spillover from the overfilling of lagoons 2 and 3. Sampling is of significance for both radiological and nonradiological contamination. This point was capped off in May 2001 and is routinely checked to verify that there is no discharge.

WNSP005 Generally in accordance with DOE/EH-0173T, 5.10.1.1 (previously in accordance with SPDES permit no. NY0000973)

Provides for the sampling of uncontrolled surface waters from this discrete drainage path after outfall 007 discharge into the drainage and before these waters flow into Erdman Brook. Waters represent surface and subsurface drainages primarily from the main plant yard area. Historically, this point was used to monitor sludge pond and utility room discharges to the drainage. These two sources have been rerouted. Migration of residual site contamination around the main plant dictates surveillance of this point, primarily for radiological parameters.

WNCOOLW Generally in accordance with DOE/EH-0173T, 5.10.1.1

Operational sampling carried out to confirm that radiological contamination is not migrating into the primary coolant loop of the high-level waste treatment facility and/or plant utility steam systems. Migration from either source might indicate radiological control failure.

Sampling locations are shown on Figure A-2.

$B-16$ 


\section{Monitoring Program \\ Environmental Surveillance}

On-Site Surface Water

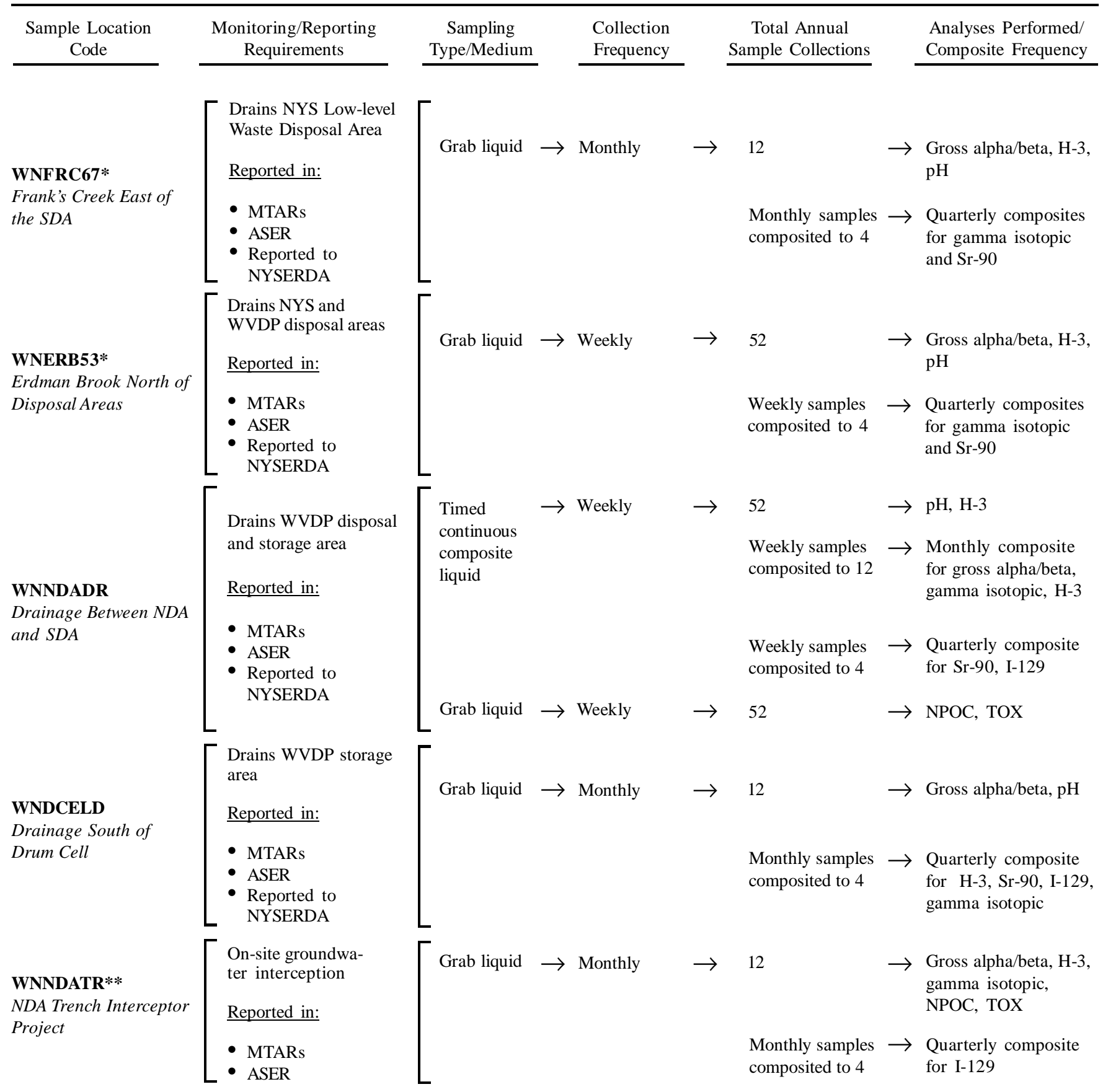

\footnotetext{
* Monthly sample also collected by NYSDOH

** Coordinated with Main Plant Operations
}

$B-17$ 


\section{Sampling Rationale}

WNFRC67 DOE/EH-0173T, 5.10.1.1

Monitors the potential influence of both the SDA and drum cell drainage into Frank's Creek east of the SDA and upstream of its confluence with Erdman Brook.

WNERB53 DOE/EH-0173T, 5.10.1.1

Monitors the potential influence of the drainages from the SDA and the WVDP storage and disposal area into Erdman Brook upstream of its confluence with Frank's Creek.

WNNDADR DOE/EH-0173T, 5.10.1.1

Monitors the potential influence of the drainages from the SDA and the WVDP storage and disposal area into Lagoon Road Creek upstream of the creek's confluence with Erdman Brook.

WNDCELD

DOE/EH-0173T, 5.10.1.1

Monitors the potential influence of drum cell drainage into Frank's Creek south of the SDA and upstream of WNFRC67.

WNNDATR Generally in accordance with DOE/EH-0173T, 5.10.1.1

Monitors groundwater in the vicinity of the NDA interceptor trench project. The grab sample is taken directly from the trench collection system.

- Sampling locations are shown on Figure A-2.

B - 18 


\section{Monitoring Program \\ Environmental Surveillance}

\section{On-Site Surface Water}

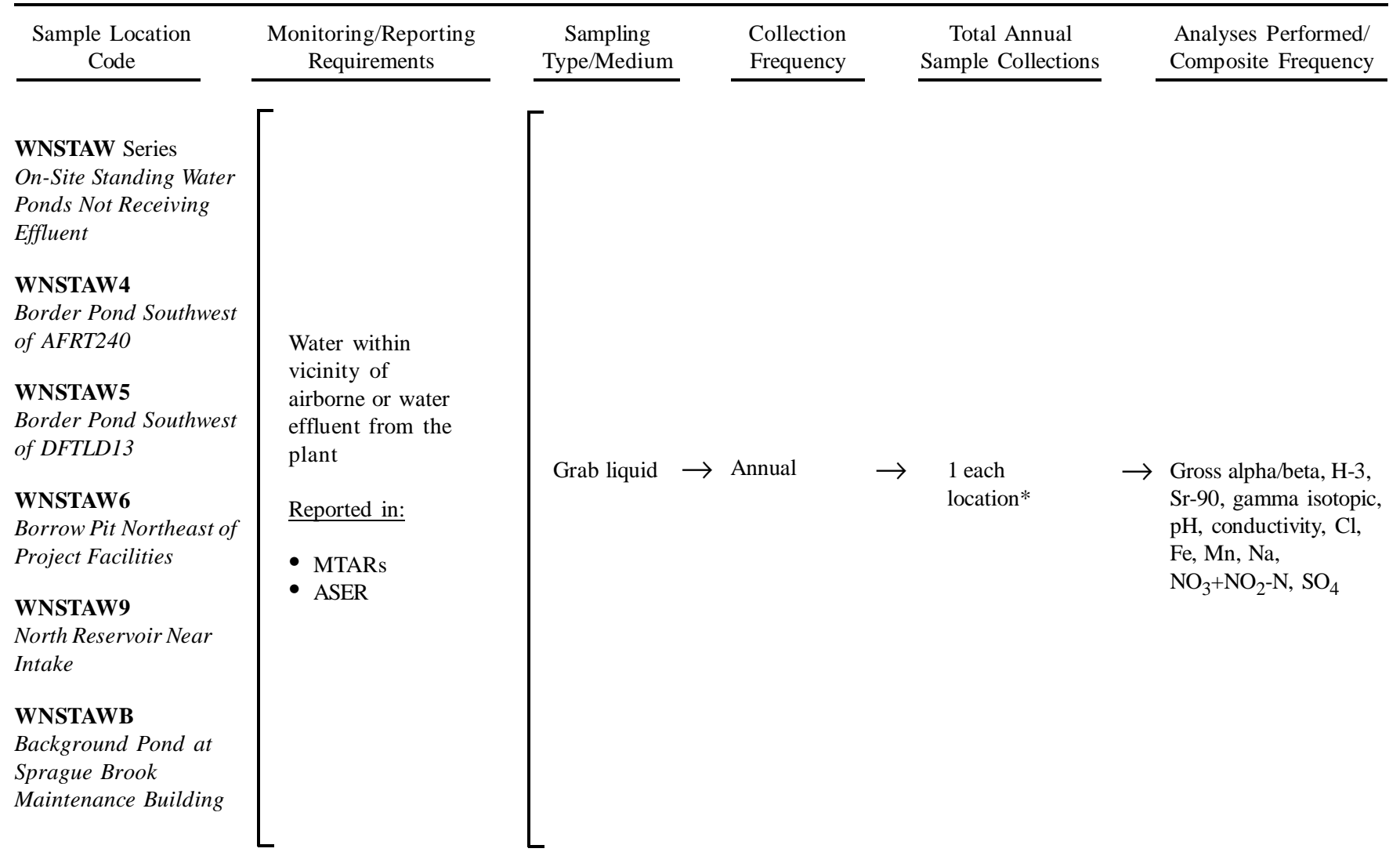

* Sampling depends upon on-site ponding conditions during the year.

$$
\text { B }-19
$$




\section{Sampling Rationale}

WNSTAW Series DOE/EH-0173T, 5.10.1.1

Monitoring of on- and off-site standing waters at locations listed below. Although none receive effluent directly, the potential for contamination is present except at the background location. Former collecting sites 1,2,3,7, and 8 were deleted from the monitoring program because they were either built over or are now dry.

WNSTAW4 Border pond located south of AFRT240. Chosen as a location for showing potentially high concentrations, based on meteorological data. This perimeter location is next to a working farm. Drainage extends through private property and is accessible by the public.

WNSTAW5 Border pond located west of Project facilities near the perimeter fence and DFTLD13. Chosen as a location for showing potentially high concentrations, based on meteorological data. Location is next to a private residence and potentially accessible by the general public.

WNSTAW6 Borrow pit northeast of Project facilities just outside the inner security fence. Considered the closest standing water to the main plant and high-level waste facilities.

WNSTAW9 North reservoir near intake. Chosen to provide data in the event of potentially contaminated site potable water supply. Location is south of main plant facilities.

WNSTAWB Pond located near the Sprague Brook maintenance building. Considered a background location; approximately 14 kilometers north of the WVDP.

Sampling locations are shown on Figures A-2, A-3, and A-13.

B - 20 


\section{Monitoring Program \\ Environmental Surveillance}

On-Site Potable Water

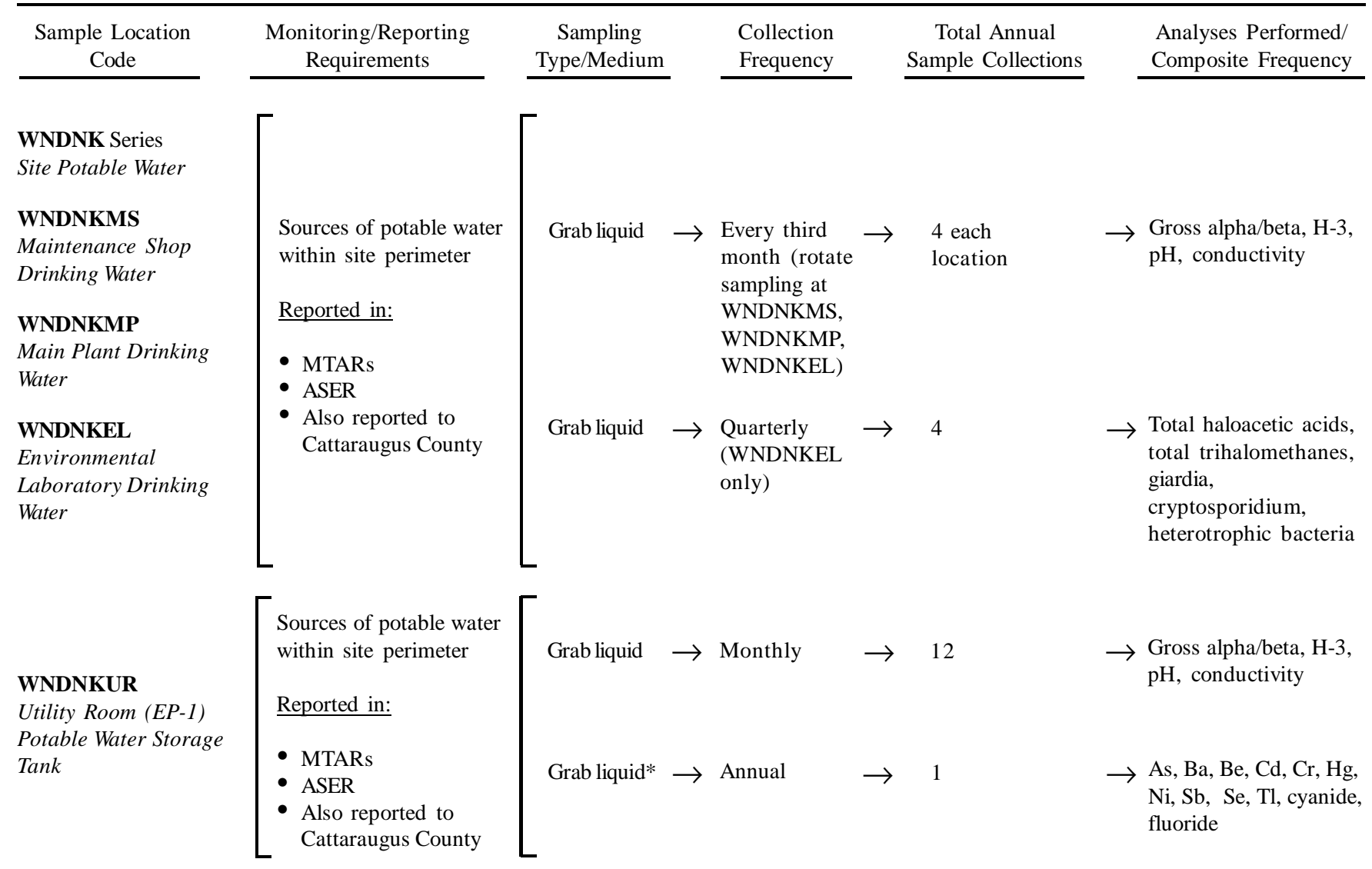
* Sample for $\mathrm{NO}_{3}$ (as total nitrate) is collected by the Cattaraugus County Health Department. $\mathrm{Pb}$ and $\mathrm{Cu}$ also are sampled at this site based upon
Cattaraugus County Health Department guidance.

$$
\text { B - } 21
$$




\section{Sampling Rationale}

WNDNK Series Site drinking water; generally according to DOE/EH-0173T, 5.10.1.2; 10 NYCRR, Part 5, Subpart 5-1

Potable water sampling to confirm no migration of radiological and/or nonradiological contamination into the site's drinking water supply.

WNDNKMS Potable water sampled at the maintenance shop in order to monitor a point that is at an intermediate distance from the point of potable water generation and that is used heavily by site personnel.

WNDNKMP Same rationale as WNDNKMS but sampled at the break room sink in the main plant.

WNDNKEL Potable water sampled at the Environmental Laboratory. Disinfectant by-products are sampled at WNDNKEL, the furthest location from the entry point (WNDNKUR).

WNDNKUR Sampled at the utility room potable water storage tank before the site drinking water distribution system. Sample location is entry point EP-1.

Sampling locations are within the site facilities and are not detailed on figures.

$B-22$ 
2004 Monitoring Program

Environmental Surveillance

On-Site Groundwater

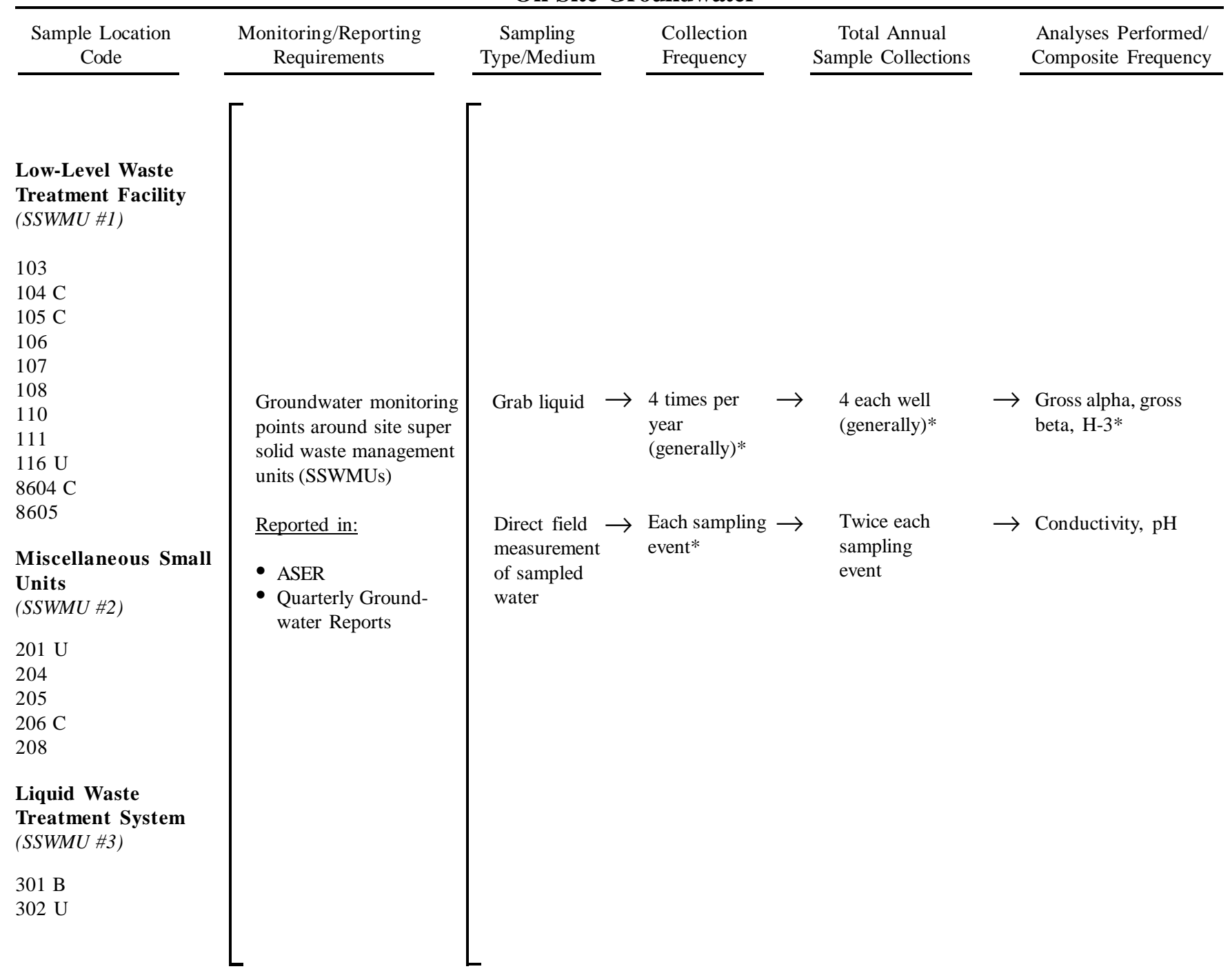

NOTE: "U" designates upgradient, "B" designates background, and "C" designates crossgradient wells. The remainder are downgradient.

* Sampling frequency and analytes vary from point to point. See Appendix $\mathrm{E}^{\mathbf{6 0}}$ for a summary listing of all monitored analytes, a listing of analytes monitored at each location, and results from each location.

$$
\text { B }-23
$$




\title{
Sampling Rationale
}

\begin{abstract}
On-Site DOE/EH-0173T, 5.10.1.3; 40 CFR, Parts 264 and 265, Subpart F
Groundwater

The on-site WVDP groundwater monitoring program provides for the determination of water quality, focusing on radiological and chemical surveillance of both active and inactive super solid waste management units (SSWMUs). In addition, using wells situated hydraulically upgradient (background) and downgradient of SSWMUs allows both detection of groundwater contamination and evaluation of the effects associated with the individual SSWMUs. Groundwater protection was addressed in the "Groundwater Protection Management Program Plan," WVDP-091. Groundwater monitoring was detailed in the "Groundwater Monitoring Plan," WVDP-239.
\end{abstract}

SSWMU \#1 Low-level waste treatment facilities, including four active lagoons - lagoons 2, 3, 4, and 5 - and an inactive, filledin lagoon - lagoon 1.

SSWMU \#2 Miscellaneous small units, including the sludge pond, the solvent dike, the paper incinerator, the equalization basin, and the kerosene tank.

SSWMU \#3 Liquid waste treatment system containing effluent from the supernatant treatment system.

Sampling locations are shown on Figures A-6 and A-7.

$B-24$ 
2004 Monitoring Program

\section{Environmental Surveillance}

On-Site Groundwater

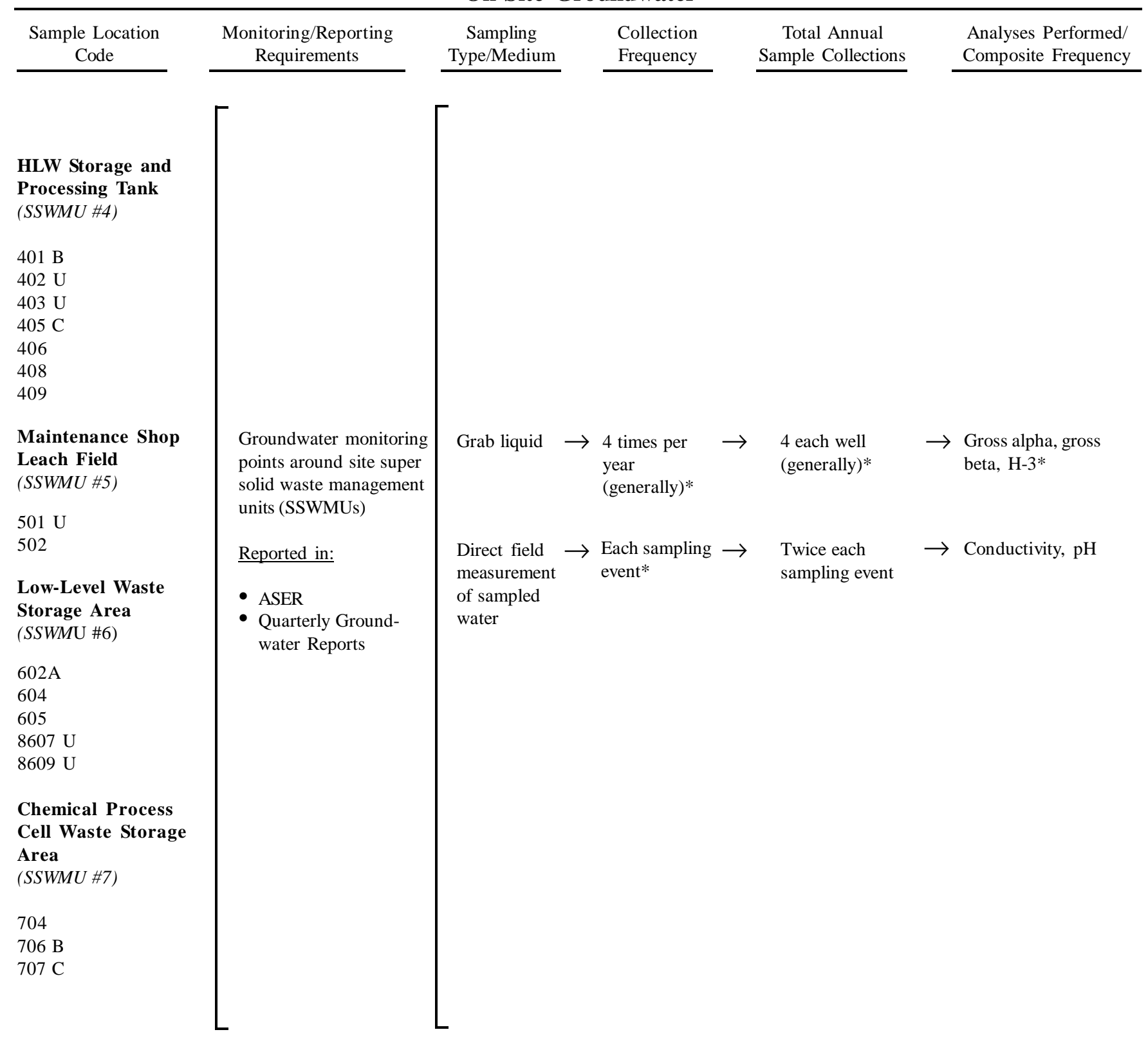

NOTE: "U" designates upgradient, "B" designates background, and "C" designates crossgradient wells. The remainder are downgradient.

* Sampling frequency and analytes vary from point to point. See Appendix $\mathrm{E}^{\mathbf{6 0}}$ for a summary listing of all monitored analytes, a listing of analytes monitored at each location, and results from each location.

$$
\text { B }-25
$$




\title{
Sampling Rationale
}

\author{
On-Site DOE/EH-0173T, 5.10.1.3; 40 CFR, Parts 264 and 265, Subpart F \\ Groundwater \\ The on-site WVDP groundwater monitoring program provides for the determination of water quality, focusing on \\ radiological and chemical surveillance of both active and inactive super solid waste management units (SSWMUs). In \\ addition, using wells situated hydraulically upgradient (background) and downgradient of SSWMUs allows both detection \\ of groundwater contamination and evaluation of the effects associated with the individual SSWMUs. Groundwater \\ protection was addressed in the "Groundwater Protection Management Program Plan," WVDP-091. Groundwater \\ monitoring was detailed in the "Groundwater Monitoring Plan," WVDP-239. \\ SSWMU \#4 High-level waste storage and processing area, including the high-level radioactive waste tanks, the supernatant \\ treatment system, and the vitrification facility. \\ SSWMU \#5 Maintenance shop sanitary leach field, formerly used by NFS and the WVDP to process domestic sewage generated by \\ the maintenance shop. \\ SSWMU \#6 Low-level waste storage area; includes metal and fabric structures housing low-level radioactive waste being stored for \\ future disposal. \\ SSWMU \#7 Chemical process cell (CPC) waste storage area, which contains packages of pipes, vessels, and debris from \\ decontamination and cleanup of the chemical process cell in the former reprocessing plant.
}

Sampling locations are shown on Figures A-6 and A-7.

$B-26$ 
2004 Monitoring Program

Environmental Surveillance

On-Site Groundwater

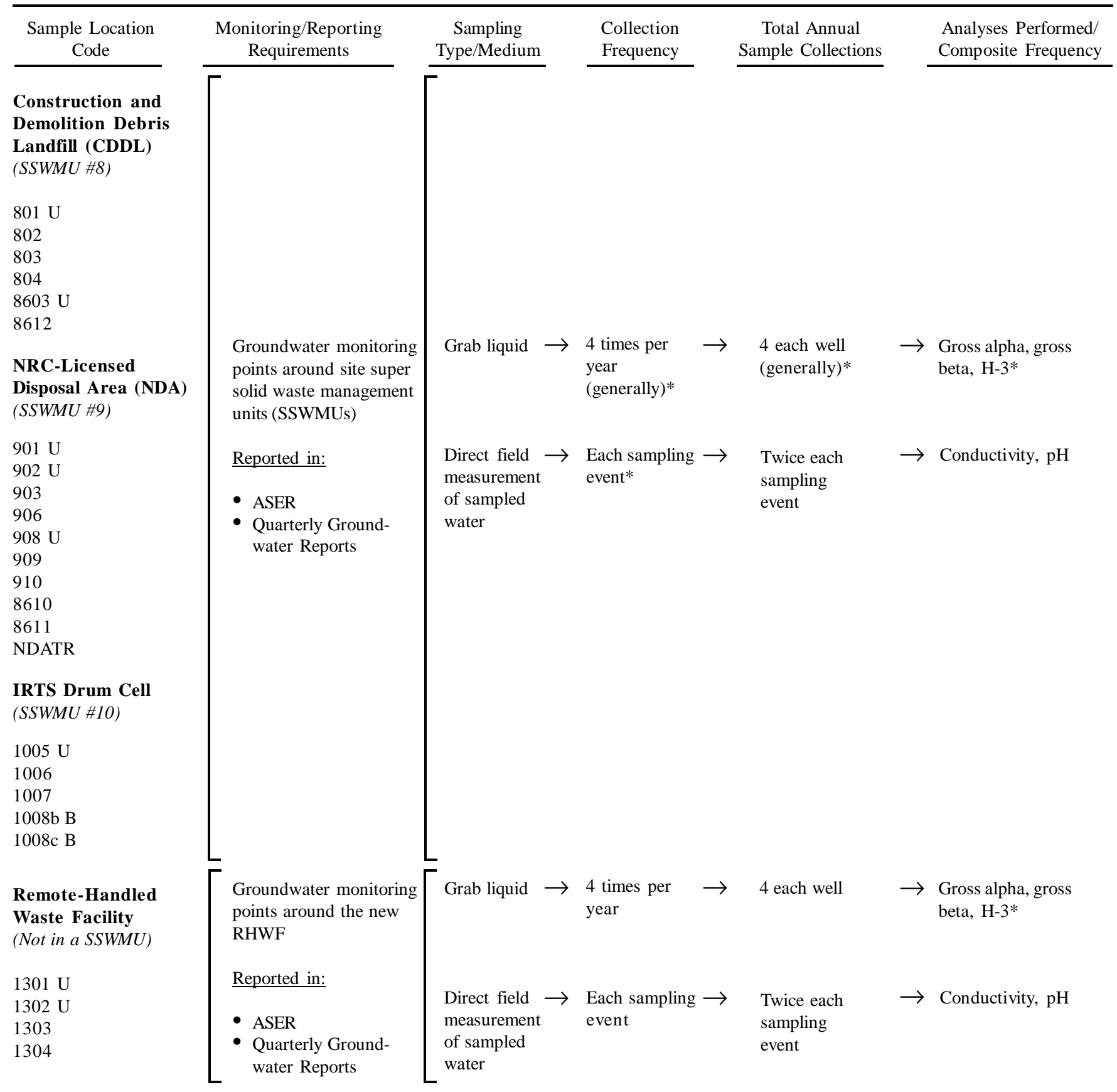

NOTE: "U" designates upgradient, "B" designates background, and "C" designates crossgradient wells. The remainder are downgradient.

* Sampling frequency and analytes vary from point to point. See Appendix $E^{\mathbf{C D}}$ for a summary listing of all monitored analytes, a listing of analytes monitored at each location, and results from each location.

$$
\text { B }-27
$$


Sampling Rationale

\begin{abstract}
On-Site DOE/EH-0173T, 5.10.1.3; 40 CFR, Parts 264 and 265, Subpart F
Groundwater

The on-site WVDP groundwater monitoring program provides for the determination of water quality, focusing on radiological and chemical surveillance of both active and inactive super solid waste management units (SSWMUs). In addition, using wells situated hydraulically upgradient (background) and downgradient of SSWMUs allows both detection of groundwater contamination and evaluation of the effects associated with the individual SSWMUs. Groundwater protection was addressed in the "Groundwater Protection Management Program Plan," WVDP-091. Groundwater monitoring was detailed in the "Groundwater Monitoring Plan," WVDP-239.

SSWMU \#8 The construction and demolition debris landfill (CDDL); used by NFS and the WVDP to dispose of nonhazardous and nonradioactive materials.

SSWMU \#9 The NRC-licensed disposal area (NDA); contains radioactive wastes generated by NFS and the WVDP. The NDA is bounded on its downgradient (northwest and northeast) perimeters by the interceptor trench, which is sampled at monitoring point NDATR.
\end{abstract}

SSWMU \#10 The integrated radioactive waste system (IRTS) treatment drum cell; stores cement-stablized low-level radioactive waste.

Remote-Handled Establish pre-operational baseline groundwater conditions in the area of the newly constructed remote-handled waste Waste Facility facility (RHWF). Monitor groundwater in the vicinity of the RHWF.

Sampling locations are shown on Figures A-6 through A-8.

$B-28$ 
2004 Monitoring Program

Environmental Surveillance

\section{On-Site Groundwater and Seeps}

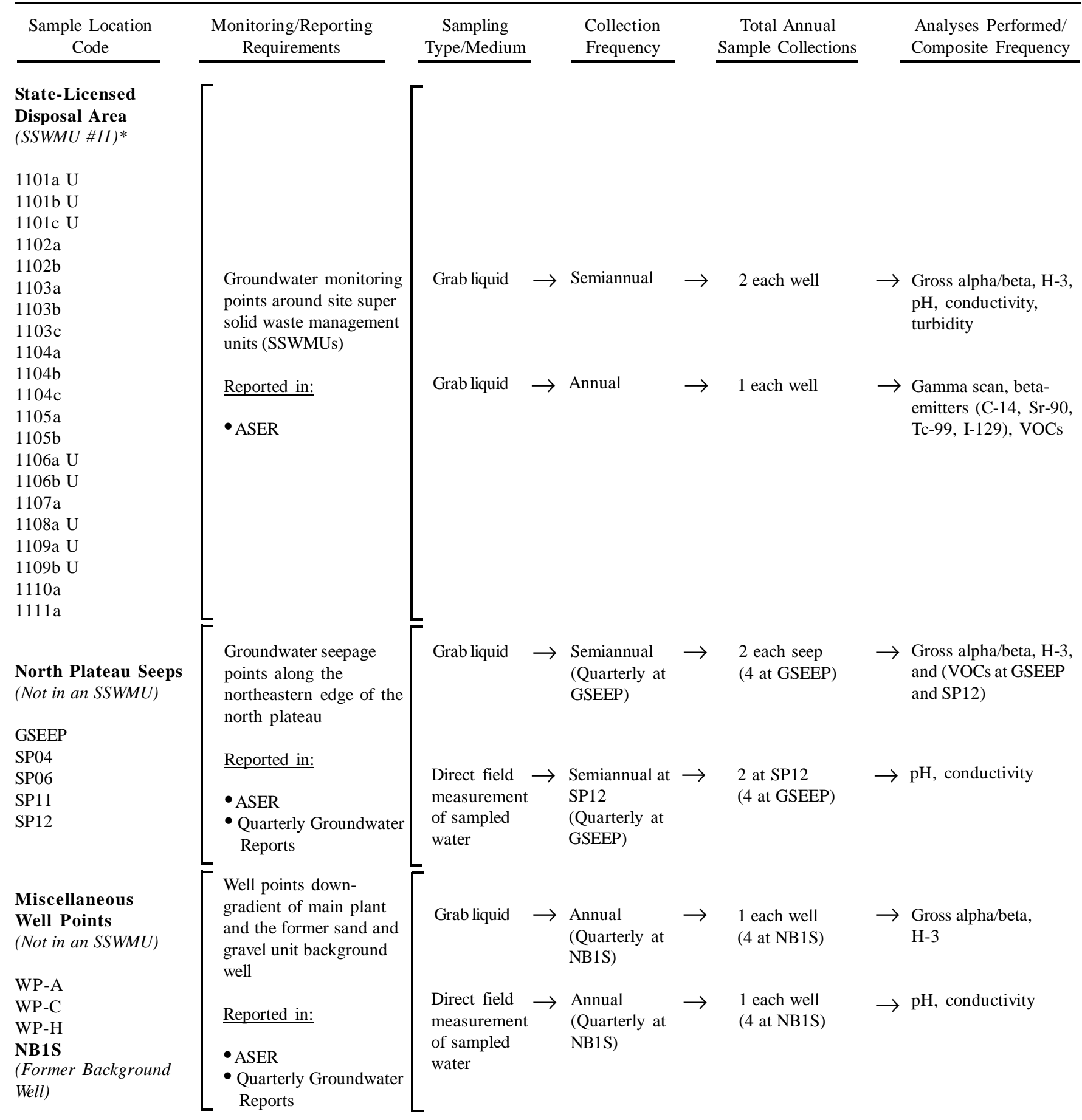

NOTE: "U" designates upgradient, "B" designates background, and "C" designates crossgradient wells. The remainder are downgradient.

* SSWMU \#11 is sampled by NYSERDA under a separate program.

B - 29 
Sampling Rationale

\begin{abstract}
On-Site DOE/EH-0173T, 5.10.1.3; 40 CFR, Parts 264 and 265, Subpart F
Groundwater

The on-site WVDP groundwater monitoring program provides for the determination of water quality, focusing on radiological and chemical surveillance of both active and inactive super solid waste management units (SSWMUs). In addition, using wells situated hydraulically upgradient (background) and downgradient of SSWMUs allows both detection of groundwater contamination and evaluation of the effects associated with the individual SSWMUs. Groundwater protection was addressed in the "Groundwater Protection Management Program Plan," WVDP-091. Groundwater monitoring was detailed in the "Groundwater Monitoring Plan," WVDP-239.
\end{abstract}

SSWMU \#11 The New York State-licensed disposal area (SDA) was operated by NFS as a commercial low-level disposal facility; it also received wastes from NFS reprocessing operations.

North Plateau Monitor groundwater emanating from the ground surface along the edge of the site's north plateau.

Seeps

Well Points Monitor groundwater of known subsurface contamination in the north plateau area. All well points are downgradient of the main plant.

WNWNB1S Former background well on the north plateau.

Sampling locations are shown on Figures A-6 through A-8. 
2004 Monitoring Program

Environmental Surveillance

Off-Site Surface Water

\begin{tabular}{|c|c|c|c|c|c|c|c|c|}
\hline $\begin{array}{l}\text { Sample Location } \\
\text { Code }\end{array}$ & $\begin{array}{l}\text { Monitoring/Reporting } \\
\text { Requirements }\end{array}$ & $\begin{array}{c}\text { Sampling } \\
\text { Type/Medium }\end{array}$ & & $\begin{array}{l}\text { Collection } \\
\text { Frequency }\end{array}$ & & $\begin{array}{c}\text { Total Annual } \\
\text { Sample Collections }\end{array}$ & & $\begin{array}{l}\text { Analyses Performed/ } \\
\text { Composite Frequency }\end{array}$ \\
\hline \multirow{6}{*}{$\begin{array}{l}\text { WFBCBKG* } \\
\text { Buttermilk Creek Near } \\
\text { Fox Valley } \\
\text { (Background) }\end{array}$} & $\begin{array}{l}\text { Unrestricted surface } \\
\text { water, background }\end{array}$ & {$\left[\begin{array}{l}\text { Timed } \\
\text { continuous } \\
\text { composite } \\
\text { liquid }\end{array}\right.$} & $\rightarrow$ & Weekly & $\rightarrow$ & $\begin{array}{l}52 \text { weekly } \\
\text { samples } \\
\text { composited to } 12 \\
\text { Weekly samples } \\
\text { composited to } 4\end{array}$ & $\rightarrow$ & $\begin{array}{l}\text { Quarterly composite for } \\
\text { gamma isotopic, C-14, } \\
\text { Sr-90, Tc-99, I-129, U-232, } \\
\text { U-233/234, U-235/236, } \\
\text { U-238, total U, Pu-238, } \\
\text { Pu-239/240, Am-241 }\end{array}$ \\
\hline & \multirow{3}{*}{$\begin{array}{l}\text { Reported in: } \\
\text { - MTARs } \\
\text { - } \text { ASER } \\
\text { - Reported to } \\
\text { NYSERDA }\end{array}$} & Grab liquid & $\rightarrow$ & Monthly & $\rightarrow$ & 12 & $\rightarrow$ & Hardness ( $\mathrm{Ca}$ and $\mathrm{Mg}$ ) \\
\hline & & Grab liquid & $\rightarrow$ & Semiannual** & $\rightarrow$ & 2 & $\rightarrow$ & $\begin{array}{l}\text { Temperature (field), } \mathrm{pH} \\
\text { (field), dissolved } \\
\text { oxygen (field), TOX, } \\
\text { oil and grease }\end{array}$ \\
\hline & & $\begin{array}{l}\text { 24-hour } \\
\text { timed } \\
\text { continuous } \\
\text { composite }\end{array}$ & $\rightarrow$ & Semiannual** & $\rightarrow$ & 2 & $\rightarrow$ & $\begin{array}{l}\text { TSS, TDS, NPOC, } \mathrm{NH}_{3} \\
\text { (as N), } \mathrm{NO}_{3} \text { (as N), } \\
\mathrm{NO}_{2} \text { (as N), bromide, } \\
\text { fluoride, chloride, } \\
\text { sulfate, total sulfide, } \\
\text { surfactant (as LAS), } \\
\text { alpha-BHC, B, Ba, Co, } \\
\mathrm{Fe}, \mathrm{Na}, \mathrm{Mn}, \mathrm{Sb}, \mathrm{Ti}, \mathrm{Tl}, \\
\text { V, dissolved Al, As, Cd, } \\
\mathrm{Cr}, \mathrm{Cu}, \mathrm{Hg} \text { (method } \\
\text { 1631), Ni, } \mathrm{Pb}, \mathrm{Se}, \mathrm{Zn}\end{array}$ \\
\hline & \multirow{5}{*}{$\begin{array}{l}\text { Restricted surface waters } \\
\text { receiving plant effluents }\end{array}$} & $\begin{array}{l}\text { Timed } \\
\text { continuous } \\
\text { composite } \\
\text { liquid }\end{array}$ & $\rightarrow$ & Weekly & $\rightarrow$ & $\begin{array}{l}52 \text { weekly } \\
\text { samples } \\
\text { composited to } 12\end{array}$ & $\rightarrow$ & $\begin{array}{l}\text { Monthly composite for } \\
\text { gross alpha/beta, H-3 }\end{array}$ \\
\hline & & & & & & $\begin{array}{l}\text { Weekly samples } \\
\text { composited to } 4\end{array}$ & $\rightarrow$ & $\begin{array}{l}\text { Quarterly composite } \\
\text { for gamma isotopic, } \\
\text { Sr-90, Tc-99 }\end{array}$ \\
\hline \multirow{3}{*}{$\begin{array}{l}\text { WFBCTCB* } \\
\text { Buttermilk Creek } \\
\text { Upstream of } \\
\text { Confluence With } \\
\text { Cattaraugus Creek at } \\
\text { Thomas Corners Road }\end{array}$} & & Grab liquid & $\rightarrow$ & Monthly & $\rightarrow$ & 12 & $\rightarrow$ & Hardness ( $\mathrm{Ca}$ and $\mathrm{Mg}$ ) \\
\hline & & Grab liquid & $\rightarrow$ & Semiannual ${ }^{* *}$ & $\rightarrow$ & 2 & $\rightarrow$ & $\begin{array}{l}\text { Temperature (field), } \mathrm{pH} \\
\text { (field), dissolved } \\
\text { oxygen (field), TOX, } \\
\text { oil and grease }\end{array}$ \\
\hline & & $\begin{array}{l}\text { 24-hour } \\
\text { timed } \\
\text { continuous } \\
\text { composite }\end{array}$ & $\rightarrow$ & Semiannual** & $\rightarrow$ & 2 & $\rightarrow$ & $\begin{array}{l}\text { TSS, TDS, NPOC, } \mathrm{NH}_{3} \\
\text { (as N), } \mathrm{NO}_{3} \text { (as N), } \\
\mathrm{NO}_{2} \text { (as } \mathrm{N} \text { ), bromide, } \\
\text { fluoride, chloride, } \\
\text { sulfate, total sulfide, } \\
\text { surfactant (as LAS), } \\
\text { alpha-BHC, } \mathrm{B}, \mathrm{Ba}, \mathrm{Co}, \\
\mathrm{Fe}, \mathrm{Na}, \mathrm{Mn}, \mathrm{Sb}, \mathrm{Ti}, \mathrm{Tl}, \\
\mathrm{V}, \text { dissolved Al, As, Cd, } \\
\mathrm{Cr}, \mathrm{Cu}, \mathrm{Hg}(\text { method } \\
\text { 1631), Ni, } \mathrm{Pb}, \mathrm{Se}, \mathrm{Zn}\end{array}$ \\
\hline
\end{tabular}

$$
\text { B }-31
$$




\section{Sampling Rationale}

WFBCBKG DOE/EH-0173T, 5.10.1.1; 6 NYCRR, Part 702-704

Monitors background conditions of Buttermilk Creek upstream of the WVDP; allows for comparison to downstream conditions. Monitoring for nonradiological parameters performed during discharges from WNSP001 and WNSP007 for comparison with downstream conditions.

WFBCTCB DOE/EH-0173T, 5.10.1.1; 6 NYCRR, Part 702-704

Buttermilk Creek is the surface water that receives all WVDP effluents. WFBCTCB monitors the potential influence of WVDP drainage into Buttermilk Creek upstream of Buttermilk Creek's confluence with Cattaraugus Creek. Monitoring for nonradiological parameters performed during discharges from WNSP001 and WNSP007 for comparison with New York State ambient water quality standards (6 NYCRR, Part 702-704).

Sampling locations are shown on Figure A-3.

$B-32$ 


\section{Monitoring Program \\ Environmental Surveillance}

\section{Off-Site Surface Water}

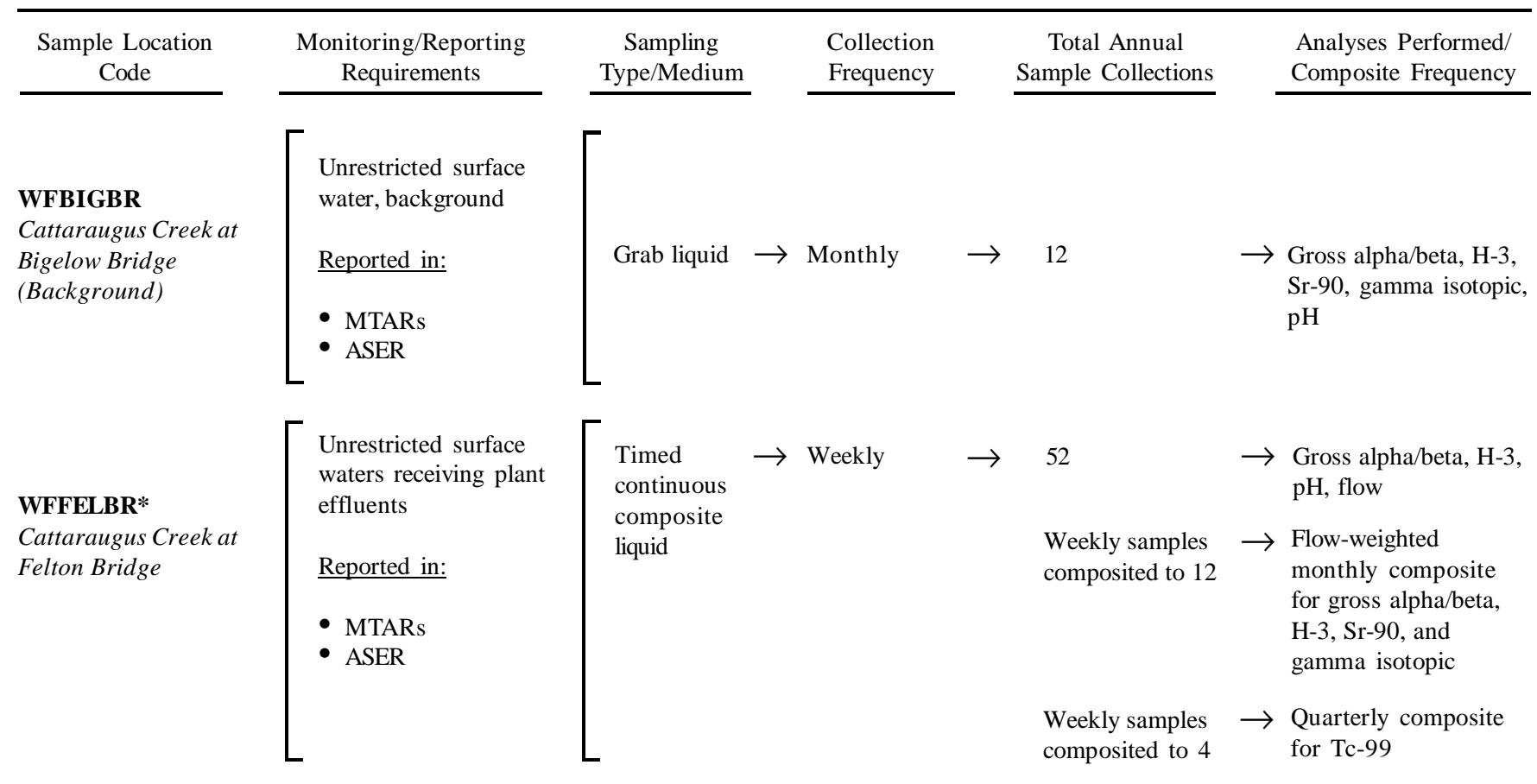

\footnotetext{
* Monthly composites are also sent to NYSDOH.
}

$$
\text { B - } 33
$$




\section{Sampling Rationale}

WFBIGBR $\quad$ DOE/EH-0173T, 5.10.1.1

Monitors background conditions of Cattaraugus Creek at Bigelow Bridge, upstream of the WVDP; allows for comparison to downstream conditions.

WFFELBR

DOE/EH-0173T, 5.10.1.1

Because Buttermilk Creek empties into Cattaraugus Creek, WFFELBR monitors the potential influence of WVDP drainage into Cattaraugus Creek directly downstream of the Cattaraugus Creek confluence with Buttermilk Creek.

Sampling locations are shown on Figure A-3.

$$
B-34
$$


2004 Monitoring Program

Environmental Surveillance

Off-Site Drinking Water

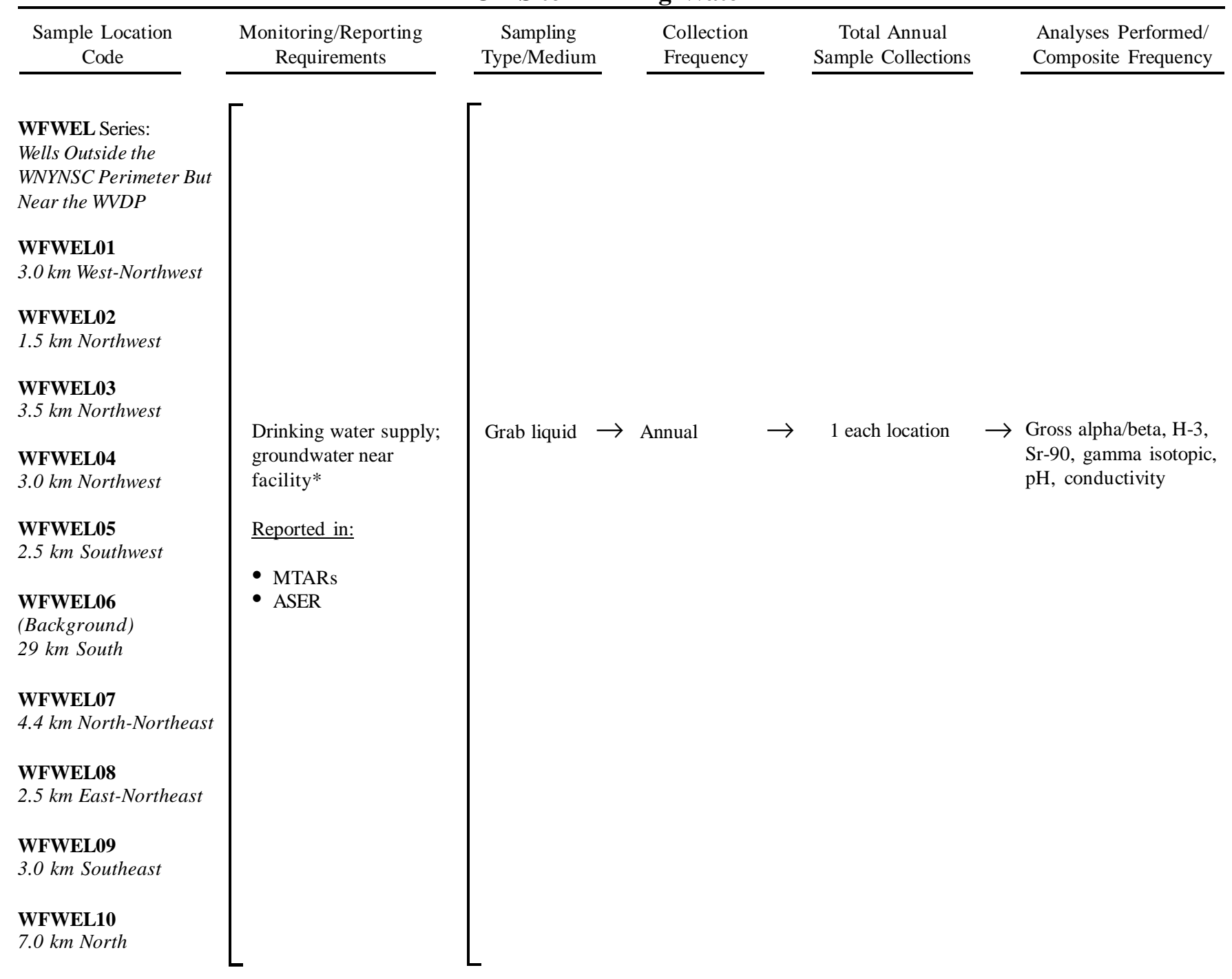

* No drinking water wells are located in hydrogeological units affected by site activity.

B - 35 


\section{Sampling Rationale}

Off-Site DOE/EH-0173T, 5.10.1.2

Drinking Water

WFWEL Series

Eight of the ten listed off-site private residential drinking water wells represent the nearest unrestricted uses of groundwater close to the WVDP. The ninth sample (WFWEL10) is taken from a public water supply from deep wells. The tenth drinking water well, WFWEL06, is located 29 kilometers south of the Project and is considered a background drinking water source.

Sampling locations are shown on Figures A-9, A-12, and A-13.

$B-36$ 


\section{Monitoring Program}

\section{Environmental Surveillance}

\section{Off-Site Air}

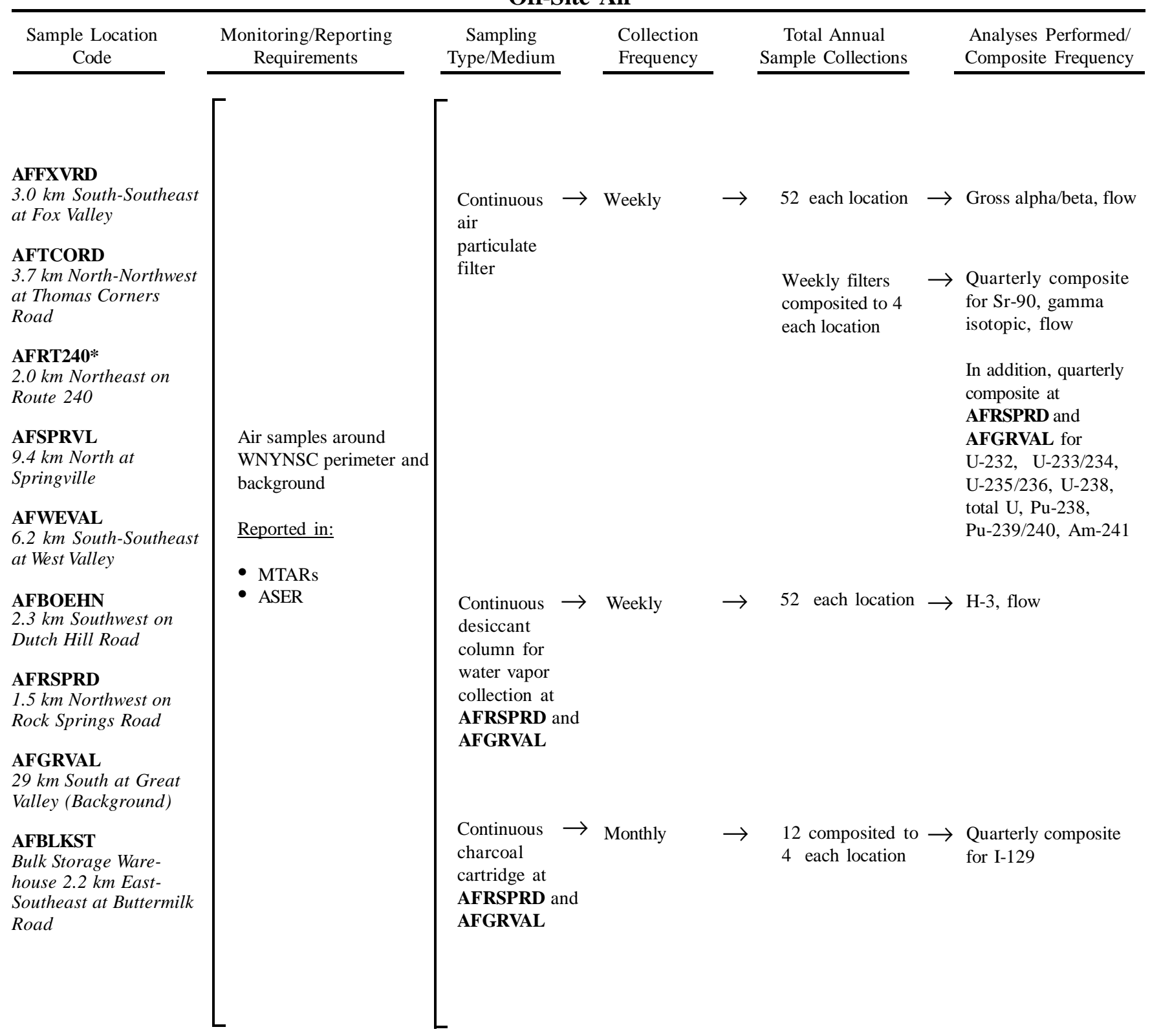

* Filter from duplicate sampler sent to NYSDOH.

$$
\text { B - } 37
$$




\title{
Sampling Rationale
}

\begin{abstract}
AFFXVRD DOE/EH-0173T, 5.7.4
AFTCORD

AFRT240

Air samplers put into service by NFS as part of the site's original monitoring program at perimeter locations chosen to obtain data from places most likely to provide highest concentrations. Choice of location based on meteorological data.
\end{abstract}

AFSPRVL DOE/EH-0173T, 5.7.4; DOE/EP-0023, 4.2.3

Off-site (remote) sampler located on private property in a nearby community within 15 kilometers of the site (north).

AFWEVAL DOE/EH-0173T, 5.7.4; DOE/EP-0023, 4.2.3

Off-site (remote) sampler located in a nearby community within 15 kilometers of the site (southeast).

AFBOEHN

DOE/EH-0173T, 5.7.4; DOE/EP-0023, 4.2.3

Perimeter location chosen to obtain data from the place most likely to provide the highest elevated release concentrations. AFBOEHN is located on NYSERDA property at the perimeter. Choice of location based on meteorological data.

AFRSPRD

DOE/EH-0173T, 5.7.4

Perimeter location chosen to obtain data from the place most likely to provide the highest ground-level release concentrations. AFRSPRD is on WNYNSC property outside the main plant operations fenceline. H-3 and I-129 are sampled here because the sampling trains were easy to incorporate and the location was most likely to receive effluent releases. Choice of location based on meteorological data.

AFGRVAL DOE/EH-0173T, 5.7.4; DOE/EP-0023, 4.2.3

Off-site (remote) sampler considered representative of natural background radiation. Located on privately owned property 29 kilometers south of the site (typically upwind). H-3 and I-129 sampled here also.

AFBLKST

DOE/EH-0173T, 5.7.4

Off-site monitoring of bulk storage warehouse, near the site perimeter.

Sampling locations are shown on Figures A-5, A-12, and A-13.

B - 38 
2004 Monitoring Program

Environmental Surveillance

Fallout, Sediment, and Soil

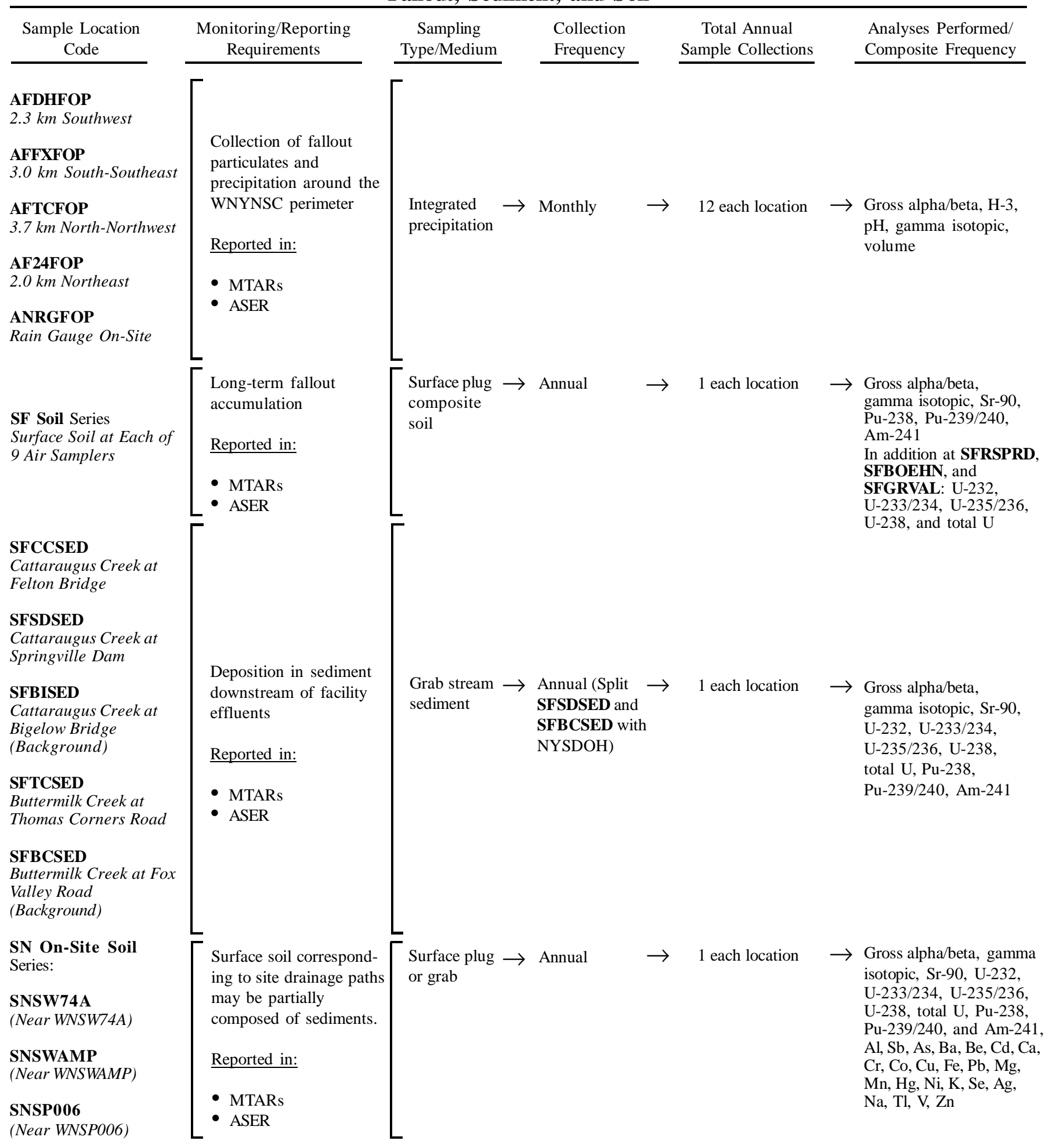

B - 39 


\section{Sampling Rationale}

\section{AFDHFOP \\ AFFXFOP \\ AFTCFOP \\ AF 24FOP}

ANRGFOP

SF Soil Series

SFSDSED

SFBISED

SFTCSED

SFBCSED

SN Soil Series
DOE/EP-0023, 4.7

Collection of fallout particles and precipitation around the site perimeter at established air sampling locations: AFDHFOP (Dutch Hill at Boehn Road), AFFXFOP (Fox Valley Road), AFTCFOP (Thomas Corners), AF24FOP (Route 240). Indicates short-term effects.

Fallout particles and precipitation collected on-site by the Environmental Laboratory at the rain gauge. Indicates short-term effects.

DOE/EH-0173T, 5.9.1

Off-site soils collected at air sampling locations: SFWEVAL (West Valley), SFFXVRD (Fox Valley Road), SFSPRVL (Springville), SFTCORD (Thomas Corners), SFRT240 (Route 240), SFBOEHN (Boehn Road-Dutch Hill), SFGRVAL (Great Valley), SFRSPRD (Rock Springs Road), and SFBLKST (bulk storage warehouse): Collection of long-term fallout data at established air sampler locations via soil sampling.

DOE/EH-0173T, 5.12.1

Sediment deposition in Cattaraugus Creek at Felton Bridge. Location is the first point of public access to Cattaraugus Creek downstream of its confluence with Buttermilk Creek.

DOE/EH-0173T, 5.12.1

Sediment deposition in Cattaraugus Creek at Springville Dam. Reservoir provides ideal settling and collection location for sediments downstream of the Buttermilk Creek confluence with Cattaraugus Creek. Located downstream of SFCCSED.

DOE/EH-0173T, 5.12.1

Sediment deposition in Cattaraugus Creek at Bigelow Bridge. Location is upstream of the Buttermilk Creek confluence with Cattaraugus Creek and serves as the Cattaraugus Creek background location.

DOE/EH-0173T, 5.12.1

Sediment deposition in Buttermilk Creek at Thomas Corners immediately downstream of all facility liquid effluents.

DOE/EH-0173T, 5.12.1

Sediment deposition in Buttermilk Creek upsteam of facility effluents (background).

DOE/EH-0173T, 5.9.1.

On-site soil. (Samples may be partially composed of sediments.) SNSW74A (surface soil near WNSW74A), SNSWAMP (surface soil near WNSWAMP), and SNSP006 (surface soil near WNSP006): Locations to be specifically defined by geographic coordinates. Correspond to site drainage pattern flows (i.e., most likely area of radiological deposition/accumulation).

Sampling locations are shown on Figures A-2 through A-5, A-12, and A-13. 


\section{Monitoring Program}

\section{Environmental Surveillance}

\section{Off-Site Biological}

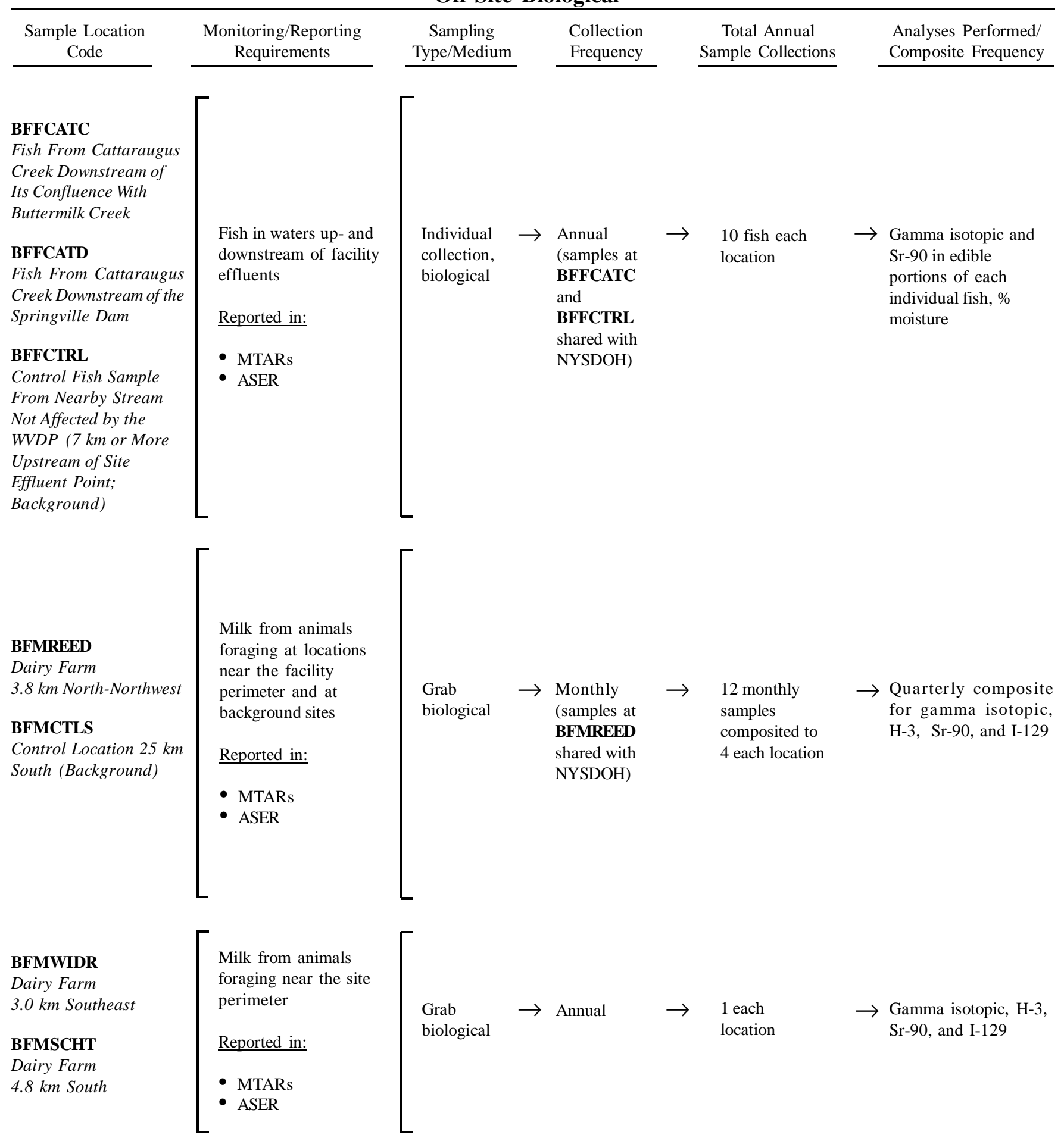

$$
B-41
$$




\title{
Sampling Rationale
}

\author{
BFFCATC DOE/EH-0173T, 5.11.1.1 \\ BFTCATD \\ Radioactivity may enter a food chain in which fish are a major component and are consumed by the local \\ population. \\ BFFCTRL Control fish sample; provides background data for comparison with data from fish caught downstream of facility \\ effluents. \\ BFMREED \\ DOE/EH-0173T, 5.8.2.1 \\ BFMCTLS \\ BFMWIDR \\ Milk is consumed by all age groups and is frequently the most important food that could contribute to the \\ BFMSCHT radiation dose. Dairy animals pastured near the site allow adequate monitoring. Control milk samples are collected \\ far from the site to provide background data for comparison with data from near-site milk samples.
}

Sampling locations are shown on Figures A-9, A-12, and A-13.

$B-42$ 


\section{Monitoring Program \\ Environmental Surveillance}

Off-Site Biological

\begin{tabular}{|c|c|c|c|c|c|c|c|c|}
\hline $\begin{array}{l}\text { Sample Location } \\
\text { Code }\end{array}$ & $\begin{array}{l}\text { Monitoring/Reporting } \\
\text { Requirements }\end{array}$ & $\begin{array}{c}\text { Sampling } \\
\text { Type/Medium }\end{array}$ & & $\begin{array}{l}\text { Collection } \\
\text { Frequency }\end{array}$ & & $\begin{array}{c}\text { Total Annual } \\
\text { Sample Collections }\end{array}$ & & $\begin{array}{l}\text { Analyses Performed/ } \\
\text { Composite Frequency }\end{array}$ \\
\hline $\begin{array}{l}\text { BFVNEAR* } \\
\text { Nearby Locations } \\
\text { BFVCTRL* } \\
\text { Remote Locations (16 } \\
\text { km or More From } \\
\text { Facility; Background) }\end{array}$ & $\begin{array}{l}\text { Fruit and vegetables } \\
\text { grown near facility } \\
\text { perimeter, downwind if } \\
\text { possible, and at back- } \\
\text { ground locations } \\
\text { Reported in: } \\
\text { - MTARs } \\
\text { - ASER }\end{array}$ & $\begin{array}{l}\text { Grab } \\
\text { biological } \\
\text { (fruits and } \\
\text { vegetables) }\end{array}$ & $\rightarrow$ & $\begin{array}{l}\text { Annual } \\
\text { (at harvest) }\end{array}$ & $\rightarrow$ & $\begin{array}{l}3 \text { each (split with } \\
\text { NYSDOH) }\end{array}$ & $\rightarrow$ & $\begin{array}{l}\text { Gamma isotopic and } \\
\text { Sr-90 analysis of } \\
\text { edible portions, H-3 in } \\
\text { free moisture, \% } \\
\text { moisture }\end{array}$ \\
\hline $\begin{array}{l}\text { BFBNEAR } \\
\text { Beef Animal From } \\
\text { Nearby Farm in } \\
\text { Downwind Direction } \\
\text { BFBCTRL } \\
\text { Beef Animal From } \\
\text { Control Location } 16 \mathrm{~km} \\
\text { or More From Facility } \\
\text { (Background) }\end{array}$ & $\begin{array}{l}\text { Meat (beef foraging } \\
\text { near facility perim- } \\
\text { eter, downwind if } \\
\text { possible, and a } \\
\text { background location) } \\
\text { Reported in: } \\
\text { - MTARs } \\
\text { - ASER }\end{array}$ & $\begin{array}{l}\text { Grab } \\
\text { biological }\end{array}$ & $\rightarrow$ & Semiannual & $\rightarrow$ & 2 each location & $\rightarrow$ & $\begin{array}{l}\text { Gamma isotopic and } \\
\text { Sr-90 analysis of } \\
\text { meat, } \mathrm{H}-3 \text { in free } \\
\text { moisture, \% moisture }\end{array}$ \\
\hline $\begin{array}{l}\text { BFDNEAR } \\
\text { Deer in Vicinity of the } \\
\text { Site }\end{array}$ & $\begin{array}{l}\text { Venison (deer foraging } \\
\text { near facility perimeter } \\
\text { and at background } \\
\text { locations) }\end{array}$ & $\begin{array}{l}\text { Individual } \\
\text { collection, } \\
\text { biological }\end{array}$ & $\rightarrow$ & $\begin{array}{l}\text { Annual, during } \\
\text { hunting season } \\
\text { (BFDNEAR } \\
\text { sample split } \\
\text { with NYSDOH) }\end{array}$ & $\rightarrow$ & 3 & $\rightarrow$ & $\begin{array}{l}\text { Gamma isotopic and } \\
\text { Sr-90 analysis of } \\
\text { meat, H-3 in free } \\
\text { moisture, \% moisture }\end{array}$ \\
\hline $\begin{array}{l}\text { BFDCTRL } \\
\text { Control Deer } 16 \text { km or } \\
\text { More From the Facility } \\
\text { (Background) }\end{array}$ & $\begin{array}{l}\text { Reported in: } \\
\text { - MTARs } \\
\text { - ASER }\end{array}$ & & & $\begin{array}{l}\text { During year as } \\
\text { available } \\
\text { (BFDCTRL } \\
\text { sample split } \\
\text { with NYSDOH) }\end{array}$ & $\rightarrow$ & 3 & $\rightarrow$ & $\begin{array}{l}\text { Gamma isotopic and } \\
\text { Sr-90 analysis of } \\
\text { meat, H-3 in free } \\
\text { moisture, \% moisture }\end{array}$ \\
\hline
\end{tabular}

\footnotetext{
* Near-site and control corn, apple, and bean samples are identified specifically as follows: corn = BFVNEAC and BFVCTRC; apples =
} BFVNEAAF and BFVCTRA; beans = BFVNEAB and BFVCTRB.

$$
\text { B }-43
$$




\section{Sampling Rationale}

\section{BFVNEAR DOE/EH-0173T, 5.8.2.2}

Fruits and vegetables (corn, apples, and beans or leafy vegetables, if available) collected from areas near the site. These samples are collected, if possible, from areas near the site predicted to have worst-case downwind concentrations of radionuclides in air and soil. Sample analysis reflects steady state/chronic uptake or contamination of foodstuffs as a result of site activities. Possible pathway directly to humans or indirectly through animals.

BFVCTRL

DOE/EH-0173T, 5.8.2.2

Fruits and vegetables collected from an area remote from the site. Background fruits and vegetables collected for comparison with near-site samples. Collected in area(s) of no possible site effects.

BFBNEAR

BFBCTRL

BFDNEAR

BFDCTRL
DOE/EH-0173T, 5.8.2.3

Beef collected from animals raised near the site and foraging downwind of the site in areas of maximum probable effects. Following the rationale for vegetable matter collected near the site (BFVNEAR), edible flesh portion of beef animals is analyzed to determine possible radionuclide content passable directly to humans.

DOE/EH-0173T, 5.8.2.3

Beef collected from animals raised far from the site. Background beef collected for comparison with near-site samples. Collected in area(s) of no possible site effects.

\section{DOE/EH-0173T, 5.8.3}

Venison from near-site deer. Samples are taken from deer killed in collisions with vehicles. Sample rationale is similar to BFBNEAR.

\section{DOE/EH-0173T, 5.8.3}

Venison from deer living far from the site. Background deer meat collected for comparison with near-site samples. Collected in area(s) of no possible site effects.

Sampling locations are shown on Figures A-9, A-12, and A-13. 


\section{Monitoring Program \\ Environmental Surveillance}

\section{Off-Site Direct Radiation}

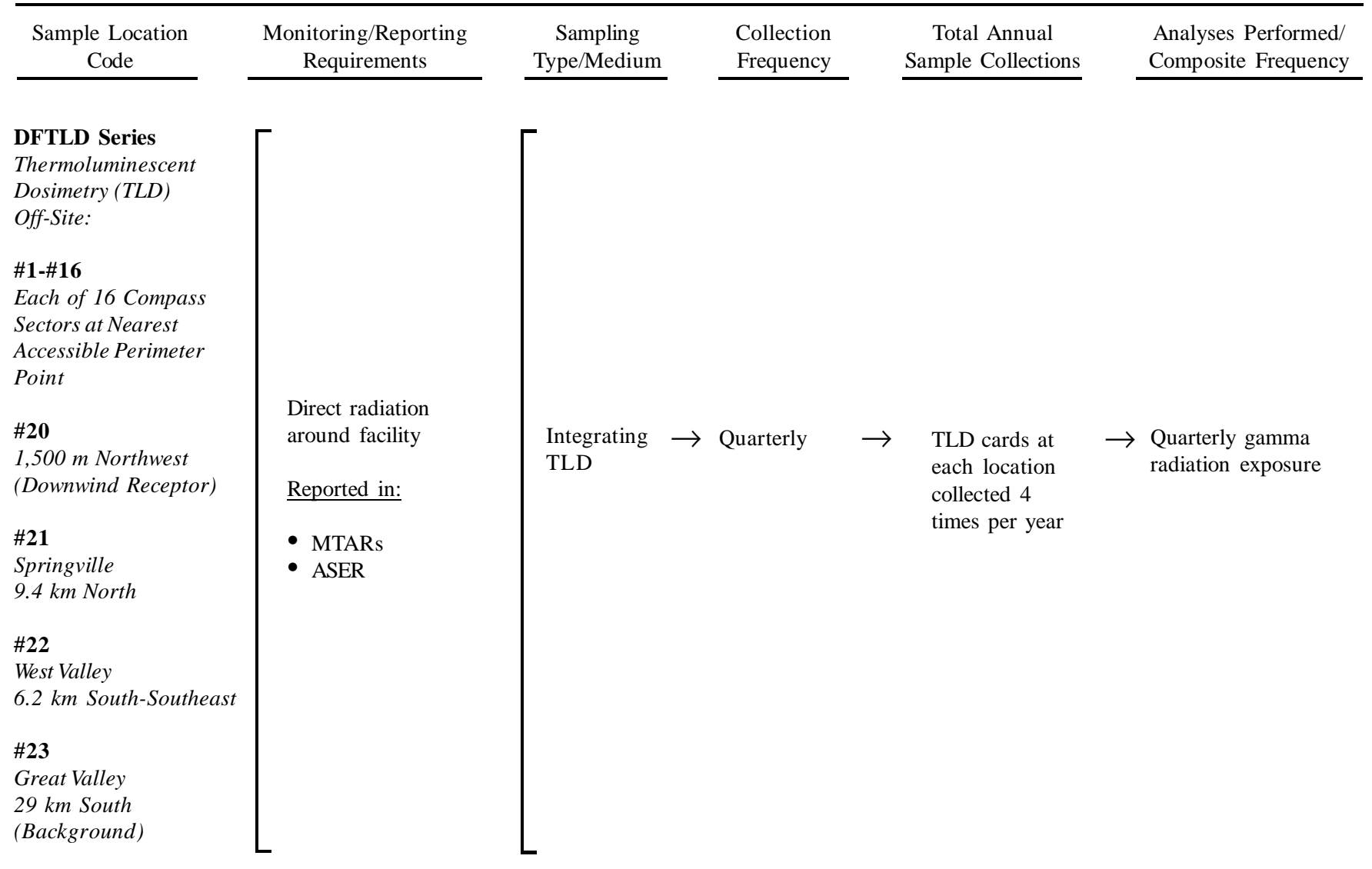

$$
B-45
$$




\section{Sampling Rationale}

Direct Radiation DOE/EH-0173T, 5.5; DOE/EP-0023, 4.6.3

Off-Site

TLDs offer continuous integrated environmental gamma-ray monitoring and have been deployed systematically about the site. Off-site TLDs are used to verify that site activities have not adversely affected the surrounding environs.

An annual high-pressure ion chamber (HPIC) gamma radiation measurement was completed at all locations in order to confirm TLD measurements.

Sampling locations are shown on Figures A-11 through A-13.

$B-46$ 


\section{Monitoring Program}

Environmental Surveillance

On-Site Direct Radiation

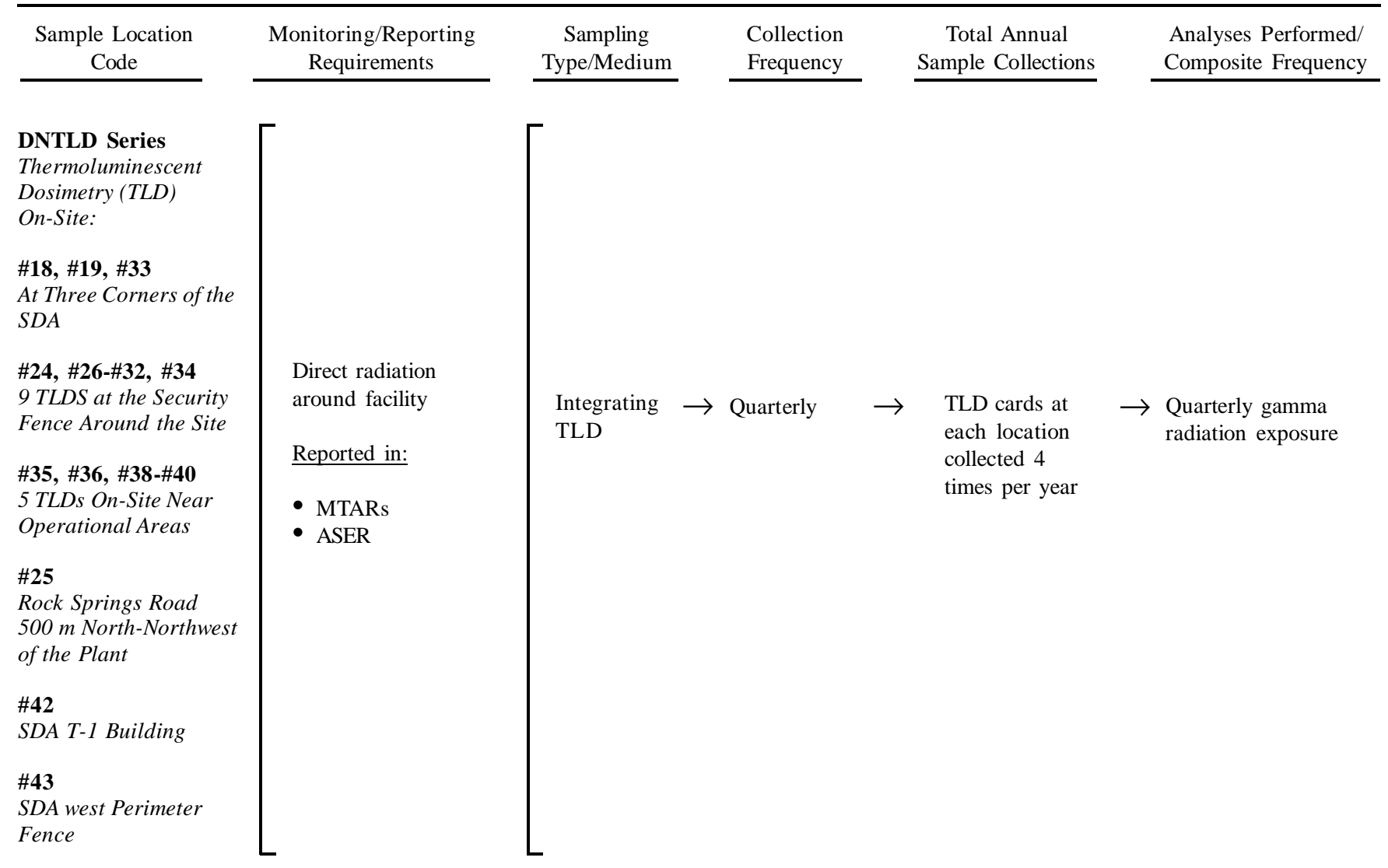

$B-47$ 


\section{Sampling Rationale}

Direct Radiation DOE/EH-0173T, 5.4 and 5.5
On-Site

On-site TLDs monitor waste management units and verify that the potential dose rate to the general public (i.e., at Rock Springs Road) is below $100 \mathrm{mrem} / \mathrm{year}(1 \mathrm{mSv} / \mathrm{year})$ from site activities.

An annual high-pressure ion chamber (HPIC) gamma radiation measurement is completed at all locations in order to confirm TLD measurements.

Potential TLD sampling locations are continually evaluated with respect to site activities.

Sampling locations are shown on Figure A-10.

$B-48$ 
This page intentionally left blank

$$
\text { B }-49
$$




\section{Appendix C-1 \\ Summary of Water Limits, Guidelines, and Standards}

$C-1$ 
This page intentionally left blank

$C-2$ 


\section{Table C-1A \\ West Valley Demonstration Project State Pollutant Discharge Elimination System (SPDES) Sampling Program}

Outfall

001 (Process and Storm Flow Wastewater)

\section{Para}

Aluminum, total

Ammonia $\left(\mathrm{NH}_{3}\right)$

Arsenic, dissolved

$\mathrm{BOD}_{5}$

Iron, total

Zinc, total recoverable

Suspended solids

Cyanide, amenable to chlorination

Settleable solids

$\mathrm{pH}$ (range)

Oil and grease

Sulfate (as S)

Sulfide, dissolved

Manganese, total

Nitrate (as N)

Nitrite (as N)

Chromium, total recoverable

Chromium, hexavalent, total recoverable

Cadmium, total recoverable

Copper, total recoverable

Copper, dissolved

Lead, total recoverable

Nickel, total recoverable

Dichlorodifluoromethane

Trichlorofluoromethane

3,3-dichlorobenzidine

Tributyl phosphate

Vanadium, total recoverable

Cobalt, total recoverable

Selenium, total recoverable

Hexachlorobenzene

Alpha - BHC

Heptachlor

Surfactants (as LAS)

Xylene

2-butanone

Total dissolved solids

Mercury, total
Daily Maximum Limit*

Monitor

$14.0 \mathrm{mg} / \mathrm{L}$

Monitor

$0.15 \mathrm{mg} / \mathrm{L}$

$10.0 \mathrm{mg} / \mathrm{L}$

Monitor

$0.48 \mathrm{mg} / \mathrm{L}$

$45.0 \mathrm{mg} / \mathrm{L}$

$0.022 \mathrm{mg} / \mathrm{L}$

$0.30 \mathrm{~mL} / \mathrm{L}$

6.5-8.5

$15.0 \mathrm{mg} / \mathrm{L}$

Monitor

$0.4 \mathrm{mg} / \mathrm{L}$

$2.0 \mathrm{mg} / \mathrm{L}$

Monitor

$0.1 \mathrm{mg} / \mathrm{L}$

$0.3 \mathrm{mg} / \mathrm{L}$

$0.011 \mathrm{mg} / \mathrm{L}$

$0.002 \mathrm{mg} / \mathrm{L}$

$0.030 \mathrm{mg} / \mathrm{L}$

Monitor

$0.006 \mathrm{mg} / \mathrm{L}$

$0.14 \mathrm{mg} / \mathrm{L}$

$0.01 \mathrm{mg} / \mathrm{L}$

$0.01 \mathrm{mg} / \mathrm{L}$

$0.01 \mathrm{mg} / \mathrm{L}$

$32 \mathrm{mg} / \mathrm{L}$

$0.014 \mathrm{mg} / \mathrm{L}$

$0.005 \mathrm{mg} / \mathrm{L}$

$0.004 \mathrm{mg} / \mathrm{L}$

$0.02 \mathrm{mg} / \mathrm{L}$

$0.00001 \mathrm{mg} / \mathrm{L}$

$0.00001 \mathrm{mg} / \mathrm{L}$

$0.4 \mathrm{mg} / \mathrm{L}$

$0.05 \mathrm{mg} / \mathrm{L}$

$0.5 \mathrm{mg} / \mathrm{L}$

Monitor

$0.0002 \mathrm{mg} / \mathrm{L}$
Sample Frequency

2 per discharge

2 per discharge

2 per discharge

2 per discharge

2 per discharge

2 per discharge

2 per discharge

2 per discharge

2 per discharge

2 per discharge

2 per discharge

2 per discharge

2 per discharge

2 per discharge

2 per discharge

2 per discharge

2 per discharge

2 per discharge

2 per discharge

2 per discharge

2 per discharge

2 per discharge

2 per discharge

2 per discharge

annual

annual

2 per discharge

2 per discharge

2 per discharge

2 per discharge

2 per discharge

2 per discharge

2 per discharge

2 per discharge

2 per discharge

2 per discharge

2 per discharge

2 per discharge

2 per discharge

\footnotetext{
* Daily average limitations are also identified in the permit but require only monitoring for all parameters except total aluminum (daily average limit $-7.0 \mathrm{mg} / \mathrm{L}$ ); suspended solids (daily average limit - $30.0 \mathrm{mg} / \mathrm{L}$ ); $B O D_{5}$ for the sum of outfalls 001, 007, and 008 (daily average limit $-5.0 \mathrm{mg} / \mathrm{L}$ ); and ammonia for the sum of outfalls 001 and 007 (daily average limit $-1.49 \mathrm{mg} / \mathrm{L}$ ).
}

$$
\text { C - } 3
$$




\section{Table C-1A (concluded) \\ West Valley Demonstration Project State Pollutant Discharge Elimination System (SPDES) Sampling Program}

\begin{tabular}{|c|c|c|c|}
\hline Outfall & Parameter & Daily Maximum Limit* & Sample Frequency \\
\hline 001 (concluded) & $\begin{array}{l}\text { Barium } \\
\text { Antimony } \\
\text { Chloroform } \\
\text { Bis(2-ethylhexyl)phthalate } \\
\text { 4-Dodecene } \\
\text { Titanium } \\
\text { Bromide } \\
\text { Boron }\end{array}$ & $\begin{array}{l}0.5 \mathrm{mg} / \mathrm{L} \\
1.0 \mathrm{mg} / \mathrm{L} \\
0.3 \mathrm{mg} / \mathrm{L} \\
1.6 \mathrm{mg} / \mathrm{L} \\
0.6 \mathrm{mg} / \mathrm{L} \\
0.65 \mathrm{mg} / \mathrm{L} \\
5.0 \mathrm{mg} / \mathrm{L} \\
2.0 \mathrm{mg} / \mathrm{L}\end{array}$ & $\begin{array}{l}\text { annual } \\
\text { annual } \\
\text { annual } \\
\text { semiannual } \\
\text { semiannual } \\
\text { semiannual } \\
\text { quarterly } \\
\text { quarterly }\end{array}$ \\
\hline $\begin{array}{l}\text { 01B (Internal Process } \\
\text { Monitoring Point) }\end{array}$ & $\begin{array}{l}\text { Flow } \\
\text { Mercury, total }\end{array}$ & $\begin{array}{l}\text { Monitor } \\
10.0 \mu \mathrm{g} / \mathrm{L}\end{array}$ & $\begin{array}{l}\text { weekly } \\
2 \text { per month }\end{array}$ \\
\hline $\begin{array}{l}007 \text { (Sanitary and } \\
\text { Utility Wastewater) }\end{array}$ & $\begin{array}{l}\text { Flow } \\
\text { Ammonia }\left(\text { as NH}_{3}\right) \\
\text { BOD }_{5} \\
\text { Iron, total } \\
\text { Solids, suspended } \\
\text { Solids, settleable } \\
\text { pH(range) } \\
\text { Nitrite (as N) } \\
\text { Oil and grease } \\
\text { Chlorine, total residual } \\
\text { Chloroform }\end{array}$ & $\begin{array}{l}\text { Monitor } \\
\text { Monitor } \\
10 \mathrm{mg} / \mathrm{L} \\
\text { Monitor } \\
45.0 \mathrm{mg} / \mathrm{L} \\
0.3 \mathrm{~mL} / \mathrm{L} \\
6.5-8.5 \\
0.1 \mathrm{mg} / \mathrm{L} \\
15 \mathrm{mg} / \mathrm{L} \\
0.1 \mathrm{mg} / \mathrm{L} \\
0.20 \mathrm{mg} / \mathrm{L}\end{array}$ & $\begin{array}{l}3 \text { per month } \\
3 \text { per month } \\
3 \text { per month } \\
3 \text { per month } \\
3 \text { per month } \\
\text { weekly } \\
\text { weekly } \\
3 \text { per month } \\
3 \text { per month } \\
\text { weekly } \\
\text { annual }\end{array}$ \\
\hline $\begin{array}{l}\text { 008 (French Drain } \\
\text { Wastewater) }\end{array}$ & $\begin{array}{l}\text { Flow } \\
\text { BOD }_{5} \\
\text { Iron, total } \\
\text { pH(range) } \\
\text { Cadmium, total recoverable } \\
\text { Lead, total recoverable } \\
\text { Silver, total } \\
\text { Zinc, total } \\
\text { Arsenic } \\
\text { Chromium }\end{array}$ & $\begin{array}{l}\text { Monitor } \\
5.0 \mathrm{mg} / \mathrm{L} \\
\text { Monitor } \\
6.5-8.5 \\
0.002 \mathrm{mg} / \mathrm{L} \\
0.006 \mathrm{mg} / \mathrm{L} \\
0.008 \mathrm{mg} / \mathrm{L} \\
0.100 \mathrm{mg} / \mathrm{L} \\
0.17 \mathrm{mg} / \mathrm{L} \\
0.13 \mathrm{mg} / \mathrm{L}\end{array}$ & $\begin{array}{l}3 \text { per month } \\
3 \text { per month } \\
3 \text { per month } \\
3 \text { per month } \\
3 \text { per month } \\
3 \text { per month } \\
\text { annual } \\
\text { annual } \\
\text { annual } \\
\text { annual }\end{array}$ \\
\hline $\begin{array}{l}\text { Sum of Outfalls 001, } \\
007 \text {, and } 008\end{array}$ & $\begin{array}{l}\text { Iron, total } \\
\mathrm{BOD}_{5}\end{array}$ & $\begin{array}{l}0.30 \mathrm{mg} / \mathrm{L} \\
\text { Monitor }\end{array}$ & $\begin{array}{l}3 \text { per month } \\
3 \text { per month }\end{array}$ \\
\hline $\begin{array}{l}\text { Sum of Outfalls } 001 \\
\text { and } 007\end{array}$ & Ammonia (as $\mathrm{NH}_{3}$ ) & $2.1 \mathrm{mg} / \mathrm{L}$ & 3 per month \\
\hline $\begin{array}{l}\text { Pseudo-monitoring } \\
\text { point (116) }\end{array}$ & Solids, total dissolved & $500 \mathrm{mg} / \mathrm{L}$ & 2 per discharge \\
\hline
\end{tabular}

\footnotetext{
* Daily average limitations are also identified in the permit but require only monitoring for all parameters except total aluminum (daily average limit - $7.0 \mathrm{mg} / \mathrm{L}$ ); suspended solids (daily average limit - $30.0 \mathrm{mg} / \mathrm{L}$ ); $B O D_{5}$ for the sum of outfalls 001, 007, and 008 (daily average limit $-5.0 \mathrm{mg} / \mathrm{L}$ ); and ammonia for the sum of outfalls 001 and 007 (daily average limit $-1.49 \mathrm{mg} / \mathrm{L}$ ).
}

$$
\text { C - } 4
$$


Table C-1B

New York Water Quality Standards and Guidelines ${ }^{a}$

\begin{tabular}{|c|c|c|c|c|c|c|}
\hline Parameter & Units & Class A & Class B & Class C & Class D & Class GA \\
\hline Gross Alphab & $\mathrm{pCi} / \mathrm{L}(\mu \mathrm{Ci} / \mathrm{mL})$ & $15(1.5 \mathrm{E}-08)$ & -- & -- & -- & $15(1.5 \mathrm{E}-08)$ \\
\hline Gross Beta $^{c}$ & $\mathrm{pCi} / \mathrm{L}(\mu \mathrm{Ci} / \mathrm{mL})$ & $1,000(1 \mathrm{E}-06)$ & -- & -- & -- & $1,000(1 \mathrm{E}-06)$ \\
\hline Tritium (H-3) & $\mathrm{pCi} / \mathrm{L}(\mu \mathrm{Ci} / \mathrm{mL})$ & $20,000(2 \mathrm{E}-05)$ & -- & -- & -- & -- \\
\hline Strontium-90 & $\mathrm{pCi} / \mathrm{L}(\mu \mathrm{Ci} / \mathrm{mL})$ & $8(8 \mathrm{E}-09)$ & -- & -- & -- & -- \\
\hline Alpha BHC & $\mathrm{mg} / \mathrm{L}$ & 0.000002 & 0.000002 & 0.000002 & 0.000002 & 0.00001 \\
\hline Aluminum, Dissolved & $\mathrm{mg} / \mathrm{L}$ & 0.10 & 0.10 & 0.10 & -- & -- \\
\hline Aluminum, Total & $\mathrm{mg} / \mathrm{L}$ & -- & -- & -- & -- & -- \\
\hline Ammonia, Total as $\mathbf{N}$ & $\mathrm{mg} / \mathrm{L}$ & $0.09-2.1$ & $0.09-2.1$ & $0.09-2.1$ & $0.67-29$ & 2.0 \\
\hline Antimony, Total & $\mathrm{mg} / \mathrm{L}$ & 0.003 & -- & -- & -- & 0.003 \\
\hline Arsenic, Dissolved & $\mathrm{mg} / \mathrm{L}$ & 0.050 & 0.150 & 0.150 & 0.340 & -- \\
\hline Arsenic, Total & $\mathrm{mg} / \mathrm{L}$ & 0.050 & -- & -- & -- & 0.025 \\
\hline Barium, Total & $\mathrm{mg} / \mathrm{L}$ & 1.00 & -- & -- & -- & 1.00 \\
\hline Beryllium, Total & $\mathrm{mg} / \mathrm{L}$ & 0.003 & d & d & -- & 0.003 \\
\hline Bicarbonate Alkalinity (as $\mathrm{CaCO}_{3}$ ) & $\mathrm{mg} / \mathrm{L}$ & -- & -- & -- & -- & -- \\
\hline Boron, Total & $\mathrm{mg} / \mathrm{L}$ & 10.0 & 10.0 & 10.0 & -- & 1.00 \\
\hline Bromide & $\mathrm{mg} / \mathrm{L}$ & 2.00 & -- & -- & -- & 2.00 \\
\hline Cadmium, Dissolved $^{\mathrm{e}}$ & $\mathrm{mg} / \mathrm{L}$ & -- & -- & -- & -- & -- \\
\hline Cadmium, Total & $\mathrm{mg} / \mathrm{L}$ & 0.005 & -- & -- & -- & 0.005 \\
\hline Calcium, Total & $\mathrm{mg} / \mathrm{L}$ & -- & -- & -- & -- & -- \\
\hline Carbonate Alkalinity (as $\mathrm{CaCO}_{3}$ ) & $\mathrm{mg} / \mathrm{L}$ & -- & -- & -- & -- & -- \\
\hline Chloride & $\mathrm{mg} / \mathrm{L}$ & 250 & -- & -- & -- & 250 \\
\hline Chromium, Dissolved $^{\mathrm{e}}$ & $\mathrm{mg} / \mathrm{L}$ & -- & -- & -- & -- & -- \\
\hline Chromium, Total & $\mathrm{mg} / \mathrm{L}$ & 0.05 & -- & -- & -- & 0.05 \\
\hline Cobalt, Total $^{\text {h }}$ & $\mathrm{mg} / \mathrm{L}$ & 0.005 & 0.005 & 0.005 & 0.110 & -- \\
\hline Conductivity & umhos/cm@25 ${ }^{\circ} \mathrm{C}$ & -- & -- & -- & -- & -- \\
\hline Copper, Dissolved $^{\mathrm{e}}$ & $\mathrm{mg} / \mathrm{L}$ & -- & -- & -- & -- & -- \\
\hline Copper, Total & $\mathrm{mg} / \mathrm{L}$ & 0.20 & -- & -- & -- & 0.20 \\
\hline Cyanide & $\mathrm{mg} / \mathrm{L}$ & 0.0052 & 0.0052 & 0.0052 & 0.22 & 0.200 \\
\hline Dissolved Oxygen (minimum) & $\mathrm{mg} / \mathrm{L}$ & 4.0 & 4.0 & 4.0 & 3.0 & -- \\
\hline Fluoride $^{\mathrm{e}}$ & $\mathrm{mg} / \mathrm{L}$ & -- & -- & -- & -- & 1.5 \\
\hline Hardness & $\mathrm{mg} / \mathrm{L}$ & -- & -- & -- & -- & -- \\
\hline Iron and Manganese (sum) & $\mathrm{mg} / \mathrm{L}$ & -- & -- & -- & -- & 0.500 \\
\hline
\end{tabular}

-- No applicable guideline or reference standard available

Note: All water quality and metals standards are presented in $\mathrm{mg} / \mathrm{L}(\mathrm{ppm})$ to provide consistency in comparisons.

a Source: 6 NYCRR Parts 701-704; The most stringent applicable pathway (e.g., wildlife, aquatic, human health)

values are reported.

${ }^{b}$ Gross alpha standard includes radium-226, but excludes radon and uranium; however WVDP results include

these isotopes.

${ }^{c}$ Gross beta standard excludes strontium-90 and alpha emitters, however WVDP results include these isotopes.

${ }^{d}$ Beryllium standard for classes " $B$ " and " $C$ " are based on stream hardness values.

${ }^{e}$ Standards for these constituents vary according to stream location hardness values.

${ }^{f} \mathrm{pH}$ shall not be lower than 6.5 or the $\mathrm{pH}$ of natural groundwater, whichever is lower, nor shall pH be greater than 8.5 or the $\mathrm{pH}$ of the natural groundwater, whichever is greater.

${ }^{g}$ Applies to the sum of those organic substances which have individual human health water source standards listed at $0.100 \mathrm{mg} / \mathrm{L}$ or less in 6 NYCRR Part 703.5

${ }^{h}$ Standards for cobalt, thallium, and vanadium are acid-soluble. 


\section{Table C-1B (concluded) \\ New York Water Quality Standards and Guidelines ${ }^{a}$}

\begin{tabular}{|c|c|c|c|c|c|c|}
\hline Parameter & Units & Class A & Class B & Class C & Class D & Class GA \\
\hline Iron, Total & $\mathrm{mg} / \mathrm{L}$ & 0.30 & 0.30 & 0.30 & 0.30 & 0.30 \\
\hline Lead, Dissolved $^{\mathrm{e}}$ & $\mathrm{mg} / \mathrm{L}$ & -- & -- & -- & -- & -- \\
\hline Lead, Total & $\mathrm{mg} / \mathrm{L}$ & 0.050 & -- & -- & -- & 0.025 \\
\hline Magnesium, Total & $\mathrm{mg} / \mathrm{L}$ & 35.0 & -- & -- & -- & 35.0 \\
\hline Manganese, Total & $\mathrm{mg} / \mathrm{L}$ & 0.30 & -- & -- & -- & 0.30 \\
\hline Mercury, Dissolved & $\mathrm{mg} / \mathrm{L}$ & 0.0000007 & 0.0000007 & 0.0000007 & 0.0000007 & -- \\
\hline Mercury, Total & $\mathrm{mg} / \mathrm{L}$ & 0.0007 & -- & -- & -- & 0.0007 \\
\hline Nickel, Dissolved $^{\mathrm{e}}$ & $\mathrm{mg} / \mathrm{L}$ & -- & -- & -- & -- & -- \\
\hline Nickel, Total & $\mathrm{mg} / \mathrm{L}$ & 0.10 & -- & -- & -- & 0.10 \\
\hline Nitrate-N & $\mathrm{mg} / \mathrm{L}$ & 10.0 & -- & -- & -- & 10.0 \\
\hline Nitrate + Nitrite & $\mathrm{mg} / \mathrm{L}$ & 10.0 & 10.0 & 10.0 & 10.0 & 10.0 \\
\hline Nitrite-N & $\mathrm{mg} / \mathrm{L}$ & 0.10 & 0.10 & 0.10 & -- & 1.00 \\
\hline NPOC $^{\mathrm{g}}$ & $\mathrm{mg} / \mathrm{L}$ & 0.10 & -- & -- & -- & -- \\
\hline Oil \& Grease & $\mathrm{mg} / \mathrm{L}$ & -- & -- & -- & -- & -- \\
\hline pH & SU & $6.5-8.5^{\mathrm{f}}$ & $6.5-8.5^{\mathrm{f}}$ & $6.5-8.5^{f}$ & $6.0-9.5$ & $6.5-8.5^{f}$ \\
\hline Potassium, Total & $\mathrm{mg} / \mathrm{L}$ & -- & -- & -- & -- & -- \\
\hline Selenium, Dissolved & $\mathrm{mg} / \mathrm{L}$ & 0.0046 & 0.0046 & 0.0046 & -- & -- \\
\hline Selenium, Total & $\mathrm{mg} / \mathrm{L}$ & 0.01 & -- & -- & -- & 0.01 \\
\hline Silver, Total & $\mathrm{mg} / \mathrm{L}$ & 0.05 & -- & -- & -- & 0.05 \\
\hline Sodium, Total & $\mathrm{mg} / \mathrm{L}$ & -- & -- & -- & -- & 20.0 \\
\hline Solids, Settleable & $\mathrm{mg} / \mathrm{L}$ & -- & -- & -- & -- & -- \\
\hline Solids, Total Dissolved & $\mathrm{mg} / \mathrm{L}$ & 500 & 500 & 500 & -- & 500 \\
\hline Solids, Total Suspended & $\mathrm{mg} / \mathrm{L}$ & -- & -- & -- & -- & -- \\
\hline Sulfate & $\mathrm{mg} / \mathrm{L}$ & 250 & -- & -- & -- & 250 \\
\hline Sulfide (undissociated form) & $\mathrm{mg} / \mathrm{L}$ & 0.002 & 0.002 & 0.002 & -- & 0.050 (as HS) \\
\hline Surfactants (as LAS) & $\mathrm{mg} / \mathrm{L}$ & 0.04 & 0.04 & 0.04 & -- & -- \\
\hline Thallium, Total $^{\mathrm{h}}$ & $\mathrm{mg} / \mathrm{L}$ & 0.0005 & 0.008 & 0.008 & 0.020 & 0.0005 \\
\hline Titanium, Total & $\mathrm{mg} / \mathrm{L}$ & -- & -- & -- & -- & -- \\
\hline TOX (total organic halides) ${ }^{\mathrm{g}}$ & $\mathrm{mg} / \mathrm{L}$ & 0.10 & -- & -- & -- & -- \\
\hline Vanadium, Total $^{\mathrm{h}}$ & $\mathrm{mg} / \mathrm{L}$ & 0.014 & 0.014 & 0.014 & 0.190 & -- \\
\hline Zinc, Dissolved $^{\mathrm{e}}$ & $\mathrm{mg} / \mathrm{L}$ & -- & -- & -- & -- & -- \\
\hline Zinc, Total & $\mathrm{mg} / \mathrm{L}$ & 2.00 & -- & -- & -- & 2.00 \\
\hline
\end{tabular}

-- No applicable guideline or reference standard available

Note: All water quality and metals standards are presented in $\mathrm{mg} / \mathrm{L}(\mathrm{ppm})$ to provide consistency in comparisons. HS - Hydrogen sulfide

${ }^{a}$ Source: 6 NYCRR Parts 701-704; The most stringent applicable pathway (e.g., wildlife, aquatic, human health) values are reported.

${ }^{b}$ Gross alpha standard includes radium-226, but excludes radon and uranium; however WVDP results include these isotopes.

${ }^{c}$ Gross beta standard excludes strontium-90 and alpha emitters, however WVDP results include these isotopes.

"Beryllium standard for classes " $B$ " and " $C$ " are based on stream hardness.

e Standards for these constituents vary according to stream location hardness values.

${ }^{f} \mathrm{pH}$ shall not be lower than 6.5 or the $\mathrm{pH}$ of natural groundwater, whichever is lower, nor shall pH be greater than 8.5 or the $\mathrm{pH}$ of the natural groundwater, whichever is greater.

${ }^{g}$ Applies to the sum of those organic substances which have individual human health water source standards listed at $0.100 \mathrm{mg} / \mathrm{L}$ or less in 6 NYCRR Part 703.5

${ }^{h}$ Standards for cobalt, thallium, and vanadium are acid-soluble. 


\section{Table C-1C \\ New York State Department of Health/U.S. Environmental Protection Agency MCLs, MCLGs, and Raw Water Standards}

\begin{tabular}{|c|c|c|c|c|}
\hline Parameter & Units & $\begin{array}{l}\text { NYSDOH or } \\
\text { EPA MCL }\end{array}$ & EPA MCLG ${ }^{b}$ & $\begin{array}{c}\text { NYSDOH Raw Water } \\
\text { Standards }^{c}\end{array}$ \\
\hline Gross Alpha & $\mathrm{pCi} / \mathrm{L}(\mu \mathrm{Ci} / \mathrm{mL})$ & $15(1.5 \mathrm{E}-08)^{\mathrm{d}}$ & 0 & -- \\
\hline Gross Beta & $\mathrm{pCi} / \mathrm{L}(\mu \mathrm{Ci} / \mathrm{mL})$ & $50(5 \mathrm{E}-08)^{\mathrm{e}}$ & 0 & $1,000(1 \mathrm{E}-06)$ \\
\hline Tritium (H-3) & $\mathrm{pCi} / \mathrm{L}(\mu \mathrm{Ci} / \mathrm{mL})$ & $20,000(2 \mathrm{E}-05)$ & -- & -- \\
\hline Strontium-90 & $\mathrm{pCi} / \mathrm{L}(\mu \mathrm{Ci} / \mathrm{mL})$ & $8(8 \mathrm{E}-09)$ & -- & $10(1 \mathrm{E}-08)$ \\
\hline Antimony, Total & $\mathrm{mg} / \mathrm{L}$ & 0.006 & 0.006 & -- \\
\hline Arsenic, Total & $\mathrm{mg} / \mathrm{L}$ & 0.05 & -- & 0.05 \\
\hline Barium, Total & $\mathrm{mg} / \mathrm{L}$ & 2.00 & 2.00 & 1 \\
\hline Beryllium, Total & $\mathrm{mg} / \mathrm{L}$ & 0.004 & 0.004 & -- \\
\hline Cadmium, Total & $\mathrm{mg} / \mathrm{L}$ & 0.005 & 0.005 & 0.01 \\
\hline Chromium, Total & $\mathrm{mg} / \mathrm{L}$ & 0.10 & 0.10 & -- \\
\hline Conductivity & $\mu \mathrm{mhos} / \mathrm{cm} @ 25^{\circ} \mathrm{C}$ & -- & -- & -- \\
\hline Cyanide & $\mathrm{mg} / \mathrm{L}$ & 0.2 & 0.2 & $<0.1$ \\
\hline E. Coli & NA & one positive sample & 0 & -- \\
\hline Fluoride & $\mathrm{mg} / \mathrm{L}$ & 2.2 & -- & 1.5 \\
\hline Free Residual Chlorine & $\mathrm{mg} / \mathrm{L}$ & $0.02(\min ) \quad 4.0(\max )$ & -- & -- \\
\hline Haloacetic Acids -Five (5) & $\mathrm{mg} / \mathrm{L}$ & 0.060 & -- & -- \\
\hline Iron, Total & $\mathrm{mg} / \mathrm{L}$ & 0.3 & -- & -- \\
\hline Mercury, Total & $\mathrm{mg} / \mathrm{L}$ & 0.002 & 0.002 & 0.005 \\
\hline Nickel, Total & $\mathrm{mg} / \mathrm{L}$ & -- & -- & -- \\
\hline Nitrate-N & $\mathrm{mg} / \mathrm{L}$ & 10 & 10 & -- \\
\hline pH & SU & -- & -- & $6.5-8.5$ \\
\hline POC $^{\mathrm{f}}$ & $\mathrm{mg} / \mathrm{L}$ & -- & 0.0005 & -- \\
\hline Selenium, Total & $\mathrm{mg} / \mathrm{L}$ & 0.05 & 0.05 & 0.01 \\
\hline Solids, Total Dissolved & $\mathrm{mg} / \mathrm{L}$ & -- & -- & 500 \\
\hline Thallium, Total & $\mathrm{mg} / \mathrm{L}$ & 0.002 & 0.0005 & -- \\
\hline Total Coliform & NA & 2 or more positive samples & zero & -- \\
\hline Total Trihalomethanes & $\mathrm{mg} / \mathrm{L}$ & 0.080 & -- & -- \\
\hline Turbidity & NTU & $1(\max )$ & -- & -- \\
\hline
\end{tabular}

-- No applicable guideline or reference standard available

Note: All water quality and metals standards are presented in $\mathrm{mg} / \mathrm{L}(\mathrm{ppm})$ to provide consistency in comparisons. NA - Not applicable

${ }^{a}$ MCL - Listed is NYSDOH or EPA Maximum Contaminant Level. Sources: 40 CFR 141 and/or 5 NYCRR 5-1.52, whichever is more stringent.

${ }^{b}$ MCLG - Maximum Contaminant Level Goal (non-enforceable) as listed in 40 CFR Part 141

c Source: 10 NYCRR Part 170.4

${ }^{d}$ Alpha guideline includes radium-226, but excludes uranium; however, WVDP results include these isotopes.

${ }^{e}$ Average annual concentration assumed to produce a total body organ dose of $4 \mathrm{mrem} / \mathrm{year}$

${ }^{f}$ POC - Principle Organic Contaminant

$$
\text { C - } 7
$$


Table C-1D

\section{U.S. Department of Energy Derived Concentration Guides $(D C G s)^{a}$}

\begin{tabular}{|c|c|c|}
\hline Radionuclide & Units & Concentration in Ingested Water \\
\hline Gross Alpha (as Am-241) & $\mu \mathrm{Ci} / \mathrm{mL}$ & $3 \mathrm{E}-08$ \\
\hline Gross Beta $\left(\right.$ as Sr-90) ${ }^{b}$ & $\mu \mathrm{Ci} / \mathrm{mL}$ & $1 \mathrm{E}-06$ \\
\hline Tritium (H-3) & $\mu \mathrm{Ci} / \mathrm{mL}$ & $2 \mathrm{E}-03$ \\
\hline Carbon-14 (C-14) & $\mu \mathrm{Ci} / \mathrm{mL}$ & 7E-05 \\
\hline Potassium-40 (K-40) & $\mu \mathrm{Ci} / \mathrm{mL}$ & 7E-06 \\
\hline Cobalt-60 (Co-60) & $\mu \mathrm{Ci} / \mathrm{mL}$ & $5 \mathrm{E}-06$ \\
\hline Strontium-90 (Sr-90) & $\mu \mathrm{Ci} / \mathrm{mL}$ & $1 \mathrm{E}-06$ \\
\hline Technetium-99 (Tc-99) & $\mu \mathrm{Ci} / \mathrm{mL}$ & $1 \mathrm{E}-04$ \\
\hline Iodine-129 (I-129) & $\mu \mathrm{Ci} / \mathrm{mL}$ & $5 \mathrm{E}-07$ \\
\hline Cesium-137 (Cs-137) & $\mu \mathrm{Ci} / \mathrm{mL}$ & $3 \mathrm{E}-06$ \\
\hline Europium-154 (Eu-154) & $\mu \mathrm{Ci} / \mathrm{mL}$ & $2 \mathrm{E}-05$ \\
\hline Uranium-232 (U-232) & $\mu \mathrm{Ci} / \mathrm{mL}$ & $1 \mathrm{E}-07$ \\
\hline Uranium-233 (U-233) & $\mu \mathrm{Ci} / \mathrm{mL}$ & $5 \mathrm{E}-07$ \\
\hline Uranium-234 (U-234) & $\mu \mathrm{Ci} / \mathrm{mL}$ & $5 \mathrm{E}-07$ \\
\hline Uranium-235 (U-235) & $\mu \mathrm{Ci} / \mathrm{mL}$ & $6 \mathrm{E}-07$ \\
\hline Uranium-236 (U-236) & $\mu \mathrm{Ci} / \mathrm{mL}$ & $5 \mathrm{E}-07$ \\
\hline Uranium-238(U-238) & $\mu \mathrm{Ci} / \mathrm{mL}$ & $6 \mathrm{E}-07$ \\
\hline Plutonium-238 (Pu-238) & $\mu \mathrm{Ci} / \mathrm{mL}$ & $4 \mathrm{E}-08$ \\
\hline Plutonium-239 (Pu-239) & $\mu \mathrm{Ci} / \mathrm{mL}$ & $3 \mathrm{E}-08$ \\
\hline Plutonium-240 (Pu-240) & $\mu \mathrm{Ci} / \mathrm{mL}$ & $3 \mathrm{E}-08$ \\
\hline Americium-241 (Am-241) & $\mu \mathrm{Ci} / \mathrm{mL}$ & 3E-08 \\
\hline
\end{tabular}

${ }^{a}$ DCGs are established in DOE Order 5400.5 and are defined as the concentration of a radionuclide that, under conditions of continuous exposure for one year by one exposure mode, would result in an effective dose equivalent of $100 \mathrm{mrem}(1 \mathrm{mSv})$.

${ }^{b}$ Because there are no DCGs for gross alpha and gross beta concentrations, the DCGs for the most restrictive alpha and beta emitters at the WVDP, americium-241 and strontium-90 (3E-08 and $1 \mathrm{E}-06 \mu \mathrm{Ci} / \mathrm{mL}$, respectively) are used as a conservative basis for comparison at locations for which there are no radionuclide-specific data, in which case a more appropriate DCG may be applied.

C- 8 


\section{Appendix C-2 Process Effluent Data}

C- 9 
Table C-2A contains a bolding convention devised to help the reader, when viewing the data, to quickly see the range of detectable measurements within a data series. A data series is a set of chemical or radionuclide measurements (e.g., gross alpha, gross beta, tritium) from a single location or from similar locations. Note that some tables contain data that should not be technically evaluated under this convention.

\section{Key to bolding convention:}

Results for each constituent constitute a single data series. If a radiological result is larger than the uncertainty term, the measurement is considered positive. Otherwise, a result is considered nondetectable. Chemical results preceded by "less than" (<) are considered nondetectable.

If all results in a data series are positive, the lowest and highest values are bolded. If a data series contains some positive results, the highest value is bolded. If all values in a data series are nondetectable, no values are bolded. 


\section{Table C-2A}

\section{Total Radioactivity (curies) of Liquid Effluents Released From Lagoon 3}

(WNSP001) in 2004

\begin{tabular}{|c|c|c|c|c|c|}
\hline Isotope & 1st Quarter & 2nd Quarter & 3rd Quarter & 4th Quarter & Annual Total \\
\hline Gross Alpha & $4.10 \pm 0.54 \mathrm{E}-04$ & $1.82 \pm 0.40 \mathrm{E}-04$ & $1.69 \pm 0.30 \mathrm{E}-04$ & $1.14 \pm 0.32 \mathrm{E}-04$ & $8.76 \pm 0.80 \mathrm{E}-04$ \\
\hline Gross Beta & $4.35 \pm 0.13 \mathrm{E}-03$ & $3.60 \pm 0.10 \mathrm{E}-03$ & $2.57 \pm 0.07 \mathrm{E}-03$ & $1.18 \pm 0.07 \mathrm{E}-03$ & $1.17 \pm 0.02 \mathrm{E}-02$ \\
\hline H-3 & $2.52 \pm 0.13 E-02$ & $2.02 \pm 0.11 \mathrm{E}-02$ & $2.14 \pm 0.11 \mathrm{E}-02$ & $1.59 \pm 0.10 \mathrm{E}-02$ & $8.27 \pm 0.22 \mathrm{E}-02$ \\
\hline C-14 & $0.99 \pm 3.97 \mathrm{E}-04$ & $-2.32 \pm 2.84 \mathrm{E}-04$ & $1.84 \pm 0.66 \mathrm{E}-04$ & $0.06 \pm 1.68 \mathrm{E}-04$ & $0.58 \pm 5.20 \mathrm{E}-04$ \\
\hline K-40 & $6.12 \pm 8.23 \mathrm{E}-04$ & $-5.17 \pm 5.72 \mathrm{E}-04$ & $0.95 \pm 4.59 \mathrm{E}-04$ & $3.79 \pm 4.59 \mathrm{E}-04$ & $0.57 \pm 1.19 \mathrm{E}-03$ \\
\hline Co-60 & $-0.64 \pm 4.63 \mathrm{E}-05$ & $-1.21 \pm 2.18 \mathrm{E}-05$ & $-2.11 \pm 3.23 \mathrm{E}-05$ & $0.41 \pm 1.74 \mathrm{E}-05$ & $-3.54 \pm 6.30 \mathrm{E}-05$ \\
\hline Sr-90 & $1.58 \pm 0.07 E-03$ & $1.39 \pm 0.05 \mathrm{E}-03$ & $9.24 \pm 0.52 \mathrm{E}-04$ & $5.37 \pm 0.44 \mathrm{E}-04$ & $4.43 \pm 0.11 \mathrm{E}-03$ \\
\hline Tc-99 & $2.80 \pm 0.28 \mathrm{E}-04$ & $3.32 \pm 0.28 \mathrm{E}-04$ & $6.11 \pm 0.35 \mathrm{E}-04$ & $2.35 \pm 0.27 \mathrm{E}-04$ & $1.46 \pm 0.06 \mathrm{E}-03$ \\
\hline I-129 & $0.83 \pm 1.59 \mathrm{E}-05$ & $1.30 \pm 1.56 \mathrm{E}-05$ & $3.06 \pm 1.20 \mathrm{E}-05$ & $4.46 \pm 1.98 \mathrm{E}-05$ & $9.65 \pm 3.22 \mathrm{E}-05$ \\
\hline Cs-137 & $1.44 \pm 0.11 E-03$ & $8.86 \pm 0.57 \mathrm{E}-04$ & $5.35 \pm 0.67 \mathrm{E}-04$ & $2.42 \pm 0.41 \mathrm{E}-04$ & $3.11 \pm 0.14 \mathrm{E}-03$ \\
\hline U-232 & $1.73 \pm 0.08 \mathrm{E}-04$ & $1.05 \pm 0.06 \mathrm{E}-04$ & $9.88 \pm 0.73 \mathrm{E}-05$ & $7.94 \pm 0.67 \mathrm{E}-05$ & $4.56 \pm 0.14 \mathrm{E}-04$ \\
\hline U-233/234 & $1.09 \pm 0.06 E-04$ & $7.20 \pm 0.51 \mathrm{E}-05$ & $6.19 \pm 0.55 \mathrm{E}-05$ & $5.52 \pm 0.56 \mathrm{E}-05$ & $2.99 \pm 0.11 \mathrm{E}-04$ \\
\hline U-235/236 & $6.61 \pm 1.53 \mathrm{E}-06$ & $5.55 \pm 1.44 \mathrm{E}-06$ & $3.33 \pm 1.37 \mathrm{E}-06$ & $3.34 \pm 1.42 \mathrm{E}-06$ & $1.88 \pm 0.29 \mathrm{E}-05$ \\
\hline U-238 & $8.77 \pm 0.55 E-05$ & $5.72 \pm 0.45 \mathrm{E}-05$ & $4.40 \pm 0.47 \mathrm{E}-05$ & $3.91 \pm 0.47 \mathrm{E}-05$ & $2.28 \pm 0.10 \mathrm{E}-04$ \\
\hline Total U (g) & $2.79 \pm 0.12 \mathrm{E}+02$ & $1.78 \pm 0.04 \mathrm{E}+02$ & $1.35 \pm 0.03 \mathrm{E}+02$ & $1.05 \pm 0.03 E+02$ & $6.98 \pm 0.13 \mathrm{E}+02$ \\
\hline Pu-238 & $2.74 \pm 0.94 \mathrm{E}-06$ & $9.56 \pm 5.11 \mathrm{E}-07$ & $8.54 \pm 6.34 \mathrm{E}-07$ & $3.00 \pm 0.92 \mathrm{E}-06$ & $7.55 \pm 1.55 \mathrm{E}-06$ \\
\hline $\mathrm{Pu}-239 / 240$ & $1.70 \pm 0.75 \mathrm{E}-06$ & $9.80 \pm 5.02 \mathrm{E}-07$ & $7.81 \pm 5.84 \mathrm{E}-07$ & $2.68 \pm 0.88 \mathrm{E}-06$ & $6.14 \pm 1.39 \mathrm{E}-06$ \\
\hline Am-241 & $2.38 \pm 0.93 \mathrm{E}-06$ & $1.16 \pm 0.45 \mathrm{E}-06$ & $7.84 \pm 5.37 \mathrm{E}-07$ & $4.11 \pm 1.04 \mathrm{E}-06$ & $8.44 \pm 1.56 \mathrm{E}-06$ \\
\hline
\end{tabular}

Note: Bolding convention applied to these data. See page C-10. 
Table C-2B

\section{Comparison of 2004 Lagoon 3 (WNSP001) Liquid Effluent Radioactivity Concentrations With U.S. Department of Energy Guidelines}

\begin{tabular}{|c|c|c|c|c|c|}
\hline Isotope $^{a}$ & Discharge Activity $^{b}$ & Radioactivity $^{\mathbf{c}}$ & Concentration & DCG & $\%$ of DCG \\
\hline & $(\mathrm{Ci})$ & (Becquerels) & $(\mu \mathrm{Ci} / \mathrm{mL})$ & $(\mu \mathrm{Ci} / \mathrm{mL})$ & \\
\hline Gross Alpha & $8.76 \pm 0.80 \mathrm{E}-04$ & $3.24 \pm 0.30 \mathrm{E}+07$ & $1.55 \pm 0.14 \mathrm{E}-08$ & $\mathrm{NA}^{\mathrm{d}}$ & NA \\
\hline Gross Beta & $1.17 \pm 0.02 \mathrm{E}-02$ & $4.33 \pm 0.07 \mathrm{E}+08$ & $2.07 \pm 0.03 \mathrm{E}-07$ & $\mathrm{NA}^{\mathrm{d}}$ & NA \\
\hline H-3 & $8.27 \pm 0.22 \mathrm{E}-02$ & $3.06 \pm 0.08 \mathrm{E}+09$ & $1.46 \pm 0.04 \mathrm{E}-06$ & $2 \mathrm{E}-03$ & 0.07 \\
\hline C-14 & $0.58 \pm 5.20 \mathrm{E}-04$ & $0.21 \pm 1.92 \mathrm{E}+07$ & $1.02 \pm 9.19 \mathrm{E}-09$ & 7E-05 & $<0.01$ \\
\hline K-40 & $0.57 \pm 1.19 \mathrm{E}-03$ & $2.11 \pm 4.42 \mathrm{E}+07$ & $1.01 \pm 2.11 \mathrm{E}-08$ & $\mathrm{NA}^{\mathrm{e}}$ & NA \\
\hline Co-60 & $-3.54 \pm 6.30 \mathrm{E}-05$ & $-1.31 \pm 2.33 \mathrm{E}+06$ & $-0.63 \pm 1.11 \mathrm{E}-09$ & $5 \mathrm{E}-06$ & $<0.02$ \\
\hline Sr-90 & $4.43 \pm 0.11 \mathrm{E}-03$ & $1.64 \pm 0.04 \mathrm{E}+08$ & $7.83 \pm 0.19 \mathrm{E}-08$ & $1 \mathrm{E}-06$ & 7.83 \\
\hline Tc-99 & $1.46 \pm 0.06 \mathrm{E}-03$ & $5.39 \pm 0.22 \mathrm{E}+07$ & $2.58 \pm 0.11 \mathrm{E}-08$ & $1 \mathrm{E}-04$ & 0.03 \\
\hline I-129 & $9.65 \pm 3.22 \mathrm{E}-05$ & $3.57 \pm 1.19 \mathrm{E}+06$ & $1.70 \pm 0.57 \mathrm{E}-09$ & $5 \mathrm{E}-07$ & 0.34 \\
\hline Cs-137 & $3.11 \pm 0.14 \mathrm{E}-03$ & $1.15 \pm 0.05 \mathrm{E}+08$ & $5.49 \pm 0.26 \mathrm{E}-08$ & 3E-06 & 1.83 \\
\hline U-232 ${ }^{\mathrm{f}}$ & $4.56 \pm 0.14 \mathrm{E}-04$ & $1.69 \pm 0.05 \mathrm{E}+07$ & $8.06 \pm 0.25 \mathrm{E}-09$ & $1 \mathrm{E}-07$ & 8.06 \\
\hline $\mathrm{U}-233 / 234^{\mathrm{f}}$ & $2.99 \pm 0.11 \mathrm{E}-04$ & $1.10 \pm 0.04 \mathrm{E}+07$ & $5.27 \pm 0.20 \mathrm{E}-09$ & $5 \mathrm{E}-07$ & 1.05 \\
\hline $\mathrm{U}-235 / 236^{\mathrm{f}}$ & $1.88 \pm 0.29 \mathrm{E}-05$ & $6.97 \pm 1.06 \mathrm{E}+05$ & $3.33 \pm 0.51 \mathrm{E}-10$ & $5 \mathrm{E}-07^{\mathrm{g}}$ & 0.07 \\
\hline$U-238^{f}$ & $2.28 \pm 0.10 \mathrm{E}-04$ & $8.44 \pm 0.36 \mathrm{E}+06$ & $4.03 \pm 0.17 \mathrm{E}-09$ & $6 \mathrm{E}-07$ & 0.67 \\
\hline Pu-238 & $7.55 \pm 1.55 \mathrm{E}-06$ & $2.79 \pm 0.57 \mathrm{E}+05$ & $1.33 \pm 0.27 \mathrm{E}-10$ & 4E-08 & 0.33 \\
\hline Pu-239/240 & $6.14 \pm 1.39 \mathrm{E}-06$ & $2.27 \pm 0.51 \mathrm{E}+05$ & $1.08 \pm 0.25 \mathrm{E}-10$ & 3E-08 & 0.36 \\
\hline Am-241 & $8.44 \pm 1.56 \mathrm{E}-06$ & $3.12 \pm 0.58 \mathrm{E}+05$ & $1.49 \pm 0.28 \mathrm{E}-10$ & 3E-08 & 0.50 \\
\hline Total \% of DCGs & & & & & 21.18 \\
\hline
\end{tabular}

NA - Not applicable

${ }^{a}$ Half-lives are listed in Table $K-1$ 무

${ }^{b}$ Total volume released: $5.66 \mathrm{E}+10 \mathrm{~mL}(1.50 \mathrm{E}+07 \mathrm{gal})$

c 1 curie $(\mathrm{Ci})=3.7 \mathrm{E}+10$ becquerels $(\mathrm{Bq}) ; 1 \mathrm{~Bq}=2.7 \mathrm{E}-11 \mathrm{Ci}$

${ }^{d}$ DOE-derived concentration guides (DCGs) do not exist for indicator parameters gross alpha and gross beta.

${ }^{e}$ Potassium-40 activity is not applicable because of its natural origin.

${ }^{f}$ Total $U(\mathrm{~g})=6.98 \pm 0.13 E+02$; Average $U(\mu \mathrm{g} / \mathrm{mL})=1.23 \pm 0.02 E-02$

${ }^{g}$ DCG for $U-236$ is used for this comparison. 
Table C-2C

2004 SPDES Results for Outfall 001 (WNSP001):

Water Quality

\begin{tabular}{|c|c|c|c|c|c|c|c|c|}
\hline & \multicolumn{2}{|c|}{$\begin{array}{l}\text { Ammonia } \\
(\mathrm{mg} / \mathrm{L})\end{array}$} & \multicolumn{2}{|c|}{$\begin{array}{c}\text { BOD }_{\mathbf{5}} \text { day } \\
(\mathrm{mg} / \mathrm{L})\end{array}$} & \multicolumn{2}{|c|}{$\begin{array}{c}\text { Cyanide } \\
\text { (amenable to chlorination) } \\
(\mathrm{mg} / \mathrm{L})\end{array}$} & \multicolumn{2}{|c|}{$\begin{array}{l}\text { Discharge Rate } \\
\text { (MGD) }\end{array}$} \\
\hline Permit limit & \multicolumn{2}{|c|}{ Monitor } & \multicolumn{2}{|c|}{$\begin{array}{l}10.0 \mathrm{mg} / \mathrm{L} \text { daily } \\
\text { maximum }\end{array}$} & \multicolumn{2}{|c|}{$\begin{array}{l}0.022 \mathrm{mg} / \mathrm{L} \text { daily } \\
\text { maximum }\end{array}$} & \multicolumn{2}{|c|}{ Monitor } \\
\hline Month & Avg & Max & Avg & Max & Avg & Max & Avg & Max \\
\hline January & 0.24 & 0.33 & $<2.4$ & 2.8 & $<0.010$ & $<0.010$ & 0.317 & 0.349 \\
\hline February $^{a}$ & -- & -- & -- & -- & -- & -- & -- & -- \\
\hline March & 0.14 & 0.15 & $<2.0$ & $<2.0$ & $<0.010$ & $<0.010$ & 0.341 & 0.379 \\
\hline April & $<0.05$ & $<0.05$ & $<2.0$ & $<2.0$ & $<0.010$ & $<0.010$ & 0.193 & 0.274 \\
\hline May & 0.061 & 0.091 & $<1.3$ & 2.1 & $<0.003$ & $<0.003$ & 0.176 & 0.288 \\
\hline June & 0.12 & 0.17 & $<0.57$ & $<0.57$ & $<0.0030$ & $<0.0030$ & 0.262 & 0.335 \\
\hline July $^{a}$ & -- & -- & -- & -- & -- & -- & -- & -- \\
\hline August & 0.028 & 0.034 & $<2.0$ & $<2.0$ & $<0.003$ & $<0.003$ & 0.271 & 0.327 \\
\hline September & $<0.019$ & 0.025 & $<2.2$ & 2.3 & $<0.003$ & $<0.003$ & 0.232 & 0.307 \\
\hline October $^{a}$ & -- & -- & -- & -- & -- & -- & -- & -- \\
\hline November $^{a}$ & -- & -- & -- & -- & -- & -- & -- & -- \\
\hline December & 0.075 & 0.090 & $<2.0$ & $<2.0$ & $<0.003$ & $<0.003$ & 0.249 & 0.277 \\
\hline
\end{tabular}

\begin{tabular}{|c|c|c|c|c|c|c|}
\hline & \multicolumn{2}{|c|}{$\begin{array}{l}\text { Nitrate (as N) } \\
\quad(\mathrm{mg} / \mathrm{L})\end{array}$} & \multicolumn{2}{|c|}{$\begin{array}{l}\text { Nitrite (as N) } \\
(\mathrm{mg} / \mathrm{L})\end{array}$} & \multicolumn{2}{|c|}{$\begin{array}{l}\text { Oil \& Grease } \\
\quad(\mathrm{mg} / \mathrm{L})\end{array}$} \\
\hline Permit limit & \multicolumn{2}{|c|}{ Monitor } & \multicolumn{2}{|c|}{$\begin{array}{l}0.1 \mathrm{mg} / \mathrm{L} \text { daily } \\
\text { maximum }\end{array}$} & \multicolumn{2}{|c|}{$\begin{array}{l}15.0 \mathrm{mg} / \mathrm{L} \text { daily } \\
\text { maximum }\end{array}$} \\
\hline Month & Avg & Max & Avg & Max & Avg & Max \\
\hline January & 0.92 & 1.0 & $<0.05$ & $<0.05$ & $<5.0$ & $<5.0$ \\
\hline February $^{a}$ & -- & -- & -- & -- & -- & -- \\
\hline March & 1.2 & 1.2 & $<0.05$ & $<0.05$ & $<5.0$ & $<5.0$ \\
\hline April & 1.4 & 1.5 & $<0.05$ & $<0.05$ & $<5.0$ & $<5.0$ \\
\hline May & 0.8 & 1.0 & $<0.05$ & 0.06 & $<1.9$ & $<1.9$ \\
\hline June & 0.46 & 0.49 & $<0.05$ & $<0.05$ & $<1.9$ & $<1.9$ \\
\hline July $^{a}$ & -- & -- & -- & -- & -- & -- \\
\hline August & $<0.036$ & $<0.036$ & $<0.05$ & $<0.05$ & $<1.9$ & $<1.9$ \\
\hline September & $<0.036$ & $<0.036$ & $<0.05$ & $<0.05$ & $<1.9$ & 1.9 \\
\hline October $^{a}$ & -- & -- & -- & -- & -- & - \\
\hline November ${ }^{a}$ & -- & -- & -- & -- & -- & -- \\
\hline December & 0.10 & 0.10 & $<0.05$ & $<0.05$ & $<2.7$ & $<2.7$ \\
\hline
\end{tabular}

Note: No results exceeded the permit limits.

${ }^{a}$ No discharge this month 
Table C-2C (concluded)

2004 SPDES Results for Outfall 001 (WNSP001):

Water Quality

\begin{tabular}{|c|c|c|c|c|c|c|c|c|}
\hline \multirow{3}{*}{$\begin{array}{l}\text { Permit limit } \\
\text { Month }\end{array}$} & \multicolumn{2}{|c|}{$\begin{array}{c}\mathbf{p H} \\
\text { (standard units) }\end{array}$} & \multicolumn{2}{|c|}{$\begin{array}{c}\text { Solids } \\
\text { Settleable } \\
(\mathrm{mL} / \mathrm{L})\end{array}$} & \multicolumn{2}{|c|}{$\begin{array}{c}\text { Solids } \\
\text { Total Dissolved } \\
(\mathrm{m} / \mathrm{L})\end{array}$} & \multicolumn{2}{|c|}{$\begin{array}{c}\text { Solids } \\
\text { Total Suspended } \\
(\mathrm{mg} / \mathrm{L})\end{array}$} \\
\hline & \multicolumn{2}{|c|}{$6.5-8.5$} & \multicolumn{2}{|c|}{$\begin{array}{l}0.30 \mathrm{~mL} / \mathrm{L} \text { daily } \\
\text { maximum }\end{array}$} & \multicolumn{2}{|c|}{ Monitor } & \multicolumn{2}{|c|}{$\begin{array}{c}45.0 \mathrm{mg} / \mathrm{L} \text { daily maximum } \\
30.0 \text { daily average }\end{array}$} \\
\hline & Min & Max & Avg & Max & Avg & Max & Avg & Max \\
\hline January & 7.1 & 7.7 & $<0.1$ & $<0.1$ & 740 & 746 & $<3.0$ & 4.0 \\
\hline February $^{a}$ & -- & -- & - & -- & -- & -- & -- & -- \\
\hline March & 7.3 & 7.3 & $<0.1$ & $<0.1$ & 728 & 740 & $<2.0$ & $<2.0$ \\
\hline April & 7.6 & 8.2 & $<0.1$ & $<0.1$ & 768 & 789 & $<2.0$ & $<2.0$ \\
\hline May & 7.4 & 8.1 & $<0.1$ & $<0.1$ & 713 & 733 & $43.8^{\mathrm{b}}$ & $78.5^{\mathrm{b}}$ \\
\hline June & 7.5 & 7.8 & $<0.1$ & $<0.1$ & 698 & 717 & $<1.0$ & $<1.0$ \\
\hline July $^{a}$ & -- & -- & - & -- & - & - & -- & -- \\
\hline August & 7.6 & 7.8 & $<0.1$ & $<0.1$ & 759 & 775 & $<6.5$ & 9.0 \\
\hline September & 7.8 & 8.0 & $<0.1$ & $<0.1$ & 738 & 741 & 10.5 & 14.0 \\
\hline October $^{a}$ & -- & -- & - & -- & -- & -- & -- & -- \\
\hline November $^{a}$ & -- & -- & - & -- & -- & -- & -- & -- \\
\hline December & 7.5 & 7.7 & $<0.1$ & $<0.1$ & 758 & 762 & $<4.0$ & $<4.0$ \\
\hline
\end{tabular}

\begin{tabular}{|c|c|c|c|c|c|c|}
\hline & \multicolumn{2}{|c|}{$\begin{array}{c}\text { Sulfate (as S) } \\
(\mathrm{mg} / \mathrm{L})\end{array}$} & \multicolumn{2}{|c|}{$\begin{array}{c}\text { Sulfide (as S) } \\
\text { Dissolved } \\
(\mathrm{mg} / \mathrm{L})\end{array}$} & \multicolumn{2}{|c|}{$\begin{array}{c}\text { Surfactants } \\
\text { as LAS } \\
(\mathrm{mg} / \mathrm{L})\end{array}$} \\
\hline Permit limit & \multicolumn{2}{|c|}{ Monitor } & \multicolumn{2}{|c|}{$\begin{array}{l}0.4 \mathrm{mg} / \mathrm{L} \text { daily } \\
\text { maximum }\end{array}$} & \multicolumn{2}{|c|}{$\begin{array}{l}0.4 \mathrm{mg} / \mathrm{L} \text { daily } \\
\text { maximum }\end{array}$} \\
\hline Month & Avg & Max & Avg & Max & Avg & Max \\
\hline January & 40 & 57 & $<0.2$ & $<0.2$ & $<0.1$ & 0.1 \\
\hline February $^{a}$ & -- & -- & - & -- & -- & -- \\
\hline March & 34 & 34 & $<0.2$ & $<0.2$ & $<0.1$ & $<0.1$ \\
\hline April & 36 & 36 & $<0.2$ & $<0.2$ & $<0.1$ & $<0.1$ \\
\hline May & 28 & 30 & 0.08 & 0.1 & $<0.03$ & 0.04 \\
\hline June & 39 & 43 & 0.1 & 0.1 & 0.04 & 0.04 \\
\hline July $^{a}$ & -- & -- & - & -- & -- & -- \\
\hline August & 58 & 63 & $<0.04$ & $<0.04$ & 0.07 & 0.08 \\
\hline September & 57 & 58 & $<0.04$ & $<0.04$ & 0.04 & 0.05 \\
\hline October $^{a}$ & -- & -- & - & -- & -- & -- \\
\hline November $^{a}$ & - & -- & - & -- & -- & -- \\
\hline December & 66 & 69 & $<0.04$ & 0.04 & 0.06 & 0.07 \\
\hline
\end{tabular}

a No discharge this month

${ }^{b}$ Exceedance of the permit limits for TSS in May 2004 
Table C-2D

2004 SPDES Results for Outfall 001 (WNSP001): Metals

\begin{tabular}{|c|c|c|c|c|c|c|c|c|}
\hline \multirow{3}{*}{$\begin{array}{l}\text { Permit limit } \\
\text { Month }\end{array}$} & \multicolumn{2}{|c|}{$\begin{array}{l}\text { Aluminum } \\
\text { Total } \\
(\mathrm{m} / \mathrm{L})\end{array}$} & \multicolumn{2}{|c|}{$\begin{array}{c}\text { Arsenic } \\
\text { Dissolved } \\
(\mathrm{mg} / \mathrm{L})\end{array}$} & \multicolumn{2}{|c|}{$\begin{array}{c}\text { Cadmium } \\
\text { Total Recoverable } \\
(\mathrm{mg} / \mathrm{L})\end{array}$} & \multicolumn{2}{|c|}{$\begin{array}{c}\text { Cobalt } \\
\text { Total Recoverable } \\
(\mathrm{mg} / \mathrm{L})\end{array}$} \\
\hline & $\begin{array}{r}14.0 \mathrm{mg} / \mathrm{L} \\
7.0 \mathrm{mg} / \mathrm{L}\end{array}$ & $\begin{array}{l}\text { maximum; } \\
\text { average }\end{array}$ & $\begin{array}{r}0.15 \mathrm{r} \\
\mathrm{me}\end{array}$ & $\begin{array}{l}\text { daily } \\
\text { Im }\end{array}$ & $\begin{array}{r}0.002 \\
\mathrm{ma}\end{array}$ & $\begin{array}{l}\text { daily } \\
\text { um }\end{array}$ & $\begin{array}{r}0.005 \\
\mathrm{~m}\end{array}$ & $\begin{array}{l}\text { daily } \\
\text { m }\end{array}$ \\
\hline & Avg & Max & Avg & Max & Avg & Max & Avg & Max \\
\hline January & $<0.275$ & 0.349 & 0.0020 & 0.0022 & $<0.001$ & $<0.001$ & $<0.004$ & $<0.004$ \\
\hline February $^{a}$ & -- & -- & -- & -- & - & -- & -- & -- \\
\hline March & 0.302 & 0.314 & 0.0014 & 0.0015 & $<0.001$ & $<0.001$ & $<0.004$ & $<0.004$ \\
\hline April & $<0.200$ & $<0.200$ & 0.0018 & 0.0018 & $<0.001$ & $<0.001$ & $<0.004$ & $<0.004$ \\
\hline May & 2.3 & 4.2 & 0.0018 & 0.0018 & $<0.0006$ & $<0.0006$ & $<0.003$ & 0.004 \\
\hline June & 0.22 & 0.259 & 0.0021 & 0.0021 & $<0.0006$ & $<0.0006$ & $<0.002$ & $<0.002$ \\
\hline July $^{a}$ & -- & -- & -- & -- & - & -- & -- & -- \\
\hline August & 0.112 & 0.139 & 0.0022 & 0.0022 & $<0.001$ & $<0.001$ & $<0.002$ & $<0.002$ \\
\hline September & 0.174 & 0.199 & 0.002 & 0.002 & $<0.0006$ & $<0.0006$ & $<0.002$ & $<0.002$ \\
\hline October $^{a}$ & -- & -- & -- & -- & - & -- & -- & -- \\
\hline November $^{a}$ & -- & -- & -- & -- & - & -- & -- & -- \\
\hline December & 0.253 & 0.294 & 0.0025 & 0.0026 & $<0.0006$ & $<0.0006$ & $<0.002$ & $<0.002$ \\
\hline
\end{tabular}

\begin{tabular}{|c|c|c|c|c|c|c|c|c|}
\hline \multirow{3}{*}{$\begin{array}{l}\text { Permit limit } \\
\text { Month }\end{array}$} & \multirow{2}{*}{\multicolumn{2}{|c|}{$\begin{array}{c}\text { Chromium } \\
\text { Total Recoverable } \\
(\mathrm{mg} / \mathrm{L})\end{array}$}} & \multirow{2}{*}{\multicolumn{2}{|c|}{$\begin{array}{c}\text { Chromium VI } \\
\text { Total Recoverable } \\
(\mathrm{mg} / \mathrm{L})\end{array}$}} & \multirow{2}{*}{\multicolumn{2}{|c|}{$\begin{array}{c}\begin{array}{c}\text { Copper } \\
\text { Dissolved } \\
(\mathrm{mg} / \mathrm{L})\end{array} \\
\text { Monitor }\end{array}$}} & \multirow{2}{*}{\multicolumn{2}{|c|}{$\begin{array}{c}\text { Copper } \\
\text { Total Recoverable } \\
(\mathrm{mg} / \mathrm{L})\end{array}$}} \\
\hline & & & & & & & & \\
\hline & Avg & Max & Avg & Max & Avg & Max & Avg & Max \\
\hline January & $<0.002$ & $<0.002$ & $<0.010$ & $<0.010$ & $<0.010$ & $<0.010$ & $<0.010$ & $<0.010$ \\
\hline February $^{a}$ & -- & -- & -- & -- & - & -- & -- & -- \\
\hline March & $<0.002$ & $<0.002$ & $<0.010$ & $<0.010$ & $<0.010$ & $<0.010$ & $<0.010$ & $<0.010$ \\
\hline April & $<0.002$ & $<0.002$ & $<0.010$ & $<0.010$ & $<0.010$ & $<0.010$ & $<0.010$ & $<0.010$ \\
\hline May & $<0.003$ & 0.004 & $<0.009$ & $<0.010$ & $<0.0024$ & $<0.0024$ & 0.0035 & 0.0045 \\
\hline June & $<0.0009$ & $<0.0009$ & $<0.008$ & $<0.008$ & $<0.0024$ & $<0.0024$ & $<0.0024$ & $<0.0024$ \\
\hline$J_{u l y}{ }^{a}$ & -- & -- & -- & -- & - & -- & -- & -- \\
\hline August & $<0.0009$ & $<0.0009$ & $<0.008$ & $<0.008$ & 0.0028 & 0.0028 & 0.0036 & 0.0040 \\
\hline September & $<0.0009$ & $<0.0009$ & $<0.008$ & $<0.008$ & 0.0050 & 0.0068 & $<0.0036$ & 0.0047 \\
\hline October $^{a}$ & -- & -- & -- & -- & - & -- & -- & -- \\
\hline November $^{a}$ & -- & -- & -- & -- & - & -- & -- & -- \\
\hline December & $<0.001$ & 0.001 & $<0.009$ & $<0.010$ & $<0.0043$ & $<0.0043$ & 0.0037 & 0.004 \\
\hline
\end{tabular}

Note: No results exceeded the permit limits.

a No discharge this month 
Table C-2D (concluded)

2004 SPDES Results for Outfall 001 (WNSP001):

Metals

\begin{tabular}{|c|c|c|c|c|c|c|c|c|c|c|}
\hline & \multicolumn{2}{|c|}{$\begin{array}{c}\text { Iron } \\
\text { Total } \\
(\mathrm{mg} / \mathrm{L})\end{array}$} & \multicolumn{2}{|c|}{$\begin{array}{c}\text { Lead } \\
\text { Total Recoverable } \\
(\mathrm{mg} / \mathrm{L})\end{array}$} & \multicolumn{2}{|c|}{$\begin{array}{l}\text { Manganese } \\
\text { Total } \\
(\mathrm{mg} / \mathrm{L})\end{array}$} & \multicolumn{2}{|c|}{$\begin{array}{c}\text { Mercury, Total } \\
\text { (per EPA Method 245.1) } \\
(\mathrm{mg} / \mathrm{L})\end{array}$} & \multicolumn{2}{|c|}{$\begin{array}{c}\text { Mercury, Total } \\
\text { (per EPA Method 1631) } \\
(\mu \mathrm{g} / \mathrm{L})\end{array}$} \\
\hline Permit limit & \multicolumn{2}{|c|}{ Monitor } & \multicolumn{2}{|c|}{$\begin{array}{l}0.006 \mathrm{mg} / \mathrm{L} \text { daily } \\
\text { maximum }\end{array}$} & \multicolumn{2}{|c|}{$\begin{array}{l}2.0 \mathrm{mg} / \mathrm{L} \text { daily } \\
\text { maximum }\end{array}$} & \multicolumn{2}{|c|}{$\begin{array}{c}0.0002 \mathrm{mg} / \mathrm{L} \text { daily } \\
\text { maximum }\end{array}$} & \multicolumn{2}{|c|}{ Monitor } \\
\hline Month & Avg & Max & Avg & Max & Avg & Max & Avg & Max & Avg & Max \\
\hline January & 0.138 & 0.164 & $<0.0005$ & 0.0006 & 0.127 & 0.206 & $<0.0002$ & $<0.0002$ & 0.0374 & 0.0439 \\
\hline February $^{a}$ & - & - & -- & -- & - & - & - & - & - & - \\
\hline March & 0.263 & & $<0.0005$ & $<0.0005$ & 0.029 & 0.030 & $<0.0002$ & $<0.0002$ & 0.0191 & 0.0203 \\
\hline April & 0.118 & 143 & $<0.0005$ & $<0.0005$ & 0.013 & 0.017 & $<0.000$ & $<0.0002$ & 0.00895 & 0.00961 \\
\hline May & 2.43 & 4.61 & $<0.001$ & 0.002 & 0.074 & 0.11 & $<0.0002$ & $<0.0002$ & 0.01045 & 0.0114 \\
\hline June & 0.268 & 0.324 & 0.0004 & 0.0004 & 0.14 & 0.15 & $<0.0002$ & $<0.0002$ & 0.00576 & 0.00648 \\
\hline July $^{a}$ & - & - & -- & -- & - & - & - & - & - & - \\
\hline August & 0.116 & 0.141 & $<0.0003$ & 0.0004 & 0.040 & 0.043 & $<0.0002$ & $<0.0002$ & 0.00470 & 0.00558 \\
\hline September & 0.168 & 0.178 & 0.0005 & 0.0005 & 0.10 & 0.13 & $<0.0002$ & $<0.0002$ & 0.00571 & 0.00634 \\
\hline October $^{a}$ & - & - & -- & -- & - & - & - & - & -- & - \\
\hline November $^{a}$ & - & - & -- & -- & - & - & - & - & - & - \\
\hline December & 0.325 & 0.389 & 0.0008 & 0.0008 & 0.017 & 0.017 & $<0.0002$ & $<0.0002$ & 0.0152 & 0.0170 \\
\hline
\end{tabular}

\begin{tabular}{|c|c|c|c|c|c|c|c|c|}
\hline \multirow{3}{*}{$\begin{array}{l}\text { Permit limit } \\
\text { Month }\end{array}$} & \multirow{2}{*}{\multicolumn{2}{|c|}{$\begin{array}{c}\text { Nickel } \\
\text { Total Recoverable } \\
(\mathrm{mg} / \mathrm{L})\end{array}$}} & \multirow{2}{*}{\multicolumn{2}{|c|}{$\begin{array}{c}\text { Selenium } \\
\text { Total Recoverable } \\
(\mathrm{mg} / \mathrm{L})\end{array}$}} & \multirow{2}{*}{\multicolumn{2}{|c|}{$\begin{array}{c}\text { Vanadium } \\
\text { Total Recoverable } \\
(\mathrm{mg} / \mathrm{L})\end{array}$}} & \multirow{2}{*}{\multicolumn{2}{|c|}{$\begin{array}{c}\text { Zinc } \\
\text { Total Recoverable } \\
(\mathrm{mg} / \mathrm{L})\end{array}$}} \\
\hline & & & & & & & & \\
\hline & Avg & Max & Avg & Max & Avg & Max & Avg & Max \\
\hline January & $<0.010$ & $<0.010$ & $<0.001$ & 0.001 & $<0.010$ & $<0.010$ & $<0.010$ & $<0.010$ \\
\hline February $^{a}$ & - & - & -- & -- & - & - & - & - \\
\hline March & $<0.010$ & $<0.010$ & $<0.001$ & $<0.001$ & $<0.010$ & $<0.010$ & $<0.010$ & $<0.010$ \\
\hline April & $<0.010$ & $<0.010$ & $<0.001$ & $<0.001$ & $<0.010$ & $<0.010$ & $<0.010$ & $<0.010$ \\
\hline May & $<0.0037$ & 0.0058 & $<0.0004$ & $<0.0004$ & 0.006 & 0.011 & 0.012 & 0.018 \\
\hline June & $<0.0016$ & $<0.0016$ & $<0.0004$ & $<0.0004$ & $<0.00098$ & $<0.00098$ & $<0.0069$ & 0.0081 \\
\hline July $^{a}$ & - & - & -- & -- & - & - & - & - \\
\hline August & 0.002 & 0.002 & $<0.0004$ & $<0.0004$ & $<0.0011$ & $<0.0011$ & $<0.0064$ & 0.0071 \\
\hline September & 0.0024 & 0.0027 & $<0.0004$ & $<0.0004$ & $<0.0011$ & $<0.0011$ & $<0.0056$ & $<0.0056$ \\
\hline October ${ }^{a}$ & - & - & -- & -- & - & - & - & - \\
\hline November $^{a}$ & - & -- & -- & -- & -- & -- & -- & -- \\
\hline December & 0.0026 & 0.0026 & $<0.0004$ & $<0.0004$ & $<0.0011$ & $<0.0011$ & 0.0071 & 0.0071 \\
\hline
\end{tabular}

Note: No results exceeded the permit limits.

${ }^{a}$ No discharge this month 
Table C-2E

2004 SPDES Results for Outfall 001 (WNSP001): Organics

SEMIVOLATILES

\begin{tabular}{|c|c|c|c|c|c|c|c|c|}
\hline \multirow{3}{*}{$\begin{array}{l}\text { Permit limit } \\
\text { Month }\end{array}$} & \multirow{2}{*}{\multicolumn{2}{|c|}{$\begin{array}{c}\text { 3,3-Dichlorobenzidine } \\
(\mathrm{mg} / \mathrm{L})\end{array}$}} & \multirow{2}{*}{\multicolumn{2}{|c|}{$\begin{array}{c}\text { Hexachlorobenzene } \\
(\mathrm{mg} / \mathrm{L})\end{array}$}} & \multirow{2}{*}{\multicolumn{2}{|c|}{$\begin{array}{c}\begin{array}{c}\text { Heptachlor } \\
(\mathrm{mg} / \mathrm{L})\end{array} \\
0.00001 \mathrm{mg} / \mathrm{L} \text { daily } \\
\text { maximum }\end{array}$}} & \multirow{2}{*}{\multicolumn{2}{|c|}{$\begin{array}{c}\text { Tributyl Phosphate } \\
(\mathrm{mg} / \mathrm{L})\end{array}$}} \\
\hline & & & & & & & & \\
\hline & Avg & Max & Avg & Max & Avg & Max & Avg & Max \\
\hline January & $<0.0099$ & $<0.0099$ & $<0.01$ & $<0.01$ & $<0.000009$ & $<0.000009$ & $<0.010$ & $<0.010$ \\
\hline February $^{a}$ & - & -- & -- & -- & -- & - & -- & -- \\
\hline March & $<0.0099$ & $<0.0099$ & $<0.01$ & $<0.01$ & $<0.000009$ & $<0.000009$ & $<0.010$ & $<0.010$ \\
\hline April & $<0.0099$ & $<0.0099$ & $<0.01$ & $<0.01$ & $<0.000006$ & $<0.000009$ & $<0.010$ & $<0.010$ \\
\hline May & $<0.007$ & $<0.007$ & $<0.007$ & $<0.007$ & $<0.000003$ & 0.000003 & $<0.0014$ & $<0.0014$ \\
\hline June & $<0.007$ & $<0.007$ & $<0.007$ & $<0.007$ & $<0.0000007$ & $<0.0000008$ & $<0.0014$ & $<0.0014$ \\
\hline July $^{a}$ & - & -- & -- & -- & -- & - & -- & -- \\
\hline August & $<0.007$ & $<0.007$ & $<0.007$ & $<0.007$ & $<0.0000008$ & $<0.0000008$ & $<0.0014$ & $<0.0014$ \\
\hline September & $<0.007$ & $<0.007$ & $<0.007$ & $<0.007$ & $<0.000001$ & $<0.000001$ & $<0.0014$ & $<0.0014$ \\
\hline October $^{a}$ & - & -- & -- & -- & -- & - & -- & -- \\
\hline November $^{a}$ & -- & -- & -- & -- & -- & -- & -- & -- \\
\hline December & $<0.007$ & $<0.007$ & $<0.007$ & $<0.007$ & $<0.0000008$ & $<0.0000008$ & $<0.0013$ & $<0.0013$ \\
\hline
\end{tabular}

VOLATILES

\begin{tabular}{|c|c|c|c|c|c|c|}
\hline & \multicolumn{2}{|c|}{$\begin{array}{c}\text { 2-Butanone } \\
(\mathrm{mg} / \mathrm{L})\end{array}$} & \multicolumn{2}{|c|}{$\begin{array}{l}\text { Xylene } \\
(\mathrm{mg} / \mathrm{L})\end{array}$} & \multicolumn{2}{|c|}{$\begin{array}{c}\text { Alpha-BHC } \\
(\mathrm{mg} / \mathrm{L})\end{array}$} \\
\hline Permit limit & $\begin{array}{r}0.5 \mathrm{r} \\
\mathrm{m}\end{array}$ & daily & $\begin{array}{r}0.05 \\
\mathrm{~m}\end{array}$ & daily & $\begin{array}{r}0.00001 \\
\max \end{array}$ & $\begin{array}{l}\mathrm{g} / \mathrm{L} \text { daily } \\
\text { lum }\end{array}$ \\
\hline Month & Avg & Max & Avg & Max & Avg & Max \\
\hline January & $<0.01$ & $<0.01$ & $<0.01$ & $<0.01$ & $<0.000009$ & $<0.000009$ \\
\hline February $^{a}$ & - & -- & -- & -- & -- & - \\
\hline March & $<0.01$ & $<0.01$ & $<0.01$ & $<0.01$ & $<0.000009$ & $<0.000009$ \\
\hline April & $<0.01$ & $<0.01$ & $<0.01$ & $<0.01$ & $<0.000009$ & $<0.000009$ \\
\hline May & $<0.005$ & $<0.005$ & $<0.007$ & $<0.007$ & $<0.000002$ & $<0.000002$ \\
\hline June & $<0.005$ & $<0.005$ & $<0.007$ & $<0.007$ & $<0.000001$ & $<0.000001$ \\
\hline July $^{a}$ & - & -- & -- & -- & -- & - \\
\hline August & $<0.005$ & $<0.005$ & $<0.007$ & $<0.007$ & $<0.000001$ & $<0.000001$ \\
\hline September & $<0.005$ & $<0.005$ & $<0.007$ & $<0.007$ & $<0.000002$ & $<0.000002$ \\
\hline October $^{a}$ & - & -- & -- & -- & -- & - \\
\hline November $^{a}$ & - & -- & -- & -- & -- & - \\
\hline December & $<0.005$ & $<0.005$ & $<0.007$ & $<0.007$ & $<0.000001$ & $<0.000001$ \\
\hline
\end{tabular}

Note: No results exceeded the permit limits.

a No discharge this month 
Table C-2F

2004 SPDES Results for Outfall 007 (WNSP007):

Water Quality and Iron

\begin{tabular}{|c|c|c|c|c|c|c|c|c|c|c|}
\hline \multirow{3}{*}{$\begin{array}{l}\text { Permit limit } \\
\text { Month }\end{array}$} & \multicolumn{2}{|c|}{$\begin{array}{c}\text { Ammonia } \\
\left(\text { as } \mathbf{N H}_{3}\right) \\
(\mathrm{mg} / \mathrm{L})\end{array}$} & \multicolumn{2}{|c|}{$\begin{array}{l}\mathbf{B O D}_{5} \\
(\mathrm{mg} / \mathrm{L})\end{array}$} & \multicolumn{2}{|c|}{$\begin{array}{c}\text { Chlorine } \\
\text { Total Residual } \\
(\mathrm{mg} / \mathrm{L})\end{array}$} & \multicolumn{2}{|c|}{$\begin{array}{l}\text { Discharge Rate } \\
\text { (MGD) }\end{array}$} & \multicolumn{2}{|c|}{$\begin{array}{l}\text { Iron } \\
\text { Total } \\
(\mathrm{mg} / \mathrm{L})\end{array}$} \\
\hline & \multicolumn{2}{|c|}{ Monitor } & \multicolumn{2}{|c|}{$\begin{array}{l}10 \mathrm{mg} / \mathrm{L} \text { daily } \\
\text { maximum }\end{array}$} & \multicolumn{2}{|c|}{$\begin{array}{l}0.1 \mathrm{mg} / \mathrm{L} \text { daily } \\
\text { maximum }\end{array}$} & \multicolumn{2}{|c|}{ Monitor } & \multicolumn{2}{|c|}{ Monitor } \\
\hline & Avg & Max & Avg & Max & Avg & Max & Avg & Max & Avg & Max \\
\hline January & $<0.62$ & 1.0 & 2.8 & 3.8 & 0.02 & 0.04 & 0.046 & 0.075 & $<0.189$ & 0.317 \\
\hline February & $<0.11$ & 0.22 & 2.2 & 2.6 & 0.02 & 0.02 & 0.043 & 0.068 & 0.085 & 0.100 \\
\hline March & $<0.050$ & $<0.050$ & $<2.0$ & $<2.0$ & 0.01 & 0.02 & 0.036 & 0.064 & 0.073 & 0.080 \\
\hline April & $<0.050$ & $<0.050$ & $<2.0$ & $<2.0$ & 0.02 & 0.05 & 0.023 & 0.033 & 0.0997 & 0.118 \\
\hline May & $<0.015$ & 0.024 & $<1.6$ & 2.3 & 0.01 & 0.02 & 0.018 & 0.028 & 0.163 & 0.216 \\
\hline June & $<0.010$ & $<0.010$ & $<1.9$ & 2.9 & 0.02 & 0.02 & 0.017 & 0.028 & 0.085 & 0.105 \\
\hline July & 0.041 & 0.051 & $<2.8$ & 4.3 & 0.02 & 0.02 & 0.016 & 0.025 & $<0.026$ & 0.0332 \\
\hline August & 0.044 & 0.061 & $<2.9$ & 3.6 & 0.01 & 0.01 & 0.013 & 0.019 & 0.0579 & 0.0959 \\
\hline September & $<0.025$ & 0.032 & $<2.4$ & 3.2 & 0.02 & 0.03 & 0.019 & 0.023 & 0.0732 & 0.0933 \\
\hline October & $<0.025$ & 0.032 & $<2.4$ & 3.2 & 0.02 & 0.03 & 0.018 & 0.030 & 0.0581 & 0.110 \\
\hline November & 0.075 & 0.16 & $<2.1$ & 2.4 & 0.02 & 0.03 & 0.020 & 0.026 & 0.0750 & 0.0912 \\
\hline December & 0.043 & 0.099 & $<2.0$ & $<2.0$ & 0.02 & 0.03 & 0.024 & 0.035 & 0.184 & 0.419 \\
\hline
\end{tabular}

\begin{tabular}{|c|c|c|c|c|c|c|c|c|c|c|}
\hline \multirow{3}{*}{$\begin{array}{l}\text { Permit limit } \\
\text { Month }\end{array}$} & \multirow{2}{*}{\multicolumn{2}{|c|}{$\begin{array}{c}\begin{array}{c}\text { Nitrite } \\
(\mathbf{a s} \mathbf{N}) \\
(\mathrm{mg} / \mathrm{L})\end{array} \\
0.1 \mathrm{mg} / \mathrm{L} \text { daily } \\
\text { maximum }\end{array}$}} & \multirow{2}{*}{\multicolumn{2}{|c|}{$\begin{array}{c}\text { Oil \& Grease } \\
(\mathrm{mg} / \mathrm{L})\end{array}$}} & \multirow{2}{*}{\multicolumn{2}{|c|}{$\begin{array}{c}\mathbf{p H} \\
\text { (standard units) } \\
6.5 \text { to } 8.5\end{array}$}} & \multirow{2}{*}{\multicolumn{2}{|c|}{$\begin{array}{c}\text { Solids } \\
\text { Settleable } \\
(\mathrm{mL} / \mathrm{L})\end{array}$}} & \multirow{2}{*}{\multicolumn{2}{|c|}{$\begin{array}{c}\text { Solids } \\
\text { Total Suspended } \\
(\mathrm{mg} / \mathrm{L})\end{array}$}} \\
\hline & & & & & & & & & & \\
\hline & Avg & Max & Avg & Max & Min & Max & Avg & Max & Avg & Max \\
\hline January & $<0.05$ & $<0.05$ & $<5.0$ & $<5.0$ & 7.3 & 8.0 & $<0.1$ & $<0.1$ & $<2.7$ & 3.0 \\
\hline February & $<0.08$ & 0.1 & $<5.0$ & $<5.0$ & 7.0 & 7.5 & $<0.2$ & $<0.3$ & $<4.0$ & 8.0 \\
\hline March & $<0.05$ & $<0.05$ & $<5.0$ & $<5.0$ & 7.7 & 8.0 & $<0.2$ & $<0.3$ & $<2.0$ & $<2.0$ \\
\hline April & $<0.05$ & $<0.05$ & $<5.0$ & $<5.0$ & 7.4 & 7.7 & $<0.1$ & $<0.1$ & $<2.0$ & $<2.0$ \\
\hline May & $<0.05$ & $<0.05$ & $<1.9$ & $<1.9$ & 7.2 & 7.5 & $<0.1$ & $<0.1$ & $<1.3$ & 2.0 \\
\hline June & $<0.05$ & $<0.05$ & $<1.9$ & $<1.9$ & 7.4 & 7.7 & $<0.1$ & $<0.1$ & $<1.0$ & $<1.0$ \\
\hline July & $<0.05$ & $<0.05$ & $<1.9$ & $<1.9$ & 7.6 & 7.9 & $<0.1$ & $<0.1$ & $<2.3$ & 5.0 \\
\hline August & $<0.05$ & $<0.05$ & $<1.9$ & $<1.9$ & 7.5 & 7.9 & $<0.1$ & $<0.1$ & $<4.0$ & $<4.0$ \\
\hline September & $<0.05$ & $<0.05$ & $<1.9$ & $<1.9$ & 7.2 & 7.7 & $<0.1$ & $<0.1$ & $<7.0$ & 12.0 \\
\hline October & $<0.05$ & $<0.05$ & $<1.9$ & $<1.9$ & 7.7 & 7.9 & $<0.1$ & $<0.1$ & $<4.0$ & $<4.0$ \\
\hline November & $<0.05$ & $<0.05$ & $<3.4$ & 4.9 & 7.1 & 7.8 & $<0.1$ & $<0.1$ & $<4.0$ & $<4.0$ \\
\hline December & $<0.05$ & $<0.05$ & $<2.7$ & $<2.7$ & 7.3 & 7.9 & $<0.1$ & $<0.1$ & $<4.0$ & $<4.0$ \\
\hline
\end{tabular}

Note: No results exceeded the permit limits. 
Table C-2G

2004 SPDES Results for Outfall 008 (WNSP008):

Water Quality

\author{
NO DISCHARGE FROM THE \\ FRENCH DRAIN (WNSP008) SINCE MAY 2001
}

C -19 
Table $\mathrm{C}-2 \mathrm{H}$

2004 SPDES Results for Sums of Outfalls 001, 007, 008, and 116:

Water Quality

2004 Results for Sums of Outfalls 001, 007 and 008

\begin{tabular}{|c|c|c|c|c|c|}
\hline \multirow{3}{*}{$\begin{array}{l}\text { Permit limit } \\
\text { Month }\end{array}$} & \multirow{2}{*}{\multicolumn{2}{|c|}{$\begin{array}{c}\text { Ammonia }^{\mathbf{a}} \\
\text { Flow-Weighted Average } \\
(\mathrm{mg} / \mathrm{L}) \\
2.1 \text { daily maximum; } \\
1.49 \text { daily average }\end{array}$}} & \multicolumn{2}{|c|}{$\begin{array}{c}\text { BOD }_{\mathbf{5}} \text { day } \\
(\mathrm{mg} / \mathrm{L})\end{array}$} & \multirow{3}{*}{$\begin{array}{c}\begin{array}{c}\text { Iron } \\
\text { Flow-Weighted Average } \\
(\mathrm{mg} / \mathrm{L})\end{array} \\
0.30 \text { daily average } \\
\mathbf{A v g}\end{array}$} \\
\hline & & & \multicolumn{2}{|c|}{5.0 daily average } & \\
\hline & Avg & Max & Avg & Max & \\
\hline January & $<0.44$ & 0.80 & $<2.3$ & 2.9 & 0.04 \\
\hline February $^{b}$ & $<0.11$ & 0.22 & 2.2 & 2.6 & 0.00 \\
\hline March & $<0.102$ & $<0.14$ & $<2.0$ & $<2.0$ & 0.00 \\
\hline April & $<0.05$ & $<0.05$ & $<2.0$ & $<2.0$ & 0.00 \\
\hline May & $<0.040$ & $<0.080$ & $<1.5$ & $<1.9$ & 0.00 \\
\hline June & $<0.074$ & $<0.15$ & $<1.4$ & 2.9 & 0.00 \\
\hline July $^{b}$ & 0.041 & 0.051 & $<2.8$ & 4.3 & 0.00 \\
\hline August & 0.032 & 0.038 & $<2.4$ & 3.1 & 0.00 \\
\hline September & $<0.017$ & 0.025 & $<2.5$ & 3.2 & 0.00 \\
\hline October $^{b}$ & $<0.025$ & 0.032 & $<2.4$ & 3.2 & 0.00 \\
\hline November $^{b}$ & 0.075 & 0.16 & $<2.1$ & 2.4 & 0.00 \\
\hline December & 0.054 & 0.091 & $<2.0$ & $<2.0$ & 0.00 \\
\hline
\end{tabular}

$\underline{2004}$ Results for Outfall 116

\begin{tabular}{|c|c|c|}
\hline & \multicolumn{2}{|c|}{$\begin{array}{c}\text { Total Dissolved Solids } \\
(\mathrm{mg} / \mathrm{L})\end{array}$} \\
\hline Permit limit & \multicolumn{2}{|c|}{$\begin{array}{l}500 \mathrm{mg} / \mathrm{L} \text { daily } \\
\text { maximum }\end{array}$} \\
\hline Month & Avg & Max \\
\hline January & 350 & 360 \\
\hline February $^{b}$ & -- & -- \\
\hline March & 281 & 320 \\
\hline April & 288 & 297 \\
\hline May & 253 & 347 \\
\hline June & 343 & 372 \\
\hline July $^{b}$ & -- & -- \\
\hline August & 381 & 381 \\
\hline September & 356 & 381 \\
\hline October $^{b}$ & -- & -- \\
\hline November $^{b}$ & -- & -- \\
\hline December & 279 & 316 \\
\hline
\end{tabular}

Note: No results exceeded the permit limits.

a Sum of Outfalls 001 and 007 only

${ }^{b}$ No discharge this month 
Table C-2I

2004 Quarterly/Semiannual/Annual SPDES Results for Outfall 001 (WNSP001): Water Quality, Metals, and Organics

\begin{tabular}{|c|c|c|c|c|}
\hline & $\begin{array}{c}\text { Action } \\
\text { Level }\end{array}$ & $\begin{array}{l}\text { Monitoring } \\
\text { Frequency }\end{array}$ & $\begin{array}{l}\text { Collection } \\
\text { Date }\end{array}$ & $\begin{array}{l}\text { Maximum } \\
\text { Measured }\end{array}$ \\
\hline $\begin{array}{l}\text { Boron, Total } \\
\quad(\mathrm{mg} / \mathrm{L})\end{array}$ & $\begin{array}{l}2.0 \mathrm{mg} / \mathrm{L} \text { daily } \\
\text { maximum }\end{array}$ & Quarterly & $\begin{array}{c}\text { March } 2004 \\
\text { May } 2004 \\
\text { August } 2004 \\
\text { December } 2004\end{array}$ & $\begin{array}{l}0.035 \\
0.040 \\
0.049 \\
0.038\end{array}$ \\
\hline $\begin{array}{l}\text { Bromide, Total } \\
\quad(\mathrm{mg} / \mathrm{L})\end{array}$ & $\begin{array}{l}5.0 \mathrm{mg} / \mathrm{L} \text { daily } \\
\text { maximum }\end{array}$ & Quarterly & $\begin{array}{c}\text { March } 2004 \\
\text { May } 2004 \\
\text { August } 2004 \\
\text { December } 2004\end{array}$ & $\begin{array}{l}1.4 \\
1.8 \\
2.0 \\
1.9\end{array}$ \\
\hline $\begin{array}{c}\text { Titanium, Total } \\
(\mathrm{mg} / \mathrm{L})\end{array}$ & $\begin{array}{l}0.65 \mathrm{mg} / \mathrm{L} \text { daily } \\
\text { maximum }\end{array}$ & Semiannual & $\begin{array}{l}\text { March } 2004 \\
\text { August } 2004\end{array}$ & $\begin{array}{l}0.0068 \\
0.0037\end{array}$ \\
\hline $\begin{array}{c}\text { Bis(2-ethylhexyl)phthalate } \\
(\mathrm{mg} / \mathrm{L})\end{array}$ & $\begin{array}{l}1.6 \mathrm{mg} / \mathrm{L} \text { daily } \\
\text { maximum }\end{array}$ & Semiannual & $\begin{array}{l}\text { March } 2004 \\
\text { August } 2004\end{array}$ & $\begin{array}{l}<0.010 \\
<0.0051\end{array}$ \\
\hline $\begin{array}{c}\text { 4-dodecene } \\
(\mathrm{mg} / \mathrm{L})\end{array}$ & $\begin{array}{l}0.6 \mathrm{mg} / \mathrm{L} \text { daily } \\
\text { maximum }\end{array}$ & Semiannual & $\begin{array}{l}\text { March } 2004 \\
\text { August } 2004\end{array}$ & $\begin{array}{l}<0.06 \\
<0.010\end{array}$ \\
\hline $\begin{array}{c}\text { Chloroform } \\
(\mathrm{mg} / \mathrm{L})\end{array}$ & $\begin{array}{l}0.3 \mathrm{mg} / \mathrm{L} \text { daily } \\
\text { maximum }\end{array}$ & Annual & March 2004 & $<0.005$ \\
\hline $\begin{array}{c}\text { Antimony, Total } \\
(\mathrm{mg} / \mathrm{L})\end{array}$ & $\begin{array}{l}1.0 \mathrm{mg} / \mathrm{L} \text { daily } \\
\text { maximum }\end{array}$ & Annual & March 2004 & $<0.020$ \\
\hline $\begin{array}{c}\text { Barium, Total } \\
(\mathrm{mg} / \mathrm{L})\end{array}$ & $\begin{array}{l}0.5 \mathrm{mg} / \mathrm{L} \text { daily } \\
\text { maximum }\end{array}$ & Annual & March 2004 & 0.03 \\
\hline $\begin{array}{l}\text { Dichlorodifluoromethane } \\
(\mathrm{mg} / \mathrm{L})\end{array}$ & $\begin{array}{l}0.01 \mathrm{mg} / \mathrm{L} \text { daily } \\
\text { maximum }\end{array}$ & Annual & March 2004 & $<0.005$ \\
\hline $\begin{array}{c}\text { Trichlorofluoromethane } \\
(\mathrm{mg} / \mathrm{L})\end{array}$ & $\begin{array}{l}0.01 \mathrm{mg} / \mathrm{L} \text { daily } \\
\text { maximum }\end{array}$ & Annual & March 2004 & $<0.005$ \\
\hline
\end{tabular}

Note: No results exceeded the permit limits.

Table C-2J

\section{Annual SPDES Results for Outfall 007 (WNSP007): Water Quality}

\begin{tabular}{|c|c|c|c|c|}
\hline & $\begin{array}{c}\text { Action } \\
\text { Level }\end{array}$ & $\begin{array}{c}\text { Monitoring } \\
\text { Frequency }\end{array}$ & $\begin{array}{c}\text { Collection } \\
\text { Date }\end{array}$ & $\begin{array}{c}\text { Maximum } \\
\text { Measured }\end{array}$ \\
\hline $\begin{array}{c}\text { Chloroform } \\
(\mathrm{mg} / \mathrm{L})\end{array}$ & $\begin{array}{c}0.20 \mathrm{mg} / \mathrm{L} \text { daily } \\
\text { maximum }\end{array}$ & Annual & February 2004 & $<0.005$ \\
\hline
\end{tabular}


Table C-2K

2004 Annual SPDES Results for Outfall 008 (WNSP008):

Water Quality

NO DISCHARGE FROM THE

FRENCH DRAIN (WNSP008) SINCE MAY 2001

Table C-2L

2004 Annual SPDES Results for Outfall $01 B$ (WNSP01B):

Water Quality

NO FLOW THROUGH INTERNAL MONITORING SYSTEM

DURING 2004

Table C-2M

2004 Radioactivity for Sewage Treatment Outfall (WNSP007)

\begin{tabular}{|l|c|c|c|c|c|c|}
\hline \multirow{2}{*}{\multicolumn{1}{c|}{ Analyte }} & \multirow{2}{*}{ Units } & \multirow{2}{*}{ N } & \multicolumn{3}{c|}{ WNSP007 Concentrations } & \multirow{2}{*}{ Guideline $^{\text {a }}$} \\
\cline { 4 - 6 } & & & Minimum & Average & Maximum & \\
\hline Gross Alpha & $\mu \mathrm{Ci} / \mathrm{mL}$ & 36 & $<1.55 \mathrm{E}-09$ & $-0.30 \pm 2.97 \mathrm{E}-09$ & $2.99 \mathrm{E}-09$ & $3 \mathrm{E}-08^{\mathrm{b}}$ \\
\hline Gross Beta & $\mu \mathrm{Ci} / \mathrm{mL}$ & 36 & $3.51 \mathrm{E}-09$ & $1.35 \pm 0.47 \mathrm{E}-08$ & $2.48 \mathrm{E}-08$ & $1 \mathrm{E}-06^{\mathrm{c}}$ \\
\hline Tritium & $\mu \mathrm{Ci} / \mathrm{mL}$ & 36 & $<6.01 \mathrm{E}-08$ & $1.96 \pm 8.06 \mathrm{E}-08$ & $1.96 \mathrm{E}-07$ & $2 \mathrm{E}-03$ \\
\hline Sr-90 & $\mu \mathrm{Ci} / \mathrm{mL}$ & 4 & $2.33 \mathrm{E}-09$ & $3.17 \pm 1.61 \mathrm{E}-09$ & $4.47 \mathrm{E}-09$ & $1 \mathrm{E}-06$ \\
\hline Cs-137 & $\mu \mathrm{Ci} / \mathrm{mL}$ & 4 & $<1.96 \mathrm{E}-09$ & $0.97 \pm 2.98 \mathrm{E}-09$ & $1.99 \mathrm{E}-09$ & $3 \mathrm{E}-06$ \\
\hline
\end{tabular}

$N$ - Number of samples

${ }^{a}$ DOE ingestion-based DCGs for $100 \mathrm{mrem} / \mathrm{yr}$ dose limit are provided as a guideline for radiological results.

${ }^{b}$ Alpha as Am-241

${ }^{c}$ Beta as $\mathrm{Sr}-90$

$C-22$ 


\section{Appendix C-3 \\ Site Surface Drainage, Subsurface Drainage, and Contained Water}

$C-23$ 
This page intentionally left blank

$$
\text { C }-24
$$


Table C-3A

2004 Radioactivity and $\mathrm{pH}$ in Surface Water at Facility Yard Drainage (WNSP005)

\begin{tabular}{|c|c|c|c|c|c|c|}
\hline \multirow{2}{*}{ Analyte } & \multirow{2}{*}{ Units } & \multirow{2}{*}{$\mathbf{N}$} & \multicolumn{3}{|c|}{ WNSP005 Concentrations } & \multirow{2}{*}{$\begin{array}{c}\text { Guideline }^{\text {a }} \text { or } \\
\text { Standard }^{\mathbf{b}}\end{array}$} \\
\hline & & & Minimum & Average & Maximum & \\
\hline Gross Alpha & $\mu \mathrm{Ci} / \mathrm{mL}$ & 12 & $<1.66 \mathrm{E}-09$ & $0.22 \pm 2.85 \mathrm{E}-09$ & $<4.28 \mathrm{E}-09$ & $3 \mathrm{E}-08^{\mathrm{c}}$ \\
\hline Gross Beta & $\mu \mathrm{Ci} / \mathrm{mL}$ & 12 & $4.06 \mathrm{E}-08$ & $1.88 \pm 0.09 \mathrm{E}-07$ & 4.42E-07 & $1 \mathrm{E}-06^{\mathrm{d}}$ \\
\hline Tritium & $\mu \mathrm{Ci} / \mathrm{mL}$ & 12 & $<7.88 \mathrm{E}-08$ & $5.62 \pm 8.19 \mathrm{E}-08$ & $1.66 \mathrm{E}-07$ & $2 \mathrm{E}-03$ \\
\hline Sr-90 & $\mu \mathrm{Ci} / \mathrm{mL}$ & 4 & 3.82E-08 & $8.82 \pm 0.56 \mathrm{E}-08$ & $1.50 \mathrm{E}-07$ & $1 \mathrm{E}-06$ \\
\hline Cs-137 & $\mu \mathrm{Ci} / \mathrm{mL}$ & 4 & $<1.89 \mathrm{E}-09$ & $0.79 \pm 1.99 \mathrm{E}-09$ & $<2.08 \mathrm{E}-09$ & $3 \mathrm{E}-06$ \\
\hline pH & SU & 12 & 6.85 & 7.42 & 7.99 & $6.0-9.5$ \\
\hline
\end{tabular}

$N$ - Number of samples

${ }^{a}$ DOE ingestion-based DCGs for $100 \mathrm{mrem} / \mathrm{yr}$ dose limit are provided as a guideline for radiological results.

${ }^{b}$ New York State Water Quality Standards for Class “D” as a comparative reference for nonradiological results

${ }^{c}$ Alpha as Am-241

${ }^{d}$ Beta as $\mathrm{Sr}-90$

Table C-3B

2004 Radioactivity in Surface Water at French Drain (WNSP008)

NO DISCHARGE FROM THE

FRENCH DRAIN SINCE MAY 2001

WVDP Annual Site Environmental Report

$C-25$

Calendar Year 2004 
Table C-3C

2004 Water Quality of Surface Water at the North Swamp (WNSW74A)

RADIOACTIVITY CONCENTRATIONS

\begin{tabular}{|c|c|c|c|c|c|c|c|}
\hline \multirow{3}{*}{ Analyte } & \multirow{3}{*}{ Units } & \multirow{3}{*}{$\mathbf{N}$} & \multirow{2}{*}{\multicolumn{2}{|c|}{$\begin{array}{c}\text { WNSW74A } \\
\text { Concentrations }\end{array}$}} & \multirow{3}{*}{$\mathbf{N}$} & \multicolumn{2}{|c|}{ Reference Values } \\
\hline & & & & & & \multirow{2}{*}{$\begin{array}{c}\text { Background Range } \\
\text { WFBCBKG }^{\mathrm{a}}\end{array}$} & \multirow{2}{*}{ Guideline $^{b}$} \\
\hline & & & Average & Maximum & & & \\
\hline Gross Alpha & $\mu \mathrm{Ci} / \mathrm{mL}$ & 53 & $-0.21 \pm 3.44 \mathrm{E}-09$ & $7.89 \mathrm{E}-09$ & 12 & $<4.53 \mathrm{E}-10-2.55 \mathrm{E}-09$ & $3 \mathrm{E}-08^{\mathrm{c}}$ \\
\hline Gross Beta & $\mu \mathrm{Ci} / \mathrm{mL}$ & 53 & $1.25 \pm 0.43 \mathrm{E}-08$ & $2.15 \mathrm{E}-08$ & 12 & $<1.16 \mathrm{E}-09-3.64 \mathrm{E}-09$ & $1 \mathrm{E}-06^{\mathrm{d}}$ \\
\hline Tritium & $\mu \mathrm{Ci} / \mathrm{mL}$ & 53 & $-0.45 \pm 7.75 \mathrm{E}-08$ & $1.16 \mathrm{E}-07$ & 12 & $<7.48 \mathrm{E}-08-1.35 \mathrm{E}-07$ & $2 \mathrm{E}-03$ \\
\hline C-14 & $\mu \mathrm{Ci} / \mathrm{mL}$ & 4 & $-0.42 \pm 2.40 \mathrm{E}-08$ & $<2.95 \mathrm{E}-08$ & 4 & $<5.38 \mathrm{E}-09-<3.03 \mathrm{E}-08$ & 7E-05 \\
\hline Sr-90 & $\mu \mathrm{Ci} / \mathrm{mL}$ & 12 & $6.23 \pm 1.94 \mathrm{E}-09$ & 8.39E-09 & 4 & $<1.13 \mathrm{E}-09-<1.30 \mathrm{E}-09$ & $1 \mathrm{E}-06$ \\
\hline I-129 & $\mu \mathrm{Ci} / \mathrm{mL}$ & 4 & $1.28 \pm 8.57 \mathrm{E}-10$ & $<1.12 \mathrm{E}-09$ & 4 & $<6.26 \mathrm{E}-10-1.21 \mathrm{E}-09$ & 5E-07 \\
\hline Cs-137 & $\mu \mathrm{Ci} / \mathrm{mL}$ & 12 & $1.72 \pm 7.35 \mathrm{E}-09$ & $<1.08 \mathrm{E}-08$ & 4 & $<1.94 \mathrm{E}-09-<2.34 \mathrm{E}-09$ & $3 \mathrm{E}-06$ \\
\hline U-232 & $\mu \mathrm{Ci} / \mathrm{mL}$ & 4 & $-0.04 \pm 4.80 \mathrm{E}-11$ & $<5.98 \mathrm{E}-11$ & 4 & $<3.46 \mathrm{E}-11-<1.00 \mathrm{E}-10$ & $1 \mathrm{E}-07$ \\
\hline U-233/234 & $\mu \mathrm{Ci} / \mathrm{mL}$ & 4 & $2.28 \pm 1.12 \mathrm{E}-10$ & $3.01 \mathrm{E}-10$ & 4 & 8.19E-11-1.81E-10 & $5 \mathrm{E}-07$ \\
\hline U-235/236 & $\mu \mathrm{Ci} / \mathrm{mL}$ & 4 & $3.49 \pm 5.67 \mathrm{E}-11$ & $6.64 \mathrm{E}-11$ & 4 & $<4.14 \mathrm{E}-11-5.25 \mathrm{E}-11$ & $5 \mathrm{E}-07^{\mathrm{e}}$ \\
\hline U-238 & $\mu \mathrm{Ci} / \mathrm{mL}$ & 4 & $1.01 \pm 0.76 \mathrm{E}-10$ & $1.56 \mathrm{E}-10$ & 4 & $<4.68 \mathrm{E}-11-8.50 \mathrm{E}-11$ & $6 \mathrm{E}-07$ \\
\hline Total U & $\mu \mathrm{g} / \mathrm{mL}$ & 4 & $3.13 \pm 0.09 \mathrm{E}-04$ & $4.27 \mathrm{E}-04$ & 4 & $3.32 \mathrm{E}-05-6.00 \mathrm{E}-04$ & -- \\
\hline Pu-238 & $\mu \mathrm{Ci} / \mathrm{mL}$ & 4 & $0.23 \pm 2.92 \mathrm{E}-11$ & $<3.53 \mathrm{E}-11$ & 4 & $<1.24 \mathrm{E}-11-<3.38 \mathrm{E}-11$ & $4 \mathrm{E}-08$ \\
\hline Pu-239/240 & $\mu \mathrm{Ci} / \mathrm{mL}$ & 4 & $0.84 \pm 2.43 \mathrm{E}-11$ & $<2.90 \mathrm{E}-11$ & 4 & $<1.25 \mathrm{E}-11-<3.85 \mathrm{E}-11$ & 3E-08 \\
\hline Am-241 & $\mu \mathrm{Ci} / \mathrm{mL}$ & 4 & $0.66 \pm 2.88 \mathrm{E}-11$ & $3.13 \mathrm{E}-11$ & 4 & $<2.21 \mathrm{E}-11-<4.85 \mathrm{E}-11$ & 3E-08 \\
\hline
\end{tabular}

$N$ - Number of samples

-- No guideline or standard available for these analytes

a Background location

${ }^{b}$ DOE ingestion-based DCGs for 100 mrem/yr dose limits are provided as a guideline for radiological results.

${ }^{c}$ Alpha as Am-241

${ }^{d}$ Beta as $\mathrm{Sr}-90$

${ }^{e}$ DCG for U-236 is used for this comparison. 


\section{Table C-3C (continued) \\ 2004 Water Quality of Surface Water at the North Swamp (WNSW74A)}

CHEMICAL CONSTITUENTS

\begin{tabular}{|c|c|c|c|c|c|c|c|}
\hline \multirow{3}{*}{ Analyte } & \multirow{3}{*}{ Units } & \multirow{3}{*}{$\mathbf{N}$} & \multirow{2}{*}{\multicolumn{2}{|c|}{$\begin{array}{c}\text { WNSW74A } \\
\text { Concentrations }\end{array}$}} & \multirow{3}{*}{$\mathbf{N}$} & \multicolumn{2}{|c|}{ Reference Values } \\
\hline & & & & & & \multirow{2}{*}{$\begin{array}{c}\text { Background Range } \\
\text { WFBCBKG }^{\mathrm{a}}\end{array}$} & \multirow{2}{*}{ Standard $^{\mathrm{b}}$} \\
\hline & & & Average & Maximum & & & \\
\hline Alpha-BHC & $\mathrm{mg} / \mathrm{L}$ & 2 & $<0.000009$ & $<0.000009$ & 2 & $<0.000009-<0.000009$ & 0.000002 \\
\hline Aluminum, Total & $\mathrm{mg} / \mathrm{L}$ & 2 & $<0.10$ & $<0.10$ & 0 & NA & -- \\
\hline Ammonia-N & $\mathrm{mg} / \mathrm{L}$ & 2 & $<0.05$ & $<0.05$ & 2 & $<0.05-0.07$ & $0.67-29$ \\
\hline Antimony, Total & $\mathrm{mg} / \mathrm{L}$ & 2 & $<0.003$ & $<0.003$ & 2 & $<0.003-<0.003$ & -- \\
\hline Arsenic, Dissolved & $\mathrm{mg} / \mathrm{L}$ & 2 & $<0.005$ & $<0.005$ & 2 & $<0.005-<0.005$ & 0.340 \\
\hline Boron, Total & $\mathrm{mg} / \mathrm{L}$ & 2 & 0.03 & 0.04 & 2 & $0.01-0.02$ & -- \\
\hline Bromide & $\mathrm{mg} / \mathrm{L}$ & 2 & $<0.72$ & 0.94 & 2 & $<0.50-<0.50$ & - \\
\hline Cadmium, Total & $\mathrm{mg} / \mathrm{L}$ & 2 & $<0.001$ & $<0.001$ & 0 & NA & - \\
\hline Calcium, Total & $\mathrm{mg} / \mathrm{L}$ & 2 & 89.3 & 96 & 12 & $23.1-46.9$ & -- \\
\hline Chromium, Total & $\mathrm{mg} / \mathrm{L}$ & 2 & $<0.01$ & $<0.01$ & 0 & NA & -- \\
\hline Cobalt, Total & $\mathrm{mg} / \mathrm{L}$ & 2 & $<0.005$ & $<0.005$ & 2 & $<0.005-<0.005$ & $0.110^{c}$ \\
\hline Copper, Dissolved & $\mathrm{mg} / \mathrm{L}$ & 2 & $<0.005$ & $<0.005$ & 2 & $<0.005-<0.005$ & $0.037^{\mathrm{d}}$ \\
\hline Copper, Total & $\mathrm{mg} / \mathrm{L}$ & 2 & $<0.005$ & $<0.005$ & 0 & NA & -- \\
\hline Fluoride & $\mathrm{mg} / \mathrm{L}$ & 2 & 0.15 & 0.16 & 2 & $<0.10-<0.10$ & $27.8^{\mathrm{d}}$ \\
\hline Hardness & $\mathrm{mg} / \mathrm{L}$ & 2 & 271 & 290 & 12 & 73-144 & -- \\
\hline Iron, Total & $\mathrm{mg} / \mathrm{L}$ & 2 & 0.14 & 0.2 & 2 & $0.51-2.16$ & 0.30 \\
\hline Lead, Total & $\mathrm{mg} / \mathrm{L}$ & 2 & $<0.0005$ & $<0.0005$ & 0 & NA & -- \\
\hline Magnesium, Total & $\mathrm{mg} / \mathrm{L}$ & 2 & 11.68 & 12.15 & 12 & $3.57-6.59$ & -- \\
\hline Manganese, Total & $\mathrm{mg} / \mathrm{L}$ & 2 & 0.08 & 0.09 & 2 & $0.04-0.04$ & -- \\
\hline Mercury, Total, Method 1631 & $\mathrm{mg} / \mathrm{L}$ & 1 & 0.00000110 & 0.00000110 & 0 & NA & -- \\
\hline Nickel, Total & $\mathrm{mg} / \mathrm{L}$ & 2 & $<0.04$ & $<0.04$ & 0 & NA & -- \\
\hline Nitrate-N & $\mathrm{mg} / \mathrm{L}$ & 2 & 0.54 & 0.56 & 2 & $<0.05-0.61$ & -- \\
\hline Nitrite-N & $\mathrm{mg} / \mathrm{L}$ & 2 & $<0.05$ & $<0.05$ & 2 & $<0.05-<0.05$ & -- \\
\hline NPOC & $\mathrm{mg} / \mathrm{L}$ & 2 & 4.4 & 4.6 & 2 & $2.0-2.4$ & -- \\
\hline Oil \& Grease & $\mathrm{mg} / \mathrm{L}$ & 2 & $<5$ & $<5$ & 2 & $<5-<5$ & -- \\
\hline pH & SU & 2 & 7.58 & 7.83 & 2 & $7.68-7.97$ & $6.0-9.5$ \\
\hline Selenium, Total & $\mathrm{mg} / \mathrm{L}$ & 2 & $<0.001$ & $<0.001$ & 0 & NA & -- \\
\hline Solids, Total Dissolved & $\mathrm{mg} / \mathrm{L}$ & 2 & 744 & 890 & 2 & $117-188$ & -- \\
\hline Solids, Total Suspended & $\mathrm{mg} / \mathrm{L}$ & 2 & $<4$ & $<5$ & 2 & $<4-39$ & -- \\
\hline
\end{tabular}

$N$ - Number of samples

NA - No data available

-- No guideline or standard available for these analytes

${ }^{a}$ Background location

${ }^{b}$ New York State Water Quality Standards, Class “D” as a comparative reference for nonradiological results at WNSW74A

${ }^{c}$ Standards for cobalt, thallium, and vanadium are acid-soluble.

${ }^{d}$ Calculated from maximum measurement of hardness of surface water drainage at WNSW74A 


\section{Table C-3C (concluded)}

2004 Water Quality of Surface Water at the North Swamp (WNSW74A)

\section{CHEMICAL CONSTITUENTS (concluded)}

\begin{tabular}{|c|c|c|c|c|c|c|c|}
\hline \multirow{3}{*}{ Analyte } & \multirow{3}{*}{ Units } & \multirow{3}{*}{$\mathbf{N}$} & \multirow{2}{*}{\multicolumn{2}{|c|}{$\begin{array}{c}\text { WNSW74A } \\
\text { Concentrations }\end{array}$}} & \multirow{3}{*}{$\mathbf{N}$} & \multicolumn{2}{|c|}{ Reference Values } \\
\hline & & & & & & \multirow{2}{*}{$\begin{array}{c}\text { Background Range } \\
\text { WFBCBKG }^{\mathrm{a}}\end{array}$} & \multirow{2}{*}{ Standard $^{\mathrm{b}}$} \\
\hline & & & Average & Maximum & & & \\
\hline Sulfate & $\mathrm{mg} / \mathrm{L}$ & 2 & 45.9 & 50.3 & 2 & $14.4-20.7$ & -- \\
\hline Sulfide & $\mathrm{mg} / \mathrm{L}$ & 2 & $<0.07$ & 0.1 & 2 & $<0.04-0.08$ & -- \\
\hline Surfactants & $\mathrm{mg} / \mathrm{L}$ & 2 & $<0.10$ & $<0.10$ & 2 & $<0.03-<0.10$ & -- \\
\hline Thallium, Total & $\mathrm{mg} / \mathrm{L}$ & 2 & $<0.008$ & $<0.008$ & 2 & $<0.008-<0.008$ & $0.020^{c}$ \\
\hline Titanium, Total & $\mathrm{mg} / \mathrm{L}$ & 2 & $<0.05$ & $<0.05$ & 2 & $<0.05-<0.05$ & -- \\
\hline TOX & $\mathrm{mg} / \mathrm{L}$ & 2 & $<0.03$ & $<0.04$ & 2 & $<0.005-<0.030$ & -- \\
\hline Vanadium, Total & $\mathrm{mg} / \mathrm{L}$ & 2 & $<0.01$ & $<0.01$ & 2 & $<0.01-<0.01$ & $0.190^{c}$ \\
\hline Zinc, Total & $\mathrm{mg} / \mathrm{L}$ & 2 & $<0.02$ & $<0.02$ & 0 & NA & -- \\
\hline
\end{tabular}

$N$ - Number of samples

NA - No data available

-- No guideline or standard available for these analytes

${ }^{a}$ Background location

${ }^{b}$ New York State Water Quality Standards, Class "D" as a comparative reference for nonradiological results at WNSW74A

${ }^{c}$ Standards for cobalt, thallium, and vanadium are acid-soluble.

$$
\text { C }-28
$$


Table C-3D

2004 Water Quality of Surface Water at the Northeast Swamp (WNSWAMP)

RADIOACTIVITY CONCENTRATIONS

\begin{tabular}{|c|c|c|c|c|c|c|c|}
\hline \multirow{3}{*}{ Analyte } & \multirow{3}{*}{ Units } & \multirow{3}{*}{$\mathbf{N}$} & \multirow{2}{*}{\multicolumn{2}{|c|}{$\begin{array}{c}\text { WNSWAMP } \\
\text { Concentrations }\end{array}$}} & \multirow{3}{*}{$\mathbf{N}$} & \multicolumn{2}{|c|}{ Reference Values } \\
\hline & & & & & & \multirow{2}{*}{$\begin{array}{c}\text { WFBCBKG } \\
\text { Background Range }\end{array}$} & \multirow{2}{*}{ Guideline $^{b}$} \\
\hline & & & Average & Maximum & & & \\
\hline Gross Alpha & $\mu \mathrm{Ci} / \mathrm{mL}$ & 53 & $0.33 \pm 2.27 \mathrm{E}-09$ & $3.91 \mathrm{E}-09$ & 12 & $<4.53 \mathrm{E}-10-2.55 \mathrm{E}-09$ & $3 \mathrm{E}-08^{\mathrm{c}}$ \\
\hline Gross Beta & $\mu \mathrm{Ci} / \mathrm{mL}$ & 53 & $2.51 \pm 0.03 \mathrm{E}-06$ & $6.68 \mathrm{E}-06$ & 12 & $<1.16 \mathrm{E}-09-3.64 \mathrm{E}-09$ & $1 \mathrm{E}-06^{\mathrm{d}}$ \\
\hline Tritium & $\mu \mathrm{Ci} / \mathrm{mL}$ & 53 & $7.75 \pm 7.99 \mathrm{E}-08$ & $1.96 \mathrm{E}-07$ & 12 & $<7.48 \mathrm{E}-08-1.35 \mathrm{E}-07$ & $2 \mathrm{E}-03$ \\
\hline C-14 & $\mu \mathrm{Ci} / \mathrm{mL}$ & 4 & $0.03 \pm 2.09 \mathrm{E}-08$ & $<2.78 \mathrm{E}-08$ & 4 & $<5.38 \mathrm{E}-09-<3.03 \mathrm{E}-08$ & $7 \mathrm{E}-05$ \\
\hline Sr-90 & $\mu \mathrm{Ci} / \mathrm{mL}$ & 12 & $1.31 \pm 0.03 \mathrm{E}-06$ & $2.48 \mathrm{E}-06$ & 4 & $<1.13 \mathrm{E}-09-<1.30 \mathrm{E}-09$ & $1 \mathrm{E}-06$ \\
\hline I-129 & $\mu \mathrm{Ci} / \mathrm{mL}$ & 4 & $4.90 \pm 8.94 \mathrm{E}-10$ & $<1.09 \mathrm{E}-09$ & 4 & $<6.26 \mathrm{E}-10-1.21 \mathrm{E}-09$ & $5 \mathrm{E}-07$ \\
\hline Cs-137 & $\mu \mathrm{Ci} / \mathrm{mL}$ & 12 & $1.34 \pm 2.03 \mathrm{E}-09$ & $2.56 \mathrm{E}-09$ & 4 & $<1.94 \mathrm{E}-09-<2.34 \mathrm{E}-09$ & $3 \mathrm{E}-06$ \\
\hline U-232 & $\mu \mathrm{Ci} / \mathrm{mL}$ & 4 & $-0.82 \pm 4.37 \mathrm{E}-11$ & $<5.87 \mathrm{E}-11$ & 4 & $<3.46 \mathrm{E}-11-<1.00 \mathrm{E}-10$ & $1 \mathrm{E}-07$ \\
\hline U-233/234 & $\mu \mathrm{Ci} / \mathrm{mL}$ & 4 & $1.53 \pm 0.90 \mathrm{E}-10$ & $2.18 \mathrm{E}-10$ & 4 & 8.19E-11-1.81E-10 & $5 \mathrm{E}-07$ \\
\hline $\mathrm{U}-235 / 236$ & $\mu \mathrm{Ci} / \mathrm{mL}$ & 4 & $2.18 \pm 4.13 \mathrm{E}-11$ & $<5.60 \mathrm{E}-11$ & 4 & $<4.14 \mathrm{E}-11-5.25 \mathrm{E}-11$ & $5 \mathrm{E}-07^{\mathrm{e}}$ \\
\hline U-238 & $\mu \mathrm{Ci} / \mathrm{mL}$ & 4 & $1.38 \pm 0.83 \mathrm{E}-10$ & $1.59 \mathrm{E}-10$ & 4 & $<4.68 \mathrm{E}-11-8.50 \mathrm{E}-11$ & $6 \mathrm{E}-07$ \\
\hline Total U & $\mu \mathrm{g} / \mathrm{mL}$ & 4 & $4.51 \pm 1.09 \mathrm{E}-04$ & $6.23 \mathrm{E}-04$ & 4 & $3.32 \mathrm{E}-05-6.00 \mathrm{E}-04$ & -- \\
\hline Pu-238 & $\mu \mathrm{Ci} / \mathrm{mL}$ & 4 & $0.48 \pm 3.35 \mathrm{E}-11$ & $<4.68 \mathrm{E}-11$ & 4 & $<1.24 \mathrm{E}-11-<3.38 \mathrm{E}-11$ & 4E-08 \\
\hline Pu-239/240 & $\mu \mathrm{Ci} / \mathrm{mL}$ & 4 & $0.73 \pm 2.82 \mathrm{E}-11$ & $<4.00 \mathrm{E}-11$ & 4 & $<1.25 \mathrm{E}-11-<3.85 \mathrm{E}-11$ & $3 \mathrm{E}-08$ \\
\hline Am-241 & $\mu \mathrm{Ci} / \mathrm{mL}$ & 4 & $1.04 \pm 4.09 \mathrm{E}-11$ & $<5.04 \mathrm{E}-11$ & 4 & $<2.21 \mathrm{E}-11-<4.85 \mathrm{E}-11$ & $3 \mathrm{E}-08$ \\
\hline
\end{tabular}

$N$ - Number of samples

-- No guideline or standard available for these analytes

a Background location

${ }^{b}$ DOE ingestion-based DCGs for $100 \mathrm{mrem} / \mathrm{yr}$ dose limit are provided as a guideline for radiological results.

${ }^{c}$ Alpha as Am-241

${ }^{d}$ Beta as $\mathrm{Sr}-90$

${ }^{e} D C G$ for U-236 is used for this comparison 
Table C-3D (continued)

2004 Water Quality of Surface Water at the Northeast Swamp (WNSWAMP)

CHEMICAL CONSTITUENTS

\begin{tabular}{|c|c|c|c|c|c|c|c|}
\hline \multirow{3}{*}{ Analyte } & \multirow{3}{*}{ Units } & \multirow{3}{*}{$\mathbf{N}$} & \multirow{2}{*}{\multicolumn{2}{|c|}{$\begin{array}{l}\text { WNSWAMP } \\
\text { Concentrations }\end{array}$}} & \multirow{3}{*}{$\mathbf{N}$} & \multicolumn{2}{|c|}{ Reference Values } \\
\hline & & & & & & \multirow{2}{*}{$\begin{array}{c}\text { WFBCBKG }^{\mathrm{a}} \\
\text { Background Range }\end{array}$} & \multirow{2}{*}{ Standard } \\
\hline & & & Average & Maximum & & & \\
\hline Alpha-BHC & $\mathrm{mg} / \mathrm{L}$ & 2 & $<0.000015$ & $<0.000021$ & 2 & $<0.000009-<0.000009$ & 0.000002 \\
\hline Aluminum, Total & $\mathrm{mg} / \mathrm{L}$ & 2 & 0.05 & 0.06 & 0 & NA & -- \\
\hline Ammonia-N & $\mathrm{mg} / \mathrm{L}$ & 2 & $<0.10$ & $<0.10$ & 2 & $<0.05-0.07$ & $0.67-29$ \\
\hline Antimony, Total & $\mathrm{mg} / \mathrm{L}$ & 2 & $<0.003$ & $<0.003$ & 2 & $<0.003-<0.003$ & -- \\
\hline Arsenic, Dissolved & $\mathrm{mg} / \mathrm{L}$ & 2 & $<0.004$ & 0.004 & 2 & $<0.005-<0.005$ & 0.340 \\
\hline Boron, Total & $\mathrm{mg} / \mathrm{L}$ & 2 & 0.04 & 0.05 & 2 & $0.01-0.02$ & -- \\
\hline Bromide & $\mathrm{mg} / \mathrm{L}$ & 2 & 0.79 & 1 & 2 & $<0.50-<0.50$ & -- \\
\hline Cadmium, Total & $\mathrm{mg} / \mathrm{L}$ & 2 & $<0.0004$ & $<0.0004$ & 0 & NA & - \\
\hline Calcium, Total & $\mathrm{mg} / \mathrm{L}$ & 2 & 113.5 & 119 & 12 & $23.1-46.9$ & -- \\
\hline Chromium, Total & $\mathrm{mg} / \mathrm{L}$ & 2 & $<0.0012$ & $<0.0012$ & 0 & NA & - \\
\hline Cobalt, Total & $\mathrm{mg} / \mathrm{L}$ & 2 & $<0.001$ & $<0.001$ & 2 & $<0.005-<0.005$ & $0.110^{c}$ \\
\hline Copper, Dissolved & $\mathrm{mg} / \mathrm{L}$ & 2 & 0.003 & 0.003 & 2 & $<0.005-<0.005$ & $0.045^{\mathrm{d}}$ \\
\hline Copper, Total & $\mathrm{mg} / \mathrm{L}$ & 2 & 0.002 & 0.003 & 0 & NA & -- \\
\hline Fluoride & $\mathrm{mg} / \mathrm{L}$ & 2 & $<0.10$ & $<0.10$ & 2 & $<0.10-<0.10$ & $34.1^{\mathrm{d}}$ \\
\hline Hardness & $\mathrm{mg} / \mathrm{L}$ & 2 & 344 & 363 & 12 & $73-144$ & -- \\
\hline Iron, Total & $\mathrm{mg} / \mathrm{L}$ & 2 & $<0.05$ & 0.06 & 2 & $0.51-2.16$ & 0.30 \\
\hline Lead, Total & $\mathrm{mg} / \mathrm{L}$ & 2 & $<0.0031$ & $<0.0031$ & 0 & NA & -- \\
\hline Magnesium, Total & $\mathrm{mg} / \mathrm{L}$ & 2 & 14.80 & 16 & 12 & $3.57-6.59$ & -- \\
\hline Manganese, Total & $\mathrm{mg} / \mathrm{L}$ & 2 & 0.10 & 0.12 & 2 & $0.04-0.04$ & -- \\
\hline Mercury, Total, Method 1631 & $\mathrm{mg} / \mathrm{L}$ & 2 & 0.00000159 & 0.00000194 & 0 & NA & -- \\
\hline Nickel, Total & $\mathrm{mg} / \mathrm{L}$ & 2 & $<0.0012$ & $<0.0012$ & 0 & NA & -- \\
\hline Nitrate-N & $\mathrm{mg} / \mathrm{L}$ & 2 & 0.10 & 0.11 & 2 & $<0.05-0.61$ & -- \\
\hline Nitrite-N & $\mathrm{mg} / \mathrm{L}$ & 2 & $<0.03$ & 0.03 & 2 & $<0.05-<0.05$ & -- \\
\hline NPOC & $\mathrm{mg} / \mathrm{L}$ & 2 & 5.1 & 5.6 & 2 & $2.0-2.4$ & -- \\
\hline Oil \& Grease & $\mathrm{mg} / \mathrm{L}$ & 2 & $<1$ & $<1$ & 2 & $<5-<5$ & -- \\
\hline pH & $\mathrm{SU}$ & 2 & 7.12 & 7.56 & 2 & $7.68-7.97$ & $6.0-9.5$ \\
\hline
\end{tabular}

$N$ - Number of samples

NA - No data available

-- No guideline or standard available for these analytes

${ }^{a}$ Background location

${ }^{b}$ New York State Water Quality Standards, Class “D” as a comparative reference for nonradiological results at WNSWAMP

${ }^{c}$ Standards for cobalt, thallium, and vanadium are acid-soluble.

${ }^{d}$ Calculated from maximum measurement of hardness of surface water drainage at WNSWAMP 
Table C-3D (concluded)

2004 Water Quality of Surface Water at the Northeast Swamp (WNSWAMP)

CHEMICAL CONSTITUENTS (concluded)

\begin{tabular}{|c|c|c|c|c|c|c|c|}
\hline \multirow{3}{*}{ Analyte } & \multirow{3}{*}{ Units } & \multirow{3}{*}{$\mathbf{N}$} & \multirow{2}{*}{\multicolumn{2}{|c|}{$\begin{array}{l}\text { WNSWAMP } \\
\text { Concentrations }\end{array}$}} & \multirow{3}{*}{$\mathbf{N}$} & \multicolumn{2}{|c|}{ Reference Values } \\
\hline & & & & & & \multirow{2}{*}{$\begin{array}{c}\text { WFBCBKG }^{\mathrm{a}} \\
\text { Background Range }\end{array}$} & \multirow{2}{*}{ Standard } \\
\hline & & & Average & Maximum & & & \\
\hline Selenium, Total & $\mathrm{mg} / \mathrm{L}$ & 2 & $<0.004$ & $<0.004$ & 0 & NA & -- \\
\hline Solids, Total Dissolved & $\mathrm{mg} / \mathrm{L}$ & 2 & 742 & 776 & 2 & $117-188$ & -- \\
\hline Solids, Total Suspended & $\mathrm{mg} / \mathrm{L}$ & 2 & $<5$ & $<5$ & 2 & $<4-39$ & -- \\
\hline Sulfate & $\mathrm{mg} / \mathrm{L}$ & 2 & 21.6 & 22.4 & 2 & $14.4-20.7$ & -- \\
\hline Sulfide & $\mathrm{mg} / \mathrm{L}$ & 2 & $<1.00$ & $<1.00$ & 2 & $<0.04-0.08$ & -- \\
\hline Surfactants & $\mathrm{mg} / \mathrm{L}$ & 2 & $<0.10$ & $<0.10$ & 2 & $<0.03-<0.10$ & -- \\
\hline Thallium, Total & $\mathrm{mg} / \mathrm{L}$ & 2 & $<0.007$ & $<0.007$ & 2 & $<0.008-<0.008$ & $0.020^{\mathrm{c}}$ \\
\hline Titanium, Total & $\mathrm{mg} / \mathrm{L}$ & 2 & $<0.0004$ & $<0.0004$ & 2 & $<0.05-<0.05$ & -- \\
\hline TOX & $\mathrm{mg} / \mathrm{L}$ & 2 & 0.03 & 0.04 & 2 & $<0.005-<0.030$ & -- \\
\hline Vanadium, Total & $\mathrm{mg} / \mathrm{L}$ & 2 & $<0.0010$ & $<0.0010$ & 2 & $<0.01-<0.01$ & $0.190^{c}$ \\
\hline Zinc, Total & $\mathrm{mg} / \mathrm{L}$ & 2 & 0.01 & 0.02 & 0 & NA & -- \\
\hline
\end{tabular}

$N$ - Number of samples

NA - No data available

-- No guideline or standard available for these analytes

${ }^{a}$ Background location

${ }^{b}$ New York State Water Quality Standards, Class "D" as a comparative reference for nonradiological results at WNSWAMP

${ }^{c}$ Standards for cobalt, thallium, and vanadium are acid-soluble. 
Table C-3E

2004 Indicator Results at Storage and Disposal Area Drainage (WNNDADR)

\begin{tabular}{|l|c|c|c|c|c|c|}
\hline \multirow{2}{*}{ Analyte } & \multirow{2}{*}{ Units } & \multirow{2}{*}{$\mathbf{N}$} & \multicolumn{3}{c|}{ WNNDADR Concentrations } & \multirow{2}{*}{ Standard $^{\mathbf{a}}$} \\
\cline { 4 - 7 } & & & Minimum & Average & Maximum & \\
\hline Gross Alpha & $\mu \mathrm{Ci} / \mathrm{mL}$ & 12 & $<9.65 \mathrm{E}-10$ & $0.59 \pm 1.31 \mathrm{E}-09$ & $2.11 \mathrm{E}-09$ & -- \\
\hline Gross Beta & $\mu \mathrm{Ci} / \mathrm{mL}$ & 12 & $1.49 \mathrm{E}-07$ & $1.97 \pm 0.06 \mathrm{E}-07$ & $2.58 \mathrm{E}-07$ & -- \\
\hline Tritium & $\mu \mathrm{Ci} / \mathrm{mL}$ & 12 & $4.04 \mathrm{E}-07$ & $8.11 \pm 0.92 \mathrm{E}-07$ & $1.30 \mathrm{E}-06$ & - \\
\hline Sr-90 & $\mu \mathrm{Ci} / \mathrm{mL}$ & 4 & $8.49 \mathrm{E}-08$ & $9.73 \pm 0.53 \mathrm{E}-08$ & $1.05 \mathrm{E}-07$ & - \\
\hline I-129 & $\mu \mathrm{Ci} / \mathrm{mL}$ & 4 & $<8.18 \mathrm{E}-10$ & $-1.46 \pm 9.22 \mathrm{E}-10$ & $<1.03 \mathrm{E}-09$ & - \\
\hline Cs-137 & $\mu \mathrm{Ci} / \mathrm{mL}$ & 12 & $<1.90 \mathrm{E}-09$ & $1.52 \pm 7.34 \mathrm{E}-09$ & $<1.23 \mathrm{E}-08$ & - \\
\hline NPOC & $\mathrm{mg} / \mathrm{L}$ & 53 & 1.1 & 5.7 & 11.8 & - \\
\hline pH & $\mathrm{SU}$ & 53 & 6.54 & 7.39 & 8.08 & $6.0-9.5$ \\
\hline TOX & $\mathrm{mg} / \mathrm{L}$ & 53 & $<0.005$ & $<0.03$ & 0.225 & - \\
\hline
\end{tabular}

$N$ - Number of samples

-- No applicable reference standard available

${ }^{a}$ New York State Water Quality Standards, Class “D” as a comparative reference for nonradiological results at WNNDADR

Table C-3F

2004 Indicator Results in Subsurface Water at the NDA Interceptor Trench (WNNDATR)

\begin{tabular}{|l|c|c|c|c|c|}
\hline \multirow{2}{*}{\multicolumn{1}{c|}{ Analyte }} & \multirow{2}{*}{ Units } & \multirow{2}{*}{$\mathbf{N}$} & \multicolumn{3}{c|}{ WNNDATR Concentrations } \\
\cline { 4 - 6 } & & & Minimum & Average & Maximum \\
\hline Gross Alpha & $\mu \mathrm{Ci} / \mathrm{mL}$ & 12 & $<1.50 \mathrm{E}-09$ & $1.26 \pm 2.40 \mathrm{E}-09$ & $4.51 \mathrm{E}-09$ \\
\hline Gross Beta & $\mu \mathrm{Ci} / \mathrm{mL}$ & 12 & $1.29 \mathrm{E}-07$ & $1.76 \pm 0.07 \mathrm{E}-07$ & $2.01 \mathrm{E}-07$ \\
\hline Tritium & $\mu \mathrm{Ci} / \mathrm{mL}$ & 12 & $2.49 \mathrm{E}-07$ & $3.75 \pm 0.17 \mathrm{E}-06$ & $6.36 \mathrm{E}-06$ \\
\hline I-129 & $\mu \mathrm{Ci} / \mathrm{mL}$ & 4 & $<8.00 \mathrm{E}-10$ & $0.55 \pm 1.33 \mathrm{E}-09$ & $<1.78 \mathrm{E}-09$ \\
\hline Cs-137 & $\mu \mathrm{Ci} / \mathrm{mL}$ & 12 & $<4.33 \mathrm{E}-09$ & $1.59 \pm 6.50 \mathrm{E}-09$ & $7.08 \mathrm{E}-09$ \\
\hline NPOC & $\mathrm{mg} / \mathrm{L}$ & 12 & 2.3 & 4.3 & 6.4 \\
\hline TOX & $\mathrm{mg} / \mathrm{L}$ & 12 & $<0.006$ & $<0.018$ & 0.033 \\
\hline
\end{tabular}

Note: No standards applicable for this location. These waters are pumped and treated at the LLWTF prior to discharge at outfall WNSP001.

$N$ - Number of samples

WVDP Annual Site Environmental Report

$C-32$

Calendar Year 2004 
Table C-3G

2004 Indicator Results at SDA Drainage (WNSDADR)

\begin{tabular}{|l|c|c|c|c|c|c|}
\hline \multirow{2}{*}{\multicolumn{1}{c|}{ Analyte }} & \multirow{2}{*}{ Units } & \multirow{2}{*}{$\mathbf{N}$} & \multicolumn{3}{c|}{ WNSDADR Concentrations } & \multirow{2}{*}{$\begin{array}{c}\text { Guideline or } \\
\text { Standard }\end{array}$} \\
\cline { 4 - 7 } & & & Minimum & Average & Maximum & \\
\hline Gross Alpha & $\mu \mathrm{Ci} / \mathrm{mL}$ & 12 & $<3.06 \mathrm{E}-10$ & $7.58 \pm 6.72 \mathrm{E}-10$ & $1.73 \mathrm{E}-09$ & - \\
\hline Gross Beta & $\mu \mathrm{Ci} / \mathrm{mL}$ & 12 & $1.71 \mathrm{E}-09$ & $5.59 \pm 0.95 \mathrm{E}-09$ & $2.18 \mathrm{E}-08$ & - \\
\hline Tritium & $\mu \mathrm{Ci} / \mathrm{mL}$ & 12 & $1.63 \mathrm{E}-07$ & $5.23 \pm 0.83 \mathrm{E}-07$ & $1.74 \mathrm{E}-06$ & - \\
\hline Cs-137 & $\mu \mathrm{Ci} / \mathrm{mL}$ & 12 & $<4.91 \mathrm{E}-09$ & $0.28 \pm 7.32 \mathrm{E}-09$ & $<1.08 \mathrm{E}-08$ & - \\
\hline pH & $\mathrm{SU}$ & 12 & 6.61 & 7.22 & 7.9 & $6.5-8.5$ \\
\hline
\end{tabular}

$N$ - Number of samples

-- No applicable reference standard available

${ }^{a}$ New York State Water Quality Standards, Class "C" as a comparative reference for nonradiological results at WNSDADR

Table $\mathrm{C}-3 \mathrm{H}$

2004 Indicator Results in Surface Water at Cooling Tower Basin (WNCOOLW)

\begin{tabular}{|l|c|c|c|c|c|}
\hline \multirow{2}{*}{\multicolumn{1}{c|}{ Analyte }} & \multirow{2}{*}{ Units } & \multirow{2}{*}{$\mathbf{N}$} & \multicolumn{3}{c|}{ WNCOOLW Concentrations } \\
\cline { 4 - 6 } & & & Minimum & Average & Maximum \\
\hline Gross Alpha & $\mu \mathrm{Ci} / \mathrm{mL}$ & 4 & $<1.06 \mathrm{E}-09$ & $0.17 \pm 1.39 \mathrm{E}-09$ & $<1.91 \mathrm{E}-09$ \\
\hline Gross Beta & $\mu \mathrm{Ci} / \mathrm{mL}$ & 4 & $<2.45 \mathrm{E}-09$ & $2.20 \pm 2.98 \mathrm{E}-09$ & $3.69 \mathrm{E}-09$ \\
\hline Tritium & $\mu \mathrm{Ci} / \mathrm{mL}$ & 4 & $<5.61 \mathrm{E}-08$ & $1.00 \pm 6.94 \mathrm{E}-08$ & $8.47 \mathrm{E}-08$ \\
\hline Sr-90 & $\mu \mathrm{Ci} / \mathrm{mL}$ & 4 & $<1.36 \mathrm{E}-09$ & $1.07 \pm 1.36 \mathrm{E}-09$ & $2.21 \mathrm{E}-09$ \\
\hline Cs-137 & $\mu \mathrm{Ci} / \mathrm{mL}$ & 4 & $<3.99 \mathrm{E}-09$ & $-2.39 \pm 7.40 \mathrm{E}-09$ & $<1.05 \mathrm{E}-08$ \\
\hline pH & $\mathrm{SU}$ & 4 & 7.79 & 8.07 & 8.56 \\
\hline
\end{tabular}

Note: No standards are applicable for this location. These waters are pumped and treated at the LLWTF prior to discharge at outfall WNSPOO1.

$N$ - Number of samples 
This page intentionally left blank

$$
C-34
$$




\section{Appendix C-4 Ambient Surface Water Data}


This page intentionally left blank

$$
\text { C }-36
$$


Table C-4A

2004 Radioactivity and $p H$ in Surface Water Downstream of the WVDP in Cattaraugus Creek at Felton Bridge (WFFELBR)

\begin{tabular}{|c|c|c|c|c|c|c|c|}
\hline \multirow{3}{*}{ Analyte } & \multirow{3}{*}{ Units } & \multirow{3}{*}{$\mathbf{N}$} & \multirow{2}{*}{\multicolumn{2}{|c|}{$\begin{array}{c}\text { WFFELBR } \\
\text { Concentrations }\end{array}$}} & \multirow{3}{*}{$\mathbf{N}$} & \multicolumn{2}{|c|}{ Reference Values } \\
\hline & & & & & & \multirow{2}{*}{$\begin{array}{c}\text { WFBIGBR }^{\mathrm{a}} \\
\text { Background Range }\end{array}$} & \multirow{2}{*}{$\begin{array}{l}\text { Guideline }^{b} \\
\text { or Standard }^{c}\end{array}$} \\
\hline & & & Average & Maximum & & & \\
\hline Gross Alpha & $\mu \mathrm{Ci} / \mathrm{mL}$ & 12 & $0.95 \pm 1.34 \mathrm{E}-09$ & $3.51 \mathrm{E}-09$ & 12 & $<8.71 \mathrm{E}-10-2.10 \mathrm{E}-09$ & $3 \mathrm{E}-08^{\mathrm{d}}$ \\
\hline Gross Beta & $\mu \mathrm{Ci} / \mathrm{mL}$ & 12 & $3.61 \pm 1.69 \mathrm{E}-09$ & 7.69E-09 & 12 & $<9.03 \mathrm{E}-10-4.16 \mathrm{E}-09$ & $1 \mathrm{E}-06^{\mathrm{e}}$ \\
\hline Tritium & $\mu \mathrm{Ci} / \mathrm{mL}$ & 12 & $-2.10 \pm 8.10 \mathrm{E}-08$ & $<8.94 \mathrm{E}-08$ & 12 & $<5.52 \mathrm{E}-08-8.98 \mathrm{E}-08$ & $2 \mathrm{E}-03$ \\
\hline Sr-90 & $\mu \mathrm{Ci} / \mathrm{mL}$ & 12 & $1.81 \pm 1.46 \mathrm{E}-09$ & 2.74E-09 & 12 & $<1.12 \mathrm{E}-09-2.24 \mathrm{E}-09$ & $1 \mathrm{E}-06$ \\
\hline Tc-99 & $\mu \mathrm{Ci} / \mathrm{mL}$ & 4 & $-1.94 \pm 2.22 \mathrm{E}-09$ & $<2.61 \mathrm{E}-09$ & 0 & NA & $1 \mathrm{E}-04$ \\
\hline Cs-137 & $\mu \mathrm{Ci} / \mathrm{mL}$ & 12 & $0.75 \pm 2.35 \mathrm{E}-09$ & 2.33E-09 & 12 & $<1.87 \mathrm{E}-09-1.97 \mathrm{E}-09$ & $3 \mathrm{E}-06$ \\
\hline pH & $\mathrm{SU}$ & 53 & 7.01 & 8.28 & 12 & $7.30-8.34$ & $6.5-8.5$ \\
\hline
\end{tabular}

$N$ - Number of samples

NA - Data not available

${ }^{a}$ Background location

${ }^{b}$ DOE ingestion-based DCGs for 100 mrem/yr dose limit are provided as a guideline for radiological results in the absence of water quality standards.

"New York State Water Quality Standards, Class “B” as a comparative reference for nonradiological results

d Alpha as Am-241

e Beta as $\mathrm{Sr}-90$

Table C-4B

2004 Water Quality of Surface Water Downstream of the WVDP in Buttermilk Creek at Thomas Corners Bridge (WFBCTCB)

RADIOACTIVITY CONCENTRATIONS

\begin{tabular}{|c|c|c|c|c|c|c|c|}
\hline \multirow{3}{*}{ Analyte } & \multirow{3}{*}{ Units } & \multirow{3}{*}{$\mathbf{N}$} & \multirow{2}{*}{\multicolumn{2}{|c|}{$\begin{array}{c}\text { WFBCTCB } \\
\text { Concentrations }\end{array}$}} & \multirow{3}{*}{$\mathbf{N}$} & \multicolumn{2}{|c|}{ Reference Values } \\
\hline & & & & & & \multirow{2}{*}{$\begin{array}{c}\text { WFBCBKG } \\
\text { Background Range }\end{array}$} & \multirow{2}{*}{ Guideline $^{\mathrm{b}}$} \\
\hline & & & Average & Maximum & & & \\
\hline Gross Alpha & $\mu \mathrm{Ci} / \mathrm{mL}$ & 12 & $6.90 \pm 9.30 \mathrm{E}-10$ & 2.11E-09 & 12 & $<4.53 \mathrm{E}-10-2.55 \mathrm{E}-09$ & $3 \mathrm{E}-08^{\mathrm{c}}$ \\
\hline Gross Beta & $\mu \mathrm{Ci} / \mathrm{mL}$ & 12 & $7.88 \pm 1.49 \mathrm{E}-09$ & $1.18 \mathrm{E}-08$ & 12 & $<1.16 \mathrm{E}-09-3.64 \mathrm{E}-09$ & $1 \mathrm{E}-06^{\mathrm{d}}$ \\
\hline Tritium & $\mu \mathrm{Ci} / \mathrm{mL}$ & 12 & $1.49 \pm 8.09 \mathrm{E}-08$ & $1.76 \mathrm{E}-07$ & 12 & $<7.48 \mathrm{E}-08-1.35 \mathrm{E}-07$ & $2 \mathrm{E}-03$ \\
\hline Sr-90 & $\mu \mathrm{Ci} / \mathrm{mL}$ & 4 & $3.67 \pm 1.64 \mathrm{E}-09$ & 4.89E-09 & 4 & $<1.13 \mathrm{E}-09-<1.30 \mathrm{E}-09$ & $1 \mathrm{E}-06$ \\
\hline Tc-99 & $\mu \mathrm{Ci} / \mathrm{mL}$ & 4 & $-2.10 \pm 2.08 \mathrm{E}-09$ & $<2.39 \mathrm{E}-09$ & 4 & $<1.44 \mathrm{E}-09-<2.27 \mathrm{E}-09$ & $1 \mathrm{E}-04$ \\
\hline Cs-137 & $\mu \mathrm{Ci} / \mathrm{mL}$ & 4 & $2.46 \pm 2.82 \mathrm{E}-09$ & 4.23E-09 & 4 & $<1.94 \mathrm{E}-09-<2.34 \mathrm{E}-09$ & $3 \mathrm{E}-06$ \\
\hline
\end{tabular}

$N$ - Number of samples

a Background location

${ }^{b}$ DOE ingestion-based DCGs for $100 \mathrm{mrem} / \mathrm{yr}$ dose limit are provided as a guideline for radiological results in the absence of water quality standards.

${ }^{c}$ Alpha as Am-241

${ }^{d}$ Beta as $\mathrm{Sr}-90$ 
Table C-4B (continued)

2004 Water Quality of Surface Water Downstream of the WVDP in Buttermilk Creek at Thomas Corners Bridge (WFBCTCB)

CHEMICAL CONSTITUENTS

\begin{tabular}{|c|c|c|c|c|c|c|c|}
\hline \multirow{3}{*}{ Analyte } & \multirow{3}{*}{ Units } & \multirow{3}{*}{$\mathbf{N}$} & \multirow{2}{*}{\multicolumn{2}{|c|}{$\begin{array}{c}\text { WFBCTCB } \\
\text { Concentrations }\end{array}$}} & \multirow{3}{*}{$\mathbf{N}$} & \multicolumn{2}{|l|}{\begin{tabular}{|c|} 
Reference Values \\
\end{tabular}} \\
\hline & & & & & & WFBCBKG ${ }^{\text {a }}$ Background & Standard ${ }^{b}$ \\
\hline & & & Average & Maximum & & Range & Standard \\
\hline Alpha-BHC & $\mathrm{mg} / \mathrm{L}$ & 2 & $<0.000009$ & $<0.000009$ & 2 & $<0.000009-<0.000009$ & 0.000002 \\
\hline Aluminum, Dissolved & $\mathrm{mg} / \mathrm{L}$ & 2 & 0.686 & 1.26 & 2 & $<0.100-0.328$ & 0.10 \\
\hline Ammonia-N & $\mathrm{mg} / \mathrm{L}$ & 2 & $<0.16$ & 0.28 & 2 & $<0.05-0.07$ & $0.09-2.1$ \\
\hline Antimony, Total & $\mathrm{mg} / \mathrm{L}$ & 2 & $<0.003$ & $<0.003$ & 2 & $<0.003-<0.003$ & -- \\
\hline Arsenic, Dissolved & $\mathrm{mg} / \mathrm{L}$ & 2 & $<0.005$ & $<0.005$ & 2 & $<0.005-<0.005$ & 0.150 \\
\hline Barium, Total & $\mathrm{mg} / \mathrm{L}$ & 2 & $<0.06$ & 0.07 & 2 & $0.06-0.10$ & -- \\
\hline Boron, Total & $\mathrm{mg} / \mathrm{L}$ & 2 & 0.02 & 0.03 & 2 & $0.01-0.02$ & 10.0 \\
\hline Bromide & $\mathrm{mg} / \mathrm{L}$ & 2 & $<0.50$ & $<0.50$ & 2 & $<0.50-<0.50$ & -- \\
\hline Cadmium, Dissolved & $\mathrm{mg} / \mathrm{L}$ & 2 & $<0.001$ & $<0.001$ & 2 & $<0.001-<0.001$ & $0.003^{\mathrm{c}}$ \\
\hline Calcium, Total & $\mathrm{mg} / \mathrm{L}$ & 12 & 38.1 & 54.4 & 12 & $23.1-46.9$ & -- \\
\hline Chloride & $\mathrm{mg} / \mathrm{L}$ & 2 & 20 & 23 & 2 & $12-13$ & -- \\
\hline Chromium, Dissolved & $\mathrm{mg} / \mathrm{L}$ & 2 & $<0.01$ & $<0.01$ & 2 & $<0.01-<0.01$ & $0.114^{\mathrm{c}}$ \\
\hline Cobalt, Total & $\mathrm{mg} / \mathrm{L}$ & 2 & $<0.005$ & $<0.005$ & 2 & $<0.005-<0.005$ & $0.005^{\mathrm{d}}$ \\
\hline Copper, Dissolved & $\mathrm{mg} / \mathrm{L}$ & 2 & $<0.005$ & $<0.005$ & 2 & $<0.005-<0.005$ & $0.014^{\mathrm{c}}$ \\
\hline Dissolved, Oxygen & $\mathrm{mg} / \mathrm{L}$ & 2 & 10.9 & 12.3 & 2 & $10.5-11.9$ & 4.0 (min) \\
\hline Fluoride & $\mathrm{mg} / \mathrm{L}$ & 2 & $<0.10$ & $<0.10$ & 2 & $<0.10-<0.10$ & $3.43^{\mathrm{c}}$ \\
\hline Hardness & $\mathrm{mg} / \mathrm{L}$ & 12 & 120 & 170 & 12 & $73-144$ & -- \\
\hline Iron, Total & $\mathrm{mg} / \mathrm{L}$ & 2 & 1.66 & 2.52 & 2 & $0.51-2.16$ & 0.30 \\
\hline Lead, Dissolved & $\mathrm{mg} / \mathrm{L}$ & 2 & $<0.0005$ & $<0.0005$ & 2 & $<0.0005-<0.0005$ & $0.007^{\mathrm{c}}$ \\
\hline Magnesium, Total & $\mathrm{mg} / \mathrm{L}$ & 12 & 5.99 & 8.22 & 12 & $3.57-6.59$ & -- \\
\hline Manganese, Total & $\mathrm{mg} / \mathrm{L}$ & 2 & 0.03 & 0.04 & 2 & $0.04-0.04$ & -- \\
\hline Mercury, Dissolved, Method 1631 & $\mathrm{mg} / \mathrm{L}$ & 2 & $<0.000000815$ & 0.00000113 & 2 & $<0.000000500-0.00000113$ & -- \\
\hline Nickel, Dissolved & $\mathrm{mg} / \mathrm{L}$ & 2 & $<0.04$ & $<0.04$ & 2 & $<0.04-<0.04$ & $0.081^{\mathrm{c}}$ \\
\hline Nitrate-N & $\mathrm{mg} / \mathrm{L}$ & 2 & 0.58 & 0.62 & 2 & $<0.05-0.61$ & -- \\
\hline Nitrite-N & $\mathrm{mg} / \mathrm{L}$ & 2 & $<0.05$ & $<0.05$ & 2 & $<0.05-<0.05$ & 0.10 \\
\hline NPOC & $\mathrm{mg} / \mathrm{L}$ & 2 & 2.4 & 2.4 & 2 & $2.0-2.4$ & -- \\
\hline
\end{tabular}

$N$ - Number of samples

-- No reference standard available for this analyte

${ }^{a}$ Background location

${ }^{b}$ New York State Water Quality Standards, Class “C”" as a comparative reference for nonradiological results

${ }^{c}$ Calculated from maximum measurement of hardness of surface water stream at WFBCTCB

${ }^{d}$ Standards for cobalt, thallium, and vanadium are acid-soluble. 


\section{Table C-4B (concluded)}

2004 Water Quality of Surface Water Downstream of the WVDP in Buttermilk Creek at Thomas Corners Bridge (WFBCTCB)

\section{CHEMICAL CONSTITUENTS (concluded)}

\begin{tabular}{|c|c|c|c|c|c|c|c|}
\hline \multirow{3}{*}{ Analyte } & \multirow{3}{*}{ Units } & \multirow{3}{*}{$\mathbf{N}$} & \multirow{2}{*}{\multicolumn{2}{|c|}{$\begin{array}{c}\text { WFBCTCB } \\
\text { Concentrations }\end{array}$}} & \multirow{3}{*}{$\mathbf{N}$} & \multicolumn{2}{|c|}{ Reference Values } \\
\hline & & & & & & \multirow{2}{*}{$\begin{array}{c}\text { WFBCBKG } \\
\text { Background Range }\end{array}$} & \multirow{2}{*}{ Standard $^{\mathbf{b}}$} \\
\hline & & & Average & Maximum & & & \\
\hline Oil \& Grease & $\mathrm{mg} / \mathrm{L}$ & 2 & $<5$ & $<5$ & 2 & $<5-<5$ & -- \\
\hline pH & $\mathrm{SU}$ & 2 & 7.85 & 7.89 & 2 & $7.68-7.97$ & $6.5-8.5$ \\
\hline Selenium, Dissolved & $\mathrm{mg} / \mathrm{L}$ & 2 & $<0.001$ & $<0.001$ & 2 & $<0.001-<0.001$ & 0.0046 \\
\hline Sodium, Total & $\mathrm{mg} / \mathrm{L}$ & 2 & 13 & 16.1 & 2 & $7.7-9.0$ & -- \\
\hline Solids, Total Dissolved & $\mathrm{mg} / \mathrm{L}$ & 2 & 178 & 229 & 2 & $117-188$ & 500 \\
\hline Solids, Total Suspended & $\mathrm{mg} / \mathrm{L}$ & 2 & $<4$ & $<4$ & 2 & $<4-39$ & -- \\
\hline Sulfate & $\mathrm{mg} / \mathrm{L}$ & 2 & 20.2 & 24.7 & 2 & $14.4-20.7$ & -- \\
\hline Sulfide & $\mathrm{mg} / \mathrm{L}$ & 2 & 0.06 & 0.08 & 2 & $<0.04-0.08$ & 0.002 \\
\hline Surfactants & $\mathrm{mg} / \mathrm{L}$ & 2 & $<0.10$ & $<0.10$ & 2 & $<0.03-<0.10$ & 0.04 \\
\hline Thallium, Total & $\mathrm{mg} / \mathrm{L}$ & 2 & $<0.008$ & $<0.008$ & 2 & $<0.008-<0.008$ & $0.008^{\mathrm{d}}$ \\
\hline Titanium, Total & $\mathrm{mg} / \mathrm{L}$ & 2 & $<0.05$ & 0.05 & 2 & $<0.05-<0.05$ & -- \\
\hline TOX & $\mathrm{mg} / \mathrm{L}$ & 2 & $<0.02$ & $<0.03$ & 2 & $<0.00-<0.03$ & -- \\
\hline Vanadium, Total & $\mathrm{mg} / \mathrm{L}$ & 2 & $<0.01$ & $<0.01$ & 2 & $<0.01-<0.01$ & $0.014^{\mathrm{d}}$ \\
\hline Zinc, Dissolved & $\mathrm{mg} / \mathrm{L}$ & 2 & $<0.02$ & $<0.02$ & 2 & $<0.02-<0.02$ & $0.130^{\mathrm{c}}$ \\
\hline
\end{tabular}

$N$ - Number of samples

-- No reference standard available for this analyte

${ }^{a}$ Background location

${ }^{b}$ New York State Water Quality Standards, Class “C” as a comparative reference for nonradiological results

${ }^{c}$ Calculated from maximum measurement of hardness of surface water stream at WFBCTCB

${ }^{d}$ Standards for cobalt, thallium, and vanadium are acid-soluble. 
Table C-4C

\section{Water Quality of Surface Water Downstream of the WVDP at Frank's Creek (WNSP006)}

RADIOACTIVITY CONCENTRATIONS

\begin{tabular}{|c|c|c|c|c|c|c|c|}
\hline \multirow{3}{*}{ Analyte } & \multirow{3}{*}{ Units } & \multirow{3}{*}{$\mathbf{N}$} & \multirow{2}{*}{\multicolumn{2}{|c|}{$\begin{array}{c}\text { WNSP006 } \\
\text { Concentrations }\end{array}$}} & \multirow{3}{*}{$\mathbf{N}$} & \multicolumn{2}{|c|}{ Reference Values } \\
\hline & & & & & & \multirow{2}{*}{$\begin{array}{c}\text { WFBCBKG } \\
\text { Background Range }\end{array}$} & \multirow{2}{*}{ Guideline $^{b}$} \\
\hline & & & Average & Maximum & & & \\
\hline Gross Alpha & $\mu \mathrm{Ci} / \mathrm{mL}$ & 53 & $0.62 \pm 1.72 \mathrm{E}-09$ & $6.91 \mathrm{E}-09$ & 12 & $<4.53 \mathrm{E}-10-2.55 \mathrm{E}-09$ & $3 \mathrm{E}-08^{\mathrm{c}}$ \\
\hline Gross Beta & $\mu \mathrm{Ci} / \mathrm{mL}$ & 53 & $4.31 \pm 0.40 \mathrm{E}-08$ & 8.28E-08 & 12 & $<1.16 \mathrm{E}-09-3.64 \mathrm{E}-09$ & $1 \mathrm{E}-06^{\mathrm{d}}$ \\
\hline Tritium & $\mu \mathrm{Ci} / \mathrm{mL}$ & 53 & $7.53 \pm 8.00 \mathrm{E}-08$ & $5.81 \mathrm{E}-07$ & 12 & $<7.48 \mathrm{E}-08-1.35 \mathrm{E}-07$ & $2 \mathrm{E}-03$ \\
\hline C-14 & $\mu \mathrm{Ci} / \mathrm{mL}$ & 4 & $-0.32 \pm 2.36 \mathrm{E}-08$ & $<2.86 \mathrm{E}-08$ & 4 & $<5.38 \mathrm{E}-09-<3.03 \mathrm{E}-08$ & $7 \mathrm{E}-05$ \\
\hline Sr-90 & $\mu \mathrm{Ci} / \mathrm{mL}$ & 12 & $2.12 \pm 0.31 \mathrm{E}-08$ & $3.52 \mathrm{E}-08$ & 4 & $<1.13 \mathrm{E}-09-<1.30 \mathrm{E}-09$ & $1 \mathrm{E}-06$ \\
\hline Tc-99 & $\mu \mathrm{Ci} / \mathrm{mL}$ & 4 & $1.04 \pm 2.25 \mathrm{E}-09$ & 3.55E-09 & 4 & $<1.44 \mathrm{E}-09-<2.27 \mathrm{E}-09$ & $1 \mathrm{E}-04$ \\
\hline I-129 & $\mu \mathrm{Ci} / \mathrm{mL}$ & 4 & $4.82 \pm 7.93 \mathrm{E}-10$ & 1.05E-09 & 4 & $<6.26 \mathrm{E}-10-1.21 \mathrm{E}-09$ & 5E-07 \\
\hline Cs-137 & $\mu \mathrm{Ci} / \mathrm{mL}$ & 12 & $2.41 \pm 7.57 \mathrm{E}-09$ & 1.14E-08 & 4 & $<1.94 \mathrm{E}-09-<2.34 \mathrm{E}-09$ & $3 \mathrm{E}-06$ \\
\hline U-232 & $\mu \mathrm{Ci} / \mathrm{mL}$ & 4 & $2.92 \pm 1.35 \mathrm{E}-10$ & 3.87E-10 & 4 & $<3.46 \mathrm{E}-11-<1.00 \mathrm{E}-10$ & 1E-07 \\
\hline U-233/234 & $\mu \mathrm{Ci} / \mathrm{mL}$ & 4 & $3.90 \pm 1.46 \mathrm{E}-10$ & 5.36E-10 & 4 & 8.19E-11-1.81E-10 & $5 \mathrm{E}-07$ \\
\hline U-235/236 & $\mu \mathrm{Ci} / \mathrm{mL}$ & 4 & $6.40 \pm 6.00 \mathrm{E}-11$ & $9.57 \mathrm{E}-11$ & 4 & $<4.14 \mathrm{E}-11-5.25 \mathrm{E}-11$ & $5 \mathrm{E}-07^{\mathrm{e}}$ \\
\hline U-238 & $\mu \mathrm{Ci} / \mathrm{mL}$ & 4 & $4.18 \pm 1.47 \mathrm{E}-10$ & $5.49 \mathrm{E}-10$ & 4 & $<4.68 \mathrm{E}-11-8.50 \mathrm{E}-11$ & $6 \mathrm{E}-07$ \\
\hline Total U & $\mu \mathrm{g} / \mathrm{mL}$ & 4 & $9.60 \pm 0.19 \mathrm{E}-04$ & $1.38 \mathrm{E}-03$ & 4 & 3.32E-05-6.00E-04 & -- \\
\hline Pu-238 & $\mu \mathrm{Ci} / \mathrm{mL}$ & 4 & $1.09 \pm 3.24 \mathrm{E}-11$ & $3.28 \mathrm{E}-11$ & 4 & $<1.24 \mathrm{E}-11-<3.38 \mathrm{E}-11$ & $4 \mathrm{E}-08$ \\
\hline Pu-239/240 & $\mu \mathrm{Ci} / \mathrm{mL}$ & 4 & $2.07 \pm 3.55 \mathrm{E}-11$ & $6.62 \mathrm{E}-11$ & 4 & $<1.25 \mathrm{E}-11-<3.85 \mathrm{E}-11$ & 3E-08 \\
\hline Am-241 & $\mu \mathrm{Ci} / \mathrm{mL}$ & 4 & $2.32 \pm 3.47 \mathrm{E}-11$ & $<4.68 \mathrm{E}-11$ & 4 & $<2.21 \mathrm{E}-11-<4.85 \mathrm{E}-11$ & $3 \mathrm{E}-08$ \\
\hline
\end{tabular}

$N$ - Number of samples

-- No guideline or standard available for these analytes

${ }^{a}$ Background location

${ }^{b}$ DOE ingestion-based DCGs for $100 \mathrm{mrem} / \mathrm{yr}$ dose limit are provided as a guideline for radiological results.

${ }^{c}$ Alpha as Am-241

${ }^{d}$ Beta as $\mathrm{Sr}-90$

${ }^{e} D C G$ for $U-236$ is used for this comparison. 
Table C-4C (continued)

2004 Water Quality of Surface Water Downstream of the WVDP at Frank's Creek (WNSP006)

CHEMICAL CONSTITUENTS

\begin{tabular}{|c|c|c|c|c|c|c|c|}
\hline \multirow{3}{*}{ Analyte } & \multirow{3}{*}{ Units } & \multirow{3}{*}{$\mathbf{N}$} & \multirow{2}{*}{\multicolumn{2}{|c|}{$\begin{array}{c}\text { WNSP006 } \\
\text { Concentrations }\end{array}$}} & \multirow{3}{*}{$\mathbf{N}$} & \multicolumn{2}{|l|}{ Reference Values } \\
\hline & & & & & & \multirow{2}{*}{$\begin{array}{c}\text { WFBCBKG }^{\mathrm{a}} \\
\text { Background Range }\end{array}$} & \multirow{2}{*}{ Standard } \\
\hline & & & Average & Maximum & & & \\
\hline Alpha-BHC & $\mathrm{mg} / \mathrm{L}$ & 2 & $<0.000009$ & $<0.000009$ & 2 & $<0.000009-<0.000009$ & 0.000002 \\
\hline Aluminum, Dissolved & $\mathrm{mg} / \mathrm{L}$ & 2 & 0.508 & 0.598 & 2 & $<0.100-0.328$ & 0.10 \\
\hline Ammonia-N & $\mathrm{mg} / \mathrm{L}$ & 2 & $<0.05$ & $<0.05$ & 2 & $<0.05-0.07$ & $0.09-2.1$ \\
\hline Antimony, Total & $\mathrm{mg} / \mathrm{L}$ & 2 & $<0.003$ & $<0.003$ & 2 & $<0.003-<0.003$ & -- \\
\hline Arsenic, Dissolved & $\mathrm{mg} / \mathrm{L}$ & 2 & $<0.005$ & $<0.005$ & 2 & $<0.005-<0.005$ & 0.150 \\
\hline Barium, Total & $\mathrm{mg} / \mathrm{L}$ & 2 & 0.07 & 0.09 & 2 & $0.06-0.10$ & -- \\
\hline Boron, Total & $\mathrm{mg} / \mathrm{L}$ & 2 & 0.03 & 0.03 & 2 & $0.01-0.02$ & 10.0 \\
\hline Bromide & $\mathrm{mg} / \mathrm{L}$ & 2 & $<0.63$ & 0.76 & 2 & $<0.50-<0.50$ & -- \\
\hline Cadmium, Dissolved & $\mathrm{mg} / \mathrm{L}$ & 2 & $<0.001$ & $<0.001$ & 2 & $<0.001-<0.001$ & $0.004^{c}$ \\
\hline Calcium, Total & $\mathrm{mg} / \mathrm{L}$ & 12 & 52.2 & 76.6 & 12 & $23.1-46.9$ & -- \\
\hline Chloride & $\mathrm{mg} / \mathrm{L}$ & 2 & 110 & 125 & 2 & $12-13$ & -- \\
\hline Chromium, Dissolved & $\mathrm{mg} / \mathrm{L}$ & 2 & $<0.01$ & $<0.01$ & 2 & $<0.01-<0.01$ & $0.153^{\mathrm{c}}$ \\
\hline Cobalt, Total & $\mathrm{mg} / \mathrm{L}$ & 2 & $<0.005$ & $<0.005$ & 2 & $<0.005-<0.005$ & $0.005^{\mathrm{d}}$ \\
\hline Conductivity & $\mu \mathrm{mhos} / \mathrm{cm} @ 25^{\circ} \mathrm{C}$ & 3 & 554 & 614 & 0 & NA & -- \\
\hline Copper, Dissolved & $\mathrm{mg} / \mathrm{L}$ & 2 & $<0.005$ & $<0.005$ & 2 & $<0.005-<0.005$ & $0.019^{c}$ \\
\hline Dissolved Oxygen & $\mathrm{mg} / \mathrm{L}$ & 2 & 10.8 & 12.7 & 2 & $10.5-11.9$ & $4.0(\mathrm{~min})$ \\
\hline Fluoride & $\mathrm{mg} / \mathrm{L}$ & 2 & $<0.10$ & $<0.10$ & 2 & $<0.10-<0.10$ & $4.72^{\mathrm{c}}$ \\
\hline Hardness & $\mathrm{mg} / \mathrm{L}$ & 12 & 167 & 242 & 12 & 73-144 & -- \\
\hline Iron, Total & $\mathrm{mg} / \mathrm{L}$ & 2 & 5.96 & 8.79 & 2 & $0.51-2.16$ & 0.30 \\
\hline Lead, Dissolved & $\mathrm{mg} / \mathrm{L}$ & 2 & $<0.0005$ & $<0.0005$ & 2 & $<0.0005-<0.0005$ & $0.010^{\mathrm{c}}$ \\
\hline Magnesium, Total & $\mathrm{mg} / \mathrm{L}$ & 12 & 8.93 & 12.1 & 12 & $3.57-6.59$ & -- \\
\hline Manganese, Total & $\mathrm{mg} / \mathrm{L}$ & 2 & 0.17 & 0.26 & 2 & $0.04-0.04$ & -- \\
\hline Mercury, Dissolved, Method 1631 & $\mathrm{mg} / \mathrm{L}$ & 2 & $<0.00000228$ & 0.00000405 & 2 & $<0.000000500-0.00000405$ & -- \\
\hline Nickel, Dissolved & $\mathrm{mg} / \mathrm{L}$ & 2 & $<0.04$ & $<0.04$ & 2 & $<0.04-<0.04$ & $0.11^{\mathrm{c}}$ \\
\hline Nitrate-N & $\mathrm{mg} / \mathrm{L}$ & 2 & 0.58 & 0.58 & 2 & $<0.05-0.61$ & -- \\
\hline Nitrite-N & $\mathrm{mg} / \mathrm{L}$ & 2 & $<0.06$ & 0.06 & 2 & $<0.05-<0.05$ & 0.10 \\
\hline NPOC & $\mathrm{mg} / \mathrm{L}$ & 2 & 2.9 & 3.5 & 2 & $2.0-2.4$ & -- \\
\hline Oil \& Grease & $\mathrm{mg} / \mathrm{L}$ & 2 & $<5$ & $<5$ & 2 & $<5-<5$ & -- \\
\hline pH & SU & 2 & 6.88 & 7.83 & 2 & $7.68-7.97$ & $6.5-8.5$ \\
\hline
\end{tabular}

$N$ - Number of samples

NA - No data available

-- No guideline or standard available for these analytes

${ }^{a}$ Background location

${ }^{b}$ New York Water Quality Standards for Class "C" surface waters as a comparative reference for nonradiological results.

${ }^{c}$ Calculated from maximum measured hardness of surface water stream at WNSP006.

${ }^{d}$ Standards for cobalt, thallium, and vanadium are acid-soluble. 
Table C-4C (concluded)

2004 Water Quality of Surface Water Downstream of the WVDP at

Frank's Creek (WNSP006)

CHEMICAL CONSTITUENTS (concluded)

\begin{tabular}{|c|c|c|c|c|c|c|c|}
\hline \multirow{3}{*}{ Analyte } & \multirow{3}{*}{ Units } & \multirow{3}{*}{$\mathbf{N}$} & \multirow{2}{*}{\multicolumn{2}{|c|}{$\begin{array}{c}\text { WNSP006 } \\
\text { Concentrations }\end{array}$}} & \multirow{3}{*}{$\mathbf{N}$} & \multicolumn{2}{|c|}{ Reference Values } \\
\hline & & & & & & \multirow{2}{*}{$\begin{array}{c}\text { WFBCBKG }^{\mathrm{a}} \\
\text { Background Range }\end{array}$} & \multirow{2}{*}{ Standard ${ }^{\mathrm{b}}$} \\
\hline & & & Average & Maximum & & & \\
\hline Selenium, Dissolved & $\mathrm{mg} / \mathrm{L}$ & 2 & $<0.001$ & $<0.001$ & 2 & $<0.001-<0.001$ & 0.0046 \\
\hline Sodium, Total & $\mathrm{mg} / \mathrm{L}$ & 2 & 87.4 & 93.1 & 2 & 7.7-9.0 & -- \\
\hline Solids, Total Dissolved & $\mathrm{mg} / \mathrm{L}$ & 40 & 314 & 489 & 2 & $117-188$ & 500 \\
\hline Solids, Total Suspended & $\mathrm{mg} / \mathrm{L}$ & 2 & 86 & 113 & 2 & $<4-39$ & -- \\
\hline Sulfate & $\mathrm{mg} / \mathrm{L}$ & 2 & 46.0 & 57.8 & 2 & $14.4-20.7$ & -- \\
\hline Sulfide & $\mathrm{mg} / \mathrm{L}$ & 2 & $<0.04$ & $<0.04$ & 2 & $<0.04-0.08$ & 0.002 \\
\hline Surfactants & $\mathrm{mg} / \mathrm{L}$ & 2 & $<0.06$ & $<0.10$ & 2 & $<0.03-<0.10$ & 0.40 \\
\hline Thallium, Total & $\mathrm{mg} / \mathrm{L}$ & 2 & $<0.008$ & $<0.008$ & 2 & $<0.008-<0.008$ & $0.008^{\mathrm{d}}$ \\
\hline Titanium, Total & $\mathrm{mg} / \mathrm{L}$ & 2 & 0.06 & 0.07 & 2 & $<0.05-<0.05$ & -- \\
\hline TOX & $\mathrm{mg} / \mathrm{L}$ & 2 & 0.01 & 0.01 & 2 & $<0.00-<0.03$ & -- \\
\hline Vanadium, Total & $\mathrm{mg} / \mathrm{L}$ & 2 & $<0.01$ & 0.01 & 2 & $<0.01-<0.01$ & $0.014^{\mathrm{d}}$ \\
\hline Zinc, Dissolved & $\mathrm{mg} / \mathrm{L}$ & 2 & $<0.02$ & $<0.02$ & 2 & $<0.02-<0.02$ & $0.18^{\mathrm{c}}$ \\
\hline
\end{tabular}

$N$ - Number of samples

-- No guideline or standard available for these analytes

${ }^{a}$ Background location

${ }^{b}$ New York Water Quality Standards for Class "C" surface waters as a comparative reference for nonradiological results.

${ }^{c}$ Calculated from maximum measured hardness of surface water stream at WNSP006.

${ }^{d}$ Standards for cobalt, thallium, and vanadium are acid-soluble. 
Table C-4D

2004 Total Dissolved Solids From Outfall WNSP116

\begin{tabular}{|l|c|c|c|c|c|}
\hline \multirow{2}{*}{ Month } & \multirow{2}{*}{ Units } & \multirow{2}{*}{ N } & \multicolumn{2}{c|}{ Total Dissolved Solids } & Daily Maximum \\
Limit
\end{tabular}

$N$ - Number of samples

${ }^{a}$ No discharge this month

Table C-4E

2004 Indicator Results in Surface Water at Erdman Brook (WNERB53)

\begin{tabular}{|c|c|c|c|c|c|c|}
\hline \multirow{2}{*}{ Analyte } & \multirow{2}{*}{ Units } & \multirow{2}{*}{$\mathbf{N}$} & \multicolumn{3}{|c|}{ WNERB53 Concentrations } & \multirow{2}{*}{$\begin{array}{c}\text { Reference } \\
\text { Guideline }^{\text {a }} \text { or } \\
\text { Standard }^{\text {b }}\end{array}$} \\
\hline & & & Minimum & Average & Maximum & \\
\hline Gross Alpha & $\mu \mathrm{Ci} / \mathrm{mL}$ & 53 & $<9.33 \mathrm{E}-10$ & $-0.13 \pm 1.89 \mathrm{E}-09$ & 2.44E-09 & $3 \mathrm{E}-08^{\mathrm{c}}$ \\
\hline Gross Beta & $\mu \mathrm{Ci} / \mathrm{mL}$ & 53 & $1.00 \mathrm{E}-08$ & $1.78 \pm 0.27 \mathrm{E}-08$ & $3.32 \mathrm{E}-08$ & $1 \mathrm{E}-06^{\mathrm{d}}$ \\
\hline Tritium & $\mu \mathrm{Ci} / \mathrm{mL}$ & 53 & $<5.54 \mathrm{E}-08$ & $4.75 \pm 7.71 \mathrm{E}-08$ & $1.77 \mathrm{E}-07$ & $2 \mathrm{E}-03$ \\
\hline Sr-90 & $\mu \mathrm{Ci} / \mathrm{mL}$ & 4 & $7.20 \mathrm{E}-09$ & $7.96 \pm 2.03 \mathrm{E}-09$ & 8.79E-09 & $1 \mathrm{E}-06$ \\
\hline Cs-137 & $\mu \mathrm{Ci} / \mathrm{mL}$ & 4 & $<2.05 \mathrm{E}-09$ & $0.44 \pm 5.63 \mathrm{E}-09$ & $2.41 \mathrm{E}-09$ & $3 \mathrm{E}-06$ \\
\hline pH & $\mathrm{SU}$ & 53 & 6.52 & 7.52 & 8.08 & $6.0-9.5$ \\
\hline
\end{tabular}

$N$ - Number of samples

${ }^{a}$ DOE ingestion-based DCGs for 100 mrem/yr dose limit are provided as a guideline for radiological results.

${ }^{b}$ New York State Water Quality Standards, Class “D” for surface waters as a standard for nonradiological results

c Alpha as Am-241

${ }^{d}$ Beta as Sr-90 
Table $\mathrm{C}-\mathbf{4 F}$

\section{Indicator Results in Surface Water at Frank's Creek East of the SDA (WNFRC67)}

\begin{tabular}{|c|c|c|c|c|c|c|}
\hline \multirow{3}{*}{ Analyte } & \multirow{3}{*}{ Units } & \multirow{3}{*}{$\mathbf{N}$} & \multirow{2}{*}{\multicolumn{3}{|c|}{ WNFRC67 Concentrations }} & \multirow{3}{*}{$\begin{array}{c}\text { Reference } \\
\text { Guideline }^{\mathrm{a}} \text { or } \\
\text { Standard }^{\mathbf{b}}\end{array}$} \\
\hline & & & & & & \\
\hline & & & Minimum & Average & Maximum & \\
\hline Gross Alpha & $\mu \mathrm{Ci} / \mathrm{mL}$ & 12 & $<4.90 \mathrm{E}-10$ & $-0.35 \pm 8.03 \mathrm{E}-10$ & $<1.43 \mathrm{E}-09$ & $3 \mathrm{E}-08^{\mathrm{c}}$ \\
\hline Gross Beta & $\mu \mathrm{Ci} / \mathrm{mL}$ & 12 & $<1.08 \mathrm{E}-09$ & $1.90 \pm 1.19 \mathrm{E}-09$ & $3.86 \mathrm{E}-09$ & $1 \mathrm{E}-06^{\mathrm{d}}$ \\
\hline Tritium & $\mu \mathrm{Ci} / \mathrm{mL}$ & 12 & $<5.64 \mathrm{E}-08$ & $4.84 \pm 8.35 \mathrm{E}-08$ & $1.82 \mathrm{E}-07$ & $2 \mathrm{E}-03$ \\
\hline Sr-90 & $\mu \mathrm{Ci} / \mathrm{mL}$ & 4 & $<8.49 \mathrm{E}-10$ & $0.62 \pm 1.19 \mathrm{E}-09$ & $<1.47 \mathrm{E}-09$ & $1 \mathrm{E}-06$ \\
\hline Cs-137 & $\mu \mathrm{Ci} / \mathrm{mL}$ & 4 & $<1.98 \mathrm{E}-09$ & $1.02 \pm 2.83 \mathrm{E}-09$ & $<3.54 \mathrm{E}-09$ & $3 \mathrm{E}-06$ \\
\hline pH & $\mathrm{SU}$ & 12 & 7.34 & 7.59 & 8.06 & $6.5-8.5$ \\
\hline
\end{tabular}

$N$ - Number of samples

${ }^{a}$ DOE ingestion-based DCGs for $100 \mathrm{mrem} / \mathrm{yr}$ dose limit are provided as a guideline for radiological results in the absence of water quality standards.

${ }^{b}$ New York State Water Quality Standards for Class “C” surface waters as a comparative reference for nonradiological results.

${ }^{c}$ Alpha as Am-241

${ }^{d}$ Beta as $\mathrm{Sr}-90$

Table C-4G

2004 Indicator Results in Surface Water at Drum Cell Drainage (WNDCELD)

\begin{tabular}{|l|c|c|c|c|c|c|}
\hline \multirow{2}{*}{ Analyte } & \multirow{2}{*}{ Units } & \multirow{2}{*}{$\mathbf{N}$} & \multicolumn{3}{c|}{ WNDCELD Concentrations $^{\text {Reference }}$} \\
\cline { 4 - 7 } & & & Minimum & Average & $\begin{array}{c}\text { Muideline }^{\text {a }} \\
\text { or Standard }^{\mathbf{b}}\end{array}$ \\
\hline Gross Alpha & $\mu \mathrm{Ci} / \mathrm{mL}$ & 12 & $<4.84 \mathrm{E}-10$ & $-0.94 \pm 8.74 \mathrm{E}-10$ & $1.28 \mathrm{E}-09$ & $3 \mathrm{E}-08^{\mathrm{c}}$ \\
\hline Gross Beta & $\mu \mathrm{Ci} / \mathrm{mL}$ & 12 & $<1.08 \mathrm{E}-09$ & $1.89 \pm 1.21 \mathrm{E}-09$ & $2.82 \mathrm{E}-09$ & $1 \mathrm{E}-06^{\mathrm{d}}$ \\
\hline Tritium & $\mu \mathrm{Ci} / \mathrm{mL}$ & 4 & $<7.86 \mathrm{E}-08$ & $5.50 \pm 8.21 \mathrm{E}-08$ & $9.79 \mathrm{E}-08$ & $2 \mathrm{E}-03$ \\
\hline Sr-90 & $\mu \mathrm{Ci} / \mathrm{mL}$ & 4 & $<1.20 \mathrm{E}-09$ & $1.76 \pm 1.63 \mathrm{E}-09$ & $4.66 \mathrm{E}-09$ & $1 \mathrm{E}-06$ \\
\hline I-129 & $\mu \mathrm{Ci} / \mathrm{mL}$ & 4 & $<4.98 \mathrm{E}-10$ & $2.15 \pm 8.41 \mathrm{E}-10$ & $9.56 \mathrm{E}-10$ & $5 \mathrm{E}-07$ \\
\hline Cs-137 & $\mu \mathrm{Ci} / \mathrm{mL}$ & 4 & $4.54 \mathrm{E}-09$ & $1.18 \pm 5.80 \mathrm{E}-09$ & $4.54 \mathrm{E}-09$ & $3 \mathrm{E}-06$ \\
\hline pH & $\mathrm{SU}$ & 12 & 6.94 & 7.48 & 7.85 & $6.5-8.5$ \\
\hline
\end{tabular}

$N$ - Number of samples

${ }^{a}$ DOE ingestion-based DCGs for 100 mrem/yr dose limit are provided as a guideline for radiological results in the absence of water quality standards.

${ }^{b}$ New York State Water Quality Standards for Class “ C" surface waters as a comparative reference for nonradiological results.

c Alpha as Am-241

${ }^{d}$ Beta as Sr-90 
Table $\mathrm{C}-\mathbf{4 H}$

2004 Water Quality of Surface Water at the Standing Water (WNSTAW-Series) Locations

\begin{tabular}{|c|c|c|c|c|c|c|}
\hline \multirow[b]{2}{*}{ Analyte } & \multirow[b]{2}{*}{ Units } & \multirow[b]{2}{*}{$\mathbf{N}$} & \multirow[b]{2}{*}{ WNSTAW4 } & \multirow[b]{2}{*}{ WNSTAW5 } & \multicolumn{2}{|c|}{ Reference Values } \\
\hline & & & & & $\begin{array}{c}\text { WNSTAWB }^{\mathrm{a}} \\
\text { Background Location }^{\text {W }}\end{array}$ & $\begin{array}{l}\text { Guideline }^{\mathrm{b}} \\
\text { or Standard }^{\mathrm{c}}\end{array}$ \\
\hline Gross Alpha & $\mu \mathrm{Ci} / \mathrm{mL}$ & 1 & $-5.48 \pm 3.88 \mathrm{E}-10$ & $-6.63 \pm 2.72 \mathrm{E}-10$ & $0.57 \pm 8.09 \mathrm{E}-10$ & $3 \mathrm{E}-08^{\mathrm{d}}$ \\
\hline Gross Beta & $\mu \mathrm{Ci} / \mathrm{mL}$ & 1 & $4.16 \pm 0.88 \mathrm{E}-09$ & $1.92 \pm 0.64 \mathrm{E}-09$ & $2.17 \pm 0.93 \mathrm{E}-09$ & $1 \mathrm{E}-06^{\mathrm{e}}$ \\
\hline Tritium & $\mu \mathrm{Ci} / \mathrm{mL}$ & 1 & $-1.85 \pm 8.27 \mathrm{E}-08$ & $1.76 \pm 5.77 \mathrm{E}-08$ & $6.11 \pm 8.07 \mathrm{E}-08$ & $2 \mathrm{E}-03$ \\
\hline Sr-90 & $\mu \mathrm{Ci} / \mathrm{mL}$ & 1 & $1.93 \pm 1.55 \mathrm{E}-09$ & $0.85 \pm 1.08 \mathrm{E}-09$ & $1.72 \pm 0.97 \mathrm{E}-09$ & $1 \mathrm{E}-06$ \\
\hline Cs-137 & $\mu \mathrm{Ci} / \mathrm{mL}$ & 1 & $0.46 \pm 8.38 \mathrm{E}-09$ & $1.15 \pm 6.79 \mathrm{E}-09$ & $-0.01 \pm 1.21 \mathrm{E}-08$ & $3 \mathrm{E}-06$ \\
\hline Chloride & $\mathrm{mg} / \mathrm{L}$ & 1 & 6 & $<1$ & 22 & -- \\
\hline Conductivity & $\mu \mathrm{mhos} / \mathrm{cm} @ 25^{\circ} \mathrm{C}$ & 1 & 95 & 47 & 321 & -- \\
\hline Iron, Total & $\mathrm{mg} / \mathrm{L}$ & 1 & 0.63 & 0.68 & 0.2 & 0.3 \\
\hline Manganese, Total & $\mathrm{mg} / \mathrm{L}$ & 1 & 0.04 & 0.08 & 0.1 & -- \\
\hline Nitrate+Nitrite & $\mathrm{mg} / \mathrm{L}$ & 1 & $<0.05$ & $<0.05$ & $<0.05$ & -- \\
\hline pH & $\mathrm{SU}$ & 1 & 7.88 & 8.19 & 7.97 & $6.0-9.5$ \\
\hline Sodium, Total & $\mathrm{mg} / \mathrm{L}$ & 1 & 4.5 & $<1.0$ & 13 & -- \\
\hline Sulfate & $\mathrm{mg} / \mathrm{L}$ & 1 & 5.4 & 5.8 & 11 & -- \\
\hline
\end{tabular}

\begin{tabular}{|c|c|c|c|c|c|}
\hline \multirow[b]{2}{*}{ Analyte } & \multirow[b]{2}{*}{ Units } & \multirow[b]{2}{*}{$\mathbf{N}$} & \multirow[b]{2}{*}{ WNSTAW6 } & \multicolumn{2}{|c|}{ Reference Values } \\
\hline & & & & $\begin{array}{c}\text { WNSTAWB }^{\text {a }} \\
\text { Background Location }\end{array}$ & $\begin{array}{c}\text { Guideline }^{b} \text { or } \\
\text { Standard }^{c}\end{array}$ \\
\hline Gross Alpha & $\mu \mathrm{Ci} / \mathrm{mL}$ & 1 & $-7.53 \pm 6.85 \mathrm{E}-10$ & $0.57 \pm 8.09 \mathrm{E}-10$ & $3 \mathrm{E}-08^{\mathrm{d}}$ \\
\hline Gross Beta & $\mu \mathrm{Ci} / \mathrm{mL}$ & 1 & $3.15 \pm 1.00 \mathrm{E}-09$ & $2.17 \pm 0.93 \mathrm{E}-09$ & $1 \mathrm{E}-06^{\mathrm{e}}$ \\
\hline Tritium & $\mu \mathrm{Ci} / \mathrm{mL}$ & 1 & $-5.51 \pm 7.93 \mathrm{E}-08$ & $6.11 \pm 8.07 \mathrm{E}-08$ & $2 \mathrm{E}-03$ \\
\hline Sr-90 & $\mu \mathrm{Ci} / \mathrm{mL}$ & 1 & $0.10 \pm 1.52 \mathrm{E}-09$ & $1.72 \pm 0.97 \mathrm{E}-09$ & $1 \mathrm{E}-06$ \\
\hline Cs-137 & $\mu \mathrm{Ci} / \mathrm{mL}$ & 1 & $4.36 \pm 5.05 \mathrm{E}-09$ & $-0.01 \pm 1.21 \mathrm{E}-08$ & $3 \mathrm{E}-06$ \\
\hline Chloride & $\mathrm{mg} / \mathrm{L}$ & 1 & 3 & 22 & -- \\
\hline Conductivity & $\mu \mathrm{mhos} / \mathrm{cm} @ 25^{\circ} \mathrm{C}$ & 1 & 200 & 321 & -- \\
\hline Iron, Total & $\mathrm{mg} / \mathrm{L}$ & 1 & $<0.10$ & 0.2 & 0.3 \\
\hline Manganese, Total & $\mathrm{mg} / \mathrm{L}$ & 1 & $<0.02$ & 0.1 & -- \\
\hline Nitrate+Nitrite & $\mathrm{mg} / \mathrm{L}$ & 1 & $<0.05$ & $<0.05$ & -- \\
\hline pH & $\mathrm{SU}$ & 1 & 8.26 & 7.97 & $6.0-9.5$ \\
\hline Sodium, Total & $\mathrm{mg} / \mathrm{L}$ & 1 & 1.4 & 13 & -- \\
\hline Sulfate & $\mathrm{mg} / \mathrm{L}$ & 1 & 6.6 & 11 & -- \\
\hline
\end{tabular}

$N$ - Number of samples

-- No guideline or standard available for these analytes

a Background location

${ }^{b}$ DOE ingestion-based DCGs for $100 \mathrm{mrem} / \mathrm{yr}$ dose limit are provided as a guideline for radiological results.

'New York State Water Quality Standards Class “D” surface waters as a comparative standard for nonradiological results

${ }^{d}$ Alpha as Am-241

e Beta as Sr-90 


\section{Table C-4H (concluded) \\ 2004 Water Quality of Surface Water at the Standing Water (WNSTAW-Series) Locations}

\begin{tabular}{|c|c|c|c|c|c|}
\hline \multirow[b]{2}{*}{ Analyte } & \multirow[b]{2}{*}{ Units } & \multirow[b]{2}{*}{$\mathbf{N}$} & \multirow[b]{2}{*}{ WNSTAW9 } & \multicolumn{2}{|c|}{ Reference Values } \\
\hline & & & & $\begin{array}{c}\text { WNSTA WB }^{\mathrm{a}} \\
\text { Background Location }\end{array}$ & $\begin{array}{c}\text { Guideline }^{b} \text { or } \\
\text { Standard }^{c}\end{array}$ \\
\hline Gross Alpha & $\mu \mathrm{Ci} / \mathrm{mL}$ & 1 & $-0.38 \pm 5.36 \mathrm{E}-10$ & $0.57 \pm 8.09 \mathrm{E}-10$ & $3 \mathrm{E}-08^{\mathrm{d}}$ \\
\hline Gross Beta & $\mu \mathrm{Ci} / \mathrm{mL}$ & 1 & $2.20 \pm 0.90 \mathrm{E}-09$ & $2.17 \pm 0.93 \mathrm{E}-09$ & $1 \mathrm{E}-06^{\mathrm{e}}$ \\
\hline Tritium & $\mu \mathrm{Ci} / \mathrm{mL}$ & 1 & $-5.20 \pm 8.07 \mathrm{E}-08$ & $6.11 \pm 8.07 \mathrm{E}-08$ & $2 \mathrm{E}-03$ \\
\hline Sr-90 & $\mu \mathrm{Ci} / \mathrm{mL}$ & 1 & $0.41 \pm 1.21 \mathrm{E}-09$ & $1.72 \pm 0.97 \mathrm{E}-09$ & $1 \mathrm{E}-06$ \\
\hline Cs-137 & $\mu \mathrm{Ci} / \mathrm{mL}$ & 1 & $6.38 \pm 6.30 \mathrm{E}-09$ & $-0.01 \pm 1.21 \mathrm{E}-08$ & $3 \mathrm{E}-06$ \\
\hline Chloride & $\mathrm{mg} / \mathrm{L}$ & 1 & 6 & 22 & -- \\
\hline Conductivity & $\mu \mathrm{mhos} / \mathrm{cm} @ 25^{\circ} \mathrm{C}$ & 1 & 185 & 321 & -- \\
\hline Iron, Total & $\mathrm{mg} / \mathrm{L}$ & 1 & 0.48 & 0.2 & 0.3 \\
\hline Manganese, Total & $\mathrm{mg} / \mathrm{L}$ & 1 & 0.29 & 0.1 & -- \\
\hline Nitrate+Nitrite & $\mathrm{mg} / \mathrm{L}$ & 1 & $<0.05$ & $<0.05$ & -- \\
\hline pH & SU & 1 & 7.86 & 7.97 & $6.5-8.5$ \\
\hline Sodium, Total & $\mathrm{mg} / \mathrm{L}$ & 1 & 4.8 & 13 & -- \\
\hline Sulfate & $\mathrm{mg} / \mathrm{L}$ & 1 & 13.2 & 11 & -- \\
\hline
\end{tabular}

$N$ - Number of samples

-- No guideline or standard available for these analytes

${ }^{a}$ Background location

${ }^{b}$ DOE ingestion-based DCGs for 100 mrem/yr dose limit are provided as a guideline for radiological results.

"New York State Water Quality Standards Class “C” surface waters as a comparative standard for nonradiological results at WNSTAW9

${ }^{d}$ Alpha as Am-241

e Beta as Sr-90 


\section{Appendix C-5 \\ Potable Water (Drinking Water) Data}


This page intentionally left blank

$C-48$ 


\section{Table C-5A}

\section{Indicator Results in Potable Well Water Around the WVDP}

\begin{tabular}{|c|c|c|c|c|c|c|c|}
\hline \multirow{3}{*}{ Analyte } & \multirow{3}{*}{ Units } & \multirow{3}{*}{$\mathbf{N}$} & \multirow{2}{*}{\multicolumn{3}{|c|}{ Annual Concentrations at Potable Wells }} & \multicolumn{2}{|c|}{ Reference Values } \\
\hline & & & & & & \multirow{2}{*}{$\begin{array}{c}\text { Background }^{\mathrm{a}} \\
\text { WFWEL06 }\end{array}$} & \multirow{2}{*}{ Standard ${ }^{\mathrm{b},}$} \\
\hline & & & WFWEL01 & WFWELO2 & WFWEL03 & & \\
\hline Gross Alpha & $\mu \mathrm{Ci} / \mathrm{mL}$ & 1 & $0.22 \pm 1.06 \mathrm{E}-09$ & $-0.36 \pm 1.39 \mathrm{E}-09$ & $0.92 \pm 1.09 \mathrm{E}-09$ & $-2.26 \pm 7.02 \mathrm{E}-10$ & $1.5 \mathrm{E}-08^{\mathrm{d}}$ \\
\hline Gross Beta & $\mu \mathrm{Ci} / \mathrm{mL}$ & 1 & $4.24 \pm 1.31 \mathrm{E}-09$ & $1.82 \pm 1.47 \mathrm{E}-09$ & $1.22 \pm 1.41 \mathrm{E}-09$ & $1.77 \pm 8.44 \mathrm{E}-10$ & $1 \mathrm{E}-06^{\mathrm{e}}$ \\
\hline Tritium & $\mu \mathrm{Ci} / \mathrm{mL}$ & 1 & $5.46 \pm 8.37 \mathrm{E}-08$ & $-2.54 \pm 7.72 \mathrm{E}-08$ & $-2.76 \pm 7.74 \mathrm{E}-08$ & $-8.11 \pm 7.99 \mathrm{E}-08$ & -- \\
\hline Sr-90 & $\mu \mathrm{Ci} / \mathrm{mL}$ & 1 & $1.59 \pm 1.52 \mathrm{E}-09$ & $0.20 \pm 1.56 \mathrm{E}-09$ & $0.28 \pm 1.38 \mathrm{E}-09$ & $0.58 \pm 1.25 \mathrm{E}-09$ & -- \\
\hline Cs-137 & $\mu \mathrm{Ci} / \mathrm{mL}$ & 1 & $2.66 \pm 5.70 \mathrm{E}-09$ & $0.32 \pm 1.28 \mathrm{E}-08$ & $-0.10 \pm 6.66 \mathrm{E}-09$ & $-3.34 \pm 6.39 \mathrm{E}-09$ & -- \\
\hline Conductivity & $\mu \mathrm{mhos} / \mathrm{cm} @ 25^{\circ} \mathrm{C}$ & 1 & 406 & 404 & 206 & 270 & -- \\
\hline pH & SU & 1 & 7.89 & 7.55 & 7.97 & 8.14 & $6.5-8.5$ \\
\hline
\end{tabular}

\begin{tabular}{|c|c|c|c|c|c|c|c|}
\hline \multirow{3}{*}{ Analyte } & \multirow{3}{*}{ Units } & \multirow{3}{*}{$\mathbf{N}$} & \multirow{2}{*}{\multicolumn{3}{|c|}{ Annual Concentrations at Potable Wells }} & \multicolumn{2}{|c|}{ Reference Values } \\
\hline & & & & & & \multirow{2}{*}{$\begin{array}{c}\text { Background }^{\mathrm{a}} \\
\text { WFWELO6 }^{2}\end{array}$} & \multirow{2}{*}{ Standard ${ }^{b, c}$} \\
\hline & & & WFWEL04 & WFWEL05 & WFWEL07 & & \\
\hline Gross Alpha & $\mu \mathrm{Ci} / \mathrm{mL}$ & 1 & $7.76 \pm 4.25 \mathrm{E}-09$ & $1.09 \pm 8.96 \mathrm{E}-10$ & $-3.64 \pm 8.05 \mathrm{E}-10$ & $-2.26 \pm 7.02 \mathrm{E}-10$ & $1.5 \mathrm{E}-08^{\mathrm{d}}$ \\
\hline Gross Beta & $\mu \mathrm{Ci} / \mathrm{mL}$ & 1 & $2.46 \pm 3.33 \mathrm{E}-09$ & $2.35 \pm 0.97 \mathrm{E}-09$ & $1.22 \pm 0.88 \mathrm{E}-09$ & $1.77 \pm 8.44 \mathrm{E}-10$ & $1 \mathrm{E}-06^{\mathrm{e}}$ \\
\hline Tritium & $\mu \mathrm{Ci} / \mathrm{mL}$ & 1 & $6.65 \pm 8.36 \mathrm{E}-08$ & $2.87 \pm 5.53 \mathrm{E}-08$ & $-4.22 \pm 8.13 \mathrm{E}-08$ & $-8.11 \pm 7.99 \mathrm{E}-08$ & -- \\
\hline Sr-90 & $\mu \mathrm{Ci} / \mathrm{mL}$ & 1 & $1.30 \pm 1.39 \mathrm{E}-09$ & $2.77 \pm 1.31 \mathrm{E}-09$ & $-1.69 \pm 8.35 \mathrm{E}-10$ & $0.58 \pm 1.25 \mathrm{E}-09$ & -- \\
\hline Cs-137 & $\mu \mathrm{Ci} / \mathrm{mL}$ & 1 & $-1.97 \pm 6.23 \mathrm{E}-09$ & $0.99 \pm 1.76 \mathrm{E}-08$ & $4.39 \pm 7.60 \mathrm{E}-09$ & $-3.34 \pm 6.39 \mathrm{E}-09$ & -- \\
\hline Conductivity & $\mu \mathrm{mhos} / \mathrm{cm} @ 25^{\circ} \mathrm{C}$ & 1 & 1,580 & 262 & 288 & 270 & -- \\
\hline pH & SU & 1 & 8.12 & 6.56 & 7.55 & 8.14 & $6.5-8.5$ \\
\hline
\end{tabular}

\begin{tabular}{|c|c|c|c|c|c|c|c|}
\hline \multirow{3}{*}{ Analyte } & \multirow{3}{*}{ Units } & \multirow{3}{*}{$\mathbf{N}$} & \multirow{2}{*}{\multicolumn{3}{|c|}{ Annual Concentrations at Potable Wells }} & \multicolumn{2}{|c|}{ Reference Values } \\
\hline & & & & & & \multirow{2}{*}{$\begin{array}{c}\text { Background }^{\mathrm{a}} \\
\text { WFWELO6 }^{2}\end{array}$} & \multirow{2}{*}{ Standard $^{\mathbf{b}, \mathbf{c}}$} \\
\hline & & & WFWEL08 & WFWEL09 & WFWEL10 & & \\
\hline Gross Alpha & $\mu \mathrm{Ci} / \mathrm{mL}$ & 1 & $1.92 \pm 1.38 \mathrm{E}-09$ & $2.10 \pm 1.70 \mathrm{E}-09$ & $-3.14 \pm 1.95 \mathrm{E}-09$ & $-2.26 \pm 7.02 \mathrm{E}-10$ & $1.5 \mathrm{E}-08^{\mathrm{d}}$ \\
\hline Gross Beta & $\mu \mathrm{Ci} / \mathrm{mL}$ & 1 & $2.23 \pm 1.50 \mathrm{E}-09$ & $2.45 \pm 1.51 \mathrm{E}-09$ & $2.42 \pm 1.54 \mathrm{E}-09$ & $1.77 \pm 8.44 \mathrm{E}-10$ & $1 \mathrm{E}-06^{\mathrm{e}}$ \\
\hline Tritium & $\mu \mathrm{Ci} / \mathrm{mL}$ & 1 & $-1.20 \pm 0.74 \mathrm{E}-07$ & $-2.96 \pm 7.70 \mathrm{E}-08$ & $4.35 \pm 8.11 \mathrm{E}-08$ & $-8.11 \pm 7.99 \mathrm{E}-08$ & -- \\
\hline Sr-90 & $\mu \mathrm{Ci} / \mathrm{mL}$ & 1 & $1.15 \pm 1.53 \mathrm{E}-09$ & $3.06 \pm 1.60 \mathrm{E}-09$ & $1.30 \pm 1.39 \mathrm{E}-09$ & $0.58 \pm 1.25 \mathrm{E}-09$ & -- \\
\hline Cs-137 & $\mu \mathrm{Ci} / \mathrm{mL}$ & 1 & $-3.82 \pm 4.19 \mathrm{E}-09$ & $1.23 \pm 7.04 \mathrm{E}-09$ & $-0.79 \pm 1.00 \mathrm{E}-08$ & $-3.34 \pm 6.39 \mathrm{E}-09$ & -- \\
\hline Conductivity & $\mu \mathrm{mhos} / \mathrm{cm} @ 25^{\circ} \mathrm{C}$ & 1 & 429 & 501 & 724 & 270 & -- \\
\hline pH & SU & 1 & 7.05 & 8.14 & 7.38 & 8.14 & $6.5-8.5$ \\
\hline
\end{tabular}

$N$ - Number of samples

-- No guideline or standard available for these analytes

${ }^{a}$ Background location

${ }^{b}$ New York State Water Quality Standard for Class “GA” for fresh groundwater

${ }^{c}$ NYSDOH raw water supply standards (10 NYCRR Part 170.4)

${ }^{d}$ Alpha standard excludes radon and uranium, however, the WVDP results include these isotopes.

${ }^{e}$ Beta standard excludes strontium and alpha emitters. The WVDP results include strontium and other beta emitters. 
Table C-5B

2004 Indicator Results in Main Plant Potable Water (WNDNKMP)

\begin{tabular}{|l|c|c|c|c|c|c|}
\hline \multirow{2}{*}{\multicolumn{1}{c|}{ Analyte }} & \multirow{2}{*}{ Units } & \multirow{2}{*}{$\mathbf{N}$} & \multicolumn{3}{c|}{ Annual Concentration } & \multirow{2}{*}{ Standard $^{\text {a }}$} \\
\cline { 1 - 5 } & & & Minimum & Average & Maximum & \\
\hline Gross Alpha & $\mu \mathrm{Ci} / \mathrm{mL}$ & 4 & $<3.50 \mathrm{E}-10$ & $1.06 \pm 5.83 \mathrm{E}-10$ & $<8.74 \mathrm{E}-10$ & $1.5 \mathrm{E}-08$ \\
\hline Gross Beta & $\mu \mathrm{Ci} / \mathrm{mL}$ & 4 & $9.51 \mathrm{E}-10$ & $1.64 \pm 0.75 \mathrm{E}-09$ & $2.55 \mathrm{E}-09$ & $5 \mathrm{E}-08$ \\
\hline Tritium & $\mu \mathrm{Ci} / \mathrm{mL}$ & 4 & $<8.12 \mathrm{E}-08$ & $3.25 \pm 8.15 \mathrm{E}-08$ & $<8.22 \mathrm{E}-08$ & $2 \mathrm{E}-05$ \\
\hline Conductivity & $\mu \mathrm{mhos} / \mathrm{cm} @ 25^{\circ} \mathrm{C}$ & 4 & 153 & 184 & 207 & -- \\
\hline pH & $\mathrm{SU}$ & 4 & 7.65 & 7.99 & 8.5 & -- \\
\hline
\end{tabular}

2004 Indicator Results in Environmental Laboratory Potable Water (WNDNKEL)

\begin{tabular}{|l|c|c|c|c|c|c|}
\hline \multirow{2}{*}{\multicolumn{1}{c|}{ Analyte }} & \multirow{2}{*}{ Units } & \multirow{2}{*}{$\mathbf{N}$} & \multicolumn{3}{c|}{ Annual Concentration } & \multirow{2}{*}{ Standard $^{\mathbf{a}}$} \\
\cline { 4 - 6 } & & & Minimum & Average & Maximum & \\
\hline Gross Alpha & $\mu \mathrm{Ci} / \mathrm{mL}$ & 4 & $<4.05 \mathrm{E}-10$ & $-1.95 \pm 5.29 \mathrm{E}-10$ & $<6.94 \mathrm{E}-10$ & $1.5 \mathrm{E}-08$ \\
\hline Gross Beta & $\mu \mathrm{Ci} / \mathrm{mL}$ & 4 & $1.07 \mathrm{E}-09$ & $1.29 \pm 0.74 \mathrm{E}-09$ & $1.57 \mathrm{E}-09$ & $5 \mathrm{E}-08$ \\
\hline Tritium & $\mu \mathrm{Ci} / \mathrm{mL}$ & 4 & $<5.43 \mathrm{E}-08$ & $3.09 \pm 7.57 \mathrm{E}-08$ & $1.01 \mathrm{E}-07$ & $2 \mathrm{E}-05$ \\
\hline Conductivity & $\mu \mathrm{mhos} / \mathrm{cm} @ 25^{\circ} \mathrm{C}$ & 4 & 161 & 200 & 259 & - \\
\hline Haloacetic Acids-Five (5) & $\mathrm{mg} / \mathrm{L}$ & 3 & $<0.013$ & $<0.021$ & $<0.033$ & 0.06 \\
\hline pH & $\mathrm{SU}$ & 4 & 7.87 & 7.99 & 8.12 & - \\
\hline Total Trihalomethanes & $\mathrm{mg} / \mathrm{L}$ & 3 & $<0.011$ & $<0.026$ & $<0.053$ & 0.08 \\
\hline
\end{tabular}

2004 Indicator Results in Maintenance Shop Potable Water (WNDNKMS)

\begin{tabular}{|l|c|c|c|c|c|c|}
\hline \multirow{2}{*}{\multicolumn{1}{c|}{ Analyte }} & \multirow{2}{*}{ Units } & \multirow{2}{*}{$\mathbf{N}$} & \multicolumn{3}{c|}{ Annual Concentration } & \multirow{2}{*}{ Standard $^{\mathbf{a}}$} \\
\cline { 4 - 6 } & & & Minimum & Average & Maximum & \\
\hline Gross Alpha & $\mu \mathrm{Ci} / \mathrm{mL}$ & 4 & $<3.96 \mathrm{E}-10$ & $-1.13 \pm 5.41 \mathrm{E}-10$ & $7.27 \mathrm{E}-10$ & $1.5 \mathrm{E}-08$ \\
\hline Gross Beta & $\mu \mathrm{Ci} / \mathrm{mL}$ & 4 & $1.44 \mathrm{E}-09$ & $1.82 \pm 0.76 \mathrm{E}-09$ & $2.30 \mathrm{E}-09$ & $5 \mathrm{E}-08$ \\
\hline Tritium & $\mu \mathrm{Ci} / \mathrm{mL}$ & 4 & $<5.55 \mathrm{E}-08$ & $4.01 \pm 8.43 \mathrm{E}-08$ & $1.08 \mathrm{E}-07$ & $2 \mathrm{E}-05$ \\
\hline Conductivity & $\mu \mathrm{mhos} / \mathrm{cm} @ 25^{\circ} \mathrm{C}$ & 4 & 198 & 209 & 225 & -- \\
\hline pH & $\mathrm{SU}$ & 4 & 7.87 & 8.05 & 8.19 & -- \\
\hline
\end{tabular}

$N$ - Number of samples

-- No guideline or standard available for these analytes

${ }^{a}$ New York State Department of Health MCLs for drinking water used as a comparative reference 
Table C-5C

2004 Water Quality Results in Utility Room Potable Water (WNDNKUR)

\begin{tabular}{|c|c|c|c|c|c|c|}
\hline \multirow{2}{*}{ Analyte } & \multirow{2}{*}{ Units } & \multirow{2}{*}{$\mathbf{N}$} & \multicolumn{3}{|c|}{ WNDNKUR Concentrations } & \multirow{2}{*}{$\begin{array}{c}\text { Standard } \\
\text { or } \\
\text { Guideline }^{\mathrm{a}}\end{array}$} \\
\hline & & & Minimum & Average & Maximum & \\
\hline Gross Alpha & $\mu \mathrm{Ci} / \mathrm{mL}$ & 12 & $<3.16 \mathrm{E}-10$ & $-0.72 \pm 5.30 \mathrm{E}-10$ & $<8.96 \mathrm{E}-10$ & $1.5 \mathrm{E}-08$ \\
\hline Gross Beta & $\mu \mathrm{Ci} / \mathrm{mL}$ & 12 & 1.09E-09 & $1.49 \pm 0.74 \mathrm{E}-09$ & $1.96 \mathrm{E}-09$ & $5 \mathrm{E}-08$ \\
\hline Tritium & $\mu \mathrm{Ci} / \mathrm{mL}$ & 12 & $<5.88 \mathrm{E}-08$ & $3.27 \pm 7.85 \mathrm{E}-08$ & $1.23 \mathrm{E}-07$ & $2 \mathrm{E}-05$ \\
\hline Antimony, Total & $\mathrm{mg} / \mathrm{L}$ & 1 & NA & NA & $<0.001$ & 0.006 \\
\hline Arsenic, Total & $\mathrm{mg} / \mathrm{L}$ & 1 & NA & NA & $<0.025$ & 0.05 \\
\hline Barium, Total & $\mathrm{mg} / \mathrm{L}$ & 1 & NA & NA & $<0.20$ & 2.00 \\
\hline Beryllium, Total & $\mathrm{mg} / \mathrm{L}$ & 1 & NA & NA & $<0.0003$ & 0.004 \\
\hline Cadmium, Total & $\mathrm{mg} / \mathrm{L}$ & 1 & NA & NA & $<0.002$ & 0.005 \\
\hline Chromium, Total & $\mathrm{mg} / \mathrm{L}$ & 1 & NA & NA & $<0.01$ & 0.10 \\
\hline Conductivity & $\mu \mathrm{mhos} / \mathrm{cm}^{@} 25^{\circ} \mathrm{C}$ & 12 & 144 & 194 & 263 & -- \\
\hline Cyanide, Total & $\mathrm{mg} / \mathrm{L}$ & 1 & NA & NA & $<0.01$ & 0.2 \\
\hline Fluoride & $\mathrm{mg} / \mathrm{L}$ & 1 & NA & NA & $<0.20$ & 2.2 \\
\hline Free Residual Chlorine & $\mathrm{mg} / \mathrm{L}$ & 1,097 & 0.43 & NA & 2.95 & $0.2-4.0$ \\
\hline Mercury, Total & $\mathrm{mg} / \mathrm{L}$ & 1 & NA & NA & $<0.0004$ & 0.002 \\
\hline Nickel, Total & $\mathrm{mg} / \mathrm{L}$ & 1 & NA & NA & $<0.005$ & -- \\
\hline pH & $\mathrm{SU}$ & 12 & 7.89 & 8.04 & 8.32 & -- \\
\hline Selenium, Total & $\mathrm{mg} / \mathrm{L}$ & 1 & NA & NA & $<0.002$ & 0.05 \\
\hline Thallium, Total & $\mathrm{mg} / \mathrm{L}$ & 1 & NA & NA & $<0.001$ & 0.002 \\
\hline Turbidity & NTU & 2,194 & $<0.1$ & NA & 1.6 & $1.0^{\mathrm{b}}$ \\
\hline
\end{tabular}

$N$ - Number of samples

NA - Not available, constituents sampled annually

-- No guideline or standard available for these analytes

${ }^{a}$ New York State Department of Health MCLs for drinking water or EPA MCLGs, whichever is more stringent

${ }^{b} A$ treatment standard of 0.3 NTU applies to the 95th percentile on a monthly basis. 
Table C-5D

2004 Water Quality Results in Utility Room Raw (Untreated) Water (WNURRAW)

\begin{tabular}{|l|c|c|c|c|c|}
\hline \multirow{2}{*}{ Analyte } & \multirow{2}{*}{ Units } & \multirow{2}{*}{$\mathbf{N}$} & \multicolumn{3}{|c|}{ WNURRAW Concentrations } \\
\cline { 4 - 6 } & & & Minimum & Average & Maximum \\
\hline Iron, Total & $\mathrm{mg} / \mathrm{L}$ & 52 & 0.13 & 1.28 & 14.4 \\
\hline Solids, Total Dissolved & $\mathrm{mg} / \mathrm{L}$ & 24 & 61 & 110 & \\
\hline
\end{tabular}

$N$ - Number of samples

Table C-5E

2004 Biological and Chlorine Results From Various Site Tap Water Locations (Analyzed by Cattaraugus County Department of Health)

\begin{tabular}{|l|c|c|c|c|}
\hline \multicolumn{1}{|c|}{ Analyte } & Units & N & $\begin{array}{c}\text { Various Site Tap Water Locations } \\
\text { Results }\end{array}$ & Standard $^{\mathbf{a}}$ \\
\hline E. coli & NA & 12 & Negative & one positive sample \\
\hline Free Residual Chlorine & $\mathrm{mg} / \mathrm{L}$ & 11 & Range: $0.08-1.78$ & 4.0 (max) \\
\hline Total Coliform & NA & 12 & Negative & two or more positive samples \\
\hline
\end{tabular}

$N$ - Number of samples

NA - Not applicable

${ }^{a}$ New York State Department of Health MCLs for drinking water or EPA MCLGs, whichever is more stringent

\section{Table C-5F}

2004 Tap Water Nitrate Results From WVDP Restroom Sink (Analyzed by Cattaraugus County Department of Health)

\begin{tabular}{|l|c|c|c|c|c|}
\hline \multicolumn{1}{|c|}{ Analyte } & Units & $\mathbf{N}$ & Date Collected & Annual Concentration & Standard $^{\mathrm{a}}$ \\
\hline Nitrate-N & $\mathrm{mg} / \mathrm{L}$ & 1 & $3 / 17 / 04$ & 0.700 & 10 \\
\hline
\end{tabular}

$N$ - Number of samples

${ }^{a}$ New York State Department of Health MCLs for drinking water or EPA MCLGs, whichever is more stringent 


\section{Appendix D Summary of Air Monitoring Data}

$D-1$ 
This page intentionally left blank

$D-2$ 
Table D-1

2004 Effluent Airborne Radioactivity at Main Stack (ANSTACK)

\begin{tabular}{|c|c|c|c|c|c|c|}
\hline Isotope $^{a}$ & $\mathbf{N}$ & $\begin{array}{c}\text { Total } \\
\text { Activity Released } \\
\text { (Ci) }\end{array}$ & $\begin{array}{c}\text { Average } \\
\text { Concentration } \\
(\mu \mathrm{Ci} / \mathrm{mL})\end{array}$ & $\begin{array}{c}\text { Maximum } \\
\text { Concentration } \\
(\mu \mathrm{Ci} / \mathbf{m L})\end{array}$ & $\begin{array}{c}\mathrm{DCG}^{\mathrm{c}} \\
(\mu \mathrm{Ci} / \mathrm{mL})\end{array}$ & $\begin{array}{l}\text { Average } \\
\% \text { DCG }\end{array}$ \\
\hline Gross Alpha & 53 & $3.93 \pm 0.17 \mathrm{E}-06$ & $5.19 \pm 0.22 \mathrm{E}-15$ & $2.48 \mathrm{E}-14$ & -- & -- \\
\hline Gross Beta & 53 & $1.30 \pm 0.01 \mathrm{E}-04$ & $1.71 \pm 0.01 \mathrm{E}-13$ & $9.31 \mathrm{E}-13$ & -- & -- \\
\hline H-3 & 53 & $5.57 \pm 0.11 \mathrm{E}-03$ & $7.34 \pm 0.15 \mathrm{E}-12$ & 3.24E-11 & 1E-07 & 0.01 \\
\hline Co-60 & 4 & $6.00 \pm 6.58 \mathrm{E}-08$ & $7.91 \pm 8.68 \mathrm{E}-17$ & 2.82E-16 & $8 \mathrm{E}-11$ & $<0.01$ \\
\hline Sr-90 & 4 & $3.15 \pm 0.03 \mathrm{E}-05$ & $4.15 \pm 0.04 \mathrm{E}-14$ & 7.56E-14 & 9E-12 & 0.46 \\
\hline I-129 & 4 & $2.78 \pm 0.22 \mathrm{E}-05$ & $3.67 \pm 0.29 \mathrm{E}-14$ & $5.64 \mathrm{E}-14$ & $7 \mathrm{E}-11$ & 0.05 \\
\hline Cs-137 & 4 & $5.47 \pm 0.16 \mathrm{E}-05$ & $7.21 \pm 0.21 \mathrm{E}-14$ & $1.23 \mathrm{E}-13$ & 4E-10 & 0.02 \\
\hline Eu-154 & 4 & $0.57 \pm 1.69 \mathrm{E}-07$ & $0.75 \pm 2.23 \mathrm{E}-16$ & $<4.71 \mathrm{E}-16$ & $5 \mathrm{E}-11$ & $<0.01$ \\
\hline U-232 ${ }^{d}$ & 4 & $2.31 \pm 0.68 \mathrm{E}-08$ & $3.05 \pm 0.90 \mathrm{E}-17$ & $4.90 \mathrm{E}-17$ & $2 \mathrm{E}-14$ & 0.15 \\
\hline $\mathrm{U}-233 / 234^{\mathrm{d}}$ & 4 & $4.25 \pm 0.92 \mathrm{E}-08$ & $5.60 \pm 1.21 \mathrm{E}-17$ & $9.65 \mathrm{E}-17$ & 9E-14 & 0.06 \\
\hline $\mathrm{U}-235 / 236^{\mathrm{d}}$ & 4 & $1.11 \pm 0.59 \mathrm{E}-08$ & $1.47 \pm 0.77 \mathrm{E}-17$ & $1.67 \mathrm{E}-17$ & $1 \mathrm{E}-13$ & 0.01 \\
\hline $\mathrm{U}-\mathbf{2 3 8}^{\mathrm{d}}$ & 4 & $3.80 \pm 0.80 \mathrm{E}-08$ & $5.01 \pm 1.06 \mathrm{E}-17$ & $6.99 \mathrm{E}-17$ & $1 \mathrm{E}-13$ & 0.05 \\
\hline Pu-238 & 4 & $7.61 \pm 0.36 \mathrm{E}-07$ & $1.00 \pm 0.05 \mathrm{E}-15$ & $1.86 \mathrm{E}-15$ & $3 \mathrm{E}-14$ & 3.35 \\
\hline Pu-239/240 & 4 & $8.03 \pm 0.37 \mathrm{E}-07$ & $1.06 \pm 0.05 \mathrm{E}-15$ & $2.01 \mathrm{E}-15$ & 2E-14 & 5.30 \\
\hline Am-241 & 4 & $2.08 \pm 0.06 \mathrm{E}-06$ & $2.75 \pm 0.08 \mathrm{E}-15$ & $5.38 \mathrm{E}-15$ & $2 \mathrm{E}-14$ & 13.73 \\
\hline Total \% of DCGs & & & & & & 23.19 \\
\hline
\end{tabular}

$N$ - Number of samples

-- DCGs are not specified for gross alpha and beta activity.

${ }^{a}$ Half-lives are listed in Table $K$ - 1 co

${ }^{b}$ Total volume released at 50,000 $\mathrm{cfm}=7.58 \mathrm{E}+14 \mathrm{~mL} /$ year

${ }^{c}$ Derived concentration guides (DCGs) are listed for reference only. They are applicable to average concentrations at the site boundary but not to stack concentrations, as might be inferred from their inclusion in this table.

${ }^{d}$ Total Uranium: $9.25 \pm 0.09 \mathrm{E}-02 \mathrm{~g}$; average $=1.22 \mathrm{E} \pm 0.01 \mathrm{E}-10 \mu \mathrm{g} / \mathrm{mL}$

$D-3$ 
Table D-2

2004 Effluent Airborne Radioactivity at Vitrification System HVAC (ANVITSK)

\begin{tabular}{|c|c|c|c|c|c|}
\hline Isotope & $\mathbf{N}$ & $\begin{array}{c}\text { Total } \\
\text { Activity Released } \\
\text { (Ci) }\end{array}$ & $\begin{array}{c}\text { Average } \\
\text { Concentration } \\
(\mu \mathrm{Ci} / \mathrm{mL})\end{array}$ & $\begin{array}{c}\text { Maximum } \\
\text { Concentration } \\
(\mu \mathrm{Ci} / \mathrm{mL})\end{array}$ & $\begin{array}{c}\text { DCG }^{\mathrm{a}} \\
(\mu \mathrm{Ci} / \mathrm{mL})\end{array}$ \\
\hline Gross Alpha & 53 & $-0.90 \pm 2.95 \mathrm{E}-08$ & $-2.37 \pm 7.78 \mathrm{E}-17$ & $5.80 \mathrm{E}-16$ & -- \\
\hline Gross Beta & 53 & $2.88 \pm 6.34 \mathrm{E}-08$ & $0.76 \pm 1.67 \mathrm{E}-16$ & $1.50 \mathrm{E}-15$ & -- \\
\hline Co-60 & 4 & $0.93 \pm 3.13 \mathrm{E}-08$ & $2.45 \pm 8.25 \mathrm{E}-17$ & $<2.34 \mathrm{E}-16$ & $8 \mathrm{E}-11$ \\
\hline Sr-90 & 4 & $1.70 \pm 2.42 \mathrm{E}-08$ & $4.48 \pm 6.38 \mathrm{E}-17$ & $1.77 \mathrm{E}-16$ & $9 \mathrm{E}-12$ \\
\hline I-129 & 4 & $3.20 \pm 0.94 \mathrm{E}-07$ & $8.44 \pm 2.48 \mathrm{E}-16$ & $1.67 \mathrm{E}-15$ & 7E-11 \\
\hline Cs-137 & 4 & $1.03 \pm 2.40 \mathrm{E}-08$ & $2.72 \pm 6.33 \mathrm{E}-17$ & $<1.61 \mathrm{E}-16$ & $4 \mathrm{E}-10$ \\
\hline Eu-154 & 4 & $1.04 \pm 9.09 \mathrm{E}-08$ & $0.27 \pm 2.40 \mathrm{E}-16$ & $<7.63 \mathrm{E}-16$ & $5 \mathrm{E}-11$ \\
\hline $\mathrm{U}^{-232^{b}}$ & 4 & $2.09 \pm 2.74 \mathrm{E}-09$ & $5.51 \pm 7.23 \mathrm{E}-18$ & $1.77 \mathrm{E}-17$ & $2 \mathrm{E}-14$ \\
\hline $\mathrm{U}-233 / 234^{\mathrm{b}}$ & 4 & $1.60 \pm 0.38 \mathrm{E}-08$ & $4.22 \pm 1.00 \mathrm{E}-17$ & 5.99E-17 & 9E-14 \\
\hline $\mathrm{U}-235 / 236^{\mathrm{b}}$ & 4 & $6.04 \pm 2.39 \mathrm{E}-09$ & $1.59 \pm 0.63 \mathrm{E}-17$ & $3.20 \mathrm{E}-17$ & 1E-13 \\
\hline $\mathrm{U}_{-238}{ }^{\mathrm{b}}$ & 4 & $1.41 \pm 0.35 \mathrm{E}-08$ & $2.73 \pm 9.23 \mathrm{E}-17$ & $4.15 \mathrm{E}-17$ & $1 \mathrm{E}-13$ \\
\hline Pu-238 & 4 & $-0.01 \pm 1.62 \mathrm{E}-09$ & $-0.03 \pm 4.27 \mathrm{E}-18$ & $<1.29 \mathrm{E}-17$ & $3 \mathrm{E}-14$ \\
\hline Pu-239/240 & 4 & $0.57 \pm 1.61 \mathrm{E}-09$ & $1.50 \pm 4.25 \mathrm{E}-18$ & $<8.65 \mathrm{E}-18$ & $2 \mathrm{E}-14$ \\
\hline Am-241 & 4 & $4.91 \pm 3.05 \mathrm{E}-09$ & $1.29 \pm 0.80 \mathrm{E}-17$ & $2.95 \mathrm{E}-17$ & $2 \mathrm{E}-14$ \\
\hline
\end{tabular}

$N$ - Number of samples

-- DCGs are not specified for gross alpha and beta activity.

${ }^{a}$ Derived concentration guides (DCGs) are listed for reference only. They are applicable to average concentrations at the site boundary but not to stack concentrations, as might be inferred from their inclusion in this table.

${ }^{b}$ Total Uranium: $4.16 \pm 0.04 \mathrm{E}-02 \mathrm{~g}$; average $=1.10 \pm 0.01 \mathrm{E}-10 \mu \mathrm{g} / \mathrm{mL}$

$D-4$ 
Table D-3

2004 Effluent Airborne Radioactivity at 01-14 Building (ANCSSTK)

\begin{tabular}{|c|c|c|c|c|c|}
\hline Isotope & $\mathbf{N}$ & $\begin{array}{c}\text { Total } \\
\text { Activity Released } \\
\text { (Ci) }\end{array}$ & $\begin{array}{c}\text { Average } \\
\text { Concentration } \\
(\mu \mathrm{Ci} / \mathrm{mL})\end{array}$ & $\begin{array}{c}\text { Maximum } \\
\text { Concentration } \\
(\mu \mathrm{Ci} / \mathrm{mL})\end{array}$ & $\begin{array}{c}D_{C G}{ }^{a} \\
(\mu C i / m L)\end{array}$ \\
\hline Gross Alpha & 53 & $0.79 \pm 1.22 \mathrm{E}-08$ & $5.37 \pm 8.29 \mathrm{E}-17$ & 1.13E-15 & -- \\
\hline Gross Beta & 53 & $3.44 \pm 2.57 \mathrm{E}-08$ & $2.34 \pm 1.75 \mathrm{E}-16$ & $1.78 \mathrm{E}-15$ & -- \\
\hline Co-60 & 4 & $0.05 \pm 1.19 \mathrm{E}-08$ & $0.34 \pm 8.09 \mathrm{E}-17$ & $<1.85 \mathrm{E}-16$ & $8 \mathrm{E}-11$ \\
\hline Sr-90 & 4 & $2.22 \pm 9.02 \mathrm{E}-09$ & $1.51 \pm 6.13 \mathrm{E}-17$ & $<1.38 \mathrm{E}-16$ & 9E-12 \\
\hline I-129 & 4 & $3.46 \pm 2.47 \mathrm{E}-08$ & $2.35 \pm 1.68 \mathrm{E}-16$ & $6.66 \mathrm{E}-16$ & 7E-11 \\
\hline Cs-137 & 4 & $1.29 \pm 1.16 \mathrm{E}-08$ & $8.77 \pm 7.88 \mathrm{E}-17$ & 1.61E-16 & $4 \mathrm{E}-10$ \\
\hline Eu-154 & 4 & $4.59 \pm 3.53 \mathrm{E}-08$ & $3.12 \pm 2.40 \mathrm{E}-16$ & $<5.44 \mathrm{E}-16$ & $5 \mathrm{E}-11$ \\
\hline U-232 ${ }^{b}$ & 4 & $0.31 \pm 1.10 \mathrm{E}-09$ & $2.11 \pm 7.48 \mathrm{E}-18$ & $<1.90 \mathrm{E}-17$ & $2 \mathrm{E}-14$ \\
\hline U-233/234 ${ }^{b}$ & 4 & $7.73 \pm 1.75 \mathrm{E}-09$ & $5.25 \pm 1.19 \mathrm{E}-17$ & $6.87 \mathrm{E}-17$ & 9E-14 \\
\hline $\mathrm{U}-235 / 236^{\mathrm{b}}$ & 4 & $1.42 \pm 0.93 \mathrm{E}-09$ & $9.65 \pm 6.32 \mathrm{E}-18$ & $9.17 \mathrm{E}-18$ & $1 \mathrm{E}-13$ \\
\hline U-238 ${ }^{b}$ & 4 & $7.95 \pm 1.69 \mathrm{E}-09$ & $5.40 \pm 1.15 \mathrm{E}-17$ & $6.72 \mathrm{E}-17$ & $1 \mathrm{E}-13$ \\
\hline Pu-238 & 4 & $-2.93 \pm 7.42 \mathrm{E}-10$ & $-1.99 \pm 5.04 \mathrm{E}-18$ & $<1.55 \mathrm{E}-17$ & $3 \mathrm{E}-14$ \\
\hline Pu-239/240 & 4 & $-0.47 \pm 8.26 \mathrm{E}-10$ & $-0.32 \pm 5.61 \mathrm{E}-18$ & $<1.36 \mathrm{E}-17$ & $2 \mathrm{E}-14$ \\
\hline Am-241 & 4 & $1.26 \pm 1.01 \mathrm{E}-09$ & $8.56 \pm 6.86 \mathrm{E}-18$ & 9.99E-18 & 2E-14 \\
\hline
\end{tabular}

$N$ - Number of samples

-- DCGs are not specified for gross alpha and beta activity.

${ }^{a}$ Derived concentration guides (DCGs) are listed for reference only. They are applicable to average concentrations at the site boundary but not to stack concentrations, as might be inferred from their inclusion in this table.

${ }^{b}$ Total Uranium: $3.60 \pm 0.03 E-02 \mathrm{~g}$; average $=2.45 \pm 0.02 \mathrm{E}-10 \mu \mathrm{g} / \mathrm{mL}$

Table D-4

2004 Airborne Radioactivity at Contact Size-Reduction Facility (ANCSRFK)

\author{
VENTILATION OFF DURING CY 2004
}

$D-5$ 
Table D-5

2004 Effluent Airborne Radioactivity at Supernatant Treatment System (ANSTSTK)

\begin{tabular}{|c|c|c|c|c|c|}
\hline Isotope & $\mathbf{N}$ & $\begin{array}{c}\text { Total } \\
\text { Activity Released } \\
\text { (Ci) }\end{array}$ & $\begin{array}{c}\text { Average } \\
\text { Concentration } \\
(\mu \mathrm{Ci} / \mathrm{mL})\end{array}$ & $\begin{array}{c}\text { Maximum } \\
\text { Concentration } \\
(\mu \mathrm{Ci} / \mathbf{m L})\end{array}$ & $\begin{array}{c}\text { DCG }^{\mathrm{a}} \\
(\mu \mathrm{Ci} / \mathrm{mL})\end{array}$ \\
\hline Gross Alpha & 53 & $0.09 \pm 6.41 \mathrm{E}-09$ & $0.13 \pm 9.39 \mathrm{E}-17$ & $8.45 \mathrm{E}-16$ & -- \\
\hline Gross Beta & 53 & $1.23 \pm 1.37 \mathrm{E}-08$ & $1.80 \pm 2.01 \mathrm{E}-16$ & $1.38 \mathrm{E}-15$ & -- \\
\hline H-3 & 53 & $3.15 \pm 0.48 \mathrm{E}-05$ & $4.61 \pm 0.70 \mathrm{E}-13$ & $1.94 \mathrm{E}-12$ & $1 \mathrm{E}-07$ \\
\hline Co-60 & 4 & $1.14 \pm 0.70 \mathrm{E}-08$ & $1.67 \pm 1.03 \mathrm{E}-16$ & $3.19 \mathrm{E}-16$ & $8 \mathrm{E}-11$ \\
\hline Sr-90 & 4 & $2.84 \pm 5.01 \mathrm{E}-09$ & $4.16 \pm 7.34 \mathrm{E}-17$ & $<1.44 \mathrm{E}-16$ & 9E-12 \\
\hline I-129 & 4 & $1.38 \pm 0.09 \mathrm{E}-05$ & $2.02 \pm 0.13 \mathrm{E}-13$ & $3.25 \mathrm{E}-13$ & $7 \mathrm{E}-11$ \\
\hline Cs-137 & 4 & $9.40 \pm 6.11 \mathrm{E}-09$ & $1.38 \pm 0.90 \mathrm{E}-16$ & $1.69 \mathrm{E}-16$ & 4E-10 \\
\hline Eu-154 & 4 & $-0.09 \pm 1.47 \mathrm{E}-08$ & $-0.13 \pm 2.15 E-16$ & $<4.61 \mathrm{E}-16$ & $5 \mathrm{E}-11$ \\
\hline $\mathrm{U}^{-232^{b}}$ & 4 & $5.82 \pm 5.60 \mathrm{E}-10$ & $8.53 \pm 8.20 \mathrm{E}-18$ & $1.84 \mathrm{E}-17$ & $2 \mathrm{E}-14$ \\
\hline $\mathrm{U}-233 / 234^{b}$ & 4 & $4.25 \pm 0.93 \mathrm{E}-09$ & $6.23 \pm 1.36 \mathrm{E}-17$ & $6.23 \mathrm{E}-17$ & 9E-14 \\
\hline $\mathrm{U}-235 / 236^{\mathrm{b}}$ & 4 & $1.13 \pm 0.48 \mathrm{E}-09$ & $1.66 \pm 0.70 \mathrm{E}-17$ & $2.57 \mathrm{E}-17$ & $1 \mathrm{E}-13$ \\
\hline U-238 ${ }^{b}$ & 4 & $3.92 \pm 0.85 \mathrm{E}-09$ & $4.28 \pm 1.25 \mathrm{E}-17$ & $6.19 \mathrm{E}-17$ & 1E-13 \\
\hline Pu-238 & 4 & $1.08 \pm 3.96 \mathrm{E}-10$ & $1.58 \pm 5.80 \mathrm{E}-18$ & $<1.45 \mathrm{E}-17$ & 3E-14 \\
\hline Pu-239/240 & 4 & $1.82 \pm 3.97 \mathrm{E}-10$ & $2.67 \pm 5.82 \mathrm{E}-18$ & $<1.42 \mathrm{E}-17$ & $2 \mathrm{E}-14$ \\
\hline Am-241 & 4 & $1.16 \pm 0.58 \mathrm{E}-09$ & $1.70 \pm 0.85 \mathrm{E}-17$ & $1.85 \mathrm{E}-17$ & $2 \mathrm{E}-14$ \\
\hline
\end{tabular}

$N$ - Number of samples

-- DCGs are not specified for gross alpha and beta activity.

${ }^{a}$ Derived concentration guides (DCGs) are listed for reference only. They are applicable to average concentrations at the site boundary but not to stack concentrations, as might be inferred from their inclusion in this table.

${ }^{b}$ Total Uranium: $9.08 \pm 0.09 \mathrm{E}-03 \mathrm{~g}$; average $=1.33 \pm 0.01 \mathrm{E}-10 \mu \mathrm{g} / \mathrm{mL}$

$D-6$ 
Table D-6

2004 Effluent Airborne Radioactivity at Container Sorting and Packaging Facility (ANCSPFK)

\begin{tabular}{|c|c|c|c|c|c|}
\hline Isotope & $\mathbf{N}$ & $\begin{array}{c}\text { Total } \\
\text { Activity Released } \\
\text { (Ci) }\end{array}$ & $\begin{array}{c}\text { Average } \\
\text { Concentration } \\
(\mu \mathrm{Ci} / \mathrm{mL})\end{array}$ & $\begin{array}{c}\text { Maximum } \\
\text { Concentration } \\
(\mu \mathrm{Ci} / \mathrm{mL})\end{array}$ & $\begin{array}{c}\text { DCG }^{\mathrm{a}} \\
(\mu \mathrm{Ci} / \mathrm{mL})\end{array}$ \\
\hline Gross Alpha & 53 & $3.90 \pm 1.60 \mathrm{E}-09$ & $2.20 \pm 0.90 \mathrm{E}-16$ & $1.21 \mathrm{E}-15$ & -- \\
\hline Gross Beta & 53 & $4.16 \pm 3.09 \mathrm{E}-09$ & $2.35 \pm 1.74 \mathrm{E}-16$ & $3.63 \mathrm{E}-15$ & -- \\
\hline Co-60 & 4 & $1.60 \pm 1.38 \mathrm{E}-09$ & $9.02 \pm 7.78 \mathrm{E}-17$ & $<1.86 \mathrm{E}-16$ & 8E-11 \\
\hline Sr-90 & 4 & $0.43 \pm 1.09 \mathrm{E}-09$ & $2.42 \pm 6.15 \mathrm{E}-17$ & $1.40 \mathrm{E}-16$ & $9 \mathrm{E}-12$ \\
\hline I-129 & 4 & $1.78 \pm 0.14 \mathrm{E}-07$ & $1.00 \pm 0.08 \mathrm{e}-14$ & $1.54 \mathrm{E}-14$ & 7E-11 \\
\hline Cs-137 & 4 & $-0.29 \pm 1.23 \mathrm{E}-09$ & $-1.63 \pm 6.93 \mathrm{E}-17$ & $<1.69 \mathrm{E}-16$ & $4 \mathrm{E}-10$ \\
\hline Eu-154 & 4 & $0.83 \pm 3.49 \mathrm{E}-09$ & $0.47 \pm 1.97 \mathrm{E}-16$ & $<4.65 \mathrm{E}-16$ & $5 \mathrm{E}-11$ \\
\hline $\mathrm{U}-\mathbf{2 3 2}^{\mathrm{b}}$ & 4 & $1.38 \pm 1.31 \mathrm{E}-10$ & $7.78 \pm 7.39 \mathrm{E}-18$ & $2.08 \mathrm{E}-17$ & 2E-14 \\
\hline $\mathrm{U}-233 / 234^{\mathrm{b}}$ & 4 & $1.10 \pm 0.21 \mathrm{E}-09$ & $6.20 \pm 1.18 \mathrm{E}-17$ & $8.25 \mathrm{E}-17$ & 9E-14 \\
\hline $\mathrm{U}-235 / 236^{b}$ & 4 & $1.78 \pm 1.18 \mathrm{E}-10$ & $1.00 \pm 0.66 \mathrm{E}-17$ & $3.55 \mathrm{E}-17$ & $1 \mathrm{E}-13$ \\
\hline $\mathrm{U}-\mathbf{2 3 8}^{\mathrm{b}}$ & 4 & $1.22 \pm 0.21 \mathrm{E}-09$ & $6.88 \pm 1.18 \mathrm{E}-17$ & $9.28 \mathrm{E}-17$ & $1 \mathrm{E}-13$ \\
\hline Pu-238 & 4 & $0.26 \pm 1.33 \mathrm{E}-10$ & $1.47 \pm 7.50 \mathrm{E}-18$ & $<2.18 \mathrm{E}-17$ & 3E-14 \\
\hline Pu-239/240 & 4 & $0.45 \pm 9.20 \mathrm{E}-11$ & $0.25 \pm 5.19 \mathrm{E}-18$ & $<1.18 \mathrm{E}-17$ & 2E-14 \\
\hline Am-241 & 4 & $0.89 \pm 1.19 \mathrm{E}-10$ & $5.02 \pm 6.71 \mathrm{E}-18$ & $1.89 \mathrm{E}-17$ & 2E-14 \\
\hline
\end{tabular}

$N$ - Number of samples

-- DCGs are not specified for gross alpha and gross beta activity.

${ }^{a}$ Derived concentration guides (DCGs) are listed for reference only. They are applicable to average concentrations at the site boundary but not to stack concentrations, as might be inferred from their inclusion in this table.

${ }^{b}$ Total Uranium: $3.06 \pm 0.03 E-03 \mathrm{~g} ;$ average $=1.73 \pm 0.02 \mathrm{E}-10 \mu \mathrm{g} / \mathrm{mL}$

$D-7$ 
Table D-7

2004 Effluent Airborne Radioactivity at Outdoor Ventilation Enclosures/ Portable Ventilation Units (OVEs/PVUs)

\begin{tabular}{|c|c|c|c|c|c|}
\hline Isotope & $\mathbf{N}$ & $\begin{array}{c}\text { Total } \\
\text { Activity Released } \\
\text { (Ci) }\end{array}$ & $\begin{array}{c}\text { Average } \\
\text { Concentration } \\
(\mu \mathrm{Ci} / \mathrm{mL})\end{array}$ & $\begin{array}{c}\text { Maximum } \\
\text { Concentration } \\
(\mu \mathrm{Ci} / \mathrm{mL})\end{array}$ & $\begin{array}{c}D G^{a} \\
(\mu \mathrm{Ci} / \mathbf{m L})\end{array}$ \\
\hline Gross Alpha & 82 & $3.70 \pm 0.52 \mathrm{E}-08$ & $6.55 \pm 0.92 \mathrm{E}-16$ & $1.36 \mathrm{E}-14$ & -- \\
\hline Gross Beta & 82 & $5.06 \pm 0.89 \mathrm{E}-08$ & $8.96 \pm 1.58 \mathrm{E}-16$ & $1.64 \mathrm{E}-14$ & -- \\
\hline Co-60 & 6 & 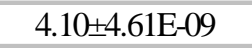 & $7.26 \pm 8.17 \mathrm{E}-17$ & 3.71E-16 & $8 \mathrm{E}-11$ \\
\hline Sr-90 & 6 & $3.89 \pm 3.88 \mathrm{E}-09$ & $6.89 \pm 6.87 \mathrm{E}-17$ & $2.08 \mathrm{E}-16$ & $9 \mathrm{E}-12$ \\
\hline Cs-137 & 6 & $2.35 \pm 0.63 \mathrm{E}-08$ & $4.16 \pm 1.11 \mathrm{E}-16$ & $9.81 \mathrm{E}-16$ & $4 \mathrm{E}-10$ \\
\hline Eu-154 & 6 & $0.48 \pm 1.53 \mathrm{E}-08$ & $0.86 \pm 2.72 \mathrm{E}-16$ & $<4.95 \mathrm{E}-15$ & $5 \mathrm{E}-11$ \\
\hline $\mathrm{U}^{-232^{b}}$ & 6 & $2.31 \pm 5.56 \mathrm{E}-10$ & $4.09 \pm 9.85 \mathrm{E}-18$ & $<1.63 \mathrm{E}-15$ & $2 \mathrm{E}-14$ \\
\hline $\mathrm{U}-233 / 234^{b}$ & 6 & $4.40 \pm 0.69 \mathrm{E}-09$ & $7.79 \pm 1.22 \mathrm{E}-17$ & $1.63 \mathrm{E}-16$ & $9 \mathrm{E}-14$ \\
\hline $\mathrm{U}-235 / 236^{b}$ & 6 & $1.28 \pm 0.42 \mathrm{E}-09$ & $2.26 \pm 0.74 \mathrm{E}-17$ & 7.48E-17 & $1 \mathrm{E}-13$ \\
\hline $\mathrm{U}-238^{\mathrm{b}}$ & 6 & $3.59 \pm 0.61 \mathrm{E}-09$ & $6.36 \pm 1.07 \mathrm{E}-17$ & $1.37 \mathrm{E}-16$ & $1 \mathrm{E}-13$ \\
\hline Pu-238 & 6 & $8.36 \pm 1.00 \mathrm{E}-09$ & $1.48 \pm 0.18 \mathrm{E}-16$ & $4.04 \mathrm{E}-16$ & $3 \mathrm{E}-14$ \\
\hline $\mathrm{Pu}-239 / 240$ & 6 & $9.85 \pm 1.05 \mathrm{E}-09$ & $1.74 \pm 0.19 \mathrm{E}-16$ & $4.56 \mathrm{E}-16$ & $2 \mathrm{E}-14$ \\
\hline Am-241 & 6 & $2.91 \pm 0.14 \mathrm{E}-08$ & $5.16 \pm 0.25 \mathrm{E}-16$ & $1.23 \mathrm{E}-15$ & $2 \mathrm{E}-14$ \\
\hline
\end{tabular}

$N$ - Number of samples

-- DCGs are not specified for gross alpha and gross beta activity.

${ }^{a}$ Derived concentration guides (DCGs) are listed for reference only. They are applicable to average concentrations at the site boundary but not to stack concentrations, as might be inferred from their inclusion in this table.

${ }^{b}$ Total Uranium: $1.00 \pm 0.01 \mathrm{E}-02 \mathrm{~g}$; average $=1.78 \pm 0.01 \mathrm{E}-10 \mu \mathrm{g} / \mathrm{mL}$

$D-8$ 
Table D-8

2004 Effluent Airborne Radioactivity at Remote-Handled Waste Facility Stack (ANRHWFK)

\begin{tabular}{|c|c|c|c|c|c|}
\hline Isotope & $\mathbf{N}$ & $\begin{array}{c}\text { Total } \\
\text { Activity Released } \\
\text { (Ci) }\end{array}$ & $\begin{array}{c}\text { Average } \\
\text { Concentration } \\
(\mu \mathrm{Ci} / \mathrm{mL})\end{array}$ & $\begin{array}{c}\text { Maximum } \\
\text { Concentration } \\
(\mu \mathrm{Ci} / \mathrm{mL})\end{array}$ & $\begin{array}{c}D_{C G}{ }^{a} \\
(\mu \mathrm{Ci} / \mathrm{mL})\end{array}$ \\
\hline Gross Alpha & 34 & $-0.23 \pm 1.11 \mathrm{E}-08$ & $-0.35 \pm 1.66 \mathrm{E}-16$ & 7.90E-16 & -- \\
\hline Gross Beta & 34 & $1.99 \pm 2.43 \mathrm{E}-08$ & $2.99 \pm 3.66 \mathrm{E}-16$ & $1.55 \mathrm{E}-15$ & -- \\
\hline Co-60 & 3 & $0.20 \pm 1.19 \mathrm{E}-08$ & $0.31 \pm 1.78 \mathrm{E}-16$ & $<4.48 \mathrm{E}-16$ & $8 \mathrm{E}-11$ \\
\hline Sr-90 & 3 & $-3.36 \pm 9.40 \mathrm{E}-09$ & $-0.51 \pm 1.41 \mathrm{E}-16$ & $<3.08 \mathrm{E}-16$ & $9 \mathrm{E}-12$ \\
\hline I-129 & 3 & $4.80 \pm 2.64 \mathrm{E}-08$ & $7.22 \pm 3.97 \mathrm{E}-16$ & $9.30 \mathrm{E}-16$ & 7E-11 \\
\hline Cs-137 & 3 & $0.18 \pm 1.08 \mathrm{E}-08$ & $0.27 \pm 1.63 \mathrm{E}-16$ & $<2.87 \mathrm{E}-16$ & $4 \mathrm{E}-10$ \\
\hline Eu-154 & 3 & $0.49 \pm 2.36 \mathrm{E}-08$ & $0.73 \pm 3.55 \mathrm{E}-16$ & $8.56 \mathrm{E}-16$ & $5 \mathrm{E}-11$ \\
\hline $\mathrm{U}-\mathbf{2 3 2}^{\mathrm{b}}$ & 3 & $0.55 \pm 1.23 \mathrm{E}-09$ & $0.83 \pm 1.84 \mathrm{E}-17$ & $<4.87 \mathrm{E}-17$ & 2E-14 \\
\hline $\mathrm{U}-233 / 234^{\mathrm{b}}$ & 3 & $5.25 \pm 1.55 \mathrm{E}-09$ & $7.90 \pm 2.34 \mathrm{E}-17$ & $5.45 \mathrm{E}-17$ & 9E-14 \\
\hline $\mathrm{U}-235 / 236^{\mathrm{b}}$ & 3 & $2.22 \pm 1.22 \mathrm{E}-09$ & $3.34 \pm 1.52 \mathrm{E}-17$ & $3.20 \mathrm{E}-17$ & $1 \mathrm{E}-13$ \\
\hline $\mathrm{U}_{-238}{ }^{\mathrm{b}}$ & 3 & $6.55 \pm 1.63 \mathrm{E}-09$ & $9.85 \pm 2.46 \mathrm{E}-17$ & $7.72 \mathrm{E}-17$ & $1 \mathrm{E}-13$ \\
\hline Pu-238 & 3 & $1.85 \pm 6.44 \mathrm{E}-10$ & $2.79 \pm 9.69 \mathrm{E}-18$ & $2.45 \mathrm{E}-17$ & 3E-14 \\
\hline Pu-239/240 & 3 & $4.32 \pm 7.73 \mathrm{E}-10$ & $0.65 \pm 1.16 \mathrm{E}-17$ & $<2.53 \mathrm{E}-17$ & $2 \mathrm{E}-14$ \\
\hline Am-241 & 3 & $1.81 \pm 1.24 \mathrm{E}-09$ & $2.72 \pm 1.87 \mathrm{E}-17$ & $1.81 \mathrm{E}-17$ & 2E-14 \\
\hline
\end{tabular}

$N$ - Number of samples

-- DCGs are not specified for gross alpha and gross beta activity.

${ }^{a}$ Derived concentration guides (DCGs) are listed for reference only. They are applicable to average concentrations at the site boundary but not to stack concentrations, as might be inferred from their inclusion in this table.

${ }^{b}$ Total Uranium: $1.78 \pm 0.02 \mathrm{E}-02 \mathrm{~g}$; average $=2.68 \pm 0.03 \mathrm{E}-10 \mu \mathrm{g} / \mathrm{mL}$

$D-9$ 
Table D-9

2004 Ambient Airborne Radioactivity at Lag Storage (ANLAGAM)

\begin{tabular}{|c|c|c|c|c|c|c|}
\hline \multirow[t]{2}{*}{ Isotope } & \multirow[t]{2}{*}{$\mathbf{N}$} & \multicolumn{2}{|c|}{$\begin{array}{l}\text { ANLAGAM } \\
\boldsymbol{\mu C i} / \mathbf{m L}\end{array}$} & \multirow[t]{2}{*}{$\mathbf{N}$} & \multirow{2}{*}{$\begin{array}{c}\text { AFGRVAL }^{\mathrm{a}} \\
\mu \mathrm{Ci} / \mathrm{mL} \\
\text { Background Range }\end{array}$} & \multirow[t]{2}{*}{$\mathbf{D C G}^{\mathrm{b}}$} \\
\hline & & Average & Maximum & & & \\
\hline Gross Alpha & 53 & $7.15 \pm 7.68 \mathrm{E}-16$ & $1.45 \mathrm{E}-15$ & 53 & $<5.59 \mathrm{E}-16-2.16 \mathrm{E}-15$ & -- \\
\hline Gross Beta & 53 & $1.75 \pm 0.24 \mathrm{E}-14$ & $3.26 \mathrm{E}-14$ & 53 & 8.58E-15-3.06E-14 & -- \\
\hline K-40 & 4 & $2.93 \pm 2.84 \mathrm{E}-15$ & $5.57 \mathrm{E}-15$ & 4 & $<3.71 \mathrm{E}-15-6.07 \mathrm{E}-15$ & 9E-10 \\
\hline Co-60 & 4 & $0.59 \pm 1.86 \mathrm{E}-16$ & $2.21 \mathrm{E}-16$ & 4 & $<2.09 \mathrm{E}-16-<3.27 \mathrm{E}-16$ & $8 \mathrm{E}-11$ \\
\hline Sr-90 & 4 & $0.43 \pm 1.40 \mathrm{E}-16$ & $<1.85 \mathrm{E}-16$ & 4 & $<1.41 \mathrm{E}-16-2.05 \mathrm{E}-16$ & 9E-12 \\
\hline Cs-137 & 4 & $-0.22 \pm 1.42 \mathrm{E}-16$ & $<1.96 \mathrm{E}-16$ & 4 & $<1.92 \mathrm{E}-16-<2.56 \mathrm{E}-16$ & $4 \mathrm{E}-10$ \\
\hline Eu-154 & 4 & $0.35 \pm 4.97 \mathrm{E}-16$ & $<7.04 \mathrm{E}-16$ & 4 & $<5.37 \mathrm{E}-16-<7.92 \mathrm{E}-16$ & $5 \mathrm{E}-11$ \\
\hline $\mathrm{U}-232^{\mathrm{c}}$ & 4 & $-0.05 \pm 1.39 \mathrm{E}-17$ & $<1.81 \mathrm{E}-17$ & 4 & $<8.81 \mathrm{E}-18-<4.96 \mathrm{E}-17$ & $2 \mathrm{E}-14$ \\
\hline $\mathrm{U}-233 / 234^{\mathrm{c}}$ & 4 & $4.62 \pm 2.15 \mathrm{E}-17$ & $5.83 \mathrm{E}-17$ & 4 & 5.51E-17-1.27E-16 & 9E-14 \\
\hline $\mathrm{U}-235 / 236^{\mathrm{c}}$ & 4 & $1.35 \pm 1.35 \mathrm{E}-17$ & $3.88 \mathrm{E}-17$ & 4 & 1.25E-17-2.65E-17 & $1 \mathrm{E}-13$ \\
\hline $\mathrm{U}-238^{\mathrm{c}}$ & 4 & $6.72 \pm 2.40 \mathrm{E}-17$ & $1.40 \mathrm{E}-16$ & 4 & 4.68E-17-6.64E-17 & $1 \mathrm{E}-13$ \\
\hline Pu-238 & 4 & $1.01 \pm 9.05 \mathrm{E}-18$ & $<1.50 \mathrm{E}-17$ & 4 & $<8.43 \mathrm{E}-18-<2.25 \mathrm{E}-17$ & $3 \mathrm{E}-14$ \\
\hline Pu-239/240 & 4 & $3.38 \pm 1.71 \mathrm{E}-17$ & $1.31 \mathrm{E}-16$ & 4 & $<1.31 \mathrm{E}-17-<1.53 \mathrm{E}-17$ & $2 \mathrm{E}-14$ \\
\hline Am-241 & 4 & $1.75 \pm 1.71 \mathrm{E}-17$ & $3.24 \mathrm{E}-17$ & 4 & $<1.70 \mathrm{E}-17-2.30 \mathrm{E}-17$ & $2 \mathrm{E}-14$ \\
\hline
\end{tabular}

$N$ - Number of samples

-- DCGs are not specified for gross alpha and gross beta activity.

${ }^{a}$ Background air sampling location

${ }^{b}$ Derived concentration guides (DCGs) are applicable to average concentrations at the site boundary.

${ }^{c}$ Total Uranium: ANLAGAM average $=1.79 \pm 0.07 \mathrm{E}-10 \mu \mathrm{g} / \mathrm{mL} ;$ AFGRVAL average $=1.66 \pm 0.03 \mathrm{E}-10 \mu \mathrm{g} / \mathrm{mL}$ 
Table D-10

2004 Ambient Airborne Radioactivity at the NDA (ANNDAAM)

\begin{tabular}{|c|c|c|c|c|c|c|}
\hline \multirow[t]{2}{*}{ Isotope } & \multirow[t]{2}{*}{$\mathbf{N}$} & \multicolumn{2}{|c|}{$\begin{array}{c}\text { ANNDAAM } \\
\mu \mathrm{Ci} / \mathrm{mL}\end{array}$} & \multirow[t]{2}{*}{$\mathbf{N}$} & \multirow{2}{*}{$\begin{array}{c}\text { AFGRVAL }^{\mathrm{a}} \\
\mu \mathrm{Ci} / \mathrm{mL} \\
\text { Background Range }\end{array}$} & \multirow[t]{2}{*}{ DCG $^{\mathrm{b}}$} \\
\hline & & Average & Maximum & & & \\
\hline Gross Alpha & 53 & $8.60 \pm 8.13 \mathrm{E}-16$ & $2.03 \mathrm{E}-15$ & 53 & $<5.59 \mathrm{E}-16-2.16 \mathrm{E}-15$ & -- \\
\hline Gross Beta & 53 & $1.71 \pm 0.24 \mathrm{E}-14$ & 2.90E-14 & 53 & 8.58E-15-3.06E-14 & -- \\
\hline K-40 & 4 & $2.60 \pm 2.07 \mathrm{E}-15$ & $3.38 \mathrm{E}-15$ & 4 & $<3.71 \mathrm{E}-15-6.07 \mathrm{E}-15$ & $9 \mathrm{E}-10$ \\
\hline Co-60 & 4 & $0.43 \pm 1.63 \mathrm{E}-16$ & $<1.86 \mathrm{E}-16$ & 4 & $<2.09 \mathrm{E}-16-<3.27 \mathrm{E}-16$ & $8 \mathrm{E}-11$ \\
\hline Sr-90 & 4 & $0.45 \pm 1.16 \mathrm{E}-16$ & $<1.50 \mathrm{E}-16$ & 4 & $<1.41 \mathrm{E}-16-2.05 \mathrm{E}-16$ & $9 \mathrm{E}-12$ \\
\hline Cs-137 & 4 & $0.41 \pm 2.08 \mathrm{E}-16$ & $<3.52 \mathrm{E}-16$ & 4 & $<1.92 \mathrm{E}-16-<2.56 \mathrm{E}-16$ & $4 \mathrm{E}-10$ \\
\hline Eu-154 & 4 & $0.95 \pm 4.16 \mathrm{E}-16$ & $<4.29 \mathrm{E}-16$ & 4 & $<5.37 \mathrm{E}-16-<7.92 \mathrm{E}-16$ & $5 \mathrm{E}-11$ \\
\hline $\mathrm{U}-232^{\mathrm{c}}$ & 4 & $1.10 \pm 1.88 \mathrm{E}-17$ & $<2.82 \mathrm{E}-17$ & 4 & $<8.81 \mathrm{E}-18-<4.96 \mathrm{E}-17$ & $2 \mathrm{E}-14$ \\
\hline $\mathrm{U}-233 / 234^{\mathrm{c}}$ & 4 & $5.28 \pm 2.40 \mathrm{E}-17$ & $6.04 \mathrm{E}-17$ & 4 & 5.51E-17-1.27E-16 & $9 \mathrm{E}-14$ \\
\hline $\mathrm{U}-235 / 236^{\mathrm{C}}$ & 4 & $1.25 \pm 1.47 \mathrm{E}-17$ & $3.21 \mathrm{E}-17$ & 4 & $1.25 \mathrm{E}-17-2.65 \mathrm{E}-17$ & $1 \mathrm{E}-13$ \\
\hline $\mathrm{U}^{-238}{ }^{\mathrm{c}}$ & 4 & $3.32 \pm 1.87 \mathrm{E}-17$ & $4.50 \mathrm{E}-17$ & 4 & 4.68E-17-6.64E-17 & $1 \mathrm{E}-13$ \\
\hline Pu-238 & 4 & $0.44 \pm 1.27 \mathrm{E}-17$ & $<1.84 \mathrm{E}-17$ & 4 & $<8.43 \mathrm{E}-18-<2.25 \mathrm{E}-17$ & 3E-14 \\
\hline Pu-239/240 & 4 & $0.23 \pm 1.08 \mathrm{E}-17$ & $<1.33 \mathrm{E}-17$ & 4 & $<1.31 \mathrm{E}-17-<1.53 \mathrm{E}-17$ & 2E-14 \\
\hline Am-241 & 4 & $0.46 \pm 1.21 \mathrm{E}-17$ & $1.57 \mathrm{E}-17$ & 4 & $<1.70 \mathrm{E}-17-2.30 \mathrm{E}-17$ & $2 \mathrm{E}-14$ \\
\hline
\end{tabular}

$N$ - Number of samples

-- DCGs are not specified for gross alpha and gross beta activity.

${ }^{a}$ Background air sampling location

${ }^{b}$ Derived concentration guides (DCGs) are applicable to average concentrations at the site boundary.

${ }^{c}$ Total Uranium: ANNDAAM average $=9.81 \pm 0.17 \mathrm{E}-11 \mu \mathrm{g} / \mathrm{mL} ;$ AFGRVAL average $=1.66 \pm 0.03 \mathrm{E}-10 \mu \mathrm{g} / \mathrm{mL}$

Table D-11

2004 Ambient Airborne Radioactivity at SDA Trench 9 (ANSDAT9)

\begin{tabular}{|c|c|c|c|c|c|c|}
\hline \multirow[t]{2}{*}{ Isotope } & \multirow[t]{2}{*}{$\mathbf{N}$} & \multicolumn{2}{|c|}{$\begin{array}{c}\text { ANSDAT9 } \\
\mu \mathrm{Ci} / \mathrm{mL}\end{array}$} & \multirow[t]{2}{*}{$\mathbf{N}$} & \multirow{2}{*}{$\begin{array}{c}\text { AFGRVAL }^{\mathrm{a}} \\
\mu \mathrm{Ci} / \mathrm{mL}\end{array}$} & \multirow[t]{2}{*}{$\mathbf{D C G}^{\mathrm{b}}$} \\
\hline & & Average & Maximum & & & \\
\hline Gross Alpha & 52 & $0.60 \pm 1.09 \mathrm{E}-15$ & $2.44 \mathrm{E}-15$ & 53 & $<5.59 \mathrm{E}-16-2.16 \mathrm{E}-15$ & -- \\
\hline Gross Beta & 52 & $1.63 \pm 0.32 \mathrm{E}-14$ & 3.69E-14 & 53 & 8.58E-15-3.06E-14 & -- \\
\hline Tritium & 52 & $9.40 \pm 6.10 \mathrm{E}-13$ & $5.51 \mathrm{E}-12$ & 53 & 5.76E-14-1.05E-12 & 1E-07 \\
\hline K-40 & 4 & $3.51 \pm 4.09 \mathrm{E}-15$ & $4.43 \mathrm{E}-15$ & 4 & $<3.71 \mathrm{E}-15-6.07 \mathrm{E}-15$ & $9 \mathrm{E}-10$ \\
\hline Co-60 & 4 & $0.23 \pm 2.41 \mathrm{E}-16$ & $<3.32 \mathrm{E}-16$ & 4 & $<2.09 \mathrm{E}-16-<3.27 \mathrm{E}-16$ & $8 \mathrm{E}-11$ \\
\hline I-129 & 4 & $0.26 \pm 2.52 \mathrm{E}-16$ & $<3.23 \mathrm{E}-16$ & 4 & 3.02E-16-3.89E-16 & $7 \mathrm{E}-11$ \\
\hline Cs-137 & 4 & $0.15 \pm 2.35 \mathrm{E}-16$ & $<3.47 \mathrm{E}-16$ & 4 & $<1.92 \mathrm{E}-16-<2.56 \mathrm{E}-16$ & $4 \mathrm{E}-10$ \\
\hline
\end{tabular}

N- Number of samples

Note: Samples taken on July 6, 2004 were rejected for gross alpha, gross beta, and tritium.

-- DCGs are not specified for gross alpha and gross beta activity.

${ }^{a}$ Background air sampling location

${ }^{b}$ Derived concentration guides (DCGs) are applicable to average concentrations at the site boundary. 
Table D-12

2004 Ambient Airborne Radioactivity at Rock Springs Road (AFRSPRD)

\begin{tabular}{|c|c|c|c|c|c|c|}
\hline \multirow[t]{2}{*}{ Isotope } & \multirow[t]{2}{*}{$\mathbf{N}$} & \multicolumn{2}{|c|}{$\begin{array}{r}\text { AFRSPRD } \\
\mu \mathrm{Ci} / \mathrm{mL}\end{array}$} & \multirow[t]{2}{*}{$\mathbf{N}$} & \multirow{2}{*}{$\begin{array}{c}\text { AFGRVAL }^{\mathrm{a}} \\
\mu \mathrm{Ci} / \mathrm{mL} \\
\text { Background Range }\end{array}$} & \multirow[t]{2}{*}{ DCG $^{\mathbf{b}}$} \\
\hline & & Average & Maximum & & & \\
\hline Gross Alpha & 53 & $0.66 \pm 1.04 \mathrm{E}-15$ & $2.03 \mathrm{E}-15$ & 53 & $<5.59 \mathrm{E}-16-2.16 \mathrm{E}-15$ & -- \\
\hline Gross Beta & 53 & $1.66 \pm 0.31 \mathrm{E}-14$ & $3.46 \mathrm{E}-14$ & 53 & 8.58E-15-3.06E-14 & -- \\
\hline Tritium & 53 & $-0.21 \pm 6.66 \mathrm{E}-13$ & $1.17 \mathrm{E}-12$ & 53 & $5.76 \mathrm{E}-14-1.05 \mathrm{E}-12$ & 1E-07 \\
\hline K-40 & 4 & $2.17 \pm 3.53 \mathrm{E}-15$ & $<4.98 \mathrm{E}-15$ & 4 & $<3.71 \mathrm{E}-15-6.07 \mathrm{E}-15$ & $9 \mathrm{E}-10$ \\
\hline Co-60 & 4 & $0.05 \pm 2.45 \mathrm{E}-16$ & $<3.61 \mathrm{E}-16$ & 4 & $<2.09 \mathrm{E}-16-<3.27 \mathrm{E}-16$ & $8 \mathrm{E}-11$ \\
\hline Sr-90 & 4 & $-0.39 \pm 1.96 \mathrm{E}-16$ & $<2.88 \mathrm{E}-16$ & 4 & $<1.41 \mathrm{E}-16-2.05 \mathrm{E}-16$ & 9E-12 \\
\hline I-129 & 4 & $-0.11 \pm 3.92 \mathrm{E}-16$ & $<4.53 \mathrm{E}-16$ & 4 & 3.02E-16-3.89E-16 & 7E-11 \\
\hline Cs-137 & 4 & $-0.01 \pm 1.76 \mathrm{E}-16$ & $<1.95 \mathrm{E}-16$ & 4 & $<1.92 \mathrm{E}-16-<2.56 \mathrm{E}-16$ & $4 \mathrm{E}-10$ \\
\hline Eu-154 & 4 & $0.13 \pm 7.40 \mathrm{E}-16$ & $<1.10 \mathrm{E}-15$ & 4 & $<5.37 \mathrm{E}-16-<7.92 \mathrm{E}-16$ & $5 \mathrm{E}-11$ \\
\hline $\mathrm{U}-232^{\mathrm{C}}$ & 4 & $-0.36 \pm 2.18 \mathrm{E}-17$ & $<2.53 \mathrm{E}-17$ & 4 & $<8.81 \mathrm{E}-18-<4.96 \mathrm{E}-17$ & $2 \mathrm{E}-14$ \\
\hline $\mathrm{U}-233 / 234^{\mathrm{c}}$ & 4 & $8.74 \pm 3.82 \mathrm{E}-17$ & $1.22 \mathrm{E}-16$ & 4 & 5.51E-17-1.27E-16 & 9E-14 \\
\hline $\mathrm{U}-235 / 236^{\mathrm{C}}$ & 4 & $2.65 \pm 2.43 \mathrm{E}-17$ & $5.02 \mathrm{E}-17$ & 4 & $1.25 \mathrm{E}-17-2.65 \mathrm{E}-17$ & $1 \mathrm{E}-13$ \\
\hline $\mathrm{U}-238^{\mathrm{c}}$ & 4 & $6.42 \pm 3.47 \mathrm{E}-17$ & $9.12 \mathrm{E}-17$ & 4 & 4.68E-17-6.64E-17 & 1E-13 \\
\hline Pu-238 & 4 & $-0.21 \pm 1.71 \mathrm{E}-17$ & $<2.28 \mathrm{E}-17$ & 4 & $<8.43 \mathrm{E}-18-<2.25 \mathrm{E}-17$ & $3 \mathrm{E}-14$ \\
\hline Pu-239/240 & 4 & $0.70 \pm 1.92 \mathrm{E}-17$ & $1.89 \mathrm{E}-17$ & 4 & $<1.31 \mathrm{E}-17-<1.53 \mathrm{E}-17$ & 2E-14 \\
\hline Am-241 & 4 & $1.41 \pm 2.15 \mathrm{E}-17$ & $3.42 \mathrm{E}-17$ & 4 & $<1.70 \mathrm{E}-17-2.30 \mathrm{E}-17$ & $2 \mathrm{E}-14$ \\
\hline
\end{tabular}

$N$ - Number of samples

-- DCGs are not specified for gross alpha and gross beta activity.

${ }^{a}$ Background air sampling location

${ }^{b}$ Derived concentration guides (DCGs) are applicable to average concentrations at the site boundary.

${ }^{c}$ Total Uranium: AFRSPRD average $=1.48 \pm 0.03 \mathrm{E}-10 \mu \mathrm{g} / \mathrm{mL} ;$ AFGRVAL average $=1.66 \pm 0.03 \mathrm{E}-10 \mu \mathrm{g} / \mathrm{mL}$ 
Table D-13

2004 Ambient Airborne Radioactivity at Dutch Hill Road (AFBOEHN)

\begin{tabular}{|c|c|c|c|c|c|c|}
\hline \multirow[t]{2}{*}{ Isotope } & \multirow[t]{2}{*}{$\mathbf{N}$} & \multicolumn{2}{|c|}{$\begin{array}{c}\text { AFBOEHN } \\
\mu \mathrm{Ci} / \mathrm{mL}\end{array}$} & \multirow[t]{2}{*}{$\mathbf{N}$} & \multirow{2}{*}{$\begin{array}{c}\text { AFGRVAL }^{\mathrm{a}} \\
\mu \mathrm{Ci} / \mathrm{mL} \\
\text { Background Range }\end{array}$} & \multirow[t]{2}{*}{$\mathbf{D C G}^{\mathrm{b}}$} \\
\hline & & Average & Maximum & & & \\
\hline Gross Alpha & 53 & $0.82 \pm 1.09 \mathrm{E}-15$ & $2.97 \mathrm{E}-15$ & 53 & $<5.59 \mathrm{E}-16-2.16 \mathrm{E}-15$ & -- \\
\hline Gross Beta & 53 & $1.79 \pm 0.32 \mathrm{E}-14$ & 3.05E-14 & 53 & 8.58E-15-3.06E-14 & -- \\
\hline K-40 & 4 & $1.76 \pm 3.81 \mathrm{E}-15$ & 3.91E-15 & 4 & $<3.71 \mathrm{E}-15-6.07 \mathrm{E}-15$ & $9 \mathrm{E}-10$ \\
\hline Co-60 & 4 & $1.14 \pm 2.89 \mathrm{E}-16$ & $3.49 \mathrm{E}-16$ & 4 & $<2.09 \mathrm{E}-16-<3.27 \mathrm{E}-16$ & $8 \mathrm{E}-11$ \\
\hline Sr-90 & 4 & $0.66 \pm 1.90 \mathrm{E}-16$ & $<2.55 \mathrm{E}-16$ & 4 & $<1.41 \mathrm{E}-16-2.05 \mathrm{E}-16$ & $9 \mathrm{E}-12$ \\
\hline Cs-137 & 4 & $-0.47 \pm 2.28 \mathrm{E}-16$ & $<3.38 \mathrm{E}-16$ & 4 & $<1.92 \mathrm{E}-16-<2.56 \mathrm{E}-16$ & $4 \mathrm{E}-10$ \\
\hline
\end{tabular}

$N$ - Number of samples

-- DCGs are not specified for gross alpha and gross beta activity.

${ }^{a}$ Background air sampling location

${ }^{b}$ Derived concentration guides (DCGs) are applicable to average concentrations at the site boundary.

Table D-14

2004 Ambient Airborne Radioactivity at Fox Valley Road (AFFXVRD)

\begin{tabular}{|c|c|c|c|c|c|c|}
\hline \multirow[t]{2}{*}{ Isotope } & \multirow[t]{2}{*}{$\mathbf{N}$} & \multicolumn{2}{|c|}{$\begin{array}{c}\text { AFFXVRD } \\
\mu \mathrm{Ci} / \mathrm{mL}\end{array}$} & \multirow[t]{2}{*}{$\mathbf{N}$} & \multirow{2}{*}{$\begin{array}{c}\text { AFGRVAL }^{\mathrm{a}} \\
\mu \mathrm{Ci} / \mathrm{mL} \\
\text { Background Range }\end{array}$} & \multirow[t]{2}{*}{ DCG $^{\mathrm{b}}$} \\
\hline & & Average & Maximum & & & \\
\hline Gross Alpha & 53 & $0.78 \pm 1.10 \mathrm{E}-15$ & $2.08 \mathrm{E}-15$ & 53 & $<5.59 \mathrm{E}-16-2.16 \mathrm{E}-15$ & -- \\
\hline Gross Beta & 53 & $1.65 \pm 0.31 \mathrm{E}-14$ & 3.05E-14 & 53 & 8.58E-15-3.06E-14 & -- \\
\hline K-40 & 4 & $2.89 \pm 3.82 \mathrm{E}-15$ & 2.69E-15 & 4 & $<3.71 \mathrm{E}-15-6.07 \mathrm{E}-15$ & 9E-10 \\
\hline Co-60 & 4 & $-0.75 \pm 2.75 \mathrm{E}-16$ & $<4.26 \mathrm{E}-16$ & 4 & $<2.09 \mathrm{E}-16-<3.27 \mathrm{E}-16$ & $8 \mathrm{E}-11$ \\
\hline Sr-90 & 4 & $0.91 \pm 1.98 \mathrm{E}-16$ & $2.13 \mathrm{E}-16$ & 4 & $<1.41 \mathrm{E}-16-2.05 \mathrm{E}-16$ & $9 \mathrm{E}-12$ \\
\hline Cs-137 & 4 & $1.15 \pm 2.26 \mathrm{E}-16$ & 3.74E-16 & 4 & $<1.92 \mathrm{E}-16-<2.56 \mathrm{E}-16$ & $4 \mathrm{E}-10$ \\
\hline
\end{tabular}

$N$ - Number of samples

-- DCGs are not specified for gross alpha and gross beta activity.

${ }^{a}$ Background air sampling location

${ }^{b}$ Derived concentration guides (DCGs) are applicable to average concentrations at the site boundary. 
Table D-15

2004 Ambient Airborne Radioactivity at the Bulk Storage Warehouse (AFBLKST)

\begin{tabular}{|c|c|c|c|c|c|c|}
\hline \multirow[t]{2}{*}{ Isotope } & \multirow[t]{2}{*}{$\mathbf{N}$} & \multicolumn{2}{|c|}{$\begin{array}{c}\text { AFBLKST } \\
\mu \mathrm{Ci} / \mathrm{mL}\end{array}$} & \multirow[t]{2}{*}{$\mathbf{N}$} & \multirow{2}{*}{$\begin{array}{c}\text { AFGRVAL }^{\mathrm{a}} \\
\mu \mathrm{Ci} / \mathrm{mL} \\
\text { Background Range }\end{array}$} & \multirow[t]{2}{*}{ DCG $^{b}$} \\
\hline & & Average & Maximum & & & \\
\hline Gross Alpha & 53 & $0.70 \pm 1.06 \mathrm{E}-15$ & $2.12 \mathrm{E}-15$ & 53 & $<5.59 \mathrm{E}-16-2.16 \mathrm{E}-15$ & -- \\
\hline Gross Beta & 53 & $1.63 \pm 0.31 \mathrm{E}-14$ & $2.82 \mathrm{E}-14$ & 53 & 8.58E-15-3.06E-14 & -- \\
\hline K-40 & 4 & $2.09 \pm 5.46 \mathrm{E}-15$ & $<7.47 \mathrm{E}-15$ & 4 & $<3.71 \mathrm{E}-15-6.07 \mathrm{E}-15$ & 9E-10 \\
\hline Co-60 & 4 & $-0.16 \pm 2.20 \mathrm{E}-16$ & $<3.21 \mathrm{E}-16$ & 4 & $<2.09 \mathrm{E}-16-<3.27 \mathrm{E}-16$ & $8 \mathrm{E}-11$ \\
\hline Sr-90 & 4 & $0.47 \pm 1.71 \mathrm{E}-16$ & $<2.49 \mathrm{E}-16$ & 4 & $<1.41 \mathrm{E}-16-2.05 \mathrm{E}-16$ & 9E-12 \\
\hline Cs-137 & 4 & $1.18 \pm 2.12 \mathrm{E}-16$ & $1.57 \mathrm{E}-16$ & 4 & $<1.92 \mathrm{E}-16-<2.56 \mathrm{E}-16$ & $4 \mathrm{E}-10$ \\
\hline
\end{tabular}

$N$ - Number of samples

-- DCGs are not specified for gross alpha and gross beta activity.

${ }^{a}$ Background air sampling location

${ }^{b}$ Derived concentration guides (DCGs) are applicable to average concentrations at the site boundary.

Table D-16

2004 Ambient Airborne Radioactivity at Route 240 (AFRT240)

\begin{tabular}{|c|c|c|c|c|c|c|}
\hline \multirow[t]{2}{*}{ Isotope } & \multirow[t]{2}{*}{$\mathbf{N}$} & \multicolumn{2}{|c|}{$\begin{array}{c}\text { AFRT240 } \\
\mu \mathrm{Ci} / \mathrm{mL}\end{array}$} & \multirow[t]{2}{*}{$\mathbf{N}$} & \multirow{2}{*}{$\begin{array}{c}\text { AFGRVAL }^{\mathrm{a}} \\
\mu \mathrm{Ci} / \mathrm{mL} \\
\text { Background Range }\end{array}$} & \multirow[t]{2}{*}{ DCG $^{\mathbf{b}}$} \\
\hline & & Average & Maximum & & & \\
\hline Gross Alpha & 53 & $0.59 \pm 1.05 \mathrm{E}-15$ & $1.93 \mathrm{E}-15$ & 53 & $<5.59 \mathrm{E}-16-2.16 \mathrm{E}-15$ & -- \\
\hline Gross Beta & 53 & $1.70 \pm 0.32 \mathrm{E}-14$ & $2.68 \mathrm{E}-14$ & 53 & 8.58E-15-3.06E-14 & -- \\
\hline K-40 & 4 & $3.20 \pm 3.12 \mathrm{E}-15$ & 5.97E-15 & 4 & $<3.71 \mathrm{E}-15-6.07 \mathrm{E}-15$ & 9E-10 \\
\hline Co-60 & 4 & $0.13 \pm 2.14 \mathrm{E}-16$ & $1.48 \mathrm{E}-16$ & 4 & $<2.09 \mathrm{E}-16-<3.27 \mathrm{E}-16$ & $8 \mathrm{E}-11$ \\
\hline Sr-90 & 4 & $0.33 \pm 1.73 \mathrm{E}-16$ & $2.50 \mathrm{E}-16$ & 4 & $<1.41 \mathrm{E}-16-2.05 \mathrm{E}-16$ & 9E-12 \\
\hline Cs-137 & 4 & $0.33 \pm 2.00 \mathrm{E}-16$ & $<3.02 \mathrm{E}-16$ & 4 & $<1.92 \mathrm{E}-16-<2.56 \mathrm{E}-16$ & $4 \mathrm{E}-10$ \\
\hline
\end{tabular}

$N$ - Number of samples

-- DCGs are not specified for gross alpha and gross beta activity.

a Background air sampling location

${ }^{b}$ Derived concentration guides (DCGs) are applicable to average concentrations at the site boundary. 
Table D-17

2004 Ambient Airborne Radioactivity at Thomas Corners Road (AFTCORD)

\begin{tabular}{|c|c|c|c|c|c|c|}
\hline \multirow[t]{2}{*}{ Isotope } & \multirow[t]{2}{*}{$\mathbf{N}$} & \multicolumn{2}{|c|}{$\begin{array}{c}\text { AFTCORD } \\
\mu \mathrm{Ci} / \mathrm{mL}\end{array}$} & \multirow[t]{2}{*}{$\mathbf{N}$} & \multirow{2}{*}{$\begin{array}{c}\text { AFGRVAL }^{\mathrm{a}} \\
\mu \mathrm{Ci} / \mathrm{mL} \\
\text { Background Range }\end{array}$} & \multirow[t]{2}{*}{ DCG $^{\mathrm{b}}$} \\
\hline & & Average & Maximum & & & \\
\hline Gross Alpha & 53 & $0.85 \pm 1.11 \mathrm{E}-15$ & $2.68 \mathrm{E}-15$ & 53 & $<5.59 \mathrm{E}-16-2.16 \mathrm{E}-15$ & -- \\
\hline Gross Beta & 53 & $1.70 \pm 0.31 \mathrm{E}-14$ & 3.13E-14 & 53 & 8.58E-15-3.06E-14 & -- \\
\hline K-40 & 4 & $1.73 \pm 3.51 \mathrm{E}-15$ & $4.84 \mathrm{E}-15$ & 4 & $<3.71 \mathrm{E}-15-6.07 \mathrm{E}-15$ & 9E-10 \\
\hline Co-60 & 4 & $-0.35 \pm 2.21 \mathrm{E}-16$ & $<2.65 \mathrm{E}-16$ & 4 & $<2.09 \mathrm{E}-16-<3.27 \mathrm{E}-16$ & $8 \mathrm{E}-11$ \\
\hline Sr-90 & 4 & $0.13 \pm 1.82 \mathrm{E}-16$ & $<2.32 \mathrm{E}-16$ & 4 & $<1.41 \mathrm{E}-16-2.05 \mathrm{E}-16$ & $9 \mathrm{E}-12$ \\
\hline Cs-137 & 4 & $1.52 \pm 1.84 \mathrm{E}-16$ & $<2.37 \mathrm{E}-16$ & 4 & $<1.92 \mathrm{E}-16-<2.56 \mathrm{E}-16$ & $4 \mathrm{E}-10$ \\
\hline
\end{tabular}

$N$ - Number of samples

-- DCGs are not specified for gross alpha and gross beta activity.

${ }^{a}$ Background air sampling location

${ }^{b}$ Derived concentration guides (DCGs) are applicable to average concentrations at the site boundary.

Table D-18

2004 Ambient Airborne Radioactivity at West Valley (AFWEVAL)

\begin{tabular}{|c|c|c|c|c|c|c|}
\hline \multirow[t]{2}{*}{ Isotope } & \multirow[t]{2}{*}{$\mathbf{N}$} & \multicolumn{2}{|c|}{$\begin{array}{c}\text { AFWEVAL } \\
\mu \mathrm{Ci} / \mathrm{mL}\end{array}$} & \multirow[t]{2}{*}{$\mathbf{N}$} & \multirow{2}{*}{$\begin{array}{c}\text { AFGRVAL }^{\mathrm{a}} \\
\mu \mathrm{Ci} / \mathrm{mL} \\
\text { Background Range }\end{array}$} & \multirow[t]{2}{*}{ DCG $^{\text {b }}$} \\
\hline & & Average & Maximum & & & \\
\hline Gross Alpha & 53 & $0.83 \pm 1.11 \mathrm{E}-15$ & $3.04 \mathrm{E}-15$ & 53 & $<5.59 \mathrm{E}-16-2.16 \mathrm{E}-15$ & -- \\
\hline Gross Beta & 53 & $1.76 \pm 0.32 \mathrm{E}-14$ & $3.14 \mathrm{E}-14$ & 53 & $8.58 \mathrm{E}-15-3.06 \mathrm{E}-14$ & -- \\
\hline K-40 & 4 & $4.43 \pm 4.98 \mathrm{E}-15$ & $6.91 \mathrm{E}-15$ & 4 & $<3.71 \mathrm{E}-15-6.07 \mathrm{E}-15$ & $9 \mathrm{E}-10$ \\
\hline Co-60 & 4 & $0.02 \pm 2.54 \mathrm{E}-16$ & $<3.04 \mathrm{E}-16$ & 4 & $<2.09 \mathrm{E}-16-<3.27 \mathrm{E}-16$ & $8 \mathrm{E}-11$ \\
\hline Sr-90 & 4 & $0.44 \pm 1.68 \mathrm{E}-16$ & $<2.06 \mathrm{E}-16$ & 4 & $<1.41 \mathrm{E}-16-2.05 \mathrm{E}-16$ & 9E-12 \\
\hline Cs-137 & 4 & $-0.55 \pm 2.43 \mathrm{E}-16$ & $<3.06 \mathrm{E}-16$ & 4 & $<1.92 \mathrm{E}-16-<2.56 \mathrm{E}-16$ & $4 \mathrm{E}-10$ \\
\hline
\end{tabular}

$N$ - Number of samples

-- DCGs are not specified for gross alpha and gross beta activity.

${ }^{a}$ Background air sampling location

${ }^{b}$ Derived concentration guides (DCGs) are applicable to average concentrations at the site boundary. 
Table D-19

2004 Ambient Airborne Radioactivity at Springville (AFSPRVL)

\begin{tabular}{|c|c|c|c|c|c|c|}
\hline \multirow[t]{2}{*}{ Isotope } & \multirow[t]{2}{*}{$\mathbf{N}$} & \multicolumn{2}{|c|}{$\begin{array}{c}\text { AFSPRVL } \\
\mu \mathrm{Ci} / \mathrm{mL}\end{array}$} & \multirow[t]{2}{*}{$\mathbf{N}$} & \multirow{2}{*}{$\begin{array}{c}\text { AFGRVAL }^{\mathrm{a}} \\
\mu \mathrm{Ci} / \mathrm{mL} \\
\text { Background Range }\end{array}$} & \multirow[t]{2}{*}{ DCG $^{\text {b }}$} \\
\hline & & Average & Maximum & & & \\
\hline Gross Alpha & 53 & $0.74 \pm 1.07 \mathrm{E}-15$ & $3.25 \mathrm{E}-15$ & 53 & $<5.59 \mathrm{E}-16-2.16 \mathrm{E}-15$ & -- \\
\hline Gross Beta & 53 & $1.70 \pm 0.31 \mathrm{E}-14$ & 3.13E-14 & 53 & 8.58E-15-3.06E-14 & -- \\
\hline K-40 & 4 & $4.57 \pm 4.48 \mathrm{E}-15$ & $1.28 \mathrm{E}-14$ & 4 & $<3.71 \mathrm{E}-15-6.07 \mathrm{E}-15$ & $9 \mathrm{E}-10$ \\
\hline Co-60 & 4 & $0.92 \pm 2.45 \mathrm{E}-16$ & $<2.84 \mathrm{E}-16$ & 4 & $<2.09 \mathrm{E}-16-<3.27 \mathrm{E}-16$ & $8 \mathrm{E}-11$ \\
\hline Sr-90 & 4 & $1.03 \pm 1.82 \mathrm{E}-16$ & $1.83 \mathrm{E}-16$ & 4 & $<1.41 \mathrm{E}-16-2.05 \mathrm{E}-16$ & $9 \mathrm{E}-12$ \\
\hline Cs-137 & 4 & $0.54 \pm 1.96 \mathrm{E}-16$ & $1.92 \mathrm{E}-16$ & 4 & $<1.92 \mathrm{E}-16-<2.56 \mathrm{E}-16$ & $4 \mathrm{E}-10$ \\
\hline
\end{tabular}

$N$ - Number of samples

-- DCGs are not specified for gross alpha and gross beta activity.

${ }^{a}$ Background air sampling location

${ }^{b}$ Derived concentration guides (DCGs) are applicable to average concentrations at the site boundary.

$D-16$ 
Table D-20

2004 Radioactivity in Fallout: Dutch Hill (AFDHFOP)

\begin{tabular}{|l|c|c|c|c|c|}
\hline \multicolumn{1}{|c|}{ Analyte } & Units & N & Minimum & Average & Maximum \\
\hline Gross Alpha & $\mathrm{nCi} / \mathrm{m}^{2}$ & 12 & $1.13 \mathrm{E}-02$ & $2.80 \pm 1.18 \mathrm{E}-02$ & $6.34 \mathrm{E}-02$ \\
\hline Gross Beta & $\mathrm{nCi} / \mathrm{m}^{2}$ & 12 & $1.69 \mathrm{E}-01$ & $4.84 \pm 0.41 \mathrm{E}-01$ & $1.17 \mathrm{E}+00$ \\
\hline H-3 & $\mu \mathrm{Ci} / \mathrm{mL}$ & 12 & $<5.46 \mathrm{E}-08$ & $-1.82 \pm 7.80 \mathrm{E}-08$ & $9.50 \mathrm{E}-08$ \\
\hline K-40 & $\mathrm{nCi} / \mathrm{m}^{2}$ & 12 & $<8.59 \mathrm{E}-01$ & $0.18 \pm 6.79 \mathrm{E}+00$ & $2.82 \mathrm{E}+00$ \\
\hline Cs-137 & $\mathrm{nCi} / \mathrm{m}^{2}$ & 12 & $<8.55 \mathrm{E}-02$ & $2.57 \pm 5.09 \mathrm{E}-01$ & $1.46 \mathrm{E}+00$ \\
\hline
\end{tabular}

$N$ - Number of samples

Table D-21

2004 Radioactivity in Fallout: Rain Gauge (ANRGFOP)

\begin{tabular}{|l|c|c|c|c|c|}
\hline \multicolumn{1}{|c|}{ Analyte } & Units & N & Minimum & Average & Maximum \\
\hline Gross Alpha & $\mathrm{nCi} / \mathrm{m}^{2}$ & 12 & $1.44 \mathrm{E}-02$ & $4.07 \pm 1.62 \mathrm{E}-02$ & $1.02 \mathrm{E}-01$ \\
\hline Gross Beta & $\mathrm{nCi} / \mathrm{m}^{2}$ & 12 & $2.14 \mathrm{E}-01$ & $5.13 \pm 0.51 \mathrm{E}-01$ & $1.05 \mathrm{E}+00$ \\
\hline H-3 & $\mu \mathrm{Ci} / \mathrm{mL}$ & 12 & $<7.66 \mathrm{E}-08$ & $-0.48 \pm 8.09 \mathrm{E}-08$ & $1.03 \mathrm{E}-07$ \\
\hline K-40 & $\mathrm{nCi} / \mathrm{m}^{2}$ & 12 & $<2.57 \mathrm{E}+00$ & $0.59 \pm 9.80 \mathrm{E}+00$ & $4.83 \mathrm{E}+00$ \\
\hline Cs-137 & $\mathrm{nCi} / \mathrm{m}^{2}$ & 12 & $<1.57 \mathrm{E}-01$ & $0.45 \pm 7.50 \mathrm{E}-01$ & $1.73 \mathrm{E}+00$ \\
\hline
\end{tabular}

$N$ - Number of samples

Table D-22

2004 Radioactivity in Fallout: Route 240 (AF24FOP)

\begin{tabular}{|l|c|c|c|c|c|}
\hline \multicolumn{1}{|c|}{ Analyte } & Units & N & Minimum & Average & Maximum \\
\hline Gross Alpha & $\mathrm{nCi} / \mathrm{m}^{2}$ & 12 & $1.35 \mathrm{E}-02$ & $3.26 \pm 1.41 \mathrm{E}-02$ & $1.01 \mathrm{E}-01$ \\
\hline Gross Beta & $\mathrm{nCi} / \mathrm{m}^{2}$ & 12 & $2.21 \mathrm{E}-01$ & $5.26 \pm 0.47 \mathrm{E}-01$ & $1.00 \mathrm{E}+00$ \\
\hline H-3 & $\mu \mathrm{Ci} / \mathrm{mL}$ & 12 & $<7.61 \mathrm{E}-08$ & $0.20 \pm 8.14 \mathrm{E}-08$ & $1.32 \mathrm{E}-07$ \\
\hline K-40 & $\mathrm{nCi} / \mathrm{m}^{2}$ & 12 & $<9.84 \mathrm{E}-01$ & $-3.43 \pm 7.68 \mathrm{E}+00$ & $3.40 \mathrm{E}+00$ \\
\hline Cs-137 & $\mathrm{nCi} / \mathrm{m}^{2}$ & 12 & $<8.07 \mathrm{E}-02$ & $0.11 \pm 5.87 \mathrm{E}-01$ & $<1.38 \mathrm{E}+00$ \\
\hline
\end{tabular}

$N$ - Number of samples

$D-17$

WVDP Annual Site Environmental Report

Calendar Year 2004 
Table D-23

2004 Radioactivity in Fallout: Thomas Corners (AFTCFOP)

\begin{tabular}{|l|c|c|c|c|c|}
\hline \multicolumn{1}{|c|}{ Analyte } & Units & N & Minimum & Average & Maximum \\
\hline Gross Alpha & $\mathrm{nCi} / \mathrm{m}^{2}$ & 12 & $1.93 \mathrm{E}-02$ & $3.46 \pm 1.50 \mathrm{E}-02$ & $5.65 \mathrm{E}-02$ \\
\hline Gross Beta & $\mathrm{nCi} / \mathrm{m}^{2}$ & 12 & $2.86 \mathrm{E}-01$ & $6.19 \pm 0.54 \mathrm{E}-01$ & $1.13 \mathrm{E}+00$ \\
\hline H-3 & $\mu \mathrm{Ci} / \mathrm{mL}$ & 12 & $<7.67 \mathrm{E}-08$ & $0.09 \pm 8.12 \mathrm{E}-08$ & $8.54 \mathrm{E}-08$ \\
\hline K-40 & $\mathrm{nCi} / \mathrm{m}^{2}$ & 12 & $<1.32 \mathrm{E}+00$ & $-2.97 \pm 8.66 \mathrm{E}+00$ & $5.69 \mathrm{E}+00$ \\
\hline Cs-137 & $\mathrm{nCi} / \mathrm{m}^{2}$ & 12 & $<1.05 \mathrm{E}-01$ & $0.15 \pm 5.74 \mathrm{E}-01$ & $<1.17 \mathrm{E}+00$ \\
\hline
\end{tabular}

$N$ - Number of samples

Table D-24

2004 Radioactivity in Fallout: Fox Valley Road (AFFXFOP)

\begin{tabular}{|l|c|c|c|c|c|}
\hline \multicolumn{1}{|c|}{ Analyte } & Units & N & Minimum & Average & Maximum \\
\hline Gross Alpha & $\mathrm{nCi} / \mathrm{m}^{2}$ & 12 & $1.65 \mathrm{E}-02$ & $4.78 \pm 1.71 \mathrm{E}-02$ & $1.06 \mathrm{E}-01$ \\
\hline Gross Beta & $\mathrm{nCi} / \mathrm{m}^{2}$ & 12 & $2.52 \mathrm{E}-01$ & $5.59 \pm 0.52 \mathrm{E}-01$ & $1.13 \mathrm{E}+00$ \\
\hline Tritium & $\mu \mathrm{Ci} / \mathrm{mL}$ & 12 & $7.04 \mathrm{E}-08$ & $0.80 \pm 8.02 \mathrm{E}-08$ & $7.04 \mathrm{E}-08$ \\
\hline K-40 & $\mathrm{nCi} / \mathrm{m}^{2}$ & 12 & $<1.41 \mathrm{E}+00$ & $0.58 \pm 8.47 \mathrm{E}+00$ & $1.00 \mathrm{E}+01$ \\
\hline Cs-137 & $\mathrm{nCi} / \mathrm{m}^{2}$ & 12 & $<1.21 \mathrm{E}-01$ & $0.55 \pm 6.05 \mathrm{E}-01$ & $1.25 \mathrm{E}-01$ \\
\hline
\end{tabular}

$N$ - Number of samples

$D-18$ 


\section{Appendix $E$ Summary of Groundwater Monitoring Data}

E- 1 


\section{Groundwater Sampling Methodology}

Groundwater samples are collected from monitoring wells using either dedicated Teflon ${ }^{\circledR}$ well bailers or bladder pumps. Bailers are used in low-yield wells; bladder pumps are used in wells with good water-yielding characteristics. This sampling equipment is dedicated to an individual well to reduce the likelihood of sample contamination from external materials or cross contamination.

To ensure that only representative groundwater is sampled, three well volumes are removed (purged) from the well before the actual samples are collected. In low-yield wells, pumping or bailing to dryness provides sufficient purging. Conductivity and $\mathrm{pH}$ are measured before and after sampling to confirm the geochemical stability of the groundwater during sampling.

The bailer, a tube with a check valve at the bottom, is lowered slowly into the well to minimize agitation of the water column. The bailer containing the groundwater is then withdrawn from the well and emptied into a sample container. Bladder pumps use compressed air that is pumped from the surface to gently squeeze a Teflon ${ }^{\circledR}$ bladder encased in a stainless-steel tube near the bottom of the well. Groundwater flowing into the bladder is pumped into a sample container, allowing additional groundwater to enter the bladder with a minimum of agitation and mixing. A check valve ensures that the water flows in only one direction.

Groundwater samples are cooled and preserved, with chemicals if required, to minimize chemical and/or biological changes after sample collection. A strict chain-of-custody protocol is followed for all samples collected by the WVDP.

\section{Key to bolding convention:}

Tables E-2 through E-11 ${ }^{\text {GD }}$ contain a bolding convention devised to help the reader, when viewing the data, to quickly see the range of detectable measurements within a data series. A data series is a set of chemical or radionuclide measurements (e.g., gross alpha, gross beta, tritium) from a single location or from similar locations. Note that some tables contain data that should not be technically evaluated under this convention.

Results for each analyte constitute a single data series. If a radiological result is larger than the uncertainty term, the measurement is considered positive. Otherwise, a result is considered nondetectable. Chemical results preceded by "less than" $(<)$ are considered nondetectable. The bolding convention is not applied to data series consisting of less than three values.

If all results in a data series are positive, the lowest and highest values are bolded.

If a data series contains some positive results, the highest value is bolded.

If all values in a data series are nondetectable, no values are bolded.

$$
E-2
$$




\section{Groundwater Sampling and Analysis Agenda}

\section{Analyte Group}

Contamination Indicator Parameters (I)

Radiological Indicator Parameters (RI)

Volatile Organic Compounds (V)

Semivolatile Organic Compounds (SV)

6 NYCRR Appendix 33 Metals (M)

Special Monitoring Parameters

for Early Warning Wells (SM)

Radioisotopic Analyses:

alpha-, beta-, and gamma-emitters (R)

Strontium-90 (S)

\section{Description of Parameters ${ }^{1}$}

$\mathrm{pH}$, specific conductance (field measurements)

Gross alpha, gross beta, tritium

6 NYCRR Appendix 33 Volatile Organic Compounds (VOCs) (See Table E-12 $2^{\text {at }}$.)

6 NYCRR Appendix 33 Semivolatile Organic Compounds (SVOCs) and tributyl phosphate (TBP) (See Table E-12 ${ }^{\mathrm{Wx}}$.)

Antimony, arsenic, barium, beryllium, cadmium, chromium, cobalt, copper, lead, mercury, nickel, selenium, silver, thallium, tin, vanadium, zinc

Aluminum, iron, manganese

Carbon-14, strontium-90, technetium-99, iodine-129, cesium-137, radium-226, radium-228, uranium-232, uranium-233/234, uranium-235/236, uranium-238, total uranium

Strontium-90

2004 Quarterly Monitoring Schedule:

1st Qtr-December 1, 2003 to February 28, 2004

2nd Qtr - March 1, 2004 to May 31, 2004

3rd Qtr - June 1, 2004 to August 31, 2004

4th Qtr-September 1, 2004 to November 30, 2004

${ }^{1}$ Analysis performed for selected active monitoring locations only. See Table E-1 ${ }^{\mathbf{6 0}}$ for the analytes assigned to each monitoring location.

$$
E-3
$$


Table E-1

Groundwater Monitoring Network: Super Solid Waste Management Units

Sand and Gravel Wells

\begin{tabular}{|c|c|c|c|c|c|c|c|}
\hline Well ID & SSWMU & $\begin{array}{c}\text { Gradient } \\
\text { Position }\end{array}$ & $\begin{array}{c}\text { Analytical } \\
\text { Parameters in } 2004^{1}\end{array}$ & Well ID & SSWMU & $\begin{array}{c}\text { Gradient } \\
\text { Position }\end{array}$ & $\begin{array}{c}\text { Analytical } \\
\text { Parameters in } 2004^{1}\end{array}$ \\
\hline $103^{*}$ & 1,3 & D & I, RI, V & 802 & 8 & D & I, RI, V \\
\hline 104 & 1 & C & I, RI, SV, V & 803 & 8 & D & I, RI, SV, V \\
\hline 105 & 1 & C & I, RI, V & $804^{*}$ & 8 & D & I, RI, V \\
\hline 106 & 1 & D & I, RI, V & $1302^{2}$ & NA & D & I, RI, M, R, SV, V \\
\hline $111^{*}$ & 1 & D & I, RI, M, S, SV, V & $1304^{2}$ & NA & U & I, RI, M, R, SV, V \\
\hline $116^{*}$ & 1,8 & C, U & I, RI, S, V & 8603 & 8 & U & I, RI, SV, V \\
\hline 201 & 2 & U & I, RI, V & 8604 & 1 & C & I, RI, V \\
\hline 205 & 2,3 & D & I, RI & $8605^{*}$ & 1,2 & D & I, RI, M, R, SV, V \\
\hline $301^{*}$ & 3 & B & I, RI & $8607^{*}$ & 6,4 & U, D & I, RI, V \\
\hline $401^{*}$ & 4,3 & B & I, RI, R & $8609^{*}$ & $3,4,6$ & D, D, U & I, RI, S, V \\
\hline 403 & 4 & U & I, RI, V & $8612^{*}$ & 8 & D & I, RI, SV, V \\
\hline $406^{*}$ & 4,6 & D, U & I, RI, R, V & NB-1S $^{3}$ & NA & B & I, RI \\
\hline $408^{*}$ & 4,3 & D & I, RI, R, V & WP-A $^{4}$ & NA & D & I, RI \\
\hline $501^{*}$ & 5 & U & I, RI, S, V & WP-C $^{4}$ & NA & D & I, RI \\
\hline $502^{*}$ & 5 & D & I, RI, S, SM, V & WP-H $^{4}$ & NA & D & I, RI \\
\hline $602 \mathrm{~A}$ & 6 & D & I, RI, S & SP04 $^{5}$ & NA & D & RI \\
\hline 604 & 6 & D & I, RI & SP06 & NA & D & RI \\
\hline 605 & 6 & D & I, RI, S & SP11 $^{5}$ & NA & D & RI \\
\hline $706^{*}$ & 7 & B & I, RI, M, R, SV, V & SP12 & NA & D & I, RI, V \\
\hline $801^{*}$ & 8,6 & U, D & I, RI, S, V & GSEEP $^{5}$ & NA & D & I, RI, V \\
\hline
\end{tabular}

Legend: $\quad$ Gradient Positions
$B$ (background)
$C$ (crossgradient)
$D$ (downgradient)
$U$ (upgradient)

NA - Not applicable

${ }^{1}$ See p. E-3 for a description of codes and analytes.

${ }^{2}$ Monitor upgradient and downgradient of remote-handled waste facility

${ }^{3}$ Former background well

${ }^{4}$ Monitor locations north and east of main plant

${ }^{5}$ Monitor groundwater emanating from seeps along the edge of the north plateau

* Monitoring for certain parameters is required by the RCRA $\$ 3008(h)$ Order on Consent. 
Table E-1 (continued)

Groundwater Monitoring Network: Super Solid Waste Management Units

Lavery Till Sand Wells

\begin{tabular}{|c|c|c|c|}
\hline Well ID & SSWMU & $\begin{array}{c}\text { Gradient } \\
\text { Position }\end{array}$ & $\begin{array}{c}\text { Analytical } \\
\text { Parameters in } 2004^{1}\end{array}$ \\
\hline $204^{*}$ & 2,3 & D & I, RI \\
\hline 206 & 2 & C & I, RI \\
\hline 208 & 2 & D & I, RI, V \\
\hline 302 & 3 & U & I, RI \\
\hline 402 & 4 & B & I, RI \\
\hline
\end{tabular}

Weathered Lavery Till Wells

\begin{tabular}{|c|c|c|c|c|c|c|c|}
\hline Well ID & SSWMU & $\begin{array}{c}\text { Gradient } \\
\text { Position }\end{array}$ & $\begin{array}{c}\text { Analytical } \\
\text { Parameters in } 2004^{1}\end{array}$ & Well ID & SSWMU & $\begin{array}{c}\text { Gradient } \\
\text { Position }\end{array}$ & $\begin{array}{c}\text { Analytical } \\
\text { Parameters in } 2004^{1}\end{array}$ \\
\hline $906^{*}$ & 9 & D & I, RI & $1005^{*}$ & 9,10 & C, U & I, RI \\
\hline $908^{*}$ & 9 & B & I, RI & $1006^{*}$ & 9,10 & C, D & I, RI \\
\hline $909^{*}$ & 9 & D & I, RI, M, R, SV, V & 1007 & 10 & D & I, RI \\
\hline NDATR* $^{*}$ & 9 & D & I, RI, M, R, SV, V & $1008 C^{*}$ & 9,10 & U & I, RI \\
\hline
\end{tabular}

Unweathered Lavery Till Wells

\begin{tabular}{|c|c|c|c|c|c|c|c|}
\hline Well ID & SSWMU & $\begin{array}{c}\text { Gradient } \\
\text { Position }\end{array}$ & $\begin{array}{c}\text { Analytical } \\
\text { Parameters in } 2004^{1}\end{array}$ & Well ID & SSWMU & $\begin{array}{c}\text { Gradient } \\
\text { Position }\end{array}$ & $\begin{array}{c}\text { Analytical } \\
\text { Parameters in } 2004^{1}\end{array}$ \\
\hline 107 & 1 & D & I, RI, V & 409 & 4 & D & I, RI \\
\hline 108 & 1 & D & I, RI, V & 704 & 7 & D & I, RI, V \\
\hline $110^{*}$ & 1 & D & I, RI, V & $910^{*}$ & 9 & D & I, RI \\
\hline 405 & 4 & B & I, RI, M, R, SV, V & $1301^{2}$ & NA & D & I, RI, M, R, SV, V \\
\hline 407 & 4 & D & I, RI & $1303^{2}$ & NA & U & I, RI, M, R, SV, V \\
\hline
\end{tabular}

Legend: $\quad$ Gradient Positions

$B$ (background)

$C$ (crossgradient)

$D$ (downgradient)

$U$ (upgradient)

NA - Not applicable

${ }^{1}$ See p. E-3 for a description of codes and analytes.

${ }^{2}$ Monitor upgradient and downgradient of remote-handled waste facility

* Monitoring for certain parameters is required by the RCRA $\$ 3008(h)$ Order on Consent.

$$
E-5
$$


Table E-1 (concluded)

Groundwater Monitoring Network: Super Solid Waste Management Units

Kent Recessional Sequence Wells

\begin{tabular}{|c|c|c|c|c|c|c|c|}
\hline Well ID & SSWMU & $\begin{array}{c}\text { Gradient } \\
\text { Position }\end{array}$ & $\begin{array}{c}\text { Analytical } \\
\text { Parameters in 2004 }\end{array}$ & Well ID & SSWMU & $\begin{array}{c}\text { Gradient } \\
\text { Position }\end{array}$ & $\begin{array}{c}\text { Analytical } \\
\text { Parameters in 2004 }\end{array}$ \\
\hline $901^{*}$ & 4 & B & I, RI & $1008 B$ & 10 & U & I, RI \\
\hline $902^{*}$ & 9 & U & I, RI & $8610^{*}$ & 9 & D & I, RI \\
\hline $903^{*}$ & 9 & D & I, RI & $8611^{*}$ & 9 & D & I, RI \\
\hline
\end{tabular}

State-Licensed Disposal Area (SDA) Wells

(Note: The SDA wells are sampled by NYSERDA under an independent monitoring program)

\begin{tabular}{|c|c|c|c|c|c|}
\hline Well ID & $\begin{array}{c}\text { Geologic } \\
\text { Unit }\end{array}$ & $\begin{array}{c}\text { Gradient } \\
\text { Position }\end{array}$ & Well ID & $\begin{array}{c}\text { Geologic } \\
\text { Unit }\end{array}$ & $\begin{array}{c}\text { Gradient } \\
\text { Position }\end{array}$ \\
\hline $1101 \mathrm{~A}$ & $\mathrm{~W}$ & $\mathrm{U}$ & $1105 \mathrm{~A}$ & $\mathrm{~W}$ & $\mathrm{D}$ \\
\hline $1101 \mathrm{~B}$ & $\mathrm{U}$ & $\mathrm{U}$ & $1105 \mathrm{~B}$ & $\mathrm{U}$ & $\mathrm{D}$ \\
\hline $1101 \mathrm{C}$ & $\mathrm{K}$ & $\mathrm{U}$ & $1106 \mathrm{~A}$ & $\mathrm{~W}$ & $\mathrm{U}$ \\
\hline $1102 \mathrm{~A}$ & $\mathrm{~W}$ & $\mathrm{D}$ & $1106 \mathrm{~B}$ & $\mathrm{U}$ & $\mathrm{U}$ \\
\hline $1102 \mathrm{~B}$ & $\mathrm{U}$ & $\mathrm{D}$ & $1107 \mathrm{~A}$ & $\mathrm{~W}$ & $\mathrm{D}$ \\
\hline $1103 \mathrm{~A}$ & $\mathrm{~W}$ & $\mathrm{D}$ & $1108 \mathrm{~A}$ & $\mathrm{~W}$ & $\mathrm{U}$ \\
\hline $1103 \mathrm{~B}$ & $\mathrm{U}$ & $\mathrm{D}$ & $1109 \mathrm{~A}$ & $\mathrm{~W}$ & $\mathrm{U}$ \\
\hline $1103 \mathrm{C}$ & $\mathrm{K}$ & $\mathrm{D}$ & $1109 \mathrm{~B}$ & $\mathrm{U}$ & $\mathrm{U}$ \\
\hline $1104 \mathrm{~A}$ & $\mathrm{~W}$ & $\mathrm{D}$ & $1110 \mathrm{~A}$ & $\mathrm{~W}$ & $\mathrm{D}$ \\
\hline $1104 \mathrm{~B}$ & $\mathrm{U}$ & $\mathrm{D}$ & $1111 \mathrm{~A}$ & $\mathrm{~W}$ & $\mathrm{D}$ \\
\hline $1104 \mathrm{C}$ & $\mathrm{K}$ & $\mathrm{D}$ & & & \\
\hline
\end{tabular}

Legend: $\quad$ Gradient Positions

Geologic Unit

$B$ (background)

$K$ (Kent recessional sequence)

$C$ (crossgradient)

$U$ (unweathered Lavery till)

$D$ (downgradient)

$W$ (weathered Lavery till)

$U$ (upgradient)

${ }^{1}$ See $p$. E-3 for a description of codes and analytes.

Note: Additional monitoring wells used for measurement of water elevations only are illustrated on Figures A-6 and A-7.

* Monitoring for certain parameters is required by the RCRA $\$ 3008(h)$ Order on Consent. 


\section{Table E-2 \\ 2004 Indicator Results From the Sand and Gravel Unit}

\begin{tabular}{|c|c|c|c|c|c|c|}
\hline $\begin{array}{l}\text { Location } \\
\text { Code }\end{array}$ & $\begin{array}{l}\text { Hydraulic } \\
\text { Position }\end{array}$ & $\begin{array}{l}\mathbf{p H} \\
(\mathrm{SU})\end{array}$ & $\begin{array}{c}\text { Conductivity } \\
\left(\mu \mathrm{mhos} / \mathrm{cm} @ 25^{\circ} \mathrm{C}\right)\end{array}$ & $\begin{array}{c}\text { Gross Alpha } \\
(\mu \mathrm{Ci} / \mathrm{mL})\end{array}$ & $\begin{array}{c}\text { Gross Beta } \\
(\mu \mathrm{Ci} / \mathrm{mL})\end{array}$ & $\begin{array}{l}\text { Tritium } \\
(\mu \mathrm{Ci} / \mathrm{mL})\end{array}$ \\
\hline 301 & UP(1) & 6.56 & 898 & $1.90 \pm 1.95 \mathrm{E}-09$ & $8.04 \pm 3.68 \mathrm{E}-09$ & $0.17 \pm 5.64 \mathrm{E}-08$ \\
\hline 301 & UP(2) & 6.43 & 2,220 & $0.00 \pm 3.97 \mathrm{E}-09$ & $1.72 \pm 0.47 \mathrm{E}-08$ & $1.11 \pm 0.78 \mathrm{E}-07$ \\
\hline 301 & UP(3) & 6.40 & 975 & $1.30 \pm 2.87 \mathrm{E}-09$ & $1.02 \pm 0.37 \mathrm{E}-08$ & $5.82 \pm 8.13 \mathrm{E}-08$ \\
\hline 301 & UP(4) & 6.58 & 1,765 & $-2.61 \pm 5.11 \mathrm{E}-09$ & $9.07 \pm 3.84 \mathrm{E}-09$ & $5.46 \pm 5.45 \mathrm{E}-08$ \\
\hline 401 & UP(1) & 6.44 & 4,003 & $-0.12 \pm 9.23 \mathrm{E}-09$ & $3.51 \pm 7.77 \mathrm{E}-09$ & $1.17 \pm 0.83 \mathrm{E}-07$ \\
\hline 401 & UP(2) & 6.62 & 4,393 & $-1.99 \pm 7.89 \mathrm{E}-09$ & $7.20 \pm 7.97 \mathrm{E}-09$ & $4.08 \pm 7.79 \mathrm{E}-08$ \\
\hline 401 & UP(3) & 6.58 & 4,162 & $8.62 \pm 7.95 \mathrm{E}-09$ & $5.23 \pm 7.54 \mathrm{E}-09$ & $1.32 \pm 0.83 \mathrm{E}-07$ \\
\hline 401 & UP(4) & 6.50 & 2,795 & $-8.59 \pm 7.34 \mathrm{E}-09$ & $7.34 \pm 6.74 \mathrm{E}-09$ & $8.06 \pm 7.74 \mathrm{E}-08$ \\
\hline 403 & $\mathrm{UP}(1)$ & 6.79 & 562 & $-3.25 \pm 9.24 \mathrm{E}-10$ & $9.45 \pm 2.69 \mathrm{E}-09$ & $9.98 \pm 7.99 \mathrm{E}-08$ \\
\hline 403 & UP(2) & 6.82 & 2,292 & $-1.87 \pm 3.81 \mathrm{E}-09$ & $8.61 \pm 4.93 \mathrm{E}-09$ & $4.41 \pm 7.66 \mathrm{E}-08$ \\
\hline 403 & UP(3) & 6.69 & 1,228 & $-0.35 \pm 2.10 \mathrm{E}-09$ & $8.38 \pm 2.59 \mathrm{E}-09$ & $6.72 \pm 8.14 \mathrm{E}-08$ \\
\hline 403 & UP(4) & 6.84 & 1,222 & $1.21 \pm 3.49 \mathrm{E}-09$ & $8.75 \pm 2.71 \mathrm{E}-09$ & $7.96 \pm 7.75 \mathrm{E}-08$ \\
\hline 706 & UP(1) & 6.65 & 794 & $-1.76 \pm 1.91 \mathrm{E}-09$ & $8.78 \pm 2.33 \mathrm{E}-09$ & $7.81 \pm 8.01 \mathrm{E}-08$ \\
\hline 706 & UP(2) & 6.63 & 803 & $0.12 \pm 1.34 \mathrm{E}-09$ & $8.34 \pm 2.09 \mathrm{E}-09$ & $2.32 \pm 7.90 \mathrm{E}-08$ \\
\hline 706 & UP(3) & 6.78 & 672 & $0.44 \pm 2.19 \mathrm{E}-09$ & $1.17 \pm 0.25 \mathrm{E}-08$ & $6.34 \pm 8.07 \mathrm{E}-08$ \\
\hline 706 & UP(4) & 6.53 & 1,298 & $-1.70 \pm 2.40 \mathrm{E}-09$ & $1.42 \pm 0.24 \mathrm{E}-08$ & $1.68 \pm 0.79 \mathrm{E}-07$ \\
\hline 1304 & $\mathrm{UP}(1)$ & 7.45 & 1,926 & $-1.60 \pm 3.12 \mathrm{E}-09$ & $3.54 \pm 3.47 \mathrm{E}-09$ & $8.68 \pm 8.25 \mathrm{E}-08$ \\
\hline 1304 & UP(2) & 6.91 & 4,018 & $-2.15 \pm 5.77 \mathrm{E}-09$ & $1.33 \pm 0.78 \mathrm{E}-08$ & $-5.10 \pm 5.80 \mathrm{E}-08$ \\
\hline 1304 & UP(3) & 6.88 & 3,826 & $-0.33 \pm 1.04 \mathrm{E}-08$ & $8.71 \pm 8.12 \mathrm{E}-09$ & $3.18 \pm 8.14 \mathrm{E}-08$ \\
\hline 1304 & UP(4) & 7.10 & 1,992 & $-7.29 \pm 6.22 \mathrm{E}-09$ & $5.23 \pm 6.48 \mathrm{E}-09$ & $3.55 \pm 7.93 \mathrm{E}-08$ \\
\hline NB1S & UP(1) & 6.43 & 458 & $-0.37 \pm 1.29 \mathrm{E}-09$ & $1.18 \pm 1.84 \mathrm{E}-09$ & $7.76 \pm 8.24 \mathrm{E}-08$ \\
\hline NB1S & UP(2) & 6.48 & 592 & $-0.19 \pm 1.04 \mathrm{E}-09$ & $2.31 \pm 1.72 \mathrm{E}-09$ & $-4.63 \pm 7.83 \mathrm{E}-08$ \\
\hline NB1S & UP(3) & 6.59 & 719 & $-0.68 \pm 1.36 \mathrm{E}-09$ & $2.38 \pm 1.36 \mathrm{E}-09$ & $-0.95 \pm 8.40 \mathrm{E}-08$ \\
\hline NB1S & UP(4) & 6.52 & 778 & $0.47 \pm 1.88 \mathrm{E}-09$ & $3.77 \pm 1.73 \mathrm{E}-09$ & $3.32 \pm 8.22 \mathrm{E}-08$ \\
\hline 201 & DOWN(1) & 6.47 & 2,275 & $0.41 \pm 3.81 \mathrm{E}-09$ & $4.64 \pm 0.69 \mathrm{E}-08$ & $1.34 \pm 0.81 \mathrm{E}-07$ \\
\hline 201 & DOWN(2) & 6.37 & 2,856 & $0.41 \pm 5.19 \mathrm{E}-09$ & $5.25 \pm 0.74 \mathrm{E}-08$ & $8.64 \pm 7.77 \mathrm{E}-08$ \\
\hline 201 & DOWN(3) & 6.36 & 3,164 & $3.81 \pm 4.45 \mathrm{E}-09$ & $5.90 \pm 0.65 \mathrm{E}-08$ & $1.03 \pm 8.39 \mathrm{E}-08$ \\
\hline 201 & DOWN(4) & 6.45 & 3,449 & $-2.10 \pm 4.90 \mathrm{E}-09$ & $5.16 \pm 0.51 \mathrm{E}-08$ & $0.75 \pm 7.85 \mathrm{E}-08$ \\
\hline 305 & DOWN(1) & 7.01 & 2,242 & $1.46 \pm 4.16 \mathrm{E}-09$ & $1.19 \pm 0.49 \mathrm{E}-08$ & $-3.36 \pm 8.53 \mathrm{E}-08$ \\
\hline 307 & DOWN(1) & 6.80 & 2,217 & $-0.92 \pm 5.40 \mathrm{E}-09$ & $1.44 \pm 0.46 \mathrm{E}-08$ & $8.42 \pm 8.06 \mathrm{E}-08$ \\
\hline 1302 & DOWN(1) & 7.10 & 1,399 & $0.83 \pm 1.67 \mathrm{E}-09$ & $2.91 \pm 2.31 \mathrm{E}-09$ & $1.15 \pm 0.83 \mathrm{E}-07$ \\
\hline 1302 & DOWN(2) & 6.85 & 2,035 & $0.28 \pm 3.21 \mathrm{E}-09$ & $-0.23 \pm 3.43 \mathrm{E}-09$ & $-6.55 \pm 8.16 \mathrm{E}-08$ \\
\hline 1302 & DOWN(3) & 7.23 & 2,044 & $3.16 \pm 6.04 \mathrm{E}-09$ & $5.62 \pm 4.21 \mathrm{E}-09$ & $1.15 \pm 0.82 \mathrm{E}-07$ \\
\hline 1302 & DOWN(4) & 7.69 & 2,654 & $1.27 \pm 2.90 \mathrm{E}-09$ & $0.01 \pm 2.67 \mathrm{E}-09$ & $-3.89 \pm 7.81 \mathrm{E}-08$ \\
\hline 103 & DOWN(1) & 8.22 & 2,577 & $2.98 \pm 3.93 \mathrm{E}-09$ & $4.26 \pm 0.63 \mathrm{E}-08$ & $1.56 \pm 8.01 \mathrm{E}-08$ \\
\hline 103 & DOWN(2) & 8.02 & 7,232 & $-0.94 \pm 7.15 \mathrm{E}-09$ & $2.57 \pm 0.16 \mathrm{E}-07$ & $9.34 \pm 8.05 \mathrm{E}-08$ \\
\hline 103 & DOWN(3) & 7.90 & 6,035 & $4.97 \pm 8.74 \mathrm{E}-09$ & $1.92 \pm 0.16 \mathrm{E}-07$ & $-1.18 \pm 0.82 \mathrm{E}-07$ \\
\hline 103 & DOWN(4) & 7.99 & 3,712 & $6.37 \pm 7.49 \mathrm{E}-09$ & $6.99 \pm 1.01 \mathrm{E}-08$ & $-1.70 \pm 7.55 \mathrm{E}-08$ \\
\hline
\end{tabular}

Note: Bolding convention applied to these data. (See p. E-2 ${ }^{\mathbf{6 0}}$ )

Sample collection quarter is noted in parentheses next to hydraulic position. Hydraulic position is relative to other wells within the same hydrogeologic unit.

$$
\text { E - } 7
$$




\section{Table E-2 (continued)}

\section{Indicator Results From the Sand and Gravel Unit}

\begin{tabular}{|c|c|c|c|c|c|c|}
\hline $\begin{array}{l}\text { Location } \\
\text { Code }\end{array}$ & $\begin{array}{l}\text { Hydraulic } \\
\text { Position }\end{array}$ & $\begin{array}{c}\mathbf{p H} \\
(\mathrm{SU})\end{array}$ & $\begin{array}{c}\text { Conductivity } \\
\left(\mu \mathrm{mhos} / \mathrm{cm} @ 25^{\circ} \mathrm{C}\right)\end{array}$ & $\begin{array}{l}\text { Gross Alpha } \\
\quad(\mu \mathrm{Ci} / \mathrm{mL})\end{array}$ & $\begin{array}{c}\text { Gross Beta } \\
(\mu \mathrm{Ci} / \mathrm{mL})\end{array}$ & $\begin{array}{l}\text { Tritium } \\
(\mu \mathrm{Ci} / \mathrm{mL})\end{array}$ \\
\hline 104 & $\operatorname{DOWN}(1)$ & 6.88 & 1,717 & $1.45 \pm 2.59 \mathrm{E}-09$ & $6.54 \pm 0.01 \mathrm{E}-05$ & $3.79 \pm 0.88 E-07$ \\
\hline 104 & DOWN(2) & 6.88 & 1,616 & $0.04 \pm 1.86 \mathrm{E}-09$ & $5.57 \pm 0.01 \mathrm{E}-05$ & $2.81 \pm 0.81 \mathrm{E}-07$ \\
\hline 104 & DOWN(3) & 6.91 & $\mathbf{1 , 8 8 3}$ & $0.91 \pm 3.16 \mathrm{E}-09$ & $7.16 \pm 0.01 E-05$ & $2.42 \pm 0.75 E-07$ \\
\hline 104 & DOWN(4) & 6.96 & 1,870 & $4.10 \pm 3.14 \mathrm{E}-09$ & $6.45 \pm 0.01 \mathrm{E}-05$ & $2.54 \pm 0.80 \mathrm{E}-07$ \\
\hline 111 & DOWN(1) & 6.58 & 788 & $2.64 \pm 2.37 \mathrm{E}-09$ & $6.05 \pm 0.05 \mathrm{E}-06$ & $2.77 \pm 0.61 E-07$ \\
\hline 111 & $\operatorname{DOWN}(2)$ & 6.33 & 563 & $2.67 \pm 1.81 \mathrm{E}-09$ & $2.21 \pm 0.03 E-06$ & $7.07 \pm 7.96 \mathrm{E}-08$ \\
\hline 111 & $\operatorname{DOWN}(3)$ & 6.42 & 626 & $3.15 \pm 2.74 \mathrm{E}-09$ & $5.03 \pm 0.05 \mathrm{E}-06$ & $2.36 \pm 0.86 \mathrm{E}-07$ \\
\hline 111 & DOWN(4) & 6.39 & 1,323 & 7.51 $\pm 3.96 \mathrm{E}-09$ & $1.18 \pm 0.01 E-05$ & $1.91 \pm 0.79 \mathrm{E}-07$ \\
\hline 205 & $\operatorname{DOWN}(1)$ & 7.08 & 1,628 & $0.00 \pm 3.62 \mathrm{E}-09$ & $5.52 \pm 6.68 \mathrm{E}-09$ & $5.26 \pm 7.95 \mathrm{E}-08$ \\
\hline 205 & $\operatorname{DOWN}(2)$ & 6.95 & 3,372 & $-4.04 \pm 6.49 \mathrm{E}-09$ & $1.89 \pm 0.82 E-08$ & $1.22 \pm 7.65 \mathrm{E}-08$ \\
\hline 205 & DOWN(3) & 6.95 & 2,262 & $2.47 \pm 4.20 \mathrm{E}-09$ & $9.34 \pm 6.94 \mathrm{E}-09$ & $-5.21 \pm 8.29 \mathrm{E}-08$ \\
\hline 205 & DOWN(4) & 6.73 & 3,910 & 7.99 $98.07 \mathrm{E}-09$ & $8.71 \pm 7.80 \mathrm{E}-09$ & $1.35 \pm 0.78 E-07$ \\
\hline 406 & DOWN(1) & 6.74 & 1,084 & $-1.26 \pm 2.68 \mathrm{E}-09$ & $5.46 \pm 3.90 \mathrm{E}-09$ & $1.66 \pm 0.58 E-07$ \\
\hline 406 & DOWN(2) & 6.64 & 1,746 & $-1.82 \pm 2.93 \mathrm{E}-09$ & $6.96 \pm 3.99 \mathrm{E}-09$ & $1.38 \pm 0.78 \mathrm{E}-07$ \\
\hline 406 & DOWN(3) & 7.22 & 1,010 & $1.50 \pm 2.88 \mathrm{E}-09$ & $8.97 \pm 4.06 \mathrm{E}-09$ & $1.33 \pm 8.39 \mathrm{E}-08$ \\
\hline 406 & DOWN(4) & 6.68 & 1,213 & $-0.86 \pm 3.38 \mathrm{E}-09$ & $8.57 \pm 3.71 \mathrm{E}-09$ & $1.49 \pm 6.79 \mathrm{E}-08$ \\
\hline 408 & $\operatorname{DOWN}(1)$ & 6.59 & 1,691 & $0.23 \pm 1.71 \mathrm{E}-09$ & $1.98 \pm 0.01 E-04$ & $5.64 \pm 2.45 E-07$ \\
\hline 408 & DOWN(2) & 6.72 & 1,657 & $2.62 \pm 2.24 \mathrm{E}-09$ & $2.62 \pm 0.01 \mathrm{E}-04$ & $2.24 \pm 1.05 \mathrm{E}-07$ \\
\hline 408 & DOWN(3) & 6.62 & 2,013 & $3.04 \pm 7.16 \mathrm{E}-09$ & $2.92 \pm 0.01 E-04$ & $2.79 \pm 1.18 \mathrm{E}-07$ \\
\hline 408 & DOWN(4) & 6.71 & 1,568 & $3.13 \pm 9.60 \mathrm{E}-10$ & $2.24 \pm 0.01 \mathrm{E}-04$ & $1.66 \pm 1.11 E-07$ \\
\hline 501 & $\operatorname{DOWN}(1)$ & 6.90 & 1,409 & $0.18 \pm 2.86 \mathrm{E}-09$ & $1.31 \pm 0.01 \mathrm{E}-04$ & $1.05 \pm 0.84 \mathrm{E}-07$ \\
\hline 501 & $\operatorname{DOWN}(2)$ & 7.09 & 1,370 & $1.29 \pm 2.46 \mathrm{E}-09$ & $1.22 \pm 0.01 E-04$ & $1.53 \pm 0.56 E-07$ \\
\hline 501 & DOWN(3) & 6.74 & 1,708 & $-0.52 \pm 4.34 \mathrm{E}-09$ & $1.61 \pm 0.01 E-04$ & $1.19 \pm 0.60 \mathrm{E}-07$ \\
\hline 501 & DOWN(4) & 7.05 & 1,416 & 4.04 $\pm 3.49 \mathrm{E}-09$ & $1.22 \pm 0.01 E-04$ & $3.49 \pm 7.93 \mathrm{E}-08$ \\
\hline 502 & DOWN(1) & 6.94 & 1,588 & $2.39 \pm 3.40 \mathrm{E}-09$ & $1.35 \pm 0.01 \mathrm{E}-04$ & $1.41 \pm 0.85 E-07$ \\
\hline 502 & $\operatorname{DOWN}(2)$ & 7.05 & 1,474 & $1.13 \pm 2.54 \mathrm{E}-09$ & $1.17 \pm 0.01 E-04$ & $1.33 \pm 0.56 \mathrm{E}-07$ \\
\hline 502 & DOWN(3) & 6.87 & 1,697 & $-0.53 \pm 4.39 \mathrm{E}-09$ & $1.38 \pm 0.01 E-04$ & $9.27 \pm 8.48 \mathrm{E}-08$ \\
\hline 502 & $\operatorname{DOWN}(4)$ & 6.99 & 1,558 & $1.14 \pm 3.56 \mathrm{E}-09$ & $1.19 \pm 0.01 \mathrm{E}-04$ & $6.97 \pm 8.08 \mathrm{E}-08$ \\
\hline $602 \mathrm{~A}$ & $\operatorname{DOWN}(1)$ & 6.97 & 543 & $-1.36 \pm 1.37 \mathrm{E}-09$ & $1.07 \pm 0.24 \mathrm{E}-08$ & $2.15 \pm 0.82 \mathrm{E}-07$ \\
\hline $602 \mathrm{~A}$ & $\operatorname{DOWN}(2)$ & 6.98 & 551 & $-0.50 \pm 1.02 \mathrm{E}-09$ & $1.18 \pm 0.22 \mathrm{E}-08$ & $2.03 \pm 0.79 E-07$ \\
\hline $602 \mathrm{~A}$ & DOWN(3) & 6.71 & 575 & $0.23 \pm 1.31 \mathrm{E}-09$ & $1.01 \pm 0.16 E-08$ & $2.34 \pm 0.61 \mathrm{E}-07$ \\
\hline $602 \mathrm{~A}$ & DOWN(4) & 6.98 & 581 & $-0.87 \pm 1.18 \mathrm{E}-09$ & $1.21 \pm 0.15 E-08$ & $3.14 \pm 0.81 E-07$ \\
\hline 604 & $\operatorname{DOWN}(1)$ & 6.25 & 1,070 & $2.09 \pm 2.32 \mathrm{E}-09$ & $8.58 \pm 4.34 E-09$ & $0.29 \pm 8.25 \mathrm{E}-08$ \\
\hline 604 & $\operatorname{DOWN}(2)$ & 6.33 & 938 & $-0.45 \pm 1.77 \mathrm{E}-09$ & $3.57 \pm 2.54 \mathrm{E}-09$ & $2.10 \pm 8.25 \mathrm{E}-08$ \\
\hline 604 & DOWN(3) & 6.32 & 1,121 & $2.72 \pm 3.35 \mathrm{E}-09$ & $4.82 \pm 2.64 \mathrm{E}-09$ & $-9.65 \pm 8.27 \mathrm{E}-08$ \\
\hline 604 & DOWN(4) & 6.24 & 1,367 & $0.19 \pm 3.08 \mathrm{E}-09$ & $8.06 \pm 2.64 \mathrm{E}-09$ & $5.34 \pm 7.87 \mathrm{E}-08$ \\
\hline
\end{tabular}

Note: Bolding convention applied to these data. (See p. E-2 ${ }^{\mathbf{6 0}}$ )

Sample collection quarter is noted in parentheses next to hydraulic position. Hydraulic position is relative to other wells within the same hydrogeologic unit.

$$
E-8
$$




\section{Table E-2 (continued)}

\section{Indicator Results From the Sand and Gravel Unit}

\begin{tabular}{|c|c|c|c|c|c|c|}
\hline $\begin{array}{l}\text { Location } \\
\text { Code }\end{array}$ & $\begin{array}{c}\text { Hydraulic } \\
\text { Position }\end{array}$ & $\begin{array}{c}\mathbf{p H} \\
(\mathrm{SU})\end{array}$ & $\begin{array}{c}\text { Conductivity } \\
\left(\mu \mathrm{mhos} / \mathrm{cm} @ 25^{\circ} \mathrm{C}\right)\end{array}$ & $\begin{array}{l}\text { Gross Alpha } \\
\quad(\mu \mathrm{Ci} / \mathrm{mL})\end{array}$ & $\begin{array}{c}\text { Gross Beta } \\
(\mu \mathrm{Ci} / \mathrm{mL})\end{array}$ & $\begin{array}{c}\text { Tritium } \\
(\mu \mathrm{Ci} / \mathrm{mL})\end{array}$ \\
\hline 8605 & DOWN(1) & 6.56 & 1,584 & $6.78 \pm 2.90 \mathrm{E}-09$ & $1.11 \pm 0.01 \mathrm{E}-05$ & $4.68 \pm 0.90 \mathrm{E}-07$ \\
\hline 8605 & $\operatorname{DOWN}(2)$ & 6.43 & 1,444 & $8.02 \pm 3.80 \mathrm{E}-09$ & $1.15 \pm 0.01 \mathrm{E}-05$ & $4.18 \pm 0.59 \mathrm{E}-07$ \\
\hline 8605 & $\operatorname{DOWN}(3)$ & 6.63 & 1,852 & $1.39 \pm 0.64 \mathrm{E}-08$ & $9.96 \pm 0.07 E-06$ & $3.02 \pm 0.62 \mathrm{E}-07$ \\
\hline 8605 & DOWN(4) & 6.71 & 1,542 & $2.08 \pm 0.58 E-08$ & $1.23 \pm 0.01 E-05$ & $1.26 \pm 0.80 \mathrm{E}-07$ \\
\hline 8607 & DOWN(1) & 6.41 & 646 & $0.94 \pm 8.82 \mathrm{E}-10$ & $1.23 \pm 0.28 E-08$ & $2.04 \pm 0.83 E-07$ \\
\hline 8607 & DOWN(2) & 6.30 & 1,766 & $-1.34 \pm 2.63 \mathrm{E}-09$ & $3.42 \pm 0.51 \mathrm{E}-08$ & $-0.74 \pm 8.08 \mathrm{E}-08$ \\
\hline 8607 & DOWN(3) & 6.47 & 914 & $-0.27 \pm 1.38 \mathrm{E}-09$ & $3.01 \pm 0.36 \mathrm{E}-08$ & $0.44 \pm 8.46 \mathrm{E}-08$ \\
\hline 8607 & DOWN(4) & 6.41 & 1,059 & $-2.94 \pm 2.51 \mathrm{E}-09$ & $2.69 \pm 0.35 \mathrm{E}-08$ & $-2.31 \pm 7.88 \mathrm{E}-08$ \\
\hline 8609 & $\operatorname{DOWN}(1)$ & 6.70 & 1,962 & $-1.74 \pm 4.32 \mathrm{E}-09$ & $1.90 \pm 0.03 \mathrm{E}-06$ & $4.18 \pm 0.89 E-07$ \\
\hline 8609 & $\operatorname{DOWN}(2)$ & 6.97 & 1,810 & $0.66 \pm 3.51 \mathrm{E}-09$ & $1.58 \pm 0.03 \mathrm{E}-06$ & $3.46 \pm 0.84 \mathrm{E}-07$ \\
\hline 8609 & $\operatorname{DOWN}(3)$ & 6.72 & 2,195 & $0.36 \pm 6.12 \mathrm{E}-09$ & $1.51 \pm 0.03 E-06$ & $2.54 \pm 0.87 E-07$ \\
\hline 8609 & DOWN(4) & 6.95 & 2,445 & $-0.13 \pm 3.27 \mathrm{E}-09$ & $2.14 \pm 0.02 E-06$ & $2.79 \pm 0.82 \mathrm{E}-07$ \\
\hline 105 & $\operatorname{DOWN}(1)$ & 6.61 & 2,005 & $0.98 \pm 4.05 \mathrm{E}-09$ & $4.98 \pm 0.02 \mathrm{E}-05$ & $3.42 \pm 0.88 E-07$ \\
\hline 105 & DOWN(2) & 6.56 & 1,877 & $4.46 \pm 3.82 \mathrm{E}-09$ & $4.94 \pm 0.01 \mathrm{E}-05$ & $3.10 \pm 0.82 \mathrm{E}-07$ \\
\hline 105 & DOWN(3) & 6.54 & 1,834 & $0.62 \pm 3.58 \mathrm{E}-09$ & $4.57 \pm 0.01 E-05$ & $1.86 \pm 0.86 \mathrm{E}-07$ \\
\hline 105 & DOWN(4) & 6.29 & 1,896 & $4.60 \pm 4.58 \mathrm{E}-09$ & $5.51 \pm 0.02 E-05$ & $3.31 \pm 0.80 \mathrm{E}-07$ \\
\hline 106 & $\operatorname{DOWN}(1)$ & 6.64 & 1,609 & $1.28 \pm 3.20 \mathrm{E}-09$ & $1.66 \pm 0.45 E-08$ & $1.10 \pm 0.07 \mathrm{E}-06$ \\
\hline 106 & $\operatorname{DOWN}(2)$ & 6.79 & 1,571 & $1.44 \pm 2.23 \mathrm{E}-09$ & $2.40 \pm 0.32 \mathrm{E}-08$ & $8.29 \pm 0.61 \mathrm{E}-07$ \\
\hline 106 & DOWN(3) & 6.64 & 1,401 & $-0.85 \pm 2.36 \mathrm{E}-09$ & $3.50 \pm 0.36 \mathrm{E}-08$ & $6.84 \pm 0.88 E-07$ \\
\hline 106 & DOWN(4) & 6.65 & 1,581 & $6.61 \pm 4.32 \mathrm{E}-09$ & $4.29 \pm 0.57 \mathrm{E}-08$ & $1.20 \pm 0.07 E-06$ \\
\hline 116 & $\operatorname{DOWN}(1)$ & 7.08 & 1,508 & $0.00 \pm 3.14 \mathrm{E}-09$ & $1.46 \pm 0.02 \mathrm{E}-06$ & $1.58 \pm 0.60 \mathrm{E}-07$ \\
\hline 116 & DOWN(2) & 6.62 & 4,090 & $2.55 \pm 4.54 \mathrm{E}-09$ & $1.93 \pm 0.04 E-06$ & $1.09 \pm 0.80 \mathrm{E}-07$ \\
\hline 116 & DOWN(3) & 6.61 & 1,217 & $-2.50 \pm 3.92 \mathrm{E}-09$ & $1.16 \pm 0.03 E-06$ & $8.52 \pm 8.40 \mathrm{E}-08$ \\
\hline 116 & DOWN(4) & 6.74 & 1,464 & $3.70 \pm 4.69 \mathrm{E}-09$ & $1.33 \pm 0.03 \mathrm{E}-06$ & $8.06 \pm 7.90 \mathrm{E}-08$ \\
\hline 605 & $\operatorname{DOWN}(1)$ & 6.84 & 474 & $-0.67 \pm 1.26 \mathrm{E}-09$ & $3.69 \pm 0.33 \mathrm{E}-08$ & $8.65 \pm 5.66 \mathrm{E}-08$ \\
\hline 605 & $\operatorname{DOWN}(2)$ & 7.07 & 910 & $-0.66 \pm 1.08 \mathrm{E}-09$ & $4.83 \pm 0.26 E-08$ & $0.33 \pm 7.64 \mathrm{E}-08$ \\
\hline 605 & DOWN(3) & 6.68 & 792 & $1.98 \pm 2.14 \mathrm{E}-09$ & $3.18 \pm 0.33 E-08$ & $-0.17 \pm 8.17 \mathrm{E}-08$ \\
\hline 605 & DOWN(4) & 6.70 & 706 & $-1.51 \pm 1.74 \mathrm{E}-09$ & $4.00 \pm 0.33 \mathrm{E}-08$ & $1.34 \pm 0.78 \mathrm{E}-07$ \\
\hline 801 & $\operatorname{DOWN}(1)$ & 6.93 & 1,032 & $0.15 \pm 2.34 \mathrm{E}-09$ & $4.12 \pm 0.04 \mathrm{E}-06$ & $2.00 \pm 0.86 E-07$ \\
\hline 801 & DOWN(2) & 6.59 & 2,110 & $5.45 \pm 4.21 \mathrm{E}-09$ & 7.04 $\pm 0.06 \mathrm{E}-06$ & $1.22 \pm 0.78 \mathrm{E}-07$ \\
\hline 801 & DOWN(3) & 6.53 & 1,824 & $0.27 \pm 4.58 \mathrm{E}-09$ & $5.90 \pm 0.05 \mathrm{E}-06$ & $1.09 \pm 0.85 E-07$ \\
\hline 801 & DOWN(4) & 6.62 & 1,696 & $2.49 \pm 3.91 \mathrm{E}-09$ & $5.14 \pm 0.05 \mathrm{E}-06$ & $1.85 \pm 0.81 \mathrm{E}-07$ \\
\hline 802 & $\operatorname{DOWN}(1)$ & 6.34 & 502 & $-0.60 \pm 1.47 \mathrm{E}-09$ & $2.06 \pm 0.32 \mathrm{E}-08$ & $8.78 \pm 8.03 \mathrm{E}-08$ \\
\hline 802 & $\operatorname{DOWN}(2)$ & 6.25 & 135 & $0.00 \pm 1.02 \mathrm{E}-09$ & $5.80 \pm 3.32 \mathrm{E}-09$ & $7.19 \pm 5.65 \mathrm{E}-08$ \\
\hline 802 & DOWN(3) & 6.83 & 190 & $0.73 \pm 1.23 \mathrm{E}-09$ & $1.10 \pm 0.36 \mathrm{E}-08$ & $6.82 \pm 8.53 \mathrm{E}-08$ \\
\hline 802 & DOWN(4) & 6.72 & 1,268 & $-2.13 \pm 3.68 \mathrm{E}-09$ & $9.10 \pm 0.70 \mathrm{E}-08$ & $1.28 \pm 0.78 E-07$ \\
\hline
\end{tabular}

Note: Bolding convention applied to these data. (See p. E-2 띠)

Sample collection quarter is noted in parentheses next to hydraulic position. Hydraulic position is relative to other wells within the same hydrogeologic unit.

$$
E-9
$$


Table E-2 (concluded)

\section{Indicator Results From the Sand and Gravel Unit}

\begin{tabular}{|c|c|c|c|c|c|c|}
\hline $\begin{array}{l}\text { Location } \\
\text { Code }\end{array}$ & $\begin{array}{l}\text { Hydraulic } \\
\text { Position }\end{array}$ & $\begin{array}{c}\mathbf{p H} \\
(\mathrm{SU})\end{array}$ & $\begin{array}{c}\text { Conductivity } \\
\left(\mu \mathrm{mhos} / \mathrm{cm} @ 25^{\circ} \mathrm{C}\right)\end{array}$ & $\begin{array}{l}\text { Gross Alpha } \\
\quad(\mu \mathrm{Ci} / \mathrm{mL})\end{array}$ & $\begin{array}{c}\text { Gross Beta } \\
(\mu \mathrm{Ci} / \mathrm{mL})\end{array}$ & $\begin{array}{c}\text { Tritium } \\
(\mu \mathrm{Ci} / \mathrm{mL})\end{array}$ \\
\hline 803 & $\operatorname{DOWN}(1)$ & 6.79 & 1,250 & $3.53 \pm 3.14 E-09$ & $1.72 \pm 0.44 \mathrm{E}-08$ & $2.06 \pm 0.82 E-07$ \\
\hline 803 & $\operatorname{DOWN}(2)$ & 6.86 & 1,198 & $1.20 \pm 2.87 \mathrm{E}-09$ & $1.46 \pm 0.41 \mathrm{E}-08$ & $7.23 \pm 8.30 \mathrm{E}-08$ \\
\hline 803 & DOWN(3) & 7.06 & 1,095 & $3.17 \pm 3.13 \mathrm{E}-09$ & $1.78 \pm 0.42 E-08$ & $1.46 \pm 0.58 \mathrm{E}-07$ \\
\hline 803 & DOWN(4) & 6.75 & 1,296 & $-2.41 \pm 2.89 \mathrm{E}-09$ & $1.40 \pm 0.28 E-08$ & $1.58 \pm 0.78 \mathrm{E}-07$ \\
\hline 804 & $\operatorname{DOWN}(1)$ & 6.67 & 1,020 & $-0.84 \pm 1.60 \mathrm{E}-09$ & $1.40 \pm 0.05 E-07$ & $2.05 \pm 0.81 E-07$ \\
\hline 804 & $\operatorname{DOWN}(2)$ & 6.92 & 1,360 & $0.88 \pm 3.05 \mathrm{E}-09$ & $5.93 \pm 0.14 E-07$ & $7.05 \pm 8.16 \mathrm{E}-08$ \\
\hline 804 & $\operatorname{DOWN}(3)$ & 6.77 & 1,096 & $1.21 \pm 2.36 \mathrm{E}-09$ & $2.19 \pm 0.08 \mathrm{E}-07$ & $1.12 \pm 0.85 \mathrm{E}-07$ \\
\hline 804 & DOWN(4) & 6.53 & 1,064 & $-1.92 \pm 2.67 \mathrm{E}-09$ & $1.95 \pm 0.08 \mathrm{E}-07$ & $1.21 \pm 0.78 \mathrm{E}-07$ \\
\hline 8603 & $\operatorname{DOWN}(1)$ & 7.12 & 1,936 & $-0.75 \pm 3.80 \mathrm{E}-09$ & $6.58 \pm 0.02 E-05$ & $3.33 \pm 0.88 E-07$ \\
\hline 8603 & $\operatorname{DOWN}(2)$ & 6.57 & 1,829 & $-1.14 \pm 2.74 \mathrm{E}-09$ & $5.89 \pm 0.02 E-05$ & $1.80 \pm 0.80 \mathrm{E}-07$ \\
\hline 8603 & DOWN(3) & 7.18 & 1,851 & $-0.29 \pm 4.89 \mathrm{E}-09$ & $6.03 \pm 0.02 \mathrm{E}-05$ & $2.39 \pm 0.87 \mathrm{E}-07$ \\
\hline 8603 & DOWN(4) & 7.30 & 1,822 & $4.39 \pm 4.62 \mathrm{E}-09$ & $6.16 \pm 0.02 \mathrm{E}-05$ & $2.22 \pm 0.81 \mathrm{E}-07$ \\
\hline 8604 & DOWN(1) & 7.07 & 1,768 & $-0.22 \pm 3.41 \mathrm{E}-09$ & $4.89 \pm 0.01 \mathrm{E}-05$ & $3.45 \pm 0.88 E-07$ \\
\hline 8604 & $\operatorname{DOWN}(2)$ & 6.69 & 1,630 & $0.96 \pm 2.66 \mathrm{E}-09$ & $4.59 \pm 0.01 E-05$ & $2.50 \pm 0.82 E-07$ \\
\hline 8604 & DOWN(3) & 6.79 & 1,778 & $-2.43 \pm 4.26 \mathrm{E}-09$ & $5.26 \pm 0.02 \mathrm{E}-05$ & $2.56 \pm 0.87 \mathrm{E}-07$ \\
\hline 8604 & DOWN(4) & 7.26 & 1,718 & $3.74 \pm 4.17 \mathrm{E}-09$ & $5.32 \pm 0.02 E-05$ & $2.84 \pm 0.57 \mathrm{E}-07$ \\
\hline 8612 & $\operatorname{DOWN}(1)$ & 7.23 & 1,250 & $-4.42 \pm 3.27 \mathrm{E}-09$ & $-2.09 \pm 3.52 \mathrm{E}-09$ & $5.37 \pm 0.87 \mathrm{E}-07$ \\
\hline 8612 & $\operatorname{DOWN}(2)$ & 6.99 & 1,338 & $-0.73 \pm 2.58 \mathrm{E}-09$ & $3.50 \pm 3.45 E-09$ & $3.70 \pm 0.84 \mathrm{E}-07$ \\
\hline 8612 & $\operatorname{DOWN}(3)$ & 7.01 & 1,250 & $2.34 \pm 4.04 \mathrm{E}-09$ & $1.25 \pm 3.53 \mathrm{E}-09$ & $3.56 \pm 0.87 E-07$ \\
\hline 8612 & DOWN(4) & 7.06 & 1,438 & $0.07 \pm 3.92 \mathrm{E}-09$ & $1.26 \pm 3.51 \mathrm{E}-09$ & $4.16 \pm 0.82 E-07$ \\
\hline GSEEP & DOWN(1) & 6.52 & 849 & $-0.60 \pm 1.75 \mathrm{E}-09$ & $1.31 \pm 1.73 \mathrm{E}-09$ & $6.12 \pm 0.87 E-07$ \\
\hline GSEEP & DOWN(2) & 6.12 & 839 & $-0.29 \pm 1.56 \mathrm{E}-09$ & $4.62 \pm 2.41 \mathrm{E}-09$ & $2.65 \pm 0.81 E-07$ \\
\hline GSEEP & DOWN(3) & 6.60 & 854 & $-1.40 \pm 2.09 \mathrm{E}-09$ & $1.94 \pm 2.42 \mathrm{E}-09$ & $3.72 \pm 0.85 \mathrm{E}-07$ \\
\hline GSEEP & DOWN(4) & 6.51 & 1,087 & $-2.93 \pm 2.68 \mathrm{E}-09$ & 7.11 $\pm 2.57 \mathrm{E}-09$ & $4.14 \pm 0.82 \mathrm{E}-07$ \\
\hline SP04 & DOWN(1) & NS & NS & $1.70 \pm 2.58 \mathrm{E}-09$ & $1.63 \pm 2.52 \mathrm{E}-09$ & $3.64 \pm 0.86 \mathrm{E}-07$ \\
\hline SP04 & $\operatorname{DOWN}(3)$ & NS & NS & $0.21 \pm 3.41 \mathrm{E}-09$ & $8.18 \pm 3.90 \mathrm{E}-09$ & $2.71 \pm 0.84 \mathrm{E}-07$ \\
\hline SP06 & DOWN(1) & NS & NS & $0.12 \pm 1.48 \mathrm{E}-09$ & $0.87 \pm 1.30 \mathrm{E}-09$ & $1.61 \pm 0.83 \mathrm{E}-07$ \\
\hline SP06 & DOWN(3) & NS & NS & $-0.25 \pm 2.03 \mathrm{E}-09$ & $1.52 \pm 1.89 \mathrm{E}-09$ & $6.79 \pm 8.45 \mathrm{E}-08$ \\
\hline SP11 & DOWN(1) & NS & NS & $-2.05 \pm 1.96 \mathrm{E}-09$ & $3.88 \pm 0.32 \mathrm{E}-08$ & $2.35 \pm 0.83 \mathrm{E}-07$ \\
\hline SP11 & DOWN(3) & NS & NS & $-0.25 \pm 2.98 \mathrm{E}-09$ & $7.13 \pm 0.53 \mathrm{E}-08$ & $1.04 \pm 0.84 \mathrm{E}-07$ \\
\hline SP12 & DOWN(1) & 6.45 & 833 & $-1.13 \pm 2.40 \mathrm{E}-09$ & $2.62 \pm 2.58 \mathrm{E}-09$ & $3.66 \pm 0.84 \mathrm{E}-07$ \\
\hline SP12 & $\operatorname{DOWN}(3)$ & 7.58 & 750 & $1.74 \pm 2.73 \mathrm{E}-09$ & $4.51 \pm 2.59 \mathrm{E}-09$ & $3.06 \pm 0.86 \mathrm{E}-07$ \\
\hline WP-A & DOWN(4) & 7.21 & 123 & $0.26 \pm 3.99 \mathrm{E}-10$ & $1.81 \pm 0.13 \mathrm{E}-08$ & $1.26 \pm 0.04 \mathrm{E}-05$ \\
\hline WP-C & DOWN(4) & 6.46 & 204 & $-0.91 \pm 4.57 \mathrm{E}-10$ & $5.03 \pm 0.21 \mathrm{E}-08$ & $5.35 \pm 0.16 \mathrm{E}-05$ \\
\hline WP-H & $\operatorname{DOWN}(1)$ & 6.63 & 1,007 & $2.26 \pm 2.47 \mathrm{E}-09$ & $6.97 \pm 0.05 \mathrm{E}-06$ & $2.12 \pm 0.12 \mathrm{E}-06$ \\
\hline WP-H & DOWN(4) & 5.94 & 1,443 & $1.59 \pm 0.29 \mathrm{E}-08$ & $5.78 \pm 0.04 \mathrm{E}-06$ & $1.49 \pm 0.08 \mathrm{E}-06$ \\
\hline
\end{tabular}

Note: Bolding convention applied to these data. (See p. E-2 ${ }^{\mathbf{6}}$ )

NS - Not sampled

Sample collection quarter is noted in parentheses next to hydraulic position. Hydraulic position is relative to other wells within the same hydrogeologic unit. 
Table E-3

\section{Indicator Results From the Lavery Till-Sand Unit}

\begin{tabular}{|c|c|c|c|c|c|c|}
\hline $\begin{array}{l}\text { Location } \\
\text { Code }\end{array}$ & $\begin{array}{l}\text { Hydraulic } \\
\text { Position }\end{array}$ & $\begin{array}{c}\mathbf{p H} \\
(\mathrm{SU})\end{array}$ & $\begin{array}{c}\text { Conductivity } \\
\left(\mu \mathrm{mhos} / \mathrm{cm} @ 25^{\circ} \mathrm{C}\right)\end{array}$ & $\begin{array}{l}\text { Gross Alpha } \\
\qquad(\mu \mathrm{Ci} / \mathrm{mL})\end{array}$ & $\begin{array}{c}\text { Gross Beta } \\
(\mu \mathrm{Ci} / \mathrm{mL})\end{array}$ & $\begin{array}{l}\text { Tritium } \\
(\mu \mathrm{Ci} / \mathrm{mL})\end{array}$ \\
\hline 302 & UP(1) & 6.81 & 3,207 & $0.00 \pm 5.51 \mathrm{E}-09$ & $0.00 \pm 6.84 \mathrm{E}-09$ & $1.93 \pm 8.02 \mathrm{E}-08$ \\
\hline 302 & $\mathrm{UP}(2)$ & 6.89 & 3,024 & $-7.57 \pm 5.93 \mathrm{E}-09$ & $-5.04 \pm 6.89 \mathrm{E}-09$ & $9.26 \pm 7.74 \mathrm{E}-08$ \\
\hline 302 & UP(3) & 6.88 & 3,084 & $-5.15 \pm 9.77 \mathrm{E}-09$ & $-2.04 \pm 7.42 \mathrm{E}-09$ & $9.79 \pm 8.15 \mathrm{E}-08$ \\
\hline 302 & $\mathrm{UP}(4)$ & 6.71 & 3,908 & $-0.07 \pm 1.11 \mathrm{E}-08$ & $9.50 \pm 7.30 \mathrm{E}-09$ & $7.45 \pm 7.72 \mathrm{E}-08$ \\
\hline 402 & UP(1) & 6.96 & 2,552 & $4.84 \pm 4.24 \mathrm{E}-09$ & $2.18 \pm 4.91 \mathrm{E}-09$ & $-4.55 \pm 8.03 \mathrm{E}-08$ \\
\hline 402 & $\mathrm{UP}(2)$ & 7.12 & 2,376 & $0.45 \pm 5.62 \mathrm{E}-09$ & $0.44 \pm 6.94 \mathrm{E}-09$ & $-0.95 \pm 8.21 \mathrm{E}-08$ \\
\hline 402 & $\mathrm{UP}(3)$ & 7.20 & 2,053 & $3.38 \pm 9.50 \mathrm{E}-09$ & $2.68 \pm 7.36 \mathrm{E}-09$ & $1.13 \pm 0.84 E-07$ \\
\hline 402 & $\mathrm{UP}(4)$ & 6.95 & 2,734 & $-2.80 \pm 7.44 \mathrm{E}-09$ & $6.00 \pm 6.64 \mathrm{E}-09$ & $6.90 \pm 7.76 \mathrm{E}-08$ \\
\hline 204 & $\operatorname{DOWN}(1)$ & 7.54 & 1,150 & $2.66 \pm 2.37 \mathrm{E}-09$ & $1.94 \pm 3.33 \mathrm{E}-09$ & $0.33 \pm 8.50 \mathrm{E}-08$ \\
\hline 204 & DOWN(2) & 7.42 & 1,067 & $0.63 \pm 2.69 \mathrm{E}-09$ & $-0.11 \pm 3.45 \mathrm{E}-09$ & $2.19 \pm 7.99 \mathrm{E}-08$ \\
\hline 204 & DOWN(3) & 7.53 & 949 & $0.92 \pm 1.81 \mathrm{E}-09$ & $2.22 \pm 3.31 \mathrm{E}-09$ & $8.45 \pm 5.78 E-08$ \\
\hline 204 & DOWN(4) & 7.55 & 1,157 & $-1.17 \pm 3.09 \mathrm{E}-09$ & $5.08 \pm 3.43 E-09$ & $0.32 \pm 7.88 \mathrm{E}-08$ \\
\hline 206 & DOWN(1) & 7.60 & 1,188 & $0.81 \pm 2.63 \mathrm{E}-09$ & $1.50 \pm 3.55 \mathrm{E}-09$ & $7.87 \pm 8.01 \mathrm{E}-08$ \\
\hline 206 & DOWN(2) & 7.41 & 1,257 & $0.00 \pm 2.33 \mathrm{E}-09$ & $0.77 \pm 3.33 \mathrm{E}-09$ & $-0.17 \pm 7.78 \mathrm{E}-08$ \\
\hline 206 & DOWN(3) & 7.33 & 1,168 & $1.20 \pm 2.78 \mathrm{E}-09$ & $2.72 \pm 3.40 \mathrm{E}-09$ & $-2.40 \pm 8.43 \mathrm{E}-08$ \\
\hline 206 & DOWN(4) & 7.31 & 1,226 & 4.54 $\pm 3.34 E-09$ & $-0.89 \pm 3.49 \mathrm{E}-09$ & $1.27 \pm 0.78 E-07$ \\
\hline 208 & DOWN(1) & 7.77 & 254 & $5.15 \pm 5.54 \mathrm{E}-10$ & $0.38 \pm 5.70 \mathrm{E}-10$ & $6.28 \pm 7.93 \mathrm{E}-08$ \\
\hline 208 & DOWN(2) & 7.78 & 253 & $5.29 \pm 8.05 \mathrm{E}-10$ & $0.73 \pm 1.19 \mathrm{E}-09$ & $1.45 \pm 0.79 E-07$ \\
\hline 208 & DOWN(3) & $\mathbf{7 . 8 0}$ & 231 & $1.18 \pm 0.81 E-09$ & $0.87 \pm 1.09 \mathrm{E}-09$ & $1.91 \pm 8.38 \mathrm{E}-08$ \\
\hline 208 & DOWN(4) & 7.80 & 264 & $0.18 \pm 1.00 \mathrm{E}-09$ & $2.18 \pm 1.16 \mathrm{E}-09$ & $-1.16 \pm 0.77 \mathrm{E}-07$ \\
\hline
\end{tabular}

Note: Bolding convention applied to these data. (See p. E-2 $\mathbf{6 0}$ )

Sample collection quarter is noted in parentheses next to hydraulic position. Hydraulic position is relative to other wells within the same hydrogeologic unit. 


\section{Table E-4}

\section{Indicator Results From the Weathered Lavery Till Unit}

\begin{tabular}{|c|c|c|c|c|c|c|}
\hline $\begin{array}{l}\text { Location } \\
\text { Code }\end{array}$ & $\begin{array}{l}\text { Hydraulic } \\
\text { Position }\end{array}$ & $\begin{array}{c}\mathbf{p H} \\
(\mathrm{SU})\end{array}$ & $\begin{array}{c}\text { Conductivity } \\
\left(\mu \mathrm{mhos} / \mathrm{cm} @ 25^{\circ} \mathrm{C}\right)\end{array}$ & $\begin{array}{l}\text { Gross Alpha } \\
\qquad(\mu \mathrm{Ci} / \mathrm{mL})\end{array}$ & $\begin{array}{c}\text { Gross Beta } \\
(\mu \mathrm{Ci} / \mathrm{mL})\end{array}$ & $\begin{array}{l}\text { Tritium } \\
(\mu \mathrm{Ci} / \mathrm{mL})\end{array}$ \\
\hline 908 & UP(1) & 6.80 & 2,680 & $1.57 \pm 3.20 \mathrm{E}-09$ & $9.52 \pm 6.90 \mathrm{E}-09$ & $3.11 \pm 5.73 \mathrm{E}-08$ \\
\hline 908 & $\mathrm{UP}(3)$ & 6.61 & 2,501 & $1.09 \pm 0.62 \mathrm{E}-08$ & $1.35 \pm 0.57 \mathrm{E}-08$ & $1.01 \pm 0.82 \mathrm{E}-07$ \\
\hline 1005 & $\mathrm{UP}(1)$ & 6.98 & 839 & $4.69 \pm 2.78 \mathrm{E}-09$ & $-1.08 \pm 1.62 \mathrm{E}-09$ & $1.83 \pm 0.82 \mathrm{E}-07$ \\
\hline 1005 & $\mathrm{UP}(3)$ & 7.05 & 715 & $3.09 \pm 2.85 \mathrm{E}-09$ & $2.19 \pm 2.43 \mathrm{E}-09$ & $-1.02 \pm 0.83 \mathrm{E}-07$ \\
\hline $1008 \mathrm{C}$ & $\mathrm{UP}(1)$ & 7.42 & 592 & $-0.46 \pm 1.36 \mathrm{E}-09$ & $-0.04 \pm 1.24 \mathrm{E}-09$ & $1.33 \pm 0.82 \mathrm{E}-07$ \\
\hline $1008 \mathrm{C}$ & $\mathrm{UP}(3)$ & 7.43 & 520 & $1.12 \pm 1.76 \mathrm{E}-09$ & $0.65 \pm 1.84 \mathrm{E}-09$ & $0.95 \pm 8.38 \mathrm{E}-08$ \\
\hline 906 & $\operatorname{DOWN}(1)$ & 7.31 & 596 & $0.00 \pm 2.06 \mathrm{E}-09$ & $1.93 \pm 1.95 \mathrm{E}-09$ & $1.22 \pm 0.81 \mathrm{E}-07$ \\
\hline 906 & $\operatorname{DOWN}(3)$ & 7.13 & 536 & $1.69 \pm 2.15 \mathrm{E}-09$ & $9.00 \pm 2.28 \mathrm{E}-09$ & $8.90 \pm 8.42 \mathrm{E}-08$ \\
\hline 1006 & DOWN(1) & 6.63 & 1,786 & $-0.30 \pm 3.73 E-09$ & $0.80 \pm 3.34 \mathrm{E}-09$ & $7.18 \pm 8.11 \mathrm{E}-08$ \\
\hline 1006 & DOWN(3) & 6.86 & 1,590 & $6.23 \pm 5.49 \mathrm{E}-09$ & $2.62 \pm 4.83 \mathrm{E}-09$ & $-3.80 \pm 8.45 \mathrm{E}-08$ \\
\hline 1007 & $\operatorname{DOWN}(1)$ & 6.89 & 1,338 & $4.36 \pm 3.46 \mathrm{E}-09$ & $4.77 \pm 3.76 \mathrm{E}-09$ & $1.55 \pm 0.81 \mathrm{E}-07$ \\
\hline 1007 & DOWN(3) & 6.69 & 1,224 & $2.46 \pm 3.27 \mathrm{E}-09$ & $4.26 \pm 3.75 \mathrm{E}-09$ & $4.94 \pm 5.90 \mathrm{E}-08$ \\
\hline NDATR & DOWN(1) & 7.41 & 836 & $1.27 \pm 1.36 \mathrm{E}-09$ & $1.81 \pm 0.05 \mathrm{E}-07$ & $4.68 \pm 0.19 E-06$ \\
\hline NDATR & DOWN(2) & 7.59 & 1,150 & $1.58 \pm 2.76 \mathrm{E}-09$ & $1.91 \pm 0.08 \mathrm{E}-07$ & $4.57 \pm 0.19 \mathrm{E}-06$ \\
\hline NDATR & DOWN(3) & 7.78 & 779 & $2.49 \pm 1.97 \mathrm{E}-09$ & 1.74 $\pm 0.07 E-07$ & $3.81 \pm 0.17 \mathrm{E}-06$ \\
\hline NDATR & DOWN(4) & 7.63 & 827 & $1.98 \pm 2.00 \mathrm{E}-09$ & 1.97 $\pm 0.08 E-07$ & $2.81 \pm 0.14 \mathrm{E}-06$ \\
\hline 909 & DOWN(1) & 6.61 & 1,295 & $-0.53 \pm 3.20 \mathrm{E}-09$ & $2.70 \pm 0.11 \mathrm{E}-07$ & $9.26 \pm 0.96 \mathrm{E}-07$ \\
\hline 909 & DOWN(3) & 6.89 & 1,209 & $1.93 \pm 3.28 \mathrm{E}-09$ & $3.29 \pm 0.14 \mathrm{E}-07$ & $6.86 \pm 0.92 \mathrm{E}-07$ \\
\hline
\end{tabular}

Note: Bolding convention applied to these data. (See p. E-2 2 (0)

Sample collection quarter is noted in parentheses next to hydraulic position. Hydraulic position is relative to other wells within the same hydrogeologic unit.

$E-12$ 


\section{Table E-5 \\ 2004 Indicator Results From the Unweathered Lavery Till Unit}

\begin{tabular}{|c|c|c|c|c|c|c|}
\hline $\begin{array}{l}\text { Location } \\
\text { Code }\end{array}$ & $\begin{array}{c}\text { Hydraulic } \\
\text { Position }\end{array}$ & $\begin{array}{c}\mathbf{p H} \\
(\mathrm{SU})\end{array}$ & $\begin{array}{c}\text { Conductivity } \\
\left(\mu \mathrm{mhos} / \mathrm{cm} @ 25^{\circ} \mathrm{C}\right)\end{array}$ & $\begin{array}{l}\text { Gross Alpha } \\
\quad(\mu \mathrm{Ci} / \mathrm{mL})\end{array}$ & $\begin{array}{c}\text { Gross Beta } \\
(\mu \mathrm{Ci} / \mathrm{mL})\end{array}$ & $\begin{array}{c}\text { Tritium } \\
(\mu \mathrm{Ci} / \mathrm{mL})\end{array}$ \\
\hline 405 & UP(1) & 7.28 & 1,194 & $-0.95 \pm 3.30 \mathrm{E}-09$ & $0.75 \pm 4.76 \mathrm{E}-09$ & $1.88 \pm 7.90 \mathrm{E}-08$ \\
\hline 405 & $\mathrm{UP}(2)$ & 7.16 & 2,507 & $-1.04 \pm 3.78 \mathrm{E}-09$ & $1.37 \pm 0.53 E-08$ & $6.07 \pm 5.42 E-08$ \\
\hline 405 & UP(3) & 7.07 & 1,638 & $5.12 \pm 4.75 \mathrm{E}-09$ & $1.26 \pm 0.51 \mathrm{E}-08$ & $-1.07 \pm 0.87 \mathrm{E}-07$ \\
\hline 405 & $\mathrm{UP}(4)$ & 7.10 & 1,800 & $-3.76 \pm 4.75 \mathrm{E}-09$ & $8.41 \pm 4.69 \mathrm{E}-09$ & $-8.48 \pm 5.53 \mathrm{E}-08$ \\
\hline 1303 & UP(1) & 7.77 & 292 & $2.24 \pm 1.03 E-09$ & $9.38 \pm 1.53 \mathrm{E}-09$ & $0.98 \pm 8.25 \mathrm{E}-08$ \\
\hline 1303 & $\mathrm{UP}(2)$ & 7.25 & 351 & $7.94 \pm 8.20 \mathrm{E}-10$ & $3.70 \pm 1.32 \mathrm{E}-09$ & $-1.29 \pm 0.81 \mathrm{E}-07$ \\
\hline 1303 & $\mathrm{UP}(3)$ & 7.31 & 358 & $1.72 \pm 1.30 \mathrm{E}-09$ & $2.95 \pm 1.30 \mathrm{E}-09$ & $-5.81 \pm 8.30 \mathrm{E}-08$ \\
\hline 1303 & $\mathrm{UP}(4)$ & 7.76 & 367 & $3.14 \pm 8.32 \mathrm{E}-10$ & $2.10 \pm 1.30 \mathrm{E}-09$ & $-2.97 \pm 7.89 \mathrm{E}-08$ \\
\hline 110 & $\operatorname{DOWN}(1)$ & 7.32 & 502 & $0.56 \pm 1.13 \mathrm{E}-09$ & $2.49 \pm 1.70 \mathrm{E}-09$ & $1.43 \pm 0.10 \mathrm{E}-06$ \\
\hline 110 & $\operatorname{DOWN}(2)$ & 7.27 & 515 & $0.83 \pm 1.05 \mathrm{E}-09$ & $0.42 \pm 1.26 \mathrm{E}-09$ & $1.27 \pm 0.10 \mathrm{E}-06$ \\
\hline 110 & DOWN(3) & 7.43 & 430 & $1.82 \pm 1.58 \mathrm{E}-09$ & $2.33 \pm 1.67 \mathrm{E}-09$ & $1.17 \pm 0.10 \mathrm{E}-06$ \\
\hline 110 & DOWN(4) & 7.20 & 537 & $0.22 \pm 1.73 \mathrm{E}-09$ & $2.90 \pm 1.66 \mathrm{E}-09$ & $1.06 \pm 0.09 E-06$ \\
\hline 704 & $\operatorname{DOWN}(1)$ & 6.46 & 782 & $-0.14 \pm 1.68 \mathrm{E}-09$ & $2.59 \pm 1.78 E-09$ & $-0.48 \pm 8.01 \mathrm{E}-08$ \\
\hline 704 & $\operatorname{DOWN}(2)$ & 6.41 & 690 & $-0.14 \pm 1.53 \mathrm{E}-09$ & $4.34 \pm 2.37 \mathrm{E}-09$ & $6.30 \pm 7.75 \mathrm{E}-08$ \\
\hline 704 & $\operatorname{DOWN}(3)$ & 6.52 & 712 & $1.38 \pm 2.39 \mathrm{E}-09$ & $7.88 \pm 2.90 \mathrm{E}-09$ & $-6.87 \pm 8.32 \mathrm{E}-08$ \\
\hline 704 & DOWN(4) & 6.57 & 886 & $0.62 \pm 2.52 \mathrm{E}-09$ & $9.78 \pm 2.67 \mathrm{E}-09$ & $-6.75 \pm 7.86 \mathrm{E}-08$ \\
\hline 707 & $\operatorname{DOWN}(1)$ & 6.53 & 366 & $-0.56 \pm 1.06 \mathrm{E}-09$ & $4.71 \pm 1.67 \mathrm{E}-09$ & $2.81 \pm 8.40 \mathrm{E}-08$ \\
\hline 707 & $\operatorname{DOWN}(2)$ & 6.46 & 354 & $1.41 \pm 8.93 \mathrm{E}-10$ & $3.73 \pm 1.58 \mathrm{E}-09$ & $0.03 \pm 5.62 \mathrm{E}-08$ \\
\hline 707 & DOWN(3) & 6.37 & 548 & $-0.78 \pm 1.70 \mathrm{E}-09$ & $2.10 \pm 1.58 E-09$ & $-2.28 \pm 0.90 \mathrm{E}-07$ \\
\hline 707 & DOWN(4) & 6.56 & 534 & $-0.10 \pm 1.51 \mathrm{E}-09$ & $5.52 \pm 1.54 \mathrm{E}-09$ & $-1.83 \pm 7.87 \mathrm{E}-08$ \\
\hline 107 & $\operatorname{DOWN}(1)$ & 7.27 & 660 & $0.97 \pm 1.47 \mathrm{E}-09$ & $6.94 \pm 2.63 E-09$ & $3.84 \pm 0.84 E-07$ \\
\hline 107 & $\operatorname{DOWN}(2)$ & 7.29 & 674 & $0.65 \pm 1.56 \mathrm{E}-09$ & $8.01 \pm 2.58 \mathrm{E}-09$ & $2.32 \pm 0.79 \mathrm{E}-07$ \\
\hline 107 & DOWN(3) & 7.19 & 710 & $-0.33 \pm 1.99 \mathrm{E}-09$ & $1.17 \pm 0.27 \mathrm{E}-08$ & $2.17 \pm 0.83 \mathrm{E}-07$ \\
\hline 107 & DOWN(4) & 7.12 & 791 & $-0.32 \pm 2.39 \mathrm{E}-09$ & $1.31 \pm 0.28 E-08$ & $1.58 \pm 0.57 E-07$ \\
\hline 108 & $\operatorname{DOWN}(1)$ & 7.82 & 488 & 1.57 $\pm 1.19 \mathrm{E}-09$ & $2.05 \pm 1.35 E-09$ & $2.04 \pm 0.81 E-07$ \\
\hline 108 & $\operatorname{DOWN}(2)$ & 7.65 & 503 & $1.06 \pm 1.23 \mathrm{E}-09$ & $2.64 \pm 1.74 \mathrm{E}-09$ & $1.94 \pm 0.79 \mathrm{E}-07$ \\
\hline 108 & $\operatorname{DOWN}(3)$ & 7.50 & 460 & $1.01 \pm 1.40 \mathrm{E}-09$ & $3.60 \pm 1.75 \mathrm{E}-09$ & $1.82 \pm 0.83 \mathrm{E}-07$ \\
\hline 108 & DOWN(4) & 7.68 & 534 & $-0.50 \pm 1.49 \mathrm{E}-09$ & $4.52 \pm 1.75 \mathrm{E}-09$ & $1.81 \pm 7.88 \mathrm{E}-08$ \\
\hline 409 & $\operatorname{DOWN}(1)$ & 7.94 & 345 & $0.28 \pm 1.02 \mathrm{E}-09$ & $2.05 \pm 1.31 \mathrm{E}-09$ & $-3.33 \pm 5.76 \mathrm{E}-08$ \\
\hline 409 & $\operatorname{DOWN}(2)$ & 7.91 & 325 & $6.33 \pm 8.04 \mathrm{E}-10$ & $3.11 \pm 1.24 \mathrm{E}-09$ & $4.99 \pm 7.68 \mathrm{E}-08$ \\
\hline 409 & $\operatorname{DOWN}(3)$ & 7.95 & 300 & $0.36 \pm 1.00 \mathrm{E}-09$ & $2.72 \pm 1.28 \mathrm{E}-09$ & $-8.56 \pm 5.83 \mathrm{E}-08$ \\
\hline 409 & $\operatorname{DOWN}(4)$ & 7.41 & 351 & $0.87 \pm 1.21 \mathrm{E}-09$ & $2.72 \pm 1.20 \mathrm{E}-09$ & $1.07 \pm 0.78 E-07$ \\
\hline 910 & $\operatorname{DOWN}(1)$ & 6.91 & 1,254 & $3.25 \pm 2.73 \mathrm{E}-09$ & $9.45 \pm 3.88 \mathrm{E}-09$ & $-0.43 \pm 8.27 \mathrm{E}-08$ \\
\hline 910 & $\operatorname{DOWN}(3)$ & 7.22 & 1,118 & $3.12 \pm 1.88 \mathrm{E}-09$ & $1.23 \pm 0.27 \mathrm{E}-08$ & $3.69 \pm 8.43 \mathrm{E}-08$ \\
\hline
\end{tabular}

Note: Bolding convention applied to these data. (See p. E-2 6 (9)

Sample collection quarter is noted in parentheses next to hydraulic position. Hydraulic position is relative to other wells within the same hydrogeologic unit. 


\section{Table E-6}

\section{Indicator Results From the Kent Recessional Sequence}

\begin{tabular}{ccccccr}
$\begin{array}{c}\text { Location } \\
\text { Code }\end{array}$ & $\begin{array}{c}\text { Hydraulic } \\
\text { Position }\end{array}$ & $\begin{array}{c}\text { pH } \\
(\mathrm{SU})\end{array}$ & $\begin{array}{c}\text { Conductivity } \\
\left(\mu \mathrm{mhos} / \mathrm{cm} @ 25^{\circ} \mathrm{C}\right)\end{array}$ & $\begin{array}{c}\text { Gross Alpha } \\
(\mu \mathrm{Ci} / \mathrm{mL})\end{array}$ & $\begin{array}{c}\text { Gross Beta } \\
(\mu \mathrm{Ci} / \mathrm{mL})\end{array}$ & \multicolumn{1}{c}{$\begin{array}{c}\text { Tritium } \\
(\mu \mathrm{Ci} / \mathrm{mL})\end{array}$} \\
901 & UP(1) & 7.77 & 354 & $5.31 \pm 6.76 \mathrm{E}-10$ & $1.41 \pm 0.64 \mathrm{E}-09$ & $4.38 \pm 8.06 \mathrm{E}-08$ \\
901 & $\mathrm{UP}(3)$ & 7.61 & 347 & $1.56 \pm 1.16 \mathrm{E}-09$ & $3.66 \pm 1.41 \mathrm{E}-09$ & $1.09 \pm 8.06 \mathrm{E}-08$ \\
& & & & & & \\
902 & $\mathrm{UP}(1)$ & 7.83 & 425 & $1.77 \pm 1.29 \mathrm{E}-09$ & $1.18 \pm 1.06 \mathrm{E}-09$ & $1.12 \pm 0.82 \mathrm{E}-07$ \\
902 & $\mathrm{UP}(3)$ & 7.45 & 378 & $0.76 \pm 1.31 \mathrm{E}-09$ & $2.54 \pm 1.60 \mathrm{E}-09$ & $-1.36 \pm 0.82 \mathrm{E}-07$ \\
& & & & & & \\
$1008 \mathrm{~B}$ & $\mathrm{UP}(1)$ & 7.82 & 365 & $0.77 \pm 1.06 \mathrm{E}-09$ & $2.26 \pm 8.41 \mathrm{E}-10$ & $3.02 \pm 8.06 \mathrm{E}-08$ \\
$1008 \mathrm{~B}$ & $\mathrm{UP}(3)$ & 7.68 & 412 & $1.02 \pm 1.26 \mathrm{E}-09$ & $2.67 \pm 1.32 \mathrm{E}-09$ & $-7.31 \pm 8.33 \mathrm{E}-08$ \\
& & & & & & \\
903 & DOWN(1) & 7.46 & 902 & $4.29 \pm 2.37 \mathrm{E}-09$ & $4.12 \pm 2.62 \mathrm{E}-09$ & $1.01 \pm 0.82 \mathrm{E}-07$ \\
903 & DOWN(3) & 7.31 & 806 & $0.62 \pm 1.86 \mathrm{E}-09$ & $-0.08 \pm 2.36 \mathrm{E}-09$ & $-1.88 \pm 0.83 \mathrm{E}-07$ \\
& & & & & \\
8610 & DOWN(1) & 7.78 & 1,040 & $1.43 \pm 1.73 \mathrm{E}-09$ & $3.55 \pm 2.47 \mathrm{E}-09$ & $2.58 \pm 8.01 \mathrm{E}-08$ \\
8610 & DOWN(3) & 7.50 & 989 & $1.32 \pm 2.52 \mathrm{E}-09$ & $2.83 \pm 2.50 \mathrm{E}-09$ & $8.32 \pm 8.43 \mathrm{E}-08$ \\
& & & & & & \\
8611 & DOWN(1) & 7.25 & 893 & $3.03 \pm 2.08 \mathrm{E}-09$ & $2.38 \pm 2.37 \mathrm{E}-09$ & $-1.50 \pm 7.94 \mathrm{E}-08$ \\
8611 & DOWN(3) & 7.34 & 779 & $1.19 \pm 2.27 \mathrm{E}-09$ & $2.71 \pm 2.46 \mathrm{E}-09$ & $-2.91 \pm 8.32 \mathrm{E}-08$
\end{tabular}

Note: Bolding convention is not applicable to these data.

Sample collection quarter is noted in parentheses next to hydraulic position. Hydraulic position is relative to other wells within the same hydrogeologic unit.

$E-14$ 


\section{Table E-7 \\ 2004 Volatile Organic Compound Results at Selected Groundwater Monitoring Locations}

\begin{tabular}{|c|c|c|c|c|c|c|c|}
\hline $\begin{array}{l}\text { Location } \\
\text { Code }\end{array}$ & $\begin{array}{l}\text { Sampling } \\
\text { Quarter }\end{array}$ & $\begin{array}{c}\text { 1,1-DCA } \\
(\mu \mathrm{g} / \mathrm{L})\end{array}$ & $\begin{array}{c}\text { DCDFMeth } \\
(\mu \mathrm{g} / \mathrm{L})\end{array}$ & $\begin{array}{c}\text { 1,1-DCE } \\
(\mu \mathrm{g} / \mathrm{L})\end{array}$ & $\underset{(\mu \mathrm{g} / \mathrm{L})}{\text { 1,2-DCE(total) }}$ & $\begin{array}{c}\text { 1,2-DCE(trans) } \\
(\mu \mathrm{g} / \mathrm{L})\end{array}$ & $\begin{array}{c}\text { 1,1,1-TCA } \\
(\mu \mathrm{g} / \mathrm{L})\end{array}$ \\
\hline \multirow[t]{2}{*}{ SP12 } & 1 & $<5.0$ & $<1.0$ & $<5.0$ & NS & $<1.0$ & $<5.0$ \\
\hline & 3 & $<5.0$ & $<1.0$ & $<5.0$ & NS & $<1.0$ & $<5.0$ \\
\hline \multirow[t]{4}{*}{803} & 1 & $<5.0$ & $<1.0$ & $<5.0$ & NS & $<1.0$ & $<5.0$ \\
\hline & 2 & $<5.0$ & $<1.0$ & $<5.0$ & NS & $<1.0$ & $<5.0$ \\
\hline & 3 & $<5.0$ & $<1.0$ & $<5.0$ & NS & $<1.0$ & $<5.0$ \\
\hline & 4 & $<5.0$ & $<1.0$ & $<5.0$ & NS & $<1.0$ & $<5.0$ \\
\hline 8609 & 1 & $<5.0$ & $<5.0$ & $<5.0$ & NS & $<5.0$ & $<5.0$ \\
\hline \multirow[t]{4}{*}{8612} & 1 & 11.0 & $<5.0^{*}$ & $<5.0^{*}$ & 26.0 & $<5.0$ & $<5.0^{*}$ \\
\hline & 2 & 8.9 & $<5.0^{*}$ & $<5.0^{*}$ & 23.0 & $<5.0^{*}$ & $<5.0^{*}$ \\
\hline & 3 & 9.9 & $<5.0^{*}$ & $<5.0^{*}$ & 24.0 & $<5.0$ & $<5.0^{*}$ \\
\hline & 4 & 9.1 & $<5.0$ & $<5.0^{*}$ & 24.3 & $<5.0^{*}$ & $<5.0^{*}$ \\
\hline
\end{tabular}

See Table E-12 $\mathbf{\text { जo }}$ for compound definition.

Note: Bolding convention applied to these data. (See p. E-2 2 (0)

NS - Not sampled.

* Compound was reported at an estimated concentration less than the practical quantitation limit.

\section{Table E-8 \\ 2004 Tributyl Phosphate Results at Selected Groundwater Monitoring Locations}

$\begin{array}{ccc}\begin{array}{c}\text { Location } \\ \text { Code }\end{array} & \begin{array}{c}\text { Sampling } \\ \text { Quarter }\end{array} & \begin{array}{c}\text { Tributyl Phosphate (TBP) } \\ (\mu \mathrm{g} / \mathrm{L})\end{array} \\ 111 & 1 & <10.0^{*} \\ & 3 & 12.0 \\ 8605 & 1 & 410 \\ & 3 & 400\end{array}$

Practical quantitation limit is $10 \mu \mathrm{g} / \mathrm{L}$.

Note: Bolding convention not applicable to these data.

* Compound was reported at an estimated concentration less than the practical quantitation limit. 
Table E-9

2004 Results for Metals in Groundwater $(\mu \mathrm{g} / \mathrm{L})$

Title 6 NYCRR Appendix 33 List

\section{Location Hydraulic Antimony Arsenic Barium Beryllium Cadmium Chromium Cobalt Copper Code Position}

Sand and Gravel

\begin{tabular}{|c|c|c|c|c|c|c|c|c|c|}
\hline 706 & UP(1) & $<10$ & $<10$ & 156 & $<1$ & $<5$ & 51 & $<50$ & $<25$ \\
\hline 706 & UP(2) & $<10$ & $<10$ & 153 & $<1$ & $<5$ & 40 & $<50$ & $<25$ \\
\hline 706 & UP(3) & $<10$ & $<10$ & 202 & $<1$ & $<5$ & 43 & $<50$ & $<25$ \\
\hline 706 & $\mathrm{UP}(4)$ & $<10$ & $<10$ & 236 & $<1$ & $<5$ & 272 & $<50$ & $<25$ \\
\hline 1304 & UP(1) & $<10$ & 34 & 420 & 2 & $<5$ & 65 & $<50$ & 74 \\
\hline 1304 & $\mathrm{UP}(2)$ & $<10$ & 14 & 321 & 1 & $<5$ & 31 & $<50$ & 32 \\
\hline 1304 & UP(3) & $<10$ & 20 & 327 & 1 & $<5$ & 39 & $<50$ & 45 \\
\hline 1304 & UP(4) & $<10$ & $<10$ & 134 & $<1$ & $<5$ & 12 & $<50$ & $<25$ \\
\hline 1302 & $\operatorname{DOWN}(1)$ & $<10$ & 21 & 356 & 2 & $<5$ & 39 & $<50$ & 57 \\
\hline 1302 & DOWN(2) & $<10$ & $<10$ & 212 & $<1$ & $<5$ & 15 & $<50$ & $<25$ \\
\hline 1302 & DOWN(3) & $<10$ & $<10$ & 290 & $<1$ & $<5$ & 18 & $<50$ & 25 \\
\hline 1302 & DOWN(4) & $<10$ & $<10$ & 290 & $<1$ & $<5$ & 14 & $<50$ & $<25$ \\
\hline 111 & $\operatorname{DOWN}(1)$ & $<3$ & $<3$ & 96 & 0.1 & 1 & 3 & 2 & 4 \\
\hline 502 & DOWN(1) & NS & 4 & 330 & NS & $<0.3$ & 838 & 2 & 8 \\
\hline 502 & DOWN(3) & NS & $<4$ & 370 & NS & $<0.4$ & 888 & 2 & 6 \\
\hline 8605 & DOWN(1) & $<3$ & 6 & 148 & 0.17 & $<0.3$ & 2 & 2 & 3 \\
\hline
\end{tabular}

Weathered Till

\begin{tabular}{|c|c|c|c|c|c|c|c|c|}
\hline NDATR & DOWN(1) & $<10$ & $<10$ & 48 & $<1$ & $<5$ & $<5$ & $<50$ \\
\hline NDATR & $\operatorname{DOWN}(2)$ & $<10$ & $<10$ & 66 & $<1$ & $<5$ & $<5$ & $<50$ \\
\hline NDATR & DOWN(3) & $<10$ & $<10$ & 48 & $<1$ & $<5$ & $<5$ & $<50$ \\
\hline NDATR & $\operatorname{DOWN}(4)$ & $<10$ & $<10$ & 54 & $<1$ & $<5$ & $<5$ & $<50$ \\
\hline 909 & DOWN(1) & $<10$ & 12 & 191 & $<1$ & $<5$ & 10 & $<50$ \\
\hline
\end{tabular}

Unweathered Till

\begin{tabular}{|c|c|c|c|c|c|c|c|c|c|}
\hline 405 & UP(1) & $<10$ & $<10$ & 137 & $<1$ & $<5$ & 138 & $<50$ & $<25$ \\
\hline 405 & $\mathrm{UP}(2)$ & $<10$ & $<10$ & 132 & $<1$ & $<5$ & 702 & $<50$ & $<25$ \\
\hline 405 & $\mathrm{UP}(3)$ & $<10$ & $<10$ & 140 & $<1$ & $<5$ & 18 & $<50$ & $<25$ \\
\hline 405 & $\mathrm{UP}(4)$ & $<10$ & $<10$ & 169 & $<1$ & $<5$ & 173 & $<50$ & $<25$ \\
\hline 1303 & UP(1) & $<10$ & 23 & 371 & 2 & $<5$ & 60 & $<50$ & 59 \\
\hline 1303 & $\mathrm{UP}(2)$ & $<10$ & 24 & 419 & 2 & $<5$ & 60 & $<50$ & 53 \\
\hline 1303 & $\mathrm{UP}(3)$ & $<10$ & 64 & 756 & 5 & $<5$ & 139 & 95 & 138 \\
\hline 1303 & UP(4) & $<10$ & 15 & 272 & 1 & $<5$ & 29 & $<50$ & 26 \\
\hline
\end{tabular}

Note: Bolding convention applied to these data. (See p. E-2 뚜)

NS - Not sampled.

Sample collection quarter is noted in parentheses next to hydraulic position. Hydraulic position is relative to other wells within the same hydrogeologic unit.

$$
E-16
$$




\section{Table E-9 (concluded)}

\section{Results for Metals in Groundwater $(\mu \mathrm{g} / \mathrm{L})$ \\ Title 6 NYCRR Appendix 33 List}

Location
Code $\begin{gathered}\begin{array}{c}\text { Hydraulic } \\ \text { Position }\end{array} \\ \text { Lead }\end{gathered}$ Mercury Nickel Selenium Silver Thallium Tin Vanadium Zinc

Sand and Gravel

$\begin{array}{rlrrrrrrrrr}706 & \text { UP(1) } & 3 & <0.2 & <40 & <5 & <10 & <10 & <3,000 & <50 & <20 \\ 706 & \text { UP(2) } & <3 & <0.2 & <40 & <5 & <10 & <10 & <3,000 & <50 & <20 \\ 706 & \text { UP(3) } & <3 & <0.2 & 288 & <5 & <10 & <10 & <3,000 & <50 & <20 \\ 706 & \text { UP(4) } & <3 & <0.2 & \mathbf{5 3 2} & <5 & <10 & <10 & <3,000 & <50 & 36 \\ & & & & & & & <5 & \\ 1304 & \text { UP(1) } & \mathbf{4 4} & <0.2 & \mathbf{6 3} & <5 & <10 & <10 & <3,000 & \mathbf{6 3} & \mathbf{2 2 6} \\ 1304 & \text { UP(2) } & 19 & <0.2 & <40 & <5 & <10 & <10 & <3,000 & <50 & 95 \\ 1304 & \text { UP(3) } & 27 & <0.2 & <40 & <25 & <10 & <10 & <3,000 & <50 & 130 \\ 1304 & \text { UP(4) } & \mathbf{1 0} & <0.2 & <40 & <5 & <10 & <10 & <3,000 & <50 & \mathbf{4 4} \\ 1302 & \text { DOWN(1) } & \mathbf{3 4} & <0.2 & \mathbf{4 5} & <5 & <10 & <10 & <3,000 & \mathbf{5 0} & \mathbf{1 7 3} \\ 1302 & \text { DOWN(2) } & 14 & <0.2 & <40 & <5 & <10 & <10 & <3,000 & <50 & 68 \\ 1302 & \text { DOWN(3) } & 16 & <0.2 & <40 & <5 & <10 & <10 & <3,000 & <50 & 76 \\ 1302 & \text { DOWN(4) } & \mathbf{1 3} & <0.2 & <40 & <5 & <10 & <10 & <3,000 & <50 & \mathbf{4 9} \\ 111 & \text { DOWN(1) } & <3 & <0.1 & 5 & <3 & <1 & <6 & <6 & 1 & 26 \\ 502 & \text { DOWN(1) } & <3 & <0.1 & 56 & <3 & <1 & \text { NS } & \text { NS } & 3 & 9 \\ 502 & \text { DOWN(3) } & <3 & <0.1 & 38 & <4 & <1 & \text { NS } & \text { NS } & 2 & <0.5 \\ 8605 & \text { DOWN(1) } & <3 & <0.1 & 3 & <3 & <1 & <6 & <6 & 1 & <0.5\end{array}$

Weathered Till

$\begin{array}{clllllllrrr}\text { NDATR } & \text { DOWN(1) } & <3 & <0.2 & <40 & <5 & <10 & <10 & <3,000 & <50 & <20 \\ \text { NDATR } & \text { DOWN(2) } & <3 & <0.2 & <40 & <5 & <10 & <10 & <3,000 & <50 & \mathbf{2 4} \\ \text { NDATR } & \text { DOWN(3) } & <3 & <0.2 & <40 & <5 & <10 & <10 & <3,000 & <50 & <20 \\ \text { NDATR } & \text { DOWN(4) } & <3 & <0.2 & <40 & <5 & <10 & <10 & <3,000 & <50 & <20 \\ 909 & \text { DOWN(1) } & 5 & <0.2 & <40 & <5 & <10 & <10 & <3,000 & <50 & 30\end{array}$

\section{Unweathered Till}

$\begin{array}{rrrrrrrrrrr}405 & \text { UP(1) } & \mathbf{5} & <0.2 & \mathbf{6 6 8} & <5 & <10 & <10 & <3,000 & <50 & <20 \\ 405 & \text { UP(2) } & <3 & <0.2 & 1,210 & <5 & <10 & <10 & <3,000 & <50 & <20 \\ 405 & \text { UP(3) } & <3 & <0.2 & \mathbf{2 , 2 8 0} & <5 & <10 & <10 & <3,000 & <50 & <20 \\ 405 & \text { UP(4) } & <3 & <0.2 & 1,710 & <5 & <10 & <10 & <3,000 & <50 & <20 \\ & & & & & & & & & & \\ 1303 & \text { UP(1) } & 27 & <0.2 & 89 & <5 & <10 & <10 & <3,000 & 71 & 179 \\ 1303 & \text { UP(2) } & 27 & <0.2 & 89 & <5 & <10 & <10 & <3,000 & 72 & 221 \\ 1303 & \text { UP(3) } & \mathbf{8 1} & <0.2 & \mathbf{2 1 8} & <25 & <10 & <10 & <3,000 & \mathbf{1 6 1} & \mathbf{4 7 1} \\ 1303 & \text { UP(4) } & \mathbf{9} & <0.2 & \mathbf{4 4} & <5 & <10 & <10 & <3,000 & <50 & \mathbf{8 9}\end{array}$

Note: Bolding convention applied to these data. (See p. E-2 6 무) NS - Not sampled.

Sample collection quarter is noted in parentheses next to hydraulic position. Hydraulic position is relative to other wells within the same hydrogeologic unit.

$$
\text { E }-17
$$


Table E-10

2004 Metals Indicator Results for Early Warning Monitoring Wells ( $\mu g / L)$

$\begin{array}{ccccc}\begin{array}{c}\text { Location } \\ \text { Code }\end{array} & \begin{array}{c}\text { Sample } \\ \text { Quarter }\end{array} & \begin{array}{c}\text { Aluminum } \\ \text { Total }\end{array} & \begin{array}{c}\text { Iron } \\ \text { Total }\end{array} & \begin{array}{c}\text { Manganese } \\ \text { Total }\end{array} \\ 502 & (1) & 168 & 5,310 & 11.3 \\ & (3) & 213 & 4,800 & 11.3\end{array}$

Note: Bolding convention is not applicable to these data.

Sample collection quarter is noted in parentheses next to hydraulic position. Hydraulic position is relative to other wells within the same hydrogeologic unit.

$E-18$ 


\section{Table E-11 \\ 2004 Radioactivity $(\mu \mathrm{Ci} / \mathrm{mL})$ in Groundwater From Selected Monitoring Locations}

\begin{tabular}{|c|c|c|c|c|}
\hline $\begin{array}{l}\text { Location } \\
\text { Code }\end{array}$ & $\begin{array}{l}\text { Hydraulic } \\
\text { Position }\end{array}$ & C-14 & Sr-90 & Tc-99 \\
\hline \multicolumn{5}{|c|}{ Sand and Gravel } \\
\hline 401 & $\mathrm{UP}(1)$ & $-0.97 \pm 3.12 \mathrm{E}-08$ & $4.02 \pm 1.36 \mathrm{E}-09$ & $-1.84 \pm 1.55 \mathrm{E}-09$ \\
\hline 706 & UP(1) & $0.41 \pm 3.13 \mathrm{E}-08$ & $4.77 \pm 1.74 \mathrm{E}-09$ & $-4.80 \pm 2.74 \mathrm{E}-09$ \\
\hline 706 & UP(2) & $1.22 \pm 3.00 \mathrm{E}-08$ & $2.72 \pm 1.42 \mathrm{E}-09$ & $0.03 \pm 2.23 \mathrm{E}-09$ \\
\hline 706 & UP(3) & $-2.96 \pm 2.65 \mathrm{E}-08$ & $4.37 \pm 1.61 \mathrm{E}-09$ & $0.00 \pm 1.87 \mathrm{E}-09$ \\
\hline 706 & UP(4) & $2.86 \pm 4.62 \mathrm{E}-09$ & $5.39 \pm 2.19 \mathrm{E}-09$ & $1.53 \pm 2.28 \mathrm{E}-09$ \\
\hline 1304 & $\mathrm{UP}(1)$ & $-0.55 \pm 3.11 \mathrm{E}-08$ & $1.23 \pm 1.55 \mathrm{E}-09$ & $-2.64 \pm 2.10 \mathrm{E}-09$ \\
\hline 1304 & UP(2) & $3.69 \pm 2.65 \mathrm{E}-08$ & $4.67 \pm 1.63 \mathrm{E}-09$ & $-1.49 \pm 2.02 \mathrm{E}-09$ \\
\hline 1304 & UP(3) & $-1.52 \pm 2.64 \mathrm{E}-08$ & $2.44 \pm 1.43 \mathrm{E}-09$ & $0.47 \pm 1.84 \mathrm{E}-09$ \\
\hline 1304 & UP(4) & $0.00 \pm 4.44 \mathrm{E}-09$ & $1.76 \pm 1.20 \mathrm{E}-09$ & $-1.28 \pm 2.26 \mathrm{E}-09$ \\
\hline 1302 & DOWN(1) & $-1.81 \pm 3.09 \mathrm{E}-08$ & $-1.50 \pm 1.19 \mathrm{E}-09$ & $-2.88 \pm 1.98 \mathrm{E}-09$ \\
\hline 1302 & DOWN(2) & $0.14 \pm 2.62 \mathrm{E}-08$ & $0.17 \pm 1.10 \mathrm{E}-09$ & $-2.45 \pm 2.14 \mathrm{E}-09$ \\
\hline 1302 & DOWN(3) & $0.49 \pm 2.71 \mathrm{E}-08$ & $0.40 \pm 1.40 \mathrm{E}-09$ & $1.44 \pm 1.90 \mathrm{E}-09$ \\
\hline 1302 & DOWN(4) & $2.17 \pm 4.72 \mathrm{E}-09$ & $0.44 \pm 1.10 \mathrm{E}-09$ & $-1.63 \pm 2.25 \mathrm{E}-09$ \\
\hline 111 & DOWN(1) & NS & $3.00 \pm 0.05 \mathrm{E}-06$ & NS \\
\hline 406 & DOWN(1) & $-1.80 \pm 3.07 \mathrm{E}-08$ & $2.34 \pm 1.48 \mathrm{E}-09$ & $0.97 \pm 1.49 \mathrm{E}-09$ \\
\hline 408 & DOWN(1) & $-0.69 \pm 3.11 \mathrm{E}-08$ & $1.25 \pm 0.01 \mathrm{E}-04$ & $1.96 \pm 0.29 \mathrm{E}-08$ \\
\hline 501 & DOWN(1) & NS & $6.51 \pm 0.02 \mathrm{E}-05$ & NS \\
\hline 502 & DOWN(1) & NS & $6.85 \pm 0.02 \mathrm{E}-05$ & NS \\
\hline $602 \mathrm{~A}$ & DOWN(1) & NS & $6.32 \pm 1.83 \mathrm{E}-09$ & NS \\
\hline $602 \mathrm{~A}$ & DOWN(3) & NS & $4.84 \pm 1.66 \mathrm{E}-09$ & NS \\
\hline 8605 & DOWN(1) & NS & $5.69 \pm 0.06 \mathrm{E}-06$ & NS \\
\hline 8609 & DOWN(1) & NS & $9.94 \pm 0.18 \mathrm{E}-07$ & NS \\
\hline 8609 & DOWN(3) & NS & $8.01 \pm 0.31 \mathrm{E}-07$ & NS \\
\hline 116 & DOWN(1) & NS & $6.96 \pm 0.17 \mathrm{E}-07$ & NS \\
\hline 116 & DOWN(3) & NS & $5.91 \pm 0.21 \mathrm{E}-07$ & NS \\
\hline 605 & DOWN(1) & NS & $1.86 \pm 0.28 \mathrm{E}-08$ & NS \\
\hline 605 & DOWN(3) & NS & $1.79 \pm 0.25 \mathrm{E}-08$ & NS \\
\hline
\end{tabular}

Note: Bolding convention applied to these data. (See p. E-2 $\mathbf{6 0}$ )

NS - Not sampled.

Sample collection quarter is noted in parentheses next to hydraulic position. Hydraulic position is relative to other wells within the same hydrogeologic unit. 


\section{Table E-11 (continued) \\ 2004 Radioactivity $(\mu \mathrm{Ci} / \mathrm{mL})$ in Groundwater From Selected Monitoring Locations}

$\begin{array}{cc}\text { Location } & \begin{array}{c}\text { Hydraulic } \\ \text { Code }\end{array} \\ \text { Position }\end{array}$

Sand and Gravel (concluded)

$\begin{array}{ll}801 & \text { DOWN(1) } \\ 801 & \text { DOWN(2) } \\ 801 & \text { DOWN(3) } \\ 801 & \text { DOWN(4) } \\ 8603 & \text { DOWN(1) } \\ 8603 & \text { DOWN(3) }\end{array}$

\section{Weathered Till}

$\begin{array}{cc}\begin{array}{cc}\text { NDATR } \\ \text { NDATR }\end{array} & \text { DOWN(1) } \\ & \text { DOWN(3) } \\ 909 & \text { DOWN(1) } \\ \text { Unweathered Till } & \\ & \\ 405 & \text { UP(1) } \\ 405 & \text { UP(2) } \\ 405 & \text { UP(3) } \\ 405 & \text { UP(4) } \\ 1303 & \text { UP(1) } \\ 1303 & \text { UP(2) } \\ 1303 & \text { UP(3) } \\ 1303 & \text { UP(4) }\end{array}$

C-14

Sr-90

Tc-99

$\begin{array}{lll}\text { NS } & \mathbf{2 . 0 0 \pm 0 . 0 4 E - 0 6} & \text { NS } \\ \text { NS } & \mathbf{3 . 6 4 \pm 0 . 0 4 E - 0 6} & \text { NS } \\ \text { NS } & 3.19 \pm 0.05 \mathrm{E}-06 & \text { NS } \\ \text { NS } & 2.71 \pm 0.04 \mathrm{E}-06 & \text { NS } \\ & & \\ \text { NS } & 3.23 \pm 0.02 \mathrm{E}-05 & \text { NS } \\ \text { NS } & 3.14 \pm 0.02 \mathrm{E}-05 & \text { NS }\end{array}$

$-0.14 \pm 3.11 \mathrm{E}-08$

$7.57 \pm 0.51 \mathrm{E}-08$

$2.17 \pm 2.18 \mathrm{E}-09$

$-1.25 \pm 2.68 \mathrm{E}-08$

$8.50 \pm 0.52 \mathrm{E}-08$

$0.27 \pm 1.88 \mathrm{E}-09$

$-1.66 \pm 3.07 \mathrm{E}-08$

$1.90 \pm 0.06 \mathrm{E}-07$

$0.62 \pm 1.86 \mathrm{E}-09$

$\mathbf{2 . 6 3} \pm \mathbf{1 . 4 8 E}-\mathbf{0 9}$
$\mathbf{7 . 3 8} \pm \mathbf{1 . 5 3 E}-\mathbf{0 9}$
$3.85 \pm 1.50 \mathrm{E}-09$
$3.90 \pm 1.21 \mathrm{E}-09$

$0.95 \pm 1.60 \mathrm{E}-09$
$\mathbf{1 . 3 3} \pm \mathbf{1 . 2 6 E}-\mathbf{0 9}$
$0.95 \pm 1.26 \mathrm{E}-09$
$-0.26 \pm 1.30 \mathrm{E}-09$

$-2.28 \pm 1.36 \mathrm{E}-09$

$-0.57 \pm 2.03 \mathrm{E}-09$

$-0.56 \pm 1.79 \mathrm{E}-09$

$-0.64 \pm 2.70 \mathrm{E}-08$

7.43 $\pm 5.08 \mathrm{E}-09$

$-1.18 \pm 2.19 \mathrm{E}-09$

$-0.41 \pm 3.08 \mathrm{E}-08$

$-0.41 \pm 2.55 \mathrm{E}-08$

$0.90 \pm 2.69 \mathrm{E}-08$

$1.91 \pm 4.53 \mathrm{E}-09$

$-1.48 \pm 2.05 \mathrm{E}-09$

$-1.75 \pm 2.43 \mathrm{E}-09$

$1.29 \pm 2.08 \mathrm{E}-09$

$-1.24 \pm 2.25 \mathrm{E}-09$

Note: Bolding convention applied to these data. (See p. E-2 ${ }^{\mathbf{6 0}}$ )

NS - Not sampled.

Sample collection quarter is noted in parentheses next to hydraulic position. Hydraulic position is relative to other wells within the same hydrogeologic unit.

$E-20$ 


\section{Table E-11 (continued) 2004 Radioactivity $(\mu \mathrm{Ci} / \mathrm{mL})$ in Groundwater From Selected Monitoring Locations}

\section{Location Hydraulic Code Position}

Sand and Gravel

$\begin{array}{lcrr}401 & \text { UP(1) } & 0.05 \pm 1.31 \mathrm{E}-09 & -0.32 \pm 9.63 \mathrm{E}-09 \\ 706 & \mathrm{UP}(1) & 1.01 \pm 1.07 \mathrm{E}-09 & -1.48 \pm 6.96 \mathrm{E}-09 \\ 706 & \mathrm{UP}(2) & 7.19 \pm 9.72 \mathrm{E}-10 & 1.51 \pm 5.36 \mathrm{E}-09 \\ 706 & \mathrm{UP}(3) & -0.28 \pm 8.58 \mathrm{E}-10 & -0.10 \pm 1.14 \mathrm{E}-08 \\ 706 & \mathrm{UP}(4) & \mathbf{1 . 5 8} \pm \mathbf{1 . 0 9 E}-09 & 4.16 \pm 5.74 \mathrm{E}-09 \\ & & & \\ 1304 & \mathrm{UP}(1) & \mathbf{2 . 8 3} \pm \mathbf{2 . 4 8 E - 0 9} & -0.88 \pm 6.83 \mathrm{E}-09 \\ 1304 & \mathrm{UP}(2) & 0.10 \pm 1.92 \mathrm{E}-09 & -1.65 \pm 5.94 \mathrm{E}-09 \\ 1304 & \mathrm{UP}(3) & 3.65 \pm 8.43 \mathrm{E}-10 & -1.53 \pm 6.64 \mathrm{E}-09 \\ 1304 & \mathrm{UP}(4) & 0.91 \pm 2.06 \mathrm{E}-09 & -1.09 \pm 7.08 \mathrm{E}-09 \\ & & & \\ 1302 & \text { DOWN(1) } & 0.95 \pm 1.00 \mathrm{E}-09 & 2.34 \pm 8.31 \mathrm{E}-09 \\ 1302 & \text { DOWN(2) } & -3.69 \pm 7.24 \mathrm{E}-10 & 3.99 \pm 6.95 \mathrm{E}-09 \\ 1302 & \text { DOWN(3) } & 0.98 \pm 1.31 \mathrm{E}-09 & -2.94 \pm 6.94 \mathrm{E}-09 \\ 1302 & \text { DOWN(4) } & -0.46 \pm 1.12 \mathrm{E}-09 & 1.93 \pm 6.69 \mathrm{E}-09 \\ 406 & \text { DOWN(1) } & 1.34 \pm 4.01 \mathrm{E}-10 & -3.76 \pm 5.32 \mathrm{E}-09 \\ & & & \\ 408 & \text { DOWN(1) } & 1.53 \pm 3.36 \mathrm{E}-10 & -2.93 \pm 3.82 \mathrm{E}-09 \\ 8605 & \text { DOWN(1) } & \text { NS } & 1.56 \pm 9.90 \mathrm{E}-09\end{array}$

\section{Weathered Till}

$\begin{array}{ll}\text { NDATR } & \text { DOWN(1) } \\ \text { NDATR } & \text { DOWN(3) }\end{array}$

$0.50 \pm 1.04 \mathrm{E}-09$ $6.22 \pm 9.72 \mathrm{E}-10$

$$
\begin{array}{r}
2.84 \pm 6.70 \mathrm{E}-09 \\
-0.49 \pm 6.27 \mathrm{E}-09
\end{array}
$$

909

DOWN(1)

\begin{abstract}
$5.16 \pm 3.18 \mathrm{E}-09$
\end{abstract}
Unweathered Till

$\begin{array}{llr}405 & \mathrm{UP}(1) & -5.13 \pm 6.78 \mathrm{E}-10 \\ 405 & \mathrm{UP}(2) & 0.95 \pm 7.57 \mathrm{E}-10 \\ 405 & \mathrm{UP}(3) & 0.27 \pm 9.45 \mathrm{E}-10 \\ 405 & \mathrm{UP}(4) & -1.79 \pm 8.20 \mathrm{E}-10 \\ & & \\ 1303 & \mathrm{UP}(1) & 0.60 \pm 1.27 \mathrm{E}-09 \\ 1303 & \mathrm{UP}(2) & \mathbf{1 . 3 4} \pm \mathbf{1 . 1 1 E - 0 9} \\ 1303 & \mathrm{UP}(3) & -0.44 \pm 8.58 \mathrm{E}-10 \\ 1303 & \mathrm{UP}(4) & -0.28 \pm 8.22 \mathrm{E}-10\end{array}$

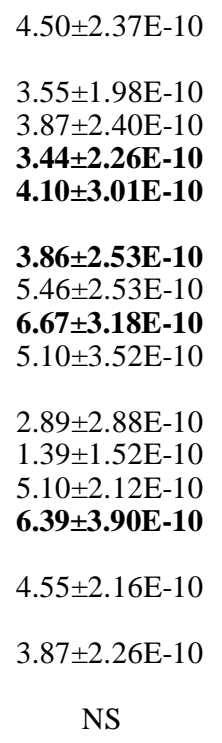

$1.66 \pm 0.49 \mathrm{E}-09$

$6.89 \pm 4.71 \mathrm{E}-10$

$4.24 \pm 4.39 \mathrm{E}-10$

$0.14 \pm 4.75 \mathrm{E}-10$

1.32 $\pm 0.54 \mathrm{E}-09$

$1.01 \pm 0.53 \mathrm{E}-09$

$1.24 \pm 0.53 E-09$

$-4.81 \pm 3.55 \mathrm{E}-10$

$0.56 \pm 4.03 \mathrm{E}-10$

$4.15 \pm 4.21 \mathrm{E}-10$

8.83 \pm 4.35E-10

$0.59 \pm 5.69 \mathrm{E}-10$

$-1.22 \pm 4.94 \mathrm{E}-10$

$4.71 \pm 4.30 \mathrm{E}-10$

$4.48 \pm 5.04 \mathrm{E}-10$

NS

$1.35 \pm 0.49 \mathrm{E}-09$

$3.10 \pm 4.13 \mathrm{E}-10$

$6.13 \pm 4.52 \mathrm{E}-10$

$7.26 \pm 4.04 \mathrm{E}-10$

$3.23 \pm 1.62 \mathrm{E}-10$ $5.26 \pm 2.92 \mathrm{E}-10$ $3.88 \pm 2.43 \mathrm{E}-10$ 3.23 $\pm 2.73 \mathrm{E}-10$

$2.70 \pm 2.12 \mathrm{E}-10$ $2.77 \pm 1.81 \mathrm{E}-10$ 3.88 $\pm 2.09 E-10$ $1.35 \pm 2.64 \mathrm{E}-10$

\section{$1.49 \pm 0.49 \mathrm{E}-09$ 6.90 $\pm 4.85 \mathrm{E}-10$ $7.15 \pm 5.04 \mathrm{E}-10$ $1.07 \pm 0.63 \mathrm{E}-09$ \\ 1.07+0.48E-09 $5.81 \pm 4.49 \mathrm{E}-10$ $1.22 \pm 3.43 \mathrm{E}-10$ $9.55 \pm 3.95 \mathrm{E}-10$}

$2.44 \pm 3.28 \mathrm{E}-11$

$1.01 \pm 8.68 \mathrm{E}-11$ $1.21 \pm 3.38 \mathrm{E}-11$ $-0.06 \pm 6.64 \mathrm{E}-11$ $0.77 \pm 1.19 \mathrm{E}-10$

$-3.06 \pm 4.01 \mathrm{E}-11$ $3.30 \pm 3.87 \mathrm{E}-11$ $-0.69 \pm 5.19 \mathrm{E}-11$ $-0.68 \pm 5.46 \mathrm{E}-11$

$7.04 \pm 7.58 \mathrm{E}-11$ $1.25 \pm 4.54 \mathrm{E}-11$ $-0.68 \pm 4.14 \mathrm{E}-11$

$1.76 \pm 6.79 \mathrm{E}-11$

$-0.77 \pm 6.59 \mathrm{E}-11$

$-0.27 \pm 4.55 \mathrm{E}-11$

NS

$3.50 \pm 6.47 \mathrm{E}-11$ $7.58 \pm 8.60 \mathrm{E}-11$

$-0.40 \pm 5.18 \mathrm{E}-11$

\section{Well Points}

WP-H DOWN(1)

NS

$-0.27 \pm 3.96 \mathrm{E}-09$

NS

NS

NS

7.76 $\pm 6.88 \mathrm{E}-11$ $5.43 \pm 4.84 \mathrm{E}-11$ $1.75 \pm 6.86 \mathrm{E}-11$ $0.48 \pm 1.25 \mathrm{E}-10$

$0.15 \pm 4.23 \mathrm{E}-11$ $1.65 \pm 6.21 \mathrm{E}-11$ $-1.68 \pm 6.40 \mathrm{E}-11$ $2.76 \pm 6.45 \mathrm{E}-11$

Note: Bolding convention applied to these data. (See p. E-2 $\mathbf{6 0}$ )

NS - Not sampled.

Sample collection quarter is noted in parentheses next to hydraulic position. Hydraulic position is relative to other wells within the same hydrogeologic unit. 


\section{Table E-11 (concluded) \\ 2004 Radioactivity $(\mu \mathrm{Ci} / \mathrm{mL})$ in Groundwater From Selected Monitoring Locations}

$\begin{array}{cccccc}\begin{array}{c}\text { Location } \\ \text { Code }\end{array} & \begin{array}{c}\text { Hydraulic } \\ \text { Position }\end{array} & \mathbf{U - 2 3 3 / 2 3 4} & \mathbf{U}-235 / 236 & \mathbf{U}-238 & \begin{array}{c}\text { Total U } \\ (\mu \mathrm{g} / \mathrm{mL})\end{array}\end{array}$

Sand and Gravel

\begin{tabular}{|c|c|c|c|c|c|}
\hline 401 & $\mathrm{UP}(1)$ & $7.84 \pm 4.86 \mathrm{E}-11$ & $0.54 \pm 3.03 \mathrm{E}-11$ & $4.57 \pm 4.12 \mathrm{E}-11$ & $1.02 \pm 0.05 \mathrm{E}-04$ \\
\hline 706 & $\mathrm{UP}(1)$ & $1.52 \pm 0.98 \mathrm{E}-10$ & $1.40 \pm 5.41 \mathrm{E}-11$ & $6.28 \pm 5.37 \mathrm{E}-11$ & $1.11 \pm 0.12 \mathrm{E}-04$ \\
\hline 706 & $\mathrm{UP}(2)$ & $1.41 \pm 1.08 \mathrm{E}-10$ & $2.33 \pm 5.26 \mathrm{E}-11$ & $1.14 \pm 0.95 \mathrm{E}-10$ & $0.00 \pm 1.98 \mathrm{E}-04$ \\
\hline 706 & $\mathrm{UP}(3)$ & $1.30 \pm 1.04 \mathrm{E}-10$ & $2.03 \pm 6.21 \mathrm{E}-11$ & $2.06 \pm 1.09 \mathrm{E}-10$ & $0.00 \pm 2.55 \mathrm{E}-04$ \\
\hline 706 & UP(4) & $1.42 \pm 0.90 \mathrm{E}-10$ & $6.29 \pm 5.61 \mathrm{E}-11$ & $1.14 \pm 0.76 \mathrm{E}-10$ & $2.18 \pm 0.09 E-04$ \\
\hline 1304 & UP(1) & $4.57 \pm 1.21 \mathrm{E}-10$ & $1.25 \pm 4.40 \mathrm{E}-11$ & $3.65 \pm 1.03 \mathrm{E}-10$ & $8.11 \pm 0.17 \mathrm{E}-04$ \\
\hline 1304 & UP(2) & $1.85 \pm 1.18 \mathrm{E}-10$ & $5.23 \pm 6.94 \mathrm{E}-11$ & $1.90 \pm 1.18 \mathrm{E}-10$ & $1.42 \pm 0.06 \mathrm{E}-03$ \\
\hline 1304 & $\mathrm{UP}(3)$ & $3.54 \pm 1.39 \mathrm{E}-10$ & $1.19 \pm 3.74 \mathrm{E}-11$ & $1.80 \pm 0.91 E-10$ & $6.93 \pm 0.52 E-04$ \\
\hline 1304 & $\mathrm{UP}(4)$ & $3.72 \pm 1.57 \mathrm{E}-10$ & $6.92 \pm 7.68 \mathrm{E}-11$ & $2.10 \pm 1.22 \mathrm{E}-10$ & $5.45 \pm 0.09 \mathrm{E}-04$ \\
\hline 1302 & $\operatorname{DOWN}(1)$ & $5.87 \pm 1.74 \mathrm{E}-10$ & $0.48 \pm 6.00 \mathrm{E}-11$ & $5.31 \pm 1.68 \mathrm{E}-10$ & $1.28 \pm 0.03 E-03$ \\
\hline 1302 & $\operatorname{DOWN}(2)$ & $1.86 \pm 1.13 \mathrm{E}-10$ & $0.89 \pm 4.76 \mathrm{E}-11$ & $1.70 \pm 1.03 \mathrm{E}-10$ & $5.10 \pm 3.13 E-04$ \\
\hline 1302 & DOWN(3) & $3.96 \pm 1.37 \mathrm{E}-10$ & $5.75 \pm 5.77 \mathrm{E}-11$ & $1.67 \pm 0.88 \mathrm{E}-10$ & $5.99 \pm 0.37 \mathrm{E}-04$ \\
\hline 1302 & DOWN(4) & $1.48 \pm 1.14 \mathrm{E}-10$ & $1.15 \pm 0.92 E-10$ & $1.29 \pm 0.99 \mathrm{E}-10$ & $6.31 \pm 0.17 \mathrm{E}-04$ \\
\hline 406 & $\operatorname{DOWN}(1)$ & $6.86 \pm 5.37 \mathrm{E}-11$ & $3.18 \pm 3.28 \mathrm{E}-11$ & $7.39 \pm 5.47 \mathrm{E}-11$ & $0.00 \pm 1.98 \mathrm{E}-04$ \\
\hline 408 & $\operatorname{DOWN}(1)$ & $9.72 \pm 2.37 \mathrm{E}-10$ & $3.34 \pm 5.12 \mathrm{E}-11$ & $3.58 \pm 1.43 \mathrm{E}-10$ & $8.00 \pm 0.18 \mathrm{E}-04$ \\
\hline \multicolumn{6}{|c|}{ Weathered Till } \\
\hline NDATR & $\operatorname{DOWN}(1)$ & $1.92 \pm 0.25 \mathrm{E}-09$ & $3.04 \pm 1.04 \mathrm{E}-10$ & $1.27 \pm 0.20 \mathrm{E}-09$ & $3.61 \pm 0.07 \mathrm{E}-03$ \\
\hline NDATR & DOWN(3) & $1.71 \pm 0.29 \mathrm{E}-09$ & $1.04 \pm 0.79 \mathrm{E}-10$ & $1.17 \pm 0.25 \mathrm{E}-09$ & $4.06 \pm 0.17 \mathrm{E}-03$ \\
\hline 909 & $\operatorname{DOWN}(1)$ & $4.75 \pm 1.29 \mathrm{E}-10$ & $7.99 \pm 5.86 \mathrm{E}-11$ & $3.14 \pm 1.03 \mathrm{E}-10$ & $5.86 \pm 0.31 \mathrm{E}-04$ \\
\hline \multicolumn{6}{|c|}{ Unweathered Till } \\
\hline 405 & $\mathrm{UP}(1)$ & $4.74 \pm 0.94 \mathrm{E}-10$ & $1.90 \pm 2.28 \mathrm{E}-11$ & $3.61 \pm 0.83 \mathrm{E}-10$ & $9.62 \pm 0.23 E-04$ \\
\hline 405 & $\mathrm{UP}(2)$ & $5.27 \pm 1.74 \mathrm{E}-10$ & $9.48 \pm 7.92 \mathrm{E}-11$ & $3.05 \pm 1.36 \mathrm{E}-10$ & $7.30 \pm 1.67 \mathrm{E}-04$ \\
\hline 405 & $\mathrm{UP}(3)$ & $3.23 \pm 1.32 \mathrm{E}-10$ & $1.04 \pm 0.79 E-10$ & $2.44 \pm 1.11 E-10$ & $0.00 \pm 2.55 \mathrm{E}-04$ \\
\hline 405 & $\mathrm{UP}(4)$ & $6.53 \pm 2.59 \mathrm{E}-10$ & $3.39 \pm 7.65 \mathrm{E}-11$ & $3.83 \pm 2.01 E-10$ & $8.58 \pm 0.11 \mathrm{E}-04$ \\
\hline 1303 & $\mathrm{UP}(1)$ & $1.20 \pm 0.18 E-09$ & $7.16 \pm 4.80 \mathrm{E}-11$ & $1.03 \pm 0.17 \mathrm{E}-09$ & $2.12 \pm 0.04 \mathrm{E}-03$ \\
\hline 1303 & $\mathrm{UP}(2)$ & $1.31 \pm 0.30 \mathrm{E}-09$ & $8.72 \pm 8.47 E-11$ & $6.82 \pm 2.14 \mathrm{E}-10$ & $2.69 \pm 0.11 E-03$ \\
\hline 1303 & $\mathrm{UP}(3)$ & $6.57 \pm 1.74 \mathrm{E}-10$ & $6.16 \pm 7.25 \mathrm{E}-11$ & $6.01 \pm 1.64 \mathrm{E}-10$ & $1.48 \pm 0.07 E-03$ \\
\hline 1303 & $\mathrm{UP}(4)$ & $6.36 \pm 2.19 \mathrm{E}-10$ & $7.56 \pm 7.40 \mathrm{E}-11$ & $2.73 \pm 1.43 E-10$ & $1.58 \pm 0.03 \mathrm{E}-03$ \\
\hline
\end{tabular}

Note: Bolding convention applied to these data. (See p. E-2 $\mathbf{\text { G0 }}$ )

Sample collection quarter is noted in parentheses next to hydraulic position. Hydraulic position is relative to other wells within the same hydrogeologic unit.

$E-22$ 


\section{Table E-12 \\ Practical Quantitation Limits (PQLs)}

COMPOUND

6 NYCRR Appendix 33 Volatiles

$\begin{array}{lc}\text { Acetone } & 10 \\ \text { Acetonitrile } & 100 \\ \text { Acrolein } & 11 \\ \text { Acrylonitrile } & 5 \\ \text { Allyl chloride } & 5 \\ \text { Benzene } & 5 \\ \text { Bromodichloromethane } & 5 \\ \text { Bromoform } & 5 \\ \text { Bromomethane } & 10 \\ \text { Carbon disulfide } & 10 \\ \text { Carbon tetrachloride } & 5 \\ \text { Chlorobenzene } & 5 \\ \text { Chloroethane } & 10 \\ \text { Chloroform } & 5 \\ \text { Chloromethane } & 10 \\ \text { Chloroprene } & 5 \\ \text { 1,2-Dibromo-3-chloropropane } & 5 \\ \text { Dibromochloromethane } & 5 \\ \text { 1,2-Dibromoethane } & 5 \\ \text { Dichlorodifluoromethane(DCDFMeth) } & 5 \\ \text { 1,1-Dichloroethane (1,1-DCA) } & 5 \\ \text { 1,2-Dichloroethane(1,2-DCA) } & 5 \\ \text { 1,1-Dichloroethylene(1,1-DCE) } & 5 \\ \text { 1,2-Dichloropropane } & 5 \\ \text { Ethyl benzene } & 5 \\ \text { Ethyl methacrylate } & 5 \\ \text { 2-Hexanone } & 10\end{array}$

6 NYCRR Appendix 33 Metals

$\begin{array}{lc}\text { *Aluminum } & 200 \\ \text { Antimony } & 10 \\ \text { Arsenic } & 10 \\ \text { Barium } & 200 \\ \text { Beryllium } & 1 \\ \text { Cadmium } & 5 \\ \text { Chromium } & 10 \\ \text { Cobalt } & 50 \\ \text { Copper } & 25 \\ \text { *Iron } & 100\end{array}$

COMPOUND PQL

$(\mu g / L)$

6 NYCRR Appendix 33 Volatiles

Isobutyl alcohol $\quad 100$

Methacrylonitrile 5

Methyl ethyl ketone 10

Methyl iodide 5

Methyl methacrylate 5

4-Methyl-2-pentanone 10

Methylene bromide $\quad 10$

Methylene chloride 5

Pentachloroethane 5

Propionitrile $\quad 50$

Styrene 5

1,1,1,2-Tetrachloroethane 5

1,1,2,2-Tetrachloroethane 5

Tetrachloroethylene 5

Toluene 5

1,1,1-Trichloroethane (1,1,1-TCA) 5

1,1,2-Trichloroethane 5

1,2,3-Trichloropropane 5

Vinyl acetate 10

Vinyl chloride $\quad 10$

Xylene (total) 5

cis-1,3-Dichloropropene 5

trans-1,2-Dichloroethylene (1,2-DCE[trans]) 5

trans-1,3-Dichloropropene 5

trans-1,4-Dichloro-2-butene 5

Trichloroethylene (TCE) 5

Trichlorofluoromethane 5

6 NYCRR Appendix 33 Metals

$\begin{array}{lc}\text { Lead } & 3 \\ \text { *Manganese } & 15 \\ \text { Mercury } & 0.2 \\ \text { Nickel } & 40 \\ \text { Selenium } & 5 \\ \text { Silver } & 10 \\ \text { Thallium } & 10 \\ \text { Tin } & 3,000 \\ \text { Vanadium } & 50 \\ \text { Zinc } & 20\end{array}$

Note: Specific quantitation limits are highly matrix dependent and may not always be achievable.

* Not a 6 NYCRR Appendix 33 parameter; sampled for the north plateau early warning program.

$$
E-23
$$

WVDP Annual Site Environmental Report

Calendar Year 2004 


\section{Table E-12 (continued) Practical Quantitation Limits (PQLs) \\ PQL \\ $(\mu g / L)$ \\ COMPOUND PQL \\ $(\mu g / L)$}

COMPOUND

NYCRR Appendix 33 Semivolatiles

Acenaphthene 10

Acenaphthylene 10

Acetophenone 10

2-Acetylaminofluorene 10

4-Aminobiphenyl 10

Aniline 10

Anthracene 10

Aramite 10

Benzo[a]anthracene 10

Benzo[a]pyrene 10

Benzo[b]fluoranthene 10

Benzo[ghi]perylene 10

Benzo[k]fluoranthene 10

Benzyl alcohol 10

Bis(2-chlorethyl)ether $\quad 10$

Bis(2-chloroethoxy)methane $\quad 10$

Bis(2-chloroisopropyl)ether $\quad 10$

Bis(2-ethylhexyl)phthalate $\quad 10$

4-Bromophenyl phenyl ether $\quad 10$

Butyl benzyl phthalate $\quad 10$

Chlorobenzilate 10

2-Chloronaphthalene 10

2-Chlorophenol 10

4-Chlorophenyl phenyl ether $\quad 10$

Chrysene 10

Di-n-butyl phthalate $\quad 10$

Di-n-octyl phthalate $\quad 10$

Diallate 10

Dibenz[a,h]anthracene $\quad 10$

Dibenzofuran 10

3,3-Dichlorobenzidine 10

2,4-Dichlorophenol 10

2,6-Dichlorophenol 10

Diethyl phthalate $\quad 10$

Dimethoate 10

7, 12-Dimethylbenz[a]anthracene $\quad 10$

3,3-Dimethylbenzidine 21

2,4-Dimethylphenol 10

Dimethyl phthalate $\quad 10$

4,6-Dinitro-o-cresol 25

2,4-Dinitrophenol 25
NYCRR Appendix 33 Semivolatiles

2,4-Dinitrotoluene 10

2,6-Dinitrotoluene 10

Diphenylamine $\quad 10$

Ethyl methanesulfonate $\quad 10$

Famphur 10

Fluoranthene 10

Fluorene 10

Hexachlorobenzene $\quad 10$

Hexachlorobutadiene 10

Hexachlorocyclopentadiene $\quad 25$

Hexachloroethane 10

Hexachlorophene 330

Hexachloropropene 10

Indeno(1,2,3,-cd)pyrene $\quad 10$

Isodrin 10

Isophorone 10

Isosafrole 10

Kepone $\quad 50$

Methapyrilene 40

Methyl methanesulfonate $\quad 10$

3-Methylcholanthrene 10

2-Methylnaphthalene $\quad 10$

1,4-Naphthoquinone 10

1-Naphthylamine $\quad 10$

2-Naphthylamine 10

Nitrobenzene 10

5-Nitro-o-toluidine 10

4-Nitroquinoline 1-oxide 40

N-Nitrosodi-n-butylamine $\quad 10$

N-Nitrosodiethylamine 10

N-Nitrosodimethylamine 10

N-Nitrosodipropylamine 10

N-Nitrosodiphenylamine $\quad 10$

N-Nitrosomethylethylamine $\quad 10$

N-Nitrosomorpholine 10

N-Nitrosopiperidine 10

N-Nitrosopyrrolidine 10

Naphthalene 10

0,0,0-Triethyl phosphorothioate $\quad 10$

0,0-Diethyl 0-2-pyrazinyl- phosphorothioate 10

Note: Specific quantitation limits are highly matrix dependent and may not always be achievable.

$E-24$

WVDP Annual Site Environmental Report

Calendar Year 2004 


\section{Table E-12 (concluded) \\ Practical Quantitation Limits (PQLs) \\ PQL \\ $(\mu g / L)$ \\ COMPOUND PQL \\ $(\mu g / L)$}

COMPOUND

NYCRR Appendix 33 Semivolatiles

p-(Dimethylamino)azobenzene $\quad 10$

p-Chloroaniline 10

p-Chloro-m-cresol 10

p-Cresol 10

p-Dichlorobenzene 10

p-Nitroaniline 25

p-Nitrophenol 25

p-Phenylenediamine $\quad 100$

Parathion 10

Pentachlorobenzene 10

Pentachloronitrobenzene $\quad 10$

Pentachlorophenol 25

Phenacetin 10

Phenanthrene 10

Phenol 10

Pronamide 10

Pyrene 10

Safrole 10

1,2,4,5-Tetrachlorobenzene $\quad 10$

Other Organic Compounds

1,2-Dichloroethelyne (Total)

Tributyl phosphate

NYCRR Appendix 33 Semivolatiles

2,3,4,6-Tetrachlorophenol $\quad 10$

Tetraethyl dithiopyrophosphate $\quad 10$

1,2,4-Trichlorobenzene $\quad 10$

2,4,5-Trichlorophenol 25

2,4,6-Trichlorophenol 10

alpha,alpha-Dimethylphenethylamine $\quad 50$

m-Cresol 10

m-Dichlorobenzene 10

m-Dinitrobenzene 10

m-Nitroaniline 25

o-Cresol 10

o-Dichlorobenzene 10

o-Nitroaniline 25

o-Nitrophenol 10

o-Toluidine 10

sym-Trinitrobenzene 10

2-Picoline 10

Pyridine 10

1,4-Dioxane 10

Note: Specific quantitation limits are highly matrix dependent and may not always be achievable.

$E-25$ 
This page intentionally left blank

E- 26 


\section{Appendix $F$ Summary of Biological Data}

$$
F-1
$$


The following tables contain a bolding convention devised to help the reader, when viewing the data, to quickly see the range of detectable measurements within a data series. A data series is a set of chemical or radionuclide measurements (e.g., gross alpha, gross beta, tritium) from a single location or from similar locations. Note that some tables contain data that should not be technically evaluated under this convention.

\section{Key to bolding convention:}

Results for each constituent constitute a single data series. If a radiological result is larger than the uncertainty term, the measurement is considered positive. Otherwise, a result is considered nondetectable.

If all results in a data series are positive, the lowest and highest values are bolded.

If a data series contains some positive results, the highest value is bolded.

If all values in a data series are nondetectable, no values are bolded.

$$
F-2
$$




\section{Table F-1 \\ 2004 Radioactivity Concentrations $(\mu \mathrm{Ci} / \mathrm{mL})$ in Milk}

\begin{tabular}{|c|c|c|c|c|c|}
\hline Location & H-3 & K-40 & Sr-90 & I-129 & Cs-137 \\
\hline \multicolumn{6}{|l|}{$\begin{array}{l}\text { BFMCTLS } \\
\text { (Control) }\end{array}$} \\
\hline 1st Quarter & $0.98 \pm 1.10 \mathrm{E}-07$ & $1.45 \pm 0.15 \mathrm{E}-06$ & $9.43 \pm 3.87 \mathrm{E}-10$ & $-1.31 \pm 5.29 \mathrm{E}-10$ & $0.56 \pm 2.60 \mathrm{E}-09$ \\
\hline 2nd Quarter & $0.60 \pm 1.10 \mathrm{E}-07$ & $1.44 \pm 0.15 \mathrm{E}-06$ & $3.94 \pm 5.41 \mathrm{E}-10$ & $-1.34 \pm 3.44 \mathrm{E}-10$ & $1.43 \pm 2.07 \mathrm{E}-09$ \\
\hline 3rd Quarter & $0.97 \pm 1.21 \mathrm{E}-07$ & $1.37 \pm 0.17 \mathrm{E}-06$ & $-1.25 \pm 5.72 \mathrm{E}-10$ & $4.66 \pm 3.24 \mathrm{E}-10$ & $-0.34 \pm 2.91 \mathrm{E}-09$ \\
\hline 4th Quarter & $0.00 \pm 1.21 \mathrm{E}-07$ & $1.23 \pm 0.10 \mathrm{E}-06$ & $1.51 \pm 0.67 E-09$ & $-0.44 \pm 3.93 \mathrm{E}-10$ & $1.31 \pm 1.43 \mathrm{E}-09$ \\
\hline \multicolumn{6}{|l|}{$\begin{array}{l}\text { BFMREED } \\
\text { (NNW Farm) }\end{array}$} \\
\hline 1st Quarter & $0.65 \pm 1.07 \mathrm{E}-07$ & $1.42 \pm 0.16 \mathrm{E}-06$ & $6.98 \pm 3.52 \mathrm{E}-10$ & $-0.60 \pm 4.86 \mathrm{E}-10$ & $-1.30 \pm 2.17 \mathrm{E}-09$ \\
\hline 2nd Quarter & $0.59 \pm 1.08 \mathrm{E}-07$ & $1.55 \pm 0.15 \mathrm{E}-06$ & $1.09 \pm 0.69 \mathrm{E}-09$ & $-1.60 \pm 2.81 \mathrm{E}-10$ & $0.89 \pm 2.33 \mathrm{E}-09$ \\
\hline 3rd Quarter & $1.09 \pm 1.19 \mathrm{E}-07$ & $1.44 \pm 0.18 \mathrm{E}-06$ & $4.38 \pm 5.12 \mathrm{E}-10$ & $-0.70 \pm 4.08 \mathrm{E}-10$ & $2.40 \pm 3.18 \mathrm{E}-09$ \\
\hline 4th Quarter & $-1.12 \pm 1.25 \mathrm{E}-07$ & $1.30 \pm 0.08 E-06$ & $-2.23 \pm 0.64 \mathrm{E}-09$ & $0.56 \pm 3.50 \mathrm{E}-10$ & $2.27 \pm 2.23 \mathrm{E}-09$ \\
\hline \multicolumn{6}{|l|}{$\begin{array}{l}\text { BFMSCHT } \\
\text { (S Farm) }\end{array}$} \\
\hline Annual & $-0.02 \pm 1.08 \mathrm{E}-07$ & $1.20 \pm 0.14 \mathrm{E}-06$ & $1.41 \pm 0.82 \mathrm{E}-09$ & $1.40 \pm 2.97 \mathrm{E}-10$ & $-2.75 \pm 3.18 \mathrm{E}-09$ \\
\hline \multicolumn{6}{|l|}{$\begin{array}{l}\text { BFMWIDR } \\
\text { (SE Farm) }\end{array}$} \\
\hline Annual & $0.71 \pm 1.03 \mathrm{E}-07$ & $1.16 \pm 0.09 \mathrm{E}-06$ & $9.52 \pm 4.73 \mathrm{E}-10$ & $-2.06 \pm 4.43 \mathrm{E}-10$ & $0.54 \pm 1.23 \mathrm{E}-09$ \\
\hline
\end{tabular}

Note: Bolding convention applied to these data. See page F-2 $\mathbf{6 0}$

$$
F-3
$$




\section{Table $\mathrm{F}-2$ \\ 2004 Radioactivity Concentrations $(\mu \mathrm{Ci} / \mathrm{g}-\mathrm{dry})$ in Meat}

2004 Radioactivity Concentrations in Beef

\begin{tabular}{|c|c|c|c|c|c|}
\hline Location & $\%$ Moisture & $\begin{array}{c}\mathbf{H}-\mathbf{3} \\
(\mu \mathrm{Ci} / \mathrm{mL})\end{array}$ & K-40 & Sr-90 & Cs-137 \\
\hline $\begin{array}{l}\text { Beef Flesh Backgr } \\
\text { (BFBCTRL 06/04) }\end{array}$ & 75.0 & $-0.82 \pm 1.21 \mathrm{E}-07$ & $1.39 \pm 0.12 \mathrm{E}-05$ & $3.23 \pm 2.21 \mathrm{E}-09$ & $1.15 \pm 1.55 \mathrm{E}-08$ \\
\hline $\begin{array}{l}\text { Beef Flesh Backgr } \\
\text { (BFBCTRL 11/04) }\end{array}$ & 76.4 & $-0.17 \pm 1.15 \mathrm{E}-07$ & $1.15 \pm 0.07 \mathrm{E}-05$ & $-0.10 \pm 1.38 \mathrm{E}-09$ & $2.08 \pm 1.89 \mathrm{E}-08$ \\
\hline $\begin{array}{l}\text { Beef Flesh Near-S } \\
\text { (BFBNEAR 03/04) }\end{array}$ & 69.8 & $-1.24 \pm 1.17 \mathrm{E}-07$ & $7.63 \pm 0.81 \mathrm{E}-06$ & $2.82 \pm 2.83 \mathrm{E}-09$ & $1.58 \pm 1.57 \mathrm{E}-08$ \\
\hline $\begin{array}{l}\text { Beef Flesh Near-S } \\
\text { (BFBNEAR 09/04) }\end{array}$ & 72.5 & $0.00 \pm 1.16 \mathrm{E}-07$ & $1.07 \pm 0.07 \mathrm{E}-05$ & $-1.23 \pm 1.44 \mathrm{E}-09$ & $2.09 \pm 1.68 \mathrm{E}-08$ \\
\hline
\end{tabular}

$\underline{2004}$ Radioactivity Concentrations in Venison

Location

\% Moisture

H-3

K-40

Sr-90

Cs-137

Deer Flesh Background

$(\mu \mathrm{Ci} / \mathrm{mL})$

73.8

$-0.64 \pm 1.12 \mathrm{E}-07$

$1.16 \pm 0.10 \mathrm{E}-05$

$-3.40 \pm 1.74 \mathrm{E}-09$

$6.08 \pm 2.73 \mathrm{E}-08$

Deer Flesh Background

(BFDCTRL 12/04)

73.3

$-0.58 \pm 1.14 \mathrm{E}-07$

1.14+0.10E-05 $-1.01 \pm 2.32 \mathrm{E}-09$

$0.00 \pm 2.30 \mathrm{E}-08$

Deer Flesh Background

(BFDCTRL 12/04)

73.3

$-0.07 \pm 1.15 \mathrm{E}-07$

$1.34 \pm 0.14 E-05$

$-1.97 \pm 1.79 \mathrm{E}-09$

6.15 $\pm 3.99 E-08$

Deer Flesh Near-Site

(BFDNEAR 10/04)

74.7

$0.52 \pm 1.17 \mathrm{E}-07$

$1.13 \pm 0.11 E-05$

$1.78 \pm 1.86 \mathrm{E}-09$

$3.68 \pm 0.48 E-07$

Deer Flesh Near-Site

(BFDNEAR 10/04)

75.9

$-0.18 \pm 1.03 \mathrm{E}-07$

$1.43 \pm 0.11 E-05$

$1.85 \pm 2.42 \mathrm{E}-09$

$6.13 \pm 2.47 \mathrm{E}-08$

Deer Flesh Near-Site

(BFDNEAR 11/04)

1.59+1.57E-08

Note: Bolding convention applied to venison data. See page F-2 $\mathbf{6 0}$

WVDP Annual Site Environmental Report

$$
F-4
$$

WVDP Annual Site Environmental Report 


\section{Table F-3}

\section{Radioactivity Concentrations $(\mu \mathrm{Ci} / \mathrm{g}$ - dry) in Food Crops}

Location

$\%$ Moisture

H-3

K-40

Co-60

Sr-90

Cs-137

$(\mu \mathrm{Ci} / \mathrm{mL})$

CORN

Background

(BFVCTRC)

80.7

$1.64 \pm 1.03 \mathrm{E}-07$

$1.37 \pm 0.11 \mathrm{E}-05$

$0.73 \pm 1.49 \mathrm{E}-08$

$0.25 \pm 2.64 \mathrm{E}-09$

$-0.82 \pm 1.27 \mathrm{E}-08$

Near-Site

(BFVNEAC)

80.6

$1.45 \pm 0.88 \mathrm{E}-07$

$2.08 \pm 0.27 \mathrm{E}-05$

$-0.94 \pm 7.52 \mathrm{E}-08$

$-1.96 \pm 1.78 \mathrm{E}-09$

$1.72 \pm 8.40 \mathrm{E}-08$

\section{BEANS}

\section{Background}

(BFVCTRB)

91.9

$1.74 \pm 1.02 \mathrm{E}-07 \quad 3.14 \pm 0.31 \mathrm{E}-05$

$4.62 \pm 5.65 \mathrm{E}-08$

$1.13 \pm 0.10 \mathrm{E}-07$

$0.03 \pm 4.51 \mathrm{E}-08$

Near-Site

(BFVNEAB)

73.8

$1.32 \pm 1.01 \mathrm{E}-07$

$1.38 \pm 0.13 \mathrm{E}-05$

$1.47 \pm 1.76 \mathrm{E}-08$

$7.86 \pm 0.75 \mathrm{E}-08$

$2.44 \pm 2.80 \mathrm{E}-08$

\section{APPLES}

Background

(BFVCTRA)

86.0

$1.41 \pm 1.22 \mathrm{E}-07 \quad 7.65 \pm 0.92 \mathrm{E}-06$

$1.62 \pm 5.59 \mathrm{E}-08$

$0.60 \pm 1.47 \mathrm{E}-09$

$-0.32 \pm 1.79 \mathrm{E}-08$

Near-Site

(BFVNEAAF)

81.4

$2.18 \pm 1.43 \mathrm{E}-07 \quad 9.08 \pm 0.90 \mathrm{E}-06$

$-0.52 \pm 1.46 \mathrm{E}-0$

$-1.93 \pm 1.58 \mathrm{E}-09 \quad-0.51 \pm 1.29 \mathrm{E}-08$

Note: Bolding convention not applicable to these data.

$$
\text { F - } 5
$$




\title{
Table F-4 \\ 2004 Radioactivity Concentrations ( $\mu$ Ci/g - dry) in Fish Flesh From Cattaraugus Creek
}

\author{
Cattaraugus Creek above the Springville Dam (BFFCATC)
}

\begin{tabular}{lccr} 
& & \multicolumn{2}{c}{ Annual 2004 } \\
Species & \% Moisture & Sr-90 & Cs-137 \\
Hog-nosed Sucker & 75.4 & $4.22 \pm 0.78 \mathrm{E}-08$ & $3.25 \pm 3.72 \mathrm{E}-08$ \\
Hog-nosed Sucker & 72.0 & $6.36 \pm 0.61 \mathrm{E}-08$ & $3.79 \pm 6.41 \mathrm{E}-08$ \\
Hog-nosed Sucker & 74.8 & $\mathbf{6 . 8 3} \pm \mathbf{0 . 7 2 E}-\mathbf{0 8}$ & $2.16 \pm 4.03 \mathrm{E}-08$ \\
Hog-nosed Sucker & 75.1 & $3.83 \pm 0.57 \mathrm{E}-08$ & $1.06 \pm 4.18 \mathrm{E}-08$ \\
Hog-nosed Sucker & 74.7 & $5.26 \pm 0.86 \mathrm{E}-08$ & $1.34 \pm 4.34 \mathrm{E}-08$ \\
Bullhead & 79.1 & $\mathbf{1 . 0 2} \pm \mathbf{0 . 7 7 E}-\mathbf{0 8}$ & $\mathbf{6 . 3 1} \pm \mathbf{5 . 0 0 E}-\mathbf{0 8}$ \\
Hog-nosed Sucker & 74.6 & $4.90 \pm 0.47 \mathrm{E}-08$ & $-1.38 \pm 4.59 \mathrm{E}-08$ \\
Hog-nosed Sucker & 76.5 & $2.33 \pm 0.54 \mathrm{E}-08$ & $-1.12 \pm 4.52 \mathrm{E}-08$ \\
Hog-nosed Sucker & 73.3 & $2.04 \pm 0.21 \mathrm{E}-08$ & $2.03 \pm 2.59 \mathrm{E}-08$ \\
Hog-nosed Sucker & 76.8 & $2.51 \pm 0.24 \mathrm{E}-08$ & $0.00 \pm 8.45 \mathrm{E}-08$ \\
& & & \\
Average \% Moisture & 75.2 & & $<4.53 \mathrm{E}-08$ \\
& & & $6.31 \mathrm{E}-08$ \\
Median & & & \\
Maximum & & $6.83 \mathrm{E}-08$ & \\
Minimum & & $1.02 \mathrm{E}-08$ &
\end{tabular}

\section{Cattaraugus Creek below the Springville Dam (BFFCATD)}

\section{Annual 2004}

\section{Species}

Steelhead Trout

Steelhead Trout

Steelhead Trout

Steelhead Trout

Steelhead Trout

Steelhead Trout

Steelhead Trout

Steelhead Trout

Steelhead Trout

Chinook Salmon

\% Moistu
72.2
75.1
70.7
71.6
70.7
73.9
72.5
72.6
70.5
78.3

$$
\text { Sr-90 }
$$

Cs-137

Average \% Moisture

$2.74 \pm 2.51 \mathrm{E}-09$
$5.20 \pm 2.38 \mathrm{E}-09$
$1.72 \pm 2.08 \mathrm{E}-09$
$\mathbf{6 . 1 6} \pm \mathbf{2 . 4 6 E - 0 9}$
$-1.45 \pm 1.32 \mathrm{E}-09$
$1.47 \pm 1.48 \mathrm{E}-09$
$1.75 \pm 1.37 \mathrm{E}-09$
$2.15 \pm 2.90 \mathrm{E}-09$
$-0.59 \pm 2.40 \mathrm{E}-09$
$-0.76 \pm 2.02 \mathrm{E}-09$

$1.55 \pm 2.83 \mathrm{E}-08$

$1.39 \pm 2.16 \mathrm{E}-08$

$0.00 \pm 3.60 \mathrm{E}-08$

$0.29 \pm 2.25 \mathrm{E}-08$

$1.68 \pm 2.82 \mathrm{E}-08$

$0.10 \pm 1.04 \mathrm{E}-07$

$3.22 \pm 4.51 \mathrm{E}-08$

3.43 $\pm 2.46 \mathrm{E}-08$

$0.58 \pm 2.81 \mathrm{E}-08$

$0.00 \pm 2.43 \mathrm{E}-08$

72.8

Median

$\begin{array}{rr}<2.24 \mathrm{E}-09 & <2.82 \mathrm{E}-08 \\ 6.16 \mathrm{E}-09 & 3.43 \mathrm{E}-08 \\ <1.32 \mathrm{E}-09 & <2.16 \mathrm{E}-08\end{array}$

Minimum

Note: Bolding convention applied to these data. See page F-2 $\mathbf{c 0}$

$$
F-6
$$




\section{Table F-4 (concluded) \\ 2004 Radioactivity Concentrations ( $\mu$ Ci/g - dry) in Fish Flesh \\ From Cattaraugus Creek}

\section{Cattaraugus Creek Background (BFFCTRL)}

\begin{tabular}{|c|c|c|c|}
\hline \multirow[b]{2}{*}{ Species } & \multirow[b]{2}{*}{$\%$ Moisture } & \multicolumn{2}{|c|}{ Annual 2004} \\
\hline & & Sr-90 & Cs-137 \\
\hline White Sucker & 77.1 & $6.83 \pm 4.45 \mathrm{E}-09$ & $1.58 \pm 5.61 \mathrm{E}-08$ \\
\hline White Sucker & 76.4 & $2.15 \pm 1.86 \mathrm{E}-09$ & $0.00 \pm 1.46 \mathrm{E}-07$ \\
\hline White Sucker & 77.0 & $7.43 \pm 4.25 \mathrm{E}-09$ & $-0.60 \pm 4.10 \mathrm{E}-08$ \\
\hline White Sucker & 75.4 & $2.55 \pm 2.03 \mathrm{E}-09$ & $0.41 \pm 3.34 \mathrm{E}-08$ \\
\hline White Sucker & 78.2 & $8.27 \pm 3.53 E-09$ & $-0.96 \pm 4.42 \mathrm{E}-08$ \\
\hline Hog-nosed Sucker & 74.5 & 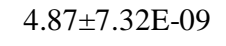 & $-2.83 \pm 5.38 \mathrm{E}-08$ \\
\hline Brown Trout & 73.1 & $3.12 \pm 3.90 \mathrm{E}-09$ & $5.57 \pm 9.57 \mathrm{E}-08$ \\
\hline Brown Trout & 71.2 & $0.86 \pm 3.82 \mathrm{E}-09$ & $3.80 \pm 4.76 \mathrm{E}-08$ \\
\hline Brown Trout & 75.1 & $-0.22 \pm 4.41 \mathrm{E}-09$ & $1.01 \pm 4.64 \mathrm{E}-08$ \\
\hline Brown Trout & 72.9 & $1.92 \pm 4.31 \mathrm{E}-09$ & $1.55 \pm 4.11 \mathrm{E}-08$ \\
\hline Average \% Moisture & 75.1 & & \\
\hline Median & & 4.36E-09 & $<4.70 \mathrm{E}-08$ \\
\hline Maximum & & 8.27E-09 & $<1.46 \mathrm{E}-07$ \\
\hline Minimum & & $2.15 \mathrm{E}-09$ & $<3.34 \mathrm{E}-08$ \\
\hline
\end{tabular}

Note: Bolding convention applied to these data. See page F-2 $\mathbf{}$

$F-7$ 
This page intentionally left blank

$$
F-8
$$




\section{Appendix G-1 \\ Summary of Soil and Aquatic Sediment \\ Guidelines and Standards}

$G-1$ 
This page intentionally left blank

$G-2$ 


\section{Table G-1A}

\section{Eastern U.S.A. Background Concentrations for Elements in Soils ${ }^{a}$}

\begin{tabular}{|l|c|c|}
\hline \multicolumn{1}{|c|}{ Analyte } & Units & $\begin{array}{c}\text { Eastern U.S.A Background } \\
\text { Concentrations for Soil }\end{array}$ \\
\hline Aluminum & $\mathrm{mg} / \mathrm{kg}(\mathrm{ppm})$ & 33,000 \\
\hline Antimony & $\mathrm{mg} / \mathrm{kg}(\mathrm{ppm})$ & -- \\
\hline Arsenic & $\mathrm{mg} / \mathrm{kg}(\mathrm{ppm})$ & $3-12^{\mathrm{b}}$ \\
\hline Barium & $\mathrm{mg} / \mathrm{kg}(\mathrm{ppm})$ & $15-600$ \\
\hline Beryllium & $\mathrm{mg} / \mathrm{kg}(\mathrm{ppm})$ & $0-1.75$ \\
\hline Cadmium & $\mathrm{mg} / \mathrm{kg}(\mathrm{ppm})$ & $0.1-1$ \\
\hline Calcium & $\mathrm{mg} / \mathrm{kg}(\mathrm{ppm})$ & $130-35,000$ \\
\hline Chromium & $\mathrm{mg} / \mathrm{kg}(\mathrm{ppm})$ & $1.5-40^{\mathrm{b}}$ \\
\hline Cobalt & $\mathrm{mg} / \mathrm{kg}(\mathrm{ppm})$ & $2.5-60^{\mathrm{b}}$ \\
\hline Copper & $\mathrm{mg} / \mathrm{kg}(\mathrm{ppm})$ & $1-50$ \\
\hline Iron & $\mathrm{mg} / \mathrm{kg}(\mathrm{ppm})$ & $2,000-550,000$ \\
\hline Lead & $\mathrm{mg} / \mathrm{kg}(\mathrm{ppm})$ & $4-61^{\mathrm{c}}$ \\
\hline Magnesium & $\mathrm{mg} / \mathrm{kg}(\mathrm{ppm})$ & $100-5,000$ \\
\hline Manganese & $\mathrm{mg} / \mathrm{kg}(\mathrm{ppm})$ & $50-5,000$ \\
\hline Mercury & $\mathrm{mg} / \mathrm{kg}(\mathrm{ppm})$ & $0.001-0.2$ \\
\hline Nickel & $\mathrm{mg} / \mathrm{kg}(\mathrm{ppm})$ & $0.5-25$ \\
\hline Potassium & $\mathrm{mg} / \mathrm{kg}(\mathrm{ppm})$ & $8,500-43,000^{\mathrm{b}}$ \\
\hline Selenium & $\mathrm{mg} / \mathrm{kg}(\mathrm{ppm})$ & $0.1-3.9$ \\
\hline Silver & $\mathrm{mg} / \mathrm{kg}(\mathrm{ppm})$ & -- \\
\hline Sodium & $\mathrm{mg} / \mathrm{kg}(\mathrm{ppm})$ & $6,000-8,000$ \\
\hline Thallium & $\mathrm{mg} / \mathrm{kg}(\mathrm{ppm})$ & -- \\
\hline Vanadium & $\mathrm{mg} / \mathrm{kg}(\mathrm{ppm})$ & $1-300$ \\
\hline Zinc & $\mathrm{mg} / \mathrm{kg}(\mathrm{ppm})$ & $9-50$ \\
\hline
\end{tabular}

-- No reference level available for these analytes

${ }^{a}$ Source: New York State Department of Environmental Conservation "Technical and Administrative Guidance Memorandum (TAGM) \#4046"

${ }^{b}$ New York State background

${ }^{c}$ Background levels for lead vary widely. Average levels in undeveloped, rural areas may range from 4-61 ppm. Average background levels in metropolitan or suburban areas or near highways are much higher and typically range from 200-500 ppm.

$G-3$ 


\section{Table G-1B}

\section{Screening Concentrations for Elements in Contaminated Sediments ${ }^{a}$}

\begin{tabular}{|c|c|c|c|}
\hline Analyte & Units & Lowest Effect Level $^{\text {b }}$ & Severe Effect Level ${ }^{c}$ \\
\hline Aluminum & $\mathrm{mg} / \mathrm{kg}(\mathrm{ppm})$ & -- & -- \\
\hline Antimony & $\mathrm{mg} / \mathrm{kg}(\mathrm{ppm})$ & $2.0(\mathrm{~L})$ & $25.0(\mathrm{~L})$ \\
\hline Arsenic & $\mathrm{mg} / \mathrm{kg}(\mathrm{ppm})$ & $6.0(\mathrm{P})$ & $33.0(\mathrm{P})$ \\
\hline Barium & $\mathrm{mg} / \mathrm{kg}(\mathrm{ppm})$ & -- & -- \\
\hline Beryllium & $\mathrm{mg} / \mathrm{kg}(\mathrm{ppm})$ & -- & -- \\
\hline Cadmium & $\mathrm{mg} / \mathrm{kg}(\mathrm{ppm})$ & $0.6(\mathrm{P})$ & $9.0(\mathrm{~L})$ \\
\hline Calcium & $\mathrm{mg} / \mathrm{kg}(\mathrm{ppm})$ & -- & -- \\
\hline Chromium & $\mathrm{mg} / \mathrm{kg}(\mathrm{ppm})$ & $26.0(\mathrm{P})$ & $110.0(\mathrm{P})$ \\
\hline Cobalt & $\mathrm{mg} / \mathrm{kg}(\mathrm{ppm})$ & -- & -- \\
\hline Copper & $\mathrm{mg} / \mathrm{kg}(\mathrm{ppm})$ & $16.0(\mathrm{P})$ & $110.0(\mathrm{P})$ \\
\hline Iron & $\%$ & $2.0(\mathrm{P})$ & $4.0(\mathrm{P})$ \\
\hline Lead & $\mathrm{mg} / \mathrm{kg}(\mathrm{ppm})$ & $31.0(\mathrm{P})$ & $110.0(\mathrm{~L})$ \\
\hline Magnesium & $\mathrm{mg} / \mathrm{kg}(\mathrm{ppm})$ & -- & -- \\
\hline Manganese & $\mathrm{mg} / \mathrm{kg}(\mathrm{ppm})$ & $460.0(\mathrm{P})$ & $1,100.0(\mathrm{~L})$ \\
\hline Mercury & $\mathrm{mg} / \mathrm{kg}(\mathrm{ppm})$ & $0.15(\mathrm{~L})$ & $1.3(\mathrm{~L})$ \\
\hline Nickel & $\mathrm{mg} / \mathrm{kg}(\mathrm{ppm})$ & $16.0(\mathrm{P})$ & $50.0(\mathrm{~L})$ \\
\hline Potassium & $\mathrm{mg} / \mathrm{kg}(\mathrm{ppm})$ & -- & -- \\
\hline Selenium & $\mathrm{mg} / \mathrm{kg}(\mathrm{ppm})$ & -- & -- \\
\hline Silver & $\mathrm{mg} / \mathrm{kg}(\mathrm{ppm})$ & $1.0(\mathrm{~L})$ & $2.2(\mathrm{~L})$ \\
\hline Sodium & $\mathrm{mg} / \mathrm{kg}(\mathrm{ppm})$ & -- & -- \\
\hline Thallium & $\mathrm{mg} / \mathrm{kg}(\mathrm{ppm})$ & -- & -- \\
\hline Vanadium & $\mathrm{mg} / \mathrm{kg}(\mathrm{ppm})$ & -- & -- \\
\hline Zinc & $\mathrm{mg} / \mathrm{kg}(\mathrm{ppm})$ & $120.0(\mathrm{P} / \mathrm{L})$ & $270.0(\mathrm{~L})$ \\
\hline
\end{tabular}

-- No reference value available for these analytes

${ }^{a}$ Source: New York State Department of Environmental Conservation "Technical Guidance for Screening Contaminated Sediments," January 1999

${ }^{b}$ The Lowest Effect Level for each metal is the lowest of the either the Persaud et al. (1992) Lowest Effect Level or the Long and Morgan (1990) Effect Range-Low

${ }^{c}$ The Severe Effect Level for each metal is the lowest of either the Persaud et al. (1992) Severe Effect Level or the Long and Morgan (1990) Effect Range-Moderate

$L$ - An " $L$ " following a criterion indicates that it was taken from Long and Morgan (1990).

$P$ - A "P" following a criterion indicates that it was taken from Persaud et al. (1992).

\section{Table G-1C}

\section{Elemental Screening Thresholds for In-Water and Riparian Management of Sediment and Dredge Material ${ }^{a}$}

\begin{tabular}{|l|c|c|}
\hline \multicolumn{1}{|c|}{ Analyte } & Units & No Appreciable Contamination Level \\
\hline Arsenic & $\mathrm{mg} / \mathrm{kg}(\mathrm{ppm})$ & 14 \\
\hline Cadmium & $\mathrm{mg} / \mathrm{kg}(\mathrm{ppm})$ & $<1.2$ \\
\hline Copper & $\mathrm{mg} / \mathrm{kg}(\mathrm{ppm})$ & $<33$ \\
\hline Lead & $\mathrm{mg} / \mathrm{kg}(\mathrm{ppm})$ & $<33$ \\
\hline Mercury & $\mathrm{mg} / \mathrm{kg}(\mathrm{ppm})$ & 0.17 \\
\hline
\end{tabular}

${ }^{a}$ Source: Draft New York State Department of Environmental Conservation Technical and Operational Guidance Series (TOGs) \#5.1.9, "In-Water and Riparian Management of Sediment and Dredge Material" 


\section{Appendix G-2}

Soil and Sediment Data 
This page intentionally left blank

$G-6$ 
Table G-2A

\section{Contaminants in On-Site Soils Downstream of the WVDP at Frank's Creek (SNSP006)}

\begin{tabular}{|c|c|c|c|c|c|c|}
\hline \multirow[b]{2}{*}{ Analyte } & \multirow[b]{2}{*}{ Units } & \multirow[b]{2}{*}{$\mathbf{N}$} & \multirow[b]{2}{*}{ SNSP006 } & \multicolumn{3}{|c|}{ Guidance Values } \\
\hline & & & & $\begin{array}{c}\text { Lowest Effect } \\
\text { Level }^{\mathrm{a}}\end{array}$ & $\begin{array}{c}\text { Severe Effect } \\
\text { Level }^{\mathbf{a}}\end{array}$ & $\begin{array}{c}\text { No Appreciable } \\
\text { Contamination } \\
\text { Level }^{b}\end{array}$ \\
\hline Gross Alpha & $\mu \mathrm{Ci} / \mathrm{g}$ & 1 & $7.21 \pm 1.90 \mathrm{E}-06$ & -- & -- & -- \\
\hline Gross Beta & $\mu \mathrm{Ci} / \mathrm{g}$ & 1 & $2.40 \pm 0.28 \mathrm{E}-05$ & -- & -- & -- \\
\hline K-40 & $\mu \mathrm{Ci} / \mathrm{g}$ & 1 & $1.55 \pm 0.13 \mathrm{E}-05$ & -- & -- & -- \\
\hline Co-60 & $\mu \mathrm{Ci} / \mathrm{g}$ & 1 & $0.28 \pm 1.42 \mathrm{E}-08$ & -- & -- & -- \\
\hline Sr-90 & $\mu \mathrm{Ci} / \mathrm{g}$ & 1 & $3.52 \pm 0.29 \mathrm{E}-07$ & -- & -- & -- \\
\hline Cs-137 & $\mu \mathrm{Ci} / \mathrm{g}$ & 1 & $5.22 \pm 0.49 \mathrm{E}-06$ & -- & -- & -- \\
\hline $\mathrm{U}-232$ & $\mu \mathrm{Ci} / \mathrm{g}$ & 1 & $0.92 \pm 4.07 \mathrm{E}-08$ & -- & -- & -- \\
\hline U-233/234 & $\mu \mathrm{Ci} / \mathrm{g}$ & 1 & $5.53 \pm 1.48 \mathrm{E}-07$ & -- & -- & -- \\
\hline U-235/236 & $\mu \mathrm{Ci} / \mathrm{g}$ & 1 & $1.04 \pm 0.64 \mathrm{E}-07$ & -- & -- & -- \\
\hline U-238 & $\mu \mathrm{Ci} / \mathrm{g}$ & 1 & $5.56 \pm 1.46 \mathrm{E}-07$ & -- & -- & -- \\
\hline Total U & $\mu \mathrm{g} / \mathrm{g}$ & 1 & $2.29 \pm 0.03 \mathrm{E}+00$ & -- & -- & -- \\
\hline Pu-238 & $\mu \mathrm{Ci} / \mathrm{g}$ & 1 & $2.94 \pm 1.83 \mathrm{E}-08$ & -- & -- & -- \\
\hline $\mathrm{Pu}-239 / 240$ & $\mu \mathrm{Ci} / \mathrm{g}$ & 1 & $5.64 \pm 7.67 \mathrm{E}-09$ & -- & -- & -- \\
\hline Am-241 & $\mu \mathrm{Ci} / \mathrm{g}$ & 1 & $3.20 \pm 2.94 \mathrm{E}-08$ & -- & -- & -- \\
\hline Aluminum & $\mathrm{mg} / \mathrm{kg}$ & 1 & 4,950 & -- & -- & -- \\
\hline Antimony & $\mathrm{mg} / \mathrm{kg}$ & 1 & $<0.25$ & 2.0 & 25.0 & -- \\
\hline Arsenic & $\mathrm{mg} / \mathrm{kg}$ & 1 & 5.1 & 6.0 & 33.0 & 14 \\
\hline Barium & $\mathrm{mg} / \mathrm{kg}$ & 1 & 52.8 & -- & -- & -- \\
\hline Beryllium & $\mathrm{mg} / \mathrm{kg}$ & 1 & 0.25 & -- & -- & -- \\
\hline Cadmium & $\mathrm{mg} / \mathrm{kg}$ & 1 & 0.08 & 0.6 & 9.0 & $<1.2$ \\
\hline Calcium & $\mathrm{mg} / \mathrm{kg}$ & 1 & 14,200 & -- & -- & -- \\
\hline Chromium & $\mathrm{mg} / \mathrm{kg}$ & 1 & 7.0 & 26.0 & 110.0 & -- \\
\hline Cobalt & $\mathrm{mg} / \mathrm{kg}$ & 1 & 7.6 & -- & -- & -- \\
\hline Copper & $\mathrm{mg} / \mathrm{kg}$ & 1 & 12.0 & 16.0 & 110.0 & $<33$ \\
\hline Iron & $\%$ & 1 & 0.001 & 2.0 & 4.0 & -- \\
\hline Lead & $\mathrm{mg} / \mathrm{kg}$ & 1 & 9.4 & 31.0 & 110.0 & $<33$ \\
\hline Magnesium & $\mathrm{mg} / \mathrm{kg}$ & 1 & 5,425 & -- & -- & -- \\
\hline Manganese & $\mathrm{mg} / \mathrm{kg}$ & 1 & 507 & 460.0 & $1,100.0$ & -- \\
\hline Mercury & $\mathrm{mg} / \mathrm{kg}$ & 1 & $<0.02$ & 0.15 & 1.3 & 0.17 \\
\hline Nickel & $\mathrm{mg} / \mathrm{kg}$ & 1 & 15.0 & 16.0 & 50.0 & -- \\
\hline Potassium & $\mathrm{mg} / \mathrm{kg}$ & 1 & 608 & -- & -- & -- \\
\hline Selenium & $\mathrm{mg} / \mathrm{kg}$ & 1 & $<0.32$ & -- & -- & -- \\
\hline Silver & $\mathrm{mg} / \mathrm{kg}$ & 1 & $<0.06$ & 1.0 & 2.2 & -- \\
\hline Sodium & $\mathrm{mg} / \mathrm{kg}$ & 1 & 57.6 & -- & -- & -- \\
\hline Thallium & $\mathrm{mg} / \mathrm{kg}$ & 1 & $<0.37$ & -- & -- & -- \\
\hline Vanadium & $\mathrm{mg} / \mathrm{kg}$ & 1 & 9 & -- & -- & -- \\
\hline Zinc & $\mathrm{mg} / \mathrm{kg}$ & 1 & 42.6 & 120.0 & 270.0 & -- \\
\hline
\end{tabular}

Note: Effects of radiological soils and sediments are addressed with the evaluation of radiological dose to biota in Chapter 2.

$N$ - Number of samples

-- No reference standard available

a Screening guidelines for chemical constituents obtained from NYSDEC "Technical Guidance for Screening Contaminated Sediments"

${ }^{b}$ NYSDEC: Draft Technical and Operational Guidance Series 5.1.9, "In-Water and Riparian Management of Sediment and Dredge Material, "January 2003.

$$
G-7
$$




\section{Table G-2B}

\section{Contaminants in On-Site Soils From North Swamp (SNSW74A)}

\begin{tabular}{|c|c|c|c|c|}
\hline Analyte & Units & $\mathbf{N}$ & SNSW74A & Reference Value \\
\hline Gross Alpha & $\mu \mathrm{Ci} / \mathrm{g}$ & 1 & $1.26 \pm 0.17 \mathrm{E}-05$ & -- \\
\hline Gross Beta & $\mu \mathrm{Ci} / \mathrm{g}$ & 1 & $1.82 \pm 0.18 \mathrm{E}-05$ & -- \\
\hline K-40 & $\mu \mathrm{Ci} / \mathrm{g}$ & 1 & $1.43 \pm 0.12 \mathrm{E}-05$ & -- \\
\hline Co-60 & $\mu \mathrm{Ci} / \mathrm{g}$ & 1 & $1.18 \pm 1.73 \mathrm{E}-08$ & -- \\
\hline Sr-90 & $\mu \mathrm{Ci} / \mathrm{g}$ & 1 & $1.16 \pm 0.21 \mathrm{E}-07$ & -- \\
\hline Cs-137 & $\mu \mathrm{Ci} / \mathrm{g}$ & 1 & $1.05 \pm 0.12 \mathrm{E}-06$ & -- \\
\hline U-232 & $\mu \mathrm{Ci} / \mathrm{g}$ & 1 & $-0.88 \pm 1.39 \mathrm{E}-08$ & -- \\
\hline U-233/234 & $\mu \mathrm{Ci} / \mathrm{g}$ & 1 & $5.30 \pm 1.35 \mathrm{E}-07$ & -- \\
\hline U-235/236 & $\mu \mathrm{Ci} / \mathrm{g}$ & 1 & $8.91 \pm 5.68 \mathrm{E}-08$ & -- \\
\hline U-238 & $\mu \mathrm{Ci} / \mathrm{g}$ & 1 & $7.86 \pm 1.62 \mathrm{E}-07$ & -- \\
\hline Total U & $\mu \mathrm{g} / \mathrm{g}$ & 1 & $2.59 \pm 0.04 \mathrm{E}+00$ & -- \\
\hline Pu-238 & $\mu \mathrm{Ci} / \mathrm{g}$ & 1 & $-0.01 \pm 1.17 \mathrm{E}-08$ & -- \\
\hline Pu-239/240 & $\mu \mathrm{Ci} / \mathrm{g}$ & 1 & $1.94 \pm 1.38 \mathrm{E}-08$ & -- \\
\hline Am-241 & $\mu \mathrm{Ci} / \mathrm{g}$ & 1 & $2.22 \pm 1.27 \mathrm{E}-08$ & -- \\
\hline Aluminum & $\mathrm{mg} / \mathrm{kg}$ & 1 & 7,250 & 33,000 \\
\hline Antimony & $\mathrm{mg} / \mathrm{kg}$ & 1 & $<0.31$ & -- \\
\hline Arsenic & $\mathrm{mg} / \mathrm{kg}$ & 1 & 10.7 & $3-12^{\mathrm{b}}$ \\
\hline Barium & $\mathrm{mg} / \mathrm{kg}$ & 1 & 69.5 & $15-600$ \\
\hline Beryllium & $\mathrm{mg} / \mathrm{kg}$ & 1 & 0.34 & $0-1.75$ \\
\hline Cadmium & $\mathrm{mg} / \mathrm{kg}$ & 1 & 0.37 & $0.1-1$ \\
\hline Calcium & $\mathrm{mg} / \mathrm{kg}$ & 1 & 45,300 & $130-35,000$ \\
\hline Chromium & $\mathrm{mg} / \mathrm{kg}$ & 1 & 14.7 & $1.5-40^{\mathrm{b}}$ \\
\hline Cobalt & $\mathrm{mg} / \mathrm{kg}$ & 1 & 7.2 & $2.5-60^{b}$ \\
\hline Copper & $\mathrm{mg} / \mathrm{kg}$ & 1 & 29.1 & $1-50$ \\
\hline Iron & $\mathrm{mg} / \mathrm{kg}$ & 1 & 22,000 & $2,000-550,000$ \\
\hline Lead & $\mathrm{mg} / \mathrm{kg}$ & 1 & 19.6 & $4-61^{\mathrm{c}}$ \\
\hline Magnesium & $\mathrm{mg} / \mathrm{kg}$ & 1 & 15,500 & $100-5,000$ \\
\hline Manganese & $\mathrm{mg} / \mathrm{kg}$ & 1 & 917 & $50-5,000$ \\
\hline Mercury & $\mathrm{mg} / \mathrm{kg}$ & 1 & $<0.02$ & $0.001-0.2$ \\
\hline Nickel & $\mathrm{mg} / \mathrm{kg}$ & 1 & 21.6 & $0.5-25$ \\
\hline Potassium & $\mathrm{mg} / \mathrm{kg}$ & 1 & 916 & $8,500-43,000^{b}$ \\
\hline Selenium & $\mathrm{mg} / \mathrm{kg}$ & 1 & $<0.39$ & $0.1-3.9$ \\
\hline Silver & $\mathrm{mg} / \mathrm{kg}$ & 1 & $<0.07$ & -- \\
\hline Sodium & $\mathrm{mg} / \mathrm{kg}$ & 1 & 184.0 & $6,000-8,000$ \\
\hline Thallium & $\mathrm{mg} / \mathrm{kg}$ & 1 & $<0.46$ & -- \\
\hline Vanadium & $\mathrm{mg} / \mathrm{kg}$ & 1 & 13.7 & $1-300$ \\
\hline Zinc & $\mathrm{mg} / \mathrm{kg}$ & 1 & 150.0 & $9-50$ \\
\hline
\end{tabular}

Note: Effects of radiological soils and sediments are addressed with the evaluation of radiological dose to biota in Chapter 2.

$N$ - Number of samples

-- No reference standard available for these analytes

${ }^{a}$ NYSDEC: Technical and Administrative Guidance Memorandum (TAGM) \#4046.

${ }^{b}$ New York State background

${ }^{c}$ Background levels vary widely. Average levels in undeveloped rural areas may range from 4-61 ppm (reported here). Average background levels in metropolitain or suburban areas, or near highways are much higher and typically range from 200-500 ppm. 
Table G-2C

2004 Contaminants in On-Site Soils From Northeast Swamp (SNSWAMP)

\begin{tabular}{|c|c|c|c|c|}
\hline Analyte & Units & $\mathbf{N}$ & SNSWAMP & Reference Value $^{\mathrm{a}}$ \\
\hline Gross Alpha & $\mu \mathrm{Ci} / \mathrm{g}$ & 1 & $1.32 \pm 0.17 \mathrm{E}-05$ & -- \\
\hline Gross Beta & $\mu \mathrm{Ci} / \mathrm{g}$ & 1 & $5.43 \pm 0.25 \mathrm{E}-05$ & -- \\
\hline K-40 & $\mu \mathrm{Ci} / \mathrm{g}$ & 1 & $1.69 \pm 0.14 \mathrm{E}-05$ & -- \\
\hline Co-60 & $\mu \mathrm{Ci} / \mathrm{g}$ & 1 & $1.00 \pm 1.68 \mathrm{E}-08$ & -- \\
\hline Sr-90 & $\mu \mathrm{Ci} / \mathrm{g}$ & 1 & $2.82 \pm 0.12 \mathrm{E}-06$ & -- \\
\hline Cs-137 & $\mu \mathrm{Ci} / \mathrm{g}$ & 1 & $1.38 \pm 0.12 \mathrm{E}-05$ & -- \\
\hline U-232 & $\mu \mathrm{Ci} / \mathrm{g}$ & 1 & $-2.65 \pm 1.79 \mathrm{E}-08$ & -- \\
\hline U-233/234 & $\mu \mathrm{Ci} / \mathrm{g}$ & 1 & $8.85 \pm 1.58 \mathrm{E}-07$ & -- \\
\hline U-235/236 & $\mu \mathrm{Ci} / \mathrm{g}$ & 1 & $5.44 \pm 4.04 \mathrm{E}-08$ & -- \\
\hline U-238 & $\mu \mathrm{Ci} / \mathrm{g}$ & 1 & $8.92 \pm 1.57 \mathrm{E}-07$ & -- \\
\hline Total U & $\mu \mathrm{g} / \mathrm{g}$ & 1 & $4.26 \pm 0.10 \mathrm{E}+00$ & -- \\
\hline Pu-238 & $\mu \mathrm{Ci} / \mathrm{g}$ & 1 & $3.47 \pm 0.55 \mathrm{E}-07$ & -- \\
\hline Pu-239/240 & $\mu \mathrm{Ci} / \mathrm{g}$ & 1 & $4.68 \pm 0.63 \mathrm{E}-07$ & -- \\
\hline Am-241 & $\mu \mathrm{Ci} / \mathrm{g}$ & 1 & $9.90 \pm 1.69 \mathrm{E}-07$ & -- \\
\hline Aluminum & $\mathrm{mg} / \mathrm{kg}$ & 1 & 10,700 & 33,000 \\
\hline Antimony & $\mathrm{mg} / \mathrm{kg}$ & 1 & 0.26 & -- \\
\hline Arsenic & $\mathrm{mg} / \mathrm{kg}$ & 1 & 10.6 & $3-12^{\mathrm{b}}$ \\
\hline Barium & $\mathrm{mg} / \mathrm{kg}$ & 1 & 73.9 & $15-600$ \\
\hline Beryllium & $\mathrm{mg} / \mathrm{kg}$ & 1 & 0.51 & $0-1.75$ \\
\hline Cadmium & $\mathrm{mg} / \mathrm{kg}$ & 1 & 0.11 & $0.1-1$ \\
\hline Calcium & $\mathrm{mg} / \mathrm{kg}$ & 1 & 4,490 & $130-35,000$ \\
\hline Chromium & $\mathrm{mg} / \mathrm{kg}$ & 1 & 14 & $1.5-40^{\mathrm{b}}$ \\
\hline Cobalt & $\mathrm{mg} / \mathrm{kg}$ & 1 & 9.2 & $2.5-60^{\mathrm{b}}$ \\
\hline Copper & $\mathrm{mg} / \mathrm{kg}$ & 1 & 23.7 & $1-50$ \\
\hline Iron & $\mathrm{mg} / \mathrm{kg}$ & 1 & 24,300 & $2,000-550,000$ \\
\hline Lead & $\mathrm{mg} / \mathrm{kg}$ & 1 & 21.9 & $4-61^{\mathrm{c}}$ \\
\hline Magnesium & $\mathrm{mg} / \mathrm{kg}$ & 1 & 4,460 & $100-5,000$ \\
\hline Manganese & $\mathrm{mg} / \mathrm{kg}$ & 1 & 563 & $50-5,000$ \\
\hline Mercury & $\mathrm{mg} / \mathrm{kg}$ & 1 & 0.04 & $0.001-0.2$ \\
\hline Nickel & $\mathrm{mg} / \mathrm{kg}$ & 1 & 22.8 & $0.5-25$ \\
\hline Potassium & $\mathrm{mg} / \mathrm{kg}$ & 1 & 1,230 & $8,500-43,000^{b}$ \\
\hline Selenium & $\mathrm{mg} / \mathrm{kg}$ & 1 & 0.29 & $0.1-3.9$ \\
\hline Silver & $\mathrm{mg} / \mathrm{kg}$ & 1 & $<0.05$ & -- \\
\hline Sodium & $\mathrm{mg} / \mathrm{kg}$ & 1 & 50.5 & $6,000-8,000$ \\
\hline Thallium & $\mathrm{mg} / \mathrm{kg}$ & 1 & $<0.33$ & -- \\
\hline Vanadium & $\mathrm{mg} / \mathrm{kg}$ & 1 & 16.3 & $1-300$ \\
\hline Zinc & $\mathrm{mg} / \mathrm{kg}$ & 1 & 92.4 & $9-50$ \\
\hline
\end{tabular}

Note: Effects of radiological soils and sediments are addressed with the evaluation of radiological dose to biota in Chapter 2.

$N$ - Number of samples

-- No reference standard available for these analytes

${ }^{a}$ NYSDEC: Technical and Administrative Guidance Memorandum (TAGM) \#4046.

${ }^{b}$ New York State background

${ }^{c}$ Background levels vary widely. Average levels in undeveloped rural areas may range from 4-61 ppm (reported here). Average background levels in metropolitain or suburban areas, or near highways are much higher and typically range from 200-500 ppm. 
Table G-2D

2004 Radioactivity in Surface Soils Collected at Air Stations Around the WVDP

\begin{tabular}{|c|c|c|c|c|c|}
\hline Analyte & Units & $\mathbf{N}$ & SFBOEHN & SFRSPRD & $\begin{array}{c}\text { Background Location } \\
\text { SFGRVAL }\end{array}$ \\
\hline Gross Alpha & $\mu \mathrm{Ci} / \mathrm{g}$ & 1 & $9.40 \pm 2.58 \mathrm{E}-06$ & $9.86 \pm 2.75 \mathrm{E}-06$ & $1.09 \pm 0.29 \mathrm{E}-05$ \\
\hline Gross Beta & $\mu \mathrm{Ci} / \mathrm{g}$ & 1 & $1.59 \pm 0.20 \mathrm{E}-05$ & $1.54 \pm 0.19 \mathrm{E}-05$ & $1.61 \pm 0.19 \mathrm{E}-05$ \\
\hline K-40 & $\mu \mathrm{Ci} / \mathrm{g}$ & 1 & $1.52 \pm 0.10 \mathrm{E}-05$ & $1.22 \pm 0.11 \mathrm{E}-05$ & $1.17 \pm 0.10 \mathrm{E}-05$ \\
\hline Co-60 & $\mu \mathrm{Ci} / \mathrm{g}$ & 1 & $0.02 \pm 1.66 \mathrm{E}-08$ & $-0.28 \pm 1.96 \mathrm{E}-08$ & $-0.53 \pm 1.63 \mathrm{E}-08$ \\
\hline Sr-90 & $\mu \mathrm{Ci} / \mathrm{g}$ & 1 & $2.90 \pm 2.40 \mathrm{E}-08$ & $8.47 \pm 2.30 \mathrm{E}-08$ & $1.03 \pm 0.23 \mathrm{E}-07$ \\
\hline Cs-137 & $\mu \mathrm{Ci} / \mathrm{g}$ & 1 & $3.86 \pm 0.39 \mathrm{E}-07$ & $8.29 \pm 1.13 \mathrm{E}-07$ & $6.21 \pm 0.70 \mathrm{E}-07$ \\
\hline $\mathrm{U}-232$ & $\mu \mathrm{Ci} / \mathrm{g}$ & 1 & $-0.52 \pm 2.16 \mathrm{E}-08$ & $0.08 \pm 2.81 \mathrm{E}-08$ & $0.58 \pm 2.24 \mathrm{E}-08$ \\
\hline $\mathrm{U}-233 / 234$ & $\mu \mathrm{Ci} / \mathrm{g}$ & 1 & $8.96 \pm 1.54 \mathrm{E}-07$ & $8.56 \pm 1.58 \mathrm{E}-07$ & $7.92 \pm 1.39 \mathrm{E}-07$ \\
\hline U-235/236 & $\mu \mathrm{Ci} / \mathrm{g}$ & 1 & $6.98 \pm 4.57 \mathrm{E}-08$ & $7.48 \pm 4.63 \mathrm{E}-08$ & $8.35 \pm 4.64 \mathrm{E}-08$ \\
\hline U-238 & $\mu \mathrm{Ci} / \mathrm{g}$ & 1 & $8.37 \pm 1.47 \mathrm{E}-07$ & $8.69 \pm 1.58 \mathrm{E}-07$ & $7.21 \pm 1.32 \mathrm{E}-07$ \\
\hline Total U & $\mu \mathrm{g} / \mathrm{g}$ & 1 & $3.35 \pm 0.19 \mathrm{E}+00$ & $3.71 \pm 0.21 \mathrm{E}+00$ & $3.40 \pm 0.19 \mathrm{E}+00$ \\
\hline Pu-238 & $\mu \mathrm{Ci} / \mathrm{g}$ & 1 & $0.37 \pm 1.17 \mathrm{E}-08$ & $0.57 \pm 1.12 \mathrm{E}-08$ & $2.82 \pm 2.61 \mathrm{E}-08$ \\
\hline Pu-239/240 & $\mu \mathrm{Ci} / \mathrm{g}$ & 1 & $1.36 \pm 1.97 \mathrm{E}-08$ & $0.43 \pm 1.15 \mathrm{E}-08$ & $4.59 \pm 3.29 \mathrm{E}-08$ \\
\hline Am-241 & $\mu \mathrm{Ci} / \mathrm{g}$ & 1 & $0.02 \pm 1.10 \mathrm{E}-08$ & $1.33 \pm 2.61 \mathrm{E}-08$ & $0.74 \pm 1.68 \mathrm{E}-08$ \\
\hline Analyte & Units & $\mathbf{N}$ & SFFXVRD & SFRT240 & $\begin{array}{c}\text { Background Location } \\
\text { SFGRVAL }\end{array}$ \\
\hline Gross Alpha & $\mu \mathrm{Ci} / \mathrm{g}$ & 1 & $1.29 \pm 0.30 \mathrm{E}-05$ & $9.22 \pm 2.47 \mathrm{E}-06$ & $1.09 \pm 0.29 \mathrm{E}-05$ \\
\hline Gross Beta & $\mu \mathrm{Ci} / \mathrm{g}$ & 1 & $1.61 \pm 0.21 \mathrm{E}-05$ & $1.43 \pm 0.19 \mathrm{E}-05$ & $1.61 \pm 0.19 \mathrm{E}-05$ \\
\hline K-40 & $\mu \mathrm{Ci} / \mathrm{g}$ & 1 & $1.04 \pm 0.06 \mathrm{E}-05$ & $1.20 \pm 0.09 \mathrm{E}-05$ & $1.17 \pm 0.10 \mathrm{E}-05$ \\
\hline Co-60 & $\mu \mathrm{Ci} / \mathrm{g}$ & 1 & $0.14 \pm 1.40 \mathrm{E}-08$ & $0.22 \pm 1.47 \mathrm{E}-08$ & $-0.53 \pm 1.63 \mathrm{E}-08$ \\
\hline Sr-90 & $\mu \mathrm{Ci} / \mathrm{g}$ & 1 & $6.82 \pm 2.23 \mathrm{E}-08$ & $7.37 \pm 2.46 \mathrm{E}-08$ & $1.03 \pm 0.23 \mathrm{E}-07$ \\
\hline Cs-137 & $\mu \mathrm{Ci} / \mathrm{g}$ & 1 & $5.22 \pm 0.35 \mathrm{E}-07$ & $4.17 \pm 0.56 \mathrm{E}-07$ & $6.21 \pm 0.70 \mathrm{E}-07$ \\
\hline Pu-238 & $\mu \mathrm{Ci} / \mathrm{g}$ & 1 & $-0.42 \pm 1.23 \mathrm{E}-08$ & $-0.42 \pm 1.23 \mathrm{E}-08$ & $2.82 \pm 2.61 \mathrm{E}-08$ \\
\hline Pu-239/240 & $\mu \mathrm{Ci} / \mathrm{g}$ & 1 & $0.88 \pm 1.66 \mathrm{E}-08$ & $2.31 \pm 2.26 \mathrm{E}-08$ & $4.59 \pm 3.29 \mathrm{E}-08$ \\
\hline Am-241 & $\mu \mathrm{Ci} / \mathrm{g}$ & 1 & $4.43 \pm 3.41 \mathrm{E}-08$ & $2.06 \pm 2.51 \mathrm{E}-08$ & $0.74 \pm 1.68 \mathrm{E}-08$ \\
\hline
\end{tabular}

$N$ - Number of samples

WVDP Annual Site Environmental Report

$G-10$

Calendar Year 2004 
Table G-2D (concluded)

2004 Radioactivity in Surface Soils Collected at Air Stations Around the WVDP

\begin{tabular}{|l|c|c|c|c|c|}
\hline \multicolumn{1}{|c|}{ Analyte } & Units & N & SFSPRVL & SFTCORD & $\begin{array}{c}\text { Background Location } \\
\text { SFGRVAL }\end{array}$ \\
\hline Gross Alpha & $\mu \mathrm{Ci} / \mathrm{g}$ & 1 & $1.57 \pm 0.31 \mathrm{E}-05$ & $1.11 \pm 0.33 \mathrm{E}-05$ & $1.09 \pm 0.29 \mathrm{E}-05$ \\
\hline Gross Beta & $\mu \mathrm{Ci} / \mathrm{g}$ & 1 & $1.75 \pm 0.20 \mathrm{E}-05$ & $2.60 \pm 0.24 \mathrm{E}-05$ & $1.61 \pm 0.19 \mathrm{E}-05$ \\
\hline K-40 & $\mu \mathrm{Ci} / \mathrm{g}$ & 1 & $1.26 \pm 0.05 \mathrm{E}-05$ & $2.11 \pm 0.16 \mathrm{E}-05$ & $1.17 \pm 0.10 \mathrm{E}-05$ \\
\hline Co-60 & $\mu \mathrm{Ci} / \mathrm{g}$ & 1 & $0.44 \pm 1.22 \mathrm{E}-08$ & $-0.50 \pm 1.54 \mathrm{E}-08$ & $-0.53 \pm 1.63 \mathrm{E}-08$ \\
\hline Sr-90 & $\mu \mathrm{Ci} / \mathrm{g}$ & 1 & $8.91 \pm 2.48 \mathrm{E}-08$ & $1.31 \pm 0.25 \mathrm{E}-07$ & $1.03 \pm 0.23 \mathrm{E}-07$ \\
\hline Cs-137 & $\mu \mathrm{Ci} / \mathrm{g}$ & 1 & $3.90 \pm 0.26 \mathrm{E}-07$ & $2.96 \pm 0.35 \mathrm{E}-07$ & $6.21 \pm 0.70 \mathrm{E}-07$ \\
\hline Pu-238 & $\mu \mathrm{Ci} / \mathrm{g}$ & 1 & $-0.13 \pm 1.10 \mathrm{E}-08$ & $-0.30 \pm 1.29 \mathrm{E}-08$ & $2.82 \pm 2.61 \mathrm{E}-08$ \\
\hline Pu-239/240 & $\mu \mathrm{Ci} / \mathrm{g}$ & 1 & $0.96 \pm 1.54 \mathrm{E}-08$ & $2.05 \pm 2.50 \mathrm{E}-08$ & $4.59 \pm 3.29 \mathrm{E}-08$ \\
\hline Am-241 & $\mu \mathrm{Ci} / \mathrm{g}$ & 1 & $2.02 \pm 2.51 \mathrm{E}-08$ & $3.02 \pm 2.08 \mathrm{E}-08$ & $0.74 \pm 1.68 \mathrm{E}-08$ \\
\hline \multicolumn{1}{|c|}{ Analyte } & Units & $\mathbf{N}$ & SFBLKST & SFWEVAL & Background Location \\
\hline Gross Alpha & $\mu \mathrm{Ci} / \mathrm{g}$ & 1 & $1.50 \pm 0.34 \mathrm{E}-05$ & $1.19 \pm 0.29 \mathrm{E}-05$ & SFGRVAL \\
\hline Gross Beta & $\mu \mathrm{Ci} / \mathrm{g}$ & 1 & $1.86 \pm 0.22 \mathrm{E}-05$ & $1.37 \pm 0.19 \mathrm{E}-05$ & $1.09 \pm 0.29 \mathrm{E}-05$ \\
\hline K-40 & $\mu \mathrm{Ci} / \mathrm{g}$ & 1 & $1.92 \pm 0.08 \mathrm{E}-05$ & $1.32 \pm 0.11 \mathrm{E}-05$ & $1.17 \pm 0.19 \mathrm{E}-05$ \\
\hline Co-60 & $\mu \mathrm{Ci} / \mathrm{g}$ & 1 & $0.19 \pm 1.84 \mathrm{E}-08$ & $-0.12 \pm 1.52 \mathrm{E}-08$ & $-0.53 \pm 1.63 \mathrm{E}-08$ \\
\hline Sr-90 & $\mu \mathrm{Ci} / \mathrm{g}$ & 1 & $1.88 \pm 2.27 \mathrm{E}-08$ & $1.88 \pm 0.68 \mathrm{E}-07$ & $1.03 \pm 0.23 \mathrm{E}-07$ \\
\hline Cs-137 & $\mu \mathrm{Ci} / \mathrm{g}$ & 1 & $1.44 \pm 0.33 \mathrm{E}-07$ & $2.66 \pm 0.38 \mathrm{E}-07$ & $6.21 \pm 0.70 \mathrm{E}-07$ \\
\hline Pu-238 & $\mu \mathrm{Ci} / \mathrm{g}$ & 1 & $0.44 \pm 1.18 \mathrm{E}-08$ & $-0.57 \pm 1.29 \mathrm{E}-08$ & $2.82 \pm 2.61 \mathrm{E}-08$ \\
\hline Pu-239/240 & $\mu \mathrm{Ci} / \mathrm{g}$ & 1 & $0.44 \pm 1.18 \mathrm{E}-08$ & $1.64 \pm 2.03 \mathrm{E}-08$ & $4.59 \pm 3.29 \mathrm{E}-08$ \\
\hline Am-241 & $\mu \mathrm{Ci} / \mathrm{g}$ & 1 & $0.73 \pm 1.07 \mathrm{E}-08$ & $-0.36 \pm 1.57 \mathrm{E}-08$ & $0.74 \pm 1.68 \mathrm{E}-08$ \\
\hline
\end{tabular}

$N$ - Number of samples

WVDP Annual Site Environmental Report

$G-11$

Calendar Year 2004 


\section{Table G-2E}

2004 Radioactivity in Stream Sediments Around the WVDP

\begin{tabular}{|l|c|c|c|c|c|}
\hline \multicolumn{1}{|c|}{ Analyte } & Units & N & SFCCSED & SFSDSED & $\begin{array}{c}\text { Background Location } \\
\text { SFBISED }\end{array}$ \\
\hline Gross Alpha & $\mu \mathrm{Ci} / \mathrm{g}$ & 1 & $6.87 \pm 2.94 \mathrm{E}-06$ & $1.36 \pm 0.34 \mathrm{E}-05$ & $9.37 \pm 2.66 \mathrm{E}-06$ \\
\hline Gross Beta & $\mu \mathrm{Ci} / \mathrm{g}$ & 1 & $1.37 \pm 0.21 \mathrm{E}-05$ & $1.98 \pm 0.24 \mathrm{E}-05$ & $1.31 \pm 0.20 \mathrm{E}-05$ \\
\hline K-40 & $\mu \mathrm{Ci} / \mathrm{g}$ & 1 & $1.18 \pm 0.09 \mathrm{E}-05$ & $1.67 \pm 0.13 \mathrm{E}-05$ & $1.23 \pm 0.09 \mathrm{E}-05$ \\
\hline Co-60 & $\mu \mathrm{Ci} / \mathrm{g}$ & 1 & $0.28 \pm 1.56 \mathrm{E}-08$ & $0.29 \pm 1.60 \mathrm{E}-08$ & $0.35 \pm 6.22 \mathrm{E}-09$ \\
\hline Sr-90 & $\mu \mathrm{Ci} / \mathrm{g}$ & 1 & $1.88 \pm 3.08 \mathrm{E}-08$ & $4.07 \pm 4.19 \mathrm{E}-08$ & $3.10 \pm 4.21 \mathrm{E}-08$ \\
\hline Cs-137 & $\mu \mathrm{Ci} / \mathrm{g}$ & 1 & $1.14 \pm 0.27 \mathrm{E}-07$ & $5.09 \pm 2.24 \mathrm{E}-08$ & $2.47 \pm 1.05 \mathrm{E}-08$ \\
\hline U-232 & $\mu \mathrm{Ci} / \mathrm{g}$ & 1 & $-0.20 \pm 3.00 \mathrm{E}-08$ & $-0.57 \pm 2.71 \mathrm{E}-08$ & $1.24 \pm 3.55 \mathrm{E}-08$ \\
\hline $\mathbf{U}-233 / 234$ & $\mu \mathrm{Ci} / \mathrm{g}$ & 1 & $5.48 \pm 1.30 \mathrm{E}-07$ & $7.64 \pm 1.57 \mathrm{E}-07$ & $6.06 \pm 1.32 \mathrm{E}-07$ \\
\hline U-235/236 & $\mu \mathrm{Ci} / \mathrm{g}$ & 1 & $7.65 \pm 4.81 \mathrm{E}-08$ & $6.48 \pm 4.65 \mathrm{E}-08$ & $6.07 \pm 4.65 \mathrm{E}-08$ \\
\hline U-238 & $\mu \mathrm{Ci} / \mathrm{g}$ & 1 & $5.40 \pm 1.29 \mathrm{E}-07$ & $7.74 \pm 1.57 \mathrm{E}-07$ & $6.34 \pm 1.34 \mathrm{E}-07$ \\
\hline Total U & $\mu \mathrm{g} / \mathrm{g}$ & 1 & $1.62 \pm 0.02 \mathrm{E}+00$ & $2.63 \pm 0.04 \mathrm{E}+00$ & $1.27 \pm 0.01 \mathrm{E}+00$ \\
\hline Pu-238 & $\mu \mathrm{Ci} / \mathrm{g}$ & 1 & $-0.16 \pm 1.12 \mathrm{E}-08$ & $0.19 \pm 1.41 \mathrm{E}-08$ & $-3.08 \pm 4.27 \mathrm{E}-09$ \\
\hline Pu-239/240 & $\mu \mathrm{Ci} / \mathrm{g}$ & 1 & $0.22 \pm 1.12 \mathrm{E}-08$ & $-0.16 \pm 1.34 \mathrm{E}-08$ & $0.64 \pm 1.26 \mathrm{E}-08$ \\
\hline Am-241 & $\mu \mathrm{Ci} / \mathrm{g}$ & 1 & $0.08 \pm 1.74 \mathrm{E}-08$ & $-0.20 \pm 1.35 \mathrm{E}-08$ & $-1.09 \pm 1.68 \mathrm{E}-08$ \\
\hline
\end{tabular}

\begin{tabular}{|l|c|c|c|c|c|}
\hline \multicolumn{1}{|c|}{ Analyte } & Units & N & SFTCSED & -- & $\begin{array}{c}\text { Background Location } \\
\text { SFBCSED }\end{array}$ \\
\hline Gross Alpha & $\mu \mathrm{Ci} / \mathrm{g}$ & 1 & $7.98 \pm 3.24 \mathrm{E}-06$ & -- & $7.99 \pm 2.88 \mathrm{E}-06$ \\
\hline Gross Beta & $\mu \mathrm{Ci} / \mathrm{g}$ & 1 & $2.04 \pm 0.24 \mathrm{E}-05$ & -- & $1.51 \pm 0.20 \mathrm{E}-05$ \\
\hline K-40 & $\mu \mathrm{Ci} / \mathrm{g}$ & 1 & $1.17 \pm 0.06 \mathrm{E}-05$ & -- & $1.25 \pm 0.11 \mathrm{E}-05$ \\
\hline Co-60 & $\mu \mathrm{Ci} / \mathrm{g}$ & 1 & $-0.42 \pm 1.48 \mathrm{E}-08$ & -- & $1.84 \pm 9.37 \mathrm{E}-09$ \\
\hline Sr-90 & $\mu \mathrm{Ci} / \mathrm{g}$ & 1 & $8.26 \pm 4.48 \mathrm{E}-08$ & -- & $4.76 \pm 2.45 \mathrm{E}-08$ \\
\hline Cs-137 & $\mu \mathrm{Ci} / \mathrm{g}$ & 1 & $6.48 \pm 0.37 \mathrm{E}-07$ & -- & $3.13 \pm 1.49 \mathrm{E}-08$ \\
\hline U-232 & $\mu \mathrm{Ci} / \mathrm{g}$ & 1 & $-1.70 \pm 2.07 \mathrm{E}-08$ & -- & $-3.18 \pm 4.87 \mathrm{E}-09$ \\
\hline U-233/234 & $\mu \mathrm{Ci} / \mathrm{g}$ & 1 & $6.49 \pm 1.35 \mathrm{E}-07$ & -- & $7.59 \pm 1.45 \mathrm{E}-07$ \\
\hline U-235/236 & $\mu \mathrm{Ci} / \mathrm{g}$ & 1 & $4.48 \pm 4.03 \mathrm{E}-08$ & -- & $9.29 \pm 5.05 \mathrm{E}-08$ \\
\hline U-238 & $\mu \mathrm{Ci} / \mathrm{g}$ & 1 & $7.69 \pm 1.47 \mathrm{E}-07$ & -- & $8.53 \pm 1.53 \mathrm{E}-07$ \\
\hline Total U & $\mu \mathrm{g} / \mathrm{g}$ & 1 & $2.07 \pm 0.03 \mathrm{E}+00$ & -- & $2.11 \pm 0.02 \mathrm{E}+00$ \\
\hline Pu-238 & $\mu \mathrm{Ci} / \mathrm{g}$ & 1 & $-0.15 \pm 1.27 \mathrm{E}-08$ & -- & $1.39 \pm 2.23 \mathrm{E}-08$ \\
\hline Pu-239/240 & $\mu \mathrm{Ci} / \mathrm{g}$ & 1 & $-0.30 \pm 1.30 \mathrm{E}-08$ & -- & $-0.19 \pm 1.59 \mathrm{E}-08$ \\
\hline Am-241 & $\mu \mathrm{Ci} / \mathrm{g}$ & 1 & $2.08 \pm 2.16 \mathrm{E}-08$ & -- & $0.47 \pm 1.19 \mathrm{E}-08$ \\
\hline
\end{tabular}

$N$ - Number of samples

-- Not applicable; no additional sampling location 
Table G-2F

2004 Contaminants in Rail Bed Soil Material

\begin{tabular}{|c|c|c|c|c|c|}
\hline Analyte & Units & $\mathbf{N}$ & Maximum & $\begin{array}{c}\text { Allowable Soil } \\
\text { Concentration Reference } \\
\text { Value }^{\mathrm{a}}\end{array}$ & $\begin{array}{l}\text { Soil Cleanup Objectives } \\
\text { to Protect Groundwater } \\
\text { Quality Reference Value }\end{array}$ \\
\hline Am-241 & $\mu \mathrm{Ci} / \mathrm{g}$ & 9 & $<6.85 \mathrm{E}-08$ & -- & -- \\
\hline Cs-137 & $\mu \mathrm{Ci} / \mathrm{g}$ & 9 & $8.52 \pm 2.59 \mathrm{E}-08$ & -- & -- \\
\hline 2,3,7,8-TCDD Dioxin & $\mathrm{mg} / \mathrm{kg}$ & 9 & $<0.000026$ & 0.0006 & 0.06 \\
\hline $2,4,5-\mathrm{T}$ & $\mathrm{mg} / \mathrm{kg}$ & 9 & $<0.0043$ & 0.019 & 1.9 \\
\hline 2,4-D & $\mathrm{mg} / \mathrm{kg}$ & 9 & $<0.0046$ & 0.005 & 0.5 \\
\hline alpha BHC & $\mathrm{mg} / \mathrm{kg}$ & 9 & $<0.000460$ & 0.002 & 0.2 \\
\hline Anthracene & $\mathrm{mg} / \mathrm{kg}$ & 9 & $<0.160$ & 7.0 & 700.0 \\
\hline Benzene & $\mathrm{mg} / \mathrm{kg}$ & 9 & $<0.001$ & 0.0006 & 0.06 \\
\hline beta BHC & $\mathrm{mg} / \mathrm{kg}$ & 9 & $<0.00023$ & 0.002 & 0.2 \\
\hline delta BHC & $\mathrm{mg} / \mathrm{kg}$ & 9 & $<0.00046$ & 0.003 & 0.3 \\
\hline Ethyl benzene & $\mathrm{mg} / \mathrm{kg}$ & 9 & $<0.0008$ & 0.055 & 5.5 \\
\hline gamma BHC (Lindane) & $\mathrm{mg} / \mathrm{kg}$ & 9 & $<0.000460$ & 0.0006 & 0.06 \\
\hline Heptachlor & $\mathrm{mg} / \mathrm{kg}$ & 9 & $<0.000250$ & 0.0010 & 0.1 \\
\hline Heptachlor epoxide & $\mathrm{mg} / \mathrm{kg}$ & 9 & $<0.000200$ & 0.0002 & 0.02 \\
\hline Lead, total & $\mathrm{mg} / \mathrm{kg}$ & 9 & 18.8 & $4-61^{\mathrm{b}}$ & $4-61^{b}$ \\
\hline Naphthalene & $\mathrm{mg} / \mathrm{kg}$ & 9 & $<0.130$ & 0.130 & 13.0 \\
\hline o-Cresol (2-methylphenol) & $\mathrm{mg} / \mathrm{kg}$ & 9 & $<0.100$ & 0.001 & 0.1 \\
\hline PCB-1016 & $\mathrm{mg} / \mathrm{kg}$ & 9 & $<2.0$ & 0.1 & 10 \\
\hline PCB-1221 & $\mathrm{mg} / \mathrm{kg}$ & 9 & $<2.0$ & 0.1 & 10 \\
\hline PCB-1232 & $\mathrm{mg} / \mathrm{kg}$ & 9 & $<2.0$ & 0.1 & 10 \\
\hline PCB-1242 & $\mathrm{mg} / \mathrm{kg}$ & 9 & $<2.0$ & 0.1 & 10 \\
\hline PCB-1248 & $\mathrm{mg} / \mathrm{kg}$ & 9 & $<2.0$ & 0.1 & 10 \\
\hline PCB-1254 & $\mathrm{mg} / \mathrm{kg}$ & 9 & $<2.0$ & 0.1 & 10 \\
\hline PCB-1260 & $\mathrm{mg} / \mathrm{kg}$ & 9 & $<2.0$ & 0.1 & 10 \\
\hline Total TCDD & $\mathrm{mg} / \mathrm{kg}$ & 9 & $<0.000026$ & 0.0006 & 0.06 \\
\hline p-Cresol (4-methylphenol) & $\mathrm{mg} / \mathrm{kg}$ & 9 & $<0.130$ & 0.009 & 0.9 \\
\hline Pentachlorophenol (8151) & $\mathrm{mg} / \mathrm{kg}$ & 9 & $<0.0045$ & 0.01 & 1.0 \\
\hline Pentachlorophenol (8270) & $\mathrm{mg} / \mathrm{kg}$ & 9 & $<0.800$ & 0.01 & 1.0 \\
\hline Silvex $(2,4,5-T P)$ & $\mathrm{mg} / \mathrm{kg}$ & 9 & $<0.0540$ & 0.007 & 0.7 \\
\hline Toluene & $\mathrm{mg} / \mathrm{kg}$ & 9 & 0.02 & 0.015 & 1.5 \\
\hline Xylene (Total) & $\mathrm{mg} / \mathrm{kg}$ & 9 & $<0.004$ & 0.012 & 1.2 \\
\hline
\end{tabular}

$N$ - Number of samples

-- No reference standard available

${ }^{a}$ NYSDEC: Technical Administrative Guidance Memorandum (TAGM) 4046

${ }^{b}$ Background levels vary widely. Average levels in undeveloped, rural areas may range from 4-61 ppm (reported here). Average background levels in metropolitan or suburban areas, or near highways are much higher and typically range from 200-500 ppm. 
This page intentionally left blank

$$
G-14
$$




\section{Appendix $\mathrm{H}$ \\ Summary of Direct Radiation Monitoring Data}

$H-1$ 
This page intentionally left blank

$H-2$ 
Table $\mathrm{H}-1$

\section{Summary of 2004 Quarterly Averages of Off-Site TLD Measurements (mR \pm 2 SD/quarter)}

$\begin{array}{lccccc}\begin{array}{l}\text { Location } \\ \text { Number* }\end{array} & \text { 1st Quarter } & \text { 2nd Quarter } & \text { 3rd Quarter } & \text { 4th Quarter } & \begin{array}{c}\text { Location } \\ \text { Average }\end{array} \\ \text { DFTLD01 } & & & & & \\ \text { DFTLD02 } & 17 \pm 4 & 20 \pm 4 & 15 \pm 4 & 17 \pm 4 & 17 \pm 4 \\ \text { DFTLD03 } & 17 \pm 4 & 22 \pm 5 & 15 \pm 4 & 18 \pm 4 & 18 \pm 4 \\ \text { DFTLD04 } & 15 \pm 3 & 17 \pm 4 & 12 \pm 3 & 16 \pm 4 & 15 \pm 4 \\ \text { DFTLD05 } & 16 \pm 4 & 19 \pm 4 & 14 \pm 4 & 19 \pm 4 & 17 \pm 4 \\ \text { DFTLD06 } & 17 \pm 4 & 19 \pm 4 & 14 \pm 4 & 17 \pm 4 & 17 \pm 4 \\ \text { DFTLD07 } & 16 \pm 4 & 19 \pm 4 & 13 \pm 4 & 16 \pm 4 & 16 \pm 4 \\ \text { DFTLD08 } & 14 \pm 3 & 17 \pm 4 & 11 \pm 3 & 12 \pm 3 & 13 \pm 3 \\ \text { DFTLD09 } & 16 \pm 4 & 21 \pm 5 & 15 \pm 4 & 18 \pm 4 & 17 \pm 4 \\ \text { DFTLD10 } & 16 \pm 4 & 20 \pm 4 & 14 \pm 4 & 16 \pm 4 & 16 \pm 4 \\ \text { DFTLD11 } & 15 \pm 3 & 18 \pm 4 & 14 \pm 4 & 17 \pm 4 & 16 \pm 4 \\ \text { DFTLD12 } & 17 \pm 3 & 18 \pm 4 & 12 \pm 3 & 14 \pm 4 & 15 \pm 4 \\ \text { DFTLD13 } & 17 \pm 4 & 20 \pm 4 & 14 \pm 4 & 17 \pm 4 & 17 \pm 4 \\ \text { DFTLD14 } & 17 \pm 4 & 21 \pm 5 & 16 \pm 4 & 17 \pm 4 & 18 \pm 4 \\ \text { DFTLD15 } & 15 \pm 3 & 20 \pm 4 & 14 \pm 4 & 16 \pm 4 & 17 \pm 4 \\ \text { DFTLD16 } & 16 \pm 4 & \mathrm{NA} & 14 \pm 4 & 16 \pm 4 & 15 \pm 3 \\ \text { DFTLD20 } & 14 \pm 3 & 19 \pm 4 & 14 \pm 4 & 16 \pm 4 & 16 \pm 4 \\ \text { DFTLD21 } & 18 \pm 4 & 18 \pm 4 & 10 \pm 3 & 13 \pm 3 & 14 \pm 3 \\ \text { DFTLD22 } & 17 \pm 4 & 21 \pm 4 & 14 \pm 4 & 17 \pm 4 & 17 \pm 4 \\ \text { DFTLD23 } & 17 \pm 4 & 21 \pm 5 & 15 \pm 4 & 18 \pm 4 & 18 \pm 4 \\ \end{array}$

NA - Not available; TLD card missing second quarter of 2004.

* Off-site locations are shown on Figures A-11, A-12, and A-13.

Conversion factor: Milliroentgen $(m R)$ units are used to report exposure rates in air. To convert $m R$ to mrem (dose to humans), a conversion factor of 1.03 must be applied. For example, a reported exposure rate of $18.1 \mathrm{mR} /$ quarter would be equivalent to $18.6 \mathrm{mrem} / q u a r t e r$ (based upon dose-equivalent phantom calibration using cesium-137).

$H-3$ 
Table $\mathrm{H}-2$

Summary of 2004 Quarterly Averages of On-Site TLD Measurements (mR $\pm 2 S D / q u a r t e r)$

$\begin{array}{lccccc}\text { Location } & \text { 1st Quarter } & \text { 2nd Quarter } & \text { 3rd Quarter } & \text { 4th Quarter } & \begin{array}{c}\text { Location } \\ \text { Average }\end{array} \\ \text { Number* } & & & & & \\ \text { DNTLD18 } & 26 \pm 5 & 30 \pm 6 & 24 \pm 5 & 27 \pm 6 & 27 \pm 6 \\ \text { DNTLD19 } & 18 \pm 4 & 22 \pm 5 & 17 \pm 4 & 19 \pm 4 & 19 \pm 4 \\ \text { DNTLD24 } & 471 \pm 92 & 473 \pm 93 & 484 \pm 95 & 472 \pm 93 & 475 \pm 93 \\ \text { DNTLD25 } & 20 \pm 4 & 24 \pm 5 & 21 \pm 5 & 23 \pm 5 & 22 \pm 5 \\ \text { DNTLD26 } & 19 \pm 4 & 25 \pm 5 & 19 \pm 4 & 20 \pm 5 & 21 \pm 5 \\ \text { DNTLD27 } & 17 \pm 4 & 20 \pm 4 & 14 \pm 4 & 19 \pm 4 & 18 \pm 4 \\ \text { DNTLD28 } & 18 \pm 4 & 22 \pm 5 & 17 \pm 4 & 20 \pm 5 & 20 \pm 4 \\ \text { DNTLD29 } & 19 \pm 4 & 24 \pm 5 & 18 \pm 4 & 22 \pm 5 & 20 \pm 4 \\ \text { DNTLD30 } & 20 \pm 4 & 24 \pm 5 & 19 \pm 5 & 23 \pm 5 & 21 \pm 5 \\ \text { DNTLD31 } & 17 \pm 4 & 21 \pm 4 & 15 \pm 4 & 17 \pm 4 & 17 \pm 4 \\ \text { DNTLD32 } & 27 \pm 5 & 21 \pm 5 & 24 \pm 5 & 26 \pm 6 & 24 \pm 5 \\ \text { DNTLD33 } & 27 \pm 5 & 31 \pm 6 & 25 \pm 5 & 28 \pm 6 & 28 \pm 6 \\ \text { DNTLD34 } & 45 \pm 9 & 49 \pm 10 & 42 \pm 9 & 47 \pm 9 & 46 \pm 9 \\ \text { DNTLD35 } & 65 \pm 13 & 71 \pm 14 & 58 \pm 12 & 53 \pm 11 & 62 \pm 12 \\ \text { DNTLD36 } & 33 \pm 7 & 22 \pm 5 & 29 \pm 6 & 45 \pm 9 & 32 \pm 7 \\ \text { DNTLD38 } & 30 \pm 6 & 35 \pm 7 & 29 \pm 6 & 55 \pm 11 & 37 \pm 8 \\ \text { DNTLD39 } & 41 \pm 8 & 50 \pm 10 & 49 \pm 10 & 50 \pm 10 & 48 \pm 10 \\ \text { DNTLD40 } & 105 \pm 21 & 117 \pm 23 & 115 \pm 23 & 112 \pm 22 & 112 \pm 22 \\ \text { DNTLD42 } & 75 \pm 15 & 73 \pm 14 & 68 \pm 14 & 68 \pm 14 & 71 \pm 14 \\ \text { DNTLD43 } & 26 \pm 5 & 30 \pm 6 & 23 \pm 5 & 26 \pm 6 & 26 \pm 5\end{array}$

* On-site locations are shown on Figure A-10.

Conversion factor: Milliroentgen $(m R)$ units are used to report exposure rates in air. To convert $m R$ to mrem (dose to humans), a conversion factor of 1.03 must be applied. For example, a reported exposure rate of $18.1 \mathrm{mR} /$ quarter would be equivalent to $18.6 \mathrm{mrem} / q u a r t e r$ (based upon dose-equivalent phantom calibration using cesium-137).

$H-4$ 
Table $\mathrm{H}-3$

Third-Quarter 2004 TLD Results and Instantaneous Exposure Rate Readings $(\mu R / h r)$ With a High-Pressure Ion Chamber (HPIC) at Each Monitoring Location

\begin{tabular}{|c|c|c|c|c|c|}
\hline $\begin{array}{l}\text { Off-Site } \\
\text { Location } \\
\text { Number }\end{array}$ & $\begin{array}{c}\text { 3rd-Quarter } \\
\text { TLD Result }\end{array}$ & $\begin{array}{l}\text { 3rd-Quarter } \\
\text { HPIC Result }\end{array}$ & $\begin{array}{l}\text { On-Site } \\
\text { Location } \\
\text { Number }\end{array}$ & $\begin{array}{c}\text { 3rd-Quarter } \\
\text { TLD Result }\end{array}$ & $\begin{array}{l}\text { 3rd-Quarter } \\
\text { HPIC Result }\end{array}$ \\
\hline DFTLD01 & 6.8 & 9.5 & DNTLD18 & 11.0 & 13.7 \\
\hline DFTLD02 & 7.1 & 9.5 & DNTLD19 & 7.9 & 9.5 \\
\hline DFTLD03 & 5.3 & 8.3 & DNTLD24 & 221.6 & 303.9 \\
\hline DFTLD04 & 6.4 & 8.1 & DNTLD25 & 9.8 & 11.3 \\
\hline DFTLD05 & 6.5 & 8.9 & DNTLD26 & 8.6 & 10.7 \\
\hline DFTLD06 & 5.9 & 9.1 & DNTLD27 & 6.6 & 8.6 \\
\hline DFTLD07 & 4.9 & 8.9 & DNTLD28 & 7.8 & 9.1 \\
\hline DFTLD08 & 6.7 & 8.6 & DNTLD29 & 8.0 & 9.6 \\
\hline DFTLD09 & 6.3 & 9.0 & DNTLD30 & 8.8 & 11.6 \\
\hline DFTLD10 & 6.3 & 8.8 & DNTLD31 & 6.7 & 8.0 \\
\hline DFTLD11 & 5.3 & 8.7 & DNTLD32 & 10.9 & 14.9 \\
\hline DFTLD12 & 6.2 & 8.9 & DNTLD33 & 11.3 & 13.3 \\
\hline DFTLD13 & 7.4 & 8.7 & DNTLD34 & 19.1 & 23.0 \\
\hline DFTLD14 & 6.6 & 8.7 & DNTLD35 & 26.6 & 36.9 \\
\hline DFTLD15 & 6.3 & 8.6 & DNTLD36 & 13.0 & 17.8 \\
\hline DFTLD16 & 6.3 & 8.6 & DNTLD38 & 13.2 & 16.9 \\
\hline DFTLD20 & 4.7 & 8.9 & DNTLD39 & 22.6 & 24.9 \\
\hline DFTLD21 & 6.6 & 9.1 & DNTLD40 & 52.7 & 54.5 \\
\hline DFTLD22 & 6.8 & 9.3 & DNTLD42 & 31.2 & 26.2 \\
\hline DFTLD23 & 6.4 & 8.9 & DNTLD43 & 10.3 & 11.9 \\
\hline
\end{tabular}

$H-5$ 


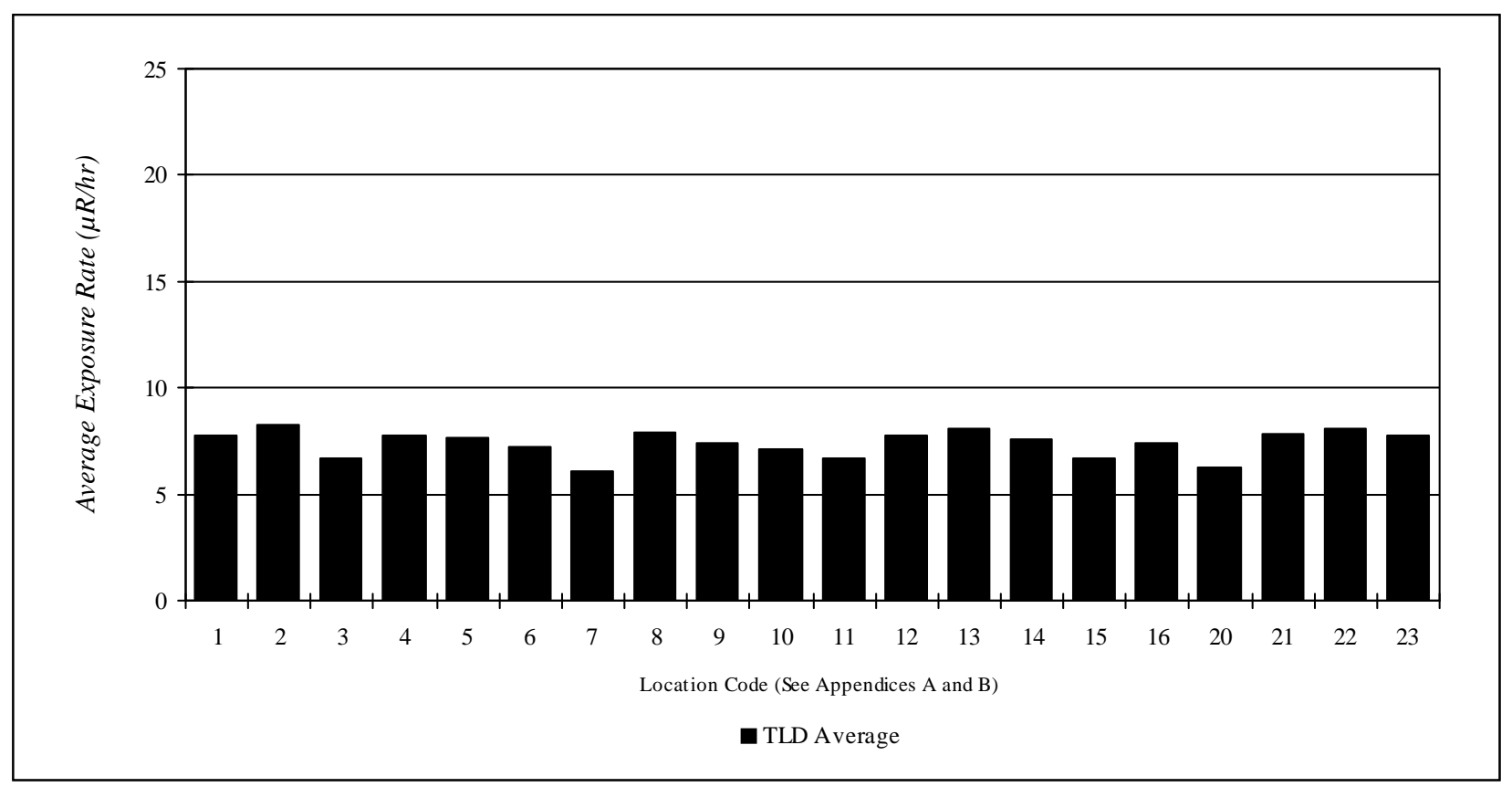

Figure H-1. 2004 Average Yearly Gamma Exposure Rates Around the WVDP

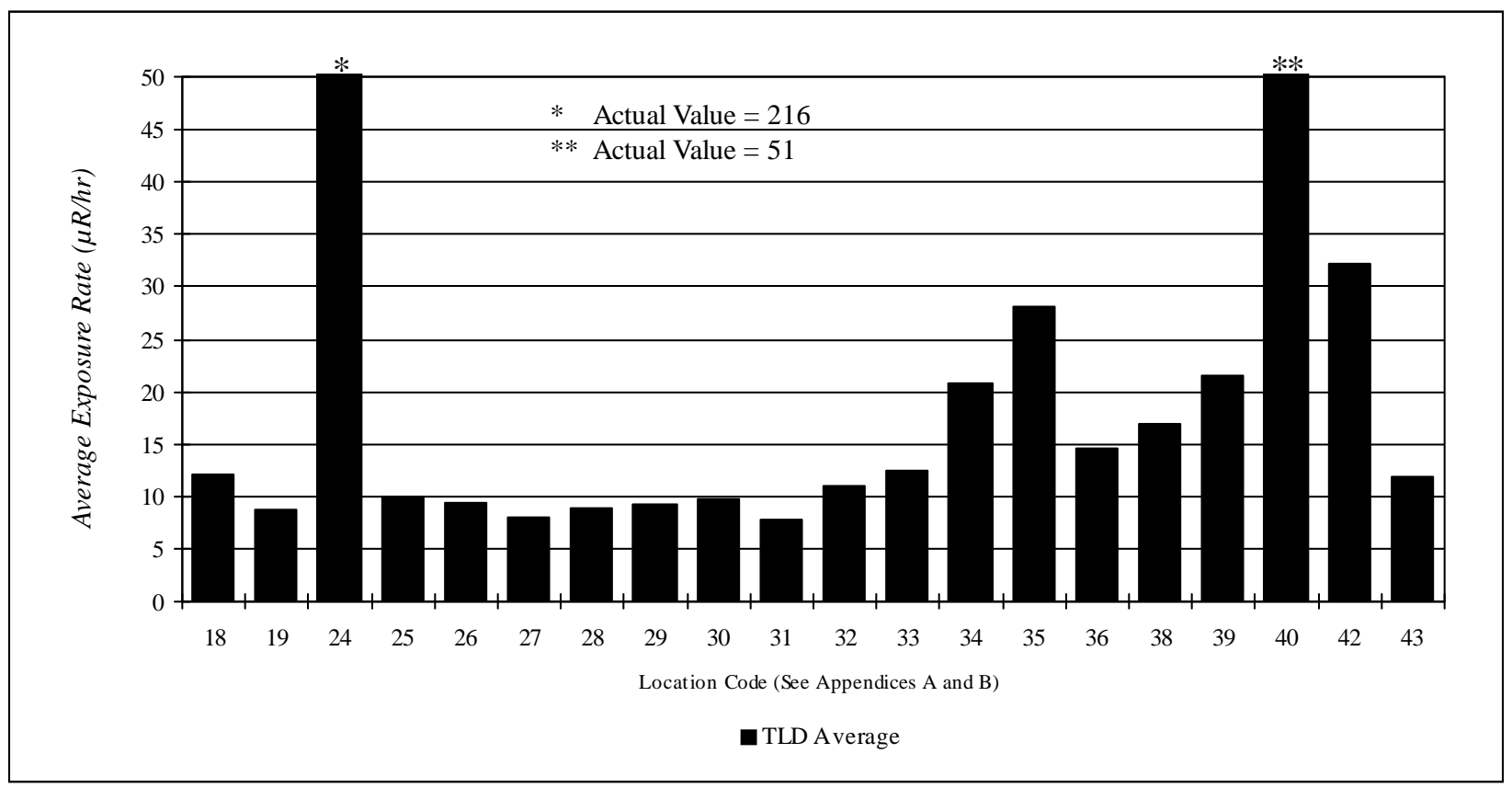

Figure H-2. 2004 Average Yearly Gamma Exposure Rates on the WVDP

$$
H-6
$$




\section{Appendix I Summary of Meteorological Data}

$I-1$ 
This page intentionally left blank

$$
I-2
$$




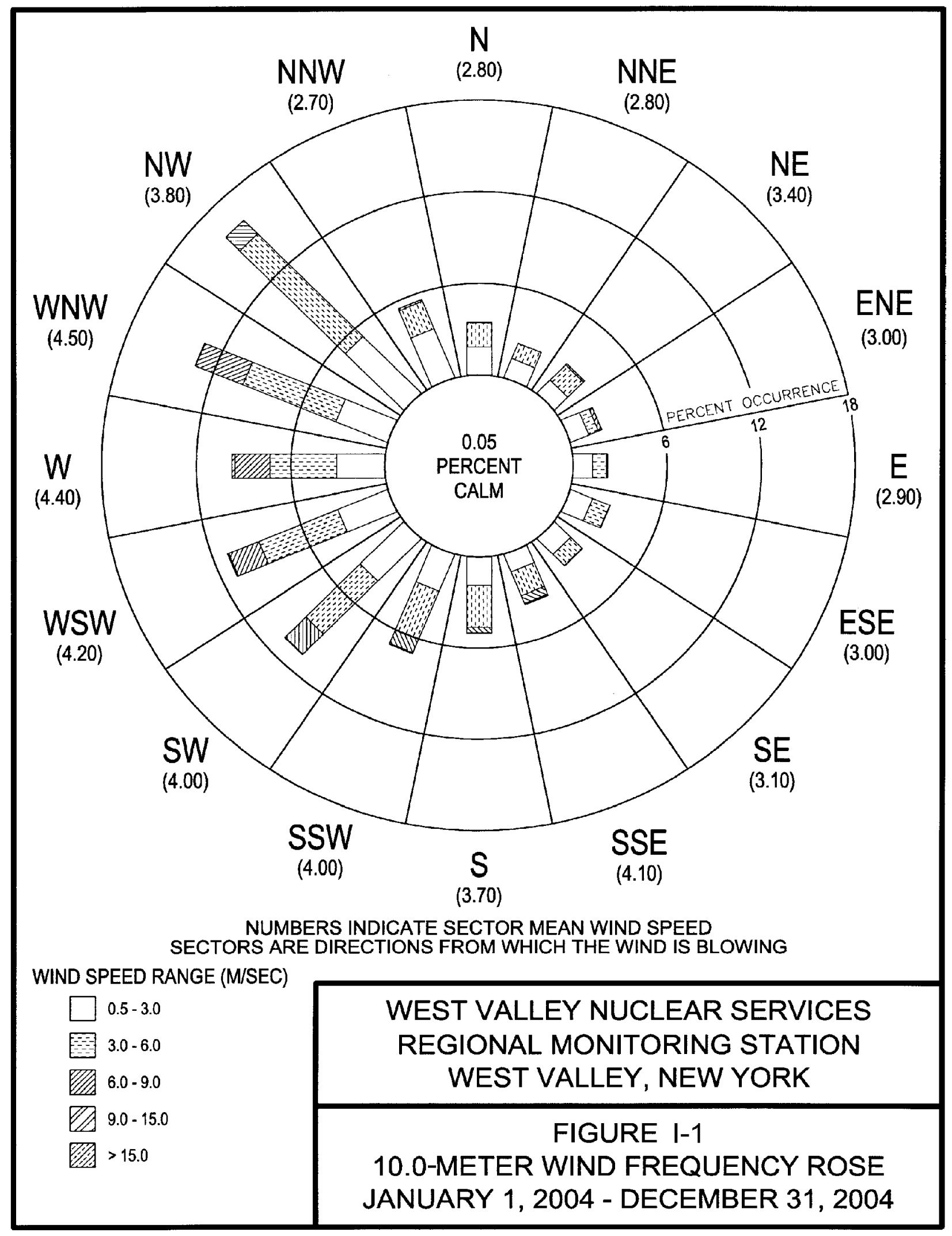

$I-3$ 


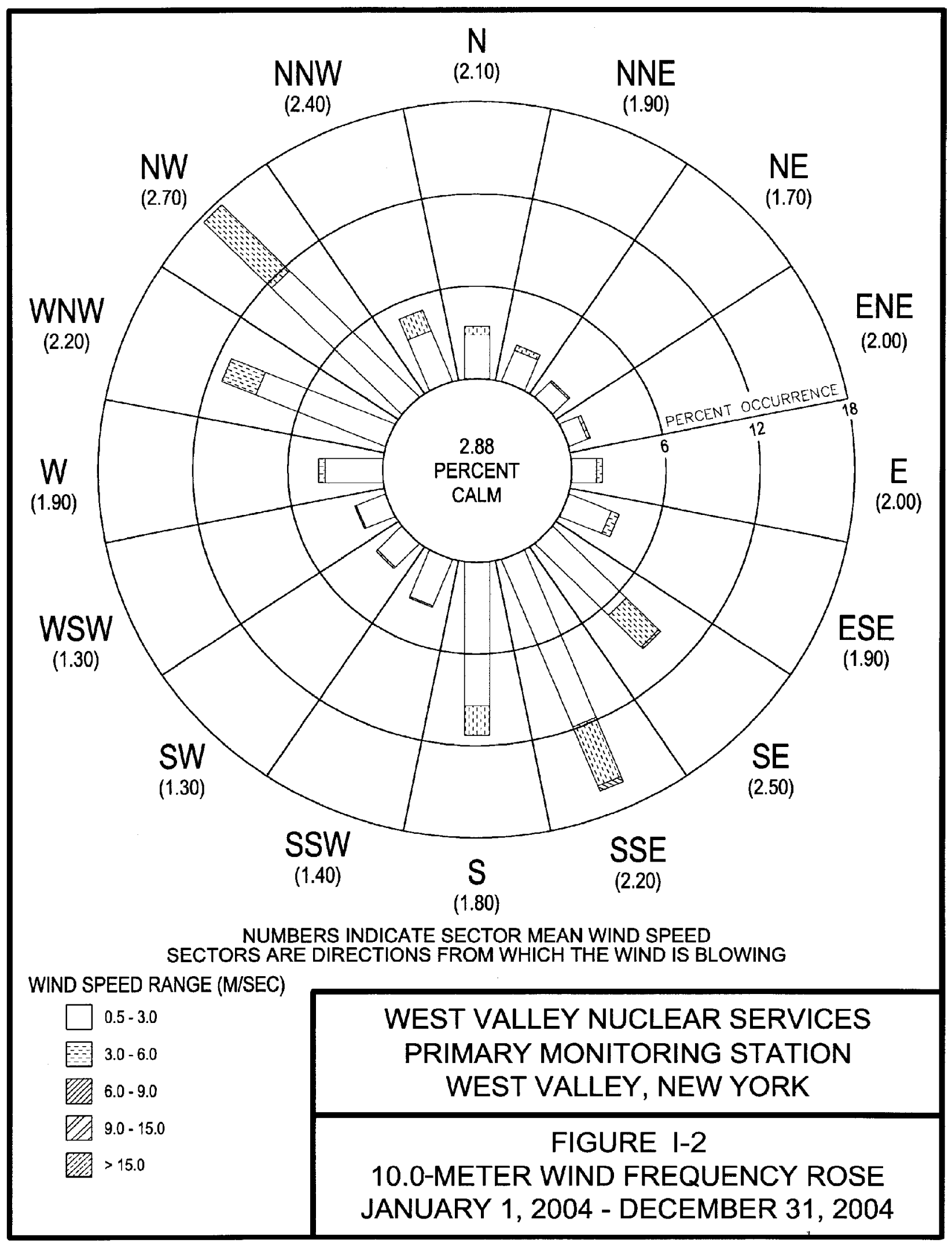

$I-4$ 


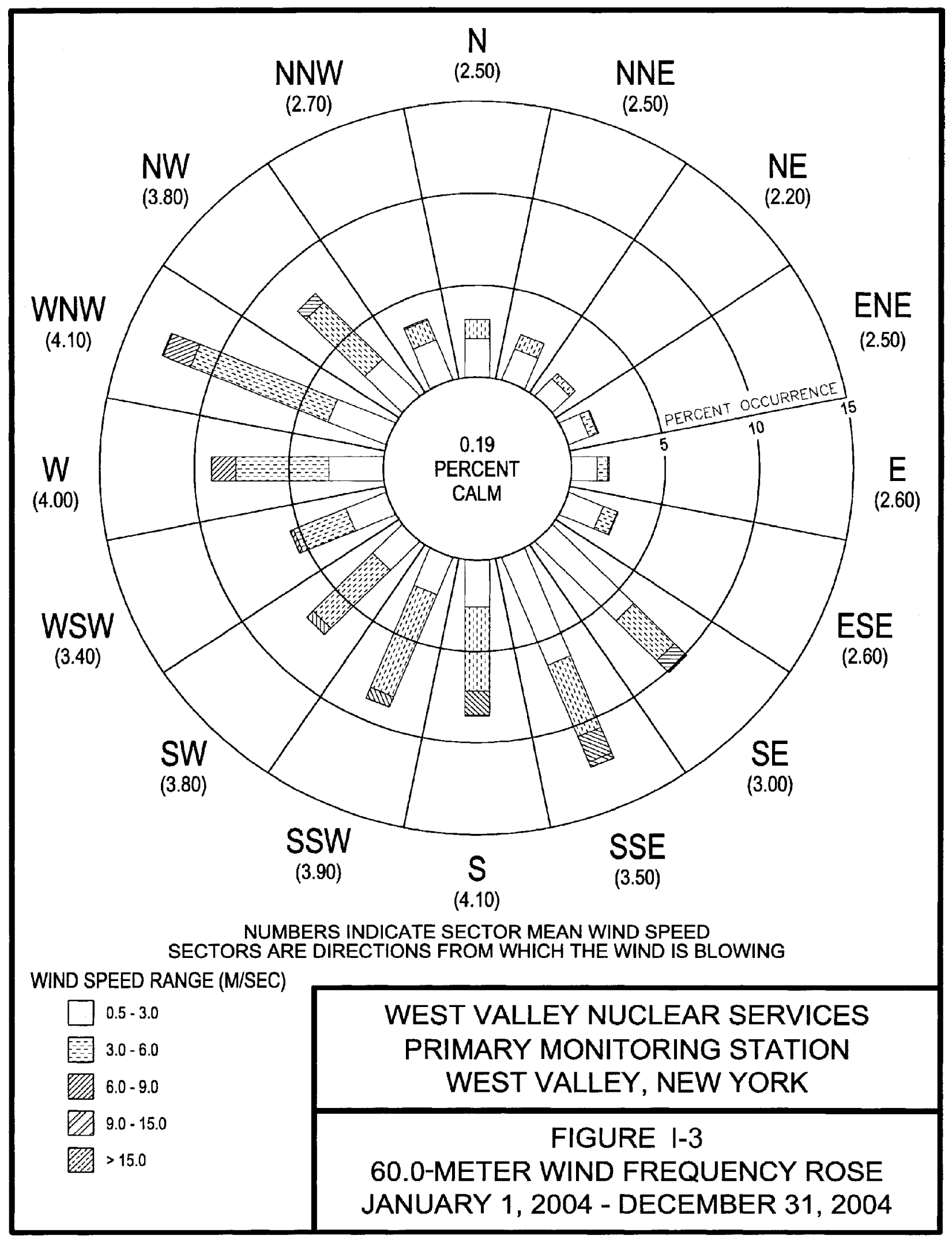

$I-5$ 


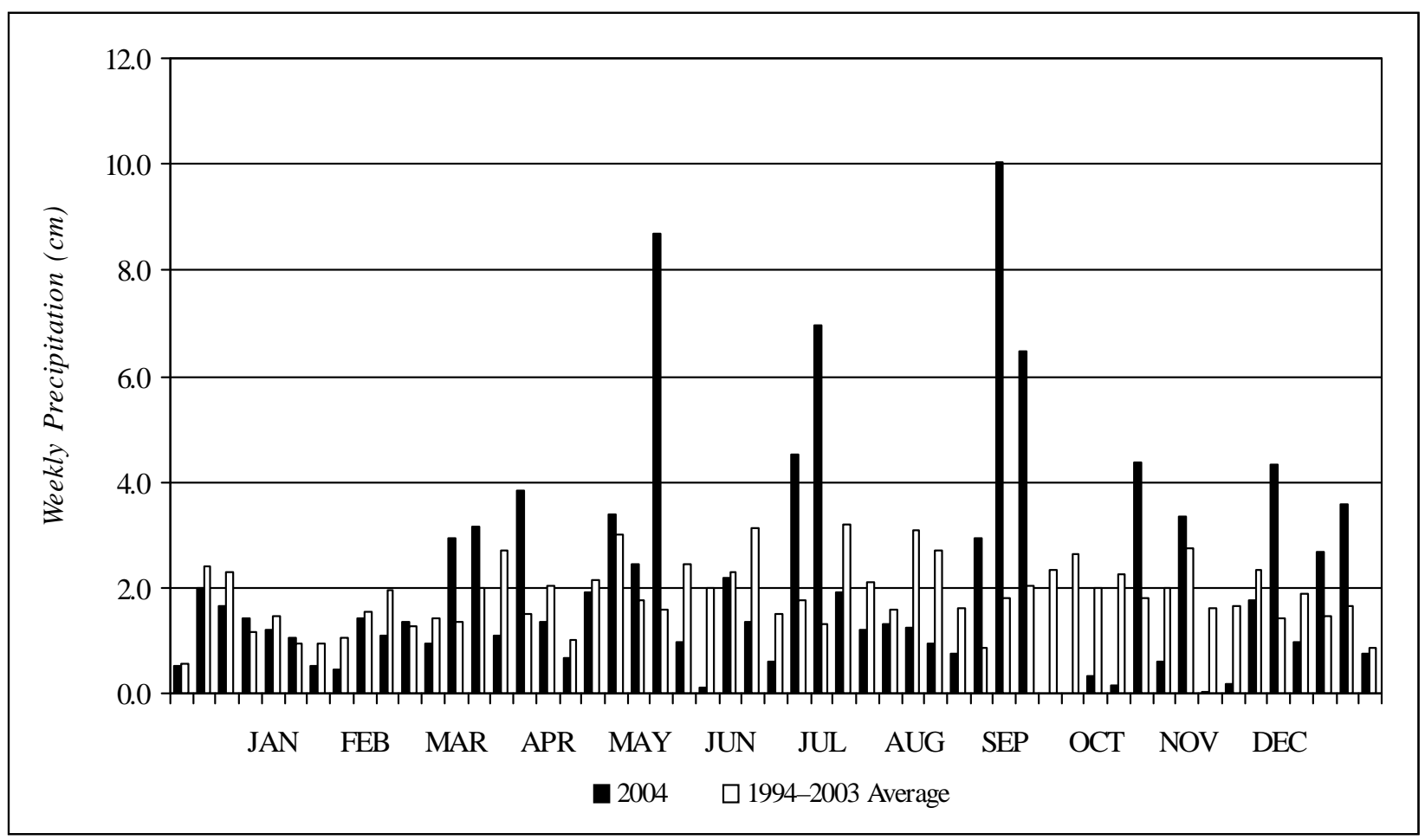

Figure I-4. Calendar Year 2004 Weekly Precipitation

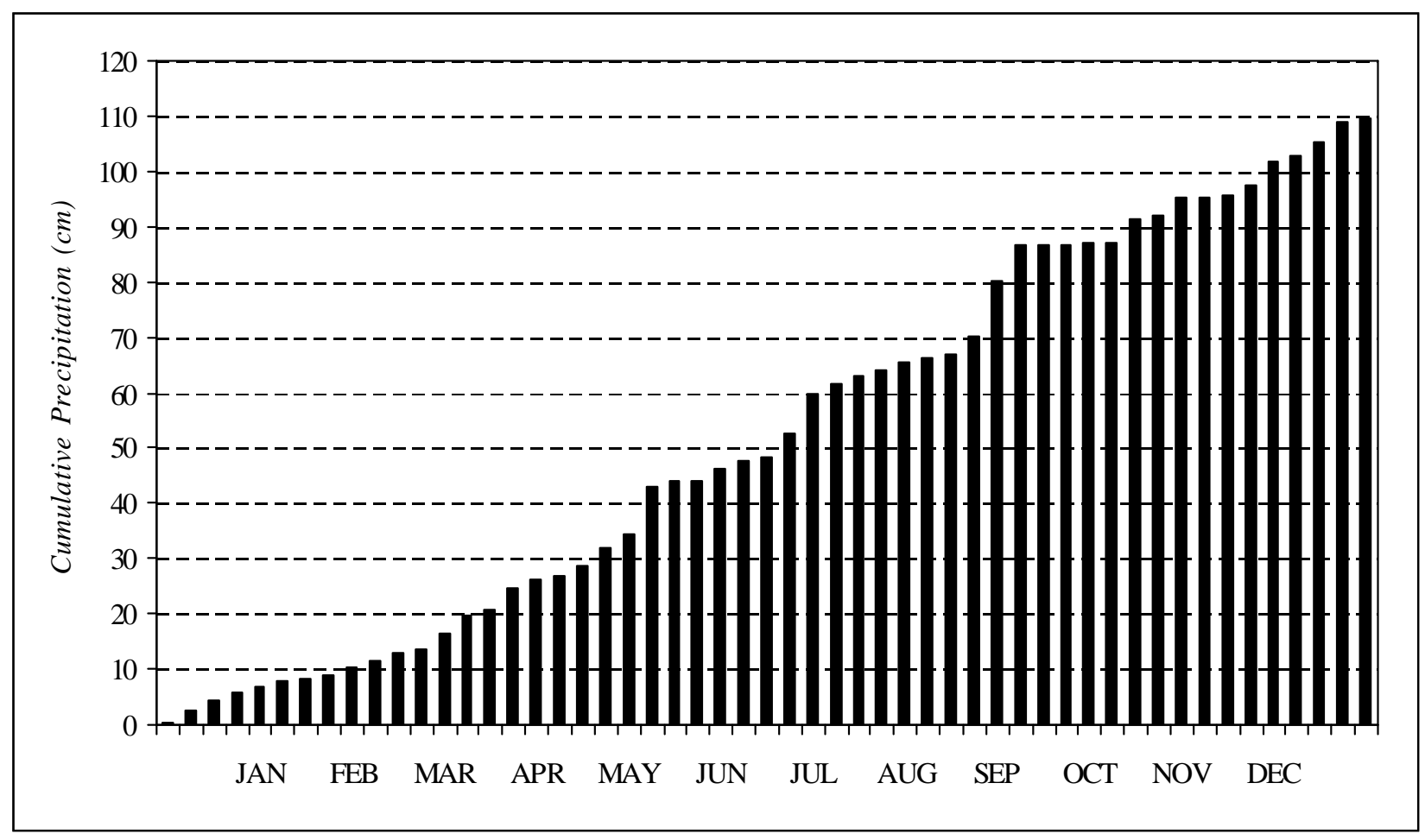

Figure I-5. Calendar Year 2004 Cumulative Precipitation

$$
I-6
$$




\section{Table I-1}

\section{Site Precipitation Collection Data}

\begin{tabular}{|c|c|c|c|c|c|c|c|c|c|}
\hline \multirow{2}{*}{$\begin{array}{l}\text { Week } \\
\text { Ending: }\end{array}$} & \multicolumn{2}{|c|}{ Weekly } & \multicolumn{2}{|c|}{ Cumulative } & \multirow{2}{*}{$\begin{array}{l}\text { Week } \\
\text { Ending: }\end{array}$} & \multicolumn{2}{|c|}{ Weekly } & \multicolumn{2}{|c|}{ Cumulative } \\
\hline & (cm) & (inches) & $(\mathrm{cm})$ & (inches) & & (cm) & (inches) & $(\mathrm{cm})$ & (inches) \\
\hline Jan 02 & 0.51 & 0.20 & 0.51 & 0.20 & Jul 02 & 0.61 & 0.24 & 48.31 & 19.02 \\
\hline Jan 09 & 1.98 & 0.78 & 2.49 & 0.98 & Jul 09 & 4.52 & 1.78 & 52.83 & 20.80 \\
\hline Jan 16 & 1.65 & 0.65 & 4.14 & 1.63 & Jul 16 & 6.96 & 2.74 & 59.79 & 23.54 \\
\hline $\operatorname{Jan} 23$ & 1.45 & 0.57 & 5.59 & 2.20 & Jul 23 & 1.93 & 0.76 & 61.72 & 24.30 \\
\hline $\operatorname{Jan} 30$ & 1.19 & 0.47 & 6.78 & 2.67 & Jul 30 & 1.19 & 0.47 & 62.92 & 24.77 \\
\hline Feb 06 & 1.07 & 0.42 & 7.85 & 3.09 & Aug 06 & 1.32 & 0.52 & 64.24 & 25.29 \\
\hline Feb 13 & 0.53 & 0.21 & 8.38 & 3.30 & Aug 13 & 1.24 & 0.49 & 65.48 & 25.78 \\
\hline Feb 20 & 0.46 & 0.18 & 8.84 & 3.48 & Aug 20 & 0.94 & 0.37 & 66.42 & 26.15 \\
\hline Feb 27 & 1.45 & 0.57 & 10.29 & 4.05 & Aug 27 & 0.74 & 0.29 & 67.16 & 26.44 \\
\hline Mar 05 & 1.09 & 0.43 & 11.38 & 4.48 & Sep 03 & 2.95 & 1.16 & 70.10 & 27.60 \\
\hline Mar 12 & 1.35 & 0.53 & 12.73 & 5.01 & Sep 10 & 10.03 & 3.95 & 80.14 & 31.55 \\
\hline Mar 19 & 0.94 & 0.37 & 13.67 & 5.38 & Sep 17 & 6.45 & 2.54 & 86.59 & 34.09 \\
\hline Mar 26 & 2.95 & 1.16 & 16.61 & 6.54 & Sep 24 & 0.00 & 0.00 & 86.59 & 34.09 \\
\hline Apr 02 & 3.15 & 1.24 & 19.76 & 7.78 & Oct 01 & 0.00 & 0.00 & 86.59 & 34.09 \\
\hline Apr 09 & 1.09 & 0.43 & 20.85 & 8.21 & Oct 08 & 0.36 & 0.14 & 86.94 & 34.23 \\
\hline Apr 16 & 3.84 & 1.51 & 24.69 & 9.72 & Oct 15 & 0.15 & 0.06 & 87.10 & 34.29 \\
\hline Apr 23 & 1.35 & 0.53 & 26.04 & 10.25 & Oct 22 & 4.37 & 1.72 & 91.47 & 36.01 \\
\hline Apr 30 & 0.66 & 0.26 & 26.70 & 10.51 & Oct 29 & 0.61 & 0.24 & 92.08 & 36.25 \\
\hline May 07 & 1.91 & 0.75 & 28.60 & 11.26 & Nov 05 & 3.35 & 1.32 & 95.43 & 37.57 \\
\hline May 14 & 3.38 & 1.33 & 31.98 & 12.59 & Nov 12 & 0.03 & 0.01 & 95.45 & 37.58 \\
\hline May 21 & 2.44 & 0.96 & 34.42 & 13.55 & Nov 19 & 0.20 & 0.08 & 95.66 & 37.66 \\
\hline May 28 & 8.69 & 3.42 & 43.10 & 16.97 & Nov 26 & 1.78 & 0.70 & 97.43 & 38.36 \\
\hline Jun 04 & 0.97 & 0.38 & 44.07 & 17.35 & Dec 03 & 4.34 & 1.71 & 101.78 & 40.07 \\
\hline Jun 11 & 0.10 & 0.04 & 44.17 & 17.39 & Dec 10 & 0.99 & 0.39 & 102.77 & 40.46 \\
\hline Jun 18 & 2.18 & 0.86 & 46.36 & 18.25 & Dec 17 & 2.67 & 1.05 & 105.44 & 41.51 \\
\hline Jun 25 & 1.35 & 0.53 & 47.70 & 18.78 & $\operatorname{Dec} 24$ & 3.58 & 1.41 & 109.02 & 42.92 \\
\hline & & & & & $\operatorname{Dec} 31$ & 0.74 & 0.29 & 109.75 & 43.21 \\
\hline
\end{tabular}

$$
I-7
$$


This page intentionally left blank

$$
I-8
$$




\section{Appendix $J$ \\ Summary of Quality Assurance Crosscheck Analyses}

$$
J-1
$$


This page intentionally left blank

$$
J-2
$$


Table J-1

Crosscheck Sample Comparisons From the DOE Environmental Measurements Laboratory (EML) Quality Assessment Program (QAP) 60; QAP 0403; June 2004

\begin{tabular}{|c|c|c|c|c|c|c|c|}
\hline Analyte & Matrix & Units & Actual & Reported & Ratio & Accept? & $\begin{array}{c}\text { Analyzed } \\
\text { by: }\end{array}$ \\
\hline Co-60 & Air filter & $\mathrm{Bq} /$ filter & 35.4 & 36.3 & 1.025 & Yes & ELAB \\
\hline Co-60 & Air filter & $\mathrm{Bq} /$ filter & 35.4 & 36.4 & 1.028 & Yes & ELAB \\
\hline Cs-137 & Air filter & $\mathrm{Bq} /$ filter & 26.4 & 27.8 & 1.053 & Yes & ELAB \\
\hline Cs-137 & Air filter & $\mathrm{Bq} /$ filter & 26.4 & 27.7 & 1.049 & Yes & ELAB \\
\hline Gross Alpha & Air filter & $\mathrm{Bq} /$ filter & 1.2 & 1.16 & 0.967 & Yes & ELAB \\
\hline Gross Beta & Air filter & $\mathrm{Bq} /$ filter & 2.85 & 2.92 & 1.025 & Yes & ELAB \\
\hline $\mathrm{Am}-241$ & Air filter & $\mathrm{Bq} /$ filter & 0.1045 & 0.093 & 0.890 & Yes & GEL \\
\hline Co-60 & Air filter & $\mathrm{Bq} /$ filter & 35.4 & 35.754 & 1.010 & Yes & GEL \\
\hline Cs-137 & Air filter & $\mathrm{Bq} /$ filter & 26.4 & 26.369 & 0.999 & Yes & GEL \\
\hline Gross Alpha & Air filter & $\mathrm{Bq} /$ filter & 1.2 & 1.181 & 0.984 & Yes & GEL \\
\hline Gross Beta & Air filter & $\mathrm{Bq} /$ filter & 2.85 & 2.326 & 0.816 & Yes & GEL \\
\hline $\mathrm{Pu}-238$ & Air filter & $\mathrm{Bq} /$ filter & 0.0405 & 0.038 & 0.938 & Pass & GEL \\
\hline $\mathrm{Pu}-239$ & Air filter & $\mathrm{Bq} /$ filter & 0.1644 & 0.157 & 0.955 & Yes & GEL \\
\hline Sr-90 & Air filter & $\mathrm{Bq} /$ filter & 1.76 & 1.72 & 0.977 & Yes & GEL \\
\hline $\mathrm{U}-234$ & Air filter & $\mathrm{Bq} /$ filter & 0.0858 & 0.079 & 0.921 & Yes & GEL \\
\hline U-238 & Air filter & $\mathrm{Bq} /$ filter & 0.085 & 0.075 & 0.882 & Pass & GEL \\
\hline $\mathrm{U}$ (total) & Air filter & $\mu \mathrm{g} /$ filter & 6.873 & 6.7 & 0.975 & Yes & GEL \\
\hline Am-241 & Soil & $\mathrm{Bq} / \mathrm{kg}$ & 13.0 & 12.925 & 0.994 & Yes & GEL \\
\hline Cs-137 & Soil & $\mathrm{Bq} / \mathrm{kg}$ & $1,323.0$ & $1,411.797$ & 1.067 & Yes & GEL \\
\hline K-40 & Soil & $\mathrm{Bq} / \mathrm{kg}$ & 539.0 & 616.667 & 1.144 & Yes & GEL \\
\hline $\mathrm{Pu}-238$ & Soil & $\mathrm{Bq} / \mathrm{kg}$ & 0.82 & 0.772 & 0.941 & Yes & GEL \\
\hline $\mathrm{Pu}-239$ & Soil & $\mathrm{Bq} / \mathrm{kg}$ & 22.82 & 22.336 & 0.979 & Yes & GEL \\
\hline Sr-90 & Soil & $\mathrm{Bq} / \mathrm{kg}$ & 51.0 & 49.765 & 0.976 & Yes & GEL \\
\hline Th-234 & Soil & $\mathrm{Bq} / \mathrm{kg}$ & 84.0 & 97.446 & 1.160 & Yes & GEL \\
\hline U-234 & Soil & $\mathrm{Bq} / \mathrm{kg}$ & 87.22 & 77.33 & 0.887 & Yes & GEL \\
\hline $\mathrm{U}-238$ & Soil & $\mathrm{Bq} / \mathrm{kg}$ & 89.73 & 86.58 & 0.965 & Yes & GEL \\
\hline $\mathrm{U}$ (total) & Soil & $\mu \mathrm{g} / \mathrm{g}$ & 7.25 & 6.763 & 0.933 & Yes & GEL \\
\hline
\end{tabular}

\section{ELAB - Environmental Laboratory \\ GEL - General Engineering Laboratory}

Note: This report has been excerpted to include only those matrix/analyte combinations performed in support of the analyses of samples collected at the WVDP and which are presented in this Annual Site Environmental Report.

Acceptance is based on the reported-to-actual ratio, assigned statistically on a case-by-case basis. Yes indicates a ratio within warning limits. Pass indicates a ratio within control limits but outside warning limits. No indicates a ratio outside control limits. 


\section{Table J-1 (concluded)}

Crosscheck Sample Comparisons From the DOE Environmental Measurements Laboratory (EML) Quality Assessment Program (QAP) 60; QAP 0403; June 2004

\begin{tabular}{|l|c|c|c|c|c|c|c|}
\hline \multicolumn{1}{|c|}{ Analyte } & Matrix & Units & Actual & Reported & Ratio & Accept? & Analyzed by: \\
\hline Am-241 & Veg & $\mathrm{Bq} / \mathrm{kg}$ & 4.93 & 4.415 & 0.896 & Yes & GEL \\
\hline Co-60 & Veg & $\mathrm{Bq} / \mathrm{kg}$ & 14.47 & 15.873 & 1.097 & Yes & GEL \\
\hline Cs-137 & Veg & $\mathrm{Bq} / \mathrm{kg}$ & 584.67 & 649.967 & 1.112 & Yes & GEL \\
\hline $\mathrm{K}-40$ & Veg & $\mathrm{Bq} / \mathrm{kg}$ & 720.0 & 830.033 & 1.153 & Yes & GEL \\
\hline Pu-238 & Veg & $\mathrm{Bq} / \mathrm{kg}$ & 0.455 & 0.545 & 1.198 & Yes & GEL \\
\hline Pu-239 & Veg & $\mathrm{Bq} / \mathrm{kg}$ & 6.81 & 6.475 & 0.951 & Yes & GEL \\
\hline Sr-90 & Veg & $\mathrm{Bq} / \mathrm{kg}$ & 734.0 & 852.702 & 1.162 & Pass & GEL \\
\hline & & & & & & & \\
\hline Co-60 & Water & $\mathrm{Bq} / \mathrm{L}$ & 163.2 & 158.0 & 0.968 & Yes & ELAB \\
\hline Cs-137 & Water & $\mathrm{Bq} / \mathrm{L}$ & 51.95 & 52.4 & 1.009 & Yes & ELAB \\
\hline Gross Alpha & Water & $\mathrm{Bq} / \mathrm{L}$ & 326.0 & 299.0 & 0.917 & Yes & ELAB \\
\hline Gross Beta & Water & $\mathrm{Bq} / \mathrm{L}$ & $1,170.0$ & $1,242.0$ & 1.062 & Yes & ELAB \\
\hline H-3 & Water & $\mathrm{Bq} / \mathrm{L}$ & 186.6 & 230.0 & 1.233 & Yes & ELAB \\
\hline Sr-90 & Water & $\mathrm{Bq} / \mathrm{L}$ & 4.76 & 5.06 & 1.063 & Yes & ELAB \\
\hline Am-241 & Water & $\mathrm{Bq} / \mathrm{L}$ & 1.31 & 1.127 & 0.860 & Pass & GEL \\
\hline Co-60 & Water & $\mathrm{Bq} / \mathrm{L}$ & 163.2 & 157.867 & 0.967 & Yes & GEL \\
\hline Cs-137 & Water & $\mathrm{Bq} / \mathrm{L}$ & 51.95 & 50.69 & 0.976 & Yes & GEL \\
\hline Gross Alpha & Water & $\mathrm{Bq} / \mathrm{L}$ & 326.0 & 336.763 & 1.033 & Yes & GEL \\
\hline Gross Beta & Water & $\mathrm{Bq} / \mathrm{L}$ & $1,170.0$ & $1,157.069$ & 0.989 & Yes & GEL \\
\hline H-3 & Water & $\mathrm{Bq} / \mathrm{L}$ & 186.6 & 202.991 & 1.088 & Yes & GEL \\
\hline Pu-238 & Water & $\mathrm{Bq} / \mathrm{L}$ & 1.1 & 1.023 & 0.930 & Yes & GEL \\
\hline Pu-239 & Water & $\mathrm{Bq} / \mathrm{L}$ & 3.08 & 2.884 & 0.936 & Yes & GEL \\
\hline Sr-90 & Water & $\mathrm{Bq} / \mathrm{L}$ & 4.76 & 5.144 & 1.081 & Yes & GEL \\
\hline U-234 & Water & $\mathrm{Bq} / \mathrm{L}$ & 2.28 & 2.199 & 0.964 & Yes & GEL \\
\hline U-238 & Water & $\mathrm{Bq} / \mathrm{L}$ & 2.25 & 2.188 & 0.972 & Yes & GEL \\
\hline $\mathrm{U}$ (total) & Water & $\mu \mathrm{g} / \mathrm{mL}$ & 0.182 & 0.1927 & 1.059 & Yes & GEL \\
\hline
\end{tabular}

ELAB - Environmental Laboratory

GEL - General Engineering Laboratory

Note: This report has been excerpted to include only those matrix/analyte combinations performed in support of the analyses of samples collected at the WVDP and which are presented in this Annual Site Environmental Report.

Acceptance is based on the reported-to-actual ratio, assigned statistically on a case-by-case basis. Yes indicates a ratio within warning limits. Pass indicates a ratio within control limits but outside warning limits. No indicates a ratio outside control limits 
Table J-2

Crosscheck Sample Comparisons From the DOE Mixed Analyte Performance Evaluation Program (MAPEP) ; May 2004

\begin{tabular}{|c|c|c|c|c|c|c|c|}
\hline Analyte & Matrix & Units & Actual & Reported & $\begin{array}{c}\text { Acceptance } \\
\text { Range }\end{array}$ & Accept? & $\begin{array}{c}\text { Analyzed } \\
\text { by: }\end{array}$ \\
\hline \multicolumn{8}{|c|}{ MAPEP - 03 - W11 } \\
\hline Antimony & Water & $\mathrm{mg} / \mathrm{L}$ & 0.1296 & 0.121 & $0.09-0.17$ & Yes & LVLI \\
\hline Arsenic & Water & $\mathrm{mg} / \mathrm{L}$ & 0.0537 & 0.0456 & $0.04-0.07$ & Yes & LVLI \\
\hline Barium & Water & $\mathrm{mg} / \mathrm{L}$ & 0.541 & 0.523 & $0.38-0.70$ & Yes & LVLI \\
\hline Beryllium & Water & $\mathrm{mg} / \mathrm{L}$ & 0.0985 & 0.0914 & $0.07-0.13$ & Yes & LVLI \\
\hline Cadmium & Water & $\mathrm{mg} / \mathrm{L}$ & 0.0799 & 0.0749 & $0.06-0.10$ & Yes & LVLI \\
\hline Copper & Water & $\mathrm{mg} / \mathrm{L}$ & 0.803 & 0.751 & $0.56-1.04$ & Yes & LVLI \\
\hline Lead & Water & $\mathrm{mg} / \mathrm{L}$ & 0.894 & 0.844 & $0.63-1.16$ & Yes & LVLI \\
\hline Nickel & Water & $\mathrm{mg} / \mathrm{L}$ & 0.495 & 0.467 & $0.35-0.64$ & Yes & LVLI \\
\hline Selenium & Water & $\mathrm{mg} / \mathrm{L}$ & 0.06981 & 0.0654 & $0.05-0.09$ & Yes & LVLI \\
\hline Silver & Water & $\mathrm{mg} / \mathrm{L}$ & -- & 0.00084 & -- & $\mathrm{Yes}^{\mathrm{b}}$ & LVLI \\
\hline Thallium & Water & $\mathrm{mg} / \mathrm{L}$ & 2.088 & 1.98 & $1.46-2.71$ & Yes & LVLI \\
\hline Vanadium & Water & $\mathrm{mg} / \mathrm{L}$ & 1.2 & 1.13 & $0.84-1.56$ & Yes & LVLI \\
\hline Zinc & Water & $\mathrm{mg} / \mathrm{L}$ & 1.037 & 0.965 & $0.73-1.35$ & Yes & LVLI \\
\hline 1,3-Dichlorobenzene & Water & $\mu \mathrm{g} / \mathrm{L}$ & 39.6 & 43 & $14.00-65.16$ & Yes & LVLI \\
\hline 1,2-Dichlorobenzene & Water & $\mu \mathrm{g} / \mathrm{L}$ & 22.7 & 25 & $9.45-36.03$ & Yes & LVLI \\
\hline 2,4-Dimethylphenol & Water & $\mu \mathrm{g} / \mathrm{L}$ & 79.2 & 79 & $40.94-117.57$ & Yes & LVLI \\
\hline 2,4-Dichlorophenol & Water & $\mu \mathrm{g} / \mathrm{L}$ & 73.1 & 74 & $30.38-115.76$ & Yes & LVLI \\
\hline 1,2,4-Trichlorobenzene & Water & $\mu \mathrm{g} / \mathrm{L}$ & 41.4 & 49 & $0.53-82.22$ & Yes & LVLI \\
\hline Napthalene & Water & $\mu \mathrm{g} / \mathrm{L}$ & 48.2 & 53 & $11.02-85.43$ & Yes & LVLI \\
\hline 4-Chloro-3-methylphenol & Water & $\mu \mathrm{g} / \mathrm{L}$ & 30.5 & 33 & $14.05-46.97$ & Yes & LVLI \\
\hline 2-Methylphenol & Water & $\mu \mathrm{g} / \mathrm{L}$ & 45.4 & 51 & $15.37-75.49$ & Yes & LVLI \\
\hline 2,6-Dichlorophenol & Water & $\mu \mathrm{g} / \mathrm{L}$ & 55.7 & 60 & $18.03-93.29$ & Yes & LVLI \\
\hline 2,6-Dinitrotoluene & Water & $\mu \mathrm{g} / \mathrm{L}$ & 74.1 & 69 & $44.30-103.91$ & Yes & LVLI \\
\hline 2,4-Dinitrotoluene & Water & $\mu \mathrm{g} / \mathrm{L}$ & 91.8 & 110 & $46.77-136.82$ & Yes & LVLI \\
\hline Fluorene & Water & $\mu \mathrm{g} / \mathrm{L}$ & 28.9 & 37 & QL-85.38 & Yes & LVLI \\
\hline Diethylphthalate & Water & $\mu \mathrm{g} / \mathrm{L}$ & 61.9 & 60 & $26.41-97.43$ & Yes & LVLI \\
\hline Phenanthrene & Water & $\mu \mathrm{g} / \mathrm{L}$ & 23.2 & 27 & QL-49.06 & Yes & LVLI \\
\hline Anthracene & Water & $\mu \mathrm{g} / \mathrm{L}$ & 35.4 & 39 & QL-78.28 & Yes & LVLI \\
\hline Pyrene & Water & $\mu \mathrm{g} / \mathrm{L}$ & 35 & 49 & QL-110.01 & Yes & LVLI \\
\hline Benzo(a)anthracene & Water & $\mu \mathrm{g} / \mathrm{L}$ & 62.1 & 66 & $4.91-119.29$ & Yes & LVLI \\
\hline Chrysene & Water & $\mu \mathrm{g} / \mathrm{L}$ & 41.1 & 46 & QL-84.03 & Yes & LVLI \\
\hline
\end{tabular}

LVLI - Lionville Laboratories, Inc.

$Q L$ - Quantitation limit

${ }^{a}$ MAPEP monitors performance and requests corrective action as required.

${ }^{b}$ Although no actual values or acceptable range was provided, the results were assessed by MAPEP as acceptable.

Note: This report has been excerpted to include only those matrix/analyte combinations performed in support of the analyses of samples collected at the WVDP and which are presented in this Annual Site Environmental Report. 
Table J-2 (concluded)

\section{Crosscheck Sample Comparisons From the DOE Mixed Analyte Performance Evaluation Program (MAPEP); May 2004}

\begin{tabular}{|l|c|c|c|c|c|c|c|}
\hline \multicolumn{1}{|c|}{ Analyte } & Matrix & Units & Actual & Reported & $\begin{array}{c}\text { Acceptance } \\
\text { Range }\end{array}$ & Accept? & $\begin{array}{c}\text { Analyzed } \\
\text { by: }\end{array}$ \\
\hline Am-241 & Water & Bq/L & -- & 0.008 & - & Yes & GEL \\
\hline Cs-137 & Water & Bq/L & 124 & 118.6 & $86.80-161.20$ & Yes & GEL \\
\hline Co-60 & Water & Bq/L & 121.8 & 122.3 & $85.26-158.34$ & Yes & GEL \\
\hline H-3 & Water & Bq/L & 379 & 389.7 & $265.30-492.70$ & Yes & GEL \\
\hline Pu-238 & Water & Bq/L & 1.49 & 1.364 & $1.04-1.94$ & Yes & GEL \\
\hline Pu-239/240 & Water & Bq/L & 2.39 & 2.232 & $1.67-3.11$ & Yes & GEL \\
\hline Sr-90 & Water & Bq/L & 17.7 & 17.132 & $12.39-23.01$ & Yes & GEL \\
\hline Tc-99 & Water & $\mathrm{Bq} / \mathrm{L}$ & 28.8 & 23.96 & $20.16-37.44$ & Yes & GEL \\
\hline U-233/234 & Water & $\mathrm{Bq} / \mathrm{L}$ & 2.35 & 2.305 & $1.64-3.05$ & Yes & GEL \\
\hline U-238 & Water & $\mathrm{Bq} / \mathrm{L}$ & 2.43 & 2.184 & $1.70-3.16$ & Yes & GEL \\
\hline
\end{tabular}

GEL - General Engineering Laboratories

${ }^{a}$ MAPEP monitors performance and requests corrective action as required.

${ }^{b}$ Although no actual values or acceptable range was provided, the results were assessed by MAPEP as acceptable.

Note: This report has been excerpted to include only those matrix/analyte combinations performed in support of the analyses of samples collected at the WVDP and which are presented in this Annual Site Environmental Report.

$J-6$ 
Table J-3

\section{Crosscheck Sample Comparisons From the DOE Mixed Analyte Performance Evaluation Program (MAPEP); November 2004}

\begin{tabular}{|c|c|c|c|c|c|c|c|}
\hline Analyte & Matrix & Units & Actual & Reported & $\begin{array}{c}\text { Acceptance } \\
\text { Range }\end{array}$ & Accept? & $\begin{array}{c}\text { Analyzed } \\
\text { by: }\end{array}$ \\
\hline \multicolumn{8}{|c|}{ MAPEP - 04 - GrF12 Gross Alpha/Beta Air Filter } \\
\hline Gross Alpha & Air Filter & Bq/filter & 0.37 & 0.123 & $>0.0-0.8$ & Yes & ELAB \\
\hline Gross Beta & Air Filter & Bq/filter & 1.21 & 1.25 & $0.6-1.8$ & Yes & ELAB \\
\hline \multicolumn{8}{|c|}{ MAPEP - 04 - GrW12 Gross Alpha/Beta Water Standard } \\
\hline Gross Alpha & Water & $\mathrm{Bq} / \mathrm{L}$ & 1.24 & 0.699 & $0.0-2.5$ & Yes & ELAB \\
\hline Gross Beta & Water & $\mathrm{Bq} / \mathrm{L}$ & 4.07 & 4.01 & $2.0-6.2$ & Yes & ELAB \\
\hline Gross Alpha & Water & $\mathrm{Bq} / \mathrm{L}$ & 1.24 & 0.949 & $0.0-2.5$ & Yes & GEL \\
\hline Gross Beta & Water & $\mathrm{Bq} / \mathrm{L}$ & 4.07 & 4.172 & $2.0-6.2$ & Yes & GEL \\
\hline \multicolumn{8}{|c|}{ MAPEP - 04 - MaS12 Soil Standard } \\
\hline Antimony & Soil & $\mathrm{mg} / \mathrm{kg}$ & 47.1 & 25.9 & $33.00-61.20$ & No & LVLI \\
\hline Arsenic & Soil & $\mathrm{mg} / \mathrm{kg}$ & 63 & 60.3 & $44.10-81.90$ & Yes & LVLI \\
\hline Barium & Soil & $\mathrm{mg} / \mathrm{kg}$ & 559.7 & 557 & $391.79-727.61$ & Yes & LVLI \\
\hline Beryllium & Soil & $\mathrm{mg} / \mathrm{kg}$ & 18.83 & 17.9 & $13.18-24.48$ & Yes & LVLI \\
\hline Cadmium & Soil & $\mathrm{mg} / \mathrm{kg}$ & 10.03 & 9.4 & $7.02-13.04$ & Yes & LVLI \\
\hline Chromium & Soil & $\mathrm{mg} / \mathrm{kg}$ & 67 & 77.0 & $46.90-87.10$ & Yes & LVLI \\
\hline Lead & Soil & $\mathrm{mg} / \mathrm{kg}$ & 62.4 & 59.8 & $43.68-81.12$ & Yes & LVLI \\
\hline Nickel & Soil & $\mathrm{mg} / \mathrm{kg}$ & 113 & 111 & $79.10-146.90$ & Yes & LVLI \\
\hline Selenium & Soil & $\mathrm{mg} / \mathrm{kg}$ & 9.09 & 8.4 & $6.36-11.82$ & Yes & LVLI \\
\hline Silver & Soil & $\mathrm{mg} / \mathrm{kg}$ & 19.8 & 19.3 & $13.86-25.74$ & Yes & LVLI \\
\hline Thallium & Soil & $\mathrm{mg} / \mathrm{kg}$ & 88.6 & 84.2 & $62.02-115.18$ & Yes & LVLI \\
\hline Vanadium & Soil & $\mathrm{mg} / \mathrm{kg}$ & 60.8 & 63.8 & $42.56-79.04$ & Yes & LVLI \\
\hline Zinc & Soil & $\mathrm{mg} / \mathrm{kg}$ & 146 & 151 & $102.20-189.80$ & Yes & LVLI \\
\hline Am-241 & Soil & $\mathrm{Bq} / \mathrm{kg}$ & 67 & 67.35 & $46.88-87.06$ & Yes & GEL \\
\hline Cs-137 & Soil & $\mathrm{Bq} / \mathrm{kg}$ & 836 & 774.040 & $585.34-1,087.06$ & Yes & GEL \\
\hline Сo-60 & Soil & $\mathrm{Bq} / \mathrm{kg}$ & 518 & 510.353 & $362.60-673.40$ & Yes & GEL \\
\hline $\mathrm{Pu}-238$ & Soil & $\mathrm{Bq} / \mathrm{kg}$ & 35.4 & 32.8 & $24.78-46.02$ & Yes & GEL \\
\hline $\mathrm{Pu}-239 / 240$ & Soil & $\mathrm{Bq} / \mathrm{kg}$ & 41.8 & 3.067 & 29.27-54.35 & No & GEL \\
\hline $\mathrm{K}-40$ & Soil & $\mathrm{Bq} / \mathrm{kg}$ & 604 & 640.717 & $422.80-785.20$ & Yes & GEL \\
\hline Sr-90 & Soil & $\mathrm{Bq} / \mathrm{kg}$ & & 1.21 & -- & $\mathrm{No}^{\mathrm{c}}$ & GEL \\
\hline U-233/234 & Soil & $\mathrm{Bq} / \mathrm{kg}$ & 37 & 24.691 & $25.90-48.10$ & No & GEL \\
\hline $\mathrm{U}-238$ & Soil & $\mathrm{Bq} / \mathrm{kg}$ & 38.9 & 30.759 & $27.19-50.50$ & $\mathrm{Yes}^{\mathrm{d}}$ & GEL \\
\hline
\end{tabular}

ELAB - Environmental Laboratory

GEL - General Engineering Laboratories

LVLI - Lionville Laboratories, Inc.

${ }^{a}$ MAPEP monitors performance and requests corrective action as required.

${ }^{b}$ False positive

${ }^{c}$ Although no actual values or acceptable range was provided, the results were assessed by MAPEP as not acceptable.

${ }^{d}$ Result acceptable with warning $20 \%<$ bias $<=30 \%$

Note: This report has been excerpted to include only those matrix/analyte combinations performed in support of the analyses of samples collected at the WVDP and which are presented in this Annual Site Environmental Report.

$$
J-7
$$


Table J-3 (continued)

\section{Crosscheck Sample Comparisons From the DOE Mixed Analyte Performance Evaluation Program (MAPEP) ; November 2004}

\begin{tabular}{|c|c|c|c|c|c|c|c|}
\hline Analyte & Matrix & Units & Actual & Reported & $\begin{array}{c}\text { Acceptance } \\
\text { Range }\end{array}$ & Accept? & $\begin{array}{l}\text { Analyzed } \\
\text { by: }\end{array}$ \\
\hline \multicolumn{8}{|c|}{ MAPEP - 04 - MaW12 Water Standard } \\
\hline Antimony & Water & $\mathrm{mg} / \mathrm{L}$ & 0.936 & 0.939 & $0.66-1.22$ & Yes & LVLI \\
\hline Arsenic & Water & $\mathrm{mg} / \mathrm{L}$ & 1.3775 & 1.400 & $0.96-1.79$ & Yes & LVLI \\
\hline Barium & Water & $\mathrm{mg} / \mathrm{L}$ & 29.3 & 29.700 & $20.51-38.09$ & Yes & LVLI \\
\hline Beryllium & Water & $\mathrm{mg} / \mathrm{L}$ & -- & 0.00010 & -- & Yes $^{\mathrm{b}}$ & LVLI \\
\hline Cadmium & Water & $\mathrm{mg} / \mathrm{L}$ & 0.5524 & 0.549 & $0.39-0.72$ & Yes & LVLI \\
\hline Chromium & Water & $\mathrm{mg} / \mathrm{L}$ & 0.956 & 0.963 & $0.67-1.24$ & Yes & LVLI \\
\hline Copper & Water & $\mathrm{mg} / \mathrm{L}$ & 9.162 & 9.230 & $6.41-11.91$ & Yes & LVLI \\
\hline Lead & Water & $\mathrm{mg} / \mathrm{L}$ & 0.503 & 0.506 & $0.35-0.65$ & Yes & LVLI \\
\hline Nickel & Water & $\mathrm{mg} / \mathrm{L}$ & 3.0806 & 3.120 & $2.16-4.00$ & Yes & LVLI \\
\hline Selenium & Water & $\mathrm{mg} / \mathrm{L}$ & -- & 0.0039 & -- & Yes & LVLI \\
\hline Thallium & Water & $\mathrm{mg} / \mathrm{L}$ & 4.202 & 4.330 & $2.94-5.46$ & Yes & LVLI \\
\hline Vanadium & Water & $\mathrm{mg} / \mathrm{L}$ & 0.506 & 0.507 & $0.35-0.66$ & Yes & LVLI \\
\hline Zinc & Water & $\mathrm{mg} / \mathrm{L}$ & 2.292 & 2.330 & $1.60-2.98$ & Yes & LVLI \\
\hline Cs-137 & Water & $\mathrm{Bq} / \mathrm{L}$ & 250 & 240 & $175.00-325.00$ & Yes & ELAB \\
\hline Co-60 & Water & $\mathrm{Bq} / \mathrm{L}$ & 163 & 159 & $114.10-211.90$ & Yes & ELAB \\
\hline $\mathrm{H}-3$ & Water & $\mathrm{Bq} / \mathrm{L}$ & 82.9 & 85.1 & $58.10-107.90$ & Yes & ELAB \\
\hline Sr-90 & Water & $\mathrm{Bq} / \mathrm{L}$ & 7.4 & 0.459 & $4.90-9.10$ & No & ELAB \\
\hline Am-241 & Water & $\mathrm{Bq} / \mathrm{L}$ & 0.59 & 0.605 & $0.42-0.78$ & Yes & GEL \\
\hline Cs-137 & Water & $\mathrm{Bq} / \mathrm{L}$ & 250 & 236.874 & $175.00-325.00$ & Yes & GEL \\
\hline Co-60 & Water & $\mathrm{Bq} / \mathrm{L}$ & 163 & 162.837 & $114.10-211.90$ & Yes & GEL \\
\hline $\mathrm{H}-3$ & Water & $\mathrm{Bq} / \mathrm{L}$ & 82.9 & 95.726 & $58.10-107.90$ & Yes & GEL \\
\hline $\mathrm{Pu}-238$ & Water & $\mathrm{Bq} / \mathrm{L}$ & 1.24 & 1.277 & $0.84-1.56$ & Yes & GEL \\
\hline $\mathrm{Pu}-239 / 240$ & Water & $\mathrm{Bq} / \mathrm{L}$ & -- & 0.020 & -- & Yes & GEL \\
\hline Sr-90 & Water & $\mathrm{Bq} / \mathrm{L}$ & 7.4 & 6.685 & $4.90-9.10$ & Yes & GEL \\
\hline Tc-99 & Water & $\mathrm{Bq} / \mathrm{L}$ & 10.4 & 9.098 & $7.00-13.00$ & Yes & GEL \\
\hline $\mathrm{U}-233 / 234$ & Water & $\mathrm{Bq} / \mathrm{L}$ & 0.144 & 0.141 & $0.10-0.19$ & Yes & GEL \\
\hline $\mathrm{U}-238$ & Water & $\mathrm{Bq} / \mathrm{L}$ & 0.94 & 0.982 & $0.63-1.17$ & Yes & GEL \\
\hline
\end{tabular}

ELAB - Environmental Laboratory

GEL - General Engineering Laboratories

LVLI - Lionville Laboratories, Inc.

${ }^{a}$ MAPEP monitors performance and requests corrective action as required.

${ }^{b}$ Although no actual values or acceptable range was provided, the results were assessed by MAPEP as acceptable.

Note: This report has been excerpted to include only those matrix/analyte combinations performed in support of the analyses of samples collected at the WVDP and which are presented in this Annual Site Environmental Report. 


\section{Table J-3 (concluded)}

\section{Crosscheck Sample Comparisons From the DOE Mixed Analyte Performance Evaluation Program (MAPEP) ; November 2004}

\begin{tabular}{|l|c|c|c|c|c|c|c|}
\hline \multicolumn{1}{|c|}{ Analyte } & Matrix & Units & Actual & Reported & $\begin{array}{c}\text { Acceptance } \\
\text { Range }\end{array}$ & Accept? & $\begin{array}{c}\text { Analyzed } \\
\text { by: }\end{array}$ \\
\hline \multicolumn{7}{|c|}{ MAPEP - 04 - RdF12 Radiological Air Filter } \\
\hline Cs-137 & Air Filter & Bq/sample & 1.96 & 1.74 & $1.40-2.60$ & Yes & ELAB \\
\hline Co-60 & Air Filter & Bq/sample & 2.35 & 2.19 & $1.61-2.99$ & Yes & ELAB \\
\hline Am-241 & Air Filter & Bq/sample & 0.1 & 0.12 & $0.07-0.13$ & Yes & GEL \\
\hline Cs-137 & Air Filter & Bq/sample & 1.96 & 1.918 & $1.40-2.60$ & Yes & GEL \\
\hline Co-60 & Air Filter & Bq/sample & 2.35 & 2.379 & $1.61-2.99$ & Yes & GEL \\
\hline Pu-238 & Air Filter & Bq/sample & 0.13 & 0.124 & $0.09-0.17$ & Yes & GEL \\
\hline Pu-239/240 & Air Filter & Bq/sample & 0.09 & 0.088 & $0.06-0.12$ & Yes & GEL \\
\hline Sr-90 & Air Filter & Bq/sample & 0.83 & 0.783 & $0.56-1.04$ & Yes & GEL \\
\hline U-233/234 & Air Filter & Bq/sample & 0.21 & 0.222 & $0.15-0.27$ & Yes & GEL \\
\hline U-238 & Air Filter & Bq/sample & 0.22 & 0.227 & $0.15-0.29$ & Yes & GEL \\
\hline
\end{tabular}

ELAB - Environmental Laboratory

GEL - General Engineering Laboratories

${ }^{a}$ MAPEP monitors performance and requests corrective action as required.

Note: This report has been excerpted to include only those matrix/analyte combinations performed in support of the analyses of samples collected at the WVDP and which are presented in this Annual Site Environmental Report.

$$
\text { J - } 9
$$


Table J-4

Crosscheck Sample Comparisons of Results Analyzed for Water Quality Parameters as Part of the EPA's 2004 Discharge Monitoring Report - Quality Assurance (DMR-QA) Study 24 for the National Pollutant Discharge Elimination System (NPDES)

\begin{tabular}{|l|c|c|c|c|c|c|}
\hline \multicolumn{1}{|c|}{ Analyte } & Units & Actual & Reported & $\begin{array}{c}\text { Acceptance } \\
\text { Range }^{\mathbf{a}}\end{array}$ & Accept? & Analyzed by \\
\hline Aluminum & $\mu \mathrm{g} / \mathrm{L}$ & 639 & 661 & $538-739$ & Yes & STL \\
\hline Ammonia (as Nitrogen) & $\mathrm{mg} / \mathrm{L}$ & 12.5 & 12.1 & $9.71-15.2$ & Yes & STL \\
\hline Arsenic & $\mu \mathrm{g} / \mathrm{L}$ & 355 & 342 & $296-417$ & Yes & STL \\
\hline Biochemical oxygen demand & $\mathrm{mg} / \mathrm{L}$ & 75.3 & 55.2 & $38.0-113$ & Yes & STL \\
\hline Cadmium & $\mu \mathrm{g} / \mathrm{L}$ & 690 & 648 & $589-783$ & Yes & STL \\
\hline Chlorine, total residual & $\mathrm{mg} / \mathrm{L}$ & 1.14 & 1.20 & $0.890-1.39$ & Yes & WVNSCO \\
\hline Chromium & $\mu \mathrm{g} / \mathrm{L}$ & 298 & 292 & $258-338$ & Yes & STL \\
\hline Cobalt & $\mu \mathrm{g} / \mathrm{L}$ & 595 & 610 & $523-667$ & Yes & STL \\
\hline Copper & $\mu \mathrm{g} / \mathrm{L}$ & 226 & 237 & $203-250$ & Yes & STL \\
\hline Cyanide, total & $\mathrm{mg} / \mathrm{L}$ & 0.449 & 0.376 & $0.308-0.580$ & Yes & STL \\
\hline Grease and Oil (Gravimetric) & $\mathrm{mg} / \mathrm{L}$ & 31.0 & 26.9 & $19.7-36.3$ & Yes & STL \\
\hline Iron & $\mu \mathrm{g} / \mathrm{L}$ & 770 & 772 & $679-872$ & Yes & STL \\
\hline Lead & $\mu \mathrm{g} / \mathrm{L}$ & 392 & 378 & $339-443$ & Yes & STL \\
\hline Manganese & $\mu \mathrm{g} / \mathrm{L}$ & 817 & 837 & $734-908$ & Yes & STL \\
\hline Mercury & $\mu \mathrm{g} / \mathrm{L}$ & 13.4 & 8.38 & $10.0-16.7$ & No & STL \\
\hline Nickel & $\mu \mathrm{g} / \mathrm{L}$ & 285 & 287 & $252-322$ & Yes & STL \\
\hline Nitrate $(a s$ Nitrogen) & $\mathrm{mg} / \mathrm{L}$ & 10.6 & 11.8 & $8.38-12.6$ & Yes & STL \\
\hline pH & $\mathrm{SU}$ & 8.43 & 8.44 & $8.18-8.67$ & Yes & WVNSCO \\
\hline Phenolics, total & $\mathrm{mg} / \mathrm{L}$ & 0.220 & 0.193 & $0.114-0.326$ & Yes & STL \\
\hline Selenium & $\mu \mathrm{g} / \mathrm{L}$ & 466 & 446 & $368-540$ & Yes & STL \\
\hline Suspended solids, total & $\mathrm{mg} / \mathrm{L}$ & 37.9 & 36.0 & $28.0-40.4$ & Yes & STL \\
\hline Vanadium & $\mu \mathrm{g} / \mathrm{L}$ & 603 & 600 & $542-662$ & Yes & STL \\
\hline Zinc & $\mu \mathrm{g} / \mathrm{L}$ & 301 & 304 & $264-342$ & Yes & STL \\
\hline
\end{tabular}

Samples provided by Environmental Research Associates (ERA)

${ }^{a}$ Acceptance limits are determined by ERA or the New York State Department of Health (NYSDOH), as applicable.

${ }^{b}$ Analyses were conducted by Severn Trent Laboratories (STL) or the WVDP Wastewater Treatment Facility Laboratory (WVNSCO). 


\section{Appendix $\mathrm{K}$ \\ Environmental Laws, Regulations, Standards, and Orders}

$K-1$ 
This page intentionally left blank

$$
K-2
$$




\section{Table K-1}

\section{U.S. Department of Energy Radiation Protection Standards and Derived Concentration Guides ${ }^{1}$}

\begin{tabular}{|c|c|c|c|c|c|c|c|}
\hline \multicolumn{8}{|c|}{$\begin{array}{l}\text { Effective Dose Equivalent Radiation Standard for Protection of the Public } \\
\text { Continuous exposure of any member of the public from routine activities: } \\
\text { All exposure pathways }=100 \text { mrem/year }(1 \mathrm{mSv} / \mathrm{yr}) \text { effective dose equivalent }\end{array}$} \\
\hline \multicolumn{8}{|c|}{$\begin{array}{l}\text { U.S. Department of Energy Derived Concentration Guides (DCGs) } \\
\text { for Inhaled Air or Ingested Water }(\mu \mathrm{Ci} / \mathrm{mL})\end{array}$} \\
\hline Radionuclide & $\begin{array}{l}\text { Half-life }^{2} \\
\text { (years) }\end{array}$ & In Air & In Water & Radionuclide & $\begin{array}{c}\text { Half-life }^{2} \\
\text { (years) }\end{array}$ & In Air & In Water \\
\hline H-3* & $1.23 \mathrm{E}+01$ & $1 \mathrm{E}-07$ & $2 \mathrm{E}-03$ & Eu-152 & $1.35 \mathrm{E}+01$ & $5 \mathrm{E}-11$ & 2E-05 \\
\hline C-14* & $5.73 \mathrm{E}+03$ & $6 \mathrm{E}-09$ & $7 \mathrm{E}-05$ & Eu-154* & $8.59 \mathrm{E}+00$ & $5 \mathrm{E}-11$ & $2 \mathrm{E}-05$ \\
\hline K-40 & $1.28 \mathrm{E}+09$ & $9 \mathrm{E}-10$ & $7 \mathrm{E}-06$ & Eu-155 & $4.76 \mathrm{E}+00$ & $3 \mathrm{E}-10$ & $1 \mathrm{E}-04$ \\
\hline Fe-55 & $2.73 \mathrm{E}+00$ & $5 \mathrm{E}-09$ & $2 \mathrm{E}-04$ & Th-232 & $1.40 \mathrm{E}+10$ & $7 \mathrm{E}-15$ & $5 \mathrm{E}-08$ \\
\hline Co-60* & $5.27 \mathrm{E}+00$ & $8 \mathrm{E}-11$ & $5 \mathrm{E}-06$ & U-232* & $6.89 \mathrm{E}+01$ & $2 \mathrm{E}-14$ & $1 \mathrm{E}-07$ \\
\hline Ni-59 & $7.60 \mathrm{E}+04$ & 4E-09 & $7 \mathrm{E}-04$ & U-233* & $1.59 \mathrm{E}+05$ & $9 \mathrm{E}-14$ & $5 \mathrm{E}-07$ \\
\hline Ni-63 & $1.00 \mathrm{E}+02$ & 2E-09 & $3 \mathrm{E}-04$ & U-234* & $2.46 \mathrm{E}+05$ & $9 \mathrm{E}-14$ & $5 \mathrm{E}-07$ \\
\hline Sr-90* & $2.88 \mathrm{E}+01$ & $9 \mathrm{E}-12$ & $1 \mathrm{E}-06$ & U-235* & $7.04 \mathrm{E}+08$ & $1 \mathrm{E}-13$ & $6 \mathrm{E}-07$ \\
\hline Y-90 & 7.30E-03 & $1 \mathrm{E}-09$ & $1 \mathrm{E}-05$ & U-236* & $2.34 \mathrm{E}+07$ & $1 \mathrm{E}-13$ & $5 \mathrm{E}-07$ \\
\hline Zr-93 & $1.53 \mathrm{E}+06$ & $4 \mathrm{E}-11$ & 9E-05 & U-238* & $4.47 \mathrm{E}+09$ & $1 \mathrm{E}-13$ & $6 \mathrm{E}-07$ \\
\hline Nb-93m & $1.61 \mathrm{E}+01$ & $4 \mathrm{E}-10$ & $3 \mathrm{E}-04$ & Np-239 & $6.45 \mathrm{E}-03$ & $5 \mathrm{E}-09$ & $5 \mathrm{E}-05$ \\
\hline Tc-99* & $2.11 \mathrm{E}+05$ & $2 \mathrm{E}-09$ & $1 \mathrm{E}-04$ & Pu-238* & $8.77 \mathrm{E}+01$ & $3 \mathrm{E}-14$ & $4 \mathrm{E}-08$ \\
\hline Ru-106 & $1.02 \mathrm{E}+00$ & $3 \mathrm{E}-11$ & $6 \mathrm{E}-06$ & Pu-239* & $2.41 \mathrm{E}+04$ & $2 \mathrm{E}-14$ & $3 \mathrm{E}-08$ \\
\hline Cd-113m & $1.41 \mathrm{E}+01$ & $8 \mathrm{E}-12$ & 9E-07 & Pu-240* & $6.56 \mathrm{E}+03$ & $2 \mathrm{E}-14$ & $3 \mathrm{E}-08$ \\
\hline Sn-126 & $1.00 \mathrm{E}+05$ & $1 \mathrm{E}-10$ & $8 \mathrm{E}-06$ & Pu-241 & $1.43 \mathrm{E}+01$ & $1 \mathrm{E}-12$ & $2 \mathrm{E}-06$ \\
\hline Sb-125 & $2.76 \mathrm{E}+00$ & $1 \mathrm{E}-09$ & $5 \mathrm{E}-05$ & Am-241* & $4.32 \mathrm{E}+02$ & $2 \mathrm{E}-14$ & 3E-08 \\
\hline Te-125m & $1.57 \mathrm{E}-01$ & 2E-09 & $4 \mathrm{E}-05$ & Am-242m & $1.41 \mathrm{E}+02$ & $2 \mathrm{E}-14$ & 3E-08 \\
\hline I-129* & $1.57 \mathrm{E}+07$ & $7 \mathrm{E}-11$ & $5 \mathrm{E}-07$ & Am-243 & $7.37 \mathrm{E}+03$ & $2 \mathrm{E}-14$ & 3E-08 \\
\hline Cs-134 & $2.07 \mathrm{E}+00$ & $2 \mathrm{E}-10$ & $2 \mathrm{E}-06$ & Cm-243 & $2.91 \mathrm{E}+01$ & $3 \mathrm{E}-14$ & $5 \mathrm{E}-08$ \\
\hline Cs-135 & $2.30 \mathrm{E}+06$ & 3E-09 & $2 \mathrm{E}-05$ & Cm-244 & $1.81 \mathrm{E}+01$ & $4 \mathrm{E}-14$ & $6 \mathrm{E}-08$ \\
\hline Cs-137* & $3.01 \mathrm{E}+01$ & $4 \mathrm{E}-10$ & $3 \mathrm{E}-06$ & Gross Alpha & NA & $2 \mathrm{E}-14$ & $3 \mathrm{E}-08$ \\
\hline Pm-147 & $2.62 \mathrm{E}+00$ & $3 \mathrm{E}-10$ & $1 \mathrm{E}-04$ & (as Am-241) & & & \\
\hline Sm-151 & $9.00 \mathrm{E}+01$ & $4 \mathrm{E}-10$ & $4 \mathrm{E}-04$ & $\begin{array}{l}\text { Gross Beta } \\
\text { (as Sr-90) }\end{array}$ & NA & $9 \mathrm{E}-12$ & $1 \mathrm{E}-06$ \\
\hline \multicolumn{8}{|c|}{$\begin{array}{l}{ }^{1} \text { DOE Order } 5400.5 \text { (February 8, 1990). Effective May 8, 1990. (See Derived Concentration Guides [p. 1-5] in } \\
\text { Chapter 1, Environmental Program Information.) }\end{array}$} \\
\hline \multicolumn{8}{|c|}{$\begin{array}{l}{ }^{2} \text { Nuclear Wallet Cards. January 2000. National Nuclear Data Center. Brookhaven National Laboratory. Upton, } \\
\text { New York. }\end{array}$} \\
\hline
\end{tabular}

$K-3$ 


\section{Table $\mathrm{K}-2$ \\ Environmental Laws, Regulations, Standards, and Orders}

The following environmental standards and laws are applicable, in whole or in part, to the West Valley Demonstration Project. Although the list covers the major activities at the West Valley Demonstration Project, it does not constitute a complete enumeration.

Atomic Energy Act of 1954, 42 United States Code (USC) §2011 et seq., as amended, and federal implementing regulations.

Clean Air Act (CAA). Pub. L. No. 84-159. 42 USC $\$ 7401$ et seq., as amended, and federal and state implementing regulations.

Comprehensive Environmental Response, Compensation, and Liability Act (CERCLA). Pub. L. No. 96-510. 42 USC $\$ 9601$ et seq. (including Superfund Amendments and Reauthorization Act [SARA] of 1986), and federal implementing regulations.

DOE Order 231.1A. August 19, 2003. Environment, Safety, and Health Reporting, replaces DOE Orders 231.1 and 232.1A, including Change 1 (June 3, 2004).

DOE Order 414.1B. April 29, 2004. Quality Assurance.

DOE Order 435.1. July 9, 1999. Radioactive Waste Management, including Change 1 (August 28, 2001).

DOE Order 440.1A. March 27, 1998. Worker Protection Management for DOE Federal and Contractor Employees.

DOE Order 450.1. January 15, 2003. Environmental Protection Program, including Change 1 (January 15, 2005). (DOE Order 450.1 canceled DOE Order 5400.1.)

DOE Order 451.1B. October 26, 2000. National Environmental Policy Act Compliance Program, including Change 1 (September 28, 2001).

DOE Order 5400.5. February 8, 1990. Radiation Protection of the Public and the Environment, including Change 2 (January 7, 1993).

DOE Order 5480.4. May 15, 1984. Environmental Protection, Safety, and Health Protection Standards, including Change 4 (January 7, 1993).

DOE Policy 141.1. May 2, 2001. Department of Energy Management of Cultural Resources.

DOE Policy 141.2. May 2, 2003. Public Participation and Community Relations.

$$
K-4
$$




\section{Table K-2 (continued) Environmental Laws, Regulations, Standards, and Orders}

DOE Regulatory Guide DOE/EH-0173T. January 1991. Environmental Regulatory Guide for

Radiological Effluent Monitoring and Environmental Surveillance.

DOE Standard DOE-STD-1153-2002. July 2002. A Graded Approach for Evaluating Radiation Doses to Aquatic and Terrestrial Biota.

Emergency Planning and Community Right-to-Know Act (EPCRA) of 1986. Pub. L. No. 99-499. 42 USC $\$ 11001$ et seq., and federal implementing regulations.

Endangered Species Act of 1973. Pub. L. No. 93-205. 16 USC $\$ 1531$ et seq., and federal and state implementing regulations.

Environmental Conservation Law of the New York State Consolidated Laws and state implementing regulations (NYCRR).

Executive Order 11988. Floodplain Management.

Executive Order 11990. Protection of Wetlands.

Executive Order 13101. Greening the Government Through Waste Prevention, Recycling, and Federal Acquisition.

Executive Order 13148. Greening the Government Through Leadership in Environmental Management.

Federal Water Pollution Control Act (Clean Water Act [CWA]). Pub. L. No. 95-217. 33 USC \$1251 et seq., as amended, and federal and state implementing regulations.

Migratory Bird Treaty Act. 16 USC §703-712 as amended, and federal and state implementing regulations.

National Environmental Policy Act (NEPA) of 1969. Pub. L. No. 91-190. 42 USC §4321 et seq., as amended, and federal implementing regulations.

National Historic Preservation Act of 1966. Pub. L. No. 102-575. 16 USC $\$ 470$ et seq., and federal implementing regulations.

Resource Conservation and Recovery Act (RCRA). Pub. L. No. 94-580. 42 USC 6901 et seq., as amended, and federal and state implementing regulations.

$K-5$ 


\section{Table K-2 (concluded) Environmental Laws, Regulations, Standards, and Orders}

Safe Drinking Water Act (SDWA). Pub. L. No. 93-523. 42 USC $\$ 300 f$ et seq., as amended, and federal and state implementing regulations.

Toxic Substances Control Act (TSCA). Pub. L. No. 94-469. 15 USC §2601 et seq., as amended, and federal implementing regulations.

U.S. Environmental Protection Agency. 1992. Region II Administrative Order on Consent. Docket No. II RCRA 3008(h)-92-0202. In the Matter of: Western New York Nuclear Service Center.

U.S. Environmental Protection Agency. 1996. West Valley Demonstration Project Federal Facilities Compliance Act Order.

Water quality standards contained in the New York State Pollutant Discharge Elimination System (SPDES) permit issued for the facility are listed in Table C-1A. Airborne emissions are regulated by the Environmental Protection Agency under the National Emission Standards for Hazardous Air Pollutants (NESHAP), 40 CFR §61 Subpart H (December 15, 1989, including amendments effective September 9, 2002).

$K-6$ 


\section{Table $\mathrm{K}-3$ \\ West Valley Demonstration Project Act \\ (Public Law 96-368 [S. 2443]; October 1, 1980)}

(As presented in Exhibit G of the Cooperative Agreement between United States Department of Energy and New York State Energy Research and Development Authority on the Western New York Nuclear Service Center at West Valley, New York; Effective October 1, 1980 as amended September 18, 1981.)

EXHIBIT G

\section{WEST VALLEY PROJECT DEMONSTRATION ACT}

PUBLIC LAW 96-368 [S. 2443]; October 1, 1980

\section{WEST VALLEY DEMONSTRATION PROJECT ACT}

For Legislative History of this and other Laws, see Table 1, Public

Laws and Legislative History, at end of final volume

An Act to authorize the Department of Energy to carry out a high-level liquid

nuclear waste management demonstratlon project

Be it enacted by the Senate and House of Representatives of the United States of America in Congress assembled,

SECTION 1. This Act may be cited as the "West Valley Demonstration Project Act".

SEc. 2. (a) The Secretary shall carry out, in accordance with this Act, a high level radioactive waste management demonstration project at the Western New York Service Center in West Valley, New York, for the purpose of demonstrating solidification techniques which can be used for preparing high level radioactive waste for disposal. Under the project the Secretary shall carry out the following activities:

(1) The Secretary shall solidify, in a form suitable for transportation and disposal, the high level radioactive waste at the Center by vitrification or by such other technology which the Secretary determines to be the most effective for solidification.

(2) The Secretary shall develop containers suitable for the permanent disposal of the high level radioactive waste solidified at the Center.

(3) The Secretary shall, as soon as feasible, transport, in accordance with applicable provisions of law, the waste solidified at the Center to an appropriate Federal repository for permanent disposal.

(4) The Secretary shall, in accordance with applicable licensing requirements, dispose of low level radioactive waste and transuranic waste produced by the solidification of the high level radioactive waste under the project.

(5) The Secretary shall decontaminate and decommission(A) the tanks and other facilities of the Center in which the high level radioactive waste solidified under the project was stored,

(B) the facilities used in the solidification of the waste, and

(C) any material and hardware used in connection with the project

in accordance with such requirements as the Commission may prescribe.

(b) Before undertaking the project and during the fiscal year ending September 30,1981 , the Secretary shall carry out the following: (1) The Secretary shall hold in the vicinity of the Center public
hearings to inform the residents of the area in which the Center is located of the activities proposed to be undertaken under the project and to receive their comments on the project.

(2) The Secretary shall consider the various technologies available for the solidification and handling of high level radioactive waste taking into account the unique characteristics of such waste at the Center.

94 STAT. 1347

\section{G-1}

$K-7$
West Valley Demonstration Project Act. 42 USC 2021a

note.

42 USC 2021a

note.

Activities. 


\begin{abstract}
(3) The Secretary shall-
(A) undertake detailed engineering and cost estimates for the project.

(B) prepare a plan for the safe removal of the high level radioactive waste at the Center for the purposes of solidification and include in the plan provisions respecting the safe breaching of the tanks in which the waste is stored, operating equipment to accomplish the removal, and sluicing techniques,

(C) conduct appropriate safety analyses of the project, and

(D) prepare required environmental impact analyses of the project.

(4) The Secretary shall enter into a cooperative agreement

42 USC 501 note.

State costs, percentage.

Licensing amendment application.

42 USC 2011 note. 42 USC 5801 note.

Publications in Federal Register. with the State in accordance with the Federal Grant and Cooperative Agreement Act of 1977 under which the State will carry out the following:

(A) The State will make available to the Secretary the facilities of the Center and the high level radioactive waste at the Center which are necessary for the completion of the project. The facilities and the waste shall be made available without the transfer of title and for such period as may be required for completion of the project.

(B) The Secretary shall provide technical assistance in securing required license amendments.

(C) The State shall pay 10 per centum of the costs of the project, as determined by the Secretary. In determining the costs of the project, the Secretary shall consider the value of the use of the Center for the project. The State may not use Federal funds to pay its share of the cost of the project, but may use the perpetual care fund to pay such share.

(D) Submission jointly by the Department of Energy and the State of New York of an application for a licensing amendment as soon as possible with the Nuclear Regulatory Commission providing for the demonstration.

(c) Within one year from the date of the enactment of this Act, the Secretary shall enter into an agreement with the Commission to establish arrangements for review and consultation by the Commission with respect to the project: Provided, That review and consultation by the Commission pursuant to this subsection shall be conducted informally by the Commission and shall not include nor require formal procedures or actions by the Commission pursuant to the Atomic Energy Act of 1954, as amended, the Energy Reorganization Act of 1974 , as amended, or any other law. The agreement shall provide for the following:

(1) The Secretary shall submit to the Commission, for its review and comment, a plan for the solidification of the high level radioactive waste at the Center, the removal of the waste for purposes of its solidification, the preparation of the waste for disposal, and the decontamination of the facilities to be used in solidifying the waste. In preparing its comments on the plan, the Commission shall specify with precision its objections to any provision of the plan. Upon submission of a plan to the Commission, the Secretary shall publish a notice in the Federal Register of the submission of the plan and of its availability for public inspection, and, upon receipt of the comments of the Commission respecting a plan, the Secretary shall publish a notice in the Federal Register of the receipt of the comments and of the availability of the comments for public inspection. If the Secre-
\end{abstract}

94 STAT. 1348

$K-8$ 
tary does not revise the plan to meet objections specified in the comments of the Commission, the Secretary shall publish in the Federal Register a detailed statement for not so revising the plan.

(2) The Secretary shall consult with the Commission with respect to the form in which the high level radioactive waste at the Center shall be solidified and the containers to be used in the permanent disposal of such waste.

(3) The Secretary shall submit to the Commission safety analysis reports and such other information as the Commission may require to identify any danger to the public health and safety which may be presented by the project.

(4) The Secretary shall afford the Commission access to the Center to enable the Commission to monitor the activities under the project for the purpose of assuring the public health and safety.

(d) In carrying out the project, the Secretary shall consult with the Administrator of the Environmental Protection Agency, the Secretary of Transportation, the Director of the Geological Survey, and the commercial operator of the Center.

SEC. 3. (a) There are authorized to be appropriated to the Secretary for the project not more than $\$ 5,000,000$ for the fiscal year ending September 30, 1981.

(b) The total amount obligated for the project by the Secretary shall be 90 per centum of the costs of the project.

(c) The authority of the Secretary to enter into contracts under this Act shall be effective for any fiscal year only to such extent or in such amounts as are provided in advance by appropriation Acts.

SEC. 4. Not later than February 1, 1981, and on February 1 of each calendar year thereafter during the term of the project, the Secretary shall transmit to the Speaker of the House of Representatives and the President pro tempore of the Senate an up-to-date report containing a detailed description of the activities of the Secretary in carrying out the project, including agreements entered into and the costs incurred during the period reported on and the activities to be undertaken in the next fiscal year and the estimated costs thereof.

SEC. 5. (a) Other than the costs and responsibilities established by this Act for the project, nothing in this Act shall be construed as affecting any rights, obligations, or liabilities of the commercial operator of the Center, the State, or any person, as is appropriate, arising under the Atomic Energy Act of 1954 or under any other law, contract, or agreement for the operation, maintenance, or decontamination of any facility or property at the Center or for any wastes at the Center. Nothing in this Act shall be construed as affecting any applicable licensing requirement of the Atomic Energy Act of 1954 or the Energy Reorganization Act of 1974. This Act shall not apply or be extended to any facility or property at the Center which is not used in conducting the project. This Act may not be construed to expand or diminish the rights of the Federal Government.

(b) This Act does not authorize the Federal Government to acquire title to any high level radioactive waste at the Center or to the Center or any portion thereof.

SEC. 6. For the purposes of this Act:

(1) The term "Secretary" means the Secretary of Energy.

(2) The term "Commission" means the Nuclear Regulatory

Reports and other information to Commission.

Consultation with

EPA and others.

Appropriation authorization. 42 USC 2021a note.

Commission.

(3) The term "State" means the State of New York.

94 STAT. 1349

$K-9$ 
(4) The term "high level radioactive waste" means the high level radioactive waste which was produced by the reprocessing at the Center of spent nuclear fuel. Such term includes both liquid wastes which are produced directly in reprocessing, dry solid material derived from such liquid waste, and such other material as the Commission designates as high level radioactive waste for purposes of protecting the public health and safety.

(5) The term "transuranic waste" means material contaminated with elements which have an atomic number greater than 92, including neptunium, plutonium, americium, and curium, and which are in concentrations greater than 10 nanocuries per gram, or in such other concentrations as the Commission may prescribe to protect the public health and safety.

(6) The term "low level radioactive waste" means radioactive waste not classified as high level radioactive waste, transuranic waste, or byproduct material as defined in section $11 \mathrm{e}$. (2) of the Atomic Energy Act of 1954.

(7) The term "project" means the project prescribed by section 42 USC 2014.

(8) The term "Center" means the Western New York Service Center in West Valley, New York.

Approved October 1, 1980. 


\begin{abstract}
Appendix L
Summary of New York State Energy Research and Development Authority (NYSERDA) Groundwater Monitoring Data for the New York State-Licensed Disposal Area (SDA)
\end{abstract}


This page intentionally left blank

$$
L-2
$$


Table L-1

2004 Contamination Indicator Results From SDA Monitoring Wells

\begin{tabular}{|c|c|c|c|c|c|}
\hline $\begin{array}{c}\text { Sample } \\
\text { Location }\end{array}$ & Date & $\begin{array}{c}\text { Conductivity } \\
\left(\mu \mathrm{mhos} / \mathrm{cm} @ 25^{\circ} \mathrm{C}\right)\end{array}$ & $\begin{array}{l}\mathbf{p H} \\
(\mathrm{SU})\end{array}$ & $\begin{array}{c}\text { Temperature } \\
\left({ }^{\circ} \mathrm{C}\right)\end{array}$ & $\begin{array}{c}\text { Turbidity } \\
\text { (NTU) }\end{array}$ \\
\hline WNW1101A & June & 649 & 7.40 & 9.4 & 1.37 \\
\hline WNW1101A & December & 632 & 6.99 & 9.3 & 1.52 \\
\hline WNW1101B & June & 614 & 7.44 & 10.1 & 6.88 \\
\hline WNW1101B & December & 611 & 7.38 & 8.2 & 3.65 \\
\hline WNW1101C & June & 409 & 7.32 & 10.1 & 27.8 \\
\hline WNW1101C & December & 350 & 7.53 & 8.1 & 256 \\
\hline WNW1102A & June & 714 & 7.49 & 9.9 & 5.23 \\
\hline WNW1102A & December & 646 & 7.36 & 9.2 & 13.5 \\
\hline WNW1102B & June & 531 & 7.42 & 10.5 & 13.3 \\
\hline WNW1102B & December & 516 & 7.32 & 8.6 & 13.7 \\
\hline WNW1103A & June & 861 & 7.03 & 11.3 & 89.8 \\
\hline WNW1103A & December & 866 & 7.31 & 9.4 & 196 \\
\hline WNW1103B & June & 601 & 7.36 & 10.2 & 5.62 \\
\hline WNW1103B & December & 624 & 7.39 & 8.2 & 23.0 \\
\hline WNW1104A & June & 698 & 7.42 & 12.4 & 2.50 \\
\hline WNW1104A & December & 700 & 7.50 & 10.2 & 4.32 \\
\hline WNW1104B & June & 556 & 7.49 & 13.0 & 1.82 \\
\hline WNW1104B & December & 551 & 7.53 & 8.0 & 0.86 \\
\hline WNW1105A & June & 628 & 7.51 & 8.5 & 223 \\
\hline WNW1105A & December & 619 & 7.57 & 8.5 & 340 \\
\hline WNW1105B & June & 622 & 7.57 & 8.6 & $>1,000$ \\
\hline WNW1105B & December & 626 & 7.66 & 7.8 & 149 \\
\hline WNW1106A & June & 703 & 7.34 & 9.4 & 2.46 \\
\hline WNW1106A & December & 711 & 7.39 & 9.9 & 8.99 \\
\hline WNW1106B & June & 700 & 7.27 & 10.8 & 116 \\
\hline WNW1106B & December & 699 & 7.17 & 9.4 & 66.6 \\
\hline WNW1107A & June & 1,854 & 6.69 & 9.4 & 1.28 \\
\hline WNW1107A & June & 1,854 & 6.69 & 9.4 & 1.28 \\
\hline WNW1107A & December & 1,818 & 6.68 & 9.9 & 1.44 \\
\hline
\end{tabular}

All data in Tables L-1 through L-3 have been provided by NYSERDA.

$$
L-3
$$


Table L-1 (concluded)

2004 Contamination Indicator Results From SDA Monitoring Wells

\begin{tabular}{|c|c|c|c|c|c|}
\hline $\begin{array}{c}\text { Sample } \\
\text { Location }\end{array}$ & Date & $\begin{array}{c}\text { Conductivity } \\
\left(\mu \mathrm{mhos} / \mathrm{cm} @ 25^{\circ} \mathrm{C}\right)\end{array}$ & $\begin{array}{l}\mathbf{p H} \\
(\mathrm{SU})\end{array}$ & $\begin{array}{c}\text { Temperature } \\
\left({ }^{\circ} \mathrm{C}\right)\end{array}$ & $\begin{array}{c}\text { Turbidity } \\
\text { (NTU) }\end{array}$ \\
\hline WNW1108A & June & 821 & 7.13 & 8.8 & $>1,000$ \\
\hline WNW1108A & December & 860 & 7.28 & 10.3 & 484 \\
\hline WNW1109A & June & 552 & 7.50 & 8.1 & 4.92 \\
\hline WNW1109A & December & 575 & 7.37 & 9.0 & 4.64 \\
\hline WNW1109B & June & 442 & 7.58 & 9.0 & 50.8 \\
\hline WNW1109B & December & 428 & 7.49 & 8.7 & 49.0 \\
\hline WNW1109B & December & 428 & 7.49 & 8.7 & 49.0 \\
\hline WNW1111A & June & 966 & 7.13 & 9.4 & 5.63 \\
\hline WNW1111A & December & 968 & 7.07 & 8.9 & 1.66 \\
\hline
\end{tabular}

All data in Tables L-1 through L-3 have been provided by NYSERDA.

$L-4$ 


\section{Table $L-2$}

\section{Radiological Indicator Results From SDA Monitoring Wells $(\mu \mathrm{Ci} / \mathrm{mL})$}

\section{Sample \\ Location}

WNW1101A

WNW1101A

WNW1101B

WNW1101B

WNW1101C

WNW1101C

WNW1102A

WNW1102A

WNW1102B

WNW1102B

WNW1103A

WNW1103A

WNW1103B

WNW1103B

WNW1103C

WNW1103C

WNW1104A

WNW1104A

WNW1104B

WNW1104B

WNW1104C

WNW1104C

WNW1105A

WNW1105A

WNW1105B

WNW1105B

WNW1106A

WNW1106A
Date

June

December

June

December

June
December

June

December

June

December

June

December

June

December

June

December

June

December

June

December

June

December

June

December

June

December

June

December
Gross Alpha

$4.17 \pm 2.10 \mathrm{E}-09$

$4.12 \pm 2.00 \mathrm{E}-09$

$5.68 \pm 2.70 \mathrm{E}-09$

$3.82 \pm 1.90 \mathrm{E}-09$

$1.10 \pm 1.10 \mathrm{E}-09$

$1.00 \pm 0.87 \mathrm{E}-09$

$4.06 \pm 2.00 \mathrm{E}-09$

$2.05 \pm 1.40 \mathrm{E}-09$

$1.24 \pm 1.00 \mathrm{E}-09$

$0.18 \pm 1.10 \mathrm{E}-09$

$8.25 \pm 3.40 \mathrm{E}-09$

$4.39 \pm 1.90 \mathrm{E}-09$

$0.86 \pm 1.20 \mathrm{E}-09$

$1.85 \pm 1.10 \mathrm{E}-09$

$0.97 \pm 1.10 \mathrm{E}-09$

$1.76 \pm 1.40 \mathrm{E}-09$

$4.56 \pm 2.30 \mathrm{E}-09$

$1.61 \pm 1.20 \mathrm{E}-09$

$1.23 \pm 1.10 \mathrm{E}-09$

$4.70 \pm 8.20 \mathrm{E}-10$

$5.46 \pm 5.20 \mathrm{E}-09$

$4.42 \pm 2.00 \mathrm{E}-09$

$4.03 \pm 2.30 \mathrm{E}-09$

$3.04 \pm 1.70 \mathrm{E}-09$

$3.25 \pm 2.10 \mathrm{E}-09$

$1.90 \pm 1.40 \mathrm{E}-09$

$4.89 \pm 2.70 \mathrm{E}-09$

$2.51 \pm 1.40 \mathrm{E}-09$
Gross Beta

$2.80 \pm 1.40 \mathrm{E}-09$

$3.44 \pm 1.80 \mathrm{E}-09$

$1.73 \pm 1.40 \mathrm{E}-09$

$1.72 \pm 1.70 \mathrm{E}-09$

$2.88 \pm 1.80 \mathrm{E}-09$

$2.00 \pm 1.70 \mathrm{E}-09$

$6.91 \pm 2.70 \mathrm{E}-09$

$3.16 \pm 1.80 \mathrm{E}-09$

$4.00 \pm 1.70 \mathrm{E}-09$

$0.55 \pm 1.70 \mathrm{E}-09$

$2.36 \pm 1.70 \mathrm{E}-09$

$3.68 \pm 2.10 \mathrm{E}-09$

$1.96 \pm 1.50 \mathrm{E}-09$

$2.28 \pm 1.70 \mathrm{E}-09$

$7.01 \pm 2.10 \mathrm{E}-09$

$6.27 \pm 2.40 \mathrm{E}-09$

$4.80 \pm 2.10 \mathrm{E}-09$

$3.42 \pm 2.10 \mathrm{E}-09$

$2.27 \pm 1.80 \mathrm{E}-09$

$2.71 \pm 1.80 \mathrm{E}-09$

$1.12 \pm 0.48 \mathrm{E}-08$

$3.27 \pm 2.00 \mathrm{E}-09$

$3.68 \pm 1.90 \mathrm{E}-09$

$4.49 \pm 1.80 \mathrm{E}-09$

$3.10 \pm 1.60 \mathrm{E}-09$

$1.45 \pm 1.70 \mathrm{E}-09$

$3.59 \pm 1.70 \mathrm{E}-09$

$3.55 \pm 1.90 \mathrm{E}-09$
H-3

$2.13 \pm 4.90 \mathrm{E}-08$

$8.46 \pm 5.80 \mathrm{E}-08$

$-2.50 \pm 4.70 \mathrm{E}-08$

$1.65 \pm 5.30 \mathrm{E}-08$

$-4.81 \pm 5.20 \mathrm{E}-08$

$0.16 \pm 5.20 \mathrm{E}-08$

$2.10 \pm 0.54 \mathrm{E}-07$

$2.74 \pm 0.68 \mathrm{E}-07$

$-0.90 \pm 5.40 \mathrm{E}-08$

3.64 $\pm 5.00 \mathrm{E}-08$

$4.55 \pm 0.85 \mathrm{E}-07$

$4.35 \pm 0.81 \mathrm{E}-07$

$-4.56 \pm 5.00 \mathrm{E}-08$

$2.47 \pm 5.00 \mathrm{E}-08$

$-3.01 \pm 4.70 \mathrm{E}-08$

$-0.04 \pm 5.20 \mathrm{E}-08$

$1.69 \pm 0.66 \mathrm{E}-07$

$1.81 \pm 0.62 \mathrm{E}-07$

$-4.03 \pm 5.20 \mathrm{E}-08$

$-1.83 \pm 4.70 \mathrm{E}-08$

$-1.60 \pm 4.80 \mathrm{E}-08$

$-6.97 \pm 4.60 \mathrm{E}-08$

$1.02 \pm 0.51 \mathrm{E}-07$

$1.20 \pm 0.56 \mathrm{E}-07$

$-4.26 \pm 4.70 \mathrm{E}-08$

$2.14 \pm 4.80 \mathrm{E}-08$

$4.61 \pm 0.61 \mathrm{E}-07$

$5.38 \pm 0.89 \mathrm{E}-07$

All data in Tables L-1 through L-3 have been provided by NYSERDA.

$$
L-5
$$




\section{Table L-2 (concluded) \\ 2004 Radiological Indicator Results From SDA Monitoring Wells $(\mu \mathrm{Ci} / \mathrm{mL})$}

\begin{tabular}{|c|c|c|c|c|}
\hline $\begin{array}{l}\text { Sample } \\
\text { Location }\end{array}$ & Date & Gross Alpha & Gross Beta & H-3 \\
\hline WNW1106B & June & $2.14 \pm 1.20 \mathrm{E}-09$ & $2.70 \pm 1.70 \mathrm{E}-09$ & $-6.51 \pm 4.60 \mathrm{E}-08$ \\
\hline WNW1106B & December & $1.67 \pm 1.10 \mathrm{E}-09$ & $2.32 \pm 1.70 \mathrm{E}-09$ & $-0.44 \pm 4.70 \mathrm{E}-08$ \\
\hline WNW1107A & June & $4.13 \pm 3.20 \mathrm{E}-09$ & $1.70 \pm 0.49 \mathrm{E}-08$ & $1.09 \pm 0.04 \mathrm{E}-05$ \\
\hline WNW1107A & June & $3.51 \pm 2.70 \mathrm{E}-09$ & $1.30 \pm 0.46 \mathrm{E}-08$ & $1.02 \pm 0.04 \mathrm{E}-05$ \\
\hline WNW1107A & December & $3.83 \pm 1.80 \mathrm{E}-09$ & $1.70 \pm 0.42 \mathrm{E}-08$ & $1.10 \pm 0.08 \mathrm{E}-05$ \\
\hline WNW1108A & June & $5.08 \pm 2.40 \mathrm{E}-09$ & $5.58 \pm 2.50 \mathrm{E}-09$ & $9.81 \pm 6.10 \mathrm{E}-08$ \\
\hline WNW1108A & December & $3.60 \pm 1.70 \mathrm{E}-09$ & $4.06 \pm 2.20 \mathrm{E}-09$ & $1.38 \pm 0.58 \mathrm{E}-07$ \\
\hline WNW1109A & June & $4.62 \pm 2.40 \mathrm{E}-09$ & $2.74 \pm 1.50 \mathrm{E}-09$ & $2.33 \pm 0.55 \mathrm{E}-07$ \\
\hline WNW1109A & December & $2.65 \pm 1.60 \mathrm{E}-09$ & $1.06 \pm 1.80 \mathrm{E}-09$ & $2.17 \pm 0.69 \mathrm{E}-07$ \\
\hline WNW1109B & June & $2.17 \pm 1.60 \mathrm{E}-09$ & $1.34 \pm 1.30 \mathrm{E}-09$ & $6.50 \pm 1.10 \mathrm{E}-07$ \\
\hline WNW1109B & December & $4.05 \pm 7.20 \mathrm{E}-10$ & $0.35 \pm 1.70 \mathrm{E}-09$ & $3.99 \pm 0.80 \mathrm{E}-07$ \\
\hline WNW1109B & December & $1.01 \pm 0.88 \mathrm{E}-09$ & $1.62 \pm 1.20 \mathrm{E}-09$ & $3.98 \pm 0.80 \mathrm{E}-07$ \\
\hline WNW1110A & June & NA & NA & $2.75 \pm 0.79 \mathrm{E}-07$ \\
\hline WNW1110A & December & $1.14 \pm 0.36 \mathrm{E}-08$ & $5.02 \pm 2.30 \mathrm{E}-09$ & $1.36 \pm 0.62 \mathrm{E}-07$ \\
\hline WNW1111A & June & $7.35 \pm 3.30 \mathrm{E}-09$ & $4.00 \pm 1.70 \mathrm{E}-09$ & $1.53 \pm 0.52 \mathrm{E}-07$ \\
\hline WNW1111A & December & $5.18 \pm 2.70 \mathrm{E}-09$ & $2.82 \pm 1.90 \mathrm{E}-09$ & $1.61 \pm 0.63 \mathrm{E}-07$ \\
\hline
\end{tabular}

All data in Tables L-1 through L-3 have been provided by NYSERDA.

NA - Not available. Some scheduled analyses could not be performed due to insufficient sample.

$L-6$ 
Table L-3

2004 Radioisotopic Results From SDA Monitoring Wells ( $\mu$ Ci/mL)

$\begin{array}{cccccc}\begin{array}{c}\text { Sample } \\ \text { Location }\end{array} & \text { Date } & \text { Actinium-228 } & \text { Bismuth-214 } & \text { Carbon-14 } & \text { Cesium-134 } \\ \text { WNW1101A } & & & & \\ \text { WNW1101B } & \text { June } & 1.35 \pm 1.40 \mathrm{E}-08 & 3.23 \pm 8.20 \mathrm{E}-09 & 0.96 \pm 3.80 \mathrm{E}-09 & 6.99 \pm 3.80 \mathrm{E}-09 \\ & \text { June } & 1.09 \pm 1.30 \mathrm{E}-08 & 8.91 \pm 9.20 \mathrm{E}-09 & 2.05 \pm 3.80 \mathrm{E}-09 & 1.35 \pm 4.10 \mathrm{E}-09 \\ \text { WNW1101C } & \text { June } & 0.66 \pm 1.60 \mathrm{E}-08 & -0.21 \pm 1.20 \mathrm{E}-08 & 1.66 \pm 3.90 \mathrm{E}-09 & -1.75 \pm 5.90 \mathrm{E}-09 \\ \text { WNW1102A } & \text { June } & 0.27 \pm 1.70 \mathrm{E}-08 & 0.38 \pm 1.00 \mathrm{E}-08 & -1.34 \pm 3.70 \mathrm{E}-09 & -5.67 \pm 5.60 \mathrm{E}-09 \\ \text { WNW1102B } & \text { June } & -4.80 \pm 9.90 \mathrm{E}-09 & 7.54 \pm 6.50 \mathrm{E}-09 & 1.56 \pm 3.90 \mathrm{E}-09 & 0.60 \pm 3.20 \mathrm{E}-09 \\ \text { WNW1103A } & \text { June } & 0.46 \pm 1.40 \mathrm{E}-08 & 0.25 \pm 8.30 \mathrm{E}-09 & 2.67 \pm 3.90 \mathrm{E}-09 & -0.59 \pm 3.40 \mathrm{E}-09 \\ \text { WNW1103B } & \text { June } & 0.51 \pm 1.00 \mathrm{E}-08 & 5.24 \pm 8.00 \mathrm{E}-09 & 1.24 \pm 3.90 \mathrm{E}-09 & 0.03 \pm 3.70 \mathrm{E}-09 \\ \text { WNW1104A } & \text { June } & -3.32 \pm 2.50 \mathrm{E}-08 & 0.16 \pm 1.30 \mathrm{E}-08 & 2.30 \pm 3.90 \mathrm{E}-09 & -4.76 \pm 6.10 \mathrm{E}-09 \\ \text { WNW1104B } & \text { June } & -1.92 \pm 2.70 \mathrm{E}-08 & -0.75 \pm 1.50 \mathrm{E}-08 & -0.22 \pm 3.80 \mathrm{E}-09 & -6.43 \pm 6.10 \mathrm{E}-09 \\ \text { WNW1105A } & \text { June } & 1.14 \pm 1.90 \mathrm{E}-08 & 1.05 \pm 1.20 \mathrm{E}-08 & -0.04 \pm 3.80 \mathrm{E}-09 & 1.44 \pm 6.20 \mathrm{E}-09 \\ \text { WNW1105B } & \text { June } & 0.10 \pm 1.90 \mathrm{E}-08 & -5.63 \pm 9.80 \mathrm{E}-09 & 0.81 \pm 3.80 \mathrm{E}-09 & -2.22 \pm 5.80 \mathrm{E}-09 \\ \text { WNW1106A } & \text { June } & 0.71 \pm 1.10 \mathrm{E}-08 & 1.17 \pm 6.30 \mathrm{E}-09 & -2.37 \pm 3.70 \mathrm{E}-09 & 0.36 \pm 3.60 \mathrm{E}-09 \\ \text { WNW1106B } & \text { June } & 1.11 \pm 1.20 \mathrm{E}-08 & 3.52 \pm 7.90 \mathrm{E}-09 & 1.56 \pm 3.80 \mathrm{E}-09 & -0.33 \pm 4.00 \mathrm{E}-09 \\ \text { WNW1107A } & \text { June } & 2.67 \pm 2.30 \mathrm{E}-08 & 0.24 \pm 1.20 \mathrm{E}-08 & 3.29 \pm 3.90 \mathrm{E}-09 & -3.91 \pm 4.90 \mathrm{E}-09 \\ \text { WNW1107A } & \text { June } & 0.52 \pm 2.10 \mathrm{E}-08 & -0.49 \pm 1.30 \mathrm{E}-08 & 2.11 \pm 3.80 \mathrm{E}-09 & 0.29 \pm 6.00 \mathrm{E}-09 \\ \text { WNW1108A } & \text { June } & 1.82 \pm 3.00 \mathrm{E}-08 & 0.80 \pm 1.60 \mathrm{E}-08 & 2.33 \pm 3.90 \mathrm{E}-09 & -1.75 \pm 6.90 \mathrm{E}-09 \\ \text { WNW1109A } & \text { June } & -0.75 \pm 2.30 \mathrm{E}-08 & -1.47 \pm 1.30 \mathrm{E}-08 & 1.22 \pm 3.80 \mathrm{E}-09 & 4.89 \pm 5.60 \mathrm{E}-09 \\ \text { WNW1109B } & \text { June } & -0.10 \pm 2.40 \mathrm{E}-08 & 0.56 \pm 1.10 \mathrm{E}-08 & -1.31 \pm 3.80 \mathrm{E}-09 & 1.40 \pm 5.50 \mathrm{E}-09 \\ \text { WNW1111A } & \text { June } & 1.16 \pm 2.00 \mathrm{E}-08 & -0.26 \pm 1.20 \mathrm{E}-08 & 3.81 \pm 3.90 \mathrm{E}-09 & -0.50 \pm 5.20 \mathrm{E}-09\end{array}$

All data in Tables L-1 through L-3 have been provided by NYSERDA.

$L-7$ 


\section{Table L-3 (continued)}

\section{Radioisotopic Results From SDA Monitoring Wells $(\mu \mathrm{Ci} / \mathrm{mL})$}

$\begin{array}{rrrrrr}\begin{array}{c}\text { Sample } \\ \text { Location }\end{array} & \text { Date } & \text { Cesium-137 } & \text { Cobalt-57 } & \text { Cobalt-60 } & \text { Iodine-129 } \\ \text { WNW1101A } & & & & & \\ \text { WNW1101B } & \text { June } & 4.76 \pm 6.30 \mathrm{E}-09 & 0.20 \pm 1.70 \mathrm{E}-08 & 2.47 \pm 4.50 \mathrm{E}-09 & -2.64 \pm 2.50 \mathrm{E}-10 \\ & \text { June } & 1.42 \pm 3.80 \mathrm{E}-09 & -0.81 \pm 1.90 \mathrm{E}-08 & -2.56 \pm 3.80 \mathrm{E}-09 & 0.38 \pm 2.30 \mathrm{E}-10 \\ \text { WNW1101C } & \text { June } & 0.73 \pm 5.20 \mathrm{E}-09 & -1.31 \pm 2.60 \mathrm{E}-08 & 1.68 \pm 4.90 \mathrm{E}-09 & 0.31 \pm 2.10 \mathrm{E}-10 \\ \text { WNW1102A } & \text { June } & -1.28 \pm 5.70 \mathrm{E}-09 & -1.31 \pm 2.60 \mathrm{E}-08 & -2.18 \pm 6.20 \mathrm{E}-09 & 1.38 \pm 3.10 \mathrm{E}-10 \\ \text { WNW1102B } & \text { June } & -9.45 \pm 4.90 \mathrm{E}-09 & 0.58 \pm 1.70 \mathrm{E}-08 & -1.77 \pm 3.40 \mathrm{E}-09 & -2.28 \pm 2.70 \mathrm{E}-10 \\ \text { WNW1103A } & \text { June } & 0.10 \pm 3.50 \mathrm{E}-09 & 0.37 \pm 2.00 \mathrm{E}-08 & 1.55 \pm 3.20 \mathrm{E}-09 & 0.03 \pm 2.80 \mathrm{E}-10 \\ \text { WNW1103B } & \text { June } & 0.54 \pm 3.30 \mathrm{E}-09 & -1.85 \pm 1.90 \mathrm{E}-08 & -0.29 \pm 3.40 \mathrm{E}-09 & 0.88 \pm 2.10 \mathrm{E}-10 \\ \text { WNW1104A } & \text { June } & 4.77 \pm 5.80 \mathrm{E}-09 & -0.23 \pm 3.10 \mathrm{E}-08 & -2.99 \pm 5.70 \mathrm{E}-09 & 1.17 \pm 2.40 \mathrm{E}-10 \\ \text { WNW1104B } & \text { June } & -2.80 \pm 6.20 \mathrm{E}-09 & -2.43 \pm 3.40 \mathrm{E}-08 & 3.21 \pm 6.60 \mathrm{E}-09 & -0.03 \pm 1.80 \mathrm{E}-10 \\ \text { WNW1104C } & \text { June } & \text { NA } & \text { NA } & \text { NA } & 2.79 \pm 3.50 \mathrm{E}-10 \\ \text { WNW1105A } & \text { June } & -3.61 \pm 4.90 \mathrm{E}-09 & -1.51 \pm 2.30 \mathrm{E}-08 & -3.12 \pm 5.50 \mathrm{E}-09 & -0.20 \pm 2.60 \mathrm{E}-10 \\ \text { WNW1105B } & \text { June } & -0.57 \pm 4.50 \mathrm{E}-09 & -0.37 \pm 2.00 \mathrm{E}-08 & -0.52 \pm 4.30 \mathrm{E}-09 & -1.25 \pm 2.00 \mathrm{E}-10 \\ \text { WNW1106A } & \text { June } & -0.48 \pm 4.90 \mathrm{E}-09 & -0.64 \pm 1.20 \mathrm{E}-08 & 0.46 \pm 3.00 \mathrm{E}-09 & 2.44 \pm 2.40 \mathrm{E}-10 \\ \text { WNW1106B } & \text { June } & -2.96 \pm 3.60 \mathrm{E}-09 & -0.32 \pm 1.50 \mathrm{E}-08 & 2.91 \pm 3.40 \mathrm{E}-09 & 0.01 \pm 2.50 \mathrm{E}-10 \\ \text { WNW1107A } & \text { June } & -2.94 \pm 4.60 \mathrm{E}-09 & 1.41 \pm 2.40 \mathrm{E}-08 & -2.07 \pm 5.40 \mathrm{E}-09 & 2.20 \pm 2.60 \mathrm{E}-10 \\ \text { WNW1107A } & \text { June } & -0.70 \pm 5.30 \mathrm{E}-09 & -0.92 \pm 2.20 \mathrm{E}-08 & 1.99 \pm 4.10 \mathrm{E}-09 & 0.20 \pm 2.00 \mathrm{E}-10 \\ \text { WNW1108A } & \text { June } & -2.51 \pm 6.20 \mathrm{E}-09 & 2.77 \pm 3.00 \mathrm{E}-08 & 0.74 \pm 7.30 \mathrm{E}-09 & -1.71 \pm 2.50 \mathrm{E}-10 \\ \text { WNW1109A } & \text { June } & -2.19 \pm 4.90 \mathrm{E}-09 & -1.46 \pm 2.20 \mathrm{E}-08 & -1.64 \pm 4.70 \mathrm{E}-09 & 0.70 \pm 2.60 \mathrm{E}-10 \\ \text { WNW1109B } & \text { June } & -3.37 \pm 4.60 \mathrm{E}-09 & -0.27 \pm 2.20 \mathrm{E}-08 & 4.58 \pm 5.10 \mathrm{E}-09 & 0.00 \pm 2.20 \mathrm{E}-10 \\ \text { WNW1111A } & \text { June } & 1.12 \pm 4.90 \mathrm{E}-09 & -1.19 \pm 2.20 \mathrm{E}-08 & 3.52 \pm 4.30 \mathrm{E}-09 & 0.07 \pm 2.30 \mathrm{E}-10\end{array}$

All data in Tables L-1 through L-3 have been provided by NYSERDA.

NA - Not available. Some scheduled analyses could not be performed due to insufficient sample.

$L-8$ 


\section{Table L-3 (continued)}

\section{Radioisotopic Results From SDA Monitoring Wells $(\mu \mathrm{Ci} / \mathrm{mL})$}

\begin{tabular}{|c|c|c|c|c|c|}
\hline $\begin{array}{l}\text { Sample } \\
\text { Location }\end{array}$ & Date & Lead-212 & Lead-214 & Potassium-40 & Radium-224 \\
\hline WNW1101A & June & $-0.99 \pm 5.00 \mathrm{E}-09$ & $7.08 \pm 7.60 \mathrm{E}-09$ & $2.44 \pm 9.80 \mathrm{E}-08$ & $-1.02 \pm 5.20 \mathrm{E}-09$ \\
\hline WNW1101B & June & $3.26 \pm 5.50 \mathrm{E}-09$ & $-0.20 \pm 8.30 \mathrm{E}-09$ & $3.00 \pm 6.80 \mathrm{E}-08$ & $3.36 \pm 5.60 \mathrm{E}-09$ \\
\hline WNW1101C & June & $4.39 \pm 6.40 \mathrm{E}-09$ & $-0.06 \pm 1.10 \mathrm{E}-08$ & $2.45 \pm 9.50 \mathrm{E}-08$ & $4.79 \pm 7.00 \mathrm{E}-09$ \\
\hline WNW1102A & June & $0.87 \pm 7.60 \mathrm{E}-09$ & $4.43 \pm 9.90 \mathrm{E}-09$ & $-0.37 \pm 1.20 \mathrm{E}-07$ & $0.90 \pm 7.80 \mathrm{E}-09$ \\
\hline WNW1102B & June & $1.23 \pm 3.80 \mathrm{E}-09$ & $-0.95 \pm 6.50 \mathrm{E}-09$ & $-1.22 \pm 6.80 \mathrm{E}-08$ & $1.35 \pm 4.10 \mathrm{E}-09$ \\
\hline WNW1103A & June & $4.17 \pm 5.20 \mathrm{E}-09$ & $-4.69 \pm 7.70 \mathrm{E}-09$ & $-6.47 \pm 8.20 \mathrm{E}-08$ & $4.55 \pm 5.70 \mathrm{E}-09$ \\
\hline WNW1103B & June & $-0.50 \pm 4.00 \mathrm{E}-09$ & $6.67 \pm 7.10 \mathrm{E}-09$ & $-5.52 \pm 5.10 \mathrm{E}-08$ & $-0.54 \pm 4.30 \mathrm{E}-09$ \\
\hline WNW1104A & June & $-2.37 \pm 9.00 \mathrm{E}-09$ & $1.41 \pm 1.00 \mathrm{E}-08$ & $-0.62 \pm 1.40 \mathrm{E}-07$ & $-2.60 \pm 9.80 \mathrm{E}-09$ \\
\hline WNW1104B & June & $-1.01 \pm 0.98 \mathrm{E}-08$ & $-0.25 \pm 1.50 \mathrm{E}-08$ & $-1.08 \pm 1.50 \mathrm{E}-07$ & $-1.10 \pm 1.10 \mathrm{E}-08$ \\
\hline WNW1105A & June & $-1.97 \pm 7.10 \mathrm{E}-09$ & $-0.25 \pm 1.00 \mathrm{E}-08$ & $0.20 \pm 1.00 \mathrm{E}-07$ & $-2.03 \pm 7.30 \mathrm{E}-09$ \\
\hline WNW1105B & June & $-3.89 \pm 7.50 \mathrm{E}-09$ & $-3.07 \pm 9.00 \mathrm{E}-09$ & $-0.43 \pm 1.10 \mathrm{E}-07$ & $-4.00 \pm 7.70 \mathrm{E}-09$ \\
\hline WNW1106A & June & $3.35 \pm 4.10 \mathrm{E}-09$ & $-2.43 \pm 5.70 \mathrm{E}-09$ & $-3.67 \pm 6.60 \mathrm{E}-08$ & $3.44 \pm 4.20 \mathrm{E}-09$ \\
\hline WNW1106B & June & $-1.20 \pm 4.40 \mathrm{E}-09$ & $5.61 \pm 7.70 \mathrm{E}-09$ & $2.17 \pm 6.40 \mathrm{E}-08$ & $-1.24 \pm 4.50 \mathrm{E}-09$ \\
\hline WNW1107A & June & $-4.25 \pm 8.00 \mathrm{E}-09$ & $1.52 \pm 0.89 \mathrm{E}-08$ & $-0.36 \pm 1.30 \mathrm{E}-07$ & $-4.37 \pm 8.20 \mathrm{E}-09$ \\
\hline WNW1107A & June & $-0.03 \pm 8.10 \mathrm{E}-09$ & $0.21 \pm 1.00 \mathrm{E}-08$ & $1.03 \pm 1.10 \mathrm{E}-07$ & $-0.03 \pm 8.30 \mathrm{E}-09$ \\
\hline WNW1108A & June & $0.29 \pm 1.20 \mathrm{E}-08$ & $1.78 \pm 1.80 \mathrm{E}-08$ & $-1.54 \pm 1.60 \mathrm{E}-07$ & $0.31 \pm 1.30 \mathrm{E}-08$ \\
\hline WNW1109A & June & $-4.89 \pm 8.60 \mathrm{E}-09$ & $0.68 \pm 1.00 \mathrm{E}-08$ & $-0.54 \pm 1.30 \mathrm{E}-07$ & $-5.03 \pm 8.80 \mathrm{E}-09$ \\
\hline WNW1109B & June & $-4.33 \pm 7.20 \mathrm{E}-09$ & $-2.58 \pm 9.10 \mathrm{E}-09$ & $1.10 \pm 0.98 \mathrm{E}-07$ & $-4.72 \pm 7.80 \mathrm{E}-09$ \\
\hline WNW1111A & June & $-1.80 \pm 7.00 \mathrm{E}-09$ & $5.68 \pm 8.70 \mathrm{E}-09$ & $-2.28 \pm 1.20 \mathrm{E}-07$ & $-1.85 \pm 7.20 \mathrm{E}-09$ \\
\hline
\end{tabular}

All data in Tables L-1 through L-3 have been provided by NYSERDA.

$$
\text { L - } 9
$$




\section{Table L-3 (continued)}

\section{Radioisotopic Results From SDA Monitoring Wells $(\mu \mathrm{Ci} / \mathrm{mL})$}

\begin{tabular}{|c|c|c|c|c|c|}
\hline $\begin{array}{l}\text { Sample } \\
\text { Location }\end{array}$ & Date & Radium-226 & Strontium-90 & Technetium-99 & Thallium-208 \\
\hline WNW1101A & June & $4.23 \pm 8.10 \mathrm{E}-09$ & $3.19 \pm 4.70 \mathrm{E}-10$ & $0.71 \pm 6.80 \mathrm{E}-10$ & $-0.32 \pm 3.80 \mathrm{E}-09$ \\
\hline WNW1101B & June & $8.91 \pm 9.20 \mathrm{E}-09$ & $4.28 \pm 4.40 \mathrm{E}-10$ & $4.22 \pm 5.30 \mathrm{E}-10$ & $2.42 \pm 4.10 \mathrm{E}-09$ \\
\hline WNW1101C & June & $-0.20 \pm 1.20 \mathrm{E}-08$ & $0.13 \pm 1.60 \mathrm{E}-10$ & $1.83 \pm 0.70 \mathrm{E}-09$ & $3.73 \pm 5.40 \mathrm{E}-09$ \\
\hline WNW1102A & June & $0.38 \pm 1.00 \mathrm{E}-08$ & $1.32 \pm 0.85 \mathrm{E}-09$ & $0.70 \pm 1.80 \mathrm{E}-09$ & $4.53 \pm 5.10 \mathrm{E}-09$ \\
\hline WNW1102B & June & $7.55 \pm 6.50 \mathrm{E}-09$ & $-2.51 \pm 2.60 \mathrm{E}-10$ & $4.39 \pm 5.70 \mathrm{E}-10$ & $0.83 \pm 2.70 \mathrm{E}-09$ \\
\hline WNW1103A & June & $0.22 \pm 8.30 \mathrm{E}-09$ & $3.24 \pm 3.60 \mathrm{E}-10$ & $4.80 \pm 6.50 \mathrm{E}-10$ & $1.21 \pm 3.30 \mathrm{E}-09$ \\
\hline WNW1103B & June & $5.22 \pm 8.00 \mathrm{E}-09$ & $1.07 \pm 3.00 \mathrm{E}-10$ & $2.48 \pm 5.40 \mathrm{E}-10$ & $-1.76 \pm 3.30 \mathrm{E}-09$ \\
\hline WNW1104A & June & $0.08 \pm 1.30 \mathrm{E}-08$ & $1.31 \pm 2.50 \mathrm{E}-10$ & $8.63 \pm 6.20 \mathrm{E}-10$ & $8.56 \pm 6.70 \mathrm{E}-09$ \\
\hline WNW1104B & June & $-0.74 \pm 1.50 \mathrm{E}-08$ & $-0.29 \pm 1.90 \mathrm{E}-10$ & $0.48 \pm 6.40 \mathrm{E}-10$ & $-9.36 \pm 6.60 \mathrm{E}-09$ \\
\hline WNW1104C & December & NA & NA & $1.62 \pm 2.00 \mathrm{E}-09$ & NA \\
\hline WNW1105A & June & $1.13 \pm 1.20 \mathrm{E}-08$ & $0.84 \pm 3.20 \mathrm{E}-10$ & $4.27 \pm 6.20 \mathrm{E}-10$ & $1.66 \pm 5.40 \mathrm{E}-09$ \\
\hline WNW1105B & June & $-5.60 \pm 9.80 \mathrm{E}-09$ & $-0.28 \pm 2.90 \mathrm{E}-10$ & $2.21 \pm 5.30 \mathrm{E}-10$ & $-1.16 \pm 5.60 \mathrm{E}-09$ \\
\hline WNW1106A & June & $2.39 \pm 6.10 \mathrm{E}-09$ & $0.50 \pm 3.30 \mathrm{E}-10$ & $3.75 \pm 5.70 \mathrm{E}-10$ & $2.04 \pm 2.90 \mathrm{E}-09$ \\
\hline WNW1106B & June & $3.54 \pm 7.90 \mathrm{E}-09$ & $5.83 \pm 3.90 \mathrm{E}-10$ & $1.25 \pm 5.20 \mathrm{E}-10$ & $0.25 \pm 3.10 \mathrm{E}-09$ \\
\hline WNW1107A & June & $0.24 \pm 1.20 \mathrm{E}-08$ & $6.56 \pm 1.30 \mathrm{E}-09$ & $9.89 \pm 6.00 \mathrm{E}-10$ & $-0.18 \pm 6.20 \mathrm{E}-09$ \\
\hline WNW1107A & June & $-0.48 \pm 1.30 \mathrm{E}-08$ & $1.01 \pm 0.19 \mathrm{E}-08$ & $1.29 \pm 0.64 \mathrm{E}-09$ & $6.71 \pm 5.40 \mathrm{E}-09$ \\
\hline WNW1108A & June & $0.80 \pm 1.60 \mathrm{E}-08$ & $0.51 \pm 2.00 \mathrm{E}-10$ & $1.45 \pm 1.10 \mathrm{E}-09$ & $-1.47 \pm 7.20 \mathrm{E}-09$ \\
\hline WNW1109A & June & $-1.47 \pm 1.30 \mathrm{E}-08$ & $3.12 \pm 3.00 \mathrm{E}-10$ & $2.33 \pm 5.50 \mathrm{E}-10$ & $-1.63 \pm 5.50 \mathrm{E}-09$ \\
\hline WNW1109B & June & $0.56 \pm 1.10 \mathrm{E}-08$ & $1.16 \pm 1.60 \mathrm{E}-10$ & $7.69 \pm 5.90 \mathrm{E}-10$ & $3.35 \pm 6.00 \mathrm{E}-09$ \\
\hline WNW1110A & December & NA & $-0.42 \pm 6.80 \mathrm{E}-10$ & $2.79 \pm 2.20 \mathrm{E}-09$ & NA \\
\hline WNW1111A & June & $-0.26 \pm 1.20 \mathrm{E}-08$ & $-0.38 \pm 2.90 \mathrm{E}-10$ & $4.52 \pm 6.10 \mathrm{E}-10$ & $-1.28 \pm 5.60 \mathrm{E}-09$ \\
\hline
\end{tabular}

All data in Tables L-1 through L-3 have been provided by NYSERDA.

NA - Not available. Some scheduled analyses could not be performed due to insufficient sample. 


\section{Table L-3 (concluded) 2004 Radioisotopic Results From SDA Monitoring Wells $(\mu \mathrm{Ci} / \mathrm{mL})$}

\begin{tabular}{|c|c|c|c|}
\hline $\begin{array}{c}\text { Sample } \\
\text { Location }\end{array}$ & Date & Thorium-234 & Uranium-235 \\
\hline WNW1101A & June & $-2.07 \pm 5.00 \mathrm{E}-07$ & $-1.36 \pm 1.70 \mathrm{E}-08$ \\
\hline WNW1101B & June & $-2.42 \pm 6.10 \mathrm{E}-07$ & $-0.98 \pm 1.80 \mathrm{E}-08$ \\
\hline WNW1101C & June & $1.20 \pm 8.50 \mathrm{E}-07$ & $-0.83 \pm 2.10 \mathrm{E}-08$ \\
\hline WNW1102A & June & $1.55 \pm 8.60 \mathrm{E}-07$ & $1.25 \pm 2.50 \mathrm{E}-08$ \\
\hline WNW1102B & June & $-2.19 \pm 4.10 \mathrm{E}-07$ & $-0.69 \pm 1.20 \mathrm{E}-08$ \\
\hline WNW1103A & June & $-6.89 \pm 5.70 \mathrm{E}-07$ & $0.50 \pm 1.90 \mathrm{E}-08$ \\
\hline WNW1103B & June & $3.82 \pm 4.70 \mathrm{E}-07$ & $1.15 \pm 1.50 \mathrm{E}-08$ \\
\hline WNW1104A & June & $1.56 \pm 7.40 \mathrm{E}-07$ & $0.76 \pm 2.40 \mathrm{E}-08$ \\
\hline WNW1104B & June & $-5.59 \pm 9.80 \mathrm{E}-07$ & $0.06 \pm 2.90 \mathrm{E}-08$ \\
\hline WNW1105A & June & $-2.88 \pm 8.00 \mathrm{E}-07$ & $-1.45 \pm 2.30 \mathrm{E}-08$ \\
\hline WNW1105B & June & $4.81 \pm 7.20 \mathrm{E}-07$ & $1.65 \pm 2.00 \mathrm{E}-08$ \\
\hline WNW1106A & June & $-2.96 \pm 4.10 \mathrm{E}-07$ & $-0.01 \pm 1.30 \mathrm{E}-08$ \\
\hline WNW1106B & June & $-2.18 \pm 4.90 \mathrm{E}-07$ & $0.37 \pm 1.70 \mathrm{E}-08$ \\
\hline WNW1107A & June & $-3.80 \pm 8.20 \mathrm{E}-07$ & $1.08 \pm 2.20 \mathrm{E}-08$ \\
\hline WNW1107A & June & $0.00 \pm 8.10 \mathrm{E}-07$ & $-0.10 \pm 2.10 \mathrm{E}-08$ \\
\hline WNW1108A & June & $-3.59 \pm 8.50 \mathrm{E}-07$ & $-1.49 \pm 2.60 \mathrm{E}-08$ \\
\hline WNW1109A & June & $3.54 \pm 8.00 \mathrm{E}-07$ & $-0.56 \pm 2.20 \mathrm{E}-08$ \\
\hline WNW1109B & June & $6.13 \pm 6.60 \mathrm{E}-07$ & $0.09 \pm 2.00 \mathrm{E}-08$ \\
\hline WNW1111A & June & $-3.66 \pm 8.00 \mathrm{E}-07$ & $1.33 \pm 2.00 \mathrm{E}-08$ \\
\hline
\end{tabular}

All data in Tables L-1 through L-3 have been provided by NYSERDA. 
This page intentionally left blank

$$
L-12
$$

